\title{
Fracture Dissolution of Carbonate Rock: An Innovative Process for Gas Storage
}

\section{FINAL TECHNICAL REPORT}

August 1, 2002 - October 30, 2006

\author{
James W. Castle ${ }^{1}$, Principal Investigator \\ Ronald W. Falta ${ }^{1}$, Co-Investigator \\ David Bruce $^{2}$, Co-Investigator \\ Larry Murdoch ${ }^{1}$, Co-Investigator \\ Scott E. Brame ${ }^{1}$, Research Associate \\ Donald Brooks ${ }^{3}$, Consultant \\ ${ }^{1}$ Department of Geological Sciences, Clemson University, Clemson, SC \\ ${ }^{2}$ Department of Chemical Engineering, Clemson University, Clemson, SC \\ ${ }^{3}$ DB Consulting, Millington, NJ
}

January 30, 2007

DE-FC26-02NT41299

Submitted by:

Clemson University

300 Brackett Hall

Box 345702

Clemson, South Carolina 29634 


\section{DISCLAIMER}

This report was prepared as an account of work sponsored by an agency of the United States Government. Neither the United States Government nor any agency thereof, nor any of their employees, makes any warranty, express or implied, or assumes any legal liability or responsibility for the accuracy, completeness, or usefulness of any information, apparatus, product, or process disclosed, or represents that its use would not infringe upon privately owned rights. Reference herein to any specific commercial product, process, or service by trade name, trademark, manufacturer, or otherwise does not necessarily constitute or imply its endorsement, recommendation, or favoring by the United States government or any agency thereof. The views and opinions of authors expressed herein do not necessarily state or reflect those of the United States Government or any agency thereof. 


\begin{abstract}
The goal of the project is to develop and assess the feasibility and economic viability of an innovative concept that may lead to commercialization of new gas-storage capacity near major markets. The investigation involves a new approach to developing underground gas storage in carbonate rock, which is present near major markets in many areas of the United States. Because of the lack of conventional gas storage and the projected growth in demand for storage capacity, many of these areas are likely to experience shortfalls in gas deliverability. Since depleted gas reservoirs and salt formations are nearly non-existent in many areas, alternatives to conventional methods of gas storage are required. The need for improved methods of gas storage, particularly for ways to meet peak demand, is increasing. Gas-market conditions are driving the need for higher deliverability and more flexibility in injection/withdrawal cycling. In order to meet these needs, the project involves an innovative approach to developing underground storage capacity by creating caverns in carbonate rock formations by acid dissolution. The basic concept of the aciddissolution method is to drill to depth, fracture the carbonate rock layer as needed, and then create a cavern using an aqueous acid to dissolve the carbonate rock.

Assessing feasibility of the acid-dissolution method included a regional geologic investigation. Data were compiled and analyzed from carbonate formations in six states: Indiana, Ohio, Kentucky, West Virginia, Pennsylvania, and New York. To analyze the requirements for creating storage volume, the following aspects of the dissolution process were examined: weight and volume of rock to be dissolved; gas storage pressure, temperature, and volume at depth; rock solubility; and acid costs. Hydrochloric acid was determined to be the best acid to use because of low cost, high acid solubility, fast reaction rates with carbonate rock, and highly soluble products (calcium chloride) that allow for the easy removal of calcium waste from the well. Physical and chemical analysis of core samples taken from prospective geologic formations for the acid dissolution process confirmed that many of the limestone samples readily dissolved in concentrated hydrochloric acid. Further, some samples contained oily residues that may help to seal the walls of the final cavern structure. These results suggest that there exist carbonate rock formations well suited for the dissolution technology and that the presence of inert impurities had no noticeable effect on the dissolution rate for the carbonate rock.

A sensitivity analysis was performed for characteristics of hydraulic fractures induced in carbonate formations to enhance the dissolution process. Multiple fracture simulations were conducted using modeling software that has a fully 3-D fracture geometry package. The simulations, which predict the distribution of fracture geometry and fracture conductivity, show that the stress difference between adjacent beds is the physical property of the formations that has the greatest influence on fracture characteristics by restricting vertical growth. The results indicate that by modifying the fracturing fluid, proppant type, or pumping rate, a fracture can be created with characteristics within a predictable range, which contributes to predicting the geometry of storage caverns created by acid dissolution of carbonate formations.

A series of three-dimensional simulations of cavern formation were used to investigate three different configurations of the acid-dissolution process: a) injection into an open borehole with production from that same borehole and no fracture; b) injection into an open borehole with production from that same borehole, with an open fracture; and c) injection into an open borehole connected by a fracture to an adjacent borehole from which the fluids are produced. The two-well configuration maximizes the overall mass transfer from the rock to the fluid, but it results in a
\end{abstract}


complex cavern shape.

Numerical simulations were performed to evaluate the ability of storage caverns produced by the acid-dissolution method to store natural gas. In addition, analyses were conducted to evaluate cavern stability during gas injection and withdrawal from storage caverns created in carbonate formations by the acid-dissolution method. The stability analyses were conducted using FLAC2D, a commercially available geotechnical analysis and design software. The analyses indicate that a tall cylindrical cavern with a domed roof and floor will be stable under the expected range of in situ and operational conditions. This result suggests that it should be feasible to avoid mechanical instabilities that could potentially diminish the effectiveness of the storage facility.

The feasibility of using pressure transients measured at the ground surface was investigated as a means to evaluate cavern formation. The results indicate that a pressure perturbation created in the acid injection pipe will be reflected by changes in cavern diameter. This should give a detectable response as the cavern diameter increases up to approximately 1 to 2 meters. Pressure transient data collected during cavern formation can be used to calibrate numerical models of the dissolution process used to create the storage cavern. Results from the calibrated model would be used to help guide the cavern dissolution process.

A process design was developed for the acid-dissolution method that incorporates the modeling results as well as proven technologies for drilling wells, storing and pumping inorganic acids, and handling the aqueous waste streams exiting the underground storage cavern. Economic analysis of this design considered capital costs, well-design options and costs, acid costs, reaction product options, and comparison with costs of other gas storage methods. The process design and economic analysis showed that the process of creating storage caverns by using acid to dissolve carbonate formations is economical, with the costs sensitive to market price of hydrochloric acid and the ability to sell a significant fraction of the produced calcium chloride at or near market value. The proposed process is cost competitive with other gas storage facilities assuming that a moderate to high purity limestone is used for cavern formation at depths shallower than 10,000 feet and that appropriate shipment methods are within reasonable proximity to the well site.

The design parameters and economic analysis will facilitate deployment of the technology for creating storage caverns by dissolution using acid. Results of our investigation are very encouraging for moving ahead to a future field demonstration of the technology. Successful demonstration has the potential for opening up new geographic areas for developing storage capacity. The technology is expected to have application to many geographic areas because of the widespread occurrence of carbonate formations. 


\section{TABLE OF CONTENTS}

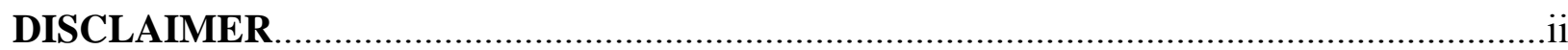

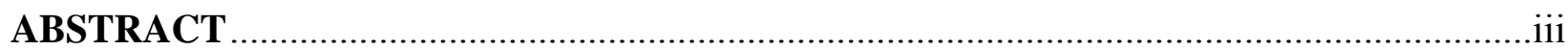

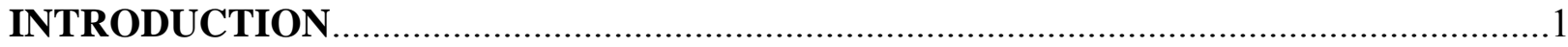

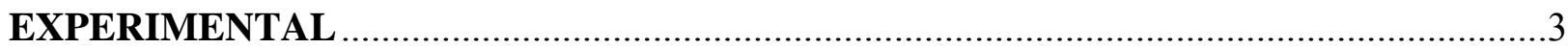

Subsurface Characteristics of Existing Storage and Producing Fields (Task 1) ...............3

Requirements for Creating Storage Volume (Task 2)................................................

Preliminary Economic Analysis (Task 3) ................................................................... 3

Regional Survey of Carbonate Formations (Task 4) ..................................................... 3

Report on Current Modeling Technology (Task 5) ........................................................

Laboratory Testing of Limestone Samples (Task 6)......................................................

Three-Dimensional Modeling of Distribution of Induced Fractures (Task 7) ..................4

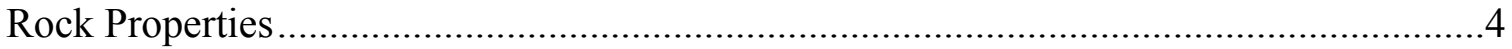

Fracture Modeling Variables ...................................................................................

Numerical Modeling to Predict Formation of Storage Volume during Dissolution Process

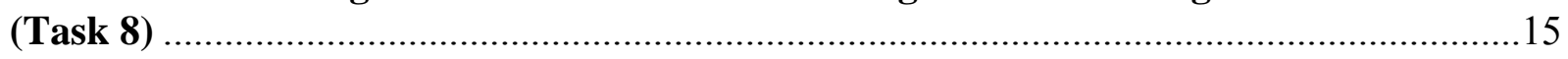

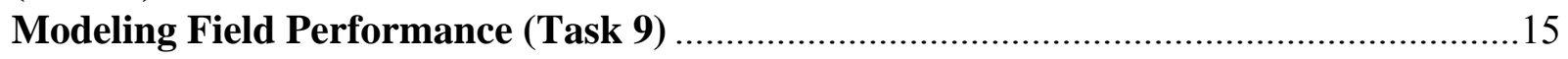

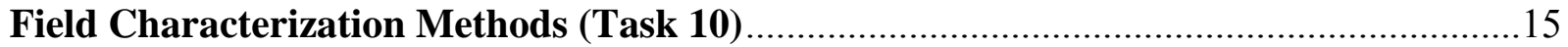

Analysis of Operational Pressure Transients to Assess Cavern Dissolution .....................16

Initial and Boundary Conditions .......................................................................... 17

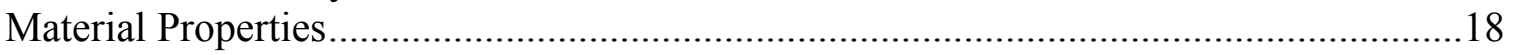

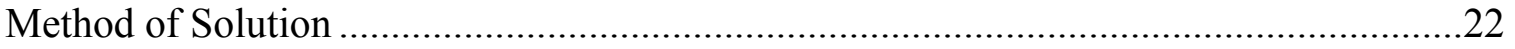

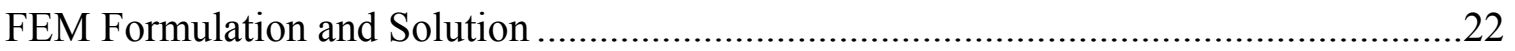

Evaluation of the Stability of a Cavern Created by Dissolution of Carbonate Rock ........23

Predicted Cavern Volume .................................................................................23

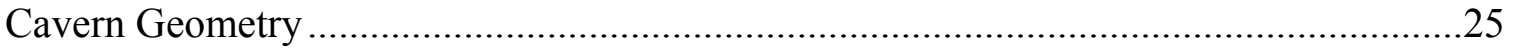

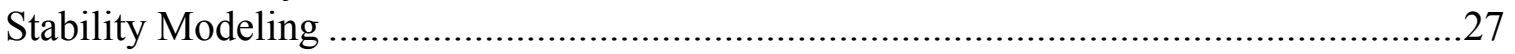

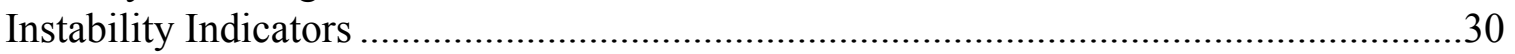

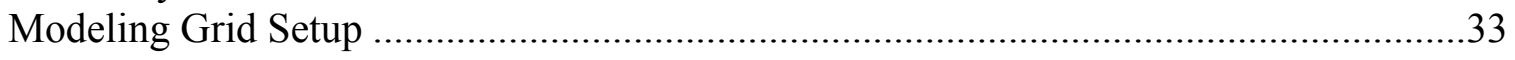

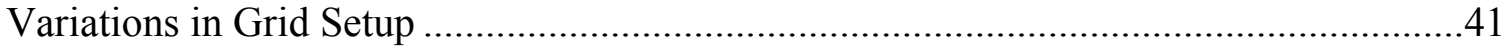

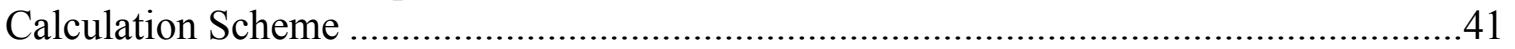

Final Design and Updated Economic Analysis (Task 11) .......................................42

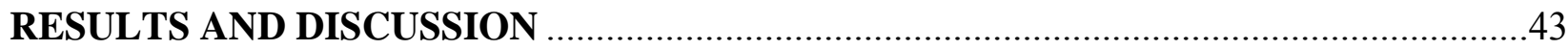

Subsurface Characteristics of Existing Storage and Producing Fields (Task 1) .............43

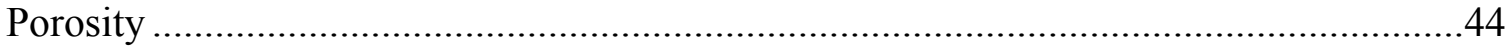

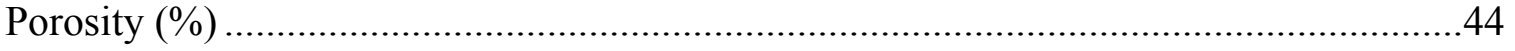


Requirements for Creating Storage Volume (Task 2)......................................................45

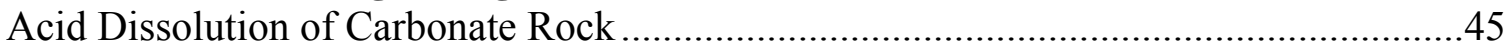

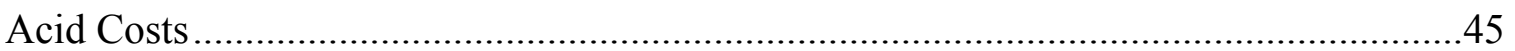

Reaction Equilibrium Constants ............................................................................46

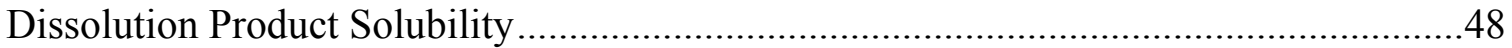

Selection of the Optimal Dissolution Acid ....................................................................48

Prediction of Gas Storage Pressure, Temperature and Volume at Depth ..........................49

Weight and Volume of Rock to be Dissolved .................................................................52

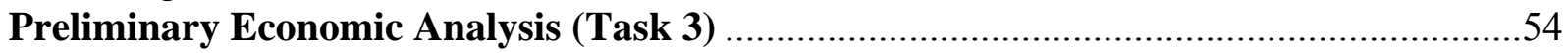

Well Design Options and Costs ..................................................................................54

Waste Treatment and Green House Gas Emissions..........................................................56

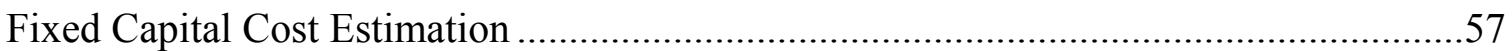

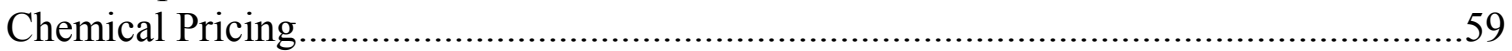

Estimation of Total Facility Costs ..........................................................................6

Comparison of Gas Storage Costs ........................................................................62

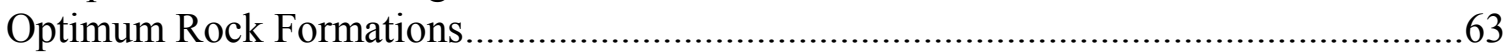

Regional Survey of Carbonate Formations (Task 4) ..........................................................65

Identification of Carbonate Units and Regional Stratigraphic Analysis ...........................65

Data Management: Selection, Filtering, and Quality Assurance.......................................71

Mapping and Analysis of Depth and Thickness Data.....................................................72

Identification of Geologically Suitable Areas for Applying the Technology .....................73

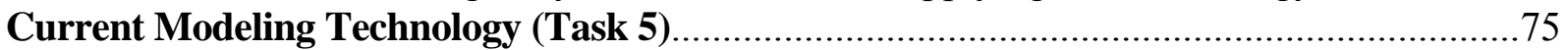

Laboratory Testing of Limestone Samples (Task 6)......................................................76

Three-Dimensional Modeling of Distribution of Induced Fractures (Task 7) ...................80

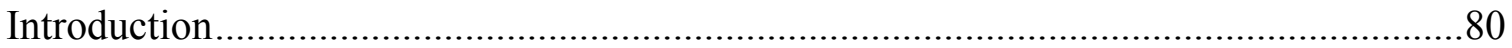

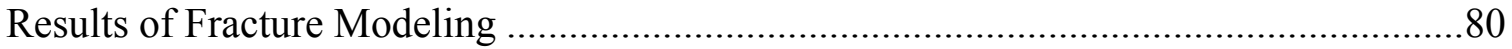

Summary of Fracture Modeling Results ....................................................................... 125

Development of a Numerical Model to Predict Formation of Storage Volume during the

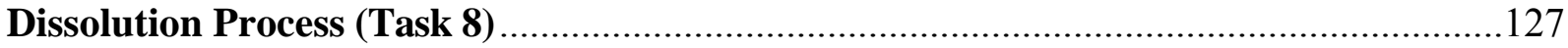

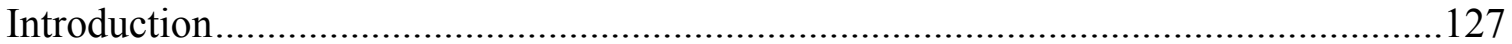

Three-Dimensional Simulation of Cavern Formation Neglecting $\mathrm{CO}_{2}$ Production .........128

Development of a Fully Coupled Numerical Simulator for the Acid Dissolution Process with

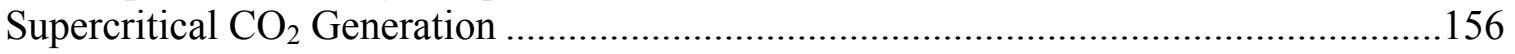

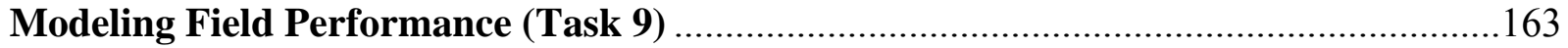

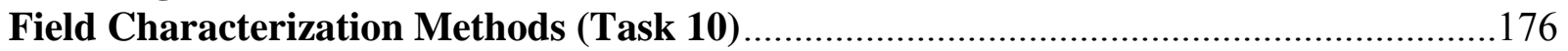

Analysis of Operational Pressure Transients to Assess Cavern Dissolution ....................176

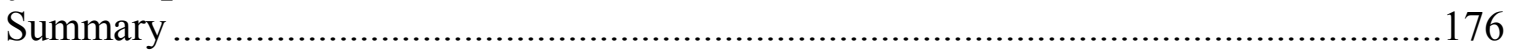

Basis of Governing Equations ..................................................................................177

Assumptions used in Derivation of Governing Equations............................................178

Continuity and Momentum Equations for Transient Fluid Flow ......................................179

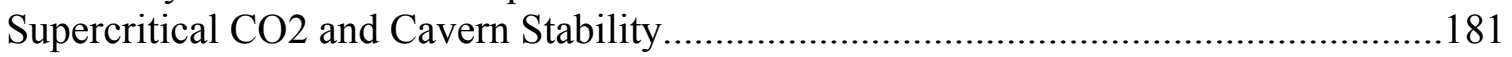

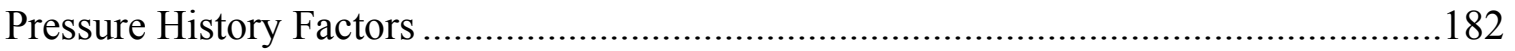

Effect of Diameter Change During Early Stage of Construction .....................................183

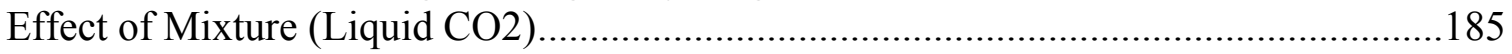

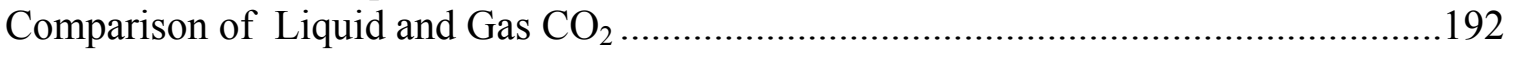


Evaluation of the Stability of a Cavern Created by Dissolution of Carbonate Rock ......195

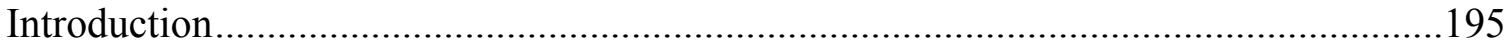

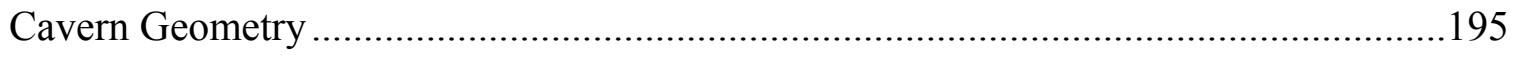

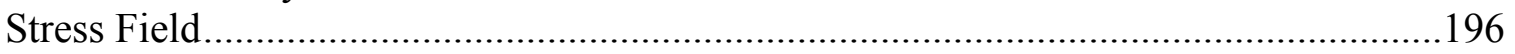

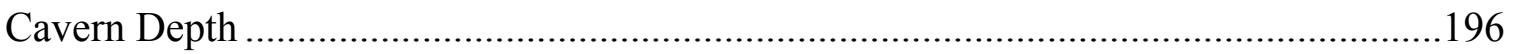

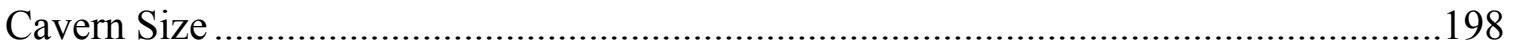

Pressure Cycling …………………………………….................................198

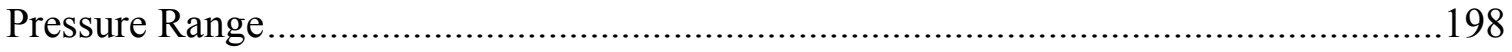

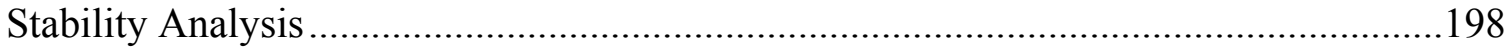

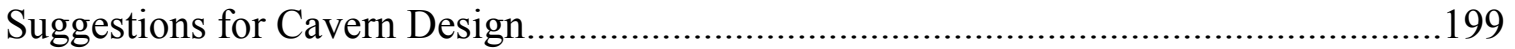

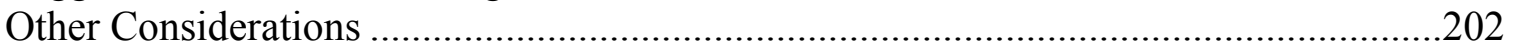

Final Design and Updated Economic Analysis (Task 11) ............................................206

Detailed Economic Analysis for the Acid Dissolution of Carbonate Rock......................206

Well Design Options and Costs ..............................................................................208

Waste Treatment and Green House Gas Emissions.....................................................208

Hydrochloric Acid Cost and Availability ……………..............................................209

Calcium Chloride Market Information and Pricing Data ................................................211

Fixed Capital Cost Estimation .................................................................................212

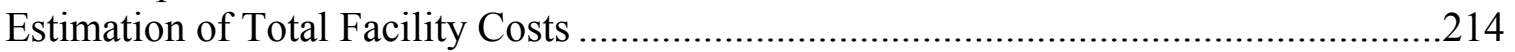

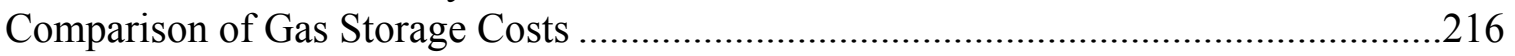

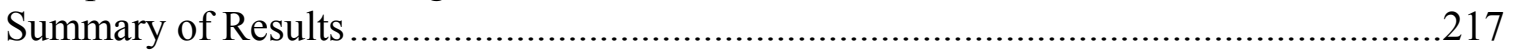

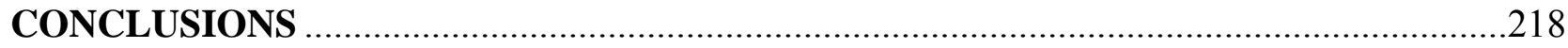

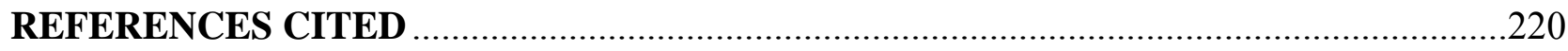




\section{INTRODUCTION}

Currently, natural gas is in high demand in many regions of the United States, especially the Northeast. Hence, there is an increasing effort to develop new methodologies that will make natural gas more readily available, which should ultimately reduce the cost of natural gas to consumers. Of particular interest are more efficient and safe means for storing large quantities of natural gas close to major pipelines or high usage areas. The primary focus of this project is to evaluate the feasibility of creating underground natural gas storage capacity in optimal locations via the acid dissolution of carbonate rock formations. The analysis includes compilation of a large amount of data from carbonate formations in six states (Indiana, Ohio, Kentucky, West Virginia, Pennsylvania, and New York), which were selected in consultation with DOE based on location near major natural-gas markets and pipelines.

The basic concept of the acid-dissolution method is to drill to depth, fracture the carbonate rock layer as needed, and then create a cavern using an aqueous acid to dissolve the carbonate rock. Following waste fluid removal, the resulting cavity can be used as a subsurface natural gas storage reservoir. Abundant carbonate rock formations worldwide make the project worthwhile for the entrepreneur and consumer alike, especially when the facility is to be located near large gas markets where current gas storage capacity is insufficient to meet demand. An additional benefit of the acid-dissolution method is its suitability for developing storage capacity of specific volume near industrial facilities or power-generating plants.

Our investigation focused on developing gas storage facilities in carbonate rock formations that have negligible innate gas storage capacity (i.e., low permeability and/or porosity). Early results showed that hydrochloric acid $(\mathrm{HCl})$ is the most suitable for the cavern creation process. The reaction of limestone with hydrochloric acid is:

$$
2 \mathrm{HCl}+\mathrm{CaCO}_{3} \Leftrightarrow \mathrm{CaCl}_{2}+\mathrm{H}_{2} \mathrm{O}+\mathrm{CO}_{2}
$$

For limestone dissolution, two moles of $\mathrm{HCl}$ react with a mole of limestone to produce one mole of calcium chloride $\left(\mathrm{CaCl}_{2}\right)$, one mole of carbon dioxide $\left(\mathrm{CO}_{2}\right)$, and a mole of water. The reaction equilibrium for the above reaction very strongly favors the products, so at equilibrium, the reaction is essentially $100 \%$ complete (see, for example, Williams et al., 1979 for calculation method). For every kilogram of limestone that is dissolved, $728.7 \mathrm{~g}$ of $\mathrm{HCl}$ are consumed, producing $1109 \mathrm{~g}$ of $\mathrm{CaCl}_{2}, 439.7 \mathrm{~g}$ of $\mathrm{CO}_{2}$, and $180 \mathrm{~g}$ of water. Using the standard density of limestone of $2710 \mathrm{~kg} / \mathrm{m}^{3}$ and a $30 \%$ (by mass) $\mathrm{HCl}$ concentration, the volumetric dissolving power is 0.175 (Williams et al., 1979). Therefore, each liter of acid solution is capable of dissolving 0.175 liters of rock. The presence of insoluble residue such as silica may affect the dissolution process, and several samples of carbonate formations were tested in the laboratory by conducting dissolution experiments. For modeling the development of caverns by acid dissolution of carbonate rock, we modified the TOUGH2 code EWASG (Battistelli et al., 1997; Pruess et al., 1999) with the ECO2 module from Pruess and Garcia (2002) to get a fully coupled simulator for the acid-rock dissolution.

Creating a cavern that will reliably contain compressed natural gas is the primary objective of this investigation. To that end, we undertook numerical simulations of the gas storage process in cylindrical caverns to evaluate the sensitivity of the process to formation permeability and gas pressure. Numerical simulations were performed using the TMVOC 
multiphase simulator (Pruess and Battistelli, 2002). This simulator can consider multiple condensable and noncondensable hydrocarbon gases using the real gas law.

Because of the importance of cavern stability, various cavern geometries were analyzed by performing simulations using $F L A C 2 D$, a commercially available geotechnical analysis and design software. The analysis considered cavern shapes resembling a tall cylinder, a roughly equidimensional cylinder, a puck-like shape (short, wide cylinder), a tunnel, a sphere, and a cone. The effects of depth, in-situ stress state, and cycling of the internal pressure on cavern stability were evaluated. The feasibility of using pressure transients measured at the ground surface was investigated as a means to characterize cavern formation. Pressure transient data collected during cavern formation can be used to calibrate numerical models of the dissolution process used to create the storage cavern.

A final process design and economic analysis yielded results that are very encouraging for moving ahead to a future demonstration of creating gas storage caverns by using acid to dissolve carbonate rock. Results presented in this report will facilitate deployment of this new technology for creating storage caverns. 


\section{EXPERIMENTAL}

If not readily available in the literature, descriptions of experimental methods and materials used in this investigation are provided in this section of the report. Standard, published experimental methods are cited rather than described.

\section{Subsurface Characteristics of Existing Storage and Producing Fields (Task 1)}

Data were compiled and examined from various sources as cited in the results section of this report. No experiments or simulations were performed in this task.

\section{Requirements for Creating Storage Volume (Task 2)}

No experiments or simulations were performed in this task.

\section{Preliminary Economic Analysis (Task 3)}

No experiments or simulations were performed in this task.

\section{Regional Survey of Carbonate Formations (Task 4)}

Data were compiled and used from various sources as cited in the results section of this report. Standard methods of spatial interpolation and analysis found in ArcGIS 8.x (ESRI, Redmond, CA.) were used in the GIS analysis.

\section{Report on Current Modeling Technology (Task 5)}

No experiments or simulations were performed in this task.

\section{Laboratory Testing of Limestone Samples (Task 6)}

By David Bruce

In order to gain information about the chemical composition of carbonate rock formations in possible dissolution test sites, samples were collected from core sections maintained by companies, government institutions, and universities. Portions of these samples were treated with aqueous hydrochloric acid (35 wt\%) in a well ventilated hood so as to ascertain the amounts of dissolvable products. An approximate time for dissolution (corresponding to the point where significant evolution of $\mathrm{CO}_{2}$ gas ceased) was recorded for each rock sample and the undissolved materials were washed with distilled water and dried at $150{ }^{\circ} \mathrm{C}$ for $24 \mathrm{hrs}$. These samples were then reweighed to determine by difference the percentage of carbonate rock (and soluble salts) in the rock samples. During acid treatment and upon drying the samples, it was observed that there were oily residues in several of the samples. Hence, some of the acid treated samples were calcined at $700{ }^{\circ} \mathrm{C}$ under a continuous flow of air, so as to determine the amount of organic (i.e., combustible) material in the samples. 
In order to ascertain the nature (i.e., structure and composition) of the non-dissolvable components of the carbonate rock samples, the dried, post-dissolution samples were analyzed by powder X-ray diffraction (PXD). PXD experiments were performed on selected samples using a SCINTAG XDS-2000 diffractometer with $\mathrm{Cu} \mathrm{K} \alpha$ radiation. The resulting diffraction data were used to identify the types of undissolved (following acid treatment) minerals that were present in the carbonate rock samples. The diffraction peaks occurring within the 2-theta range of $10^{\circ}$ to $80^{\circ}$ were compared to published X-ray diffraction data for product identification purposes.

\section{Three-Dimensional Modeling of Distribution of Induced Fractures (Task 7)} By Larry Murdoch and Jim Foley

\section{Rock Properties}

\section{Limestone Properties - Range of Published Data}

Published data from laboratory tests were compiled to find the range of values for $E, v$, and $K_{I C}$ in order to calculate the modulus and estimate the mechanical properties of the limestone formation. Data from 56 reported values of $\mathrm{E}, v$ and 47 reports of $K_{I C}$ were compiled from 7 sources (Robertson, 1959; Somerton et al. 1969; Schmidt, 1976; Atkinson and Meredith, 1987; Hatheway and Kiersch, 1989; Meredith, 1989; Ochterlony, 1989). Young's Modulus for limestone ranged from 0.31 to $14.1 \mathrm{Mpsi}$ with an average of 6.27 Mpsi (Table 1, Figure 1). The reported values of Poisson's ratio for limestone contained some data (Figure 2) that fall beyond the normal range of 0.0 to 0.5 (Goodman, 1980). These points were considered outliers and were removed for the calculation of summary statistics (Table 1). The modulus was calculated from reports of $\mathrm{E}$ and $v$ from the same material. Values for the modulus range from 0.2 to $15.4 \mathrm{Mpsi}$ with an average of $6.6 \mathrm{Mpsi}$ (Table 1). The distribution of the limestone elastic modulus indicates that $40 \%$ of the values lie between 4.6 to $8.9 \mathrm{Mpsi}$ and that $21 \%$ are less than $2.5 \mathrm{Mpsi}$ (Figure 3). The fracture toughness of limestone ranges from 325 to 1810 psi $\sqrt{ }$ in with an average of 1003 psivin (Table 1, Figure 4).

Table 1. Range of physical properties expected for limestone

\begin{tabular}{|l|l|l|l|l|}
\hline & Young's & Poisson's & & Fracture \\
\hline & Modulus $(E)$ & Ratio & Modulus $\left(E^{\prime}\right)$ & Toughness \\
\hline & $(\mathrm{Mpsi})$ & $(v)$ & $(\mathrm{Mpsi})$ & $(\mathrm{psi} \sqrt{ })$ \\
\hline Minimum & 0.31 & 0.01 & 0.3 & 325 \\
\hline Maximum & 14.1 & 0.32 & 15.4 & 1810 \\
\hline Average & 6.3 & 0.18 & 6.6 & 1003 \\
\hline Std. Dev & 3.5 & 0.1 & 3.7 & 293 \\
\hline
\end{tabular}




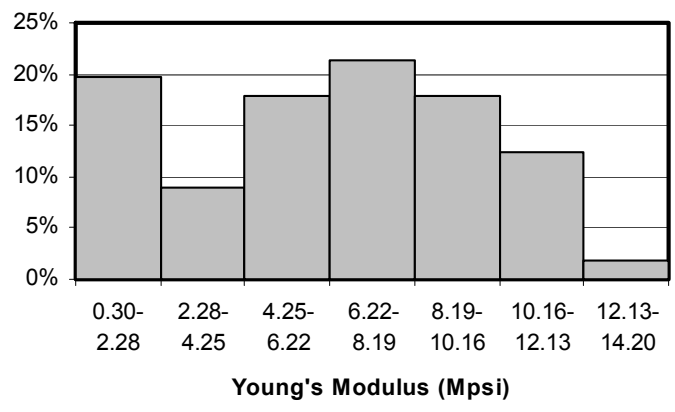

Figure 1. Distribution of Young's Modulus for limestone

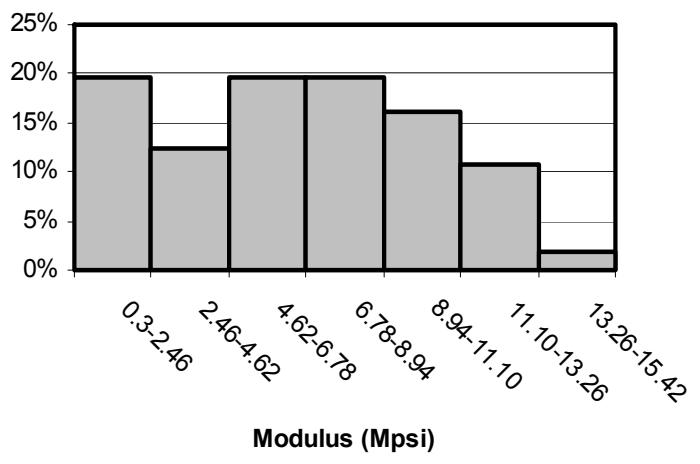

Figure 3 Distribution of limestone modulus

\section{Shale Properties}

Published data was analyzed to find the range of values for $E$, $v$, and $K_{I C}$ in order to estimate the mechanical properties of a shale formation. Data from 23 laboratory measurements of $E$ and $v$ and 32 measurements of $K_{I C}$ were collected from 4 sources (Atkinson and Meredith, 1987; Hatheway and Kiersch, 1989; Ochterlony, 1989; Chen and Zhang, 2004). Young's modulus of shale ranged from 0.06 to $9.9 \mathrm{Mpsi}$ with an average of 2.5 Mpsi (Figure 5, Table 2). The reported values of Poisson's ratio for shale contained some data (Figure 6) that fall beyond the normal range of 0.0 to 0.5 (Goodman, 1980). These points were considered outliers and were removed for the calculation of summary statistics (Table 2). Individual values of the modulus were calculated from $E$ and $v$ measurements from the same material. Values for the shale modulus range from 0.06 to $10.0 \mathrm{Mpsi}$ with an average of $2.5 \mathrm{Mpsi}$ (Table 2). The distribution of the shale elastic modulus is skewed to the left with $65 \%$ of the reported values less than 2.05 Mpsi (Figure 7). The shale fracture toughness ranges from 220 to $1177 \mathrm{psi} \sqrt{ }$ in with an average of 721 psi $\sqrt{\text { in }}$ (Table 2, Figure 8). 


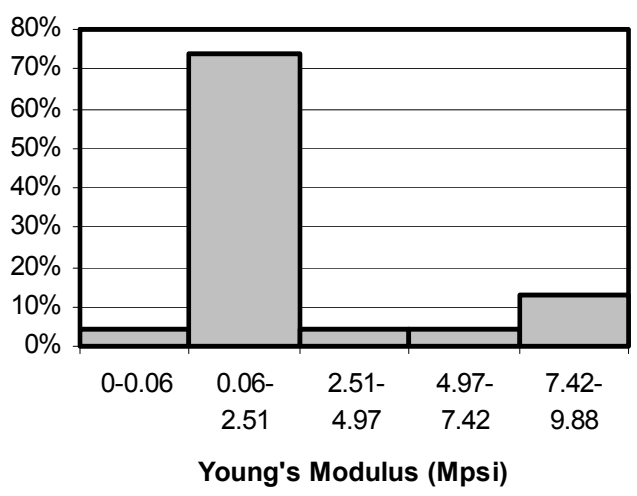

Figure 5 Distribution of Young's Modulus for shale

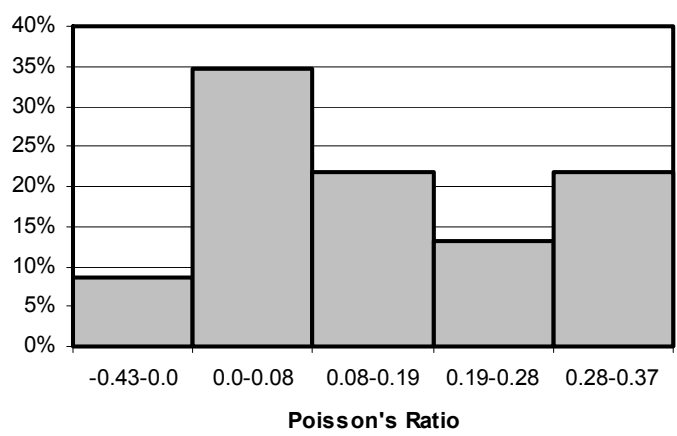

Figure 6 Distribution of Poisson's Ratio for shale

Table 2 Range of physical properties expected for shale

$\begin{array}{cccc}\text { Young's } & \text { Poisson's } & \text { Fracture } \\ \text { Modulus (E) } & \text { Ratio } & \text { Modulus (E') } & \text { Toughness }\end{array}$

\begin{tabular}{|c|c|c|c|c|}
\hline & (psi) & $(v)$ & (Mpsi) & (psivin) \\
\hline Minimum & 0.06 & 0.01 & 0.1 & 220 \\
\hline Maximum & 9.9 & 0.37 & 10 & 1177 \\
\hline Average & 2.5 & 0.16 & 2.5 & 721 \\
\hline Std. Dev & 3.1 & 0.12 & 3.1 & 260 \\
\hline
\end{tabular}

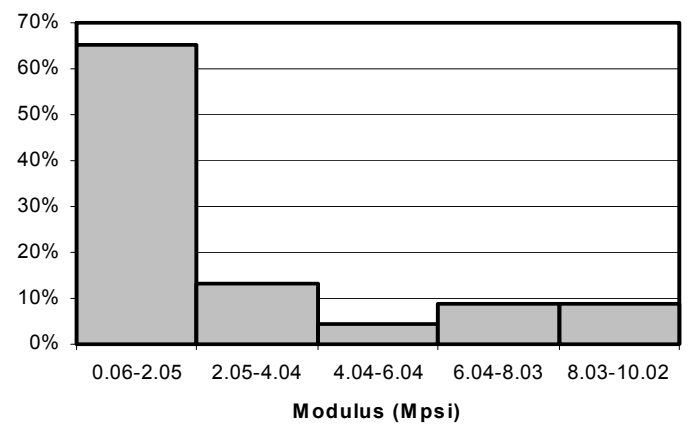

Figure 7 Distribution of shale modulus

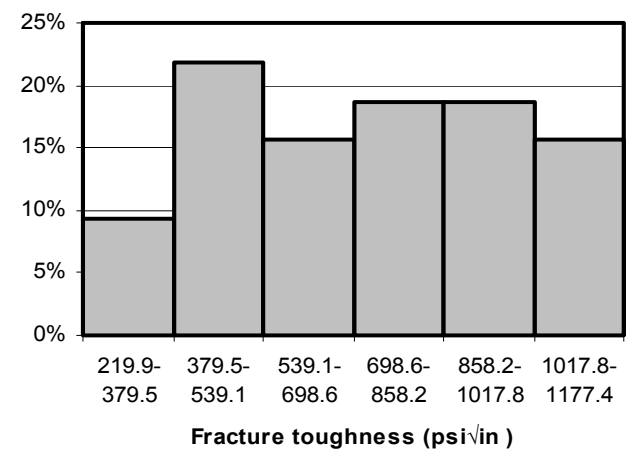

Figure 8 Distribution of shale fracture toughness 


\section{$\underline{\text { Sandstone Properties }}$}

Published data were analyzed to find the range of values for $E$, $v$, and $K_{I C}$ in order to estimate the mechanical properties of a sandstone formation. Data from 25 laboratory measurements of $E$ and $v$ and 45 measurements of $K_{I C}$ were collected from 8 sources (Baidyuk, 1967; Somerton et al. 1969; Atkinson and Meredith, 1987; Hatheway and Kiersch, 1989; Matsuki, 1989; Meredith, 1989; Ochterlony, 1989; Chen and Zhang, 2004). Young's modulus for sandstone ranged from 0.06 to $8.0 \mathrm{Mpsi}$ with an average of 2.1 Mpsi (Figure 9). Poisson's ratio for sandstone ranges from 0.06 to 0.36 with an average of 0.16 (Figure 10, Table 3 ). Individual values of the modulus were calculated from $E$ and $v$ measurements from the same material. Values for the modulus of sandstone ranged from 0.06 to $8.2 \mathrm{Mpsi}$ with an average of 2.2 Mpsi (Table 3). The distribution of the sandstone elastic modulus is skewed to the left with $39 \%$ of the reported values in the range of 1.2 to $2.4 \mathrm{Mpsi}$ (Figure 11 ). The sandstone $K_{I C}$ ranges

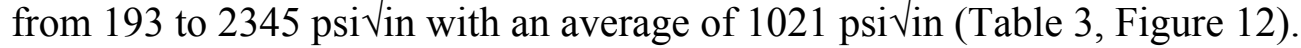

Table 3 Range of physical properties expected for sandstone

\begin{tabular}{l|c|c|c|c|} 
& \multicolumn{1}{c}{$\begin{array}{c}\text { Young's } \\
\text { Modulus }(E) \\
(\mathrm{psi})\end{array}$} & $\begin{array}{c}\text { Poisson's } \\
\text { Ratio } \\
(v)\end{array}$ & $\begin{array}{c}\text { Modulus }\left(E^{\prime}\right) \\
(\mathrm{Mpsi})\end{array}$ & $\begin{array}{c}\text { Fracture } \\
\text { Toughness } \\
(\mathrm{psi} \sqrt{ } \mathrm{in})\end{array}$ \\
\cline { 2 - 5 } Minimum & 0.1 & 0.01 & 0.06 & 193 \\
\cline { 2 - 5 } $\begin{array}{l}\text { Maximum } \\
\text { Average }\end{array}$ & 8.0 & 0.36 & 8.2 & 2345 \\
\cline { 2 - 5 } Std. Dev & 2.1 & 0.16 & 2.1 & 1021 \\
\cline { 2 - 5 } & 2.0 & 0.10 & 1.9 & 662 \\
\hline
\end{tabular}

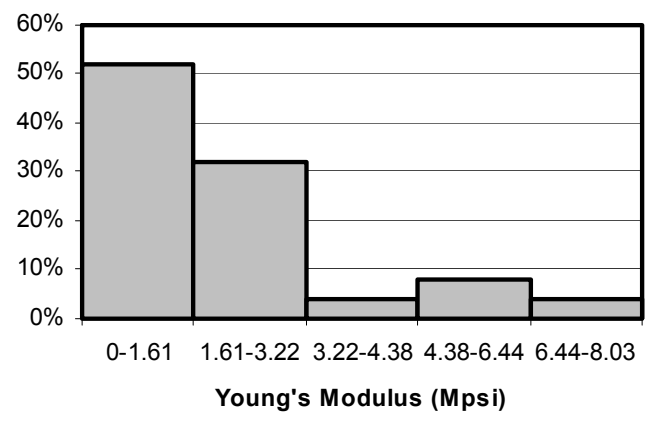

Figure 9 Distribution of Young's Modulus for sandstone

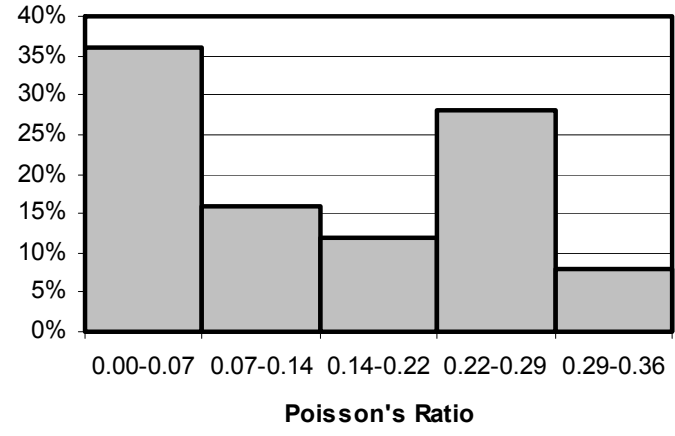

Figure 10 Distribution of Poisson's Ratio for sandstone 


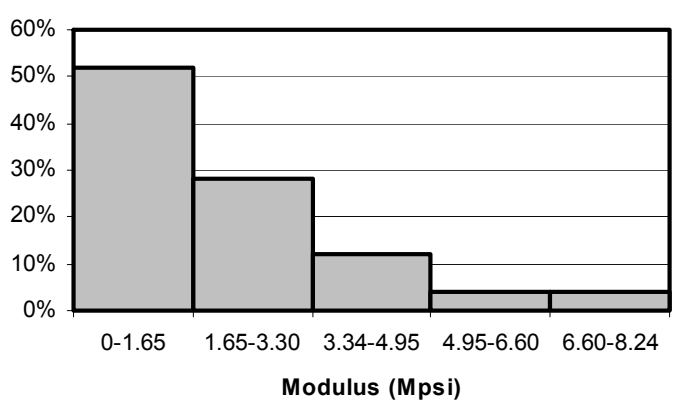

Figure 11 Distribution of sandstone modulus

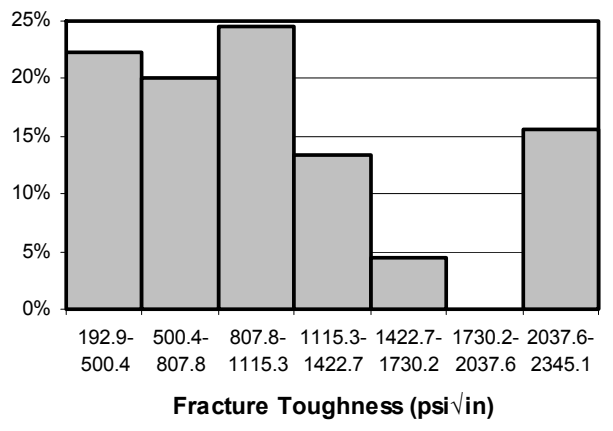

Figure 12 Distribution of sandstone fracture toughness

\section{Fracture Modeling Variables}

In order to model the characteristics of a hydraulic fracture created in limestone, a commercially available code, StimPlan by NSI Technologies was selected to run the simulations. The model has more than 25 input variables that include formation bedding, formation type, mechanical properties of the rock, in-situ stress, fracturing fluid, proppant, pumping rate, leakoff coefficient and pumping schedule. The values for the model inputs were selected based on the ranges of reported data. A representative baseline scenario was designed to characterize an ideal situation and variations of high, middle and low values for key variables were tested to determine the sensitivity of parameters.

\section{Conceptual Model}

The conceptual model of the system in which hydraulic fractures were simulated is a three layer system consisting of a target limestone formation that has an overlying and underlying formation of shale (Figure 13). It is assumed that all of the formations are homogeneous and isotropic with horizontal bedding. The thickness of the adjacent formations for the majority of simulations is $500 \mathrm{ft}$. The fracture is initiated by pumping fluid through a vertical well bore that is open to the formations only at the perforated interval. A baseline case was set up as a fracture with an idealized half length of $300 \mathrm{ft}$ in a $300 \mathrm{ft}$ thick

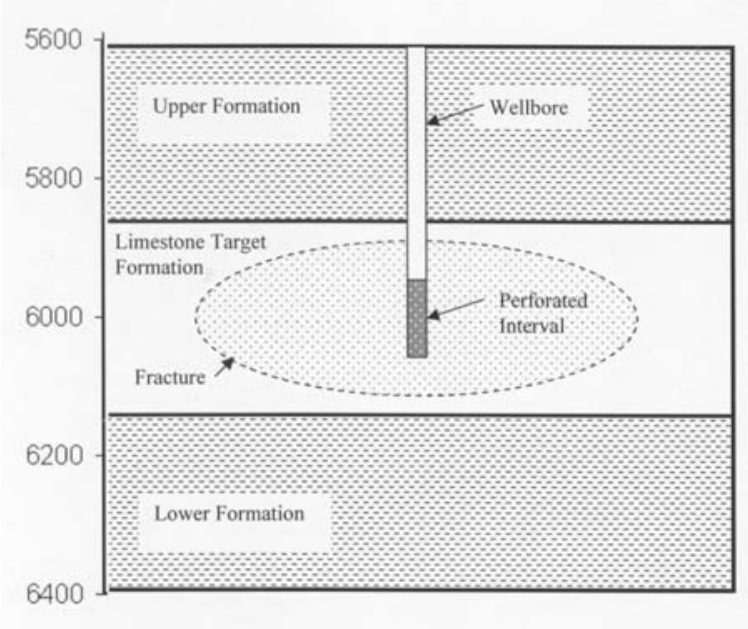

Figure 13 Conceptual model of radial fracture in a $300 \mathrm{ft}$ limestone formation bounded by $500 \mathrm{ft}$ thick shale formations. 
limestone formation. The thickness was selected to represent a realistic thickness for a limestone that would be suitable for the formation of caverns for gas storage by acid dissolution (Castle et al., 2004). The fracture length was selected to represent a fracture with a half length equal to the height of the formation. Variations in the model inputs were tested to discover the range of possible fracture characteristics as well as to demonstrate the effects of the different variables on fracture geometry and flow.

\section{Model Inputs}

The fracture simulation portion of StimPlan by NSI technologies Inc. has more than 25 input variables, including detailed stratigraphy and mechanical properties. For the sensitivity analysis of fracturing a limestone formation the data input for the model was divided into three classes; inputs that were assumed to be constant, inputs that varied at a constant rate with depth and inputs that were systematically varied for the tests. The inputs that were held constant for all of the runs are: porosity, permeability, fluid temperature, minimum Bottom Hole Flowing Pressure (BHFP), drainage area, design concentration and pump schedule. The model inputs that varied at a constant rate with depth were: closure pressure, reservoir pressure, formation temperature, and the in-situ stress. The input variables that were systematically varied were: limestone thickness, stress difference between limestone and adjacent layers, perforated interval length, limestone modulus, limestone fracture toughness, type of adjacent layer, adjacent layer modulus, adjacent layer fracture toughness, pumping rate, depth, fluid type, and proppant type.

\section{Constant Inputs}

The porosity of the limestone was assumed to be 0.1 and the permeability $0.1 \mathrm{md}$ (Table 4 ). These values were selected to characterize the properties expected for the limestone target formation as well as represent the properties observed in limestone at the target depth (Robertson 1959). The assumed values of porosity are conservatively high, but were held standard for continuity of the model. Variations in porosity and permeability are accounted for by variations of the leakoff coefficient. The temperature of the fracturing fluid was set at a constant $70^{\circ} \mathrm{F}$, a reasonable ambient temperature at the surface (Table 4). BHPF is the fluid pressure in the well, usually measured at the top of the target formation. The BHFP and drainage area are parameters that are specifically used in the model for simulations of petroleum reservoir productivity and have little effect on fracture geometry simulations. To maintain continuity of the simulations, the BHFP was set to $500 \mathrm{psi}$ and the drainage area was set to 400 acres, the defaults of the model (Table 4).
Table 4. Constant input parameters and gradients used for simulations

\begin{tabular}{|l|l|}
\hline Porosity & 0.1 \\
\hline Permeability & $0.1 \mathrm{md}$ \\
\hline Fluid Temperature & $70^{\circ} \mathrm{F}$ \\
\hline BHFP & $500 \mathrm{psi}$ \\
\hline Dranage area & $400 \mathrm{acres}$ \\
\hline $\begin{array}{l}\text { Proppant } \\
\text { Concentration }\end{array}$ & $11 \mathrm{PPG}$ \\
\hline Pumping Schedule & Table 5 \\
\hline $\begin{array}{l}\text { Formation } \\
\text { Temperature }\end{array}$ & $\begin{array}{l}48 \\
{ }^{\circ} \mathrm{F} / \mathrm{mile}\end{array}$ \\
\hline In-Situ Stress & $0.7 \mathrm{psi} / \mathrm{ft}$ \\
\hline Reservoir Pressure & $0.45 \mathrm{psi} / \mathrm{ft}$ \\
\hline
\end{tabular}




\section{Design Concentration/Pumping Schedule}

The design concentration for the mass of the proppant in the slurry for all of the simulations was 11 PPG (Table 4). That is, there are 11 pounds of proppant for every gallon of fluid. The typical range for design concentration is 6 to 14 PPG, and 11 PPG is on the high side of the mid-point of this range. The pumping schedule used for the baseline fracture simulations was derived from the design function that is part of the StimPlan software. It was created by using the baseline data to calculate a pump schedule for a fracture with an intended $300 \mathrm{ft}$ half length (Table 5). This pump schedule was used for all of the simulations that were variations of the baseline case. A different pumping schedule was designed for simulations of a fracture with a $30 \mathrm{ft}$ idealized length (Table 6). There was also a pumping schedule generated for a fracture with a proposed length of $1500 \mathrm{ft}$ (Table 7).

Table 5 Pumping schedule for $300 \mathrm{ft}$ horizontal half-length fracture

\begin{tabular}{|c|c|c|c|c|c|c|}
\hline Stage & $\begin{array}{l}\text { Slurry } \\
\text { Volume } \\
\text { (Mgal) }\end{array}$ & $\begin{array}{l}\text { Fluid } \\
\text { Volume } \\
\text { (Mgal) }\end{array}$ & $\begin{array}{l}\text { Concentratio } \\
\mathrm{n} \\
\quad(\mathrm{PPG}) \\
\end{array}$ & $\begin{array}{l}\text { Rate } \\
(\mathrm{BPM})\end{array}$ & $\begin{array}{l}\text { Cumulative } \\
\text { Proppant } \\
\text { (MLbs) }\end{array}$ & $\begin{array}{l}\text { Pump } \\
\text { Time } \\
(\min )\end{array}$ \\
\hline 1 & 6.08 & 6.08 & 0 & 30 & 0 & 4.8 \\
\hline 2 & 0.1 & 0.09 & 2 & 30 & 0.2 & 0.1 \\
\hline 3 & 0.29 & 0.25 & 3 & 30 & 1 & 0.2 \\
\hline 4 & 1 & 0.84 & 4 & 30 & 4.3 & 0.8 \\
\hline 5 & 2.77 & 2.18 & 6 & 30 & 17.4 & 2.2 \\
\hline 6 & 4.74 & 3.47 & 8 & 30 & 45.2 & 3.8 \\
\hline 7 & 4.93 & 3.39 & 10 & 30 & 79.1 & 3.9 \\
\hline 8 & 1.87 & 1.25 & 11 & 30 & 92.9 & 1.5 \\
\hline \multicolumn{2}{|c|}{ Total Slurry } & \multicolumn{2}{|c|}{ 21.8 Mgal } & \multicolumn{2}{|c|}{ Total Pump Time } & $17.3 \mathrm{~min}$ \\
\hline \multirow{2}{*}{\multicolumn{2}{|c|}{ Total Proppant }} & \multicolumn{2}{|c|}{ 92.9 MLbs } & \multicolumn{2}{|c|}{ Avg. Conc. } & 5.3 PPG \\
\hline & & \multicolumn{2}{|c|}{ 17.6 Mgal } & $\mathrm{Pad} \%$ & & $27.90 \%$ \\
\hline
\end{tabular}


Table 6 Pumping schedule for $30 \mathrm{ft}$ horizontal half-length

\begin{tabular}{|c|c|c|c|c|c|c|}
\hline Stage & $\begin{array}{l}\text { Slurry } \\
\text { Volume } \\
\text { (Mgal) }\end{array}$ & $\begin{array}{l}\text { Fluid } \\
\text { Volume } \\
\text { (Mgal) }\end{array}$ & $\begin{array}{c}\text { Concentration } \\
(\mathrm{PPG})\end{array}$ & $\begin{array}{l}\text { Rate } \\
(\mathrm{BPM})\end{array}$ & $\begin{array}{c}\text { Cumulative } \\
\text { Proppant } \\
\text { (MLbs) }\end{array}$ & $\begin{array}{l}\text { Pump } \\
\text { Time } \\
\text { (min) }\end{array}$ \\
\hline 1 & 0.22 & 0.22 & 0 & 30 & 0 & 0.2 \\
\hline 2 & 0.11 & 0.08 & 8 & 30 & 0.7 & 0.1 \\
\hline 3 & 0.28 & 0.19 & 10 & 30 & 2.6 & 0.2 \\
\hline 4 & 0.16 & 0.11 & 11 & 30 & 3.7 & 0.1 \\
\hline \multicolumn{2}{|c|}{ Total Slurry } & \multicolumn{2}{|c|}{$21.8 \mathrm{Mgal}$} & \multicolumn{2}{|c|}{ Total Pump Time } & $17.3 \mathrm{~min}$ \\
\hline \multicolumn{2}{|c|}{ Total Proppant } & \multicolumn{2}{|c|}{ 92.9 MLbs } & \multicolumn{2}{|c|}{ Avg. Conc. } & 5.3 PPG \\
\hline \multicolumn{2}{|c|}{ Total Fluid } & \multicolumn{2}{|c|}{ 17.6 Mgal } & \multicolumn{2}{|c|}{ Pad \% } & $27.90 \%$ \\
\hline
\end{tabular}

Table 7 Pumping schedule for a $1500 \mathrm{ft}$ horizontal half-length fracture

\begin{tabular}{|c|c|c|c|c|c|c|}
\hline Stage & $\begin{array}{l}\text { Slurry } \\
\text { Volume } \\
\text { (Mgal) }\end{array}$ & $\begin{array}{l}\text { Fluid } \\
\text { Volume } \\
\text { (Mgal) }\end{array}$ & $\begin{array}{l}\text { Concentratio } \\
\mathrm{n} \\
\quad(\mathrm{PPG})\end{array}$ & $\begin{array}{l}\text { Rate } \\
\text { (BPM) }\end{array}$ & $\begin{array}{l}\text { Cumulative } \\
\text { Proppant } \\
(\mathrm{MLbs})\end{array}$ & $\begin{array}{l}\text { Pump } \\
\text { Time } \\
\quad(\min )\end{array}$ \\
\hline 1 & 75.1 & 75.1 & 0 & 30 & 0 & 59.6 \\
\hline 2 & 0.77 & 0.74 & 1 & 30 & 0.7 & 0.6 \\
\hline 3 & 2.45 & 2.24 & 2 & 30 & 5.2 & 1.9 \\
\hline 4 & 4.61 & 4.06 & 3 & 30 & 17.4 & 3.7 \\
\hline 5 & 11.32 & 9.58 & 4 & 30 & 55.7 & 9 \\
\hline 6 & 23.05 & 18.12 & 6 & 30 & 164.5 & 18.3 \\
\hline 7 & 30.95 & 22.72 & 8 & 30 & 346.2 & 24.6 \\
\hline 8 & 27.54 & 18.95 & 10 & 30 & 535.7 & 21.9 \\
\hline 9 & 9.72 & 6.49 & 11 & 30 & 607.1 & 7.7 \\
\hline \multirow{3}{*}{\multicolumn{2}{|c|}{$\begin{array}{l}\text { Total Slurry } \\
\text { Total Proppant } \\
\text { Total Fluid }\end{array}$}} & \multicolumn{2}{|c|}{$185.5 \mathrm{Mgal}$} & \multicolumn{2}{|c|}{ Total Pump Time } & $158.0 \mathrm{~min}$ \\
\hline & & \multicolumn{2}{|c|}{ 607.1 MLbs } & \multicolumn{2}{|c|}{ Avg. Conc. } & $3.8 \mathrm{PPG}$ \\
\hline & & \multicolumn{2}{|c|}{$142.2 \mathrm{Mgal}$} & \multicolumn{2}{|c|}{$\operatorname{Pad} \%$} & $40.50 \%$ \\
\hline
\end{tabular}

\section{Constant Rate Variables}

Reservoir pressure, closure pressure, formation temperature and in-situ stress are all model inputs that were used in the models as variables that changed at a constant rate with depth. The gradient used for reservoir fluid pressure is $0.43 \mathrm{psi} / \mathrm{ft}$, a characteristic value for the reservoir pressure gradient (Smith and Shalyapobersky, 2000). The closure pressure $\left(\sigma_{\mathrm{cl}}\right)$ was calculated as a function of the pressure that results from the weight of the overburden $\left(\sigma_{v}\right)$, the reservoir pressure $\left(\mathrm{P}_{\text {res }}\right)$ and a poro-elastic formation constant $\left(\mathrm{K}_{\mathrm{o}}\right)$.

$$
\sigma_{\mathrm{cl}} \approx \mathrm{K}_{\mathrm{o}} *\left(\sigma_{\mathrm{v}}-\mathrm{P}_{\text {res }}\right)+\mathrm{P}_{\text {res }}
$$

The pressure that is generated by the weight of the overburden was calculated from the gradient 
of $1.0 \mathrm{psi} / \mathrm{ft}$ (Nolte, 2000, Thiercelin and Roegiers, 2000) and $\mathrm{K}_{\mathrm{o}}$ equals 0.33 (Smith and Shlyapobersky, 2000). The formation temperature was calculated from the average geothermal gradient for the Eastern states of $48^{\circ} \mathrm{F} / \mathrm{mile}\left(25^{\circ} \mathrm{C} / \mathrm{km}\right)$ (Nathenson and Guffaint, 1988). The typical in-situ stress gradient is $0.7 \mathrm{psi} / \mathrm{ft}$ (Smith and Shalyapobersky, 2000).

\section{Variables Tested}

The model inputs that were systematically varied to represent the range of expected values can be divided into to categories: in-situ parameters and parameters that can be adjusted at the surface. The in-situ parameters tested were depth, limestone thickness, stress difference, mechanical properties of the rock formations and the leakoff coefficient (Table 8). The parameters that can be adjusted from the surface are the pumping rate, perforated interval, fracturing fluid type, and proppant type (Table 9). The depth selected for the baseline simulation is $6000 \mathrm{ft}$. A shallower fracture at $4000 \mathrm{ft}$ and a deeper fracture at $8000 \mathrm{ft}$ were also simulated to test fracture characteristics within the optimal range for natural gas storage (Castle et. al., 2004). A limestone thickness of $300 \mathrm{ft}$ was selected as the baseline value. A thicker limestone of $1500 \mathrm{ft}$ and a thinner limestone of $30 \mathrm{ft}$ were also tested (Table 8).

Table 8 In-situ parameters tested

Depth

Limestone Thickness

Stress Difference

Limestone Modulus

Limestone Fracture

Toughness

Adjacent Layer Modulus

Adjacent Layer Fracture

Toughness

Leakoff Coefficient

\begin{tabular}{|c|c|c|}
\hline Low & Baseline & High \\
\hline $4000 \mathrm{ft}$ & $6000 \mathrm{ft}$ & $8000 \mathrm{ft}$ \\
\hline $30 \mathrm{ft}$ & $300 \mathrm{ft}$ & $1500 \mathrm{ft}$ \\
\hline$-900 \mathrm{psi}$ & $-300 \mathrm{psi}$ & $900 \mathrm{psi}$ \\
\hline $0.5 \mathrm{Mpsi}$ & $6.5 \mathrm{Mpsi}$ & $15 \mathrm{Mpsi}$ \\
\hline 350 psi $\sqrt{\text { in }}$ & 1000 psi $\sqrt{ }$ in & 1800 psi $\sqrt{ }$ in \\
\hline $0.1 \mathrm{Mpsi}$ & $2.5 \mathrm{Mpsi}$ & $4.3 \mathrm{Mpsi}$ \\
\hline $246 \mathrm{psi} \sqrt{ }$ in & 730 psi $\sqrt{ }$ in & 1292 psi $\sqrt{ }$ in \\
\hline $\begin{array}{l}1.0 \times 10^{-5} \\
\mathrm{ft} \sqrt{m}_{\min }\end{array}$ & $\begin{array}{l}1.0 \times 10^{-4} \\
\mathrm{ft} \sqrt{ } \min \end{array}$ & $\begin{array}{l}1.0 \times 10^{-2} \\
\mathrm{ft} \sqrt{ }{ }_{\text {min }}\end{array}$ \\
\hline
\end{tabular}

Table 9 Range of adjustable parameters tested

Pumping Rate

Perforated Interval

Fracturing Fluid Viscosity

Proppant Size/Strength

\begin{tabular}{|l|l|l|}
\multicolumn{1}{l|}{ Low } & \multicolumn{1}{l}{ Baseline } & \multicolumn{1}{l}{ High } \\
\hline $6 \mathrm{BPM}$ & $30 \mathrm{BPM}$ & $150 \mathrm{BPM}$ \\
\hline $20 \mathrm{ft}$ & $150 \mathrm{ft}$ & $300 \mathrm{ft}$ \\
\hline $45 \mathrm{cp}$ & $320 \mathrm{cp}$ & $840 \mathrm{cp}$ \\
\hline $12-20$ Sand & $20-40$ Sand & $20-40$ Bauxite \\
\hline
\end{tabular}

Limestone Properties-Values Used in Model 
The elastic modulus selected for the baseline case is $6.60 \mathrm{Mpsi}$ to represent the average value of modulus based on the data collected (Table 1). A high modulus value of $15 \mathrm{Mpsi}$ and a low modulus value of 0.5 psi were tested (Table 8 ). These values were chosen to represent the range of values possible as well as provide a broad-spectrum representation of the modulus. The value for fracture toughness used in the baseline simulation was $1000 \mathrm{psi} \sqrt{ } \mathrm{in}$. The variation in fracture toughness used to represent the reported range of values was $1800 \mathrm{psi} \backslash \mathrm{in}$ for the high end of the range and $350 \mathrm{psi} \backslash \mathrm{in}$ for the low end of the range (Table 8). The values selected to represent the limestone modulus and fracture toughness represent the range of values from reported data (Table 1).

\section{$\underline{\text { Adjacent Layers }}$}

The adjacent layers for the baseline simulation were designed to represent a 500 -ft-thick shale unit with a modulus of $2.50 \mathrm{Mpsi}$, a fracture toughness of $730 \mathrm{psi} \sqrt{ }$ in and an in-situ stress that was 300 psi greater than the stress in the limestone unit. These values were selected because they are typical for shale. The values of modulus and fracture toughness for shale are also within the range of the values for sandstone, and therefore could represent sandstone as well. A high, middle and low value of the modulus and fracture toughness were selected to test the affects on fracture characteristics (Table 10). Each of the selected values of modulus was simulated with each of the values for fracture toughness so that nine simulations were run to demonstrate the effects of modulus with different values for toughness within the expected range for shale and limestone. The nine tests were run twice, once with the stress in the limestone 300 psi less than the in-situ stress in the shale, and once with no stress difference between the units.

\section{Stress Difference}

For the baseline scenario, the adjacent shale layers had a stress difference of $300 \mathrm{psi}$ greater than the limestone formation. Four other values of the stress difference were also simulated. The values input for the limestone formation were: $-900 \mathrm{psi},-300 \mathrm{psi}, \quad 0 \mathrm{psi}, 300$ psi, and 900 psi. Negative values indicate situations where the stress in the adjacent formations was greater than the limestone formation and positive values indicate situations where the stress in the limestone was greater than in the adjacent formations.

\section{$\underline{\text { Leakoff Coefficient }}$}

The leakoff coefficient input into StimPlan is the total leakoff coefficient and is related to resistance to fluid loss due to the fracturing fluid filtrate viscosity, a resistance to fluid loss from the reservoir fluid, and to the fracturing fluid system itself forming a filter cake which retards 
fluid loss (NSI, 2004b). The range of the fluid loss coefficient was $1.0 \times 10^{-5} \mathrm{ft} \bigvee_{\min }$ to $1.0 \times 10^{-1}$ $\mathrm{ft} \sqrt{ } \mathrm{min}$. The entire range was tested in steps of half order of magnitude. The values of leakoff coefficient simulated were: $1.0 \times 10^{-5} \mathrm{ft} \sqrt{\text { min }}_{3} ; .5 \times 10^{-5} \mathrm{ft} \sqrt{\mathrm{min}}_{\min } 1.0 \times 10^{-4} \mathrm{ft} \sqrt{\mathrm{min}} ; 5.5 \times 10^{-4}$ $\mathrm{ft} V_{\min } ; 1.0 \times 10^{-3} \mathrm{ft} V_{\min } ; 5.5 \times 10^{-3} \mathrm{ft} V_{\min } ; 1.0 \times 10^{-2} \mathrm{ft} V_{\min } ; 5.5 \times 10^{-2} \mathrm{ft} V_{\min }$; and $1.0 \times 10^{-1}$ $\mathrm{ft} \sqrt{ } \min$.

\section{$\underline{\text { Perforated Interval }}$}

It was assumed that fracture initiation occurred at the same length of perforated interval for all of the simulations. Also, the midpoint of the perforated interval was located at the midpoint of the limestone formation height. The baseline perforated interval was set at $150 \mathrm{ft}$, one half of the limestone thickness. A longer perforated interval of $300 \mathrm{ft}$, perforated throughout the limestone formation, and a shorter perforated interval of $30 \mathrm{ft}$ were also simulated (Table 9).

\section{Pumping Rate}

The pumping rate for the baseline model was set at 30 barrels per minute (BPM) based on the average injection rates from 53 published fracture treatments (Ranostaj, 1976; Horton, 1981, Miller and Smith, 1989; Smith and Shalyapobersky, 2000). A pumping rate of approximately $30 \mathrm{BPM}$ is also predicted to be the most cost effective (Lacy and Smith, 1989). The pumping rate can range from 0.5 BPM to several hundred BPM. To test the effects of variations in pumping rate on fracture formation, a low pumping rate of $6 \mathrm{BPM}$ and a high rate of 150 BPM were simulated (Table 9).

\section{$\underline{\text { Fluid Properties }}$}

The fracturing fluid chosen for the baseline runs was 30\# X-Link. This is one of eight fluids included in the model database and is the fluid with the median viscosity. $30 \# \mathrm{X}$-Link is a fracturing fluid that has 30 pounds of a polymer per 1000 gallons of water with a crosslinker added. A total of five different fluid types were used to evaluate the effect of fracturing fluid rheology on fracture characteristics (Table 11).60Q/40\#fm is 60 Quality foam using 40 pounds of gel per 1000 gallons of water as the liquid phase of the foam, and 60 Quality means that the foam is $60 \%$ Nitrogen or Carbon Dioxide by volume. The data pertaining to fluid type in the model falls into two main inputs, fluid type and fluid temperature. The injection temperature for the fluid was assumed to be at an average ambient air temperature of $70^{\circ} \mathrm{F}$. Variations of fluid temperature should have a negligible effect on the fracture characteristics, so the fluid temperature was held constant.
Table 11 Different fracturing fluids tested and their viscosities at formation temperature

\begin{tabular}{|l|c|}
\hline $\begin{array}{l}\text { Fracturing } \\
\text { Fluid }\end{array}$ & $\begin{array}{l}\text { Viscosity (cp) } \\
\text { @ Formation } \\
\text { Temp }\end{array}$ \\
\hline 60Q/40\#fm & 45 \\
\hline 70Q/40\#fm & 52 \\
\hline 30\#_X-Link & 320 \\
\hline 40\#_X-Link & 640 \\
\hline 50\#_X-Link & 840 \\
\hline
\end{tabular}

\section{Proppant}


The proppant used in the baseline simulation is 20/40 sand with a design concentration of 11 ppg. The 20/40 sand was chosen because the particle size is small enough to enter into fractures with a width of 0.066 in and can be transported to deeper formations than larger sized proppants (Anderson et al., 1989). A range of proppant sizes and types were tested to evaluate how differences in proppant size and strength affect the fracture characteristics (Table 12).

Table 12. Characteristics of proppants used in simulations.

\begin{tabular}{|l|c|c|c|}
\hline Proppant & Mesh range (in) & $\begin{array}{l}\text { Specific } \\
\text { Gravity }\end{array}$ & $\begin{array}{l}\text { Damage } \\
\text { Factor }\end{array}$ \\
\hline 12-20 Sand & $0.066-0.033$ & 2.65 & 0.70 \\
\hline 16-30 Sand & $0.047-0.023$ & 2.65 & 0.70 \\
\hline 16-30 RCSandPC & $0.047-0.024$ & 2.55 & 0.80 \\
\hline 20-40 Sand & $0.033-0.017$ & 2.65 & 0.70 \\
\hline 20-40 Int_Strength & $0.033-0.017$ & 3.15 & 0.80 \\
\hline
\end{tabular}

\section{Adjacent Formation Thickness}

The thickness of the adjacent layers was $500 \mathrm{ft}$ for the majority of the simulations. The data for these simulations was used to calculate the distribution of fracture characteristics. The thickness of the adjacent layer was varied to test the effect of the adjacent formation thickness on vertical fracture growth. The adjacent layer thickness tested were $1 \mathrm{ft}, 10 \mathrm{ft}, 25 \mathrm{ft}, 50 \mathrm{ft}, 75 \mathrm{ft}$, $100 \mathrm{ft}, 150 \mathrm{ft}$ and $200 \mathrm{ft}$. The material on the above and below the shale layers is assumed to be limestone.

\section{Numerical Modeling to Predict Formation of Storage Volume during Dissolution Process (Task 8)}

For modeling the development of caverns by acid dissolution of carbonate rock, we modified the TOUGH2 code EWASG (Battistelli et al., 1997; Pruess et al., 1999) with the ECO2 module from Pruess and Garcia (2002) to get a fully coupled simulator for the acid-rock dissolution.

\section{Modeling Field Performance (Task 9)}

To evaluate the ability of caverns produced by the acid-dissolution method to store natural gas, numerical simulations were performed using the TMVOC multiphase simulator (Pruess and Battistelli, 2002). This simulator can consider multiple condensable and noncondensable hydrocarbon gases, using the real gas law.

Field Characterization Methods (Task 10) 
This part is divided into two distinct sections. The first section deals with using pressure transients measured at the surface to monitor and assess cavern formation development and the second part evaluates the stability of a cavern during acid dissolution formation.

\section{Analysis of Operational Pressure Transients to Assess Cavern Dissolution By Larry Murdoch, Jong-Won Choi, and Leonid Germanovich}

The geometric characteristics of the gas storage cavern during the construction stage can be estimated by transient pressure measurements. A perturbation can be generated by changing the injection rate of acid so that a pressure wave propagates through the acid. If the wave meets any interfaces, reflection and transmission occur at the interface.

By analyzing the characteristics of the reflected and transmitted waves at the wellhead, characteristics of the gas storage cavern can be estimated. The pressure wave propagation through the system can be considered as transient fluid flow in a pipeline. Hence, the whole system is modeled by one-dimensional transient fluid flow in two pipelines named pipe 1 and pipe 2 as shown in Figure 14.

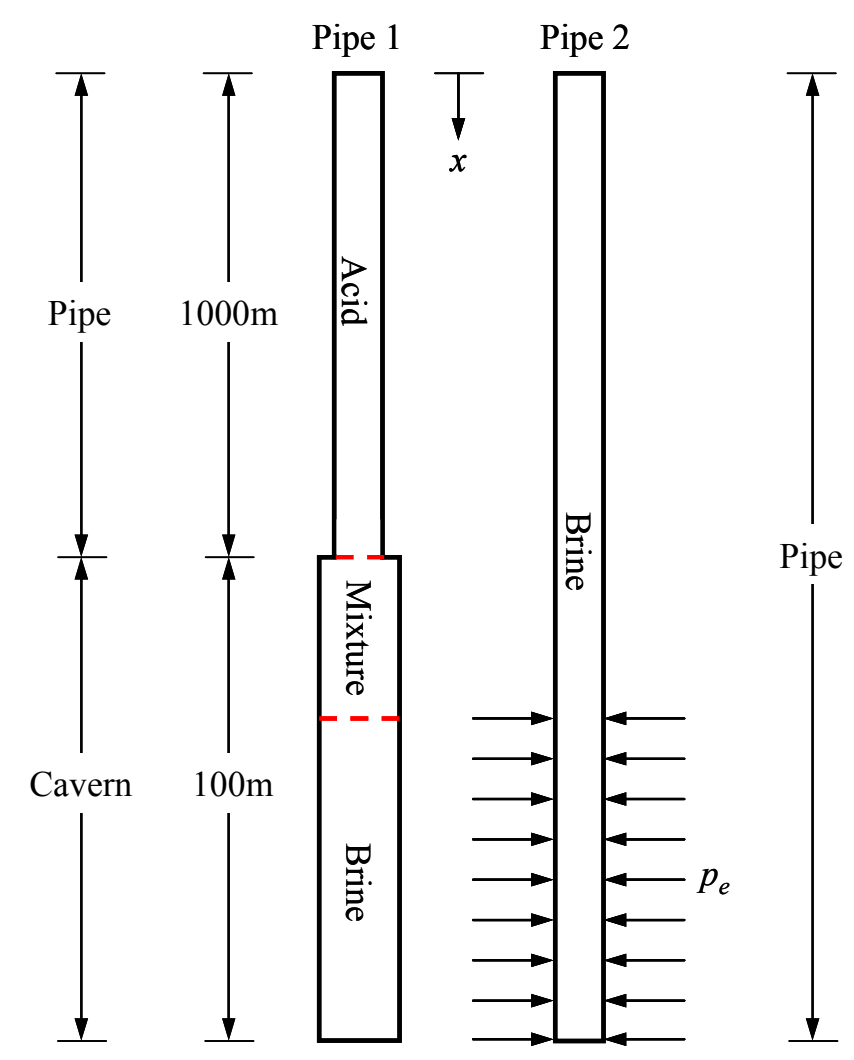

Figure 14 Geometry of problem. Pipe 1 is composed of pipe and cavern. The pipe region in pipe 1 is filled with acid where as cavern region is filled with mixture and brine. Pipe 2 is composed of only pipe region and it is filled with brine (not to scale). 
Pipe 1 is composed of two parts; a steel pipe and a cavern. The injected acid flows through the pipe part. Below the steel pipe, a cavern created by dissolution of carbonate rock is connected to the pipe. The upper part of the cavern is filled with mixture of acid, supercritical $\mathrm{CO}_{2}$, and brine. The dissolution process occurs in this region. The lower part of the cavern is filled with brine. Since density of the brine is greater than $\mathrm{CO}_{2}$, brine is located at the bottom of the cavern.

Pipe 2 is a steel pipe. Brine is collected at the bottom of pipe 2, and it is pumped out at the top of pipe 2 . The lower part of pipe 2 , which contacts the brine, is loaded externally by the pressure of brine as shown in Figure 14.

The length of the steel pipe is $1000 \mathrm{~m}$, and that of cavern in pipe 1 is $100 \mathrm{~m}$ as shown in Figure 14. However, the exact location of the interface of mixture and brine is not determined. Diameter of the pipes, that is, upper part of the pipe 1, and pipe 2, is $0.04 \mathrm{~m}$. Initial diameter of the cavern is assumed $0.15 \mathrm{~m}$, and diameter of cavern increases as the dissolution process proceeds.

\section{Initial and Boundary Conditions}

For the simplicity of calculations and analysis, it is assumed that the characterization of cavern using fluid transient is conducted in the zero initial flow rate condition. In the field, injection of acid is stopped to create zero flow rate condition. After all pressure waves due to the stoppage of injection are dissipated, a pressure wave can be generated by injecting acid during a short time. The governing equations used to describe the transient fluid flow in this study are based on the zero initial flow rate condition, so the initial pressure distribution does not affect the results of calculation if initial velocity is zero. Therefore, initial flow rate and pressure are all zero, respectively, along the whole domain.

As a boundary condition, flow rate at the top of the pipe $1(x=0 \mathrm{~m})$ is controlled, and it is shown in Figure 15. From zero to 0.375 seconds, flow rate is kept zero, and it is increased up to $6.309 \times 10^{-4} \mathrm{~m}^{3} / \mathrm{sec}(10 \mathrm{gal} / \mathrm{min})$ during 0.25 seconds. Then, it is decreased to zero during 0.25 seconds, and it is kept zero. 


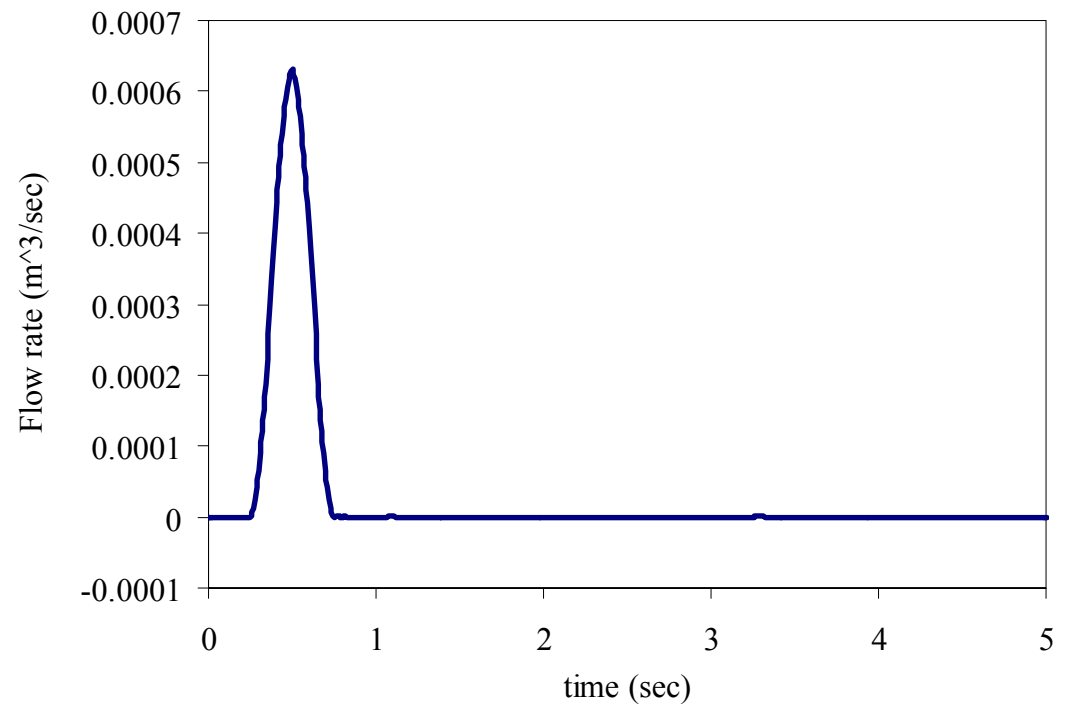

Figure 15 Flow rate at $x=0 \mathrm{~m}$ in pipe 1

At the junction of the pipe and the cavern in the pipe 1, it is assumed that flow rate and pressure is continuous. At the top of the pipe $2(x=0 \mathrm{~m})$, pressure of the brine is controlled, and in this study, it is kept constant.

Although pipe 1 and pipe 2 are modeled separately, pressure and flow rate at the bottom of them $(x=1100 \mathrm{~m})$ must be continuous. Hence, at the bottom of the pipe 1, pressure at the bottom of the pipe 1 is set the same as that at the bottom of pipe 2 whereas flow rate at the bottom of pipe 2 is the same as that at the bottom of pipe 1 .

\section{Material Properties}

In this study, the pipe material is assumed to be made of steel and the material properties of the steel and characteristics of the pipe are shown in Table 13. The material properties of a cavern made of limestone are shown in Table 14. Material properties of acid $(\mathrm{HCl})$ and brine are shown in Table 15.

Table 13 Material property of steel and characteristics of pipe (Gere and Timoshenko, 1992) (Janna, 1993)

\begin{tabular}{|l|l|}
\hline Young's modulus of steel & $200 \times 10^{9} \mathrm{~Pa}$ \\
\hline Poisson's ratio of steel & 0.28 \\
\hline Internal diameter of pipe & $0.04 \mathrm{~m}(\approx 1.5 \mathrm{inch})$ \\
\hline Thickness of diameter of pipe & $0.005 \mathrm{~m}$ \\
\hline Wall roughness & $4.6 \times 10^{-5} \mathrm{~m}$ \\
\hline
\end{tabular}


Table 14 Material property of limestone (Goodman, 1989) (Janna, 1993)

\begin{tabular}{|l|l|}
\hline Young's modulus of limestone & $56 \times 10^{9} \mathrm{~Pa}$ \\
\hline Poisson's ratio of limestone & 0.3 \\
\hline Wall roughness & $0.03 \mathrm{~m}$ \\
\hline
\end{tabular}

Table 15 Material property of acid and brine (Wikipedia, 2006b)

\begin{tabular}{|l|l|l|}
\hline Material property & Acid $(\mathrm{HCl})$ & Brine \\
\hline Density $\left(\mathrm{kg} / \mathrm{m}^{3}\right)$ & 1180 & 1230 \\
\hline Bulk modulus $(\mathrm{Pa})$ & $2.72 \times 10^{9}$ & $2.35 \times 10^{9}$ \\
\hline Dynamic viscosity $(\mathrm{Pa} \cdot \mathrm{sec})$ & $1.9 \times 10^{-3}$ & $4.9 \times 10^{-3}$ \\
\hline
\end{tabular}

The mixture located between the acid and brine in pipe 1 is composed of acid, brine, and $\mathrm{CO}_{2}$, such that its property is dependent on the component ratio of each material. Although the component ratio of each material is not known, it seems that the major component of the mixture is $\mathrm{CO}_{2}$ because there might be a separation of materials due to the difference of their densities. Hence, in this study, it is assumed that the material property of mixture is the same as that of $\mathrm{CO}_{2}$.

Since $\mathrm{CO}_{2}$ layer is located below $1000 \mathrm{~m}$, the phase of $\mathrm{CO}_{2}$ is supercritical. If $\mathrm{CO}_{2}$ is considered as a liquid, the bulk modulus and density of $\mathrm{CO}_{2}$ are required as material properties. In the case that pressure-density curve for $\mathrm{CO}_{2}$ can be considered linear, constant bulk modulus can be used instead of a non-linear one which is dependent on pressure. From the assumption of zero initial flow rate condition, pressure distribution along the pipeline is hydrostatic, so that pressure at the top of the $\mathrm{CO}_{2}$ layer is given by

$$
p_{\mathrm{CO}_{2}}=\rho_{\text {acid }} \cdot g \cdot 1000 \mathrm{~m}
$$

where $p_{\mathrm{CO}_{2}}, \rho_{\text {acid }}$, and $g$ are pressure at the top of the $\mathrm{CO}_{2}$ layer, density of acid, and acceleration of gravity, respectively. By assuming $\rho_{\text {acid }}$ is $1180 \mathrm{~kg} / \mathrm{m}^{3}$, the pressure at the top of the $\mathrm{CO}_{2}$ layer is $11.57 \mathrm{MPa}$. The pressure-density curve for $\mathrm{CO}_{2}$ in the range of $10 \sim 15 \mathrm{MPa}$ is shown in Figure 16. 


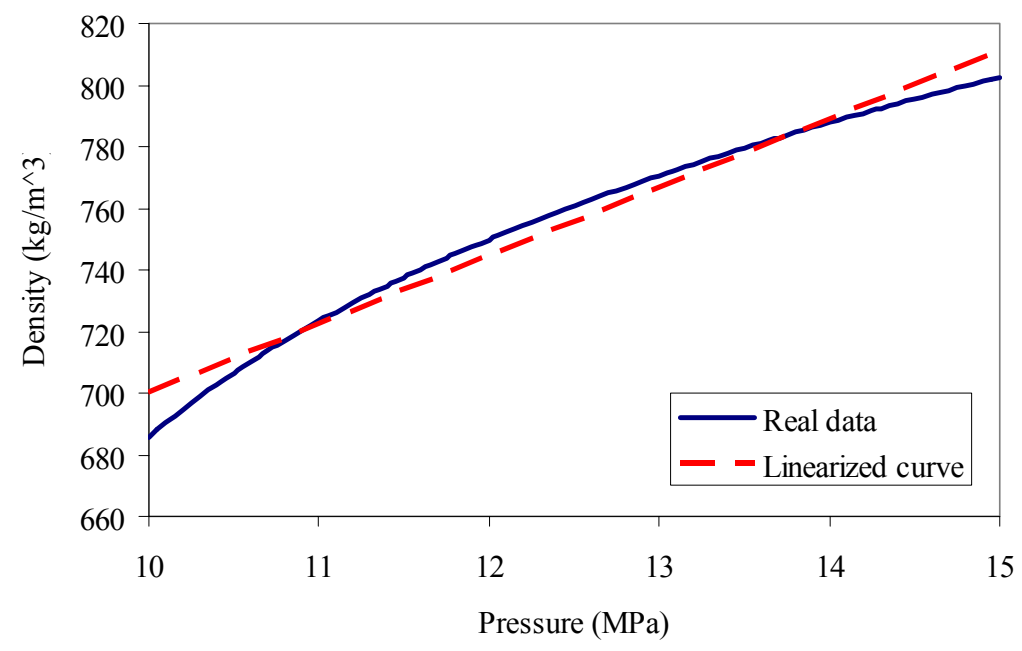

Figure 16 Relationship between pressure and density of $\mathrm{CO}_{2}$. In the rage of pressure between 10$15 \mathrm{MPa}$, the correlation of linearized curve is 0.9765 (Temperature, 310K).

In Figure 16, the pressure-density curve for $\mathrm{CO}_{2}$ in the range of $10 \sim 15 \mathrm{MPa}$ is non-linear. However, the increase of pressure in $\mathrm{CO}_{2}$ due to perturbation can be approximately estimated by assuming frictionless flow as follows (Wylie and Streeter, 1978):

$$
\Delta p=\rho a \Delta V
$$

where $\Delta p, \rho, a$, and $\Delta V$ are the change of pressure due to perturbation, density of a fluid, wave speed in the fluid, and the change of fluid velocity due to perturbation, respectively.

Let us assume that density and wave velocity of supercritical $\mathrm{CO}_{2}$ are $656 \mathrm{~kg} / \mathrm{m}^{3}$ and $1000 \mathrm{~m} / \mathrm{sec}$ (selected from wave speed in air and water). From the boundary condition, perturbation at the wellhead is $10 \mathrm{gal} / \mathrm{min}$, so that $\Delta V$ is $0.036 \mathrm{~m} / \mathrm{sec}$ if diameter of cavern is $0.15 \mathrm{~m}$. Hence, $\Delta p$ is $2.36 \times 10^{4} \mathrm{~Pa}$, and pressure in $\mathrm{CO}_{2}$ changes approximately from 11.57 to $11.59 \mathrm{MPa}$ due, although the pressure change will be much smaller due to the reflection of wave at the interface of acid and mixture and friction loss. The pressure-density curve in the range of 11 12 MPa is shown in Figure 17. 


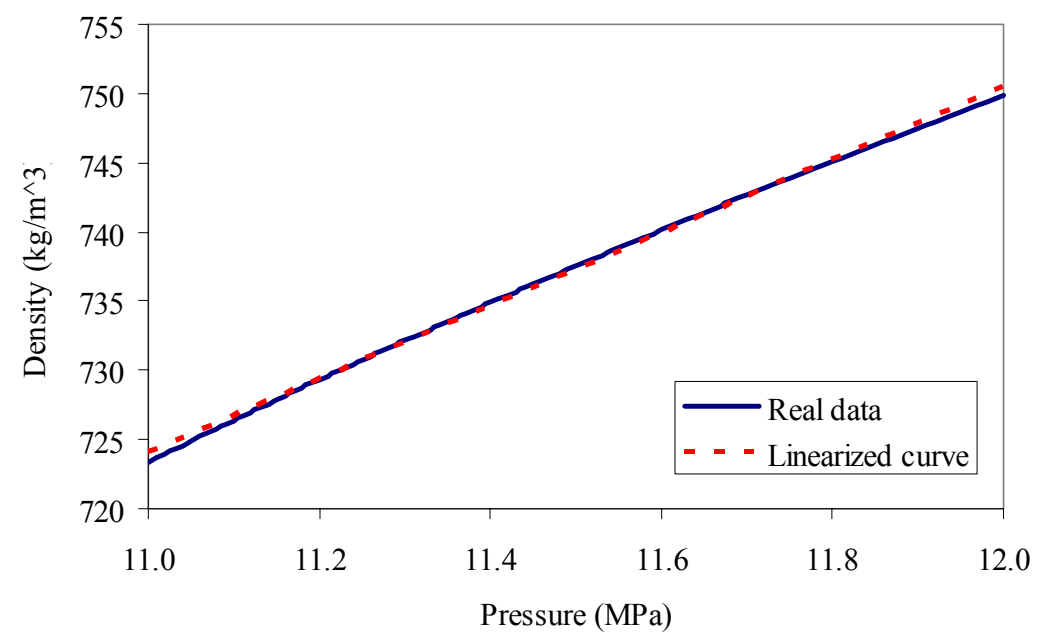

Figure 17 Relationship between pressure and density of $\mathrm{CO}_{2}$ in the rage of pressure between 10$11 \mathrm{MPa}$, the correlation of linearized curve is 0.9987 , so that relationship between pressure and density can be considered linear (Temperature, 310K).

In Figure 17, the pressure-density curve in the range of 11 12 MPa can be considered linear, which means that constant bulk modulus can be used for $\mathrm{CO}_{2}$.

On the other hand, if $\mathrm{CO}_{2}$ is considered as a gas, initial density, gas constant, temperature, and compressibility factor are required for material properties. The obtained material properties for both liquid-like $\mathrm{CO}_{2}$ and gas-like $\mathrm{CO}_{2}$ are shown in Table 16. .

Table 16 Material properties of $\mathrm{CO}_{2}$ (NIST, 2006)

\begin{tabular}{|l|l|}
\hline Density $\left(\mathrm{kg} / \mathrm{m}^{3}\right)$ & 770 \\
\hline Bulk modulus $(\mathrm{Pa})$ & $2.74 \times 10^{7}$ \\
\hline Dynamic viscosity $(\mathrm{Pa} \cdot \mathrm{sec})$ & $5.6 \times 10^{-5}$ \\
\hline Temperature $(\mathrm{K})$ & 310 \\
\hline Gas constant $(\mathrm{N} \cdot \mathrm{m} / \mathrm{mol} / \mathrm{K})$ & 8.314 \\
\hline Compressibility factor & 0.27 \\
\hline Molar weigh $(\mathrm{Kg} / \mathrm{mol})$ & 0.044 \\
\hline
\end{tabular}

For the friction factor, although fluid flow in this study is transient, Darcy-Weisbach friction factor $f$ for steady-state fluid flow is generally used in the momentum equation (Adamkowski, 2003) (Chaudhry, 1987). Since the change of wave velocity is expected to be small, it seems reasonable to use a constant friction factor for each fluid. We can approximately predict the change of fluid velocity due to perturbation, so that Reynolds number can be calculated as follows

$$
\operatorname{Re}=\frac{\rho V D}{\mu}
$$

where $\rho, V, D$, and $\mu$ are density of fluid, fluid flow velocity, diameter of pipe, and dynamic 
viscosity of fluid, respectively. After calculating Reynolds number, Darch-Weisbach friction factor can be obtained from the Moody diagram for a given wall roughness.

\section{Method of Solution}

The governing equations are non-linear partial differential equations. Analytical solution of these equations is difficult, so that numerical analysis methods are generally used. Among the numerical analysis method, finite difference method (FDM), method of characteristics (MOC), and finite element method (FEM) are widely used (Chaudhry, 1987).

Finite difference method can be divided into two categories; explicit finite difference method and implicit finite difference method. In the explicit finite difference method, partial derivatives in the partial differential equations are replaced by finite difference approximations. The solutions of each time step can be calculated directly from the solution of previous time step. However, due to the accuracy and stability of the solution, time step should be kept small (Wang and Anderson, 1980).

In the implicit finite difference method, spatial derivatives in the partial differential equations evaluated by using weighted average of approximation between current and next time step. Thus, solution to current time step is not expressed explicitly in terms of known previous solutions so that iterative method is used to obtain solution (Wang and Anderson, 1980). An advantage of the implicit finite difference method is that the time step can be larger than that of the explicit finite difference method. However, still there is a restriction in the time step. Courant Number $\left(C_{N}\right)$ should be kept close to 1.0 (Holloway and Chaudhry, 1985), where

$$
C_{N}=a \frac{\Delta t}{\Delta x} \approx 1
$$

where $a, \Delta t$, and $\Delta x$ are wave speed, time step, and size of spatial finite difference grid, respectively. If $C_{N} \neq 1$, artificial high frequency oscillations behind steep wave fronts are generated. Due to these limitation, implicit finite difference method has not become popular for the analysis of transients in closed pipes (Chaudhry, 1987).

In method of characteristics, the two partial differential equations are converted into two ordinary differential equations called compatibility equations. Then, the two ordinary differential equations are solved along the characteristic lines using finite difference methods (Streeter and Wylie, 1967). The main disadvantage of the method is that the size of the time step is restricted due to the same reason as that of explicit finite difference method. In addition, interpolations may be necessary when the pipe's diameter varies which leads to variation of wave velocity. In such a case, it is difficult to keep the Courant number close to 1, and consequently this method will always produce numerical diffusion (Szymkiewicz and Mitosek, 2005) .

The finite element method can have a larger time step than the method of characteristics and the explicit finite difference method (Arfaie and Anderson, 1991). The disadvantage of the finite element method is that it requires a greater amount of computational sophistication than the finite difference method does (Istok, 1989).

\section{FEM Formulation and Solution}

Finite-element methods available in COMSOL (2005) Multi-physics were used to solve 
the continuity and momentum equations. In the finite element method, a subdomain is partitioned into smaller meshes called elements. For example, the subdomain is divided into several line elements in 1-D problems, and triangular or quadrilateral elements in 2-D problems.

Then, the value of dependent variables at each element is approximated using a shape function; for example, in linear elements, linear shape functions are used. The partial differential equations are changed into variational form, and discretized. With given boundary conditions, the discretized variational form of the partial differential equation is solved.

\section{Evaluation of the Stability of a Cavern Created by Dissolution of Carbonate Rock By Larry Murdoch and Jim Foley}

The conceptual model for the simulations consists of a cavern that is instantaneously created in limestone and filled with water at hydrostatic pressure to represent the cavern upon the completion of acid injection. Internal pressure was applied to the interior of the cavern to represent the water and gas. Pressure was varied in the cavern to represent filling with an increasing volume of gas. The results were analyzed to identify when the limestone surrounding the cavern first exhibited yield, when the yield was greater that 20 percent of the cavern boundary and when failure occurred.

\section{Predicted Cavern Volume}

Calculations based on the ideal gas law were used in order to approximate the volume of a cavern needed to store a specific volume of natural gas at depth. The ideal gas law describes the behavior of a gas at pressures and temperatures close to atmospheric. When calculating the behavior of gases at higher pressures, natural gas compresses more than an ideal gas would and behaves as a real gas. To predict the behavior of a real gas such as methane at higher pressures, the real gas equation of state is used

$$
p V=n R T Z
$$

where $p=$ pressure $(\mathrm{Pa}), V=$ volume $\left(\mathrm{m}^{3}\right), T=$ Temperature $(\mathrm{K}), \mathrm{Z}=$ Gas compressibility factor, $R=$ Universal gas constant $\left(8.314472 \frac{\mathrm{kPa}}{\mathrm{K} * \mathrm{~mol}}\right)$, and

$$
n=\text { number of moles }=\frac{\mathrm{M}}{\mathrm{Mw}}=\frac{\text { mass of gas }(\mathrm{kg})}{\text { molecular weight of gas }(\mathrm{kg} / \mathrm{mol})} \text {. }
$$

also

$$
Z=\frac{\text { actual volume of } \mathrm{n} \text { moles of gas at certain } \mathrm{T} \text { and } \mathrm{p}}{\text { calculated volume of } \mathrm{n} \text { moles of gas at same } T \text { and } \mathrm{p}}
$$

To calculate the volume of gas at temperatures and pressures of the proposed storage cavern, equation 6 can be rewritten so that 


$$
\frac{p_{1} V_{1}}{Z_{1} T_{1}}=\frac{p_{2} V_{2}}{Z_{2} T_{2}}
$$

where the initial conditions (subscript 1) represents the properties of the gas at Standard Temperature and Pressure (STP) and subscript 2 represents the gas at conditions expected in the cavern. The natural gas composition used in calculations was based on Castle et al, (2004) and consists of $90 \%$ methane and $10 \%$ ethane with a molecular weight of $17.3 \mathrm{~g} / \mathrm{mol}$ and a density of $0.781 \mathrm{~kg} / \mathrm{m}^{3}$ at STP. Using the proposed storage volume in billion cubic feet (BCF) at STP for the initial conditions of the gas, a temperature gradient of $25^{\circ} \mathrm{C} / \mathrm{km}$ (Nathenson and Guffaint, 1988), an assumed gas pressure gradient of $12.4 \mathrm{kPa} / \mathrm{m}$ (Castle et al., 2004) and a $z$ factor of 0.85 for the expected depths (Figure 18), the approximate cavern volume necessary to store a certain volume of natural gas can be calculated (Figure 19). This is necessary in predicting the size of the cavern. For example, if a gas storage facility intended to contain $0.5 \mathrm{BCF}$ of gas were to be created at a depth of $610 \mathrm{~m}$, the cavern would need a volume of $189,730 \mathrm{~m}^{3}$, whereas if the cavern were to be created at $1830 \mathrm{~m}$ the predicted cavern volume would be $62,750 \mathrm{~m}^{3}$ (Figure 19).

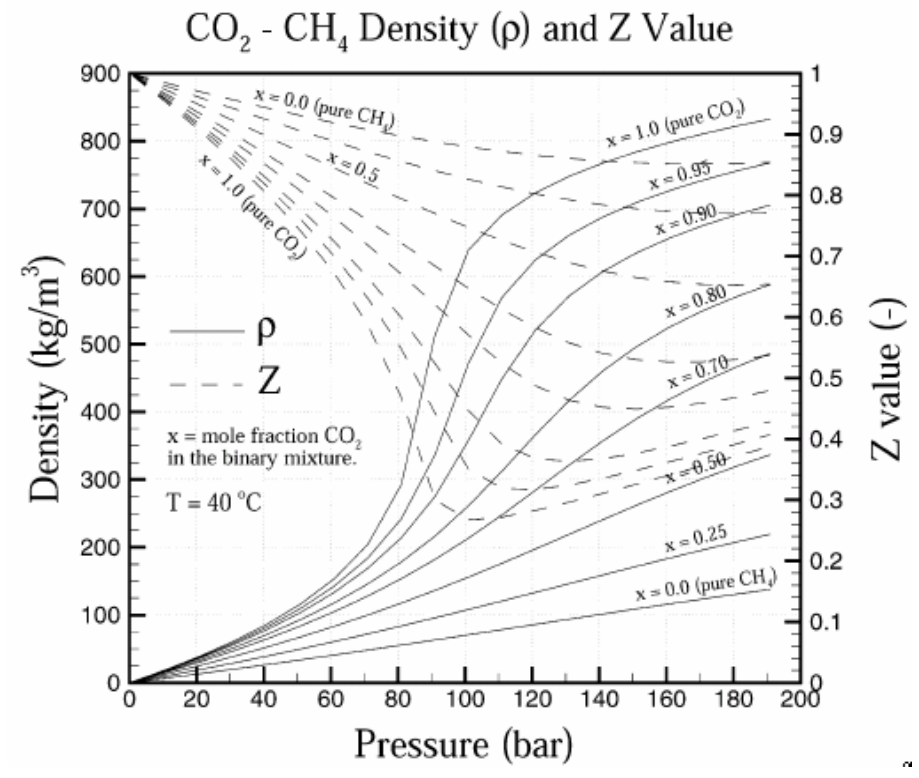

Figure 18 Density and $Z$ value of $\mathrm{CO}_{2}-\mathrm{CH}_{4}$ mixtures at $T=40{ }^{\circ} \mathrm{C}$ (Oldenburg, 2003). 


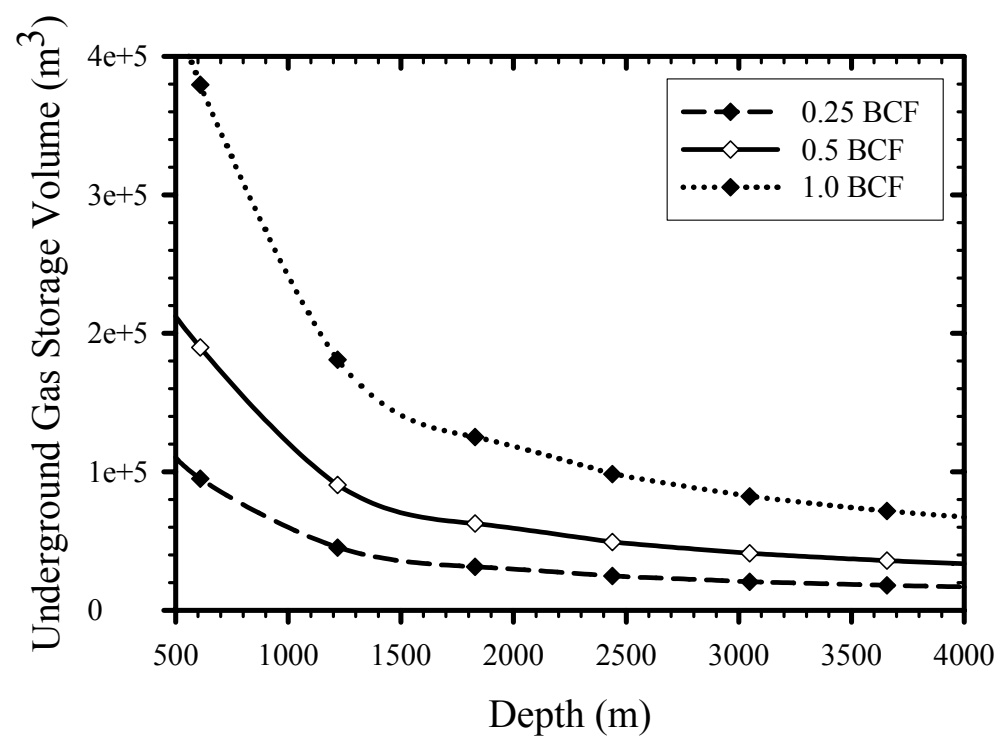

Figure 19 Variation of underground storage volume required for 0.25 to 1.0 BCF (STP) at depth.

\section{Cavern Geometry}

Seven cavern geometries of approximately the same volume of $62,570 \mathrm{~m}^{3}$ were simulated to test the effects of geometry on cavern stability (Table 17). This is the predicted volume necessary to store $0.5 \mathrm{BCF}$ of gas at $1830 \mathrm{~m}$ (Figure 19), and is the target cavern size. The baseline cavern was selected as a right cylinder with a radius of $20 \mathrm{~m}$ and a height of $50 \mathrm{~m}$. Mass calculations were conducted assuming that the cavern was a right cylinder while the actual shape modeled has rounded corners (Figure 20). A tall narrow cylinder with a radius of $10 \mathrm{~m}$ and a height of $200 \mathrm{~m}$ as well as a short wide cavern with a radius of $40 \mathrm{~m}$ and a height of $12 \mathrm{~m}$ were simulated to test the effects of caverns with different height to width ratios (Figure 21). A simulation of a circle within the grid was used to represent a cylindrical cavern that was laid on its side similar to a tunnel with a radius of $10 \mathrm{~m}$ and a length of $200 \mathrm{~m}$ (Figure 21). A spherical cavern with a radius of $24.6 \mathrm{~m}$ and a conical cavern with a base radius of $25 \mathrm{~m}$ and a height of $95.6 \mathrm{~m}$ were simulated to represent different cavern geometries (Figure 21). A cylindrical cavern based on the $10 \times 200 \mathrm{~m}$ cavern but with a domed roof and floor was also simulated (Figure 21). The caverns are referred to by their radii and height, whereas the maximum dimensions are larger (Table 17). 
Table 17 Overall dimensions of simulated caverns.

\begin{tabular}{|c|c|c|c|}
\hline Shape & Max Width (m) & Max Height (m) & Max Length (m) \\
\hline $10 \times 200$ Cylindrical & 20 & 200 & 20 \\
\hline 20 x 50 Cylindrical & 40 & 50 & 40 \\
\hline 40 x 12 Cylindrical & 80 & 12 & 80 \\
\hline Spherical & 49.2 & 49.2 & 49.2 \\
\hline Tunnel & 20 & 20 & 200 \\
\hline Conical & 50 & 95.6 & 50 \\
\hline 10 x 200 Domed Cylindrical & 20 & 200 & 20 \\
\hline
\end{tabular}

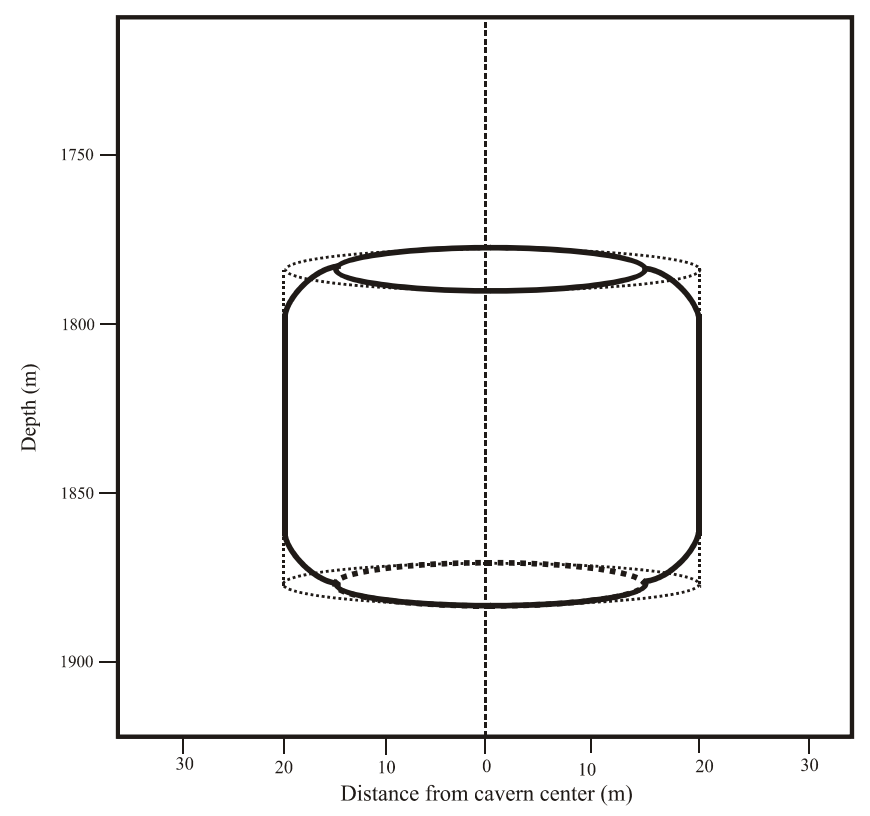

Figure 20 Idealized $20 \times 50 \mathrm{~m}$ cylindrical cavern. Dotted lines represent the shape used for mass calculations, solid lines represent the cavern simulated and the dashed line in the center represents the axis of symmetry. (Not to scale) 

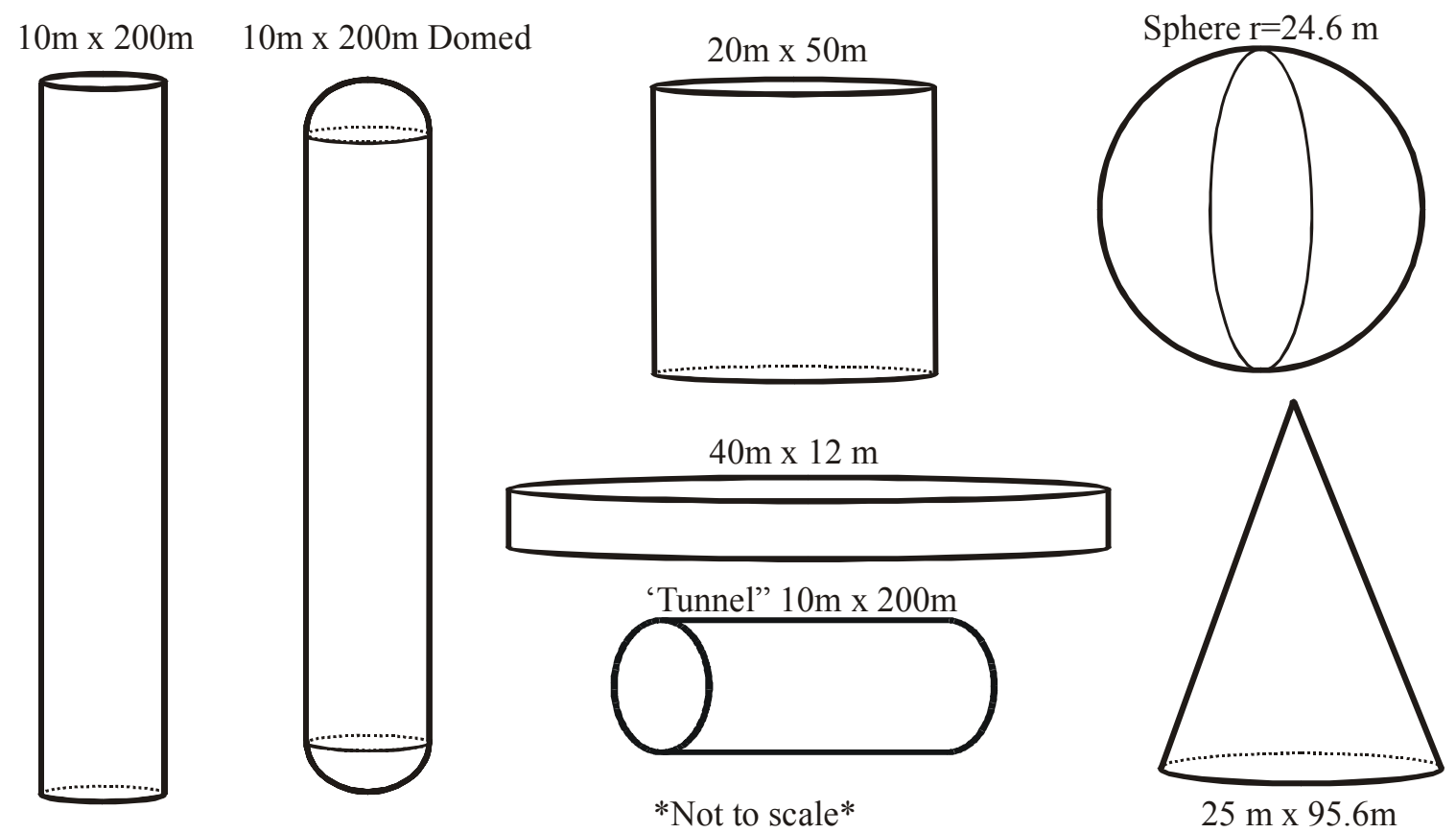

Figure 21 Idealized cavern geometries simulated, labeled as radius of circular section by height or length.

\section{Stability Modeling}

Cavern stability modeling was conducted using FLAC 2D 5.0, a commercially available code marketed by the Itasca Consulting Group, Inc. of Minneapolis, Minnesota. FLAC is a twodimensional (2-D) explicit, finite difference program that performs a Lagrangian analysis to model geomechanical problems. Simulations were run on a Dell Optiplex GX280 computer with $148 \mathrm{~GB}$ hard drive and an Intel Pentium 4 processor operating at $3.2 \mathrm{GHz}$ with $2.0 \mathrm{~GB}$ of RAM. To simulate cavern stability, the material properties of the rock, in-situ stress state, geometry of the cavern and the internal cavern pressures were defined and the Mohr-Coulomb calculation scheme in FLAC was selected. While the physical properties of the limestone were held constant, the in-situ stress, depth, cavern size, internal cavern pressure and geometry were systematically varied to test the affects on cavern stability.

\section{$\underline{\text { Formation Properties }}$}

The caverns were simulated in a homogenous, isotropic limestone formation of infinite horizontal extent with a thickness that exceeded the region simulated. Gravity was set to act on the formation at $9.81 \mathrm{~m} / \mathrm{s}^{2}$. The material database included with FLAC was used as the source for limestone mechanical data (Table 18). The limestone was assumed to behave as a MohrCoulomb material.

The effects of groundwater flow and pore pressure

Table 18 Limestone mechanical properties used for stability simulations.

\begin{tabular}{|l|c|}
\hline Density & $2700 \mathrm{Kg} / \mathrm{m}^{3}$ \\
\hline Bulk Modulus & $2.26 \times 10^{10} \mathrm{~Pa}$ \\
\hline Shear Modulus & $1.1 \times 10^{10} \mathrm{~Pa}$ \\
\hline Cohesion & $6.72 \times 10^{6} \mathrm{~Pa}$ \\
\hline Tension & $1.58 \times 10^{6} \mathrm{~Pa}$ \\
\hline Friction Angle & $42.0^{\circ}$ \\
\hline Dilation Angle & $0.0^{\circ}$ \\
\hline
\end{tabular}


were also simulated. The limestone was assumed to have a porosity of 0.1 and a permeability of $1.0 \times 10^{-16} \mathrm{~m}^{2}(0.1 \mathrm{md})$. The water was assumed to have a density of $1000 \mathrm{~kg} / \mathrm{m}^{3}$ and a bulk modulus of $2.2 \times 10^{9} \mathrm{~Pa}$. The pore pressure of the formation was assumed to be at hydrostatic pressure with a gradient of $9794 \mathrm{~Pa} / \mathrm{m}$.

\section{$\underline{\text { In-Situ Stress }}$}

The vertical stress $\left(\sigma_{y y}\right)$ that results from the weight of the overburden was included using a gradient of $22.7 \mathrm{kPa} / \mathrm{m}$. The horizontal stresses were assumed to be equal and at ratio $k$ to the vertical stress $\left(k=\frac{\sigma_{h}}{\sigma_{v}}\right)$. The $k$ ratio at the depths simulated varies from approximately 0.3 to

1.3. Simulations were run for each cavern shape with $k$ of $0.4,0.6,0.8,1.0$ and 1.2 (Table 19) to test the effects of in-situ stress on cavern stability.

Depth

The baseline $20 \times 50 \mathrm{~m}$ cylindrical cavern of was simulated at a depth of $1830 \mathrm{~m}$. To test the effects of changes in stress that occur at different depths the $20 \times 50$ m cavern was simulated at a shallower depth of $1220 \mathrm{~m}$ and deeper depth of $2440 \mathrm{~m}$ (Table 20). While the volume of gas that can be stored at these depths is different (Figure 19), the cavern size of $20 \times 50 \mathrm{~m}$ was held constant and the initial stress due to depth was the only parameter varied for the simulation.

\section{$\underline{\text { Cavern Size }}$}

The baseline storage volume was selected to be $0.5 \mathrm{BCF}$ of natural gas at standard state. At a depth of $1830 \mathrm{~m}$ the predicted cavern volume to store $0.5 \mathrm{BCF}$ of gas is $62,570 \mathrm{~m}^{3}$ (Figure 19). Cavern sizes with target volumes of $0.25 \mathrm{BCF}$ and $1.0 \mathrm{BCF}$ were also simulated to test the effect of cavern volume on stability (Table 19). To store $0.25 \mathrm{BCF}$ of gas at standard state, the predicted cavern volume at $1830 \mathrm{~m}$ is $31,285 \mathrm{~m}^{3}$ (Figure 19; Table 19). A cylindrical shape with a radius of $17 \mathrm{~m}$, height of $34 \mathrm{~m}$ and a height to radius ratio of 2.0 was simulated for the 0.25 BCF cavern. To store $1.0 \mathrm{BCF}$ of gas at standard state, the predicted cavern volume at $1830 \mathrm{~m}$ is $125,140 \mathrm{~m}^{3}$ (Figure 19; Table 19). A cylindrical shape with a radius of $27 \mathrm{~m}$, height of $55 \mathrm{~m}$ and a height to radius ratio of 2.0 was simulated for the $1.0 \mathrm{BCF}$ cavern. The dimensions of the caverns were selected to have approximately the same height to radius ratio of the $20 \times 50 \mathrm{~m}$ cylindrical cavern (2.5) and fit within the modeling grid. 
Table 19 Parameters simulated for cavern stability analysis.

\begin{tabular}{|c|c|c|c|c|c|c|}
\hline \multirow{2}{*}{\multicolumn{2}{|c|}{ Taroet Gas Volume (STP) }} & Low & Baseline & High & & \\
\hline & & $0.25 \mathrm{BCF}$ & $0.5 \mathrm{BCF}$ & $1.0 \mathrm{BCF}$ & & \\
\hline \multirow{2}{*}{\multicolumn{2}{|c|}{$\begin{array}{l}\text { Cavern Volume } \\
\text { Cavern Depth }\end{array}$}} & $31285 \mathrm{~m}^{3}$ & $62570 \mathrm{~m}^{3}$ & $125140 \mathrm{~m}^{3}$ & & \\
\hline & & $1220 \mathrm{~m}$ & $1830 \mathrm{~m}$ & $2440 \mathrm{~m}$ & & \\
\hline \multirow{4}{*}{$\begin{array}{l}\text { Horizontal to } \\
\text { Vertical Stress } \\
\text { Ratio (k) } \\
\text { Cavern Geometry } \\
\text { Base Radius } \\
\text { Height }\end{array}$} & 0.4 & 0.6 & 0.8 & 1.0 & 1.2 & \\
\hline & Tunnel-like & Cylindrical & Cylindrical & Cylindrical & Conical & Spherical \\
\hline & $10 \mathrm{~m}$ & $40 \mathrm{~m}$ & $20 \mathrm{~m}$ & $10 \mathrm{~m}$ & $25 \mathrm{~m}$ & $24.6 \mathrm{~m}$ \\
\hline & 200m (length) & $12 \mathrm{~m}$ & $50 \mathrm{~m}$ & $200 \mathrm{~m}$ & $95.6 \mathrm{~m}$ & \\
\hline & & & & + Domed & & \\
\hline
\end{tabular}

$\underline{\text { Internal Cavern Pressure }}$

At the start of each simulation, the cavern was instantaneously excavated and assumed to be filled with water at hydrostatic pressure. In order to displace the water in the cavern, it was assumed that the gas pressure at the bottom of the cavern would have to be greater than or equal to the hydrostatic pressure at the bottom of the cavern for the initial gas fill (Figure 22). The initial gas fill was set up so that the pressure at the bottom of the cavern when the cavern was initially filled was equal to the hydrostatic pressure at the bottom of the cavern. It was assumed that the cavern was instantaneously filled with gas. The internal cavern pressure was increased from the initial fill pressure in steps of 0.1 or $0.2 P^{*}$ until the model indicated that the system was unstable (discussed later). The $P^{*}$ values simulated were $1.1,1.2,1.3,1.4,1.5,1.6,1.8,2.0$, $2.2,2.4,2.6,2.8$, and 3.0. If the cavern was still stable at a $P^{*}$ value of 3.0, pressure was increased by steps of $0.2 P^{*}$ until instability was indicated. The internal cavern pressure was then reduced to predict cavern stability at low internal pressures. The pressure in the cavern was cycled back down to hydrostatic from the last internal pressure that was considered stable, as well as to internal pressures below hydrostatic, assuming no water infiltration, at $P^{*}$ values of $0.9,0.8,0.7,0.6,0.5$ and $P^{*} \approx 0$ as an extreme case. Calculating the mass in the cavern for $P^{*}$ values less than 1.0 will produce negative values because the calculations are based on the hydrostatic pressure in the cavern, but it is useful in giving a benchmark for stability effects of low pressure. 


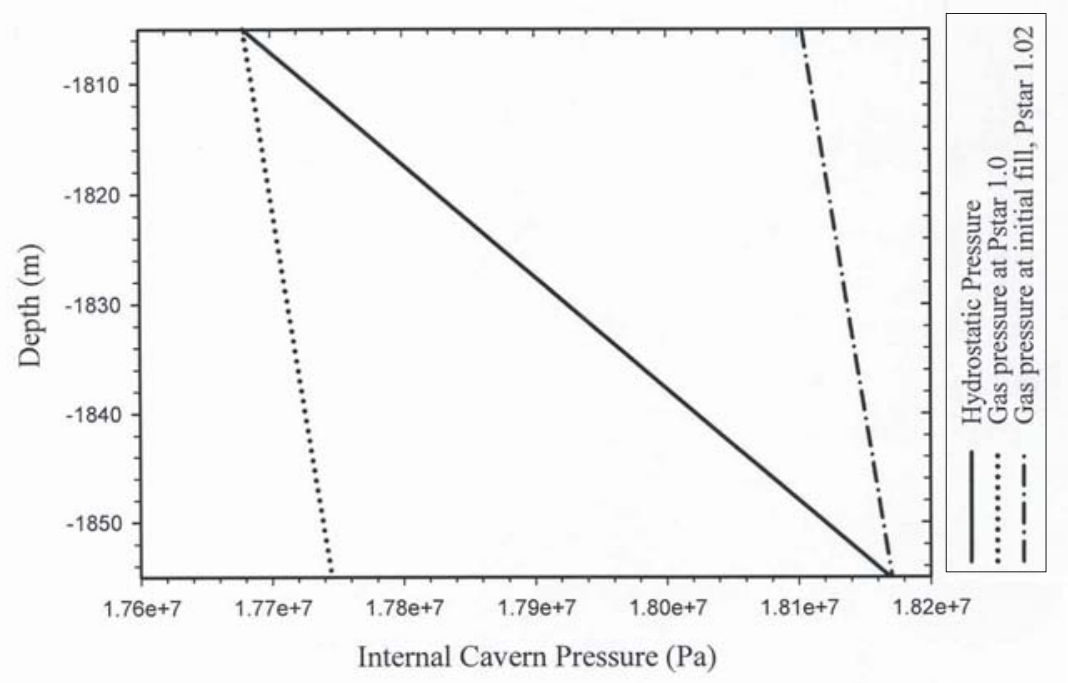

Figure 22 Pressure profiles for the 20 x $50 \mathrm{~m}$ cylindrical cavern.

\section{$\underline{\text { Internal Cavern Pressure in FLAC }}$}

The internal cavern pressures were input into FLAC as both a mechanical and a pore pressure. The mechanical pressure is a result of the gas pushing on the cavern walls, and was input as an applied pressure to the internal wall at a value equal to the expected pressure. This pressure varied with depth. The internal cavern pressure will also affect the formation pore pressure. To simulate this effect, a pore pressure was applied equal in magnitude to the mechanical pressure (Hart, 2005).

\section{Instability Indicators}

\section{$\underline{\text { Unbalanced Force }}$}

The primary indicator for cavern stability in FLAC is the maximum unbalanced force ratio (Figure 23) (Itasca, 2005b). The maximum unbalanced force ratio is a calculation of the forces acting on an element in model. When the unbalanced force ratio goes to zero, the forces are balanced and all elements in the model are stationary (Figure 23). When the unbalanced force stabilizes to a value other than zero there is some portion of the model that is in motion. The unbalanced force can also oscillate or increase with simulation steps indicating that some portion of the model has failed (Figure 23) (Itasca, 2005b). 


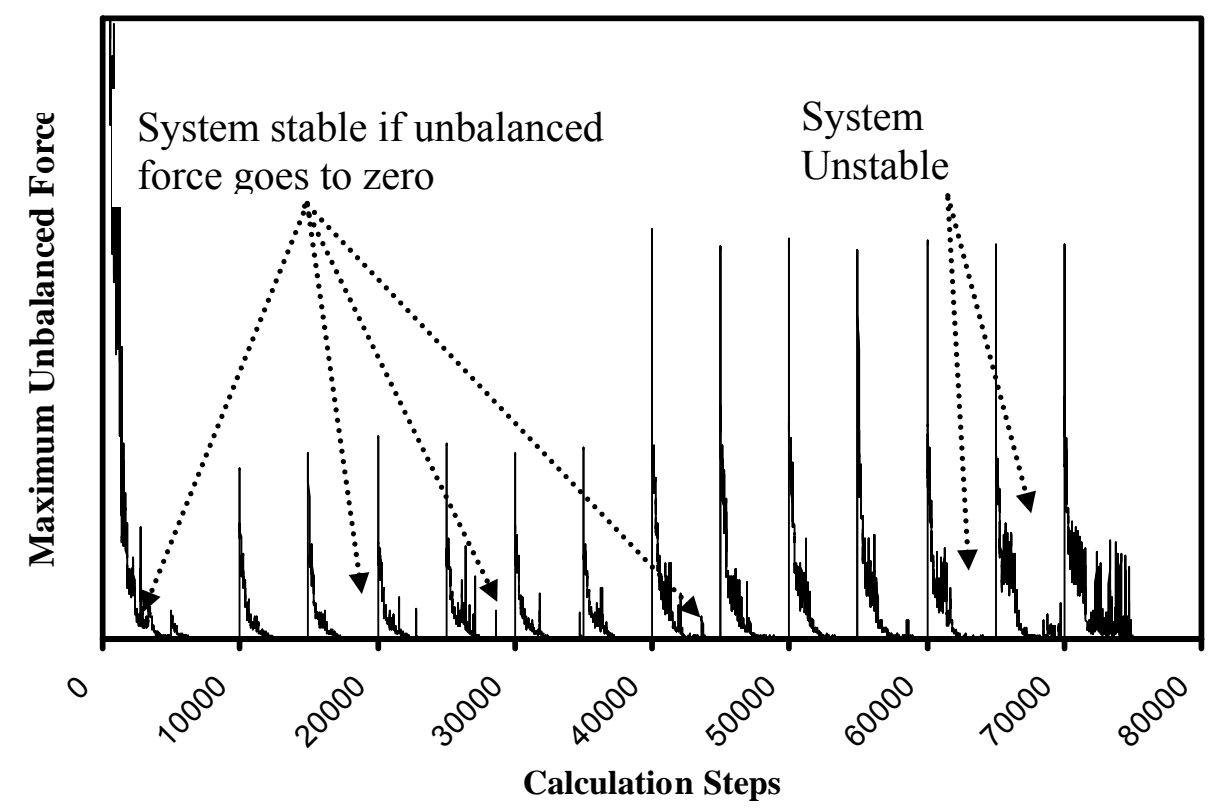

Figure 23 Maximum unbalanced force. System is stable when unbalanced force goes to zero, unstable when unbalanced force is oscillating.

\section{Displacement History}

Another indicator of cavern stability is the $x$ or $y$ displacement of a gridpoint in the model. In FLAC it is possible to mark a gridpoint in order to track its displacement during the simulation. When the system has reached equilibrium and is stable, the displacement history for a gridpoint will stabilize as a horizontal line (Figure 24). When the system is unstable and failure is indicated, the displacement history for a gridpoint will have some slope (Figure 24). A steep slope indicates that the gridpoint is moving relatively quickly and that failure is more likely (Itasca, 2005b). 


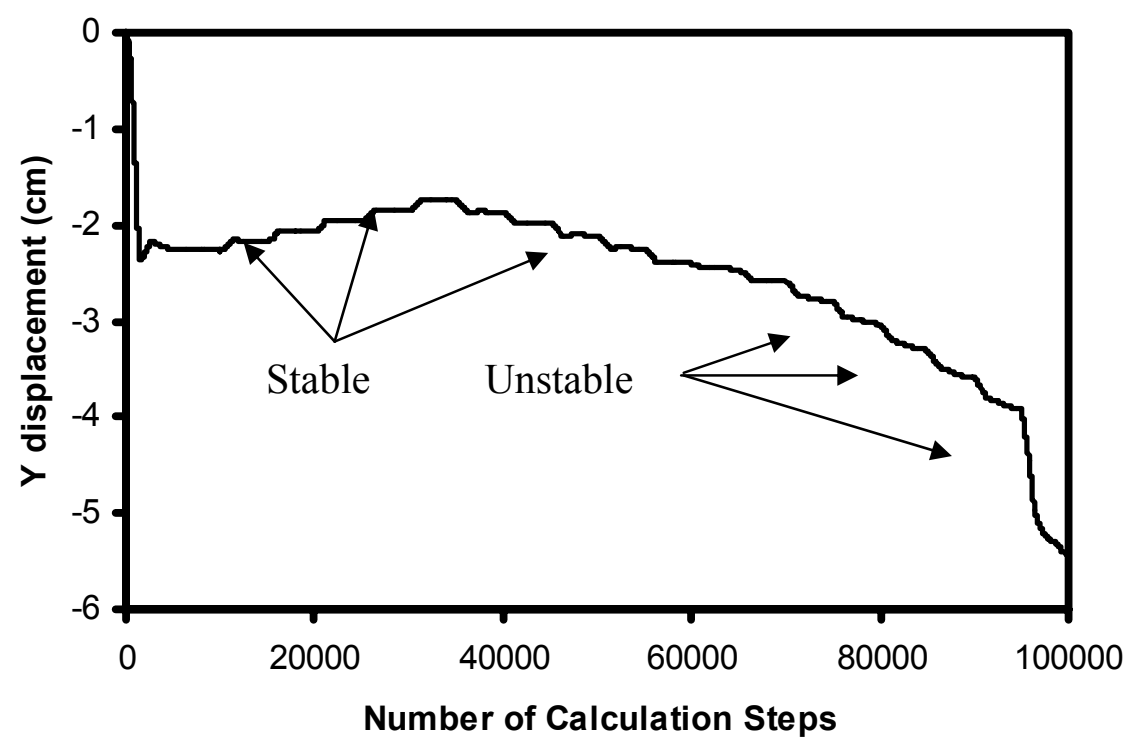

Figure 24 History of Y displacement at center of cavern. Slope $=0$ indicates stable conditions, a steep slope indicates instability.

\section{$\underline{\text { Plasticity Indicators }}$}

FLAC identifies elements in the model that are at plastic yield in tension or shear as part of the calculation scheme. These indicators were used to determine which portions of the formation were near failure as well as the mechanism of failure. "At yield in tension" means that the stresses in a portion of the rock mass have reached the tensile strength of the material. "At yield in shear" means that the shear and normal stresses in a portion of the rock mass lie on the Mohr-Coulomb failure envelope defined for the material. The plasticity indicators suggest that a portion of the material is near failure, but the system is still stable as long as the unbalanced force goes to zero (Hart, 2005). In general, at yield means that some deformation of the cavern walls may have occurred, and the portion of the cavern that is at yield is on the verge of failure. Failure could be initiated by a change in the stress that is causing yield or by heterogeneities in the limestone that would act as a nucleation point for failure. FLAC also indicates elements in the model that were at yield in past. These are regions that were at either tensile or shear yield at some point during the calculation scheme, but are no longer at yield at the end of the calculation cycle.

\section{Determining Pressure Limits}

The plasticity indicators were used as a gauge for determining the limits for internal cavern pressure. There were four regions of plasticity identified: no yield, less than 20 percent at yield, greater than 20 percent at yield, and failure indicated.

No Yield: Plasticity indicators were absent at the end of the calculation cycle.

Less than 20 percent edge at yield $(20$ pey): There was some yield indicated along 
the edge of the cavern, but it accounted for less than 20 percent of the perimeter of the simulated cavern.

Greater than 20 percent edge at yield $(20$ pey): Yield was indicated along greater than 20 percent of the cavern edge while cavern stability was maintained. This designation was kept once this criterion occurred, even if there were fewer yields in subsequent steps.

Failure indicated: Unbalanced force and displacements indicated that failure has occurred. Large portions of the cavern are at yield.

The occurrence of greater than 20 pey was set as the limit for a safe storage pressure. The internal pressure was increased until instabilities and possible failure was indicated to identify a critical maximum pressure where failure is predicted to occur. The maximum storage pressure was set as the step prior to the occurrence of 20 pey. The internal pressure was decreased from the maximum storage pressure to predict the pressure where greater than 20 pey occurs as well as the minimum critical pressure where failure is indicated.

\section{Cavern symmetry}

The cylindrical, spherical and conical caverns were assumed to be symmetrical about the center axis. The axisymmetric option in FLAC was utilized for these simulations to represent the cavern as a 2-D plane that is rotated about a vertical axis of symmetry. The simulation of the tunnel cavern was conducted as plane strain. This required a different grid setup with extended lateral boundaries and the representation of the tunnel located in the center of the grid.

\section{Modeling Grid Setup}

\section{$\underline{20 \times 50 \text { m Cavern Setup }}$}

A cylindrical cavern with a radius of $20 \mathrm{~m}$ and a height of $50 \mathrm{~m}$ was selected to be the baseline scenario as this geometry resulted in the closest 1 to 1 ratio of diameter to height while allowing for a radius that was a multiple of 10 . The mesh for the $20 \mathrm{x} 50 \mathrm{~m}$ cavern consists of a grid with systematic variation in gridblock size (Figure 25). From a depth of 1795 to $1865 \mathrm{~m}$ out to a distance of $30 \mathrm{~m}$ the mesh size is $0.2 \times 0.2 \mathrm{~m}$. From a depth of 1750 to $1910 \mathrm{~m}$ out to a distance of $100 \mathrm{~m}$ from the cavern center the mesh size is $1.0 \times 1.0 \mathrm{~m}$ (Figure 25). From a depth of $1650 \mathrm{~m}$ at the top of the model to a depth of $2010 \mathrm{~m}$ at the bottom of the model and out to a distance of $200 \mathrm{~m}$ from the cavern center the mesh size is $5.0 \times 5.0 \mathrm{~m}$ (Figure 25). From a distance of $200 \mathrm{~m}$ from the cavern center out to the boundary of $400 \mathrm{~m}$ the grid blocks are $5 \mathrm{~m}$ high and increase in size by a 1.1 ratio away from the cavern (Figure 25). The cavern is represented as a cylindrical null block from $1805 \mathrm{~m}$ to $1855 \mathrm{~m}$ out to a radius of $20 \mathrm{~m}$. The sharp corners of the cylinder are rounded as a quarter of a toroid with a radius of $5 \mathrm{~m}$.

The bottom of the mesh is fixed in both the $\mathrm{X}$ and $\mathrm{Y}$ directions while the vertical boundaries are represented as roller boundaries that are fixed in the $\mathrm{X}$ direction whereas the grid is free to move in the Y direction. The initial vertical stress is set at the lithostatic gradient with a pressure equal to the weight of the overburden applied along the top of the grid. The initial horizontal stress for 
the baseline case is 0.8 times the vertical stress.

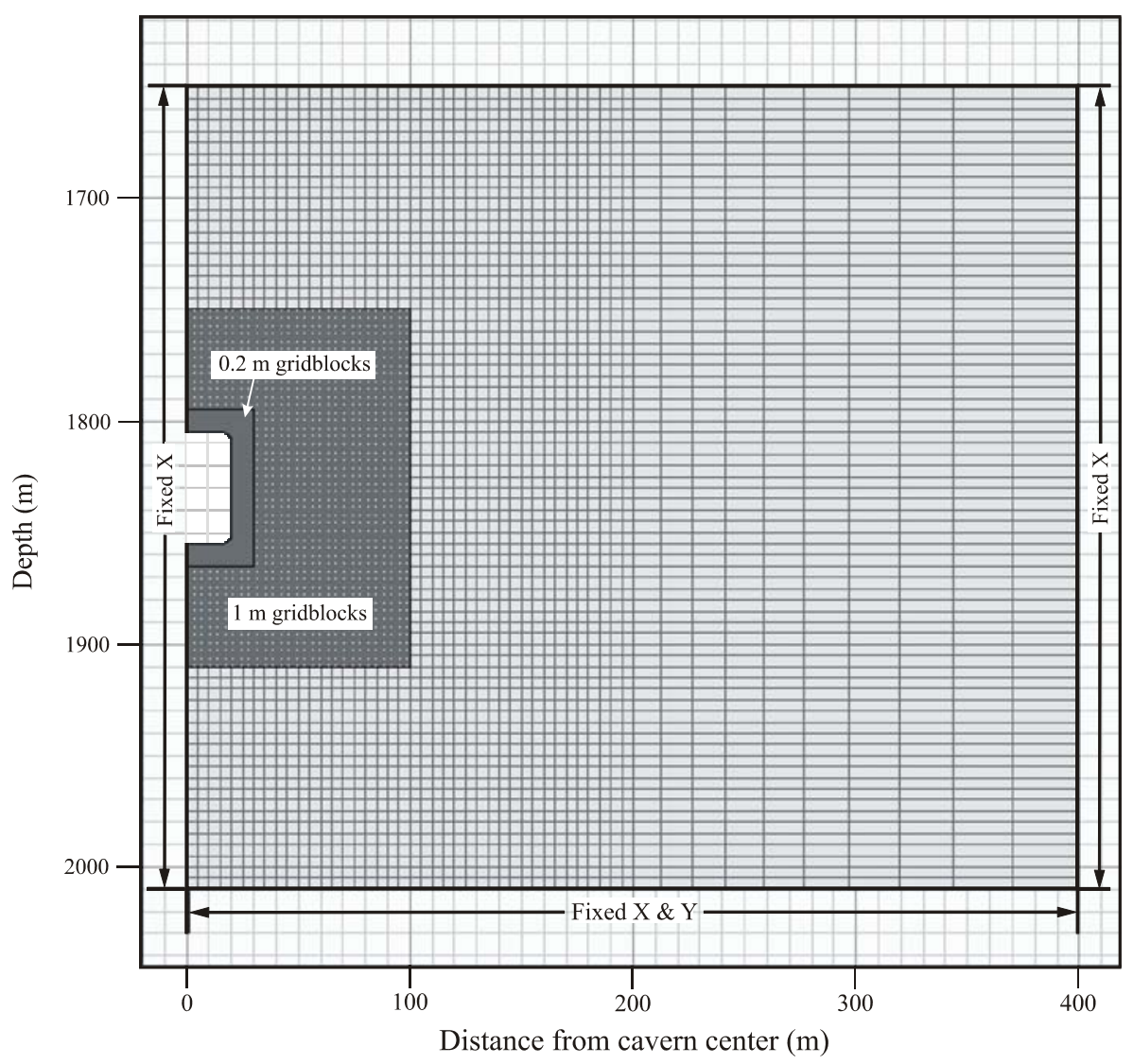

Figure 25 Grid setup for 20 x 50 m cylindrical cavern.

\section{0x200 Cavern Setup}

A cylindrical cavern with a narrow base and a tall height is represented as a cavern with a radius of $10 \mathrm{~m}$ and a height of $200 \mathrm{~m}$. The mesh for the $10 \times 200 \mathrm{~m}$ cavern consists of a grid with systematic variation in gridblock size (Figure 26). From a depth of 1770 to $1940 \mathrm{~m}$ out to a distance of $20 \mathrm{~m}$ the mesh size is $0.2 \times 0.2 \mathrm{~m}$. From a depth of 1690 to $1970 \mathrm{~m}$ out to a distance of $50 \mathrm{~m}$ from the cavern center the mesh size is $1.0 \times 1.0 \mathrm{~m}$ (Figure 26). From a depth of $1600 \mathrm{~m}$ at the top of the model to a depth of $2060 \mathrm{~m}$ at the bottom of the model and out to a distance of $100 \mathrm{~m}$ from the cavern center the mesh size is $5.0 \times 5.0 \mathrm{~m}$ (Figure 26). From a distance of $100 \mathrm{~m}$ from the cavern center out to the boundary of $400 \mathrm{~m}$ the grid blocks are $5 \mathrm{~m}$ high and increase in size by a 1.1 ratio away from the cavern (Figure 26). The cavern is represented null block in a rectangle from $1730 \mathrm{~m}$ to $1930 \mathrm{~m}$ out to a distance of $10 \mathrm{~m}$. The sharp corners of the rectangle are rounded as a quarter of a circle with a radius of $5 \mathrm{~m}$. The bottom of the mesh is fixed in both the $\mathrm{X}$ and $\mathrm{Y}$ directions while the vertical boundaries are represented as roller boundaries fixed in the $\mathrm{X}$ direction. The initial vertical stress is set at the lithostatic gradient with a pressure equal to the weight of the overburden applied along the top of the grid. 


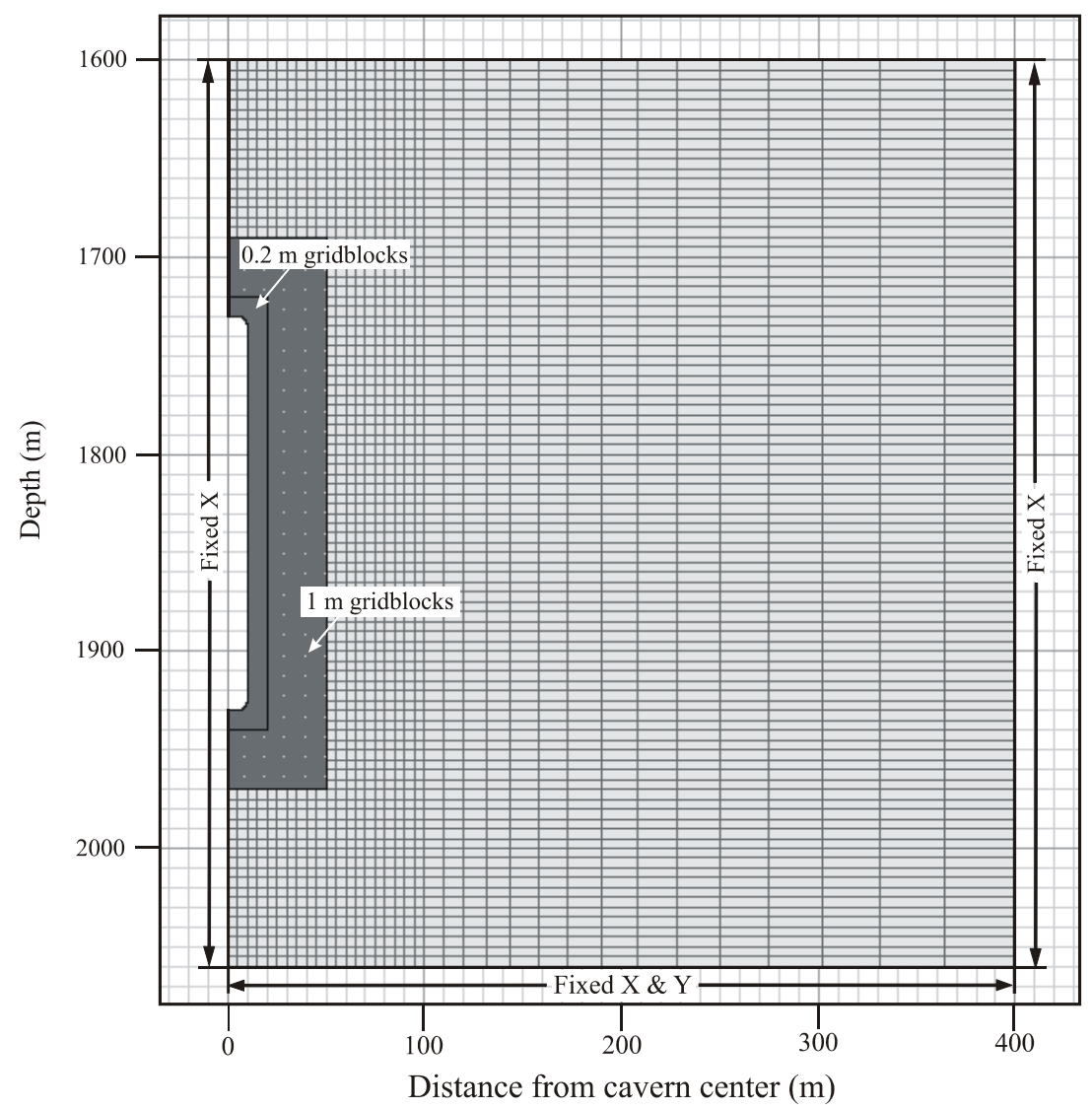

Figure 26 Grid setup for 10 x $200 \mathrm{~m}$ cylindrical cavern

\section{$\underline{40 \times 12 \mathrm{~m} \text { Cavern Setup }}$}

A short cylinder with a wide base is represented as a cavern with a radius of $40 \mathrm{~m}$ and a height of $12 \mathrm{~m}$. The mesh for the $40 \times 12 \mathrm{~m}$ cavern consists of a grid with systematic variation in gridblock size (Figure 27). From a depth of 1815 to $1845 \mathrm{~m}$ out to a distance of $50 \mathrm{~m}$ the mesh size is $0.2 \times 0.2 \mathrm{~m}$. From a depth of 1750 to $1910 \mathrm{~m}$ out to a distance of $100 \mathrm{~m}$ from the cavern center the mesh size is $1.0 \times 1.0 \mathrm{~m}$ (Figure 27). From a depth of $1650 \mathrm{~m}$ at the top of the model to a depth of $2010 \mathrm{~m}$ at the bottom of the model and out to a distance of $200 \mathrm{~m}$ from the cavern center the mesh size is $5.0 \times 5.0 \mathrm{~m}$ (Figure 27). From a distance of $200 \mathrm{~m}$ from the cavern center out to the boundary of $400 \mathrm{~m}$ the grid blocks are $5 \mathrm{~m}$ high and increase in size by a 1.1 ratio away from the cavern (Figure 27). The cavern is represented null block in a rectangle from $1824 \mathrm{~m}$ to $1836 \mathrm{~m}$ out to a distance of $40 \mathrm{~m}$. The edge of the cavern is rounded as a semicircle with a radius of $6 \mathrm{~m}$. The bottom of the mesh is fixed in both the $\mathrm{X}$ and $\mathrm{Y}$ directions while the vertical boundaries are represented as roller boundaries fixed in the $\mathrm{X}$ direction. The initial vertical stress is set at the lithostatic gradient with a pressure equal to the weight of the overburden applied along the top of the grid. 


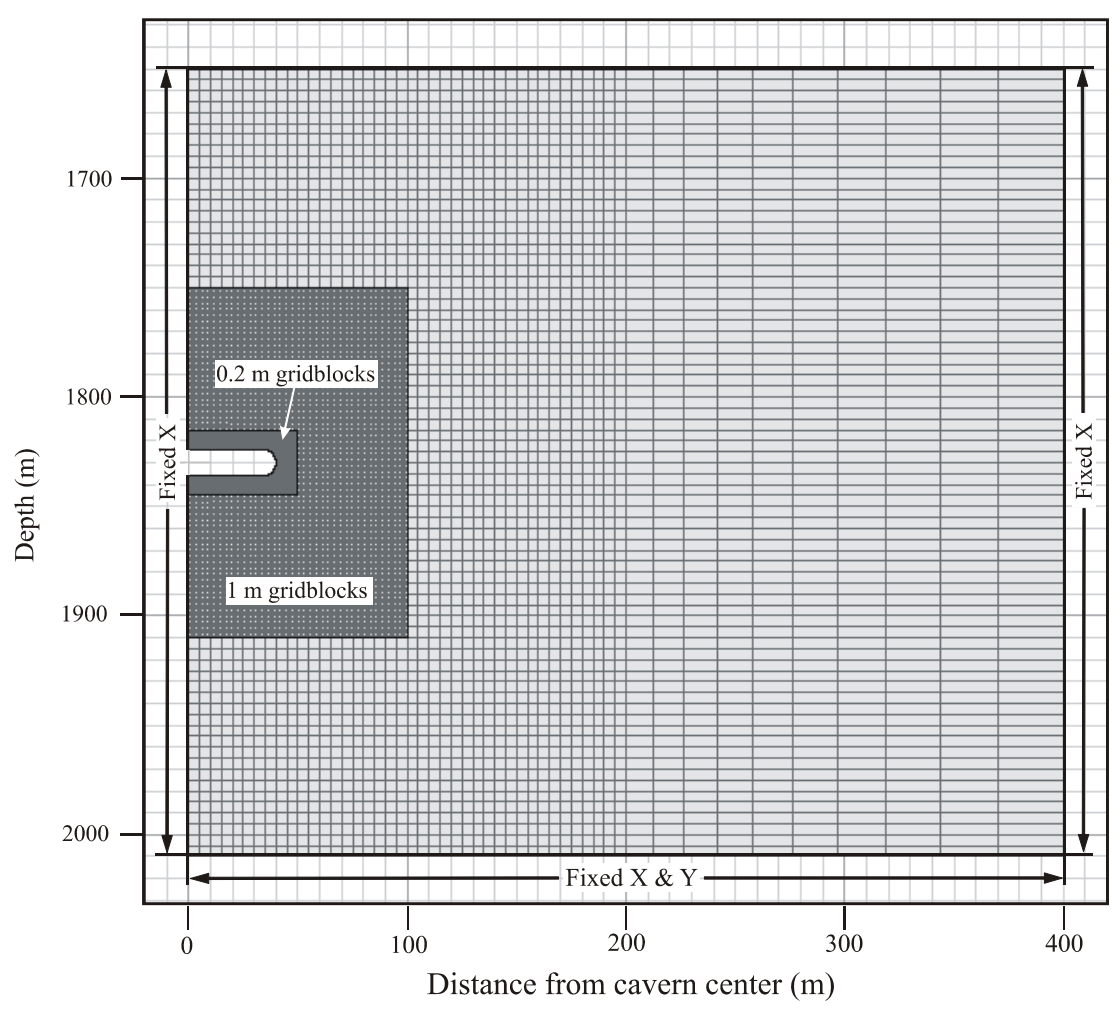

Figure 27 Grid setup for 40 x 12 m cylindrical cavern.

\section{Spherical Cavern Setup}

The mesh for the spherical cavern with a radius of $24.6 \mathrm{~m}$ consists of a grid with systematic variation in gridblock size (Figure 28). From a depth of 1795 to $1865 \mathrm{~m}$ out to a distance of $30 \mathrm{~m}$ the mesh size is $0.2 \times 0.2 \mathrm{~m}$. From a depth of 1750 to $1910 \mathrm{~m}$ out to a distance of $100 \mathrm{~m}$ from the cavern center the mesh size is $1.0 \times 1.0 \mathrm{~m}$ (Figure 28). From a depth of 1650 $\mathrm{m}$ at the top of the model to a depth of $2010 \mathrm{~m}$ at the bottom of the model and out to a distance of $200 \mathrm{~m}$ from the cavern center the mesh size is $5.0 \times 5.0 \mathrm{~m}$ (Figure 28). From a distance of $200 \mathrm{~m}$ from the cavern center out to the boundary of $400 \mathrm{~m}$ the grid blocks are $5 \mathrm{~m}$ high and increase in size by a 1.1 ratio away from the cavern (Figure 28). The cavern is represented as a null sphere with a radius of $24.6 \mathrm{~m}$.

The bottom of the mesh is fixed in both the $\mathrm{X}$ and $\mathrm{Y}$ directions while the vertical boundaries are represented as roller boundaries fixed in the $\mathrm{X}$ direction. The initial vertical stress is set at the lithostatic gradient with a pressure equal to the weight of the overburden applied along the top of the grid. 


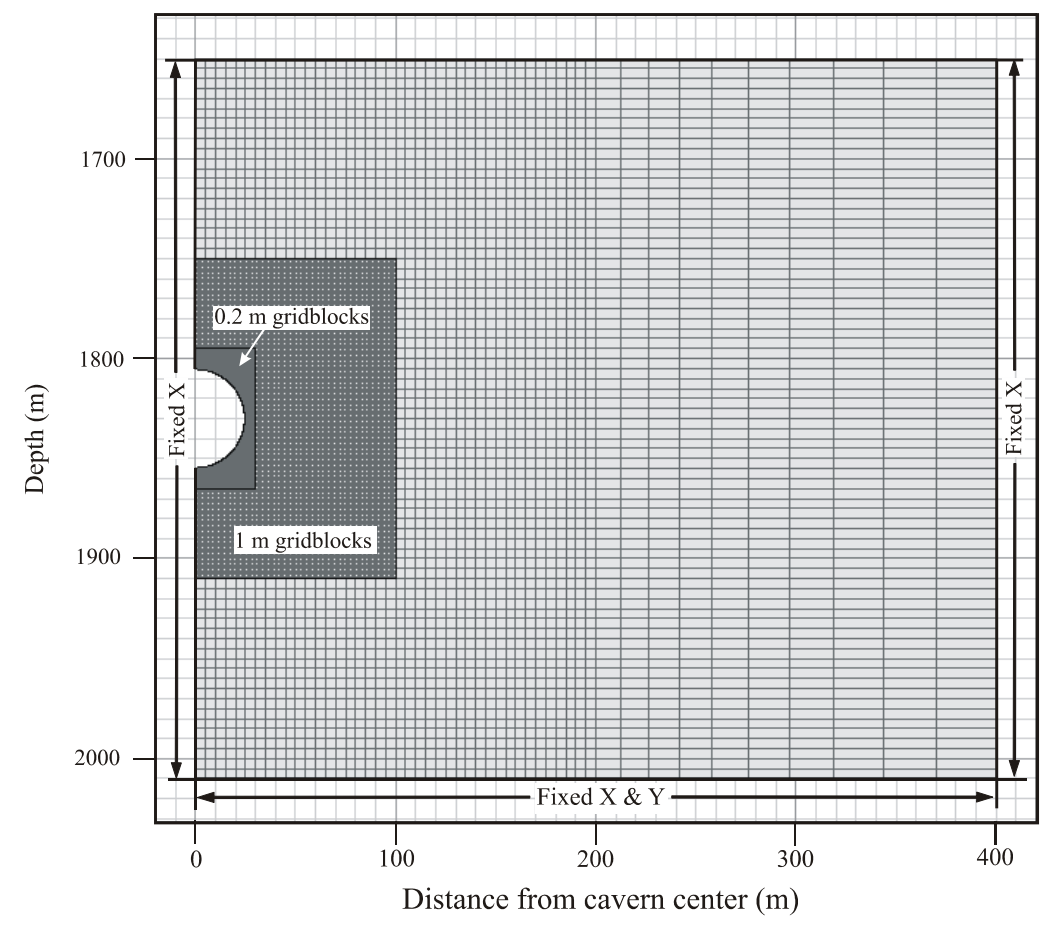

Figure 28 Grid setup for a spherical cavern

\section{Conical Cavern Setup}

The mesh for the conical cavern with a $25 \mathrm{~m}$ radius base and a height of $95.6 \mathrm{~m}$ consists of a grid with variation in gridblock size (Figure 29). From a depth of 1770 to $1890 \mathrm{~m}$ out to a distance of $35 \mathrm{~m}$ the mesh size is $0.2 \times 0.2 \mathrm{~m}$. From a depth of 1730 to $1930 \mathrm{~m}$ out to a distance of $50 \mathrm{~m}$ from the cavern center the mesh size is $1.0 \times 1.0 \mathrm{~m}$ (Figure 29). From a depth of $1650 \mathrm{~m}$ at the top of the model to a depth of $2010 \mathrm{~m}$ at the bottom of the model and out to a distance of $200 \mathrm{~m}$ from the cavern center the mesh size is $5.0 \times 5.0 \mathrm{~m}$ (Figure 29). From a distance of $200 \mathrm{~m}$ from the cavern center out to the boundary of $400 \mathrm{~m}$ the grid blocks are $5 \mathrm{~m}$ high and increase in size by a 1.1 ratio away from the cavern (Figure 29). The cavern is represented as a null cone with a base of $25 \mathrm{~m}$ and a height of $95.6 \mathrm{~m}$ with the midpoint of the height a $1830 \mathrm{~m}$. To avoid sharp corners, the edges of the triangle are rounded.

The bottom of the mesh is fixed in both the $\mathrm{X}$ and $\mathrm{Y}$ directions while the vertical boundaries are represented as roller boundaries fixed in the $\mathrm{X}$ direction. The initial vertical stress is set at the lithostatic gradient with a pressure equal to the weight of the overburden applied along the top of the grid. 


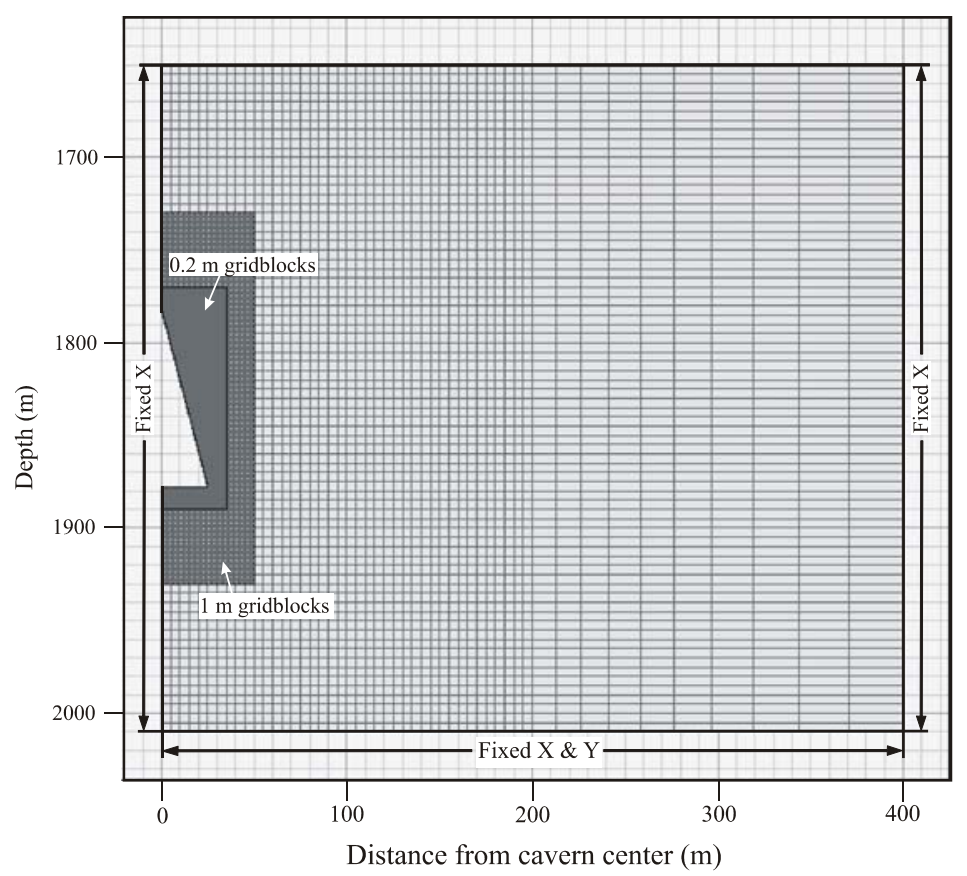

Figure 29 Grid setup for conical cavern

\section{Tunnel-Like Cavern Setup}

A cylindrical cavern that is laid down on the side similar to a tunnel is represented as a circular hole. This represents a slice of the cavern any where along the length except for the end walls of the cavern. Unlike the other grid setups, the tunnel mesh is not axisymmetric. The mesh for the tunnel cavern with a radius of $10 \mathrm{~m}$ consists of a grid with systematic variation in gridblock size (Figure 30). From a depth of 1810 to $1850 \mathrm{~m}$ and out to a distance of $20 \mathrm{~m}$ on both sides of the cavern center the mesh size is $0.2 \times 0.2 \mathrm{~m}$. From a depth of 1780 to $1880 \mathrm{~m}$ out to a distance of $50 \mathrm{~m}$ on either side of the cavern center the mesh size is $1.0 \times 1.0 \mathrm{~m}$ (Figure 30). From a depth of 1730 to $1930 \mathrm{~m}$ and out to a distance of $100 \mathrm{~m}$ from the cavern center the mesh size is $5.0 \times 5.0 \mathrm{~m}$. From a depth of $1650 \mathrm{~m}$ at the top of the model to a depth of $2010 \mathrm{~m}$ at the bottom of the model and out to a distance of $400 \mathrm{~m}$ on either side of the cavern from the cavern center the mesh size is $10.0 \times 10.0 \mathrm{~m}$ (Figure 30). The cavern is represented as a null circle with a radius of $10.0 \mathrm{~m}$.

The bottom of the mesh is fixed in both the $\mathrm{X}$ and $\mathrm{Y}$ directions while the vertical boundaries are represented as roller boundaries fixed in the $\mathrm{X}$ direction. The initial vertical stress is set at the lithostatic gradient with a pressure equal to the weight of the overburden applied along the top of the grid. 


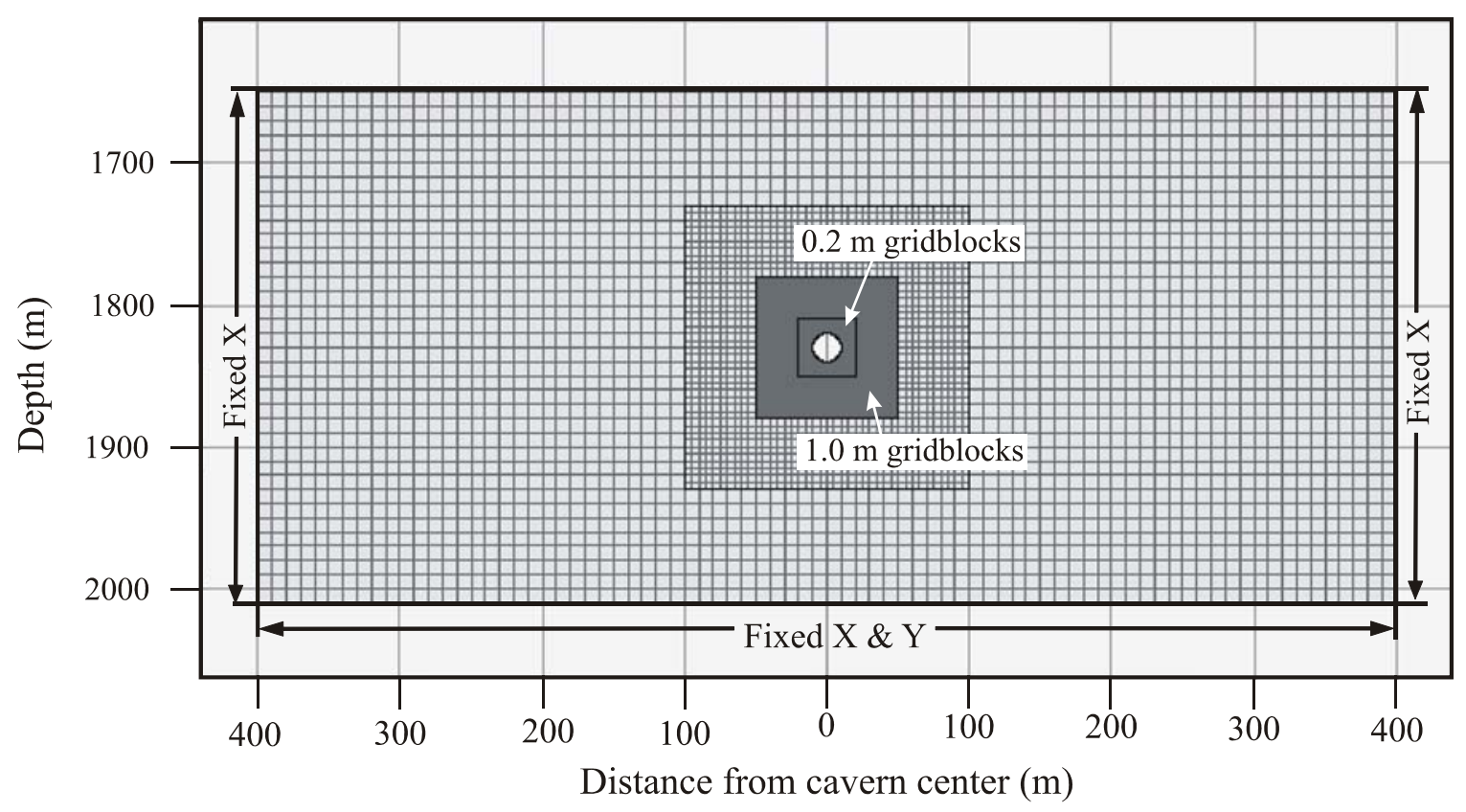

Figure 30 Grid setup for tunnel like cavern

\section{$\underline{0.25 \text { BCF Cavern Setup }}$}

A cavern with a target storage volume of $0.25 \mathrm{BCF}$ at $1830 \mathrm{~m}$ required a cavern volume of approximately $31285 \mathrm{~m}^{3}$ (Figure 19). The dimensions selected for the $0.25 \mathrm{BCF}$ cavern were a radius of $17 \mathrm{~m}$ and a height of $34 \mathrm{~m}$. These dimensions were selected so that the cavern would have a similar height to radius ratio of the baseline cavern. The setup for the $17 \times 34 \mathrm{~m}$ cavern consists of a grid with systematic variation in gridblock size (Figure 31). From a depth of 1795 to $1865 \mathrm{~m}$ out to a distance of $30 \mathrm{~m}$ the mesh size is $0.2 \times 0.2 \mathrm{~m}$. From a depth of 1750 to $1910 \mathrm{~m}$ out to a distance of $100 \mathrm{~m}$ from the cavern center the mesh size is $1.0 \times 1.0 \mathrm{~m}$ (Figure 31 ). From a depth of $1650 \mathrm{~m}$ at the top of the model to a depth of $2010 \mathrm{~m}$ at the bottom of the model and out to a distance of $200 \mathrm{~m}$ from the cavern center the mesh size is $5.0 \times 5.0 \mathrm{~m}$ (Figure 31 ). From a distance of $200 \mathrm{~m}$ from the cavern center out to the boundary of $400 \mathrm{~m}$ the grid blocks are $5 \mathrm{~m}$ high and increase in size by a 1.1 ratio away from the cavern (Figure 31 ). The cavern is represented as null region in a rectangle from $1813 \mathrm{~m}$ to $1847 \mathrm{~m}$ out to a distance of $17 \mathrm{~m}$. The sharp corners of the cylinder are rounded as a quarter toroid with a radius of $5 \mathrm{~m}$. The bottom of the mesh is fixed in both the $\mathrm{X}$ and $\mathrm{Y}$ directions while the vertical boundaries are represented as roller boundaries fixed in the $\mathrm{X}$ direction. The initial vertical stress is set at the lithostatic gradient with a pressure equal to the weight of the overburden applied along the top of the grid. The initial horizontal stress for the baseline case is 0.8 times the vertical stress. 


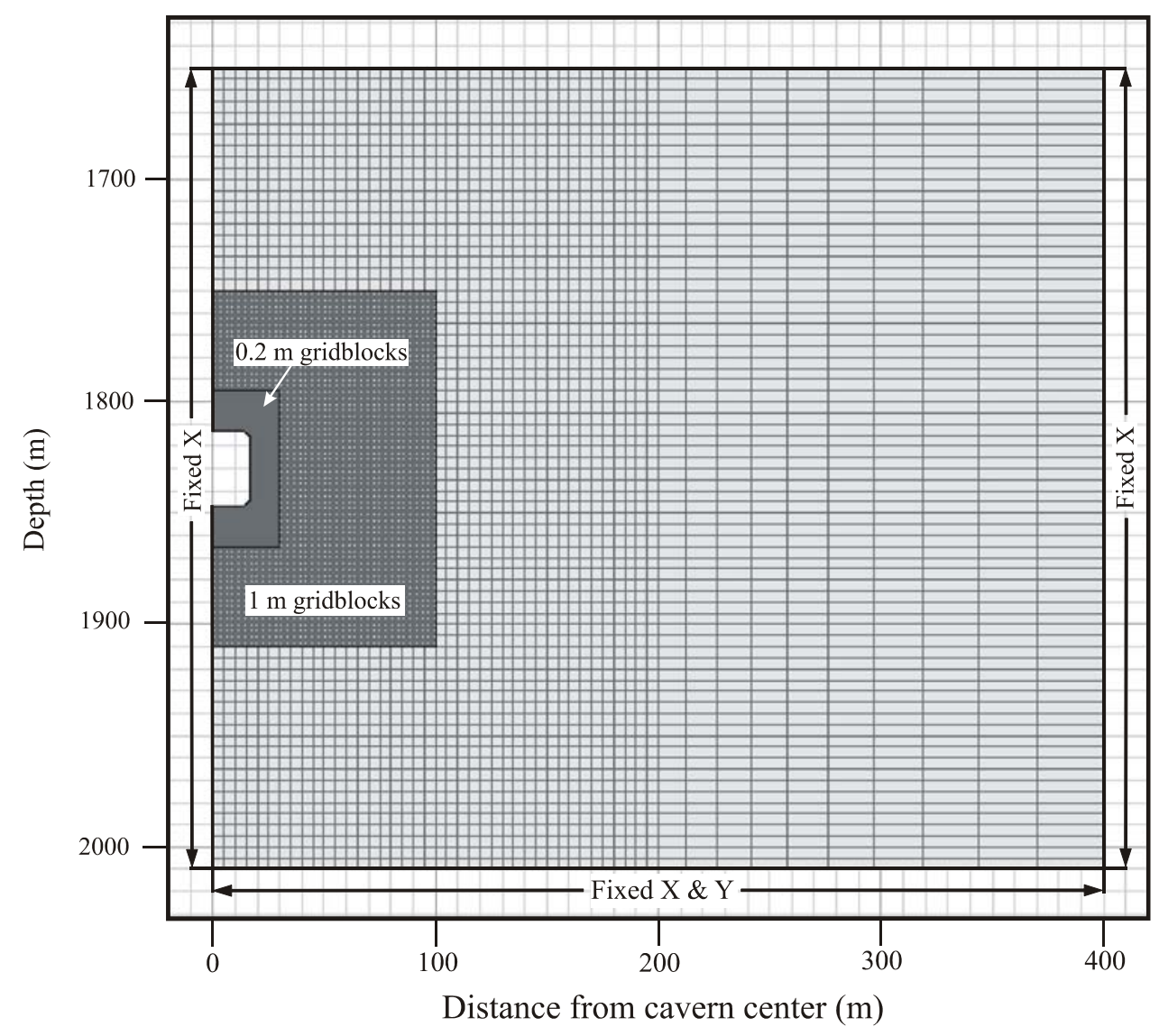

Figure 31 Grid setup for 17 x 34 m, 0.25 BCF cylindrical cavern.

\section{$\underline{1.0 \text { BCF Cavern Setup }}$}

A cavern with a target storage volume of $1.0 \mathrm{BCF}$ at $1830 \mathrm{~m}$ required a cavern volume of approximately $125140 \mathrm{~m}^{3}$ (Figure 19). The dimensions selected for the $1.0 \mathrm{BCF}$ cavern were a radius of $27 \mathrm{~m}$ and a height of $55 \mathrm{~m}$. These dimensions were selected so that the cavern would have a similar height to radius ratio of the baseline cavern. The setup for the 27 x $55 \mathrm{~m}$ cavern consists of a grid with systematic variation in gridblock size (Figure 32). From a depth of 1793 to $1868 \mathrm{~m}$ out to a distance of $40 \mathrm{~m}$ the mesh size is $0.2 \times 0.2 \mathrm{~m}$. From a depth of 1750 to $1910 \mathrm{~m}$ out to a distance of $100 \mathrm{~m}$ from the cavern center the mesh size is $1.0 \times 1.0 \mathrm{~m}$ (Figure 32). From a depth of $1650 \mathrm{~m}$ at the top of the model to a depth of $2010 \mathrm{~m}$ at the bottom of the model and out to a distance of $200 \mathrm{~m}$ from the cavern center the mesh size is $5.0 \times 5.0 \mathrm{~m}$ (Figure 32). From a distance of $200 \mathrm{~m}$ from the cavern center out to the boundary of $400 \mathrm{~m}$ the grid blocks are $5 \mathrm{~m}$ high and increase in size by a 1.1 ratio away from the cavern (Figure 32). The cavern is represented as null region in a rectangle from $1803 \mathrm{~m}$ to $1858 \mathrm{~m}$ out to a distance of $27 \mathrm{~m}$. The sharp corners of the cylinder are rounded as a quarter toroid with a radius of $5 \mathrm{~m}$.

The bottom of the mesh is fixed in both the $\mathrm{X}$ and $\mathrm{Y}$ directions while the vertical boundaries are represented as roller boundaries fixed in the $\mathrm{X}$ direction. The initial vertical stress is set at the lithostatic gradient with a pressure equal to the weight of the overburden applied along the top of the grid. The initial horizontal stress for the baseline case is 0.8 times the vertical stress. 


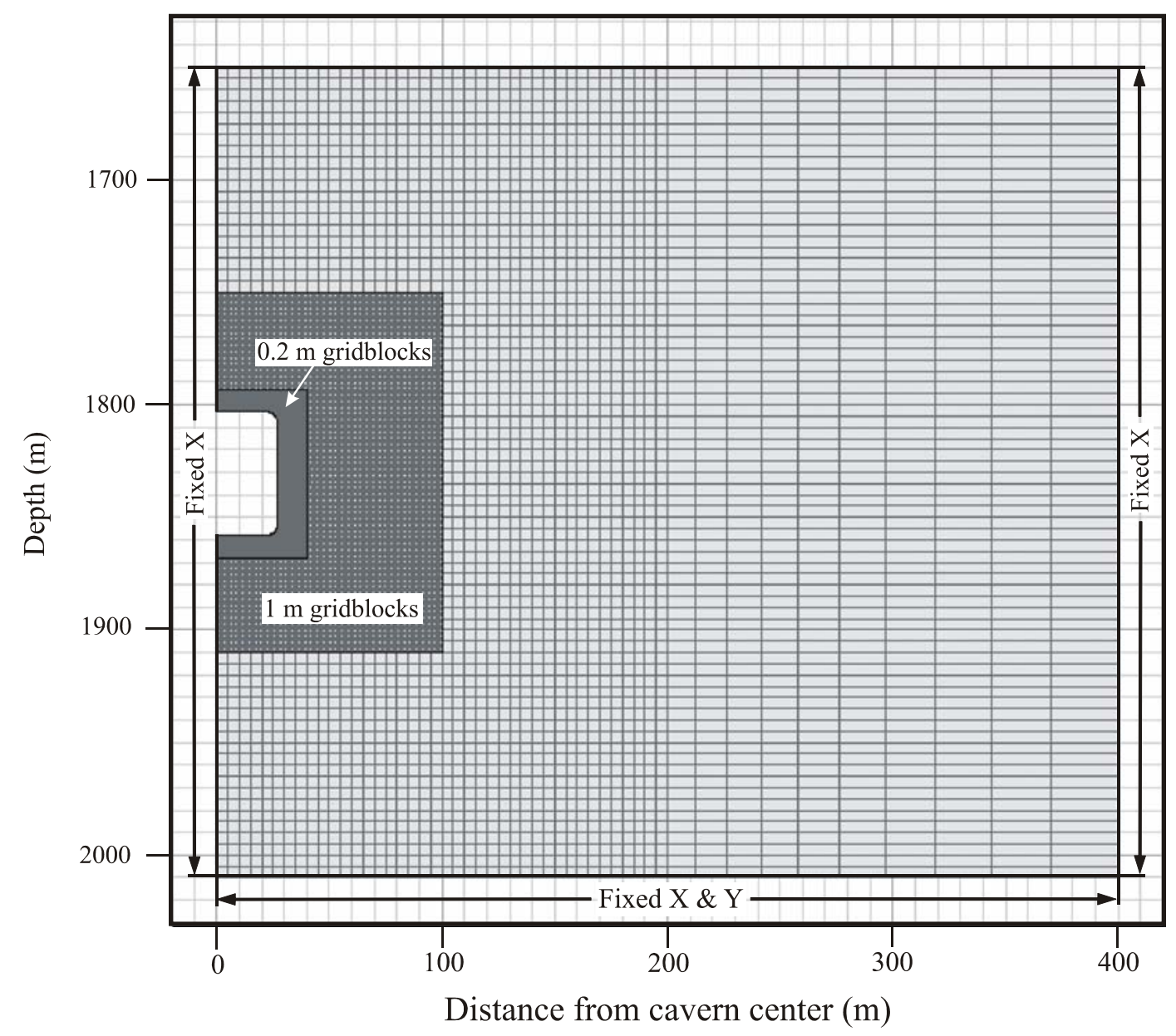

Figure 32 Grid setup for 27 x 55 m, 1.0 BCF storage cavern.

\section{Variations in Grid Setup}

Minor adjustments to the basic $F L A C$ setup for each shape are necessary to simulate changes in parameters. The primary difference involved modifying the stress field modeled. To adjust the initial stress in the models, the horizontal stresses (Sxx and Szz) were changed to correspond to one of the $k$ ratios of the vertical stress. For trials where changes in depth were simulated, the same baseline grid setup was used with the stresses changed to reflect the stresses expected at the modeled depth.

\section{Calculation Scheme}

The primary premise behind the number of calculation steps computed was to assure that the unbalanced force went to zero or indicated instability. For the majority of models, 5000 calculation cycles were computed for each pressure step. For steps where the unbalanced force was unclear, extra calculation steps were taken to see if the model stabilized or clearly indicated 
instability.

Final Design and Updated Economic Analysis (Task 11)

No experiments or simulations were performed in this task. 


\section{RESULTS AND DISCUSSION}

\section{Subsurface Characteristics of Existing Storage and Producing Fields (Task 1) By James W. Castle and Scott E. Brame}

The goal of this part of the project was to use existing databases to identify the range of geologic and reservoir properties of producing gas formations and existing underground gas storage fields in carbonate formations.

Using the major gas atlases (Kosters et al., 1989; Bebout et al., 1993; Robertson et al., 1993; Roen and Walker, 1996) and a recent publication of the American Gas Association (2002), values for basic geologic and reservoir properties for producing carbonate reservoirs were compiled (Table 20). Additionally, the GASIS Release 2 data (Energy \& Environmental Analysis, Inc., 1999) was searched, but was found not to be applicable with respect to identifying the reservoir properties.

Various data sources were investigated for identifying the geologic and reservoir properties of existing carbonate formations used for gas storage. A thorough literature search was conducted and enquiries were made at state geological surveys in the six state study area (Indiana, Kentucky, New York, Ohio, Pennsylvania, and West Virginia). One of the major impediments to finding this type of data is that there are few carbonate formations being exploited for gas storage compared to sandstone formations (American Gas Association, 2002), as sandstone formations generally have higher permeability, which is more favorable for traditional gas storage in aquifers and depleted reservoirs. Most of the data found for gas storage reservoirs in carbonate rocks are from Buschbach and Bond (1974).

The data compiled in Tables 20 and 21 apply to permeable formations used for traditional gas storage. Although they do not apply directly to development of gas storage by the fracturing and acid-dissolution method, they provide a basis for comparison with existing fields. For example, high permeability of the carbonate formation is a potentially undesirable property for creation of cavern storage by acid dissolution due to the possibility of leakage. Although initial permeability is not desirable, the presence of porosity is beneficial in contributing to the storage capacity. The presence of at least a small amount of porosity can be helpful in initiating induced fracturing. Induced fractures will be contained by using the proper fracturing technology and by the presence of overlying non-carbonate rock. Natural fractures in the rock are not desirable because of the possibility of leakage. In summary, criteria for selecting suitable carbonate rocks for the fracturing and acid-dissolution method are: low permeability, at least a small amount of porosity, and minimal natural fracturing.

A large amount of regional information was compiled for the carbonate formations of Indiana, Ohio, Kentucky, West Virginia, Pennsylvania, and New York. This information is discussed in the section of this report on "Regional Survey of Carbonate Formations". 
Table 20. Summary of geologic and reservoir properties for producing carbonate reservoirs in four major areas of the United States. Data compiled from Kosters et al. (1989), Bebout et al. (1993), Robertson et al. (1993), Roen and Walker (1996), and a recent publication of the American Gas Association (2002). Perm=permeability; Ave= average; \#obs=number of data values; $\mathrm{nd}=$ no data available

\begin{tabular}{|l|l|l|l|l|l|l|l|l|l|l|l|l|l|}
\hline & \multicolumn{3}{|l|}{ Rocky Mountain } & \multicolumn{2}{l|}{ Texas } & \multicolumn{2}{l|}{ Mid Continent } & \multicolumn{2}{l|}{ Appalachian } \\
\hline & ave & range & \#obs & ave & range & \#obs & ave & range & \#obs & ave & range & \#obs \\
\hline $\begin{array}{l}\text { Porosity } \\
\text { \%) }\end{array}$ & 8.1 & $2-25$ & 160 & 9.95 & $1.0-21.0$ & 243 & 10.9 & $2.0-22.0$ & 52 & 10 & $2-23$ & 192 \\
\hline Perm (md) & 29.4 & $0.01-500$ & 92 & 34.4 & $0.01-400$ & 201 & 95.3 & $1.0-1740.0$ & 27 & 13 & $0.1-57$ & 13 \\
\hline Depth (ft) & 8085 & $1106-18 \mathrm{~K}$ & 186 & 9596 & $1100-24 \mathrm{~K}$ & 334 & 7220 & $1744-24 \mathrm{~K}$ & 82 & 2212 & $162-7 \mathrm{~K}$ & 340 \\
\hline
\end{tabular}

Table 21. Summary of geologic and reservoir properties for gas storage in carbonate rocks. reservoirs in four major areas of the United States. Data compiled from Buschbach and Bond (1974) and American Gas Association (2002).

\begin{tabular}{|l|l|l|l|}
\hline & Range & Average & \# Observations \\
\hline Porosity (\%) & $8.9-17.5$ & 13.5 & 9 \\
\hline Perm (md) & $18-649$ & & \\
\hline Depth (ft) & $14-693$ & 235 & 6 \\
\hline Thickness (ft) & $670-3050$ & 264 & 9 \\
\hline
\end{tabular}




\title{
Requirements for Creating Storage Volume (Task 2)
}

\author{
By David Bruce
}

\section{Acid Dissolution of Carbonate Rock}

In order to dissolve large deposits of limestone using aqueous acids, two reaction fundamentals need to be considered: kinetics and equilibria. The reaction kinetics determine the rate at which dissolution can occur, and reaction equilibria combined with product solubility determine the theoretical yield and maximum concentration of species exiting from the dissolution process. Obviously, one would prefer that the dissolution reaction rate be fast and the reaction equilibria favor the formation of highly soluble salt products. Due to the common nature of the reagents involved in the dissolution process, much of the reaction kinetics, reaction equilibria, and reactant/product solubility data have already been measured and are readily available in the open literature.

Limestone deposits can be dissolved in aqueous media using an appropriate acid via the reaction mechanism shown below.

$$
\mathrm{HX}(\mathrm{aq})+\mathrm{CaCO}_{3}(\mathrm{~s}) \leftrightarrow \mathrm{CaX}_{2}(\mathrm{aq})+\mathrm{H}_{2} \mathrm{CO}_{3}(\mathrm{aq}) \leftrightarrow \mathrm{CaX}_{2}(\mathrm{aq})+\mathrm{CO}_{2}(\mathrm{~g})
$$

There are several important considerations that must be taken into account before the optimal acid can be selected. These parameters include:

1) acid cost and availability;

2) aqueous solubility of resulting calcium salts;

3) acid and/or salt toxicity;

4) waste remediation considerations;

5) corrosion characteristics;

6) the need for combustion and/or evaporation controls (for organic acids);

7) dissolution reaction rate;

8) dissolution reaction equilibrium constant;

9) $\mathrm{pKa}$ for acid dissociation in water; and

10) prior use in related oil and gas applications.

Criteria 1,2, 4, and 8 above were the primary factors used to identify organic and inorganic acids that may prove economically and chemically viable for the dissolution process. Though the other criteria were also considered, they had less of an impact on the overall viability of the dissolution process.

\section{Acid Costs}

Current bulk scale sale prices were obtained for several candidate acids and are shown below in Table 22. These prices are for materials to be delivered in the northeastern US and are for technical grade purity acids, with the exception of phosphoric acid (farm grade listed). Further significant reductions in acid cost could be realized following negotiations with acid 
producers and distributors. This is especially true given the quantity of acid to be purchased and the fact that high purity acids are not required for the dissolution process. The acid prices and purities, shown below, were also used to calculate the cost for dissolving one pound of limestone. These limestone dissolution costs provide a direct means for comparing the economic viability of the various acids. On a cost basis alone, any of the common inorganic acids appear to be a reasonable choice for the dissolution process, while the cost of most of the organic acids is prohibitive.

Table 22. Acid Cost (Chemical Market Reporter, Dec. 2003). Acids with acceptable cost are shaded.

\begin{tabular}{|l|l|l|}
\hline Acid & $\begin{array}{l}\text { Current Sale Price } \\
\text { \$ US / ton (wt \% acid) }\end{array}$ & $\begin{array}{l}\text { Acid Cost per Pound of } \\
\text { Limestone Dissolved, \$ US }\end{array}$ \\
\hline orthophosphoric acid $\left(\mathrm{H}_{3} \mathrm{PO}_{4}\right)$ & $2.7(52 \%$, farm grade) & 0.005 \\
\hline sulfuric acid $\left(\mathrm{H}_{2} \mathrm{SO}_{4}\right)$ & $25(100 \%)$ & 0.012 \\
\hline hydrochloric $(\mathrm{HCl})$ & $68\left(22{ }^{\circ} \mathrm{Be}, 34 \%\right)^{\mathrm{a}}$ & 0.075 \\
\hline nitric acid $\left(\mathrm{HNO}_{3}\right)$ & $215\left(40{ }^{\circ} \mathrm{Be}, 68 \%\right)^{\mathrm{a}}$ & 0.199 \\
\hline formic acid $\left(\mathrm{HCOOH}^{2}\right)$ & $451(85 \%)$ & 0.244 \\
\hline acetic acid $\left(\mathrm{CH}_{3} \mathrm{COOH}\right)$ & $910(95 \%)$ & 0.575 \\
\hline 3-hydroxypropionic acid $\left(\mathrm{C}_{3} \mathrm{H}_{6} \mathrm{O}_{3}\right)$ & $1100(95 \%)^{b}$ & 0.918 \\
\hline citric acid $\left(\mathrm{C}_{6} \mathrm{H}_{8} \mathrm{O}_{7}\right)$ & $940(98 \%)$ & 0.921 \\
\hline hydrobromic acid $(\mathrm{HBr})$ & $1120(48 \%)$ & 1.886 \\
\hline
\end{tabular}

a Note that degrees Baume or ${ }^{\circ} \mathrm{Be}$ is a measure of specific gravity originally based on assigning $10 \% \mathrm{NaCl}$ solution a value of 10 . In the USA, the specific gravity (i.e., purity) at $60^{\circ} \mathrm{F}$ for a fluid denser than water can be expressed as sp.gr. $=145 /(145$-Baume $)$.

b Projected sales price in 2006 (Cargill).

\section{Reaction Equilibrium Constants}

Reaction equilibria (for the carbonate dissolution reaction shown previously) determine the thermodynamic limit to which reactants can be converted into products and can be calculated using the Gibbs free energy of formation for the reagents and products. Given the elevated pressure at lower depths, it can be assumed that $\mathrm{CO}_{2}$ would remain in solution until the salt products were pumped to the surface. Additionally, the change in enthalpy (heat generation) with reaction can be calculated from similar pure components properties. These data and the relevant equations relating them are shown below in Table 23. These calculations revealed that the equilibrium reaction constant is high (favorable) for all of the listed acids except for acetic. Further, all of the dissolution reactions are exothermic; thus, localized heating effects could increase the rate of limestone dissolution. 
Calculation of Gibbs free energy of reaction from Gibbs free energy of formation values:

$$
\Delta \mathrm{G}_{\mathrm{rxn}}^{\mathrm{o}}=\sum_{\text {products }} \beta_{\mathrm{j}} \mathrm{G}_{f, \mathrm{j}}^{\mathrm{o}}-\sum_{\text {reactant } \mathrm{s}} \alpha_{\mathrm{i}} \mathrm{G}_{f, \mathrm{i}}^{\mathrm{o}}
$$

Calculation of reaction equilibrium constants $\left(\mathrm{K}_{\mathrm{eq}}\right)$ from Gibbs free energy of reaction data:

$$
-\Delta \mathrm{G}_{\mathrm{rxn}}^{\mathrm{o}}=\mathrm{RT} \ln \mathrm{K}_{\mathrm{eq}}
$$

Relationship between reagent concentrations and the reaction equilibrium constant:

$$
\mathrm{K}_{\mathrm{eq}}=\frac{\prod_{\mathrm{j}} \mathrm{C}_{\text {product, } \mathrm{j}}^{\beta}}{\prod_{\mathrm{i}} \mathrm{C}_{\text {reactant }, \mathrm{i}}^{\alpha}}
$$

Table 23. Gibbs free energy of reaction, enthalpy change with reaction, and equilibrium

\begin{tabular}{|c|c|c|c|}
\hline Reaction & $\begin{array}{l}\Delta \mathrm{G} \\
(\mathrm{kJ} / \mathrm{mol})\end{array}$ & $\begin{array}{l}\Delta \mathrm{H} \\
(\mathrm{kJ} / \mathrm{mol})\end{array}$ & ${ }^{298} \mathrm{~K}_{\mathrm{eq}}$ \\
\hline $\begin{array}{l}\operatorname{MgCa}\left(\mathrm{CO}_{3}\right)_{2}(\mathrm{~s})+4 \mathrm{HCl}(\mathrm{aq}) \leftrightarrow \mathrm{MgCl}_{2}(\mathrm{aq})+\mathrm{CaCl} 2(\mathrm{aq})+ \\
2 \mathrm{H}_{2} \mathrm{CO}_{3}(\mathrm{aq})\end{array}$ & -90.9 & -82.6 & $\begin{array}{l}8.48 \\
\cdot 10^{15} \\
\end{array}$ \\
\hline $\mathrm{CaCO}_{3}(\mathrm{~s})+\mathrm{H}_{2} \mathrm{SO}_{4}(\mathrm{aq}) \leftrightarrow \mathrm{CaSO}_{4}(\mathrm{~s})+\mathrm{H}_{2} \mathrm{CO}_{3}(\mathrm{aq})$ & -58.8 & -8.7 & $\begin{array}{l}2.02 \\
\cdot 10^{10}\end{array}$ \\
\hline $\mathrm{CaCO}_{3}(\mathrm{~s})+2 \mathrm{HCl}(\mathrm{aq}) \leftrightarrow \mathrm{CaCl}_{2}(\mathrm{aq})+\mathrm{H}_{2} \mathrm{CO}_{3}(\mathrm{aq})$ & -47.9 & -35.5 & $2.46 \cdot 10^{8}$ \\
\hline $\mathrm{CaCO}_{3}(\mathrm{~s})+2 \mathrm{HNO}_{3}(\mathrm{aq}) \leftrightarrow \mathrm{Ca}\left(\mathrm{NO}_{3}\right)_{2}(\mathrm{aq})+\mathrm{H}_{2} \mathrm{CO}_{3}(\mathrm{aq})$ & -47.8 & -104. & $2.45 \cdot 10^{8}$ \\
\hline $\mathrm{CaCO}_{3}(\mathrm{~s})+2 \mathrm{CH}_{3} \mathrm{COOH} \leftrightarrow \mathrm{Ca}\left(\mathrm{CH}_{3} \mathrm{COO}\right)(\mathrm{aq})+\mathrm{H}_{2} \mathrm{CO}_{3}(\mathrm{aq})$ & -6.79 & -38.6 & 15.5 \\
\hline
\end{tabular}
constant for several limestone and dolomite acid dissolution reactions and a possible acid regeneration reaction. The favorable reactions are shaded. 


\section{Dissolution Product Solubility}

The aqueous solubility of the resulting carbonate salt is also a key factor in determining the ideal acid for dissolving limestone. A low calcium salt solubility would require much greater quantities of water (and acid) to be pumped through the underground formation in order to prevent the salt product from precipitating out of solution. Aqueous solubility data for selected acids are shown in Table 24 below. The solubility data show that most of the monoprotic inorganic acids (e.g., hydrochloric, hydrobromic, nitric) yield calcium salts with high aqueous solubility, with the exception of orthophosphoric acid. In contrast, the calcium salts of the diprotic (e.g., sulfuric acid) and triprotic (e.g., citric acid) acids have a very low solubility in water. Finally, the monoprotic organic acids react to form calcium salts that have moderate (e.g., calcium acetate, calcium formate) to high (e.g., calcium hydroxypropionate) solubility in water. In fact, the aqueous solubility of calcium hydroxypropionate is higher than that observed for calcium chloride. In summary, the solubility of the calcium salts derived from reactions involving sulfuric, orthophosphoric, and citric acid are too low to yield a viable dissolution process. Thus, on the basis of calcium salt solubility alone, any acid yielding a calcium salt with aqueous solubility greater than $100 \mathrm{~g} / \mathrm{l}$ is acceptable though higher solubility is preferred.

Table 24. Solubility of some common calcium salts in water at STP. Acids yielding reaction products having acceptable solubility are shaded.

\begin{tabular}{|l|l|l|}
\hline Acid & Calcium Salt & $\begin{array}{l}\text { Solubility of Calcium } \\
\text { Salts in Cold Water }(\mathrm{g} / \mathrm{l})\end{array}$ \\
\hline hydrobromic acid $(\mathrm{HBr})$ & calcium bromide $\left(\mathrm{CaBr}_{2}\right)$ & 1420 \\
\hline nitric acid $\left(\mathrm{HNO}_{3}\right)$ & calcium nitrate $\left(\mathrm{Ca}\left(\mathrm{NO}_{3}\right)_{2}\right)$ & 1212 \\
\hline $\begin{array}{l}\text { 3-hydroxypropionic acid } \\
\left(\mathrm{C}_{3} \mathrm{H}_{6} \mathrm{O}_{3}\right)\end{array}$ & $\begin{array}{l}\text { calcium hydroxypropionate } \\
\left(\mathrm{Ca}\left(\mathrm{C}_{3} \mathrm{H}_{6} \mathrm{O}_{3}\right)_{2}\right)\end{array}$ & 1000 \\
\hline hydrochloric $(\mathrm{HCl})$ & calcium chloride $\left(\mathrm{CaCl}_{2}\right)$ & 745 \\
\hline acetic acid $\left(\mathrm{CH}_{3} \mathrm{COOH}\right)$ & calcium acetate $\left(\mathrm{Ca}\left(\mathrm{C}_{2} \mathrm{H}_{3} \mathrm{O}_{2}\right)_{2}\right)$ & 374 \\
\hline formic acid $(\mathrm{HCOOH})$ & calcium formate $\left(\mathrm{Ca}\left(\mathrm{CHO}_{2}\right)_{2}\right)$ & 162 \\
\hline $\begin{array}{l}\text { orthophosphoric acid } \\
\left(\mathrm{H}_{3} \mathrm{PO}_{4}\right)\end{array}$ & $\begin{array}{l}\text { calcium orthophosphate } \\
\left(\mathrm{Ca}\left(\mathrm{H}_{2} \mathrm{PO}_{4}\right)_{2} \cdot \mathrm{H}_{2} \mathrm{O}\right)\end{array}$ & 18 \\
\hline sulfuric acid $\left(\mathrm{H}_{2} \mathrm{SO}_{4}\right)$ & calcium sulfate $\left(\right.$ anhydrite, $\left.\mathrm{CaSO}_{4}\right)$ & 2 \\
\hline citric acid $\left(\mathrm{C}_{6} \mathrm{H}_{8} \mathrm{O}_{7}\right)$ & $\begin{array}{l}\text { calcium citrate } \\
\left(\mathrm{Ca} 3\left(\mathrm{C}_{6} \mathrm{H}_{5} \mathrm{O}_{7}\right)_{2} \cdot 4 \mathrm{H}_{2} \mathrm{O}\right)\end{array}$ & 1 \\
\hline
\end{tabular}

\section{Selection of the Optimal Dissolution Acid}

Several acids have been considered for the dissolution process (see lists in Tables 21-24), many of which have existing use in oil and gas operations, such as hydrochloric acid. Some of the advantages in using hydrochloric acid include: low cost, high acid solubility, fast reaction 
rates with carbonate rock, and highly soluble products (calcium chloride) that allow for the easy removal of calcium waste from the well. Furthermore, the high production of hydrochloric acid in the United States (approximately 4 million metric tons per year) is advantageous given the large quantities of acid needed to generate the proposed storage volumes. However, hydrochloric acid is corrosive to drilling equipment and the resulting waste products require greater post removal processing. Other acids that have been used previously for limestone dissolution include acetic and formic acid. Both of these organic acids are highly miscible with water, have low viscosities, are more environmentally friendly, and less corrosive to equipment. However, there are disadvantages to using acetic and formic acid: moderate reaction rates with carbonates (due to the low $\mathrm{pKa}$ of the acids in water), slightly less soluble calcium salt products, and moderately high acid costs. A relatively new organic acid is also worth considering, 3hydroxypropionic acid. This organic acid is produced from corn via fermentation, easily biodegrades, and yields calcium salts that are highly soluble in water (greater solubility than calcium chloride); however, the cost of this acid is currently too high to be considered for this type of acid dissolution project. Despite the organic acids offering certain advantages over the inorganic acids, the cost of using any of these materials is prohibitive. Thus, at this time hydrochloric acid is the most suitable for the dissolution process.

\section{Prediction of Gas Storage Pressure, Temperature and Volume at Depth}

Forecasting reservoir conditions is critical in determining the physical properties of the natural gas contained in storage as well as the cost for generating the storage facility via acid dissolution. The key parameters needed to evaluate gas properties at depth are temperature and pressure. For all of these calculations a range of gas storage capacities were investigated, 0.25 billion cubic feet (BCF) to 2.0 BCF of natural gas at atmospheric conditions (STP, standard temperature and pressure). Additionally, the depths investigated ranged from $500 \mathrm{ft}$ to $12,000 \mathrm{ft}$, which are common depths to find carbonate rock formations in the study area. In determining reservoir pressure and temperature a geophysical gradient was assumed. These gradients are accurate in areas of low tectonic activity and little underground stress, which is to be expected for the study area. A typical pressure gradient of $0.433 \mathrm{psi} / \mathrm{ft}$ was used for the hydrostatic pressure, and the pressure gradient needed to cause rock fracture was estimated to be $0.64 \mathrm{psi} / \mathrm{ft}$. This value of $0.64 \mathrm{psi} / \mathrm{ft}$ is very conservative, as fracture gradients can exceed $1.0 \mathrm{psi} / \mathrm{ft}$ in many areas, which would allow for a greater volume of gas to be stored within a given cavity volume. Also, the fracture pressure gradient is not always linear and can vary locally depending on the geological conditions such as rock composition and stress (Zoback and Healy, 1984; Fjær et al., 1992; Rocha and Bourgoyne, 1996). For all storage calculations, it was assumed that the storage cavern could be pressurized to a value greater than the hydrostatic pressure at depth but less than the pressure needed to cause rock fracture (Figure 33); thus, a pressure gradient of $0.55 \mathrm{psi} / \mathrm{ft}$ was selected for the storage facility. Similar geothermal gradients (often linear) exist in the US and range from a 20 to $30^{\circ} \mathrm{C}$ temperature increase per kilometer. For this project, a geothermal gradient of $20^{\circ} \mathrm{C}$ per kilometers and a surface temperature (actually $3 \mathrm{~m}$ deep) of $11^{\circ} \mathrm{C}$ were used to predict reservoir temperature (Lillie, 1999, Eckstein and Mauruth, 1999). Though not accounted for, a slightly lower temperature could exist because of the thick sedimentary strata found in the study area. Using these geophysical gradients reservoir conditions can be established. For instance, an $8000 \mathrm{ft}$ deep storage facility can be predicted to have a pressure of 
$4415 \mathrm{psi}$ and a temperature of $140^{\circ} \mathrm{F}$. Using these conditions, one may predict the physical behavior of the natural gas in containment and calculate the necessary cavity volume.

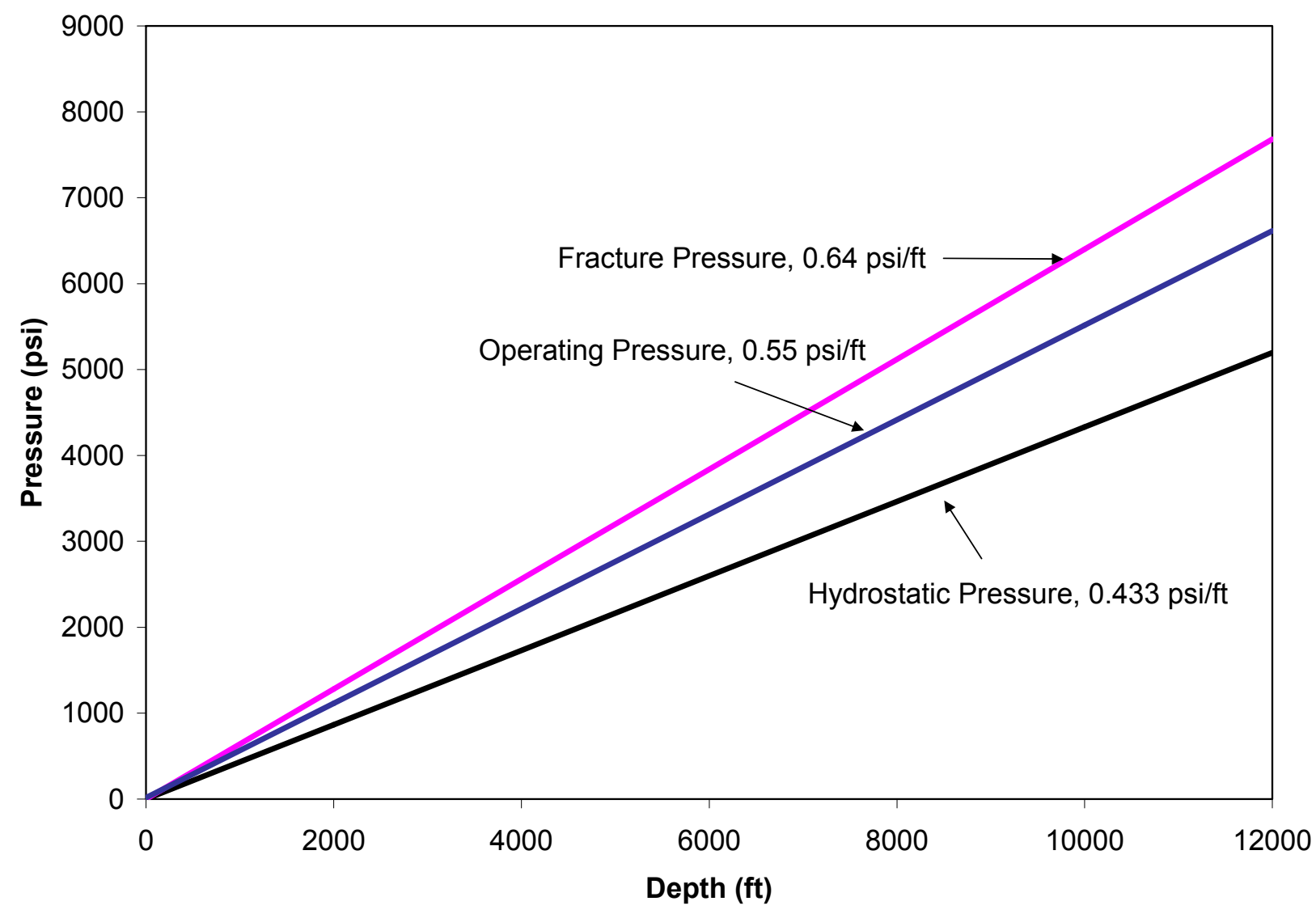

Figure 33. Estimation of hydrostatic and fracture pressures at depth. Operating pressure for gas storage facility at depth.

Natural gas is a highly compressible mixture whose density varies significantly with changes in temperature and pressure and to a lesser extent with composition. It is preferable to use experimentally measured data for natural gas density over values predicted by ideal gas law or more complicated equations of state (e.g., Peng-Robinson, SRK). The original measurements for natural gas density were reported in several journal articles, but the collected data are presented in several reference sources, including the Handbook of Natural Gas Engineering. Experimental gas density data (Standing and Katz, 1942) are shown in Figure 34. These data clearly illustrate that the average molecular weight of the gas, i.e., the composition, will affect the mixture density, especially at elevated pressures. The natural gas composition used for all calculations was $90 \%$ methane and $10 \%$ ethane, which yielded an average gas molecular weight of $17.3 \mathrm{~g} / \mathrm{mol}$, which corresponds to a 0.6 gravity gas (i.e., the specific gravity of the gas is $40 \%$ less than that of air at STP conditions). 


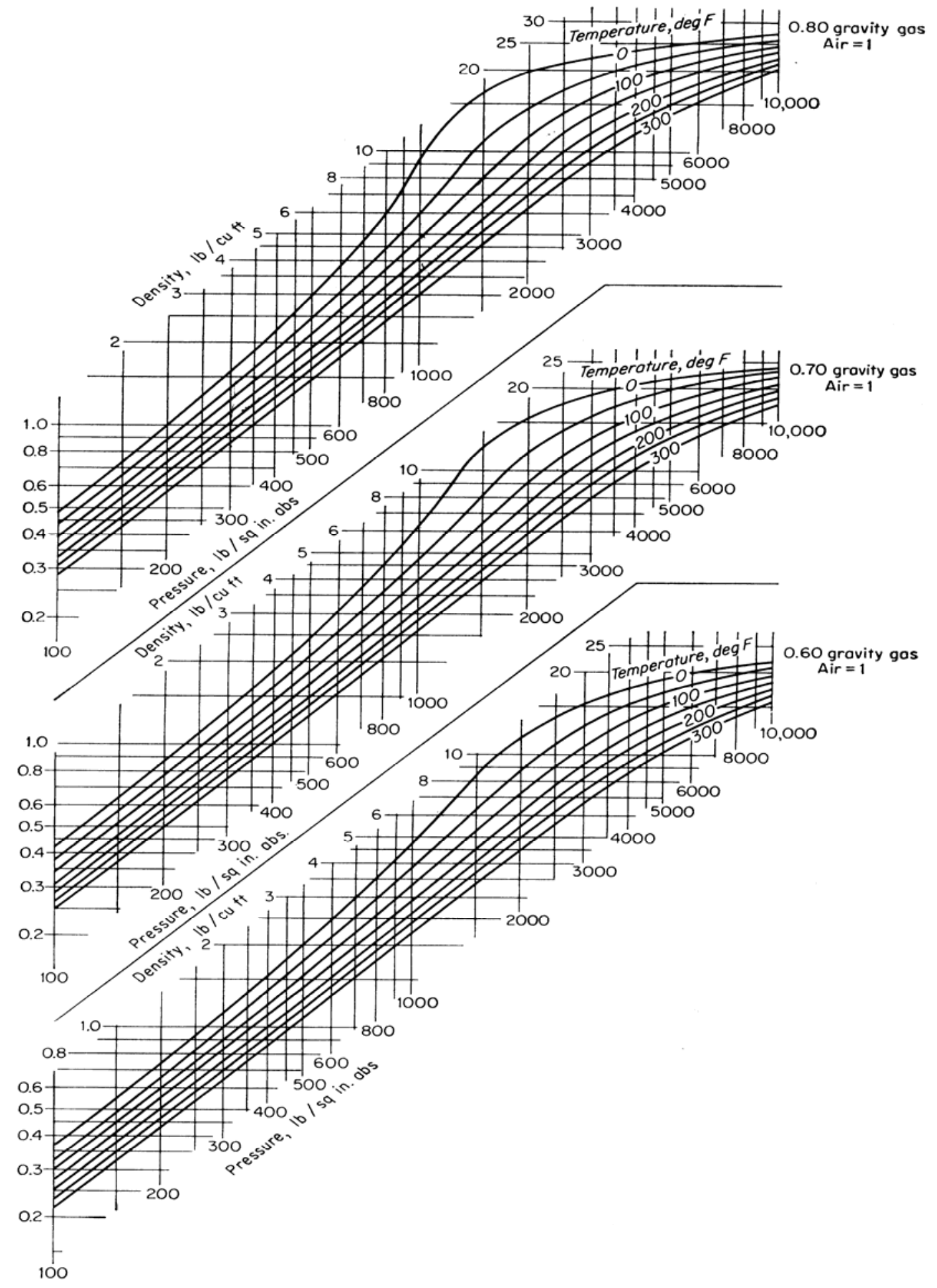

Figure 34. Density of natural gases (Standing and Katz, 1942). 
The cavity storage volume required for a given quantity of natural gas is easily calculated using the gas density at STP and storage conditions.

$$
\frac{\mathrm{V}\left(\mathrm{STP}, \mathrm{ft}^{3}\right)}{\rho\left(\mathrm{STP}, \mathrm{lb} / \mathrm{ft}^{3}\right)}=\frac{\mathrm{V}\left(\text { storage } \mathrm{T} \text { and } \mathrm{P}, \mathrm{ft}^{3}\right)}{\rho\left(\text { storage } \mathrm{T} \text { and } \mathrm{P}, \mathrm{lb} / \mathrm{ft}^{3}\right)}
$$

The volume of underground gas volume needed at a specified depth for a given quantity of natural gas is shown in Figure 35 below.

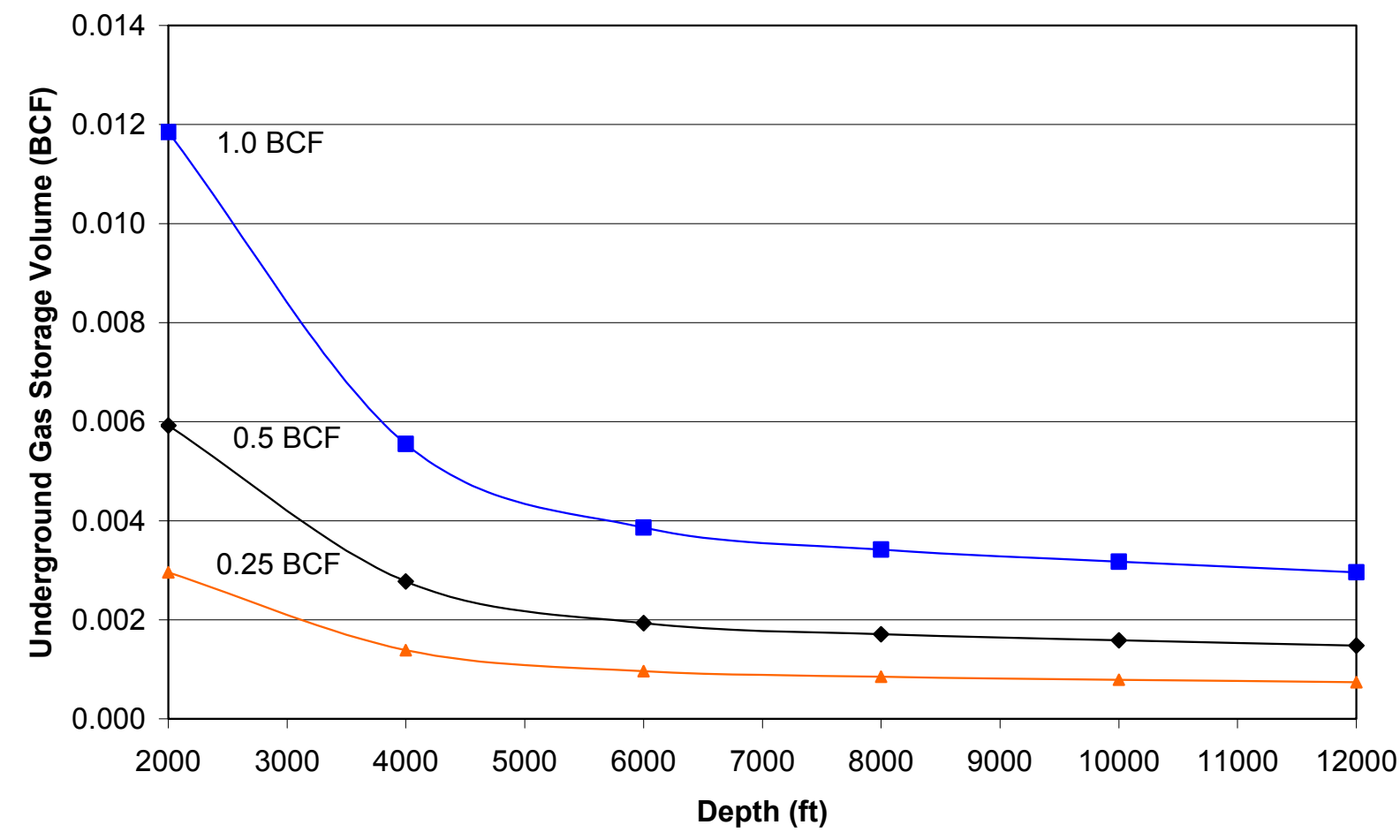

Figure 35. Variations in required underground gas storage volume with depth for 0.25 to $1 \mathrm{BCF}$ (STP or zero depth conditions) of total gas storage. The plotted relationship depends heavily on previously discussed pressure and temperature gradient assumptions.

As illustrated in Figure 35, the high compressibility of natural gas makes it advantageous to develop a storage cavern at depths greater than $4000 \mathrm{ft}$, with optimal depth below $6000 \mathrm{ft}$. Below this depth the increase is gas density with depth is greatly reduced. Additionally, advantages gained by the increased gas density at depths below $6000 \mathrm{ft}$ may be offset by higher drilling and operating costs.

\section{Weight and Volume of Rock to be Dissolved}

The volume of rock needing to be dissolved using aqueous acids is a function of the volume of gas to be stored in the reservoir (at STP conditions), gas density at depth, and the 
porosity of the carbonate rock formation:

$$
\mathrm{V}_{\text {Dissolved Rock }}\left(\mathrm{ft}^{3}\right)=\left[\frac{\mathrm{V}_{\text {gas }}\left(\mathrm{STP}, \mathrm{ft}^{3}\right) \cdot \rho_{\text {gas }}\left(\text { storage } \mathrm{T} \text { and } \mathrm{P}, \mathrm{lb} / \mathrm{ft}^{3}\right)}{\rho_{\text {gas }}\left(\mathrm{STP}, \mathrm{lb} / \mathrm{ft}^{3}\right)}\right]\left(1-\frac{\% \text { Rock Porosity }}{100}\right)
$$

The mass of rock that must be removed for a given storage capacity is simply the volume of rock (accounting for rock porosity) multiplied by the density of the rock (limestone or dolomite). Using a calcium carbonate density of approximately $170 \mathrm{lb} / \mathrm{ft}^{3}$, Figure 36 illustrates how the mass of rock to be dissolved varies with depth, rock porosity, and total gas storage volume.

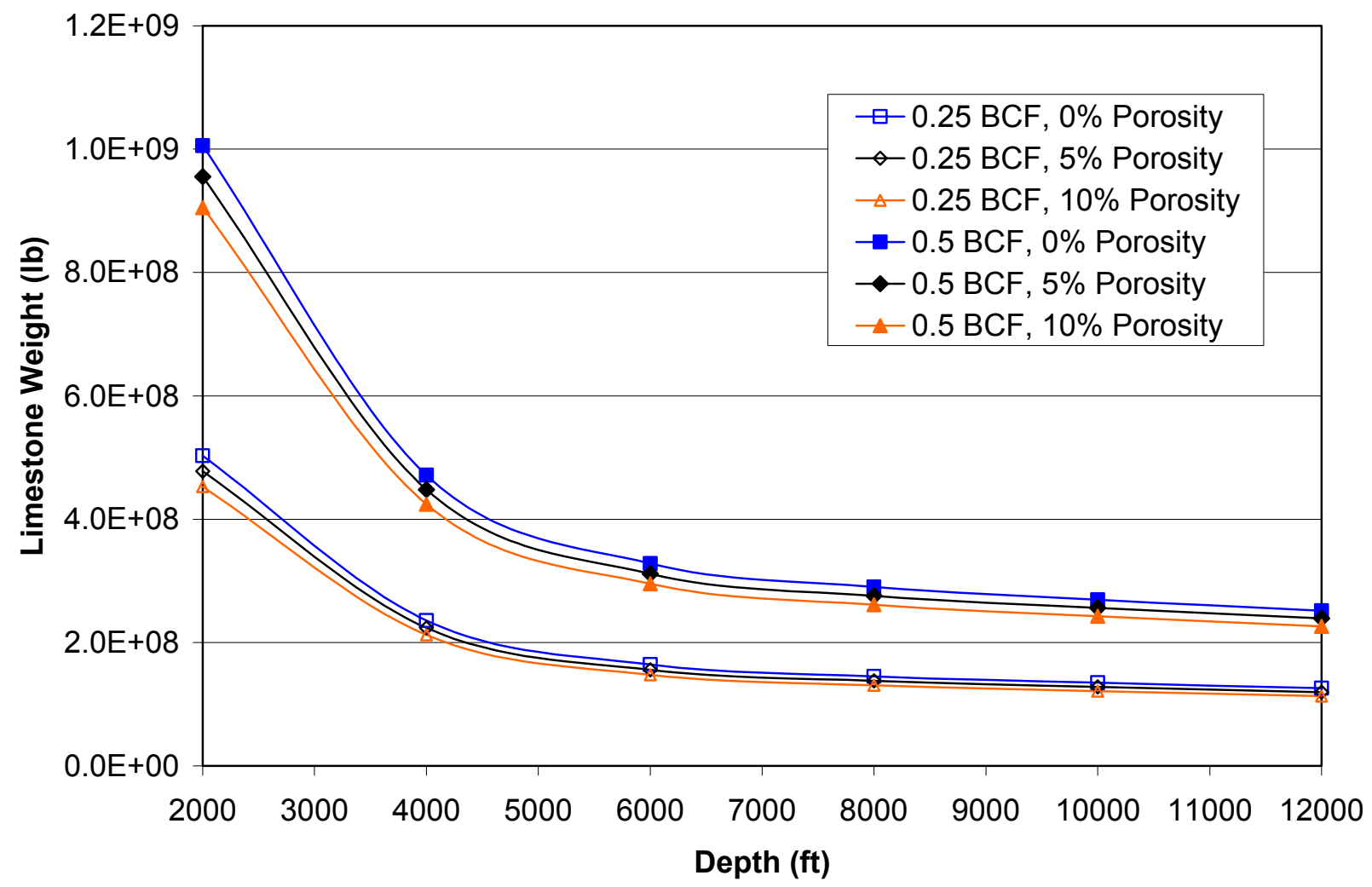

Figure 36. Weight of limestone to be removed via acid dissolution for gas storage volume of 0.25 and $0.5 \mathrm{BCF}$ and limestone porosities between 0 and $10 \%$. 


\section{Preliminary Economic Analysis (Task 3)}

By David Bruce

The new limestone dissolution process, shown in Figure 37, involves hydrochloric acid being pumped into a fractured limestone formation, where it will rapidly react and effectively dissolve the limestone deposit. The products of this reaction, calcium chloride and carbonic acid, are highly soluble in water and will be removed via a second well, leaving behind a gas storage cavity capable of high rates of gas deliverability. Some of the key components of the process are: 1) an acid collection and storage facility, 2) an acid pumping station, 3) a clarifier for evaporating water and collecting crude $\mathrm{CaCl}_{2}$ product, 4) a wetlands waste treatment facility, and 5) a $\mathrm{CaCl}_{2}$ packaging facility (not shown). A final design and updated economic analysis are presented later in this report (Task 11).

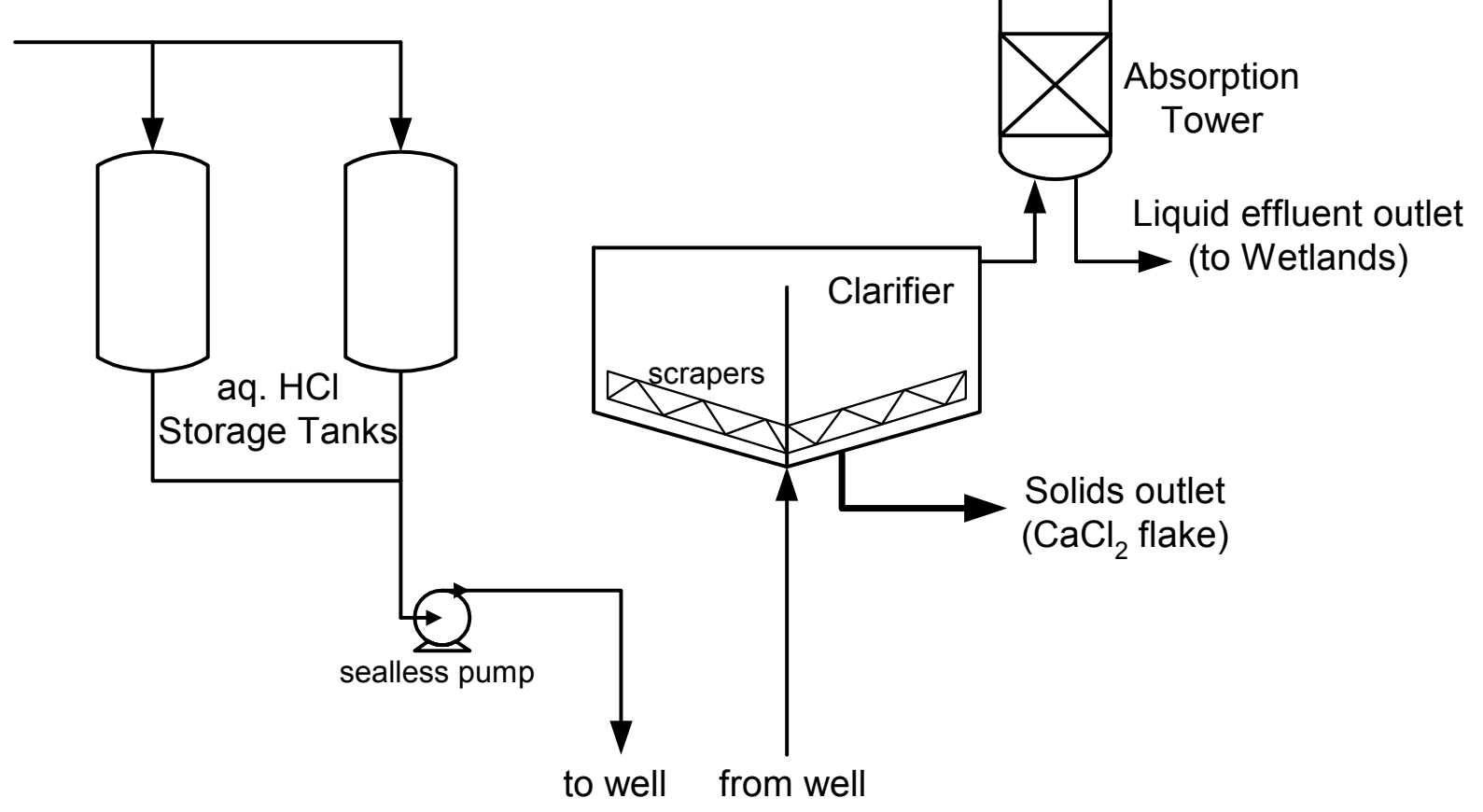

Figure 37. Simplified process flow diagram for the acid dissolution process.

\section{Well Design Options and Costs}

There exist several options for the number and placement of wells for the acid dissolution process for creating gas storage in carbonate rock. A single concentric tube design is possible and would likely yield a spherically or elliptically shaped gas storage cavern (Figure 38A). With this design, fresh acid would be pumped down the well between the inner and outer casing, similar to how salt caverns are created. Soluble salt products would be removed from the well using the smaller casing. However, there are also two-well and multi-well designs that could be used to rapidly produce an underground gas storage cavern. For the two-well designs (two-well 
with vertical fracture and two-well dogbone design), one well would be used to pump down fresh acid, while the other well would be used to remove spent acid products (Figure 38B).
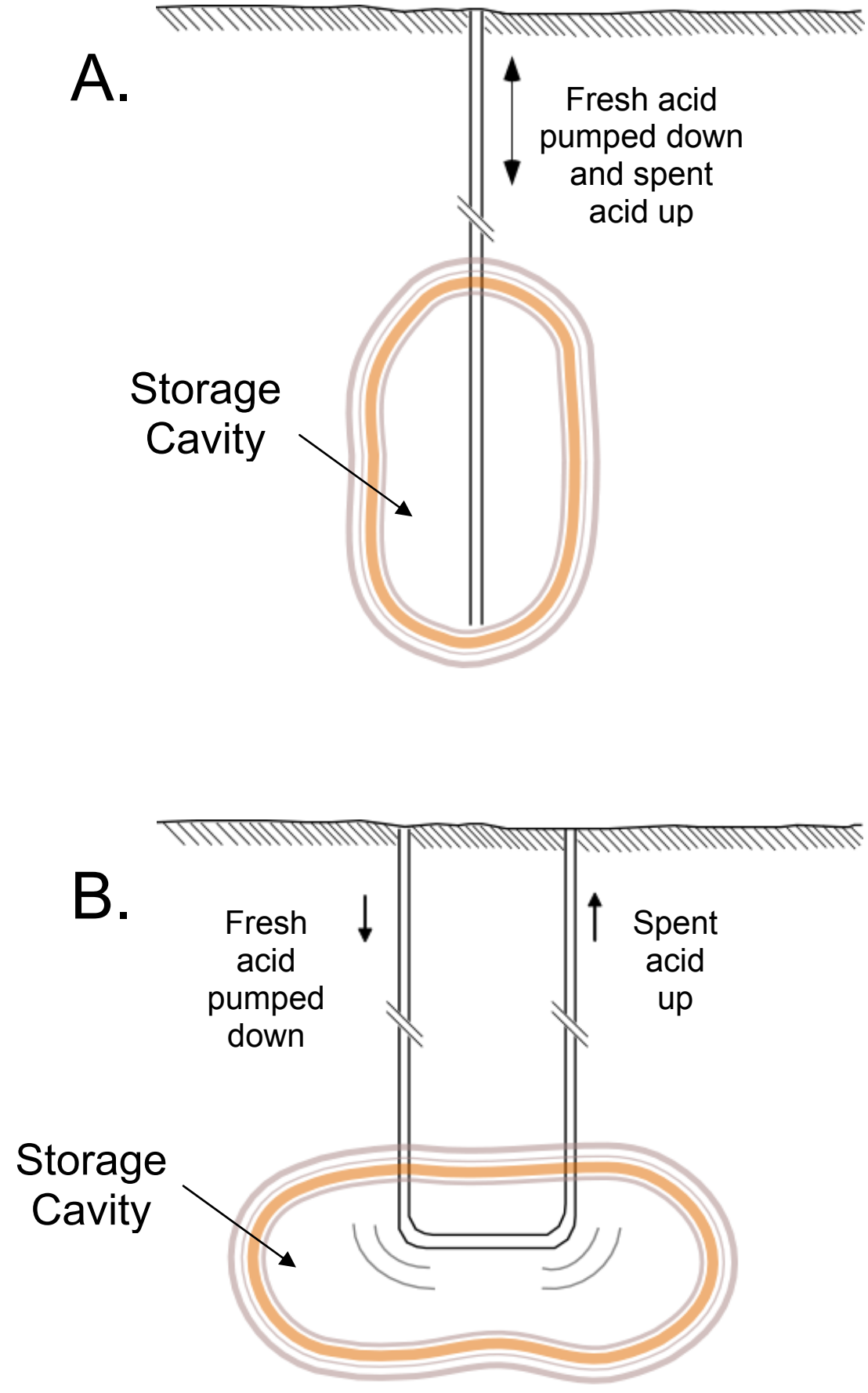

Figure 38. Well designs for creating gas-storage cavity by acid dissolution of carbonate rock. A) Single-well design; B) Two-well dogbone design.

These two-well designs differ in how a water flow channel is developed between the two wells. In one case, the limestone rock is fractured (vertical fractures below $2000 \mathrm{ft}$ ), while in the 
other case a horizontally drilled hole connects the two wells. A description of the two-well designs is listed below. For cost estimation purposes, a vertically fractured two-well design cavern was selected and the cost for this type of well is listed in Table 25 for a range of depths.

Two-well with Vertical Fracture:

Description: Drill two wells and fracture vertically to connect the wells.

Method: Drill the first well, log, perform microfracture and injection tests, drill the second well, and fracture the rock between the two wells.

Restrictions/Comments: At least $2 \%$ initial porosity is needed to fracture the rock

Two-well Dogbone Design

Description: Two vertical wells with a horizontal connector.

Method: Drill the first well, log, drill the second well, and finally drill the horizontal connector between wells.

Restrictions/Comments: Most dissolution will probably occur at the corners. Distance between wells will depend on storage capacity. No initial porosity is needed.

Table 25. Approximate drilling and fracturing costs in the Northeastern US area (Source DB).

\begin{tabular}{|c|c|c|c|c|c|}
\hline \multirow{2}{*}{$\begin{array}{l}\text { Total Depth } \\
\text { (ft) }\end{array}$} & \multirow{2}{*}{$\begin{array}{l}\text { Completed } \\
\text { Well }^{\mathrm{a}}\end{array}$} & \multirow{2}{*}{$\begin{array}{l}\text { Construction } \\
\text { Well }^{\text {b }}\end{array}$} & \multicolumn{3}{|c|}{ Additional Completed Costs } \\
\hline & & & $\begin{array}{l}\text { Horizontal } \\
\text { Connection }^{\mathrm{c}}\end{array}$ & $\begin{array}{l}\text { Acid } \\
\text { Fracturing }^{\mathrm{d}}\end{array}$ & $\begin{array}{l}\text { Hydraulic } \\
\text { Fracturing }\end{array}$ \\
\hline 4,000 & $\$ 250,000$ & $\$ 150,000$ & $\$ 50,000$ & $\$ 20,000$ & $\$ 30,000$ \\
\hline 8,000 & $\$ 1,000,000$ & $\$ 500,000$ & $\$ 100,000$ & $\$ 100,000$ & $\$ 75,000$ \\
\hline 12,000 & $\$ 2,500,000$ & $\$ 1,000,000$ & $\$ 150,000$ & $\$ 150,000$ & $\$ 200,000$ \\
\hline
\end{tabular}

a Completed injection/withdrawal storage well, 7 inch, high deliverability flow string to bottom.

b Additional slim hole well to assist in cavity building. Flow string set at total depth.

c Directionally drilled connection between wells at total depth.

d Five thousand gallon gelled acid breakdown to initiate cavity building process.

e Hydraulic fracture with proppant to initiate/accelerate cavity building process.

\section{Waste Treatment and Green House Gas Emissions}

The limestone dissolution reaction with aqueous hydrochloric acid yields calcium chloride and carbonic acid as products. These products are highly soluble in water and can be easily removed from the underground storage cavity. Upon exiting the well, these dissolution products are to be treated using two above ground process elements: a clarifier and a constructed wetland treatment system. The initial liquid/slurry will be sent to an enclosed cylindrical 
clarifier equipped with scrapers, where water can evaporate and solid calcium chloride product can be isolated. The calcium chloride will be sold in both liquid and solid form for road deicing purposes in the northern US, where it is the preferred deicing agent for roads $\left(\mathrm{CaCl}_{2}\right.$ is effective as a deicing agent at temperatures as low $-15^{\circ} \mathrm{C}$ ). The sale of this product stream will also enhance the profitability for the dissolution project by offsetting the cost for hydrochloric acid.

The secondary treatment facility consists of a constructed wetland treatment area that will cover between 5 and 10 acres (depending on the size of the gas storage cavern to be developed). Since large quantities of dissolved carbon dioxide will be generated by this process (e.g., the formation of $1 \mathrm{BCF}$ of gas storage at $4000 \mathrm{ft}$ would produce 234 thousand tons of carbon dioxide - approximately $6 \%$ of what a typical coal power plant releases annually), this constructed wetland treatment system will contribute to the reduction of green house gas emissions from the process. The plants in this wetlands area are also resilient to moderate levels of salts, such as calcium chloride, and have proven to be highly effective in applications involving the treatment of aqueous waste streams from power plant boilers and scrubbing towers. Thus, the waste treatment options described will reduce the emissions of green house gases (carbon dioxide) and provide a revenue source that is derived from the calcium chloride product from the dissolution process.

Although other options for treating the wastewater are possible, a constructed wetland treatment system provides important economic and environmental benefits. Principles of natural wetlands will be applied to constructing a treatment system designed to ensure the desired reactions at predictable rates. This is a proven approach and has been used successfully for the treatment of various waste fluids, including refinery effluent and brines produced from oilfields (e.g., Moshiri, 1993; Hawkins et al., 1997; Gillespie et al., 2000; Huddleston et al., 2000; Moore et al., 2001, Murray-Gulde, 2003).

\section{Fixed Capital Cost Estimation}

Fixed capital costs, including both direct and indirect costs, were estimated for a limestone dissolution process that would use hydrochloric acid to create a 0.5 to $1 \mathrm{BCF}$ gas storage reservoir. The various costs were calculated using Lang factors (see Table 26), which relate the costs of construction to total purchased equipment costs. The Lang factors used for this taskt were obtained from the process design text by Peters and Timmerhaus (1991) and are specifically for processes built in the US that require both liquids and solids handling. For this cost estimate, delivered equipment costs were used to estimate fixed capital costs, and these values are shown in Table 27. The key equipment items include corrosion resistant pumps, hydrochloric acid holding tanks (20,000 gal tanks), a clarifier for isolating calcium chloride products, and a wetlands wastewater treatment area for carbonic acid removal. Since these economic calculations are for only a moderately well defined process, the contingency factor (36) is higher than would be used for a process where a detailed piping and instrumentation diagram had been developed. These calculations yield a fixed capital cost of \$3,270,529 US. 
Table 26. Estimated fixed capital cost factors for a 0.5 to $1 \mathrm{BCF}$ gas storage facility created via acid dissolution of limestone using hydrochloric acid.

\begin{tabular}{|l|l|l|}
\hline Operation & $\begin{array}{l}\text { Lang Factors, Solid-Liquid } \\
\text { (Peters and Timmerhaus, 1991) }\end{array}$ & Cost (\$ US) \\
\hline Direct Costs & 100 & 799,640 \\
\hline Purchased equipment & 39 & 311,860 \\
\hline Installation & 13 & 103,953 \\
\hline Instrumentation & 31 & 247,888 \\
\hline Piping & 10 & 79,964 \\
\hline Electrical & 29 & 231,896 \\
\hline Buildings & 10 & 79,964 \\
\hline Yard Improvements & 55 & 439,802 \\
\hline Service facilities & 2 & 15,993 \\
\hline Land & \multicolumn{2}{|l}{} \\
\hline Indirect Costs & 32 & 255,885 \\
\hline Engineering \& Supervision & 34 & 271,878 \\
\hline Construction expenses & 18 & 143,935 \\
\hline Contractor's fee & 36 & 287,871 \\
\hline Contingency & $\mathbf{4 0 7}$ & $3,270,529$ \\
\hline Total Fixed Capital \\
Investment
\end{tabular}

Table 27. Estimated delivered equipment costs for a 0.5 to $1 \mathrm{BCF}$ gas storage facility created via acid dissolution of limestone using hydrochloric acid.

\begin{tabular}{|l|l|}
\hline Purchased Equipment & Cost (\$ US) \\
\hline Clarifier, (for con. $\mathrm{CaCl}_{2}$ solution) & 449,640 \\
\hline Sealless, acid-resistant centrifugal pumps & 85,000 \\
\hline Hydrochloric acid storage tanks & 265,000 \\
\hline Wetlands treatment area & 30,000 \\
\hline Total Equipment Costs (delivered) & $\mathbf{7 9 9 , 6 4 0}$ \\
\hline
\end{tabular}




\section{Chemical Pricing}

The purchase cost of hydrochloric acid and the fair market value of the calcium chloride products was derived from up-to-date pricing information in Chemical Market Reporter, which provides industry average pricing for most commodity chemicals. In order to reemphasize the need for developing gas storage at depths greater than $4000 \mathrm{ft}$, variations in the total cost of hydrochloric acid as a function of storage depth are shown in Figure 39. It should be noted that the quantities of acid are significant (e.g., a reservoir $8000 \mathrm{ft}$ below the surface capable of storing $1.0 \mathrm{BCF}$ of natural gas would require $1.8 \%$ of the nations hydrochloric acid production in 2002); therefore, it is very likely that the negotiated price for acid would be 10 to $50 \%$ less than the current market price for technical grade hydrochloric acid. Additionally, Figure 40 shows current sales prices for a variety of calcium chloride products. It was assumed for the overall cost estimate that only $75 \%$ of the calcium chloride product could be recovered and sold as $80 \%$ flake product. The exact purity and form of the calcium chloride product leaving the clarifier could vary with process conditions and with the location of the two wells (i.e., the presence of impurities in the underground limestone could affect the purity of the precipitated $\mathrm{CaCl}_{2}$ product).

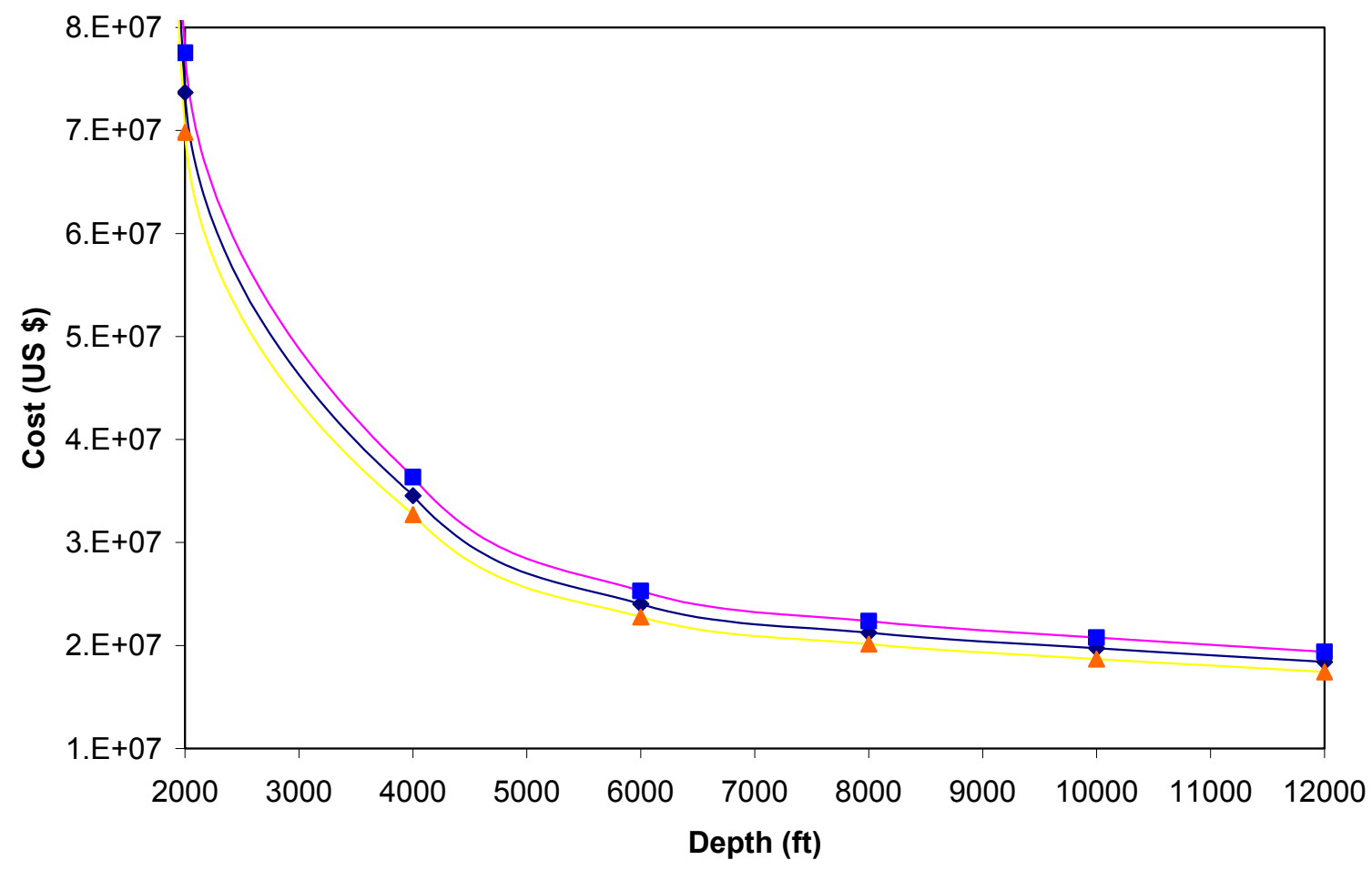

Figure 39. Cost of aqueous $\mathrm{HCl}$ (33 wt \% solution) needed for a $0.5 \mathrm{BCF}$ natural gas storage facility at varying depths in the northeastern US. 


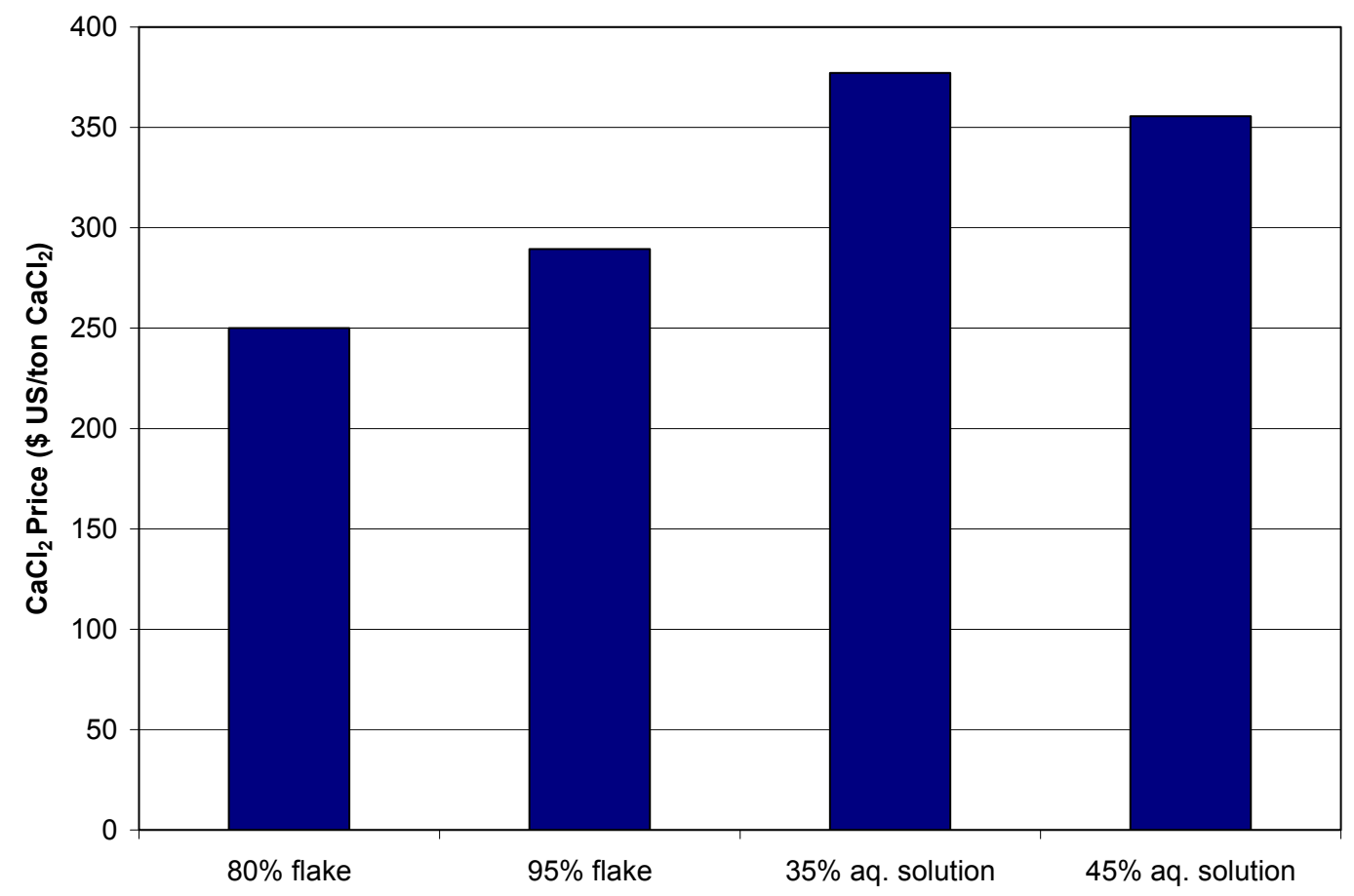

Figure 40. Commercial scale sales price for $\mathrm{CaCl} 2$ in various forms and concentrations. (Chemical Market Reporter, Dec. 2003).

\section{Estimation of Total Facility Costs}

The total gross-earnings cost for developing an underground gas storage facility via the acid dissolution of limestone equals the difference between total income derived from the sale of calcium chloride salts minus the total development cost. The total development cost for the gas storage facility can be estimated by summing the direct production costs, fixed charges, and facility overhead charges. The factors for these various costs were taken from the text by Peters and Timmerhaus (1991) and are a primarily a function of the hydrochloric acid cost, and the total capital investment cost. These economic factors are reported in Table 28 and the total grossearnings cost for a 0.25 or $0.5 \mathrm{BCF}$ gas storage facility in limestone is shown in Figure 41 as a function of limestone porosity at depth. Though no data are presented in this report on dolomite dissolution costs (for brevity), these costs were evaluated and found to be approximately $6 \%$ more than that for limestone formations. This is primarily due to the higher density of the dolomite rock as compared to limestone. 
Table 28. Estimated total production cost factors for a 0.5 to $1 \mathrm{BCF}$ gas storage facility created via acid dissolution of limestone using hydrochloric acid.

\begin{tabular}{|l|l|}
\hline Item & $\%$ Total Development Cost \\
\hline \multicolumn{2}{|l|}{ Direct Production Costs } \\
\hline Raw Materials & 49 \\
\hline Labor & 14 \\
\hline Utilities & 8 \\
\hline Maintenance & 3 \\
\hline Fixed Charges & \multicolumn{2}{|l|}{} \\
\hline $\begin{array}{l}\text { Depreciation - Fixed Capital } \\
\text { Cost }\end{array}$ & 9 \\
\hline Taxes & 1.5 \\
\hline Insurance & 0.5 \\
\hline Plant overhead & 8 \\
\hline General Expenses & 2 \\
\hline Administration Costs & 5 \\
\hline $\begin{array}{l}\text { Distribution and selling } \\
\text { costs }\end{array}$ & 100 \\
\hline Total & \\
\hline
\end{tabular}




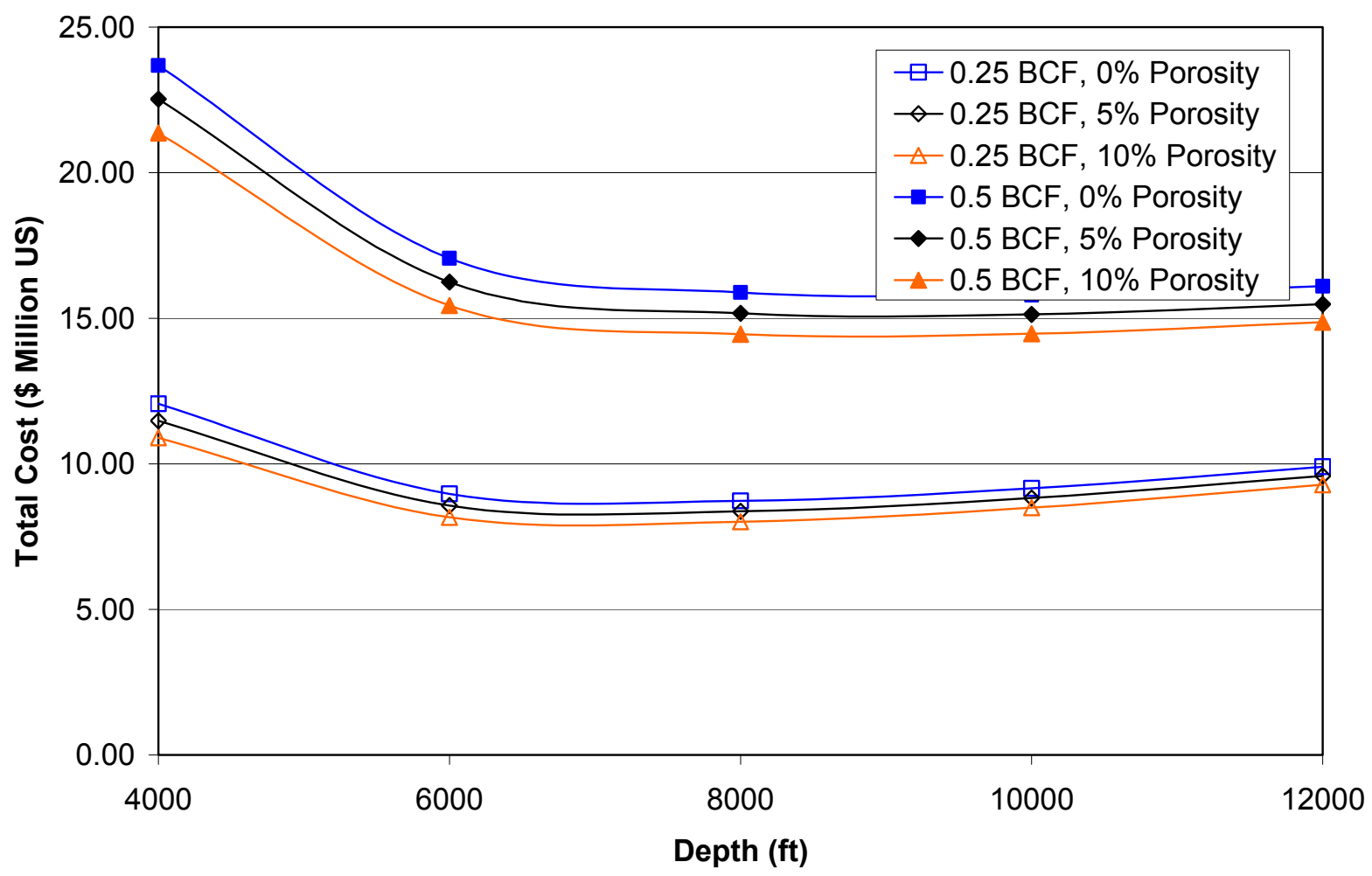

Figure 41. Total cost for a 0.25 and $0.5 \mathrm{BCF}$ natural gas storage facility in limestone of varying porosity at varying depths in the northeastern US.

\section{Comparison of Gas Storage Costs}

There exist several possibilities for increasing the availability of natural gas storage near major use markets. Some (but not all) of the possibilities are depicted in Figure 42 and include: 1) construction of new above ground gas storage vessels of varying size, 2) conversion of abandoned mines to underground gas storage facilities, 3) conversion of existing aquifers to gas storage facilities, and 4) the development of new underground gas storage facilities via the dissolution of rock (this proposal) or salt. With each of these methods there are both economic and safety considerations. The construction of large numbers of above ground gas storage vessels introduces considerable risk in the modern era of terrorism. The most feasible way to store gas above ground is to liquefy it, which is expensive, and then store it in insulated tanks as liquefied natural gas (LNG). The conversion of abandoned mines to underground gas storage facilities suffer from the fact that the mines may not be located near existing gas storage pipelines or population centers. Additionally, these mines may not be suitable for storing the natural gas because of the many containment issues of abandoned mines. 


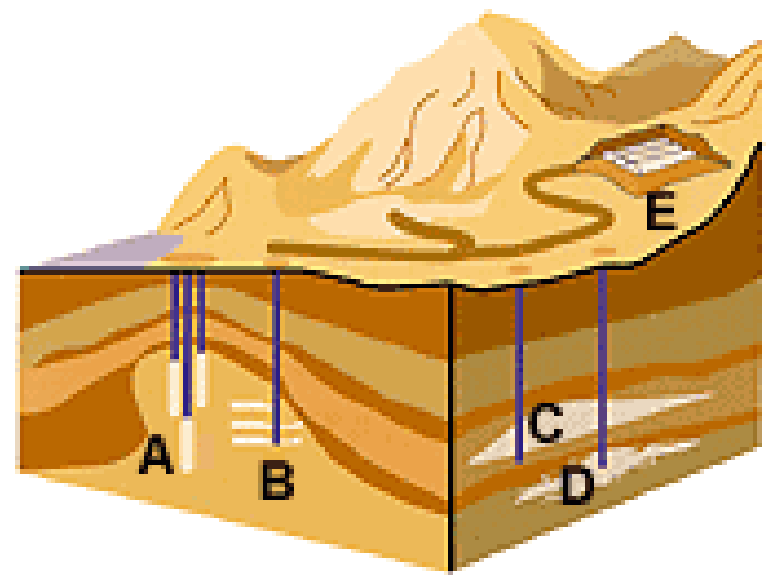

Figure 42. Types of underground natural gas storage: A) salt caverns, B) mines, C) aquifers, D) depleted oil/gas reservoirs, and E) hard rock mines. From www.fe.doe.gov/programs/ oilgas/storage.

In order to evaluate the economic feasibility of the limestone dissolution process, cost comparisons were made to existing or newly created underground gas storage facilities and are shown in Figure 43. This figure shows cost for salt storage and storage created using the new fracturing and acid-dissolution process. The total gross-earnings cost analysis shows that reductions in cost are achieved with increases in rock porosity and are significantly influenced by the sales price of hydrochloric acid and calcium chloride. If hydrochloric acids costs can be negotiated to a value lower than the average list sales price, then the new process is even more competitive with other means for creating underground gas storage. Such reductions in acid cost are very likely given the quantity of acid to be purchased and the ability to use low purity hydrochloric acid. For example, Reed Business Information's Online Purchasing Magazine lists hydrochloric acid sales prices as low as $\$ 58$ per metric ton for technical grade acid - a 23\% reduction in acid cost over that used for the primary cost estimates in this report.

\section{Optimum Rock Formations}

The gross earnings costs clearly indicate the advantages of developing limestone storage caverns at depths greater than $4000 \mathrm{ft}$, where natural gas densities are near their maximum. Additionally, the increased density of dolomite deposits requires that more acid be use to develop storage in these rock formations. Thus, the preferred rock formation is one made of limestone at depths between 6000 and $9000 \mathrm{ft}$. Further cost savings (up to 9\%) can be achieved by developing gas storage in limestone with increased porosity (up to 15\%). Such limestone deposits exist in several regions of the US (discussed later) and similar gas storage fields have been developed within this depth range (American Gas Association, 2002). 


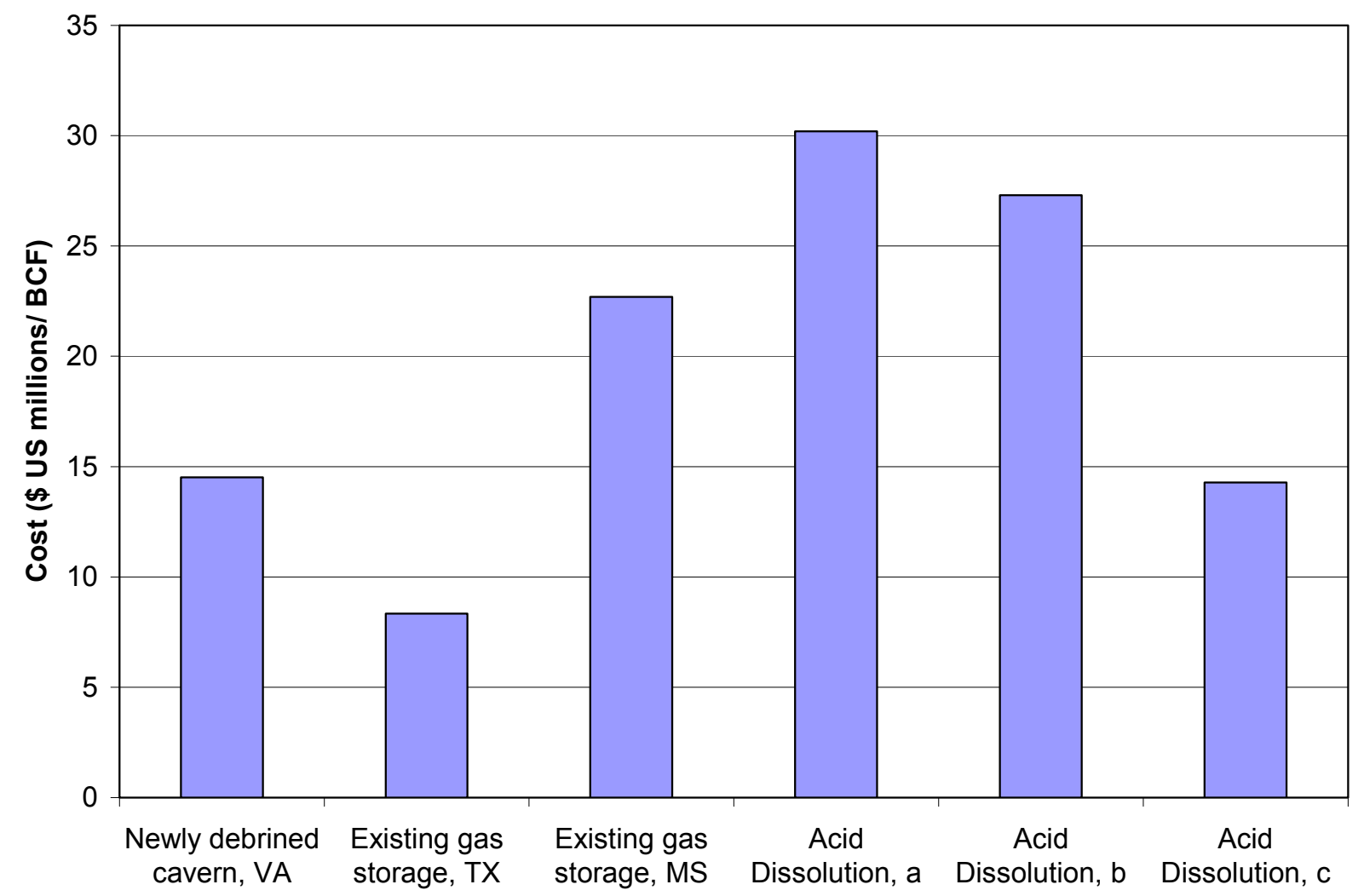

a 1 BCF, $0 \%$ Porosity, Listed Acid Cost, $75 \% \mathrm{CaCl} 2$ sold, $8000 \mathrm{ft}$.

b $1 \mathrm{BCF}, 10 \%$ Porosity, Listed Acid Cost, $75 \% \mathrm{CaCl} 2$ sold, $8000 \mathrm{ft}$.

c 1 BCF, $5 \%$ Porosity, $65 \%$ of Listed Acid Cost, $75 \%$ CaCl2 sold, $8000 \mathrm{ft}$.

Figure 43. Cost comparison between various underground gas storage methods. 


\section{Regional Survey of Carbonate Formations (Task 4) \\ By James W. Castle and Scott E. Brame}

\section{Identification of Carbonate Units and Regional Stratigraphic Analysis}

A regional survey was conducted to identify carbonate formations that are likely candidates for developing gas storage using the fracturing and acid-dissolution method. In consultation with DOE, the following states were selected for the regional survey: Indiana, Ohio, Kentucky, West Virginia, Pennsylvania, and New York. Thick, laterally continuous carbonate sequences underlie major portions of these states. To identify the regional extent of each of these units, a series of maps was produced. These maps were presented earlier in our report for Budget Period One (Castle et al., 2004).

Using the COSUNA charts for the northern and southern Appalachian Basins (Patchen et al., 1984a, 1984b) and Rupp (1991) for Indiana, seven major carbonate units were identified for mapping in each of the selected states (Table 29). These carbonate units are generally separated by non-carbonate (siliciclastic or evaporate) formations, which may help provide an overlying seal for the fracturing and acid-dissolution process. The only common exception to the presence of non-carbonate directly overlying the carbonate unit is the contact between Units 5 and 6 . In a few areas, Unit 6 directly overlies Unit 7.

The approximate values for ranges of porosity and permeability are listed in Table 29 for the carbonate units mapped. Although published values of porosity and permeability were found to be very sparse, depth and thickness values were available from the state geological surveys for most areas and were used for mapping. The porosity ranges in Table 30 include values that are equivalent to optimum values for generating storage capacity using the fracture-acid dissolution method (see the section on "Preliminary Economic Analysis" in this report).

Table 29. Regionally correlative and mappable carbonate units in the project area and their geologic age. In Indiana, Unit 4 includes the entire Silurian section because of the extensive deposition of carbonate sediment during that time.

\begin{tabular}{|c|l|}
\hline Carbonate Unit & \multicolumn{1}{c|}{ Age } \\
\hline 1 & Early Mississippian \\
\hline 2 & Middle Devonian \\
\hline 3 & Late Silurian - Early Devonian \\
\hline 4 & Late Silurian (Silurian in Indiana) \\
\hline 5 & Late Ordovician \\
\hline 6 & Late Ordovician \\
\hline 7 & Late Cambrian - Early Ordovician \\
\hline
\end{tabular}


Table 30. Approximate values for ranges of porosity and permeability of the carbonate units mapped. Data from Wickstrom at al. (1992); Riley et al. (1993); Roen and Walker (1996).

\begin{tabular}{|c|c|l|}
\hline Carbonate Unit & Porosity Range (\%) & Permeability Range (md) \\
\hline 1 & $0-27$ & $0-1$ \\
\hline 2 & $2-10$ & $0-600$ \\
\hline 3 & $2-10$ & not found \\
\hline 4 & $2-20$ & $0-54$ \\
\hline 5 & $1-20$ & $0.3-9000$ \\
\hline 6 & $1-14$ & $0.3-9000$ \\
\hline 7 & $0-22$ & $0-56$ \\
\hline
\end{tabular}

The carbonate formations included in each of the mapping units and the non-carbonate formations separating the mapping units are listed in Tables 31-36. The formations are listed in the correct stratigraphic position. In addition, the predominant lithology in each carbonate unit is listed. Not all of the carbonate units are present in all six states because of regional variations in deposition and erosion. Some comments regarding the stratigraphy in each state follow.

$\underline{\text { Indiana }}$

The Salem Limestone of Indiana is stratigraphically equivalent to the Greenbrier Group and Newman Limestone of the other states (John Rupp, Indiana Geological Survey, personal communication). In Indiana there is no specific, equivalent formation to the Silurian-Devonian carbonates (i.e., the Helderberg Group). The Lower Devonian New Harmony Group is mainly chert, and the Silurian section is almost entirely carbonate. For this reason, Unit 3 in Indiana is not mapped and the entire Silurian section is assigned to Unit 4.

$\underline{\text { Kentucky }}$

Because the Kentucky Geological Survey groups the Onondaga Limestone and Helderburg Limestone together in their database, Units 2 and Unit 3 are combined in Table 32. These formations in Kentucky are commonly difficult to differentiate using cores or logs.

New York

In general, the sedimentary units in New York are at their deepest along the southern border of the state and dip upwards toward the surface in north central New York. In New York, Unit 1 is not present and thus was not mapped.

$\underline{\text { Ohio }}$

Data for Ohio were obtained through the Ohio Geological Survey in the form of digital data files (DDFs) that can downloaded from their website. DDF 1 contains data for northwestern Ohio and DDF 2 contains data from the eastern half of Ohio. These files were merged to produce a composite map for the state. While these digital files contain many wells, the formation top data are limited. In particular, the data for formations above the Ordovician are sparse. Apparently, based on enquiries to personnel at the Ohio Survey, more data will become available to the public after their work in progress has been completed. As a result, the only formation above the 
Trenton that could be mapped was the Onondaga (Unit 2), and only a top for that formation could be obtained. Thus Units 3 and 4 could not be mapped. Unit 1 is generally not present in Ohio.

The stratigraphy of Ohio is complicated by the presence of the Findlay Arch, which cuts approximately across the middle of the state and then merges with the Cincinnati Arch in the southwestern part of the state.

\section{$\underline{\text { Pennsylvania }}$}

Most units are at their shallowest depth in the northwest corner of the state and become progressively deeper eastward into the Appalachian basin. The carbonate units become difficult to map near the structural front because of complexities such as thrust faults. For a few wells near the structural front, some formations are listed in the data base as many as four times due to thrust stacking. In these cases, depth of the deepest occurrence was mapped. Thickness of repeated section due to thrusting was used for mapping thickness only if there were no intervening non-carbonate layers. Unit 1 is not present in Pennsylvania and thus was not mapped.

Because a siliciclastic unit (Upper Sandy Member) is present consistently within Unit 7 in Pennsylvania, this unit is divided into Subunits $7 \mathrm{a}$ and $7 \mathrm{~b}$ for mapping purposes.

\section{West Virginia}

In West Virginia, Unit 3 was divided into Subunits $3 \mathrm{a}$ and $3 \mathrm{~b}$ because of the intervening Big Mountain Shale. Subunit 3a corresponds to the Helderburg Group and Subunit $3 b$ to the Tonolaway Limestone.

Table 31. Geologic formations and predominant lithology of carbonate units in Indiana.

\begin{tabular}{|c|l|l|}
\hline Unit & Formation(s) & Lithology of Carbonate Units \\
\hline 1 & Salem Limestone & Limestone \\
\hline & $\begin{array}{l}\text { Borden Group } \\
\text { New Albany Shale }\end{array}$ & - \\
\hline 2 & Muscatatuck Group & $\begin{array}{l}\text { Limestone, grades to dolomite } \\
\text { in northeast }\end{array}$ \\
\hline 3 & not present & - \\
\hline 4 & $\begin{array}{l}\text { Bainbridge Group } \\
\text { Sexton Creek Limestone }\end{array}$ & Limestone \\
\hline 5 & Maquoketa Group & - \\
\hline 6 & Trenton Limestone & $\begin{array}{l}\text { Limestone, grades to dolomite } \\
\text { in north }\end{array}$ \\
\hline & Black River Group & $\begin{array}{l}\text { Limestone, grades to dolomite } \\
\text { in northwest }\end{array}$ \\
\hline 7 & Ancell Group & - \\
\hline & Knox Group & Dolomite \\
\hline
\end{tabular}


Table 32. Geologic formations and predominant lithology of carbonate units in Kentucky.

\begin{tabular}{|c|l|l|}
\hline Unit & Formation(s) & \multicolumn{1}{c|}{$\begin{array}{c}\text { Lithology of } \\
\text { Carbonate Units }\end{array}$} \\
\hline 1 & Newman Limestone & Limestone \\
\hline $2 / 3$ & Upper Devonian Shales & - \\
\hline 4 & $\begin{array}{l}\text { Onondaga Limestone } \\
\text { Helderberg Limestone }\end{array}$ & Limestone \\
\hline & $\begin{array}{l}\text { Salina Formation } \\
\text { Lockport Dolomite }\end{array}$ & Dolomite \\
\hline & $\begin{array}{l}\text { Keefer Sandstone } \\
\text { Rose Hill Formation } \\
\text { Juniata Fm./Drakes Fm. }\end{array}$ & - \\
\hline 5 & Lexington Ls. (Trenton Ls.) & Limestone \\
\hline 6 & $\begin{array}{l}\text { High Bridge Gp. (Black River } \\
\text { Gp.) }\end{array}$ & Limestone \\
\hline 7 & St. Peter Sandstone & Dolomite \\
\hline & Knox Group & \\
\hline
\end{tabular}

Table 33. Geologic formations and predominant lithology of carbonate units in New York.

\begin{tabular}{|c|c|c|}
\hline Carbonate Unit & Formation(s) & Lithology of Carbonate Units \\
\hline 1 & not present & - \\
\hline \multirow[t]{2}{*}{2} & $\begin{array}{l}\text { Onondaga Limestone } \\
\text { Bois Blanc Limestone }\end{array}$ & Limestone \\
\hline & Oriskany Sandstone & - \\
\hline \multirow[t]{2}{*}{3} & $\begin{array}{l}\text { Helderberg Group } \\
\text { Roundout Formation } \\
\text { Cobleskill Limestone } \\
\text { Bass Islands Group }\end{array}$ & $\begin{array}{l}\text { Predominantly Limestone, } \\
\text { Minor Dolomite }\end{array}$ \\
\hline & Salina Group & - \\
\hline \multirow[t]{2}{*}{4} & Lockport Group & Dolomite/Limestone \\
\hline & $\begin{array}{l}\text { Clinton Group } \\
\text { Medina Group }\end{array}$ & - \\
\hline 5 & Trenton Group & Limestone \\
\hline \multirow[t]{2}{*}{6} & $\begin{array}{l}\text { Black River } \\
\text { Chazy Fm./Wells Creek } \\
\text { Fm. }\end{array}$ & Limestone \\
\hline & Glenwood Shale & - \\
\hline 7 & $\begin{array}{l}\text { Beekmantown Group } \\
\text { Tribes Hill Formation } \\
\text { Little Falls Formation } \\
\text { Theresa Formation } \\
\text { Copper Ridge Formation }\end{array}$ & Dolomite/Limestone \\
\hline
\end{tabular}


Table 34. Geologic formations and predominant lithology of carbonate units in Ohio.

\begin{tabular}{|c|l|l|}
\hline Unit & Formation(s) & Lithology of Carbonate Units \\
\hline 1 & not present & - \\
\hline 2 & Upper Devonian Shales & - \\
\hline & Onondaga Limestone & Limestone \\
\hline 3 & Oriskany Sandstone & - \\
\hline & $\begin{array}{l}\text { Helderberg Limestone } \\
\text { Keyser Limestone } \\
\text { Bass Islands Group }\end{array}$ & Limestone \\
\hline 4 & Salina Group & - \\
\hline & Lockport Dolomite & Dolomite \\
\hline 5 & $\begin{array}{l}\text { Clinton Group } \\
\text { Albion Group } \\
\text { Undifferentiated shales }\end{array}$ & - \\
\hline 6 & Trenton Limestone & Limestone \\
\hline 7 & $\begin{array}{l}\text { Black River Group } \\
\text { Gull River Fm. } \\
\text { Wells Creek Fm. }\end{array}$ & Limestone \\
\hline Knox Group & Dolomite \\
\hline
\end{tabular}


Table 35. Geologic formations and predominant lithology of carbonate units in Pennsylvania.

\begin{tabular}{|c|c|c|}
\hline Carbonate Unit & Formation(s) & Lithology of Carbonate Units \\
\hline 1 & not present & - \\
\hline \multirow[t]{2}{*}{2} & $\begin{array}{l}\text { Onondaga Limestone } \\
\text { Bois Blanc Formation } \\
\text { Buttermilk Limestone }\end{array}$ & Limestone \\
\hline & $\begin{array}{l}\text { Huntersville Chert } \\
\text { Oriskany Sandstone }\end{array}$ & - \\
\hline \multirow[t]{2}{*}{3} & $\begin{array}{l}\text { Helderberg Limestone } \\
\text { Keyser Formation } \\
\text { Bertie Dolomite } \\
\text { Tonolaway Limestone } \\
\text { Bass Islands Dolomite }\end{array}$ & $\begin{array}{l}\text { Predominantly Limestone, } \\
\text { Minor Dolomite }\end{array}$ \\
\hline & Salina Group & - \\
\hline \multirow[t]{2}{*}{4} & $\begin{array}{l}\text { Lockport Dolomite } \\
\text { McKenzie Member }\end{array}$ & Dolomite/Limestone \\
\hline & $\begin{array}{l}\text { Clinton Group } \\
\text { Tuscarora Sandstone } \\
\text { Reedsville Shale }\end{array}$ & - \\
\hline 5 & Trenton Limestone & Limestone \\
\hline 6 & $\begin{array}{l}\text { Black River Group } \\
\text { Loysburg Formation } \\
\text { Shadow Lake Formation }\end{array}$ & Limestone \\
\hline \multirow[t]{2}{*}{$7 \mathrm{a}$} & $\begin{array}{l}\text { Knox Group } \\
\text { Upper Gatesburg } \\
\text { Formation }\end{array}$ & Dolomite/Limestone \\
\hline & Upper Sandy Member & - \\
\hline $7 b$ & $\begin{array}{l}\text { Lower Gatesburg } \\
\text { Formation } \\
\text { Warrior Formation } \\
\text { Pleasant Hill Formation }\end{array}$ & Dolomite/Limestone \\
\hline
\end{tabular}


Table 36. Geologic formations and predominant lithology of carbonate units in West Virginia.

\begin{tabular}{|c|l|l|}
\hline Unit & Formation(s) & Lithology of Carbonate Units \\
\hline 1 & $\begin{array}{l}\text { Greenbrier Limestone } \\
\text { (Big Lime) }\end{array}$ & Limestone \\
\hline & Upper Devonian Shales & - \\
\hline 2 & not present & - \\
\hline $3 a$ & Oriskany Sandstone & - \\
\hline & Helderberg Group & Limestone \\
\hline $3 b$ & Big Mountain Shale & - \\
\hline & Tonolaway Limestone & Limestone \\
\hline 4 & Salina Formation & - \\
\hline & Lockport Dolomite & Dolomite \\
\hline & $\begin{array}{l}\text { Keefer Sandstone } \\
\text { Rose Hill Formation } \\
\text { Tuscarora Sandstone } \\
\text { Juniata Fm. } \\
\text { Martinsburg Fm. }\end{array}$ & - \\
\hline 5 & Trenton Limestone & Limestone \\
\hline 6 & $\begin{array}{l}\text { Black River Group } \\
\text { Wells Creek Formation/ } \\
\text { St. Paul Gp./Chazy Fm. }\end{array}$ & Limestone \\
\hline & St. Peter Sandstone & \\
\hline 7 & Knox Group & Dolomite \\
\hline & & \\
\hline
\end{tabular}

\section{Data Management: Selection, Filtering, and Quality Assurance}

Well data, including formation tops, were obtained from the state geological surveys. The goal of the data selection process was to obtain an even distribution of wells throughout each state. Typically, a spreadsheet or shapefile of deep oil and/or gas wells was obtained and displayed in a GIS program (ArcGIS 8.x). The wells were sorted by depth, and then a manageable number of wells (typically 200 - 300) were selected manually and using spatial analysis techniques. This list of wells was then submitted to the appropriate state survey representative, who would return a list of formation tops for each well. In most cases, not all of the wells submitted would have formation tops, as some of the older wells were drilled before well logging and required reporting. A second method of obtaining data was to submit a list of the carbonate formations to the state survey representative, who would then provide all the wells with those formations.

The formation data were imported into an Excel spreadsheet and processed using a variety of techniques. The data came in a multitude of formats, as each state has its own unique database and way of storing and presenting the data. The task of separating the data into a consistent format for incorporation into a GIS database was done manually. During this process, obvious errors were deleted. Once the data were converted into a GIS database and displayed, spurious data were eliminated using spatial analysis and manual methods. For example, when 
spatial interpolation was used to create surfaces of the formation tops and thicknesses, the anomalous points could be visually identified and examined for possible removal from the mapping database.

The following is a summary of the steps followed in the preparation and analysis of the geologic data:

1) Obtained geologic data (i.e., formation tops) from state geological surveys;

2) Put all data into a consistent format;

3) Loaded data into GIS;

4) Constructed DEMs (digital elevation models) for each state;

5) Created surface on each formation top (point data were converted to a grid surface);

6) Created depth surfaces from ground surfaces and formation top surfaces;

7) Converted depth surfaces to contours;

8) Created and contoured formation thickness maps;

9) Generated maps showing occurrence of carbonate units and limestones for specific depth intervals.

\section{Mapping and Analysis of Depth and Thickness Data}

Once data selection and quality control were completed, the formations were ready for mapping. A digital elevation model (DEM), which is essentially a topographic map of the ground surface, was constructed for each state. Each statewide DEM has a 90-meter resolution and was created by combining smaller 1-degree DEMs obtained from the USGS. The DEMs were originally in geographic coordinates (latitude-longitude), which creates slightly distorted grid cells. The grid distortion problem was solved by converting the grids to the Lambert Conformal coordinate system.

Maps showing the depth from the ground surface to the top of each carbonate unit were constructed within a GIS framework using map algebra techniques. Carbonate unit elevation (structural) tops were interpolated into surfaces, and the resulting surfaces were subtracted from the state DEMs to produce maps showing the depth to the top of each carbonate unit. The thickness of each unit was then interpolated. The depth surfaces and thickness values were contoured. The depth maps and thickness maps can be found in Castle et al. (2004).

The depth ranges and thicknesses of the carbonate units in each state are listed in Tables 37 and 38 , respectively. 
Table 37. Depth range to the top of mapped carbonate units for each state. Depths are in feet.

\begin{tabular}{|l|l|l|l|l|l|l|}
\hline Unit & Indiana & Kentucky & New York & Ohio & Penn. & W. Virginia \\
\hline $\mathbf{1}$ & $1000-3500$ & $500-4000$ & Not Present & Not Present & Not Present & $500-3000$ \\
\hline $\mathbf{2}$ & $500-4500$ & $2000-4500$ & $1000-4000$ & $500-4500$ & $2000-9000$ & Not Present \\
\hline $\mathbf{3}$ & Not Present & $2000-4500$ & $1000-5000$ & No Data & $2000-9000$ & $2000-7000$ \\
\hline $\mathbf{4}$ & $500-5000$ & $500-5000$ & $1000-6000$ & No Data & $3000-9000$ & $4000-10000$ \\
\hline $\mathbf{5}$ & $1000-6000$ & $1000-7000$ & $1000-9000$ & $2000-8000$ & $4000-15000$ & $6000-13000$ \\
\hline $\mathbf{6}$ & $1000-6000$ & $1000-6000$ & $1000-10000$ & $2000-9000$ & $5000-16000$ & $6000-14000$ \\
\hline $\mathbf{7}$ & $1000-7000$ & $1000-8000$ & $1000-10000$ & $2000-10000$ & $6000-16500$ & $4000-14000$ \\
\hline
\end{tabular}

Table 38. Thickness range of mapped carbonate units for each state. Thicknesses are in feet.

\begin{tabular}{|l|l|l|l|l|l|l|}
\hline Unit & Indiana & Kentucky & New York & Ohio & Penn. & W. Virginia \\
\hline $\mathbf{1}$ & $200-700$ & $100-400$ & Not Present & Not Present & Not Present & $100-900$ \\
\hline $\mathbf{2}$ & $200-1400$ & $100-170$ & $50-800$ & No Data & $50-250$ & Not Present \\
\hline $\mathbf{3}$ & Not Present & $100-170$ & $100-900$ & No Data & $200-1200$ & $100-1000$ \\
\hline $\mathbf{4}$ & $300-800$ & $50-300$ & $100-500$ & No Data & $500-3500$ & $100-500$ \\
\hline $\mathbf{5}$ & $50-300$ & $200-800$ & $100-1100$ & $40-280$ & $200-900$ & $200-1100$ \\
\hline $\mathbf{6}$ & $200-800$ & $500-1200$ & $100-700$ & $350-800$ & $400-2200$ & $800-1800$ \\
\hline $\mathbf{7}$ & $500-3500$ & $1500-4500$ & $200-1600$ & $200-1000$ & $500-5000$ & $1300-2900$ \\
\hline
\end{tabular}

\section{Identification of Geologically Suitable Areas for Applying the Technology}

As discussed in a previous section of the report (see the section on "Optimum Rock Formations"), design considerations and economic calculations indicate that the fracturing and acid-dissolution method will be applied most advantageously to carbonate formations deeper than 4000 feet, with limestone at depths between 6000 and 9000 feet preferred. In order to identify areas that are potentially suitable for applying the fracture-acid dissolution technology to creating storage volume, a series of maps was produced using carbonate depth and thickness criteria. To further refine the areas identified as being potentially suitable for using the fracture acid-dissolution method, maps were generated to identify areas of limestone having a minimum thickness of 300 feet. Four depth ranges were selected for producing each series of maps, which are called "suitability maps":

1) 4000 to 6000 feet;

2) 6000 to 8000 feet;

3) 8000 to 10,000 feet; and

4) 10,000 to 12,000 feet.

The suitability maps show that there are carbonate units at a suitable depth present in specific areas of all six states of the project area. Large areas of Pennsylvania, West Virginia, 
and New York are potentially suitable geologically for developing gas storage using the fracturing and acid-dissolution method. Smaller areas with the optimum thickness and depth of carbonate rocks for using the technology are present in the other states. These maps depict the best areas for using the fracture-acid-dissolution method based on unit thickness and depth; carbonate units at other depths are present in all 6 states, which open up additional areas for using the technology under with sufficient demand for storage. It's likely that potential areas for development of the new technology are present in additional areas of some of the states because not all areas could be mapped due to lack of well control (e.g., Units 6 and 7 in West Virginia; see Castle et al., 2004). Of course, specific geologic properties should be examined in greater detail than was done in this regional analysis before applying the technology in any of the areas mapped. 


\section{Current Modeling Technology (Task 5) \\ By Ronald W. Falta and Larry Murdoch}

A detailed report (Falta et al., 2004) on current modeling technology summarized the extent of information available on existing technology that is relevant to the fracturing and acid dissolution modeling that was done. An extensive list of references is included in the report. 


\section{Laboratory Testing of Limestone Samples (Task 6) by David Bruce}

Descriptions of the core samples obtained from the West Virginia Geological Survey are listed in Table 39. Approximate dissolution times are listed for each rock sample in Table 40. Post-dissolution data with regard to dried weight, \% insoluble, calcined weight, and $\%$ combustible are listed in Table 41.

Table 39. Carbonate Core Sample Information

\begin{tabular}{|l|l|l|l|l|}
\hline Well ID & County & State & Formation & Comments \\
\hline Green-6 & Greenbrier & WV & Helderberg & Sample taken at 7127-7128 \\
\hline Hamp-12 & Hampshire & WV & $\begin{array}{l}\text { Knox/ } \\
\text { Beekmantown }\end{array}$ & Sample taken at 10524 \\
\hline Harr-79-HDG & Harrison & WV & Helderberg & Sample taken at 7458 \\
\hline Jack-1366 & Jackson & WV & Black River & $\begin{array}{l}\text { Sample taken at 7908. Cherty, } \\
\text { non-limestone. }\end{array}$ \\
\hline Lewis-57 & Lewis & WV & Helderberg & Sample taken at 9304 \\
\hline Wetzel-408 & Wetzel & WV & Big Lime & \begin{tabular}{l} 
Sample taken at 1967-1968 \\
\hline $8959 R$
\end{tabular} \\
\hline Pike & KY & Big Lime & $\begin{array}{l}\text { Sample depth 1888+, cored by } \\
\text { United Fuel Gas. Taken at top } \\
\text { of formation-visibly sandy }\end{array}$ \\
\hline 8792 & Martin & KY & Big Lime & $\begin{array}{l}\text { Sample depth unknown, cored } \\
\text { by United Fuel Gas. Taken at } \\
\text { top of formation-visibly sandy. }\end{array}$ \\
\hline
\end{tabular}


Table 40. Aqueous hydrochloric acid dissolution rates for carbonate rock samples.

\begin{tabular}{|c|l|}
\hline Sample & \multicolumn{1}{|c|}{ Qualitative Dissolution Rates $^{\mathbf{a}}$} \\
\hline Lewis-57 & inert \\
\hline Green-6 & rapid dissolution \\
\hline Harr79- & rapid dissolution \\
HDG & \\
\hline Harr- & inert \\
79 SAL & \\
\hline 8792 & moderate dissolution rate (oily residue) \\
\hline Jack-1366 & moderate dissolution rate (oily residue) \\
\hline Hamp-12 & moderate dissolution rate (oily residue) \\
\hline Wetzel- & rapid dissolution \\
\hline 408 & \\
\hline $8959 \mathrm{R}$ & rapid dissolution \\
\hline
\end{tabular}

a - rapid dissolution ( $<10 \mathrm{~min}$.), moderate dissolution rate $(<4 \mathrm{hrs})$, inert (minimal dissolution after $48 \mathrm{hrs})$

Table 41. Weight of carbonate core samples before acid treatment, following acid treatment, and following calcination at $700{ }^{\circ} \mathrm{C}$ in air.

\begin{tabular}{|l|l|l|l|l|l|}
\hline \multirow{2}{*}{ Sample } & \multirow{2}{*}{$\begin{array}{c}\text { Initial } \\
\text { Sample } \\
\text { Weight (g) }\end{array}$} & $\begin{array}{c}\text { Dried } \\
\left(\mathbf{1 0 0} \mathbf{}^{\circ} \mathbf{C}\right) \\
\text { Weight } \mathbf{( g )}\end{array}$ & $\begin{array}{c}\text { Insoluble } \\
\mathbf{( \% )}\end{array}$ & $\begin{array}{c}\text { Calcined } \\
\left.\mathbf{( 7 0 0}{ }^{\circ} \mathbf{C}\right) \\
\text { Weight (g) }\end{array}$ & $\begin{array}{c}\text { Combustible } \\
\mathbf{( \% )}\end{array}$ \\
\hline Lewis-57 & 53.135 & & & & \\
\hline Green-6 & 23.8297 & 2.155 & 9.0 & & \\
\hline Harr79-HDG & 34.0793 & 6.9736 & 20.5 & 6.6807 & 0.9 \\
\hline Harr-79SAL & 32.7239 & & & & \\
\hline 8792 & 31.2792 & 1.0143 & 3.2 & 0.9494 & 0.2 \\
\hline Jack-1366 & 21.5574 & 0.3859 & 1.8 & 0.3854 & 0.002 \\
\hline Hamp-12 & 23.8199 & 1.2488 & 5.2 & & \\
\hline Wetzel-408 & 23.7258 & 7.4959 & 31.6 & & \\
\hline $8959 \mathrm{R}$ & 32.4899 & 3.1142 & 9.6 & & \\
\hline
\end{tabular}

The acid treatment studies showed that several of the rock samples reacted very aggressively with aqueous hydrochloric acid (e.g., samples Green-6, Harr79-HDG, Wetzel-408, and $8959 \mathrm{R}$ ). Formations of this type would be ideal for using acid dissolution to generate a gas storage cavern. Other less reactive rock samples included 8792, Jack-1366, and Hamp-12. Two rock samples showed no significant reaction with aqueous hydrochloric acid, specifically, Lewis-57 and Harr-79SAL. These core samples did not contain any significant carbonate rock forms; hence, the carbonate strata at these geographic locations are at depths different from where the samples were collected or the carbonate formations contain appreciable quantities of 
other rock types (e.g., shale, quartz, etc.).

Analysis of the weight loss data upon acid treatment showed that most of the samples that underwent dissolution had very low concentrations of non-dissolvable impurities. However, two samples, Harr79-HDG and Wetzel-408, contained moderately large quantities (greater than 20\%) of insoluble material. These impurities were present as small particles (less than $1 \mathrm{~mm}$ diameter) evenly dispersed in the rock sample; hence, their presence did not inhibit the dissolution of the carbonate rock sample.

The powder X-ray diffraction patterns for the non-dissolvable components of the two samples (which showed some level of dissolution) that had the highest concentration of impurities, Harr79-HDG and Wetzel-408, are shown in Figures 44 and 45. In each case, the primary insoluble component was a form of quartz ( $\mathrm{SiO} 2)$. It was observed that the sample contained slightly different forms of quartz, which may suggest that there are trace impurity differences between the two core samples. No effort was made to identify these impurities.

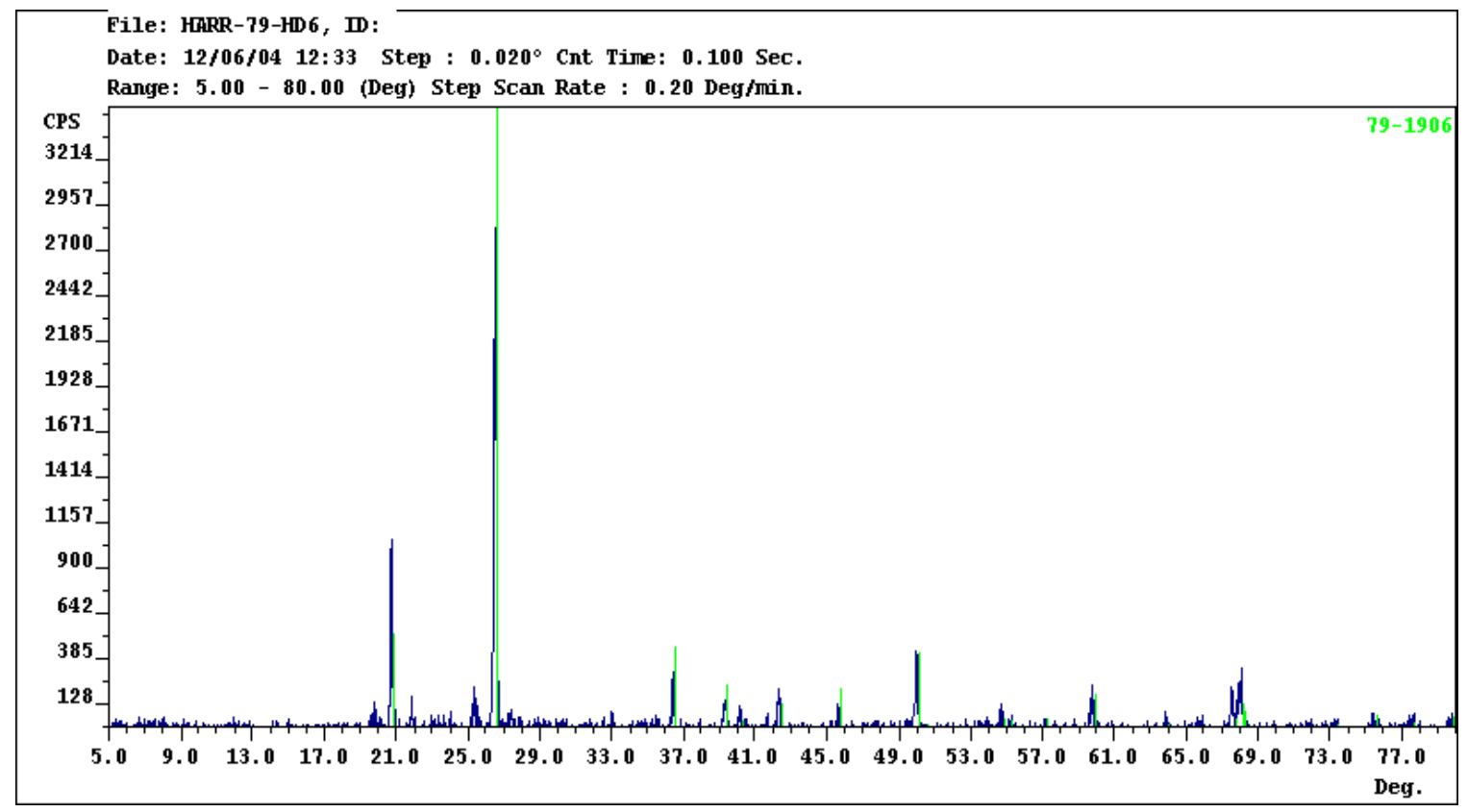

Figure 44. Powder X-ray diffraction pattern for quartz (green, reference file 79-1986) and the undissolved components from the acid treatment of rock sample Harr79-HDG. 


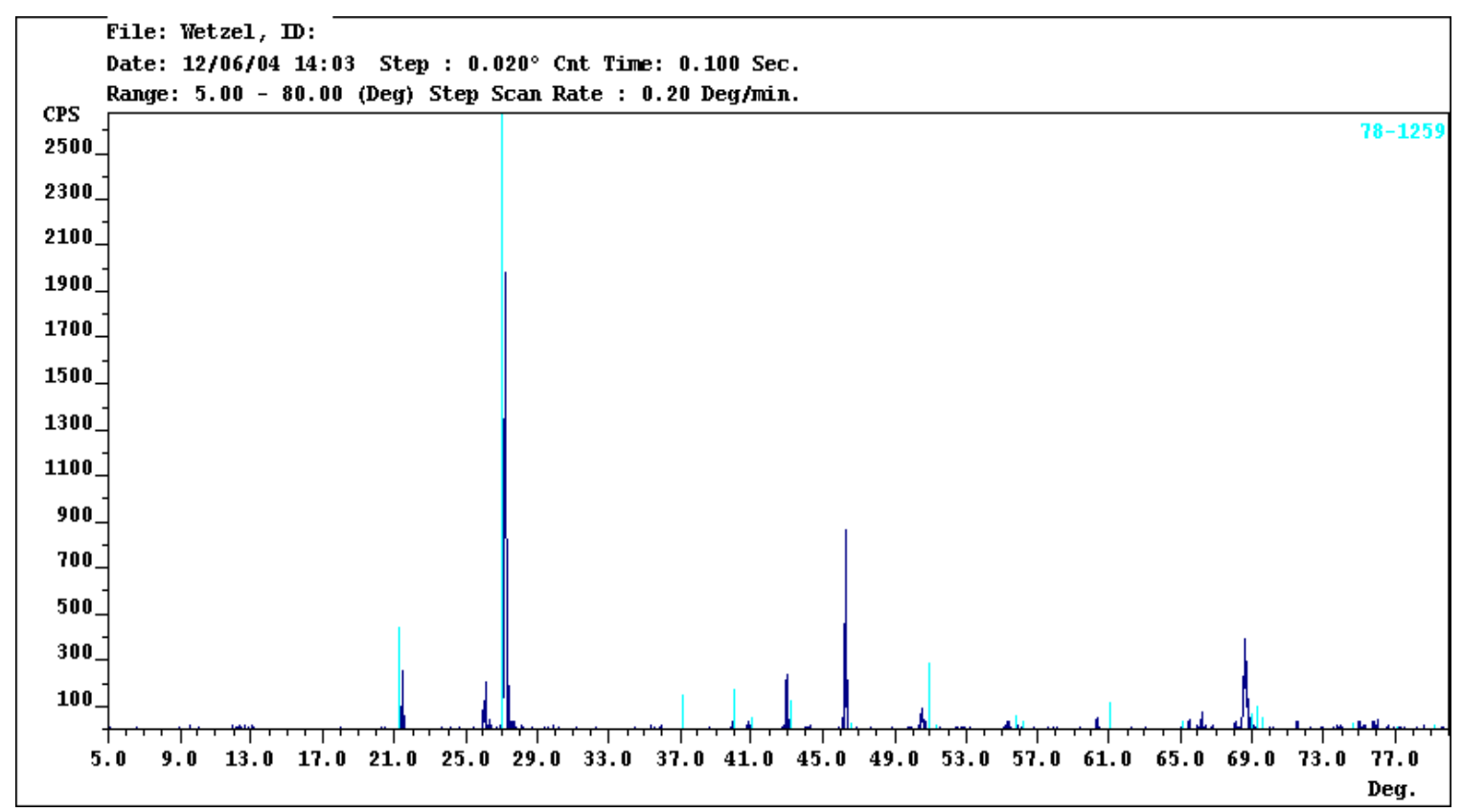

Figure 45. Powder X-ray diffraction pattern for quartz (pink, reference file 78-1259) and the undissolved components from the acid treatment of rock sample Wetzel-408. 


\section{Three-Dimensional Modeling of Distribution of Induced Fractures (Task 7) By Larry Murdoch and Jim Foley}

\section{Introduction}

This section assesses the typical fractures that that would be expected as a result of hydraulic fracturing operations in carbonate formations found in the Appalachian basin. The purpose is to determine the size, shape and fluid flow characteristics of the resulting fracture to predict what could be available to enhance limestone dissolution. Simulations were run using a commercial fracture modeling software, and the results were analyzed to identify the expected range of fracture characteristics as well as the important parameters that influence fracture characteristics.

In practice the process of hydraulic fracturing is quite complicated because of the great number of variables that are involved. Analyzing hydraulic fracture propagation can also be complicated because there are four different types of mechanics that need to be evaluated: solid, fracture, fluid and thermal (Mack and Warpinski, 2000).

One of the main objectives in conducting hydraulic fracturing operations is to design a fracture that optimizes fluid flow to the well, without negatively affecting the integrity of the formation or reservoir. There is a relatively limited amount of control on what can be done to control fracture growth. The primary means of controlling fracture propagation involve choosing (1) the most effective materials (fluids and proppants), (2) the necessary volume of material, (3) the injection rate, and (4) the injection schedule (Veatch, 1983b). In order to effectively identify an optimal fracture design, detailed information about the lithology and fracturing components needs to be utilized. These data include: (1) formation permeability and porosity, (2) static reservoir pressure, (3) formation temperature, (4) thermal conductivities of formations penetrated, (5) fracture closure pressure, (6) critical net fracturing pressure, (7) formation physical properties: modulus and fracture toughness, (8) fracturing fluid apparent viscosity, (9) fracturing fluid friction data, (10) leakoff coefficient, (11) fluid thermal conductivity, (12) proppant size distribution, (13) proppant density, (14) proppant fracture conductivity as a function of fracture closure stress, proppant type, proppant size distribution, proppant concentration in the fracture, and embedment in the formation, (14) formation embedment pressure, (15) perforation configuration, (16) stratigraphy, and (17) in-situ stresses (Veatch, 1983a; Veatch et al., 1989).

\section{Results of Fracture Modeling}

\section{$\underline{\text { Baseline Fracture }}$}

The fracture predicted by the baseline case is an elliptical shaped feature with a halflength of $291 \mathrm{ft}$ and a height of $363 \mathrm{ft}$ at the borehole that penetrated $115 \mathrm{ft}$ into the upper shale layer and $98 \mathrm{ft}$ into the lower shale layer. The pressurized fracture width is 0.33 in near the well bore and it tapers to the fracture termination at $291 \mathrm{ft}$ (Figure 46). 

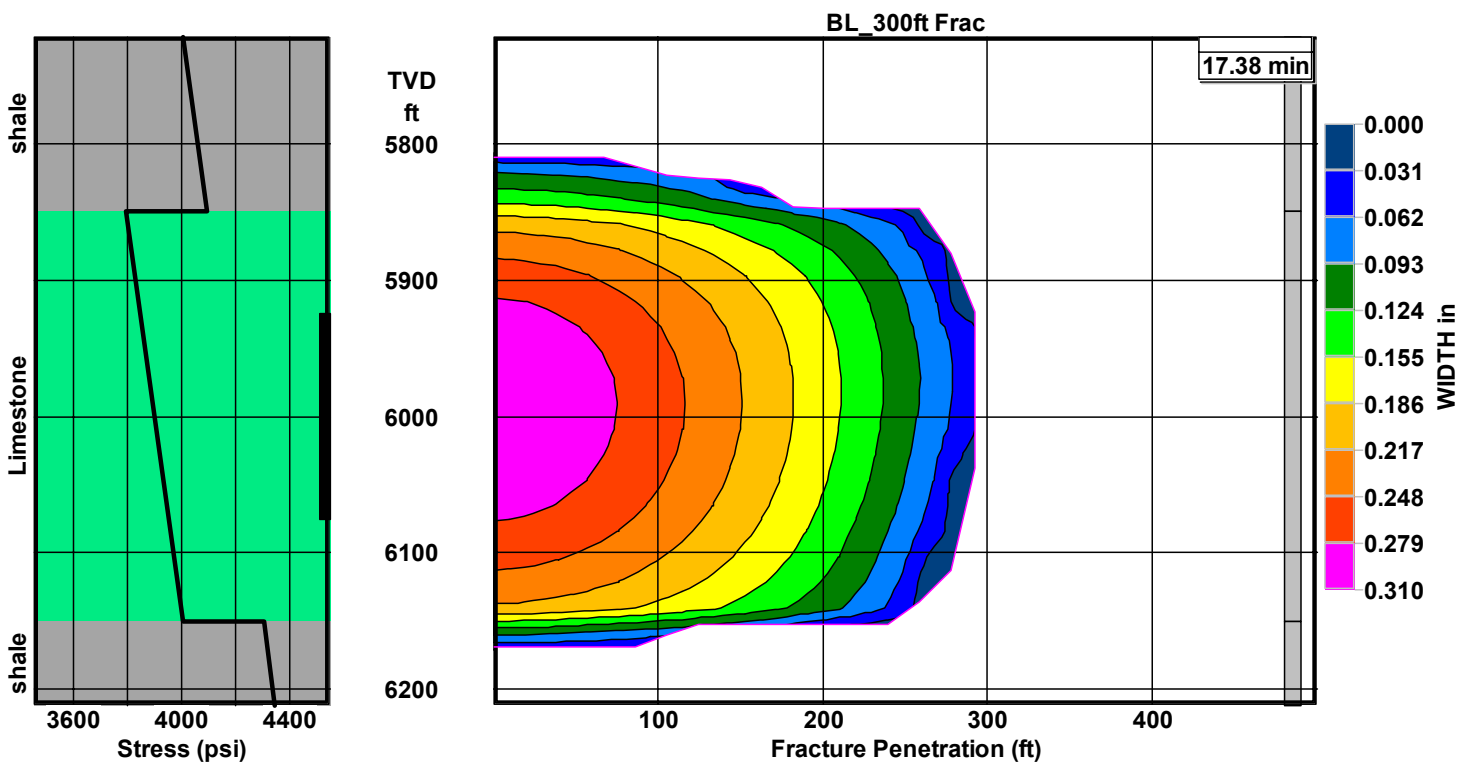

Figure 46 Pressurized width (in) for baseline fracture model with stress profile. The thick black line on right side of stress plot indicates perforated interval.

The in-situ stress is $4095 \mathrm{psi}$ at the bottom of the shale and it abruptly drops to 3795 psi at the top of the limestone. The stress increases with depth according to the stress gradient of $0.7 \mathrm{psi} / \mathrm{ft}$ until the stress at the bottom of the limestone layer is 4005 psi. The stress is 4305 psi at the top of the underlying shale. The perforated interval for the baseline case is $150 \mathrm{ft}$, initiating from the middle of the limestone layer (Figure 46). The net pressure calculated for this fracture geometry is 358 psi above closure pressure.

The cross section of the baseline fracture at the bore hole is roughly oval shaped with the long axis vertical (Figure 47). The oval pinches and become more pointed near the top and bottom, at depths of $5850 \mathrm{ft}$ and $6150 \mathrm{ft}$. These are the depths of the contacts between limestone and shale. The maximum pressurized width is 0.32 in at a depth of $6000 \mathrm{ft}$ (Figure 47).

The fracture half-length that remains propped at closure is $200 \mathrm{ft}$, approximately $70 \%$ of the total fracture half-length. The effective width of the propped fracture is 0.148 inches in the vicinity of the perforated interval (Figure 48). The large dark blue area on Figure 48 indicates the region that was fractured during injection, but was not filled with proppant. At fracture closure, this area is held open only by asperities on the fracture wall.

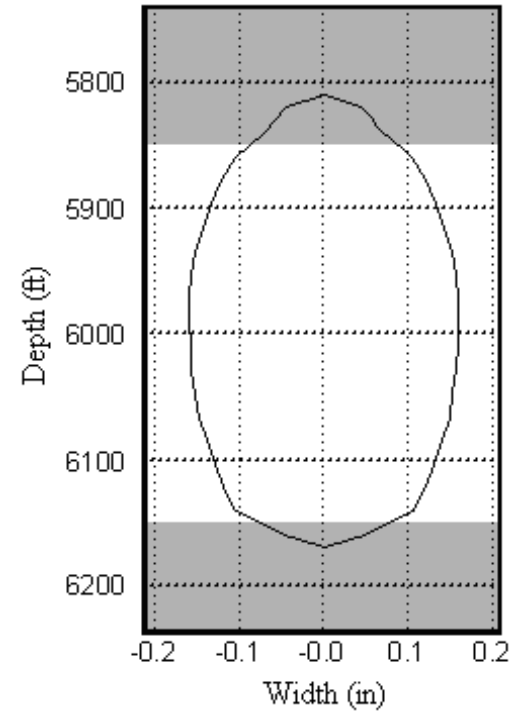

Figure 47 Cross section of baseline fracture. Grey boxes indicate adjacent layers 
The average conductivity for the baseline fracture is $396 \mathrm{md}-\mathrm{ft}$, but the distribution of conductivity is variable throughout the fracture (Figure 49). Conductivity as used in this paper refers to the product of fracture permeability and fracture width (Economides et al., 2004). There is a region around the initiation area where the conductivity is greatest (1224 md-ft), but it decreases away from the fracture and is less than $122 \mathrm{md}-\mathrm{ft}$ in the region in dark blue (Figure 49). The contours of conductivity are nearly identical to the contours for effective width because fracture width is used in the calculation of conductivity. The dark green line (Figure 49) represents the contour that has the average value for conductivity developed over the entire fracture area. This contour approaches $150 \mathrm{ft}$ from the well bore. This indicates that the region near the well bore, representing almost $1 / 2$ of the facture, has a higher conductivity than the more distal parts.
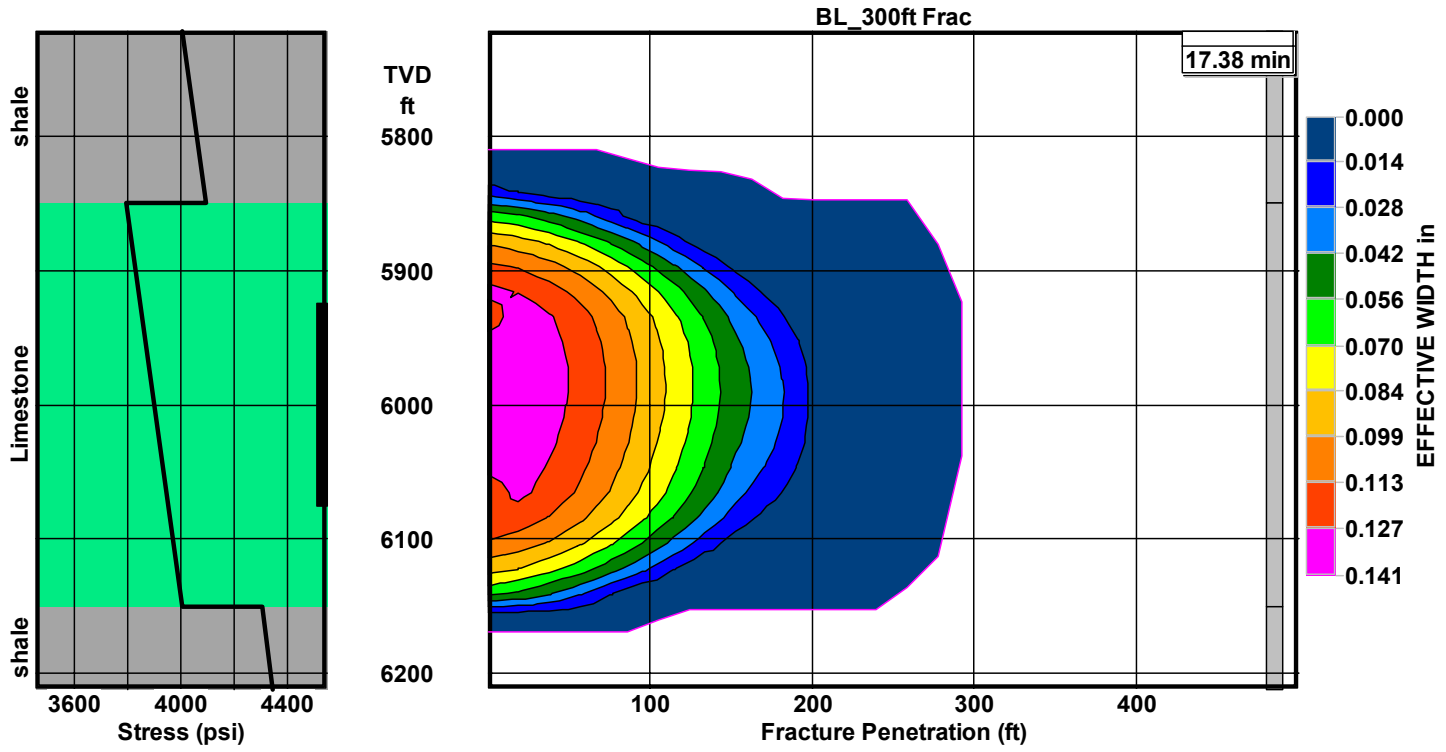

Figure 48 Effective width (in) for the baseline fracture with stress profile. The thick black line on right side of stress plot indicates perforated interval. 

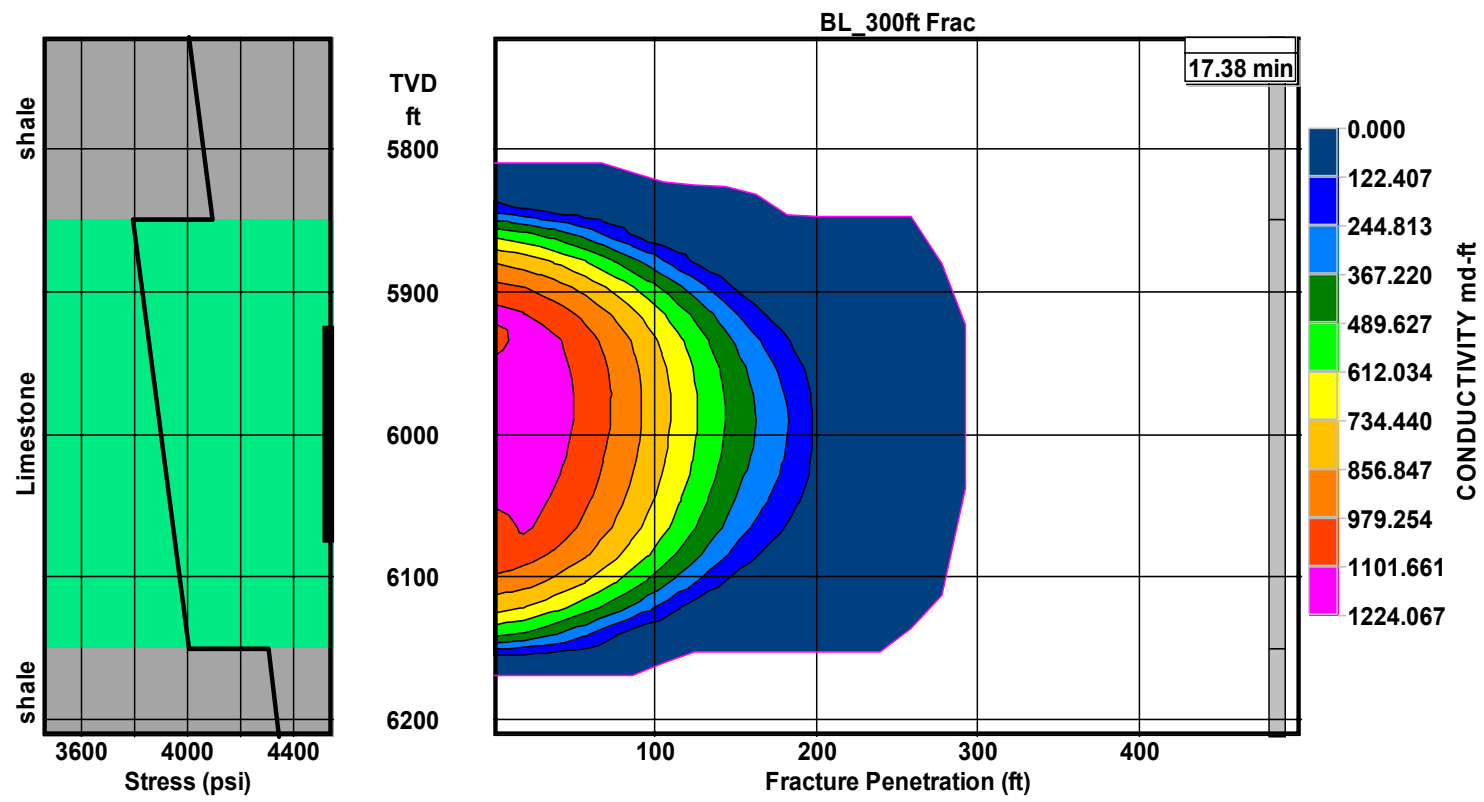

Figure 49 Conductivity for baseline fracture model with stress profile. The thick black line on right side of stress plot indicates perforated interval.

\section{$\underline{\text { Net Pressure }}$}

The net pressure is the pressure greater than the closure pressure that is necessary to cause the fracture to propagate, assuming that a crack already exists in the rock. When plotted with time, the net pressure is a function of fracture geometry. For radial geometry, the net pressure declines versus time, thus the highest net pressure would be initially. If the geometry is a confined height fracture that is growing in length, then net pressure tends to increase with time, and the highest P-Net would be at the end of pumping (Smith, 2004a).

The net pressure for the baseline simulation is initially 613 psi and decreases rapidly to the lowest pressure of 308 psi at a time of 5 min (Figure 50). As pumping continues, the net pressure increases to $372 \mathrm{psi}$ at $17 \mathrm{~min}$ and the fracture closes at the end of the pumping schedule (Figure 50). The initial decrease in pressure indicates that the fracture propagates with radial geometry until a time of 5 min when it begins to interact with the adjacent layers, confining the fracture height.

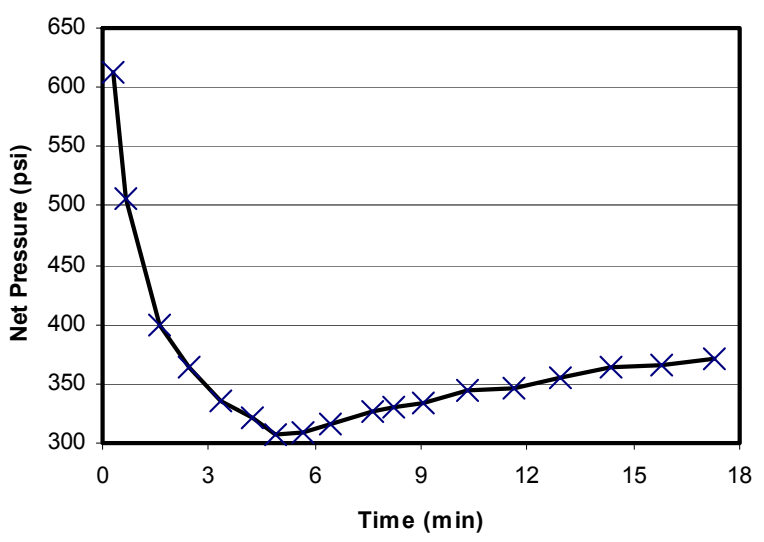

Figure 50 Net pressure vs. time for baseline simulation 


\section{$\underline{\text { Deviations from Baseline Model }}$}

The baseline fracture was assumed to represent a standard to which the results of systematic variations in the input parameters would be compared. Thirteen of the model input values were systematically varied in order to understand the range of possible fracture geometries as well as to understand the effects of the different variables on fracture geometry. The variables modified are: leakoff coefficient, formation depth, stress contrast between formations, elastic modulus and fracture toughness of adjacent formation, elastic modulus and fracture toughness of limestone, limestone thickness, perforated interval, pumping rate, fracturing fluid, and proppant type (Table 42). The inputs for the baseline case were average values for the parameters. For each input variable one trial was conducted where the variable was five times the average and one trial was conducted where the variable was one-fifth of the average. This resulted in a high, medium and low value for each of the variables. The distribution of fracture half-length, height and conductivity of the simulations were analyzed.

\section{Half-length Distribution}

The fracture half-length for the fractures simulated (Table 42) were recorded and summary statistics were calculated (Table 43). The baseline half-length of $291 \mathrm{ft}$ was 3 feet longer than the average value, within the $79 \mathrm{ft}$ standard deviation and $291 \mathrm{ft}$ is the mode of the data set (Table 43). Forty-seven percent of the simulations resulted in fractures with a half-length in the range of 232 to $295 \mathrm{ft}$ with the majority of fracture half-lengths (83\%) ranging between $169 \mathrm{ft}$ to $358 \mathrm{ft}$ (Figure 51). Four percent of the results have a half-length less than $106 \mathrm{ft}$. For these two cases, the leakoff coefficient was relatively high $\left(1.0 \times 10^{-3} \mathrm{ft} / \min\right.$ and $5.5 \times 10^{-3}$ $\mathrm{ft} \sqrt{ } \mathrm{min})$ and tip screenout occurred. Four of the trials $(9 \%)$ resulted in a fracture with a halflength greater than $421 \mathrm{ft}$ (Figure 51). For two of the cases, greater lengths occurred when fracturing fluids with a lower viscosity were used $(70 \mathrm{Q} / 40 \# \mathrm{fm}$ and $60 \mathrm{Q} / 40 \# \mathrm{fm})$, one case occurred when leakoff coefficient was $1.0 \times 10^{-4} \mathrm{ft} \sqrt{ }$ min and one case was the result of reducing the pumping rate to $6 \mathrm{BPM}$.

\section{Propped Length Distribution}

The propped length of the fracture was determined to be the furthest contour from the borehole where both the conductivity and the proppant concentration were greater than zero. The propped length for the baseline fracture is $200 \mathrm{ft}$, which corresponds with the mean, median and mode of all the trials (Table 44). More than half the results for propped length range from $166 \mathrm{ft}$ to $212 \mathrm{ft}$ and $83 \%$ ranges from $120 \mathrm{ft}$ to $258 \mathrm{ft}$ (Figure 52). Four percent of the trials resulted in fractures with half lengths less than $74 \mathrm{ft}$. The shortest propped lengths occurred during simulations using relatively large leakoff coefficients $\left(1.0 \times 10^{-3} \mathrm{ft} \sqrt{\min }\right.$ and $\left.5.5 \times 10^{-3} \mathrm{ft} \sqrt{\mathrm{min}}\right)$ which resulted in tip screen out. These are the same two models that resulted in the shortest fracture half-lengths. The four situations that resulted in the greatest half-lengths are the same trials that had the four longest propped lengths. 


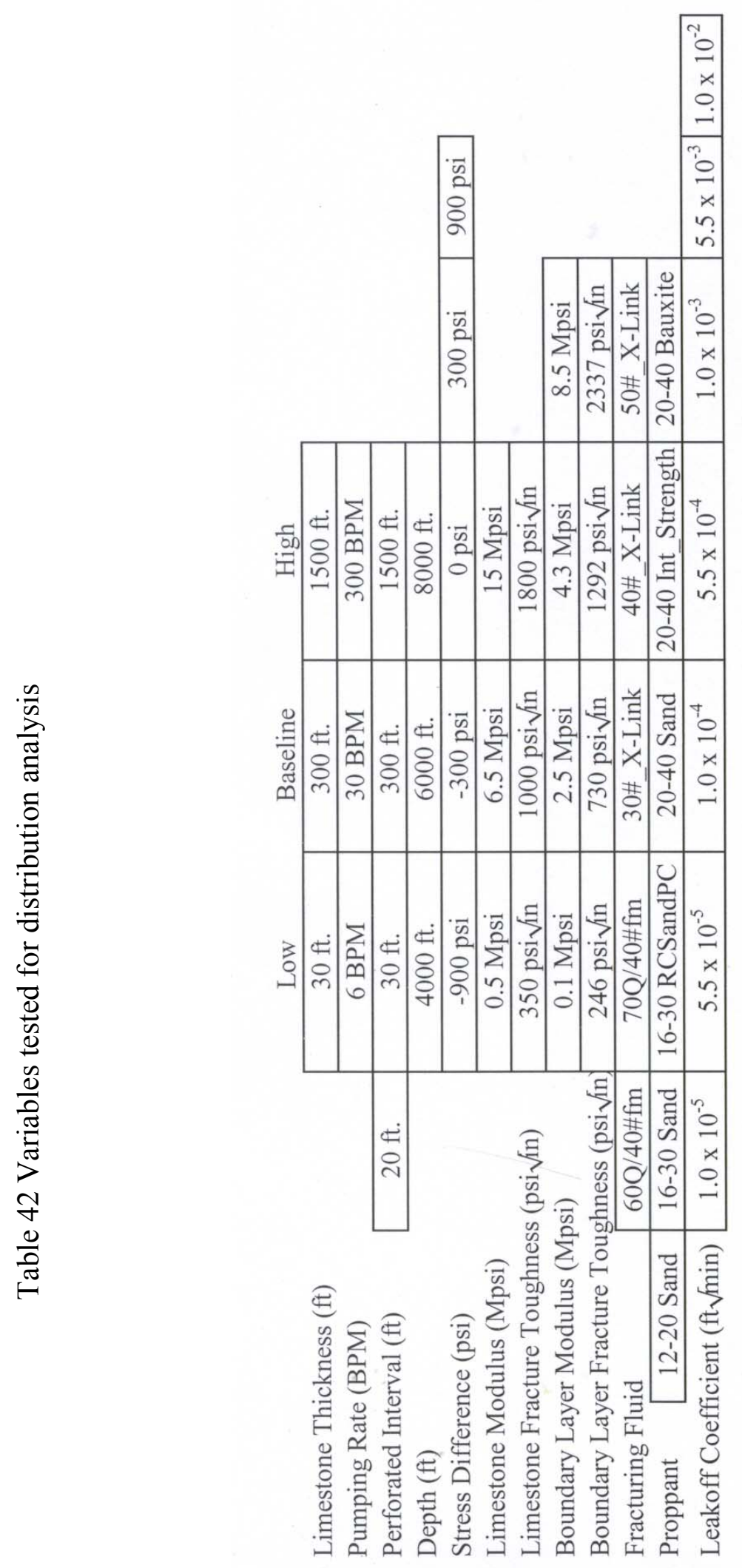




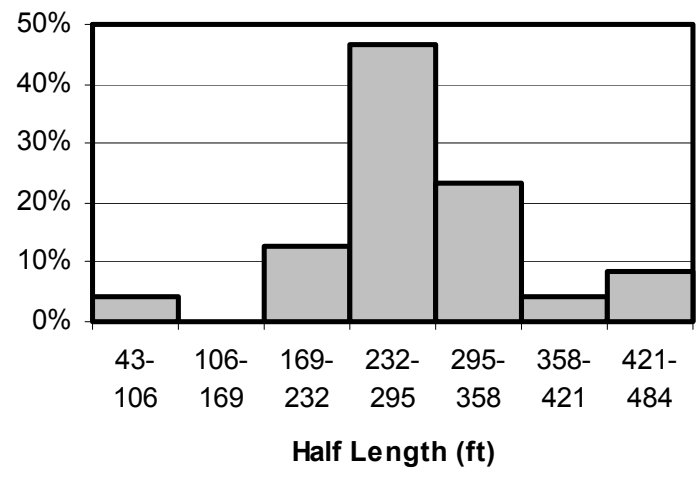

Figure 51 Distribution of horizontal halflength

Table 43 Statistics of fracture halflength distribution

\begin{tabular}{|l|r|l|}
\hline Minimum & 43 & $\mathrm{ft}$ \\
\hline Maximum & 481 & $\mathrm{ft}$ \\
\hline Median & 293 & $\mathrm{ft}$ \\
\hline Mode & 291 & $\mathrm{ft}$ \\
\hline Average & 288 & $\mathrm{ft}$ \\
\hline Std. Dev. & 79 & $\mathrm{ft}$ \\
\hline Count & 47 & \\
\hline
\end{tabular}

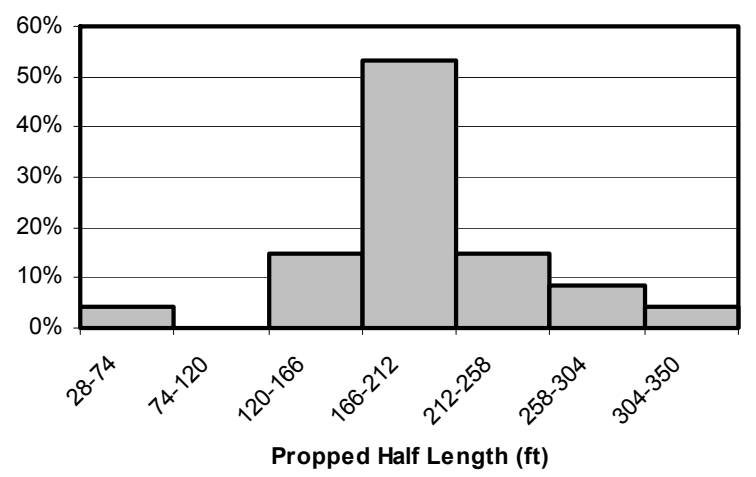

Figure 52. Distribution of propped fracture length

Table 44. Statistics of propped length distribution.

\begin{tabular}{|l|r|l|}
\hline Minimum & 28 & $\mathrm{ft}$ \\
\hline Maximum & 348 & $\mathrm{ft}$ \\
\hline Median & 200 & $\mathrm{ft}$ \\
\hline Mode & 200 & $\mathrm{ft}$ \\
\hline Average & 201 & $\mathrm{ft}$ \\
\hline Stdev & 54 & $\mathrm{ft}$ \\
\hline Count & 47 & \\
\hline
\end{tabular}

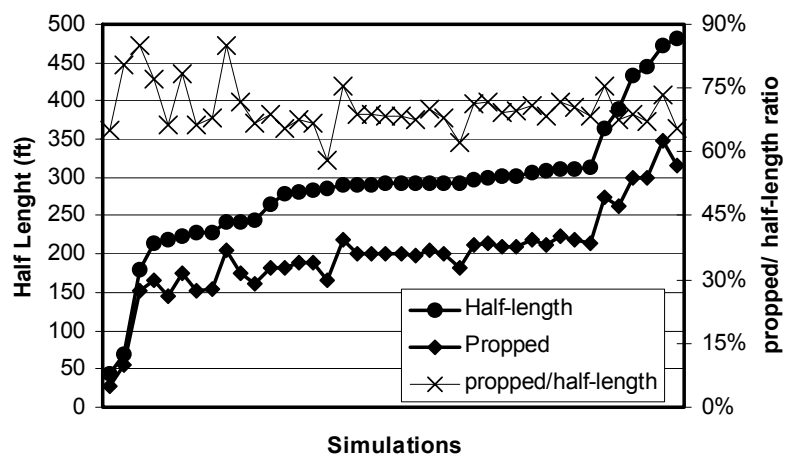

Figure 53 Half-length and propped length for models that vary from the $300 \mathrm{ft}$ baseline case

The fractures with a propped length greater than $304 \mathrm{ft}$ result from a case where the leakoff coefficient was $1.0 \times 10^{-4} \mathrm{ft} \sqrt{\mathrm{min}}$ and where the pumping rate was reduced (6 BPM). The 
four trials that had a predicted propped length of 258 to $304 \mathrm{ft}$ occurred when fracturing fluids with a lower viscosity were used $(70 \mathrm{Q} / 40 \# \mathrm{fm}$ and $60 \mathrm{Q} / 40 \# \mathrm{fm})$, when the leakoff coefficient was decreased to $5.5 \times 10^{-5} \mathrm{ft} \sqrt{ } \mathrm{min}$ and one case occurred when a $300 \mathrm{ft}$ half- length was simulated in a $60 \mathrm{ft}$ thick limestone formation.

There appears to be a relationship between half-length and the propped length (Figure 53). The propped length averages $70 \%+/-5 \%$ of the half-length. For the five simulations where the ratio of the propped length to half-length was greater than $75 \%$, three of the cases occurred when the leakoff coefficient was increased to the range of $5.5 \times 10^{-4} \mathrm{ft} \sqrt{ } \min$ to $5.5 \times 10^{-3} \mathrm{ft} \sqrt{ } \mathrm{min}$. The other two cases occurred when the limestone modulus was lower $(0.5 \mathrm{Mpsi})$ and when the stress in the limestone was 300 psi greater than in the shale. There were two cases where the ratio of the propped length to half-length was less than $65 \%$. For one of these cases, the stress difference between formations was increased from 300 psi less to 900 psi greater in the limestone. For the other case the perforated interval was increased from $150 \mathrm{ft}$ to $300 \mathrm{ft}$, corresponding to the formation height.

\section{Fracture Height Distribution}

The fracture height is reported as the total height of the fracture with the center located at the specified target depth. The baseline case resulted in fracture with $363 \mathrm{ft}$ vertical growth which corresponds to the median and mode of all the trials (Table 45). The average fracture height is $21 \mathrm{ft}$ taller than the median and the mode. This is because a few of the trials resulted in very tall fractures that increase the average. $72 \%$ of the fracture heights occur in a range of $278 \mathrm{ft}$ to $372 \mathrm{ft}$ whereas only $10 \%$ of the fractures exhibited a height growth greater than $482 \mathrm{ft}$ (Figure 54). For the four cases where height growth was greater than $485 \mathrm{ft}$, three of them were due to stress difference between the formations. These cases occurred when the stress in the adjacent layers decreased, resulting in the stress difference for the limestone increasing from -300 psi to 0 psi, $300 \mathrm{psi}$ and $900 \mathrm{psi}$. The other case occurred when the limestone thickness was increased to $1500 \mathrm{ft}$.

One of the concerns relating to fracture height growth is intrusion into an overlying confining formation. For the fracture simulations based on the baseline case $93 \%$ had some intrusion into the upper confining layer with only $7 \%$ having some un-fractured limestone clearance between the overlying formation (Figure 55). Of the three cases where there was some clearance between the fracture and the overlying formation, one occurred in a simulation of a $300 \mathrm{ft}$ fracture half length in a $1500 \mathrm{ft}$ limestone formation. The other two cases occurred when the leakoff coefficient was increased $\left(1.0 \times 10^{-2} \mathrm{ft} \sqrt{ } \mathrm{min}\right.$ and $5.5 \times 10^{-2}$ $\mathrm{ft} \sqrt{ } \mathrm{min})$ and tip screen out occurred.

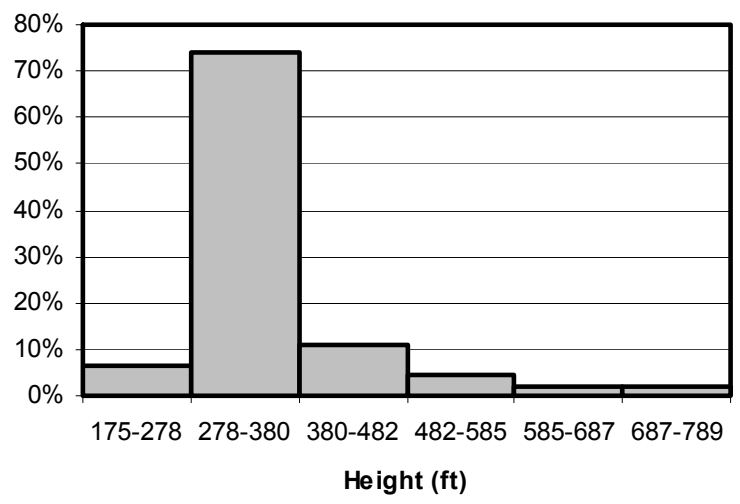

Figure 54 Distribution of fracture height for simulations based on baseline case 
Table 45 Statistics for fracture height distribution

\begin{tabular}{|l|r|l|}
\hline Minimum & 175 & $\mathrm{ft}$ \\
\hline Maximum & 789 & $\mathrm{ft}$ \\
\hline Median & 363 & $\mathrm{ft}$ \\
\hline Mode & 363 & $\mathrm{ft}$ \\
\hline Average & 384 & $\mathrm{ft}$ \\
\hline Stdev & 120 & $\mathrm{ft}$ \\
\hline Count & 47 & \\
\hline
\end{tabular}

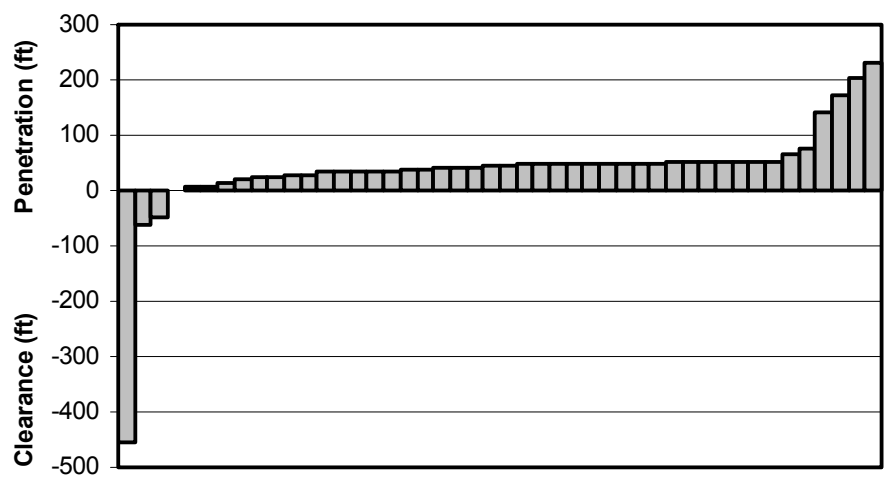

Figure 55 Fracture intrusion into upper adjacent layer. Negative values indicate clearance between fracture and overlying formation

\section{$\underline{\text { Fracture Width Distribution }}$}

The average fracture width was less than 0.32 in for $94 \%$ of simulations (Figure 56). Of the three cases that had widths greater than 0.32 in, two were beyond one standard deviation $(+/-$ $0.25 \mathrm{in})$ of the mean $(0.23 \mathrm{in})$. These two cases occurred when the leakoff coefficient was increased to $1.0 \times 10^{-2} \mathrm{ft} \sqrt{ } \mathrm{min}$ and $5.5 \times 10^{-2} \mathrm{ft} \sqrt{ } \mathrm{min}$. These cases resulted in tip screenout.

Although tip screenout is an effective method to increase fracture width and conductivity, these two cases were considered outliers and disregarded in order to calculate a fracture width distribution with higher resolution. The remaining fracture width calculations had a mean of 0.18 in and a median and mode of $0.19 \mathrm{in}$. The average width for the baseline case is $0.19 \mathrm{in}$. Sixtytwo percent of the width calculations occur within the 0.15 in to 0.19 in range when the outliers are disregarded (Figure 57). Of the three cases that comprise the outliers with an average width less than $0.12 \mathrm{in}$, two of them occur with an increase of the leakoff coefficient $\left(1.0 \times 10^{-4} \mathrm{ft} \sqrt{\mathrm{min}}\right.$ and $\left.5.5 \times 10^{-4} \mathrm{ft} \sqrt{ } \mathrm{min}\right)$. The other case occurred when the pumping rate was decreased to 6 BPM. The largest width (0.34 in) occurred when the limestone modulus was decreased to $0.5 \mathrm{Mpsi}$. 


\section{Fracture Conductivity Distribution}

Ninety-four percent of the trials resulted in a fracture with an average conductivity of less than $1305 \mathrm{md}-\mathrm{ft}$ (Figure 58). The average conductivity for all of the simulations is skewed to the left due to some exceedingly high values for cases where the leakoff coefficient was increased to $1.0 \times 10^{-2} \mathrm{ft} \sqrt{ } \mathrm{min}$ and $5.5 \times 10^{-2} \mathrm{ft} \sqrt{\mathrm{min}}$ and tip screenout occurred. These two simulations fall beyond one standard deviation ( $+/-1284 \mathrm{md}-\mathrm{ft})$ of the mean $(718 \mathrm{md}-\mathrm{ft})$ and were treated as outliers. Ignoring these two simulations, the average conductivity for the remaining trials is 470 md-ft with a median value of $394 \mathrm{md}-\mathrm{ft}$ and a mode of $396 \mathrm{md}-\mathrm{ft}$, the same average conductivity as the baseline case (Table 46). Fifty-one percent of the average conductivity values occur in the range of $338 \mathrm{md}-\mathrm{ft}$ to $514 \mathrm{md}-\mathrm{ft}$ and $80 \%$ of the values are less than $514 \mathrm{md}-\mathrm{ft}$ (Figure 59). The five cases where the average conductivity is greater than $866 \mathrm{md}-\mathrm{ft}$ occurred when proppants of varying size and strength were used (12-20 sand, 16-30 sand, 16-30 RCSandPC, 20-40 Int Strength, and 20-40 Bauxite). The four cases where the average conductivity is between 514 and $866 \mathrm{md}$-ft occur with an increase of the leakoff coefficient $\left(1.0 \times 10^{-3} \mathrm{ft} V \mathrm{~min}\right)$, an increased pumping rate (150 BPM), the fracturing fluid with the highest viscosity (50\# X-Link), as well as a the case with the lowest value for limestone modulus $(0.5 \mathrm{Mpsi})$.

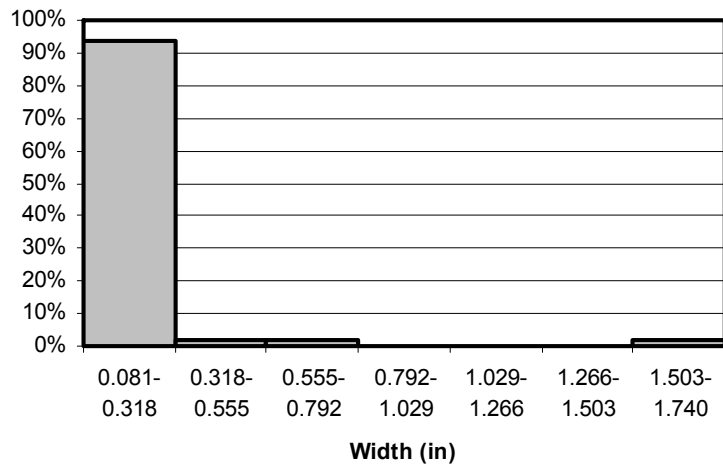

Figure 56 Average width distribution for all simulations run from the baseline case

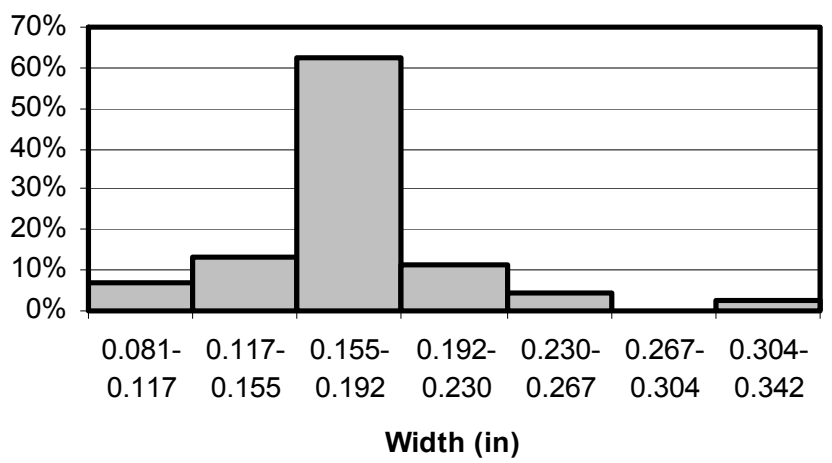

Figure 57 Distribution of average fracture width with outliers disregarded 
Table 46 Statistics of average conductivity

\begin{tabular}{|l|r|l|}
\hline Minimum & 162 & $\mathrm{md}-\mathrm{ft}$ \\
\hline Maximum & 1394 & $\mathrm{md}-\mathrm{ft}$ \\
\hline Median & 394 & $\mathrm{md}-\mathrm{ft}$ \\
\hline Mode & 396 & $\mathrm{md}-\mathrm{ft}$ \\
\hline Average & 470 & $\mathrm{md}-\mathrm{ft}$ \\
\hline Stdev & 292 & $\mathrm{md}-\mathrm{ft}$ \\
\hline Count & 45 & \\
\hline
\end{tabular}

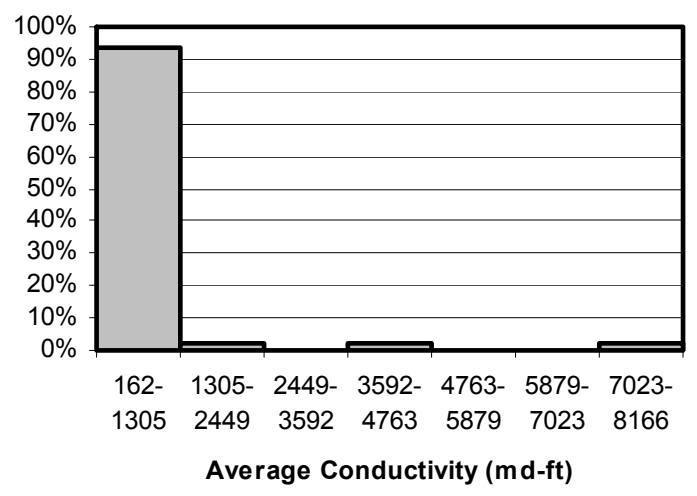

Figure 58 Average conductivity for all simulations run from baseline case

Length vs. Width relationship

The average width was plotted against propped length for all of the trials run from the baseline case, with the exception of the two outlier cases where tip screen out occurred. There is a trend where the width decreases as length increases (Figure 60). There is considerable variation at lengths less than 225 $\mathrm{ft}$. The correlation between width and length increases as lengths exceed $225 \mathrm{ft}$. One notable outlier occurs at a half length of $175 \mathrm{ft}$ and a width of $0.35 \mathrm{in}$. This fracture geometry is predicted in the run using a low limestone modulus (0.5 Mpsi).

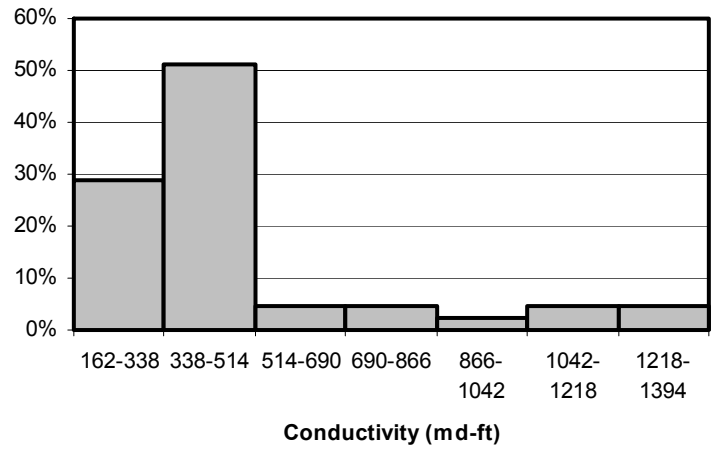

Figure 59 Distribution of fracture conductivity with outliers disregarded

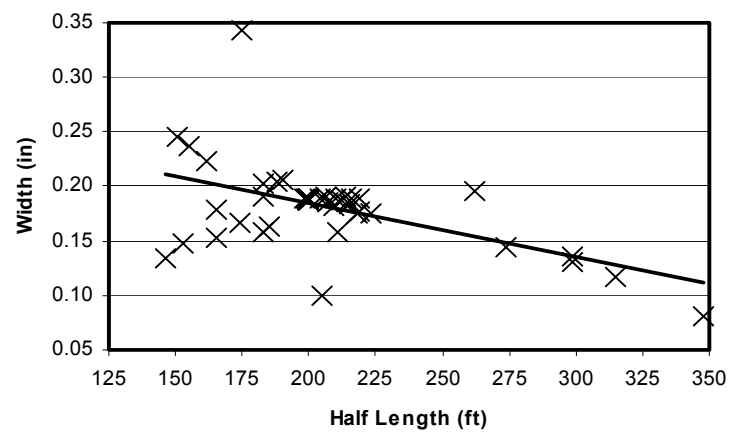

Figure 60 Average fracture width vs. propped length. Line represents a general trend of reduction in fracture width with increase in length. 
Width vs. Conductivity Relationship

The average conductivity was plotted against the average width for all simulations except the two tests that resulted in outliers (Figure 61). The general trend is an increase in conductivity with an increase in fracture width. However, five trials resulted in a large increase in conductivity without an increase in fracture width (box in Figure 61). These results occurred when different proppants were simulated (12-20 sand, 16-30 sand, 16-30 RCSandPC, 20-40 Int_Strength, and 20-40 Bauxite). The conductivity tended to increase with increasing proppant strength and decreasing size. Three other simulations appear to have a greater increase in conductivity as width increases than the majority of the trials (oval in Figure 61). These trials occur when the leakoff coefficient increased $\left(1.0 \times 10^{-4} \mathrm{ft} \sqrt{\mathrm{min}}, 5.5 \times 10^{-4} \mathrm{ft} \sqrt{\mathrm{min}}\right.$, and $1.0 \times 10^{-3}$

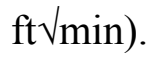

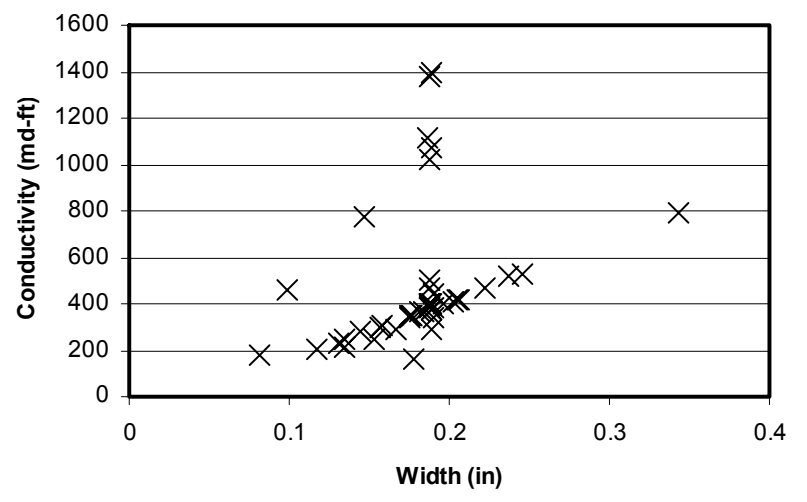

Figure 61 Relationship between average width and average conductivity.

Net Pressure Distribution

The log transform distribution of the net pressure was calculated for all of the time steps output from the simulation trials (Figure 62). The calculated net pressure ranged from $31 \mathrm{psi}$ for a simulation where the limestone modulus was low $(0.5 \mathrm{Mpsi})$ to $38582 \mathrm{psi}$ for a simulation with a high leakoff coefficient $\left(1.0 \times 10^{-2} \mathrm{ft} / \mathrm{min}\right)$ and tip screenout occurred. Ninety-three percent of the net pressure values range from $160 \mathrm{psi}$ to $1500 \mathrm{psi}$ (Figure 62). There were 21 values of net pressure less than $80 \mathrm{psi}$ that occurred when the limestone modulus was low $(0.5 \mathrm{Mpsi})$. Net pressures in the range of $80 \mathrm{psi}$ to $160 \mathrm{psi}$ occurred when the leakoff coefficient was near the midpoint of the range tested $\left(1.0 \times 10^{-4} \mathrm{ft} \sqrt{\mathrm{min}}, 5.5 \times 10^{-4} \mathrm{ft} \sqrt{\mathrm{min}}\right)$ or in the $1500 \mathrm{ft}$ thick limestone formation. All of the net pressures greater than $1500 \mathrm{psi}$ are a result of high leakoff coefficients $\left(5.5 \times 10^{-3} \mathrm{ft} \sqrt{\mathrm{min},} 1.0 \times 10^{-2} \mathrm{ft} V_{\mathrm{min}}\right)$ where tip screenout occurred.

In order for the fracture to propagate in the simulation with the low limestone modulus $(0.5 \mathrm{Mpsi})$, the pressure needed to be 30 psi greater than confining pressure. A net pressure of $160 \mathrm{psi}$ was needed to propagate the majority of fractures. To prevent unintentional propagation of fractures in the limestone formation during acid dissolution, pressures should not exceed 30 psi above the confining pressure for low modulus formations and should not exceed $80 \mathrm{psi}$ for formations with a higher modulus. If tip screenout treatments are planned, higher pressures within the fracture are predicted. This would influence the tolerances needed for the equipment 
used in creating the fracture.

\section{Fluid Loss Coefficient}

The fracture properties of half-length, propped length and average fracture conductivity were plotted against the seven variations in the leakoff coefficient (Figure 63). For the trials where the leakoff coefficient was greater than $1.0 \times 10^{-4} \mathrm{ft} V_{\mathrm{min}}$, the fracture half length decreased with increasing leakoff coefficient. Conversely, the average fracture conductivity increased from $176 \mathrm{md}-\mathrm{ft}$ to $8166 \mathrm{md}-\mathrm{ft}$ as the leakoff coefficient increased from $1.0 \times 10^{-4}$ $\mathrm{ft} \sqrt{ } \min$ to $1.0 \times 10^{-2} \mathrm{ft} \sqrt{ } \min$. The increase in conductivity was steeper for higher values of the leakoff coefficient. The conductivity increased from $4432 \mathrm{md}-\mathrm{ft}$ at a leakoff of $5.5 \times 10^{-3} \mathrm{ft} \sqrt{\mathrm{min}}$ to $8166 \mathrm{md}-\mathrm{ft}$ at a leakoff of $1.0 \times 10^{-2} \mathrm{ft} \sqrt{\mathrm{min}}$.

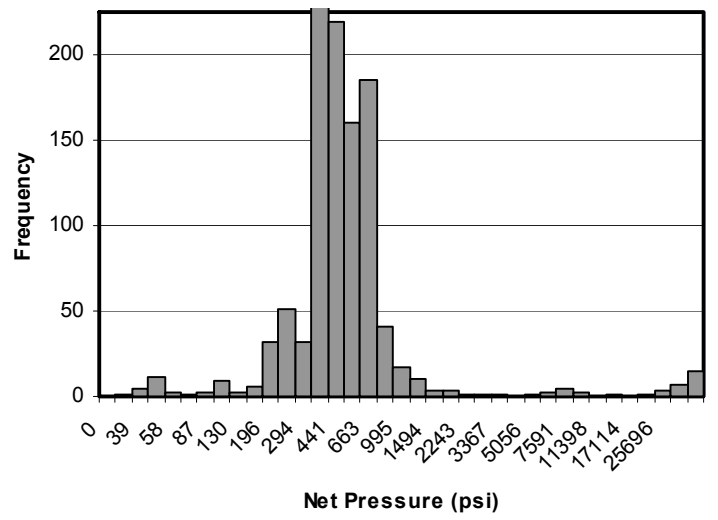

Figure 62 Distribution of log net pressure for all simulations. The category 294 psi to 360 psi has 410 occurrences.

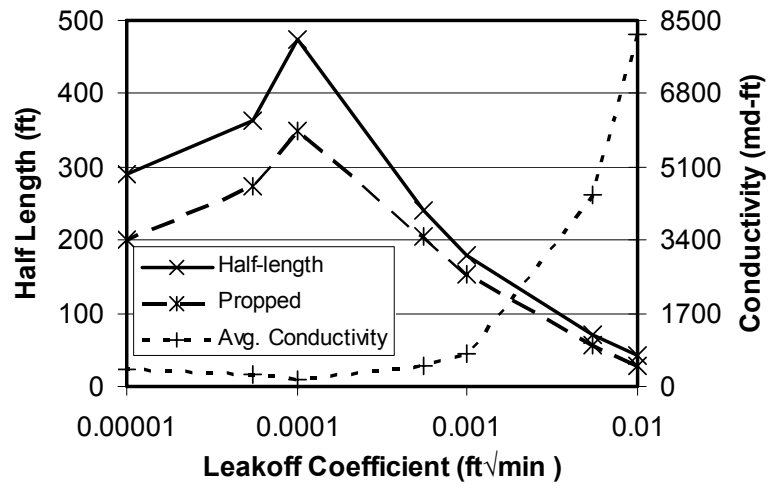

Figure 63 Relationship between leakoff coefficient and fracture properties.

Values of leakoff coefficient less than $1.0 \times 10^{-4} \mathrm{ft} \sqrt{ }$ min exhibit more detail (Figure 64). The fracture half- length is greatest at a leakoff coefficient of $1.0 \times 10^{-4} \mathrm{ft} / \mathrm{min}$ and decreases as the leakoff coefficient increases. The average fracture conductivity is the least $(176 \mathrm{ft} / \mathrm{min})$ at a leakoff coefficient of $1.0 \times 10^{-4} \mathrm{ft} \sqrt{ } \mathrm{min}$. The conductivity increases as fracture conductivity increases and decreases.

The fracture half-length at the time pumping was stopped as well as the final length was plotted against the leakoff coefficient (Figure 65) to explain the maximum fracture length at a leakoff coefficient of $1.0 \times 10^{-4} \mathrm{ft} \sqrt{ } \mathrm{min}$. The curve created by length at "pump off" is relatively smooth with fracture half-length decreasing as the leakoff coefficient increases. The final length deviates from the length at pump off for leakoff coefficients less than $1.0 \times 10^{-3} \mathrm{ft} \sqrt{ }$ min (Figure 65). For these cases the fracture continued to propagate after the pumping schedule in the simulation was completed. The fracture continued to grow for approximately $196 \mathrm{ft}$ when the leakoff was $1.0 \times 10^{-4} \mathrm{ft} \sqrt{ }$ min.

Fracture growth after "pump off" is a result of the low leakoff and the compressive stress of the formation. During pumping, the fracture width increased because the pumping pressure 
exceeded the compressive stress. The pressure within the fracture remains high when the pressure from the pump is shut off because the fracturing fluid is unable to leak into the formation. The fracturing fluid is slow to leak into the formation because of the low leakoff coefficient. In response to the pressure difference between the fracturing fluid and the formation, the fracture continues to propagate.

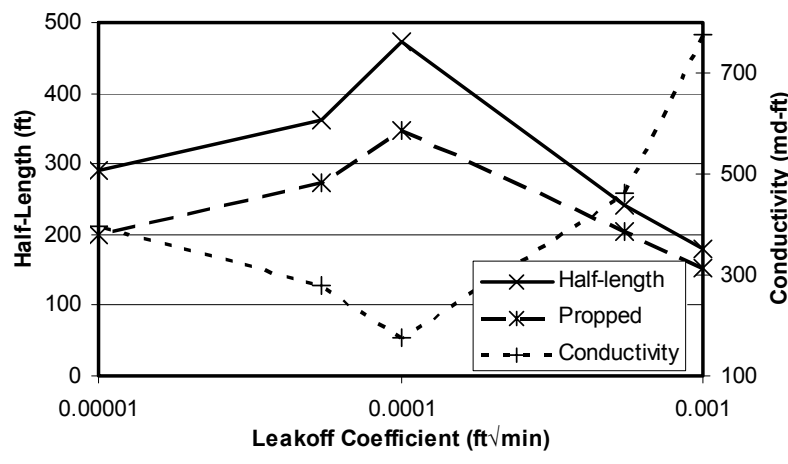

Figure 64 Leakoff coefficients less than 0.001 $\mathrm{ft} \sqrt{\min }$ and fracture characteristics.

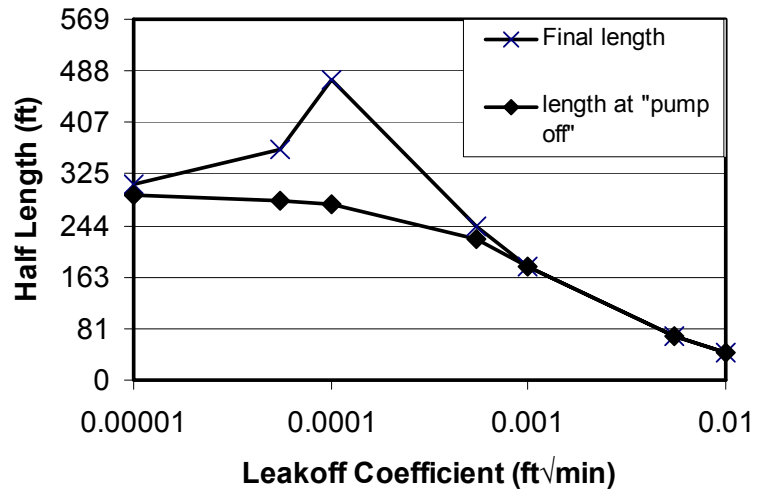

Figure 65 Fracture half-length at end of pumping and final length for varying leakoff coefficients.

\section{Depth}

The fracture half-length, propped length and average conductivity were calculated for target depths of 4000, 6000 and $8000 \mathrm{ft}$. The fracture half-length and propped length remain constant as the depth of the fracture increases (Figure 66). For all of the cases, the total fracture half-length is about $100 \mathrm{ft}$ greater than the propped length. However, the fracture conductivity decreases from $499 \mathrm{md}-\mathrm{ft}$ at a depth of $4000 \mathrm{ft}$ to $293 \mathrm{md}-\mathrm{ft}$ at a depth of $8000 \mathrm{ft}$. Stress on the proppant increases with depth and results in elastic deformation of the proppant as well as increased embedment of the proppant into the fracture walls, reducing fracture conductivity. 


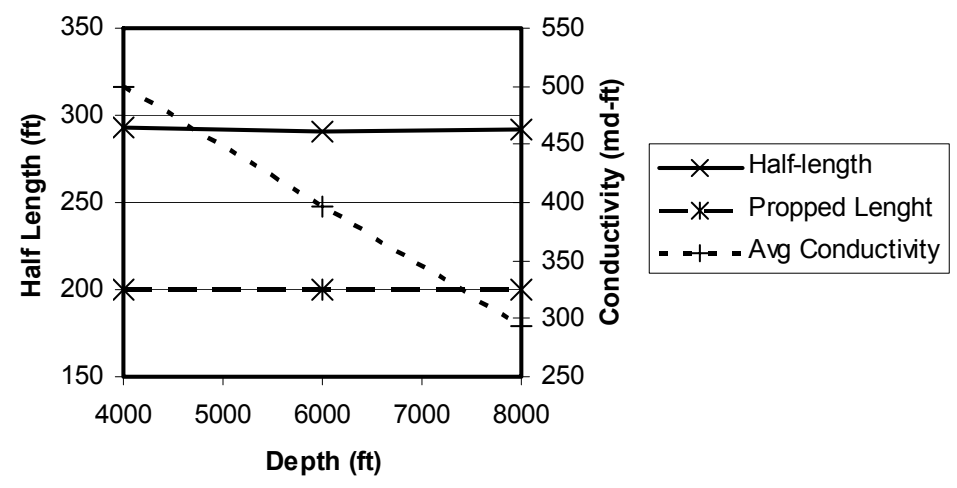

Figure 66 Variations in fracture properties with changes in depth

The fractures at $4000 \mathrm{ft}$ and $8000 \mathrm{ft}$ have similar length and width dimensions, but the distribution of fracture conductivity is different. The average conductivity for the fracture at the $4000 \mathrm{ft}$ depth (Figure 67) is greater than the average fracture conductivity at the $8000 \mathrm{ft}$ depth (Figure 68). There is also a difference in the stress profiles between the two different depths. Both stress profiles vary by the same gradient, but the average compressive stress at $4000 \mathrm{ft}$ is $2500 \mathrm{psi}$ while the average compressive stress at $8000 \mathrm{ft}$ is $5300 \mathrm{psi}$. As the stress increases, the fracture conductivity decreases.
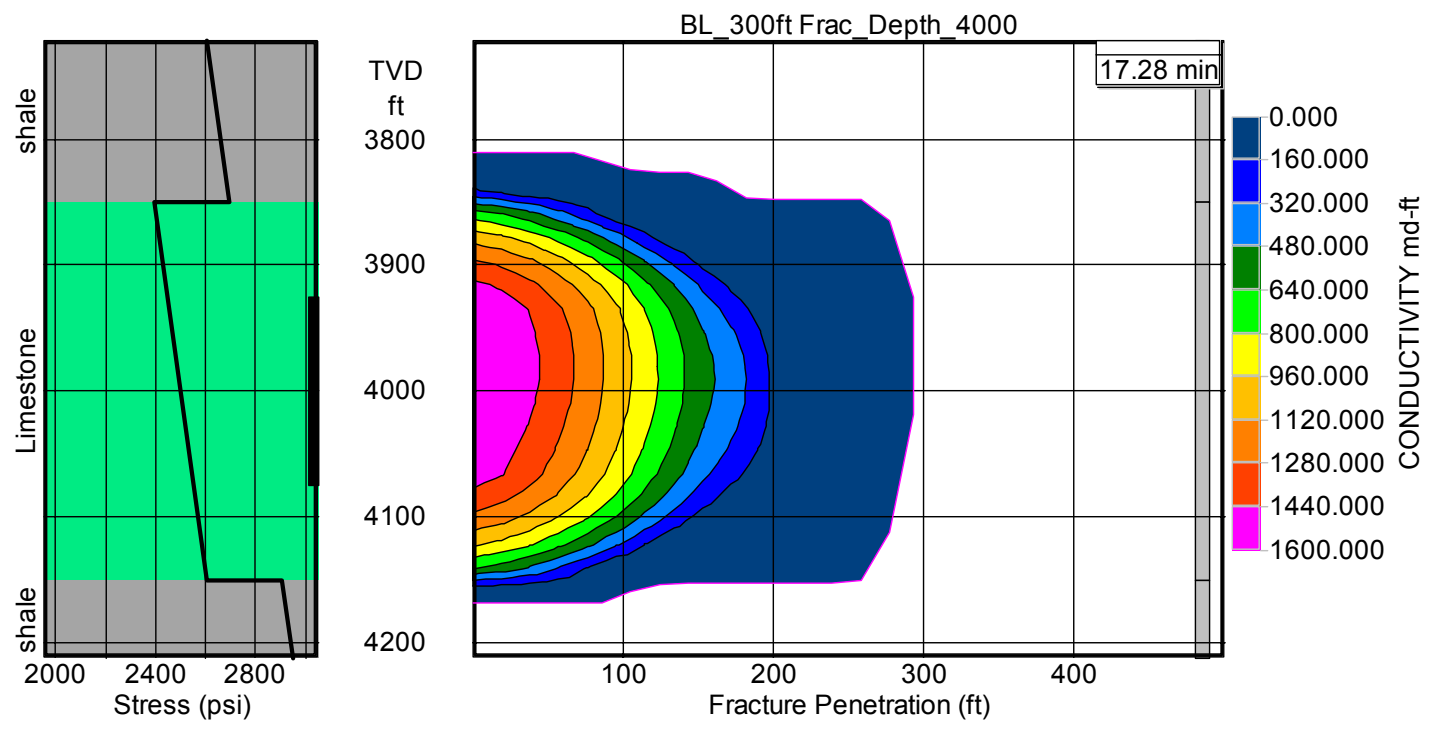

Figure 67 Conductivity for a fracture at a target depth of $4000 \mathrm{ft}$. 

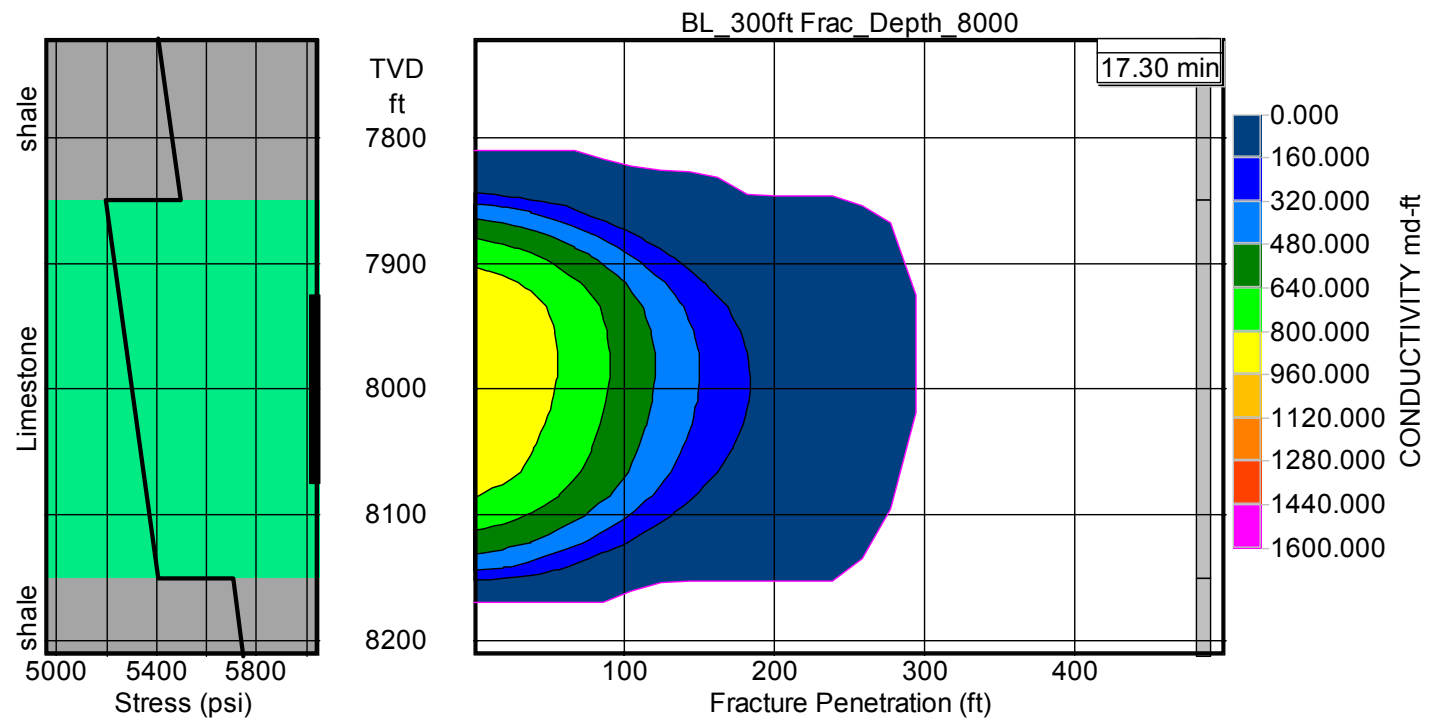

Figure 68 Conductivity for a fracture at a target depth of $8000 \mathrm{ft}$.

\section{$\underline{\text { Stress Contrast }}$}

The variation of the difference in stress between the limestone target formation and the adjacent layer affected horizontal fracture length as well as vertical height growth (Figure 69). Where the stress difference is negative, the stress in the limestone is less compressive than the stress in the adjacent layers. As the stress in the limestone increased to match that of the adjacent layer, the fracture half-length decreased from $313 \mathrm{ft}$ for the baseline to $243 \mathrm{ft}$ for zero stress difference while the propped length decreased from $214 \mathrm{ft}$ for the baseline to $174 \mathrm{ft}$. For these cases, the overall fracture height growth increased from $318 \mathrm{ft}$ for the baseline to $533 \mathrm{ft}$ for zero stress difference. The fracture half-length decreases to $214 \mathrm{ft}$ at a stress difference of $300 \mathrm{psi}$ then increases to $285 \mathrm{ft}$ at a stress difference of $900 \mathrm{psi}$. The propped length decreases to $165 \mathrm{ft}$ at a stress difference of 300 psi and 900 psi. 


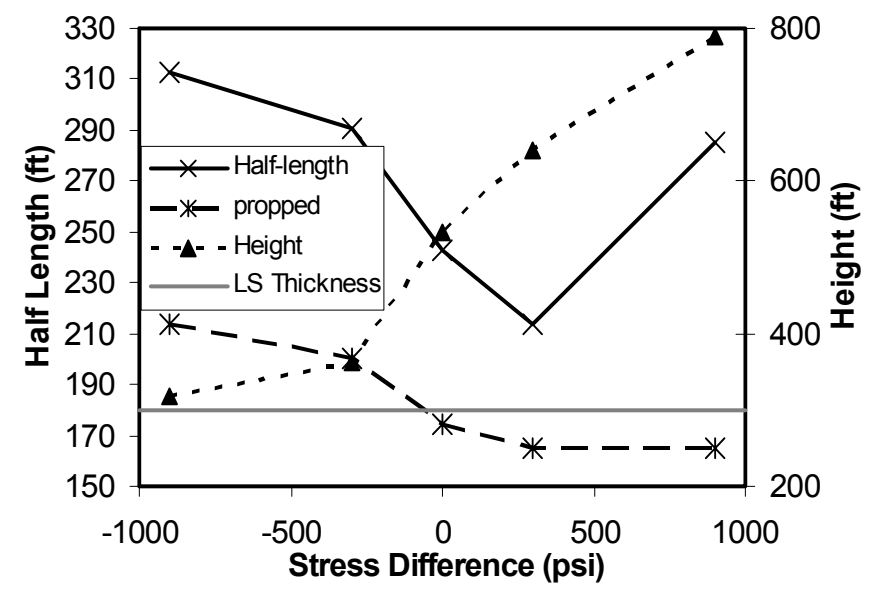

Figure 69 Effect of stress differences between adjacent layers and fracture dimensions

The fracture half-length is $313 \mathrm{ft}$ and the fracture intrudes $14 \mathrm{ft}$ vertically into the upper formation and 4 feet into the lower formation when the compressive stress in the limestone is 900 psi less than that the stress in the adjacent layers (Figure 70). Decreasing the stress difference to $300 \mathrm{psi}$ reduces the fracture half-length to $291 \mathrm{ft}$, and extends the vertical intrusion $50 \mathrm{ft}$ into the upper layer and 13 feet into the lower layer (Figure 71).
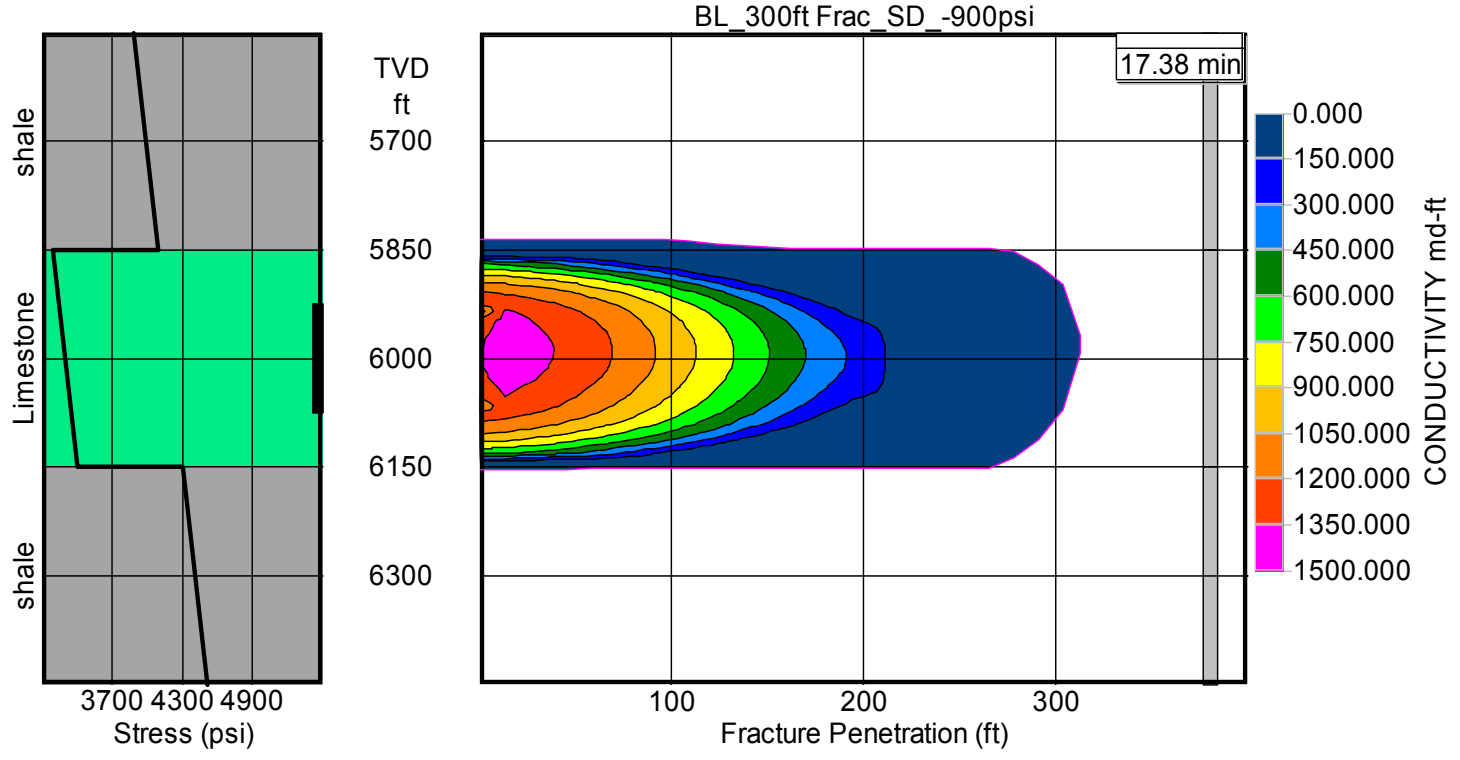

Figure 70 Fracture conductivity for a simulation where the limestone stress is 900 psi less than the shale layers, $3: 1$ horizontal exaggeration. 

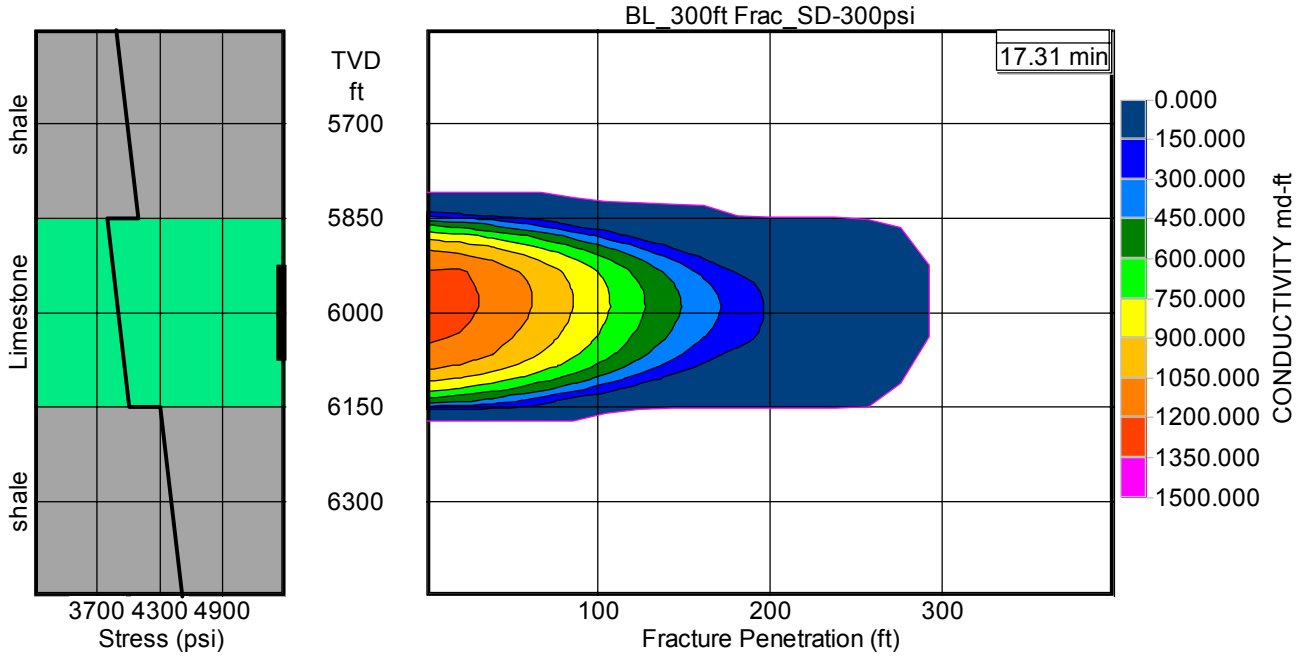

Figure 71 Fracture conductivity for a simulation where the limestone stress is 300 psi less than the shale layers, 3:1 horizontal exaggeration.

This trend is maintained when the stresses are continuous between the limestone and the adjacent layers. In this case, the half-length is $243 \mathrm{ft}$, and it intrudes $140 \mathrm{ft}$ vertically into the upper shale layer and 93 feet into the lower formation (Figure 72). For this simulation, the fracture was generally radially symmetric with the vertical fracture growth slightly greater than the horizontal length. The upward vertical growth is greater than the downward growth because of the gradient $(0.7 \mathrm{psi} / \mathrm{ft})$ in confining stress (Figure 72$)$.
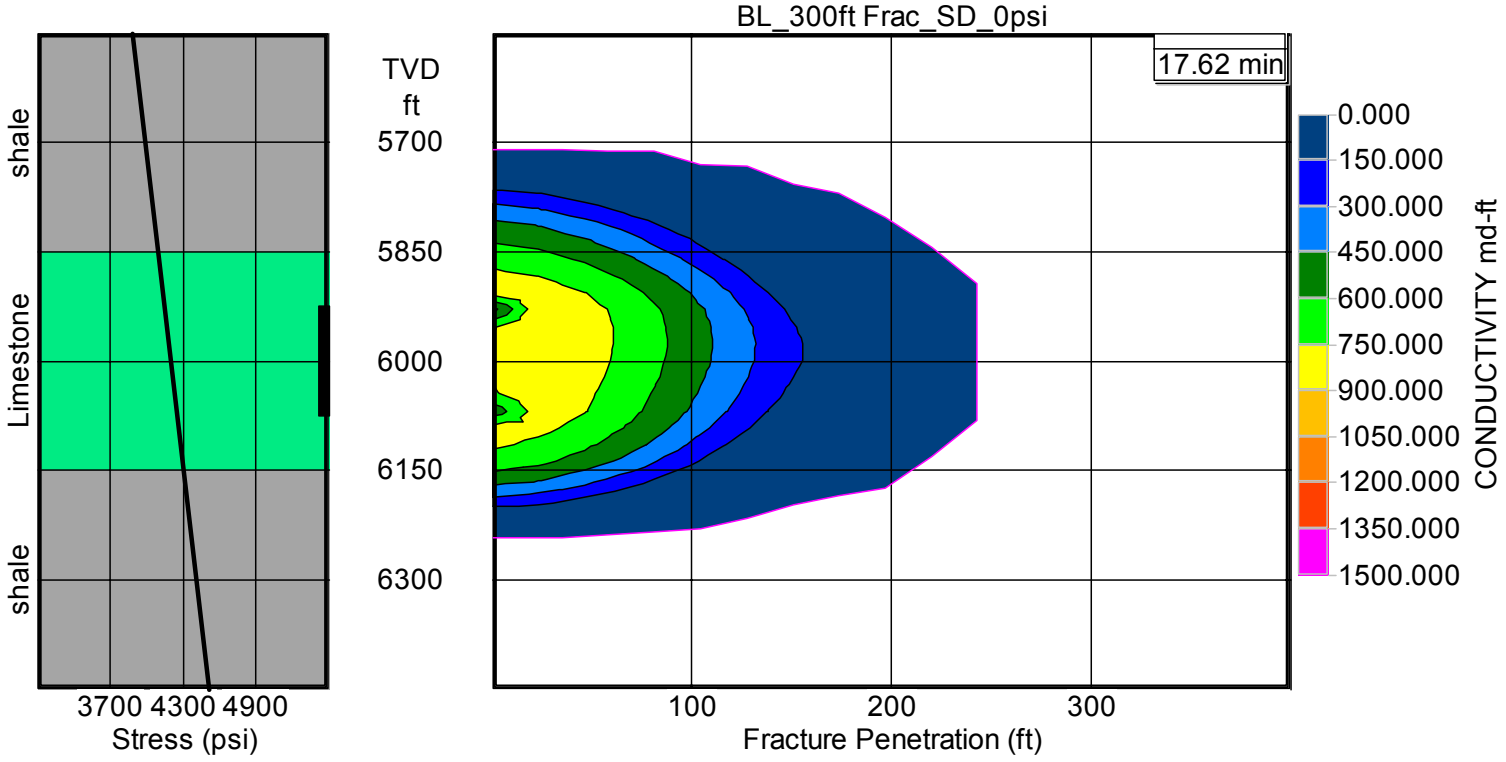

Figure 72 Fracture conductivity for a simulation with no stress difference between the limestone and the shale layers, 3:1 horizontal exaggeration. 
The fracture half-length is $214 \mathrm{ft}$ and the fracture intrudes $204 \mathrm{ft}$ vertically into the upper shale layer and 135 feet into the lower formation when the stress difference is 300 psi (Figure 73). There are two lobes of increased conductivity, one in the limestone formation and one in the upper formation (Figure 73).

The fracture half-length is $285 \mathrm{ft}$ with $233 \mathrm{ft}$ of intrusion into the upper layer and 257 feet into the lower formation when the stress difference is 900 psi (Figure 74). The predicted fracture has a greater lateral intrusion into the lower formation, but has higher conductivity regions in the upper formation (Figure 74). For both of the cases where the stress in the limestone is greater than the stress in the adjacent layers, the fracture has lobes of higher conductivity, indicating different lobes of proppant placement. Due to the higher stress in the limestone, the fracturing slurry migrates to areas of least stress, resulting in the taller fractures and lobes in the adjacent layers where the proppant flowed (Figures 73 and 74). Shale normally has a higher in-situ stress; however, inversions of this relationship have been reported (Shumbera et al., 2003).
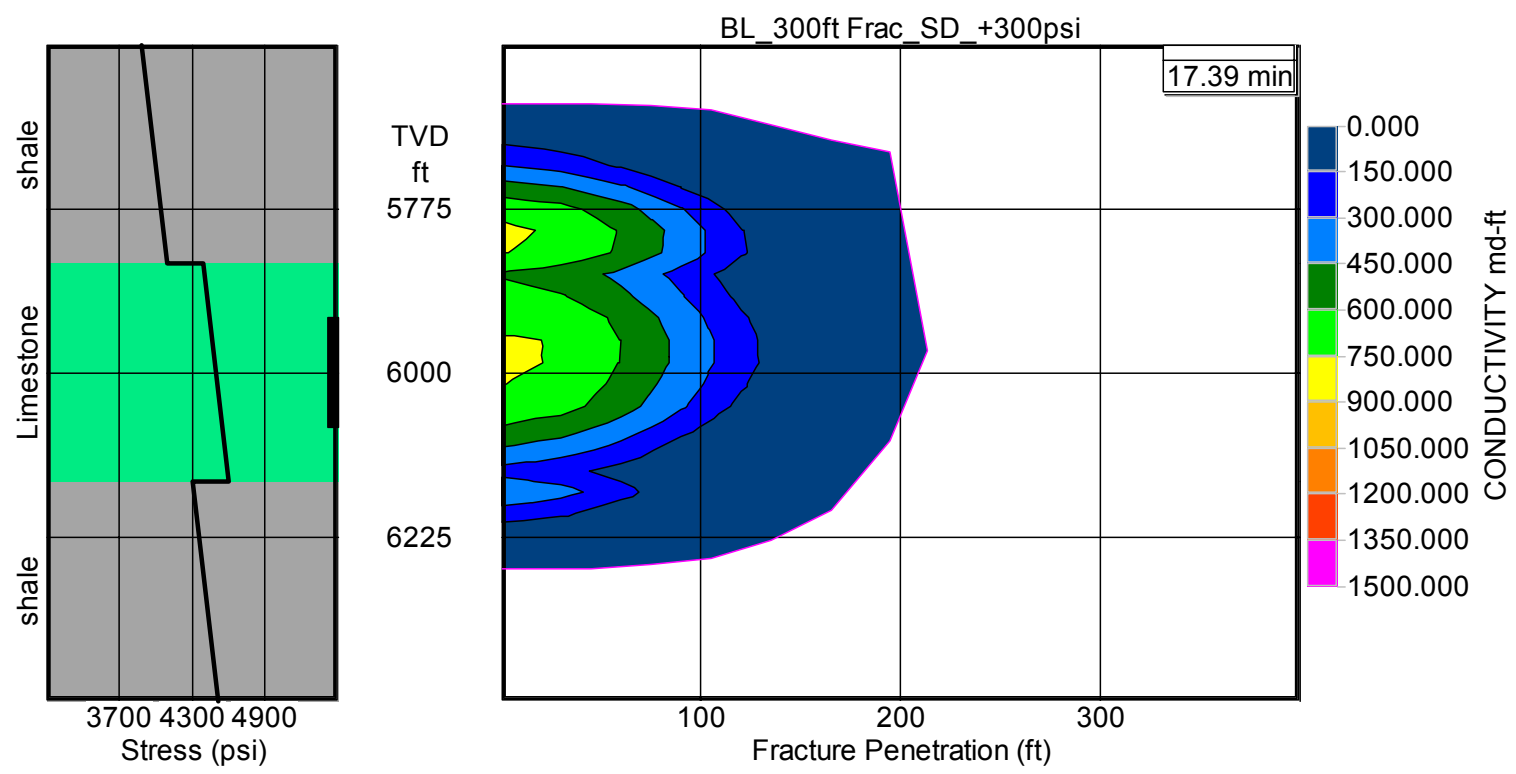

Figure 73 Fracture conductivity for a simulation where the limestone stress is 300 psi greater than the shale layers, 3:1 horizontal exaggeration. 

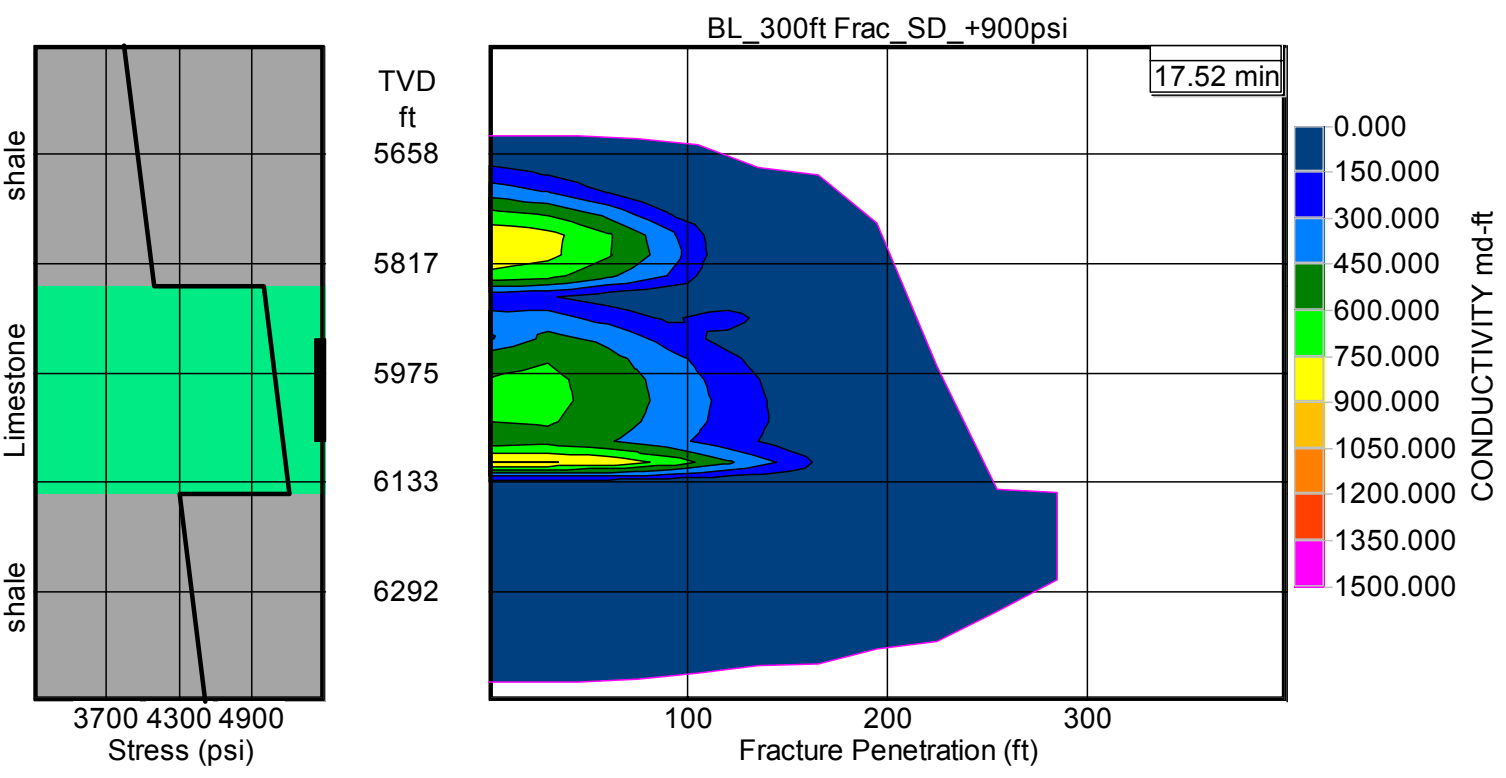

Figure 74 Fracture conductivity for a simulation where the limestone stress is 900 psi greater than the shale layers, 3:1 horizontal exaggeration.

The simulations where the stress in the limestone was less than the stress in the adjacent shale resulted in fractures with intrusion less than $50 \mathrm{ft}$ into the upper layer. Also, the fracture conductivity is greater than 750 md-ft for most of the fractures in these simulations (Figure 70, and 71). When there was no stress difference between the layers, vertical fracture growth was unimpeded and the fracture was nearly radially symmetric with a fracture conductivity $750 \mathrm{md}-\mathrm{ft}$ out to approximately $60 \mathrm{ft}$ (Figure 72). The simulations where the stress in the limestone was greater than the stress in the adjacent shale layers resulted in fractures with increased vertical fracture growth with lobes where the conductivity was $750 \mathrm{md}-\mathrm{ft}$, but the overall conductivity is less than in the other simulations (Figure 73 and 74).

For variations in the stress difference between layers, when the stress in the limestone is less than the stress in the adjacent layer, the fractures were vertically confined, had longer halflength, and areas of higher fracture conductivity (Figure 70 and 71). When the stress between the formations was the same, the fracture was generally radially symmetric with the fracture conductivity in all areas of the fracture less than $900 \mathrm{md}-\mathrm{ft}$ (Figure 72). When the stress in the limestone is greater than the stress in the adjacent layers, there was greater vertical growth than horizontal length and the fracture conductivity was less than $900 \mathrm{md}-\mathrm{ft}$ for the entire fracture with small regions were the conductivity is greater than $750 \mathrm{md}-\mathrm{ft}$ (Figures73 and 74)

\section{$\underline{\text { Adjacent Formation Physical Properties }}$}

The modulus and fracture toughness for the adjacent layers were varied to represent the range of these properties reported for shale (Table 2) and sandstone (Table 3). The intrusion of the fracture into the upper formation was plotted as a function of elastic modulus for different values of fracture toughness (Figure 75). The intrusion into the upper layer is $35 \mathrm{ft}$ when the modulus is $0.1 \mathrm{Mpsi}, 48 \mathrm{ft}$ when the modulus is $4.3 \mathrm{Mpsi}$ and $51 \mathrm{ft}$ when the modulus is $8.5 \mathrm{Mpsi}$ and the fracture toughness is 246 psivin (Figure 75). As shown in Figure 75, the intrusion into 
the upper layer is $25 \mathrm{ft}$ when the modulus is $0.1 \mathrm{Mpsi}, 43 \mathrm{ft}$ when the modulus is $4.3 \mathrm{Mpsi}$ and 46 $\mathrm{ft}$ when the modulus is $8.5 \mathrm{Mpsi}$ and the fracture toughness is $1292 \mathrm{psi}$ in. The intrusion into the upper layer is $27 \mathrm{ft}$ when the modulus is $0.1 \mathrm{Mpsi}, 36 \mathrm{ft}$ when the modulus is $4.3 \mathrm{Mpsi}$ and $43 \mathrm{ft}$ when the modulus is $8.5 \mathrm{Mpsi}$ and the fracture toughness is $2337 \mathrm{psi}$ in (Figure 75). The intrusion into the upper layer generally increases with an increase in modulus of the upper layer. The increase in intrusion is approximately $20 \mathrm{ft}$ with an increase in modulus of $8 \mathrm{Mpsi}$. Lower values of fracture toughness in the adjacent layers resulted in greater intrusion into the upper formation.

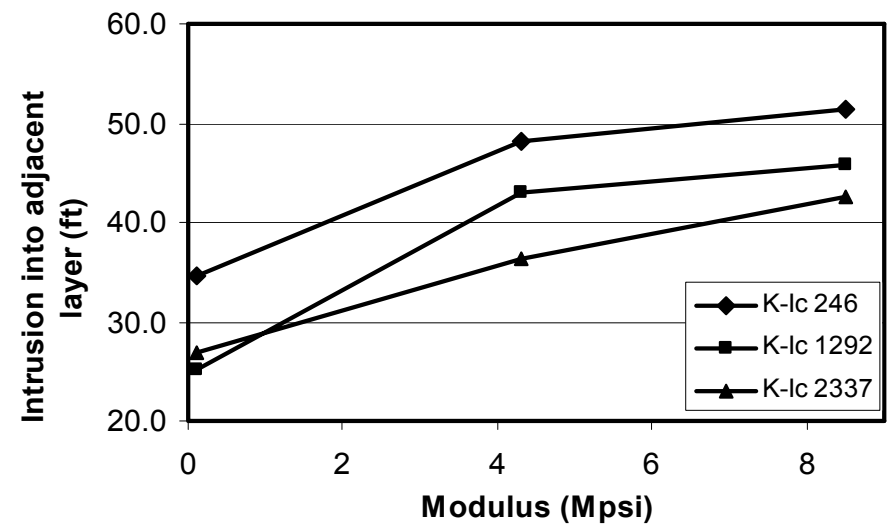

Figure 75 Intrusion into upper layer as a function of fracture toughness for different moduli.

Fracture intrusion into the upper formation was plotted against fracture toughness variations in the adjacent layer for different values of the elastic modulus of the adjacent layer (Figure 76). As shown in Figure 76, the fracture intrudes $35 \mathrm{ft}$ into the upper layer when the $K_{I C}$ is $246 \mathrm{psi} \sqrt{ }$ in, $25 \mathrm{ft}$ when the $K_{I C}$ is $1292 \mathrm{psi} \sqrt{ }$ in and $27 \mathrm{ft}$ when the $K_{I C}$ is $2337 \mathrm{psi} \sqrt{i n}$ and the modulus is $0.1 \mathrm{Mpsi}$. The fracture intruded $48 \mathrm{ft}$ into the upper layer when the $K_{I C}$ is $246 \mathrm{psi}$ in, $43 \mathrm{ft}$ when the $K_{I C}$ is $1292 \mathrm{psi} \sqrt{ }$ in and $36 \mathrm{ft}$ when the $K_{I C}$ is $2337 \mathrm{psi} \sqrt{i n}_{\mathrm{in}}$ and the modulus is 4.3 Mpsi (Figure 76). The fracture intruded $51 \mathrm{ft}$ into the upper layer when the $K_{I C}$ is $246 \mathrm{psi}$ in, 46 $\mathrm{ft}$ when the $K_{I C}$ is $1292 \mathrm{psi} \sqrt{ }$ in and $43 \mathrm{ft}$ when the $K_{I C}$ is $2337 \mathrm{psi} \sqrt{i n}_{\text {in }}$ and the modulus is 8.5 Mpsi (Figure 76). Intrusion into the upper formation decreased as the adjacent layer fracture toughness increased. The fracture intrusion increased with increasing modulus. The least intrusion into the upper layer $(25 \mathrm{ft}$ ) occurred when the elastic modulus was the smallest and the fracture toughness was $1292 \mathrm{psi} \vee$ in. The greatest fracture intrusion $(51 \mathrm{ft})$ occurred when the elastic modulus was the greatest and the fracture toughness was the least (Figure 76). 


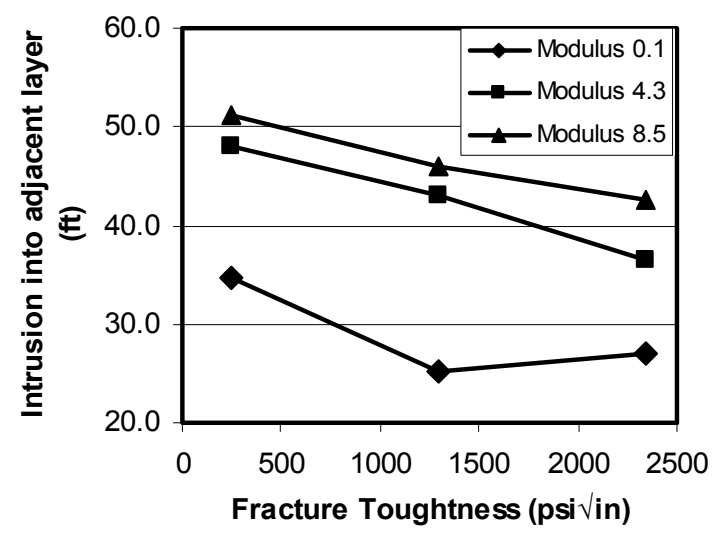

Figure 76 Intrusion into upper layer for different moduli and fracture toughness values of the adjacent layers

The results of variations of physical properties of the limestone were calculated when the lateral stress in the limestone was $300 \mathrm{psi}$ less than the adjacent layers. The simulations were rerun with zero stress difference between the layers to isolate the effects of the modulus and fracture toughness. The results of intrusion into the upper adjacent layer as a functions of elastic modulus and fracture toughness (Figure 77) and fracture intrusion into the upper layer as a function of fracture toughness for different values of the elastic modulus (Figure 78) exhibit the same trends as the trials with a stress contrast. Fracture intrusion into the upper layer increased with an increasing modulus and decreased with an increase of fracture toughness. The major difference is that the fracture penetrated about 3.5 times farther into the upper adjacent layer when the stresses are equal. Based on these results, the stress difference between layers has a greater effect on vertical height growth than the elastic modulus and fracture toughness of the overlying formation. 


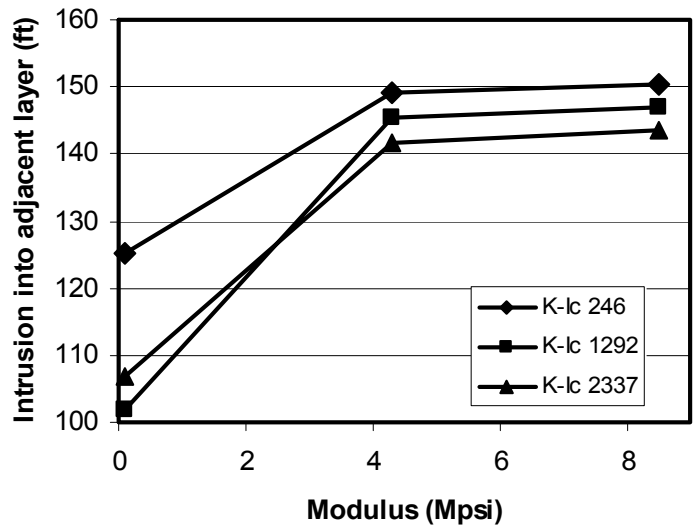

Figure 77 Intrusion into upper adjacent layer as a function of modulus and fracture toughness (adjacent layer) with zero stress difference between layers

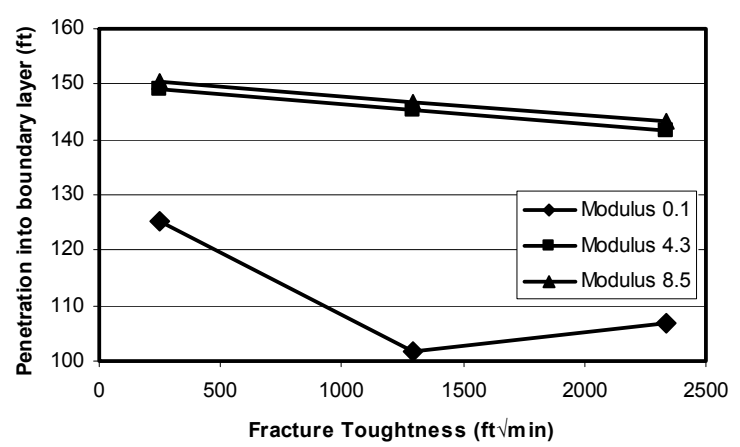

Figure 78 Intrusion into upper adjacent layer as a function of Modulus for different values of fracture toughness with zero stress difference between the layers

\section{$\underline{\text { Limestone Physical Properties }}$}

The elastic modulus and fracture toughness were varied according to the expected range for limestone. The fracture half-length increased from $223 \mathrm{ft}$ to $308 \mathrm{ft}$ as the limestone modulus increased (Figure 79). The propped length of the fracture increased as well from $161 \mathrm{ft}$ to $298 \mathrm{ft}$, approximately $70 \%$ of the penetrated length for the same simulations. The average conductivity decreased from 794 md-ft to $298 \mathrm{md}-\mathrm{ft}$ as the limestone elastic modulus increased.

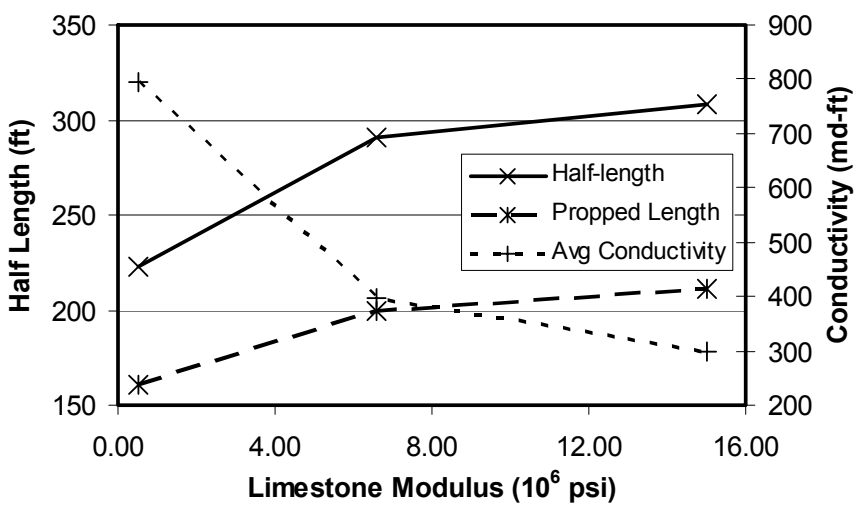

Figure 79 Effects of variations in limestone modulus on half-length, propped length and average conductivity

The variation in the limestone fracture toughness had a minor effect on fracture halflength and propped length. The horizontal fracture half-length increased approximately $10 \mathrm{ft}$, from $291 \mathrm{ft}$ to $301 \mathrm{ft}$, as the fracture toughness varied from $350 \mathrm{psi}$ in to $1800 \mathrm{psi}$ in (Figure 80 ). There was an increase in average fracture conductivity from $377 \mathrm{md}-\mathrm{ft}$ at a fracture 
toughness of $350 \mathrm{ft} \sqrt{ } \min$ to $396 \mathrm{md}-\mathrm{ft}$ when the fracture conductivity is $1000 \mathrm{ft} \sqrt{\mathrm{min}}$. When the fracture toughness increased to $1800 \mathrm{ft} \sqrt{\mathrm{min}}$, the fracture conductivity was $386 \mathrm{md}$ - $\mathrm{ft}$, resulting in a gentle maximum in conductivity when the

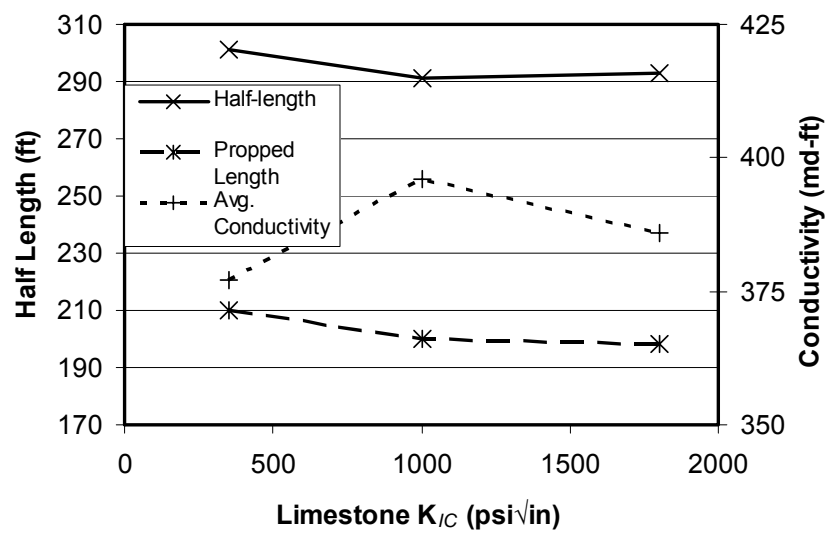

Figure 80 Effect of expected variations in limestone fracture toughness on half-length and conductivity.

fracture toughness is $1000 \mathrm{ft} \sqrt{ } \mathrm{min}$. The range of conductivity for the trials of fracture toughness is $25 \mathrm{md}-\mathrm{ft}$ so the spike is minor. The elastic modulus has a greater effect than the fracture toughness on fracture geometry for the range evaluated here.

To examine the effect of variations in limestone modulus in more detail, the fracture halflength and width were plotted against limestone modulus (Figure 81). The fracture width was greater at lower values of the limestone modulus and the width decreased as the modulus increased. Increasing the modulus reduces the opening of mode I fractures.

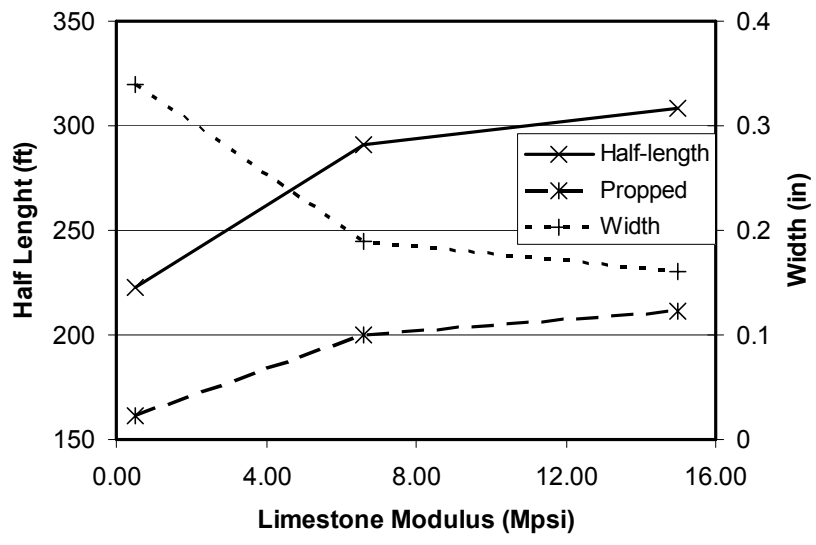

Figure 81 Effects of variations in Limestone modulus on fracture half-length and width.

\section{Limestone Thickness}

Variations in the thickness of the limestone formation were also simulated. Reducing the 
limestone thickness to $60 \mathrm{ft}$ with a fracture design length of $300 \mathrm{ft}$ represents a situation where the ideal fracture length is 5 times greater than the formation thickness. The result is a triangularshaped fracture significantly intrudes into the adjacent layers (Figure 82 ). The fracture laterally penetrates $388 \mathrm{ft}, 30 \%$ farther than the baseline case, but it penetrates $173 \mathrm{ft}$ into the upper layer and $151 \mathrm{ft}$ into the lower layer. There is a wedge of higher conductivity that cuts $100 \mathrm{ft}$ into the limestone formation as well as intruding into the upper and lower layers.

The baseline case represents a situation where the proposed fracture length is the same as the formation thickness and was described above (Figure 83). A third simulation was run where the limestone thickness was $1500 \mathrm{ft}$, five times greater than the proposed fracture length. This situation results in a fracture that has a half-length of $265 \mathrm{ft}$ and a total vertical height of $512 \mathrm{ft}$ (Figure 84). The vertical height was $40 \%$ larger than the baseline case, yet there was more than $450 \mathrm{ft}$ of clearance from the upper formation and $530 \mathrm{ft}$ of clearance from the lower formation.There is a region of higher fracture conductivity near the borehole that decreases in a radial pattern from the center.
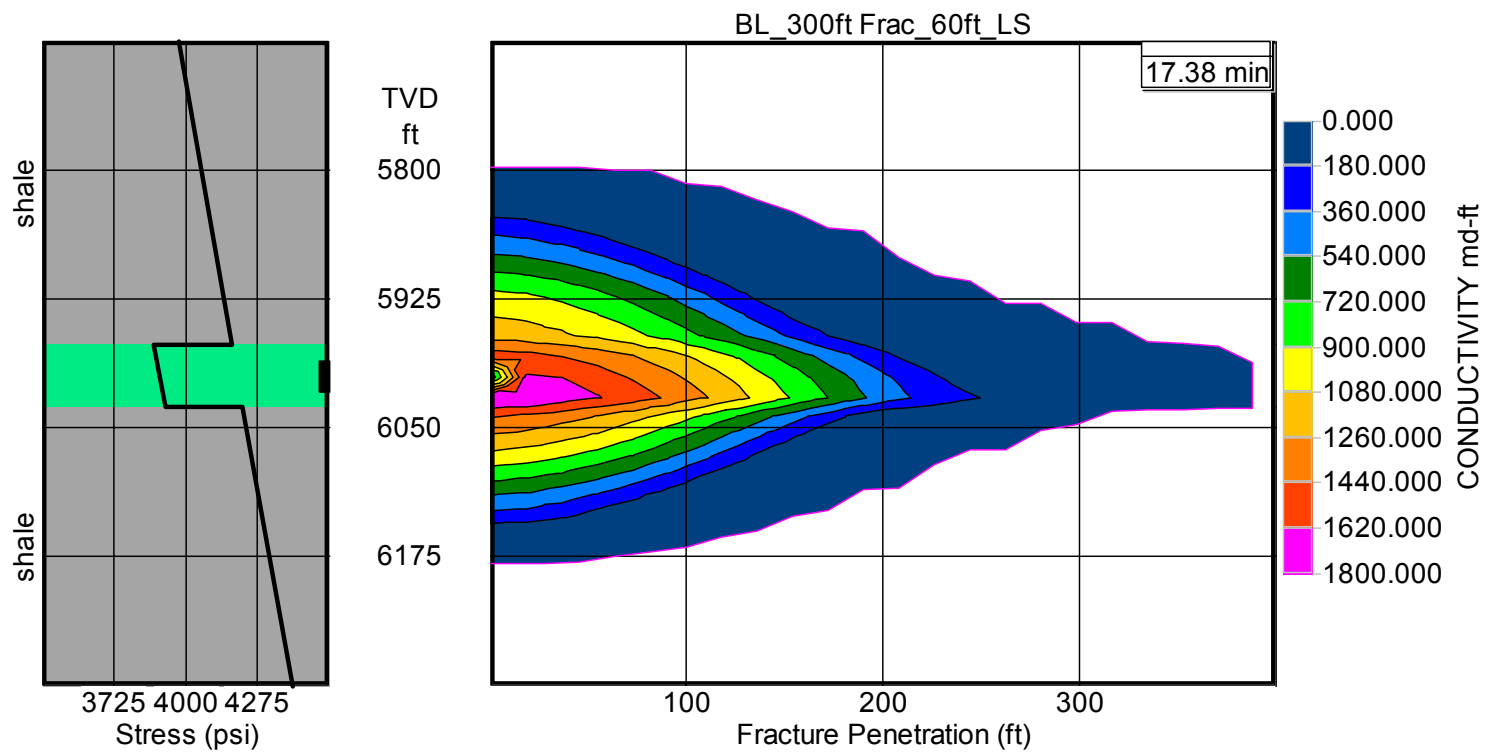

Figure 82 Conductivity for a fracture in a $60 \mathrm{ft}$ thick limestone formation. 

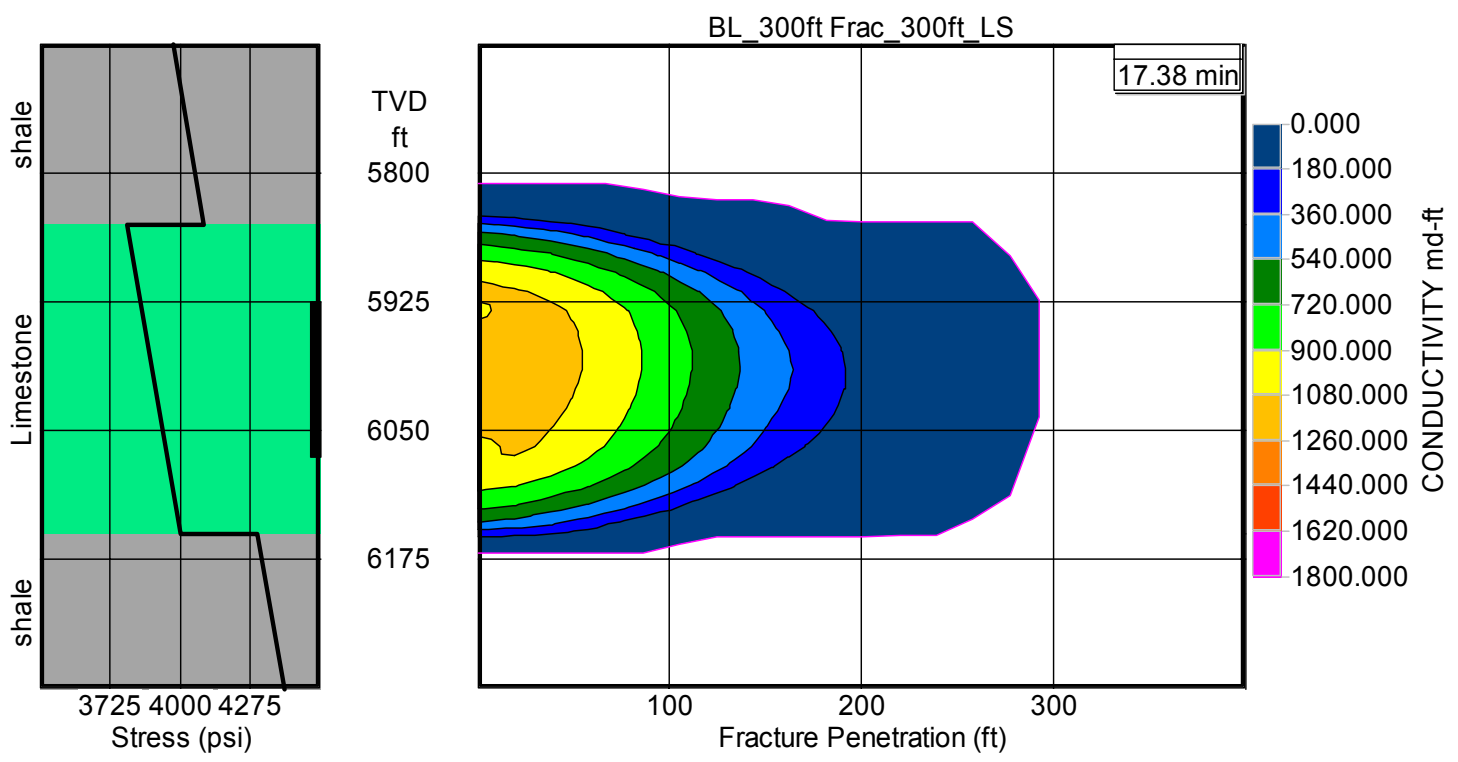

Figure 83 Conductivity for a fracture in $300 \mathrm{ft}$ thick limestone.
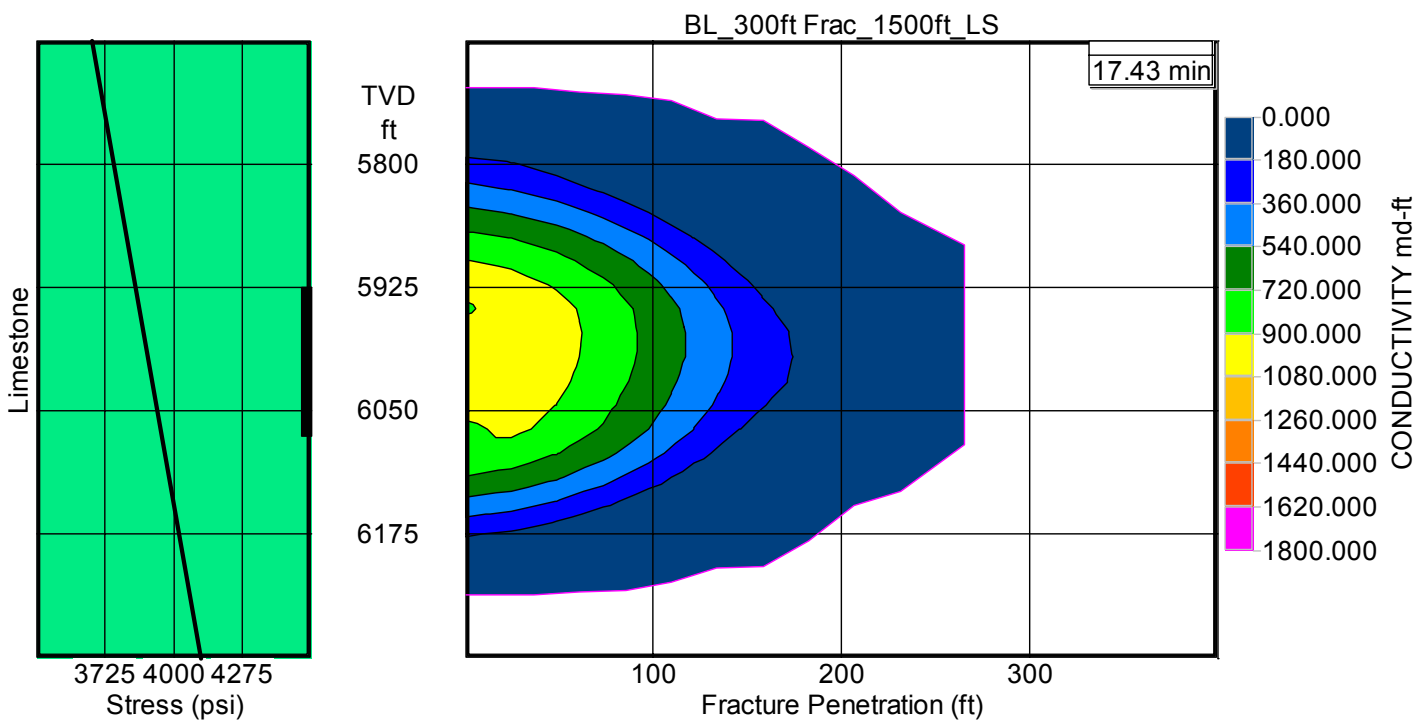

Figure 84 Conductivity for a fracture in $1500 \mathrm{ft}$ thick limestone.

\section{$\underline{\text { Perforated Interval }}$}

The perforated interval where the fracture was initiated was varied to understand how it can affect fracture dimensions. The fracture half-length exhibited minimal variation, but the propped length decreased as the perforated interval increased (Figure 85). The fracture height increased from $356 \mathrm{ft}$ to $383 \mathrm{ft}$ as the perforated interval increased from $30 \mathrm{ft}$ to $300 \mathrm{ft}$. A tenfold increase in the perforated interval resulted in increased height growth of only $27 \mathrm{ft}$. 
Although there was minimal variation in fracture height when the perforated interval was changed, reducing the perforated interval from $300 \mathrm{ft}$ to $30 \mathrm{ft}$ did reduce the intrusion into the upper formation from $64 \mathrm{ft}$ to $36 \mathrm{ft}$ (Figure 86).

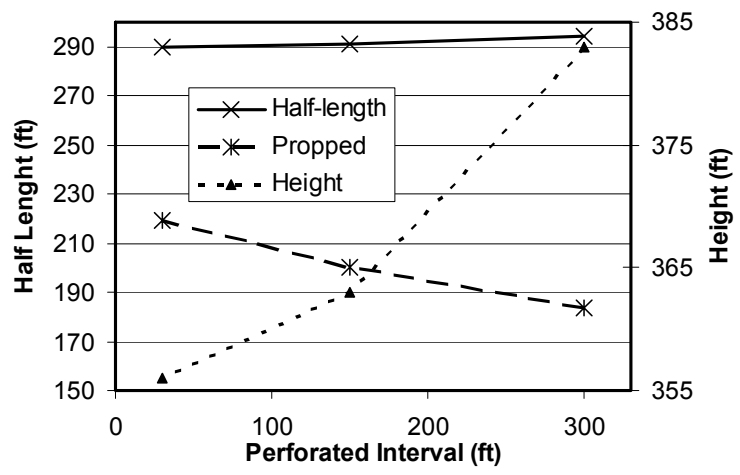

Figure 85 Effects of different perforated intervals on fracture half-length and height.

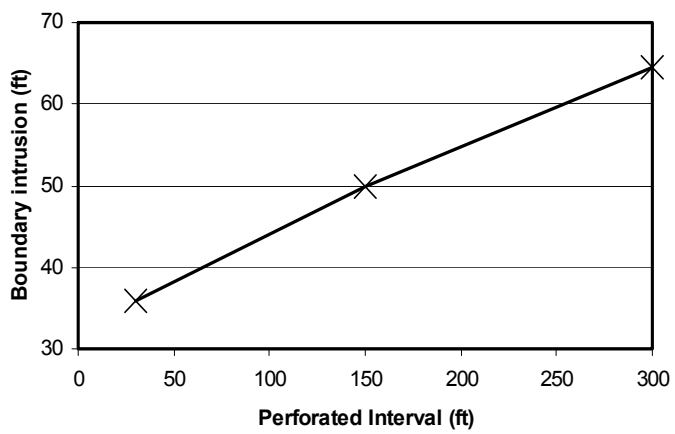

Figure 86 Intrusion into upper layer with variation of the perforated interval length.

\section{Pumping Rate}

Fracture half-length and propped length decrease as the pumping rate increases (Figure 87). There is a steep decline in fracture length when the pumping rate increases from 6 BPM to 30 BPM, but the decrease in fracture length is less steep when the pumping rate increased from $30 \mathrm{BPM}$ to $150 \mathrm{BPM}$. The average conductivity increases from $208 \mathrm{md}-\mathrm{ft}$ to $525 \mathrm{md}-\mathrm{ft}$ as the pumping increases. There is a sharp increase in average conductivity when the pumping rate increased from 6 BPM to 30 BPM and the increase was less steep as the pumping rate increased from $30 \mathrm{BPM}$ to $150 \mathrm{BPM}$. There appears to be more variability in fracture properties at lower pumping rates that at higher pumping rates.

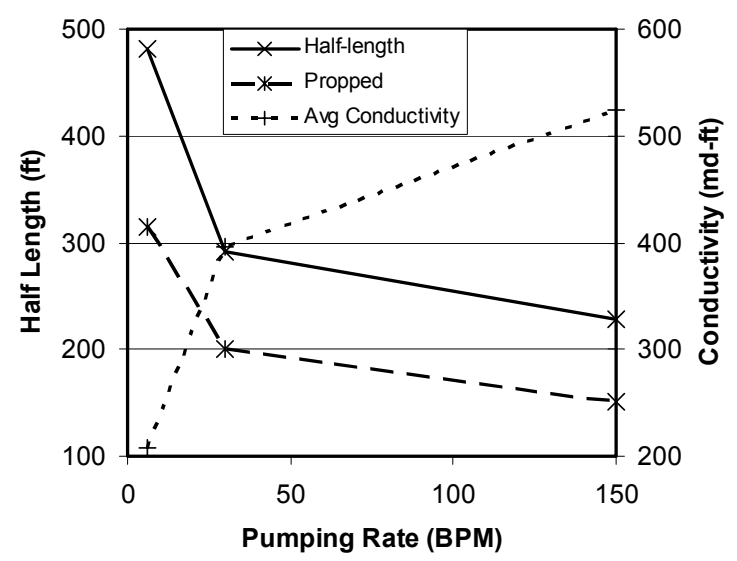

Figure 87 Effects of different pumping rate on fracture length and conductivity.

The lower pumping rate of 6 BPM produces a longer fracture with a lower average conductivity and a lower conductivity distribution (Figure 88). The pumping rate of $30 \mathrm{BPM}$ is the baseline 
case and the half-length is less than when the pumping rate is 6 BPM, and the average conductivity is greater (Figure 89). A pumping rate of $150 \mathrm{BPM}$ resulted in the shortest fracture half-length with the highest conductivity (Figure 90). The time needed to create the fracture and deliver the proppant decreased as pumping rate increased. The time required to create the fracture also changed from 86.5 min with a pumping rate of $6 \mathrm{BPM}$, to 17.3 min for a pumping rate of $30 \mathrm{BPM}$ at $3.5 \mathrm{~min}$ for a pumping rate of $150 \mathrm{BPM}$.
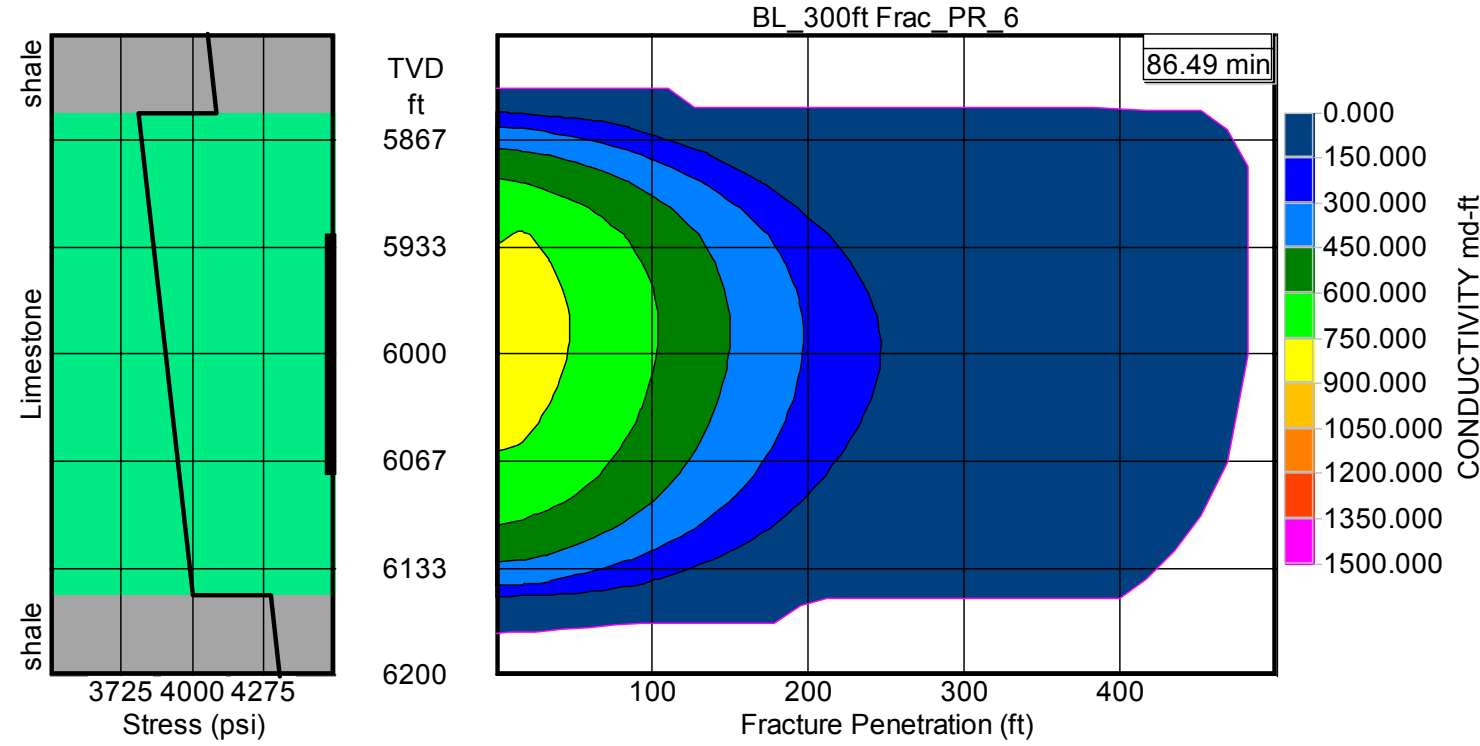

Figure 88 Conductivity with a pumping rate of 6 BPM
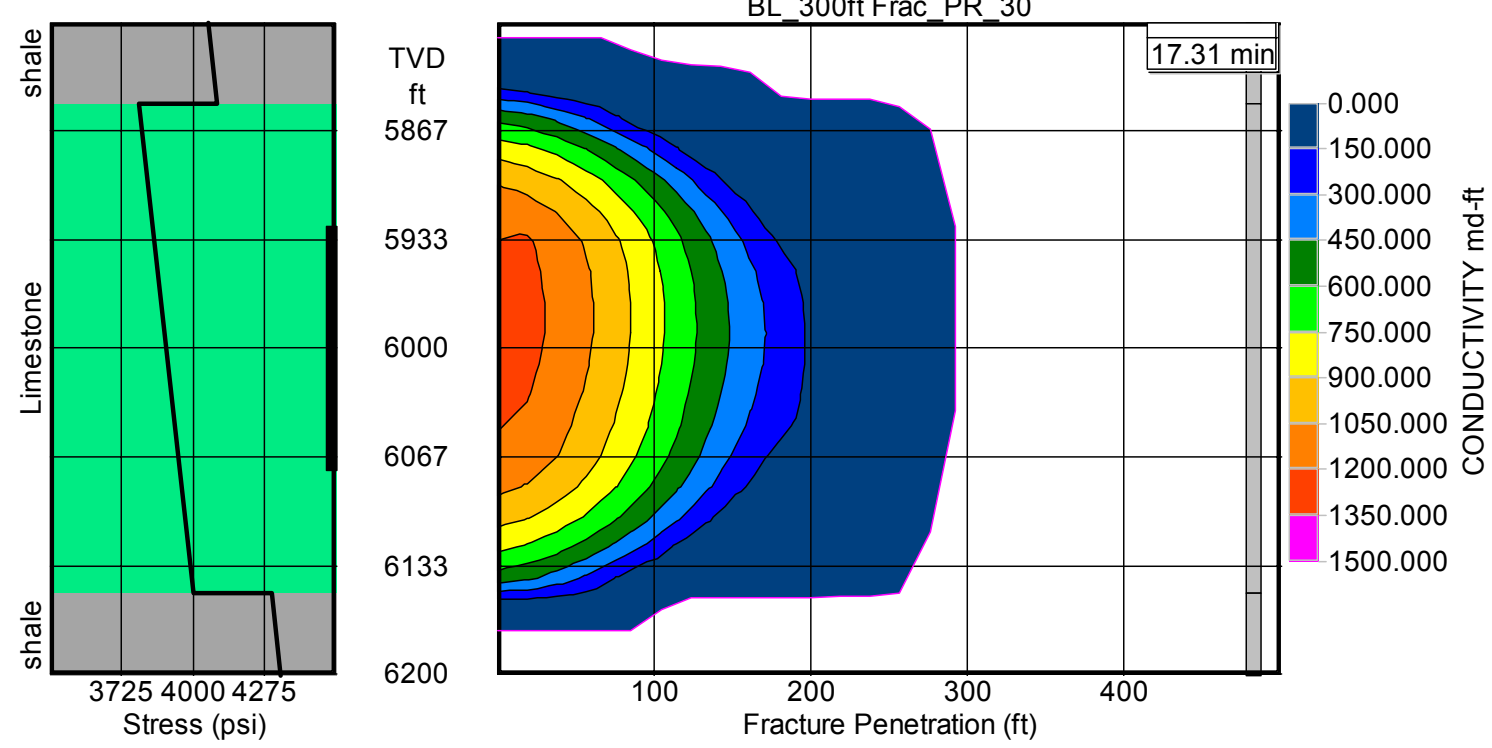

Figure 89 Conductivity with a pumping rate of $30 \mathrm{BPM}$ 

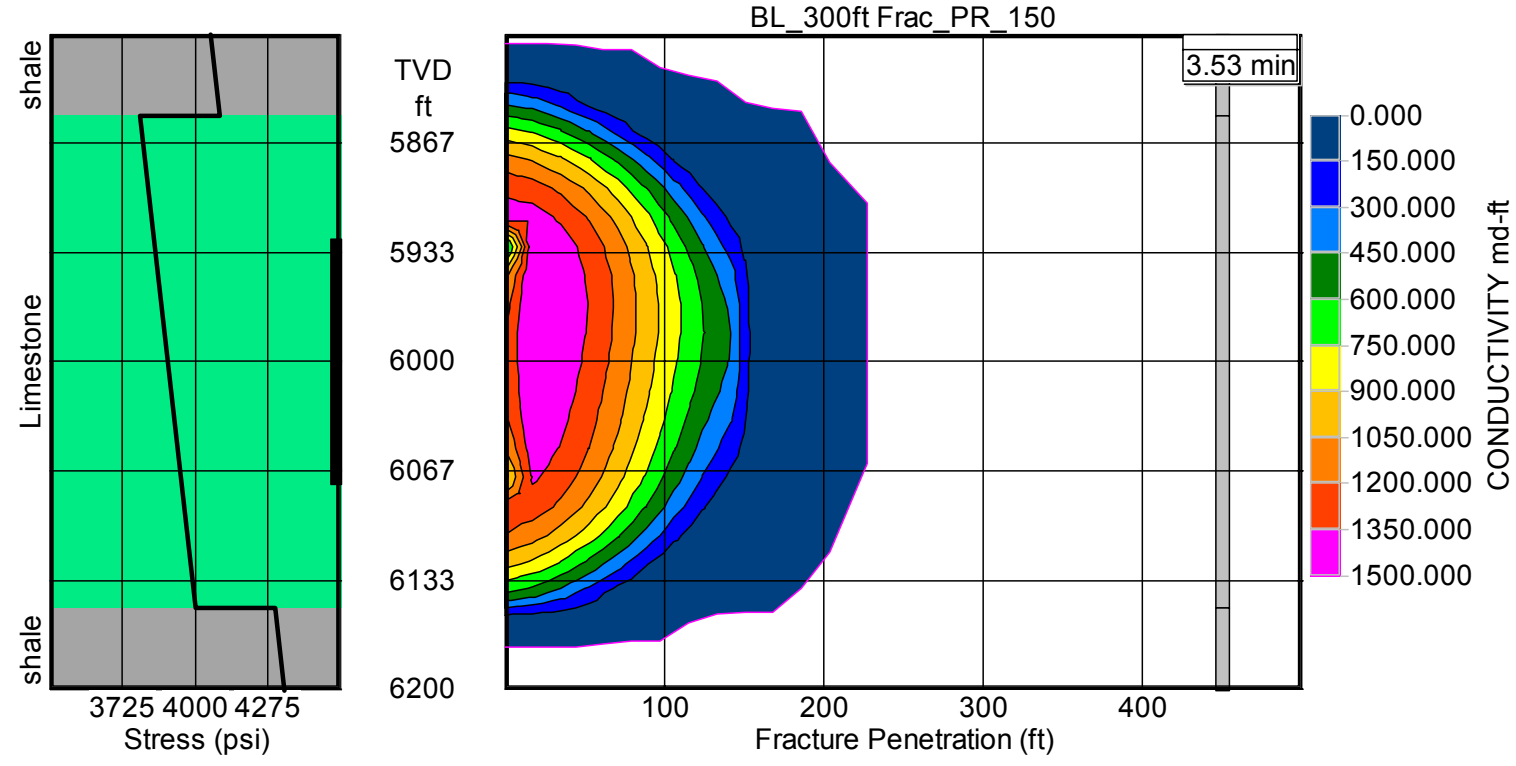

Figure 90 Conductivity with a pumping rate of $150 \mathrm{BPM}$

\section{Fracturing Fluid}

The fracturing fluid viscosity at formation temperature was used as the distinguishing characteristic of the different fluids in order to quantify the variation of the type of fracturing fluid utilized in the model. Fracture halflength, propped length and average conductivity were plotted against the viscosity of the fracturing fluid (Figure 91). As the viscosity of the fluid increased, the half-length decreased. At a viscosity of 45 cp the fracture half-length was $444 \mathrm{ft}$. When the viscosity increases to $840 \mathrm{cp}$ the fracture length decreases to $227 \mathrm{ft}$. However, as the fluid viscosity increased the average fracture conductivity increased as well. At a viscosity of $45 \mathrm{cp}$ the average conductivity was $243 \mathrm{md}-\mathrm{ft}$. When the viscosity was increased to $840 \mathrm{cp}$, the average conductivity nearly doubles to 519 md-ft.

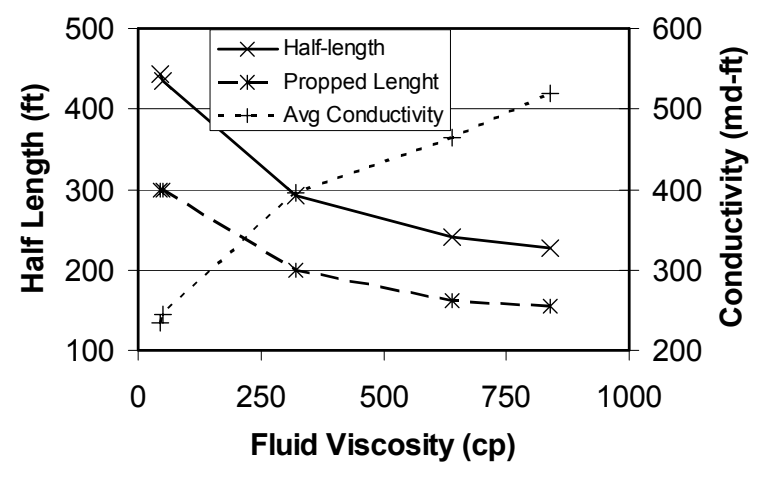

Figure 91 Effect of fracturing fluid viscosity on fracture half-length and average conductivity 


\section{Proppant Type}

Proppant size and damage factor were the two characteristics used to quantify the effects of different proppants on fracture formation. The proppant size relates to a range of mesh sizes that the proppant falls between (Table 4). The damage factor is a dimensionless variable that relates to the strength of the proppant. A damage factor of 1 represents a material that is undeformable or not crushed at any pressure (Table 4).

The average fracture conductivity was plotted as a function of the damage factor for different mesh sizes (Figure 92). Sand with a damage factor of 0.70 and a 20-40 mesh (0.066 in $0.033 \mathrm{in}$ ) size produces a fracture with an average conductivity of $470 \mathrm{md}-\mathrm{ft}$. For the same sized bauxite with a damage factor of 0.85 , the average conductivity increased to $1113 \mathrm{md}-\mathrm{ft}$. For proppants of the same grain size, the average conductivity increases with an increasing damage factor.

For proppants with the same damage factor, the average fracture conductivity increased with increasing mesh size for proppants. For sand with a damage factor of 0.70 , the average conductivity is $470 \mathrm{md}-\mathrm{ft}$ for the $20-40$ mesh ( 0.066 in $-0.033 \mathrm{in})$. The average conductivity increases to $1019 \mathrm{md}-\mathrm{ft}$ for $16-30 \mathrm{mesh}(0.047 \mathrm{in}-0.023 \mathrm{in})$ and to $1377 \mathrm{md}-\mathrm{ft}$ for $12-20 \mathrm{mesh}$ (0.033 in -0.017 in) (Figure 92).

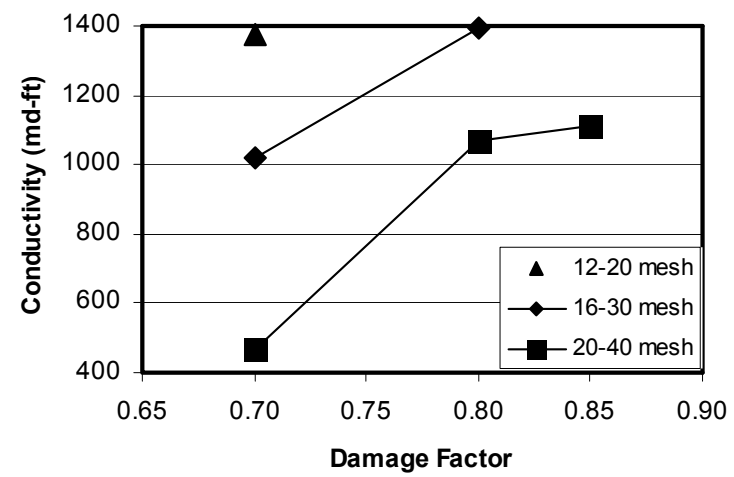

Figure 92 Average fracture conductivity as a function of damage factor for different sized proppants.

\section{$\underline{1500 \mathrm{ft} \text { Fracture }}$}

A simulation was set up to create a fracture where the ideal half-length length was five times the thickness of the formation. For this case, all of the variables were the same as the baseline case with the exception of a pumping schedule intended to create at least a $1500 \mathrm{ft}$ fracture half-length. This simulation resulted in a fracture with a half-length of $1731 \mathrm{ft}$ and a vertical growth of $591 \mathrm{ft}$ at the wellbore (Figure 93). The fracture intrudes more than $300 \mathrm{ft}$ into the upper layer out to a horizontal distance of $255 \mathrm{ft}$ where the intrusion height decreases to 50 $\mathrm{ft}$. The intrusion into the upper layer is $20 \mathrm{ft}$ beyond $700 \mathrm{ft}$ from the well bore. The pressurized 
width of the fracture is greater than 0.4 in for the limestone formation out to a distance of $200 \mathrm{ft}$ from the well bore. The fracture width decreases with length but the average width is greater than 0.19 in out to $1250 \mathrm{ft}$ from the well bore.
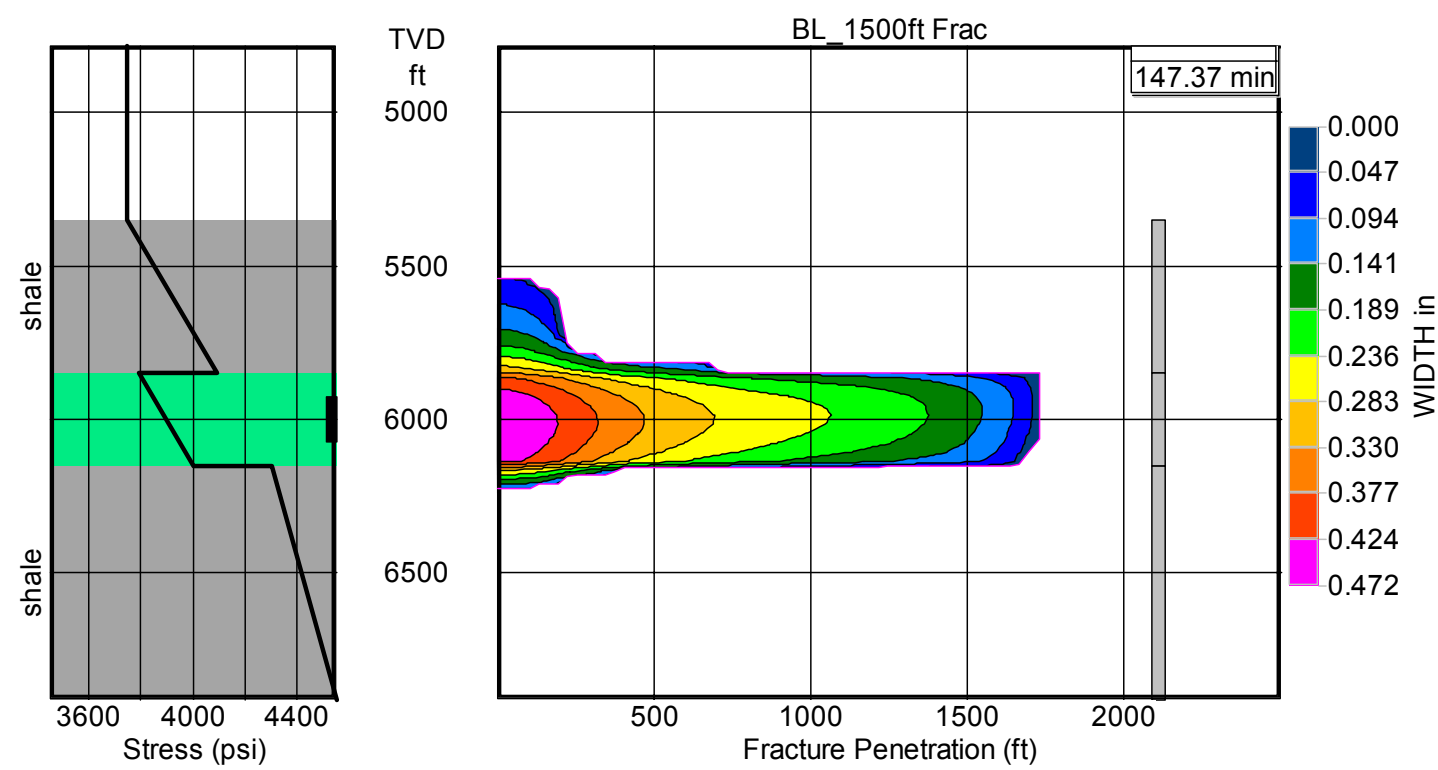

Figure 93 Fracture width for a fracture with a half-length greater than $1500 \mathrm{ft}$ in a $300 \mathrm{ft}$ thick limestone layer

The cross section of fracture width at the borehole is tear-drop shaped with a maximum width of 0.48 in at a depth of $6000 \mathrm{ft}$. The fracture width is generally greater than $0.40 \mathrm{in}$ throughout the limestone formation but decreases as the fracture approaches the adjacent layer (Figure 94). The cross section is triangular-shaped in the upper formation, decreasing in width and reaching a maximum height at $5524 \mathrm{ft}$. There is less intrusion into the lower layer than into the upper one. The predicted fracture intrudes $60 \mathrm{ft}$ into the lower layer and $362 \mathrm{ft}$ into the upper layer.

The fracture length that remains propped at closure is $915 \mathrm{ft}$, approximately $50 \%$ of the total half-length $(1731 \mathrm{ft})$. The effective width of the propped fracture is 0.223 in in the vicinity of the perforated interval, tapering to a closed fracture with no proppant $915 \mathrm{ft}$ from the borehole (Figure 95). The large dark blue area (Figure 95) indicates that the region was fractured during injection, but was not filled with proppant. At fracture closure, this area is held open only by asperities on the fracture wall. 


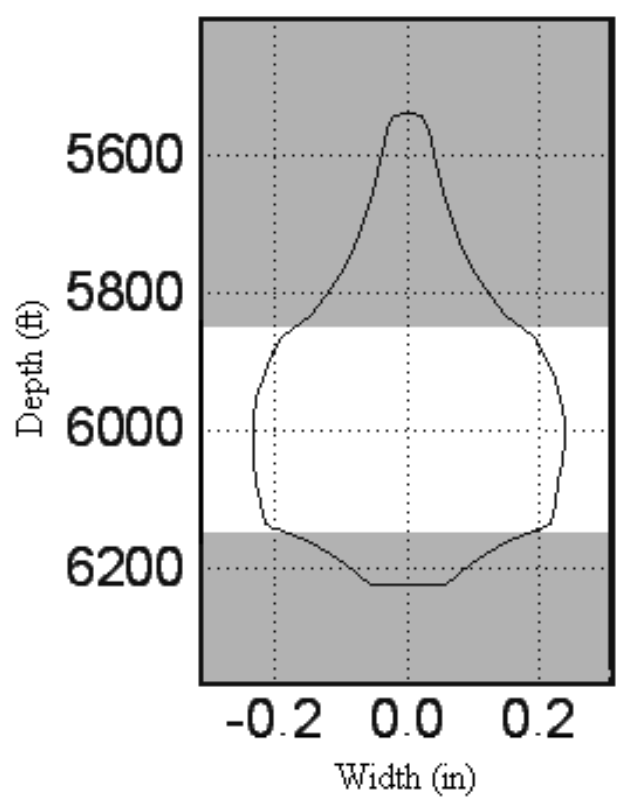

Figure 94 Cross section of fracture width at the well bore for the $1500 \mathrm{ft}$ fracture case. The grey area represents the shale layers.
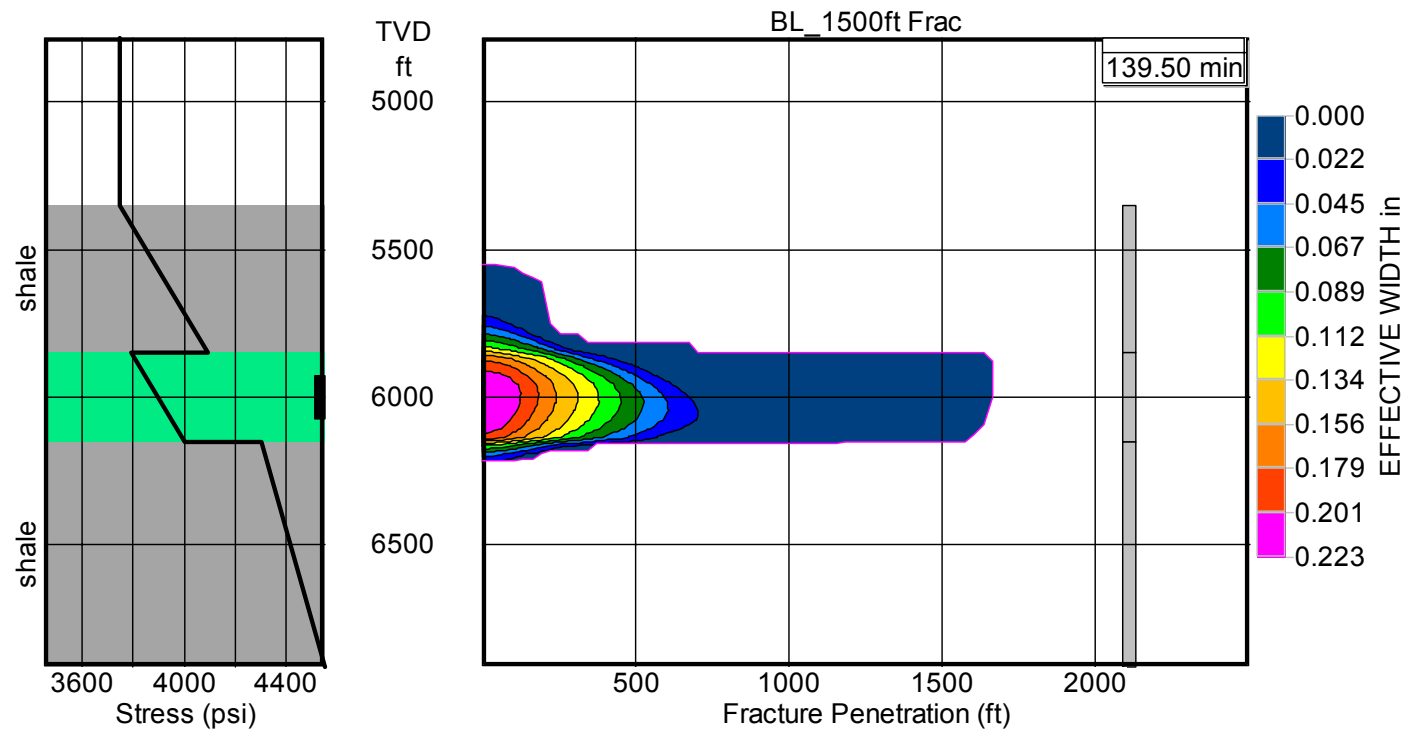

Figure 95 Effective width for a proposed $1500 \mathrm{ft}$ fracture in a $300 \mathrm{ft}$ thick limestone formation.

The average conductivity for the " $1500 \mathrm{ft}$ " fracture is $405 \mathrm{md}-\mathrm{ft}$, but the distribution of conductivity is variable throughout the fracture (Figure 96). There is a region of higher conductivity around the initiation area where the conductivity is greater than $1700 \mathrm{md}-\mathrm{ft}$ out to an approximate horizontal distance of $130 \mathrm{ft}$ from the well bore. Beyond $130 \mathrm{ft}$ the fracture conductivity decreases away from the well bore and is less than $213 \mathrm{md}-\mathrm{ft}$ in the dark blue region (Figure 96). The region of the fracture where conductivity is greater than $213 \mathrm{md}-\mathrm{ft}$ is delta-shaped, penetrating into the upper and lower adjacent formations. 

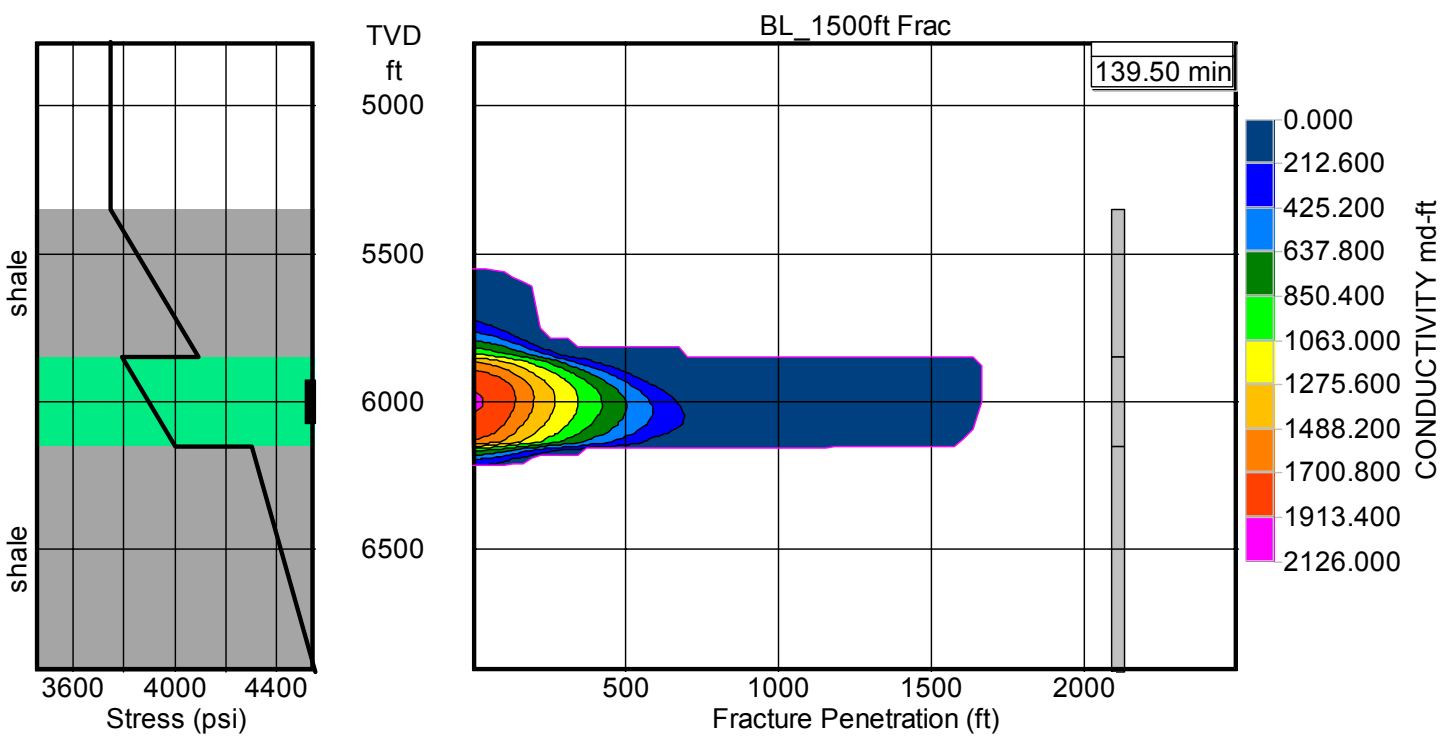

Figure 96 Conductivity for a $1500 \mathrm{ft}$ fracture in a $300 \mathrm{ft}$ limestone formation

\section{$\underline{30 \mathrm{ft} \text { Fracture }}$}

A simulation was set up to create a fracture where the ideal half- length was one fifth the thickness of the formation. For this case, all of the variables were the same as the baseline case with the exception of a pumping schedule intended to create at least a $30 \mathrm{ft}$ fracture. This situation resulted in a fracture that penetrated $47 \mathrm{ft}$ into the limestone formation and had a vertical growth of $184 \mathrm{ft}$ at the well bore (Figure 97). The fracture was contained within the limestone formation with $56 \mathrm{ft}$ of clearance between the overlying formation and $59 \mathrm{ft}$ of clearance between the underlying formation. The pressurized fracture width is 0.134 in near the well bore and decreases rapidly to fracture closure at $47 \mathrm{ft}$ (Figure 97).

The cross section of the fracture is roughly oval shaped at the bore hole (Figure 98). The fracture reaches a maximum upward growth at a depth of $5909 \mathrm{ft}$ and the maximum downward growth is reached a $6091 \mathrm{ft}$. The maximum pressurized width is 0.14 in at a depth of $6000 \mathrm{ft}$ (Figure 98).

The fracture length that remains propped at closure after injection pressure decreases is $23 \mathrm{ft}$, approximately $50 \%$ of the penetrated half length $(47 \mathrm{ft})$. The effective width of the propped fracture is 0.047 in near the center of the perforated interval, tapering to a closed fracture with no proppant $23 \mathrm{ft}$ from the borehole (Figure 99). 

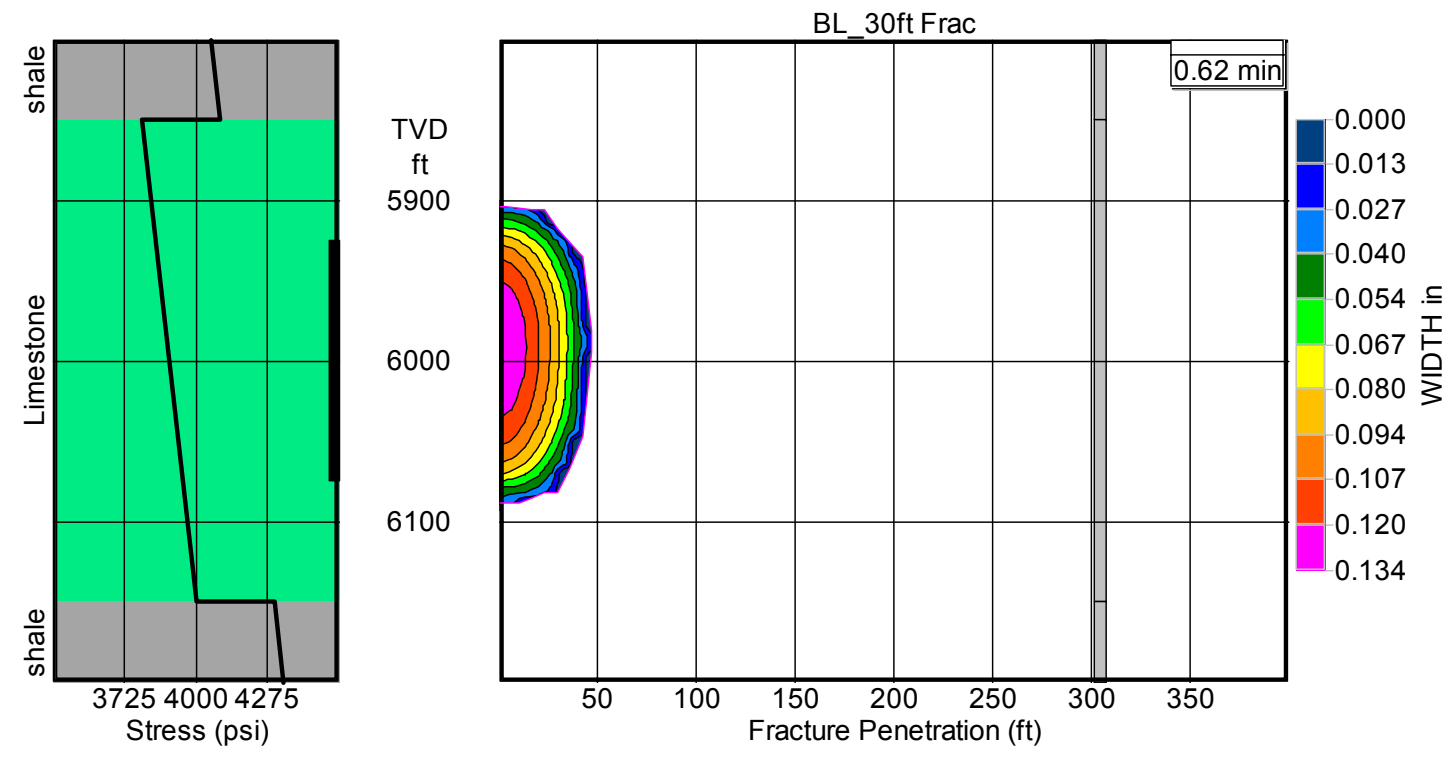

Figure 97 Contour plot of pressurized width (in) for a proposed $30 \mathrm{ft}$ fracture in a $300 \mathrm{ft}$ thick limestone formation.

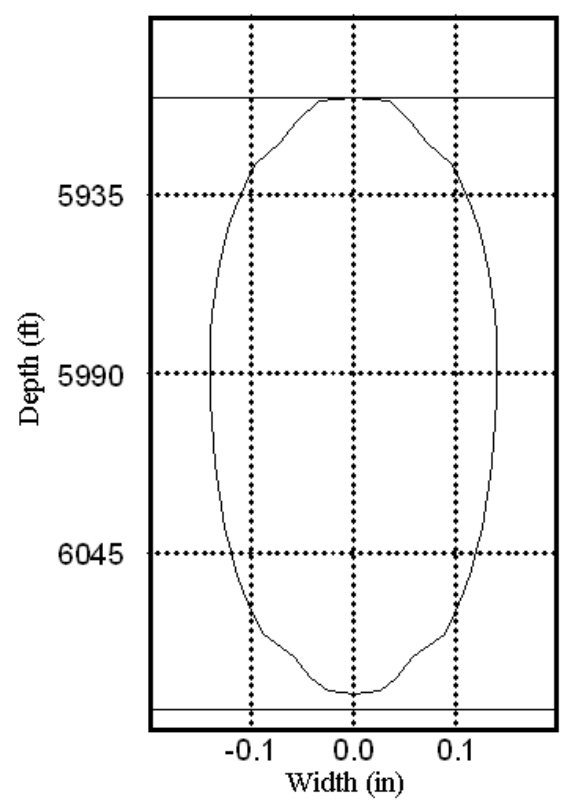

Figure 98 Cross section of fracture width for $30 \mathrm{ft}$ target fracture. 

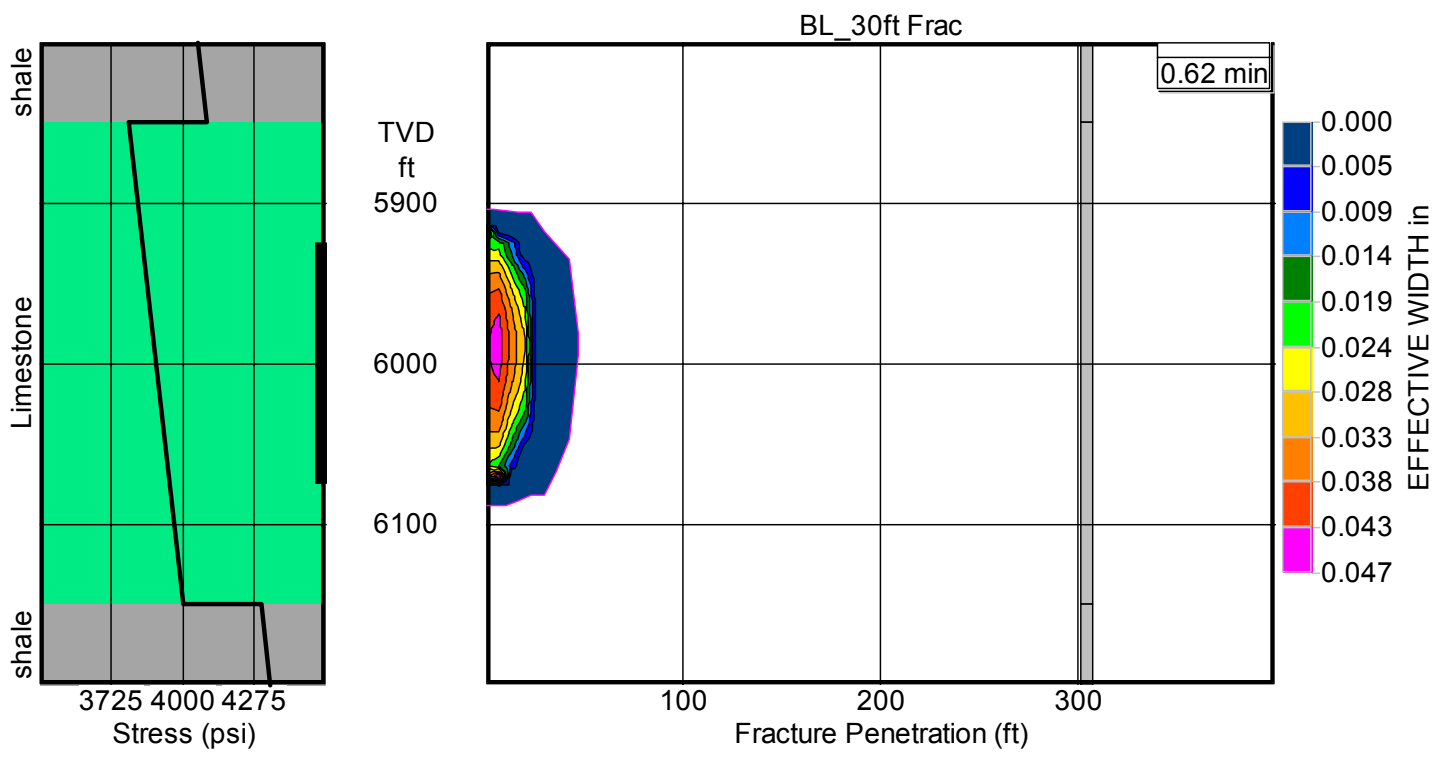

Figure 99 Effective width (in) for a proposed $30 \mathrm{ft}$ fracture in a $300 \mathrm{ft}$ limestone formation.

The average conductivity for the proposed $30 \mathrm{ft}$ fracture is $143 \mathrm{md}-\mathrm{ft}$. There is a small region of relatively high conductivity ( $408 \mathrm{md}-\mathrm{ft}$ ) near the center of the perforated interval, but it decreases rapidly and the conductivity is less than $40 \mathrm{md}-\mathrm{ft}$ only $23 \mathrm{ft}$ from the well bore (Figure 100). Overall, the fracture conductivity for the $30 \mathrm{ft}$ fracture case is less than the baseline case.
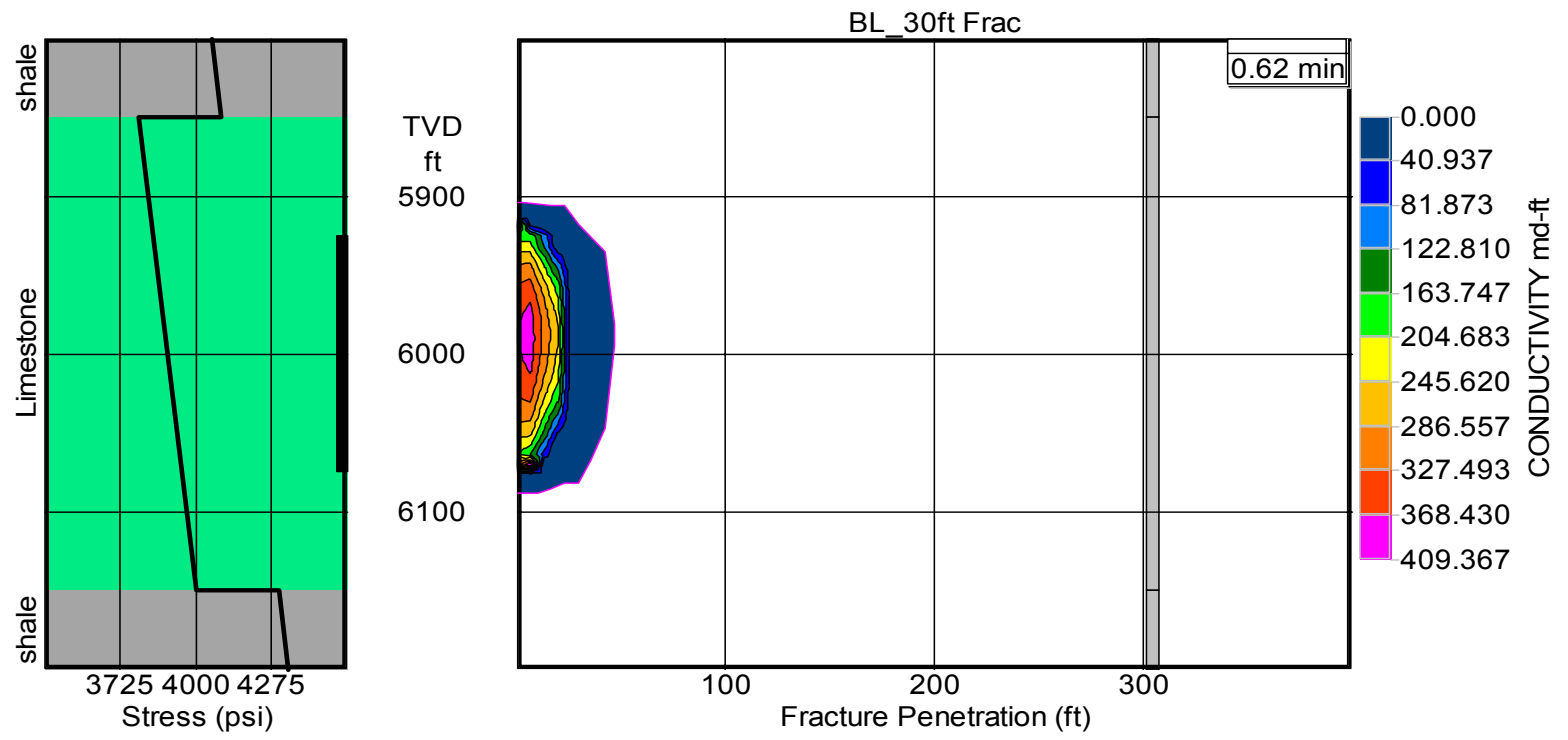

Figure 100 Conductivity for a proposed $30 \mathrm{ft}$ fracture in a $300 \mathrm{ft}$ limestone formation 


\section{Adjacent Layer 1 Foot Thick}

The simulation of a fracture in a 300-ft-thick limestone formation bounded by shale layers $1 \mathrm{ft}$ thick results in a fracture with a half-length of $384 \mathrm{ft}$ with a propped length of $255 \mathrm{ft}$ and an average conductivity of $120 \mathrm{md}-\mathrm{ft}$ (Figure 101). The maximum fracture height at the wellbore is $594 \mathrm{ft}$ and the fracture completely breaches the shale layer. There is an increase in the conductivity around the shale layers (Figure 101).
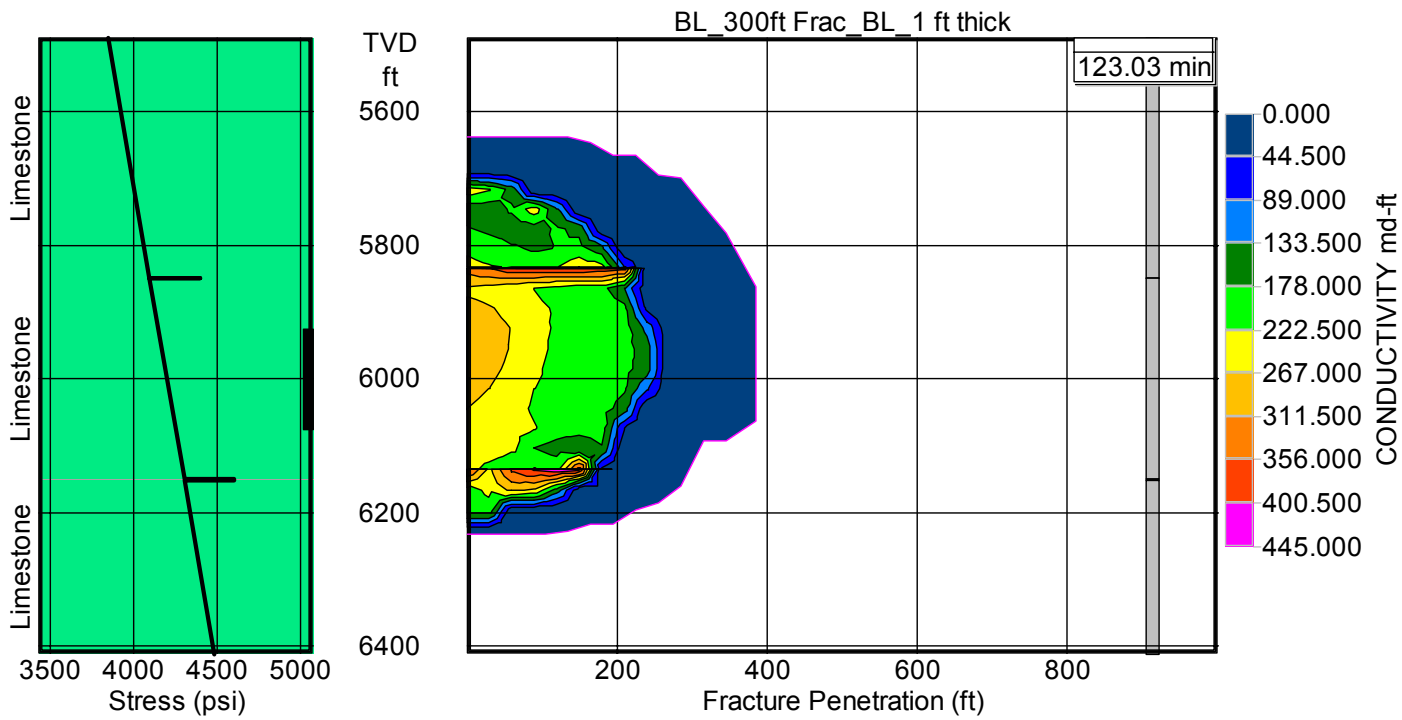

Figure 101 Conductivity for fracture simulated in $300 \mathrm{ft}$ thick limestone formation with $1 \mathrm{ft}$ thick adjacent layer

The cross section of fracture width for a fracture in a $300 \mathrm{ft}$ thick limestone formation bounded by shale layers $1 \mathrm{ft}$ thick is roughly oval shaped with indentations in the oval occurring near the shale layers (Figure 102). The fracture extends about $122 \mathrm{ft}$ above the upper shale layer and approximately $36 \mathrm{ft}$ below the lower shale layer. The maximum pressurized width is 0.28 in at a depth of $6000 \mathrm{ft}$ (Figure 102).

Compared to a simulation where the limestone thickness is $1500 \mathrm{ft}$ and there is clearance between the fracture and the adjacent layer (Figure 84), the effect of the $1 \mathrm{ft}$ shale layer is more apparent. The conductivity contours in the $1500 \mathrm{ft}$ formation are relatively smooth curves that radiate out from the perforated interval with a gradual, uniform decrease in fracture conductivity (Figure 84). For the simulation of a fracture in a $300 \mathrm{ft}$ limestone formation with a $1 \mathrm{ft}$ thick adjacent layer, the conductivity distribution is inconsistent with regions of higher conductivity in the vicinity of the shale layers (Figure 101). 


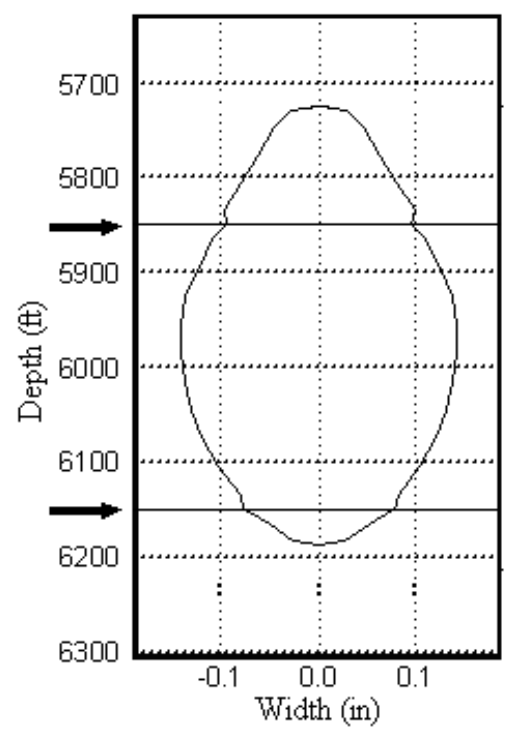

Figure 102 Cross section of fracture width for a fracture simulated in a $300 \mathrm{ft}$ thick limestone formation with a $1 \mathrm{ft}$ thick adjacent layer. Lines indicated by arrows represent the shale layer.

\section{$\underline{\text { Adjacent Layer } 10 \text { Feet Thick }}$}

The simulation of a fracture in a 300 -ft-thick limestone formation bounded by shale layers $10 \mathrm{ft}$ thick results in a fracture with a half-length of $379 \mathrm{ft}$ with a propped length of $255 \mathrm{ft}$ and an average conductivity of $115 \mathrm{md}-\mathrm{ft}$ (Figure 103). The maximum fracture height at the wellbore is $631 \mathrm{ft}$ and the fracture completely breaches the shale layer. There is a region of higher conductivity near the perforated interval that extends into a lobe that is bounded by the upper shale layer (Figure 103).

The cross section of fracture width in a $300 \mathrm{ft}$ thick limestone formation bounded by shale layers $10 \mathrm{ft}$ thick is roughly oval shaped within the limestone formation. When the fracture encounters the upper shale layer, the fracture width is reduced $20 \%$ from 0.2 to 0.16 in. Above the shale layer the fracture width increases to 0.18 in and closes in an arch shape that extends $110 \mathrm{ft}$ into the layer above the shale (Figure 104). When the fracture crosses the lower shale layer, the change in fracture width is less than across the upper layer. However, the width continues to decrease below the shale layer with the fracture penetrating $64 \mathrm{ft}$ into the formation underlying the shale layer. The maximum pressurized width is 0.29 in at a depth of $6000 \mathrm{ft}$ (Figure 104). 

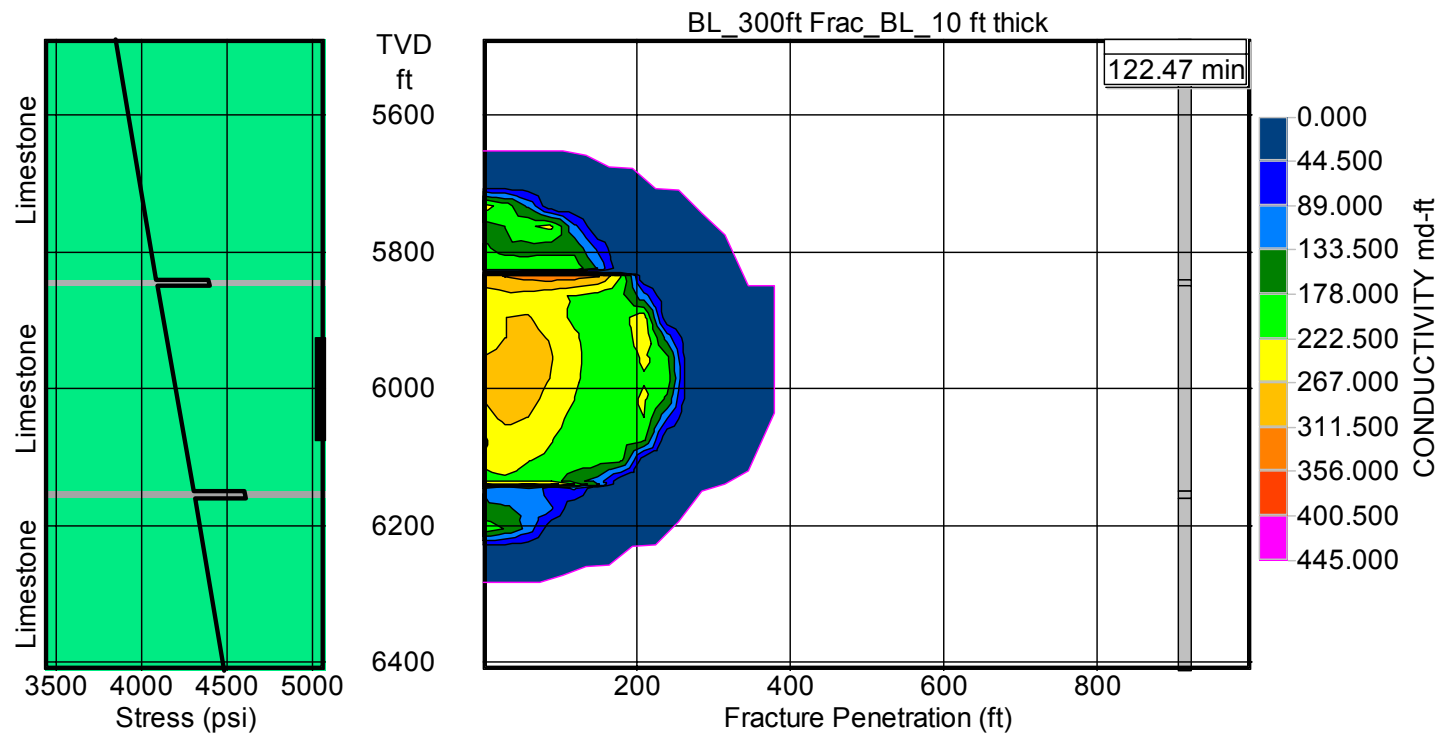

Figure 103 Conductivity for fracture simulated in $300 \mathrm{ft}$ thick limestone formation with $10 \mathrm{ft}$ thick adjacent layer

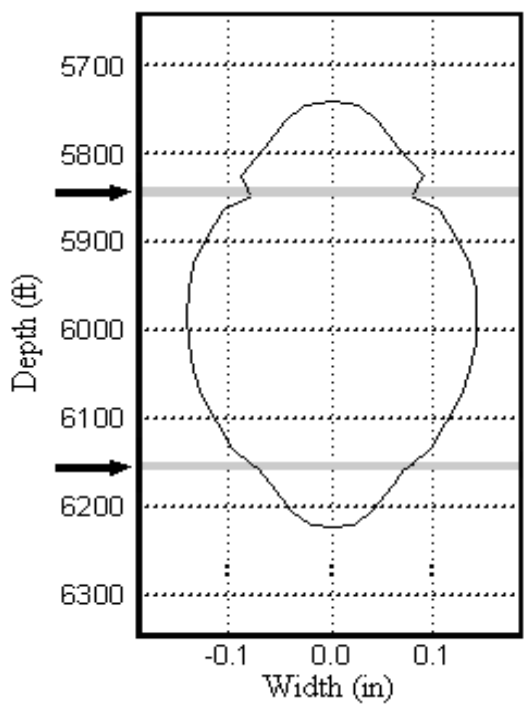

Figure 104 Cross section of fracture width for a fracture simulated in a $300 \mathrm{ft}$ thick limestone formation with a $10 \mathrm{ft}$ thick adjacent layer. Grey lines indicated by arrows represent the shale layer.

\section{Adjacent Layer 25 Feet Thick}

The simulation of a fracture in a $300 \mathrm{ft}$ thick limestone formation bounded by shale layers $25 \mathrm{ft}$ thick results in a fracture with a half-length of $427 \mathrm{ft}$ with a propped length of $285 \mathrm{ft}$ and an average conductivity of $118 \mathrm{md}-\mathrm{ft}$ (Figure 105). The maximum fracture height at the wellbore is $578 \mathrm{ft}$ and the fracture completely breaches the shale layer. There is a region of higher 
conductivity near the perforated interval that extends into a lobe that is bounded by the upper shale layer, as well as an area of increased conductivity near the tip of the propped length (Figure 105).
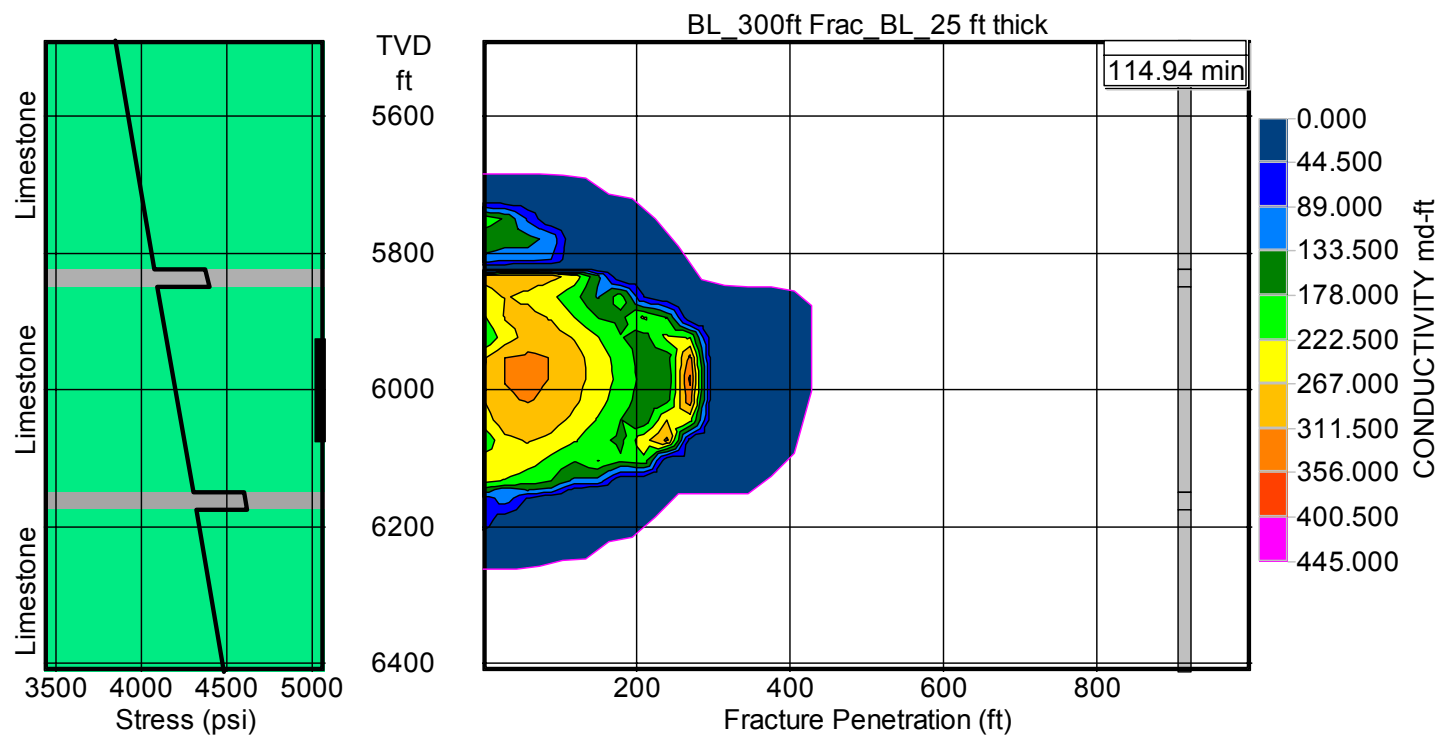

Figure 105 Conductivity for fracture simulated in $300 \mathrm{ft}$ thick limestone formation with 25 $\mathrm{ft}$ thick shale adjacent layers

The cross section of fracture width for a fracture in a $300 \mathrm{ft}$ thick limestone formation bounded by shale layers $25 \mathrm{ft}$ thick is roughly oval shaped within the limestone formation. When the fracture interacts with the upper shale layer, the fracture width is reduced by $50 \%$ from 0.2 to 0.10 in. Above the shale layer the fracture width increases to 0.14 in and closes in an arch shaped that extends $66 \mathrm{ft}$ into the layer above the shale (Figure 106). When the fracture crosses the lower shale layer, the fracture width is reduced from 0.20 to 0.09 in and continues to decrease below the shale layer. The fracture propagates $42 \mathrm{ft}$ into the formation that is below the shale layer. The maximum pressurized width is 0.30 in at a depth of $6000 \mathrm{ft}$ (Figure 106).

\section{$\underline{\text { Adjacent Layer } 50 \text { Feet Thick }}$}

The simulation of a fracture in a $300 \mathrm{ft}$ thick limestone formation bounded by shale layers $50 \mathrm{ft}$ thick results in a fracture with a half-length of $486 \mathrm{ft}$ with a propped length of $354 \mathrm{ft}$ and an average conductivity of $149 \mathrm{md}-\mathrm{ft}$ (Figure 107). The maximum fracture height at the wellbore is $427 \mathrm{ft}$ and the fracture completely breaches the shale layer. The conductivity distribution is relatively uniform with a region of higher conductivity near the perforated interval that decreases away from the well. There is also a region of increased conductivity near the tip of the propped length (Figure 107). 


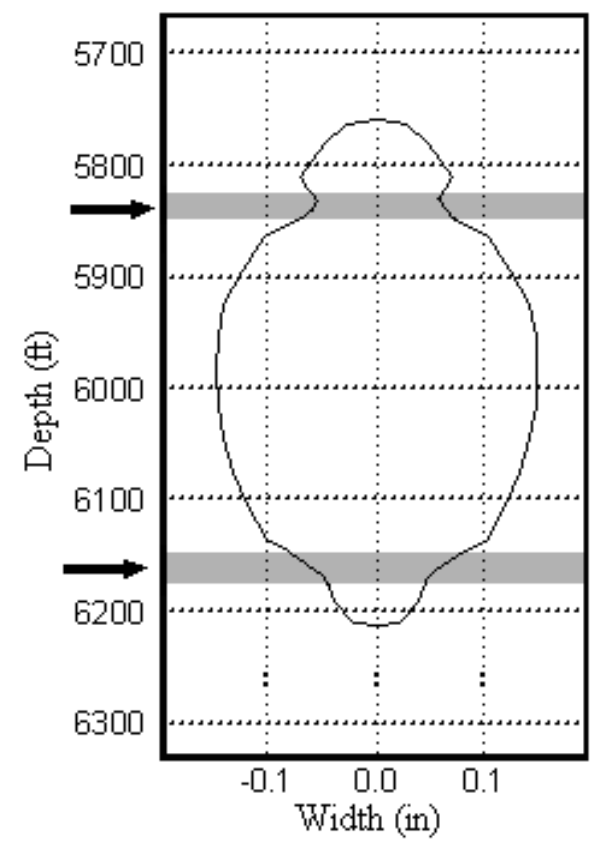

Figure 106 Cross section of fracture width for a fracture simulated in a $300 \mathrm{ft}$ thick limestone formation with a $25 \mathrm{ft}$ thick adjacent layer. Grey lines indicated by arrows represent the shale layer.
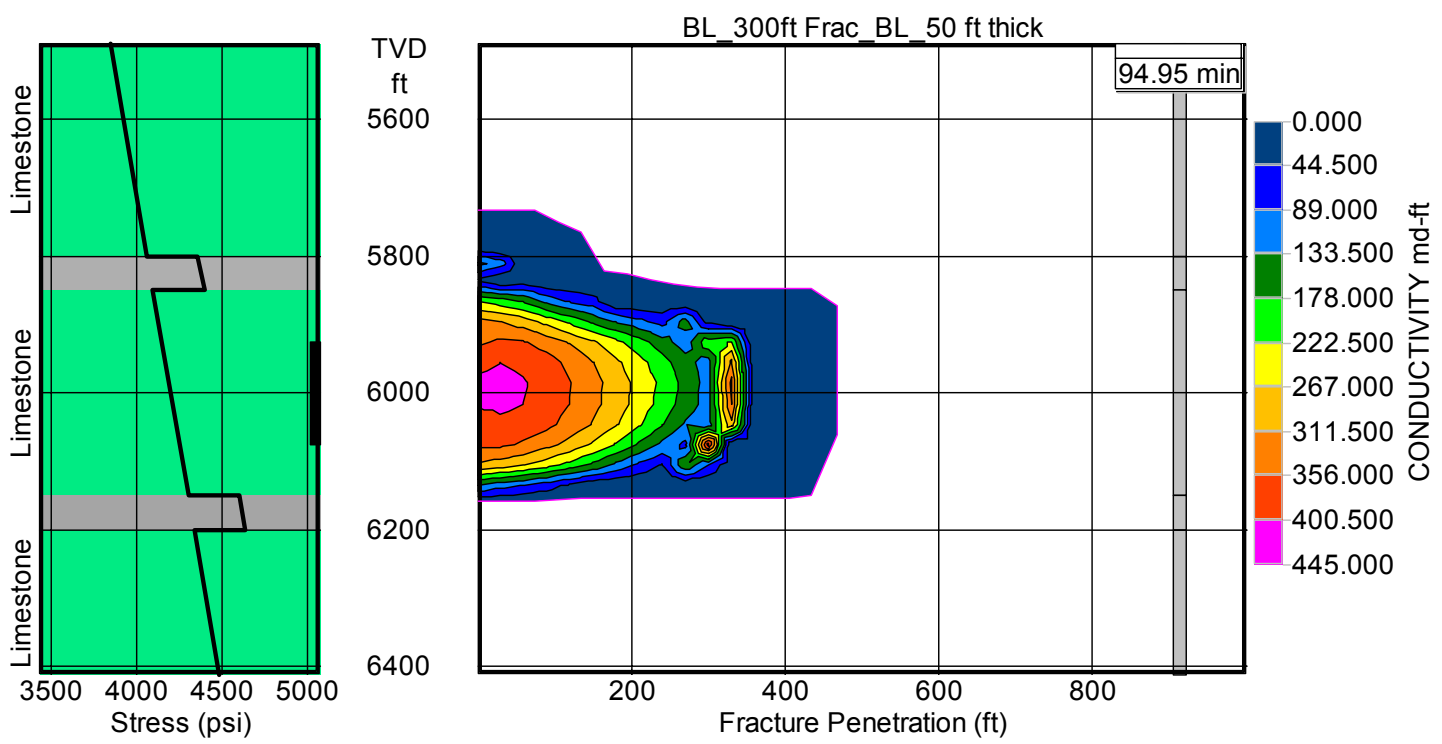

Figure 107 Conductivity for fracture simulated in $300 \mathrm{ft}$ thick limestone formation with $50 \mathrm{ft}$ thick shale layers

The cross section of fracture width for a fracture in a $300 \mathrm{ft}$ thick limestone formation bounded by shale layers $50 \mathrm{ft}$ thick is roughly oval shaped within the limestone formation (Figure 108). As the fracture approaches the lower shale layer, the curve flattens, penetrating $7 \mathrm{ft}$ into the lower layer. When the fracture interacts with the upper shale layer, the fracture width 
reduces from 0.2 in to 0.06 in $50 \mathrm{ft}$ above the contact between the shale and the limestone. Above the shale layer the fracture width increases to 0.08 in and closes at a peak $30 \mathrm{ft}$ into the layer above the shale (Figure 108). The maximum pressurized width is 0.31 in at a depth of 6000 $\mathrm{ft}$.

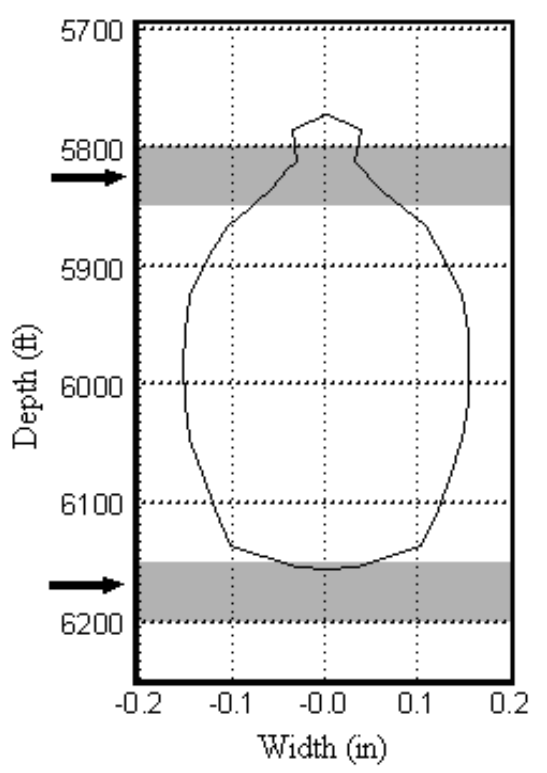

Figure 108 Cross section of fracture width for a fracture simulated in a $300 \mathrm{ft}$ thick limestone formation with a $50 \mathrm{ft}$ thick adjacent layer. Grey lines indicated by arrows represent the shale layer.

\section{Adjacent Layer 75 Feet Thick}

The simulation of a fracture in a 300-ft-thick limestone formation bounded by shale layers $75 \mathrm{ft}$ thick results in a fracture with a half-length of $482 \mathrm{ft}$, a propped length of $345 \mathrm{ft}$, and an average conductivity of $149 \mathrm{md}-\mathrm{ft}$ (Figure 109). The maximum fracture height at the wellbore is $344 \mathrm{ft}$, and the fracture is contained within the shale layer. The conductivity distribution is relatively uniform with a region of higher conductivity near the perforated interval that decreases away from the well. There is also an area of increased conductivity near the tip of the propped length (Figure 109).

The cross section of fracture width for a fracture in a $300 \mathrm{ft}$ thick limestone formation bounded by shale layers $75 \mathrm{ft}$ thick is roughly oval shaped within the limestone formation (Figure 110). As the fracture approaches the lower shale layer, the curve becomes flatter, penetrating $11 \mathrm{ft}$ into the lower layer. As the fracture interacts with the top layer, the curve of the fracture gets tighter and terminates approximately $42 \mathrm{ft}$ above the limestone shale interface. This leaves $33 \mathrm{ft}$ of clearance between the upper fracture terminus and the layer above the shale. The maximum pressurized width is 0.31 in at a depth of $6000 \mathrm{ft}$ (Figure 110). 

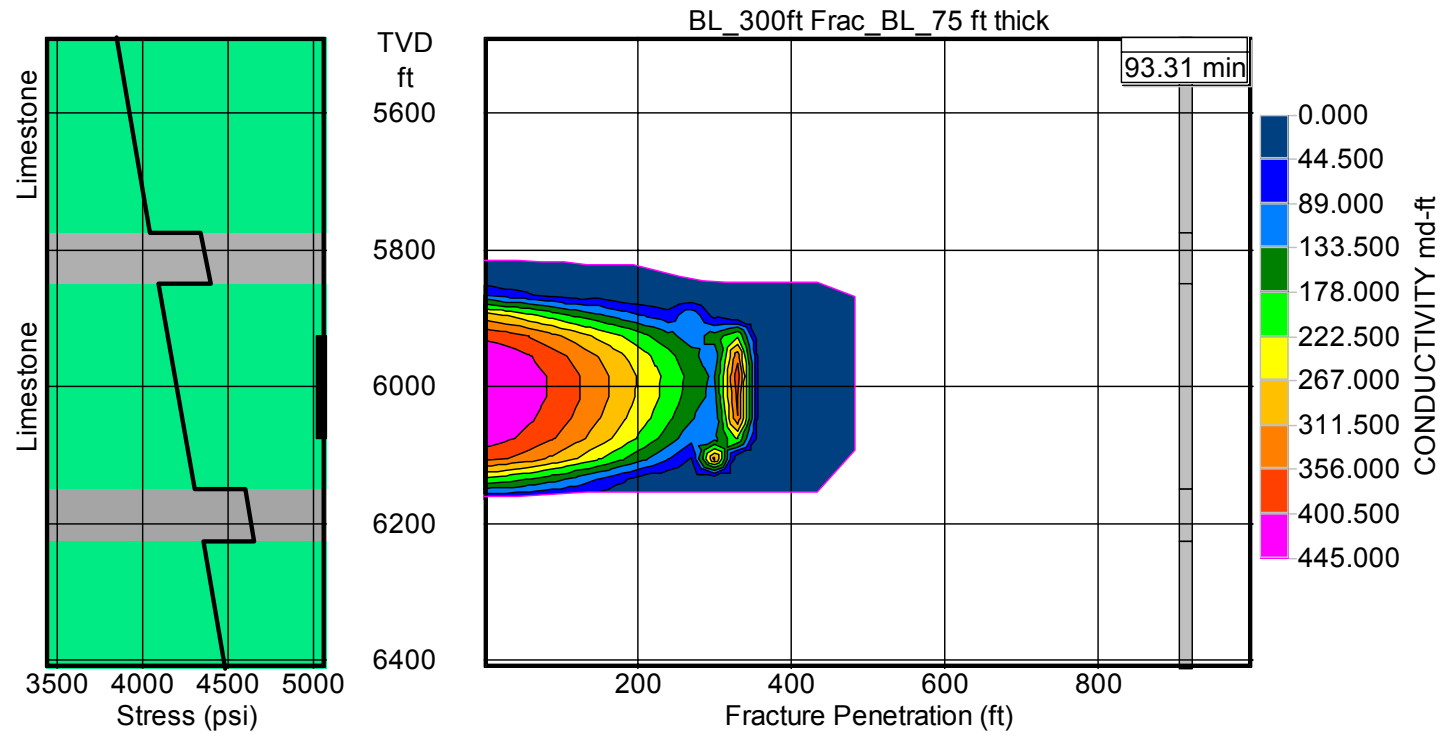

Figure 109 Conductivity for fracture simulated in $300 \mathrm{ft}$ thick limestone formation with $50 \mathrm{ft}$ thick shale layers

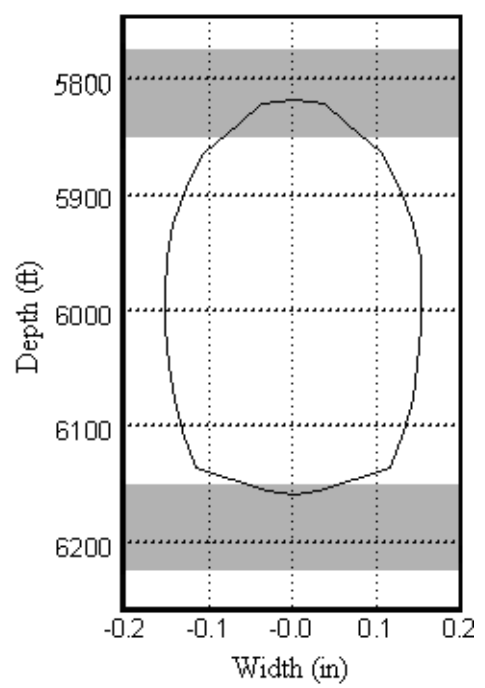

Figure 110 Cross section of fracture width for a fracture simulated in a $300 \mathrm{ft}$ thick limestone formation with a $75 \mathrm{ft}$ thick adjacent layers. Grey boxes represent the shale layers.

\section{$\underline{\text { Adjacent Layer } 100 \text { Feet Thick }}$}

The simulation of a fracture in a $300 \mathrm{ft}$ thick limestone formation bounded by shale layers $100 \mathrm{ft}$ thick results in a fracture with a half-length of $469 \mathrm{ft}$ with a propped length of $345 \mathrm{ft}$ and an average conductivity of $156 \mathrm{md}-\mathrm{ft}$ (Figure 111). The maximum fracture height at the wellbore is $352 \mathrm{ft}$ and the fracture is contained within the shale layer. The conductivity 
distribution is relatively uniform with a circular region of higher conductivity near the perforated interval that decreases away from the well. There is also a lobe of increased conductivity near the tip of the propped length (Figure 111).
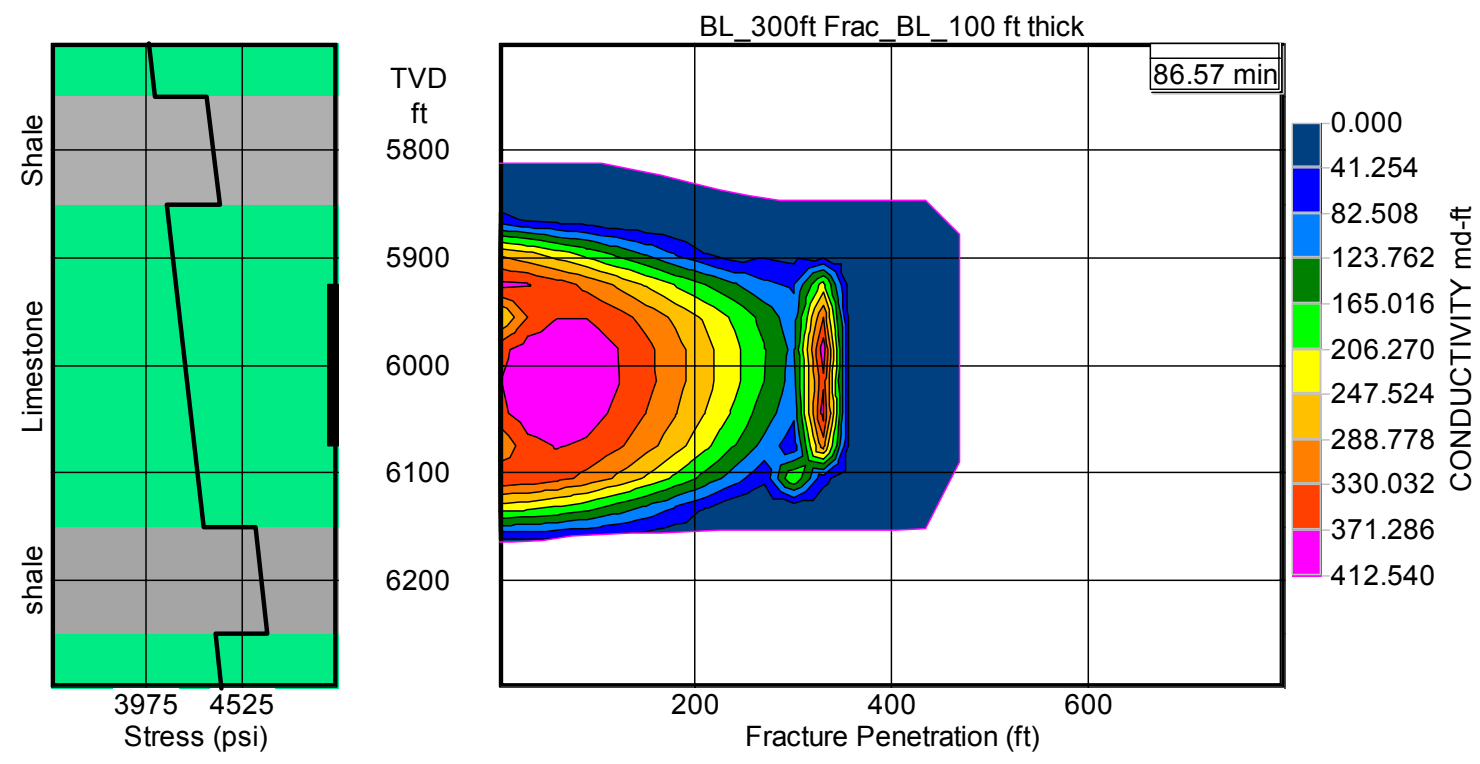

Figure 111 Contour plot of conductivity for fracture simulated in $300 \mathrm{ft}$ thick limestone formation with $100 \mathrm{ft}$ thick shale layers

The cross section of fracture width for a fracture in a $300 \mathrm{ft}$ thick limestone formation bounded by shale layers $100 \mathrm{ft}$ thick is roughly egg shaped within the limestone formation (Figure 112). As the fracture approaches the lower shale layer, the curve becomes flatter, penetrating only 12 $\mathrm{ft}$ into the lower layer. As the fracture interacts with the top layer, the curve of the fracture gets tighter and terminates approximately $18 \mathrm{ft}$ above the limestone shale interface. This leaves $82 \mathrm{ft}$ of clearance between the upper fracture terminus and the layer above the shale. The maximum pressurized width is 0.31 in at a depth of $6000 \mathrm{ft}$ (Figure 112).

\section{Adjacent Layer 150 Feet Thick}

The simulation of a fracture in a $300 \mathrm{ft}$ thick limestone formation bounded by shale layers $150 \mathrm{ft}$ thick results in a fracture with a half-length of $475 \mathrm{ft}$ with a propped length of $345 \mathrm{ft}$ and an average conductivity of $149 \mathrm{md}-\mathrm{ft}$ (Figure 113). The maximum fracture height at the wellbore is $361 \mathrm{ft}$ and the fracture is contained within the shale layer. The conductivity distribution is relatively uniform with a circular region of higher conductivity near the perforated interval that decreases away from the well. There is also a lobe of increased conductivity near the tip of the propped length (Figure 113). 


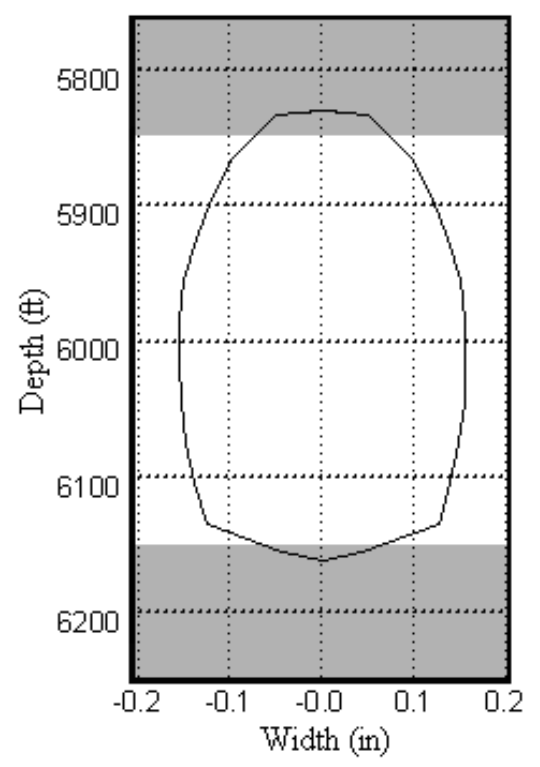

Figure 112 Cross section of fracture width for a fracture simulated in a $300 \mathrm{ft}$ thick limestone formation with a $100 \mathrm{ft}$ thick adjacent layers. Grey boxes represent the shale layers.
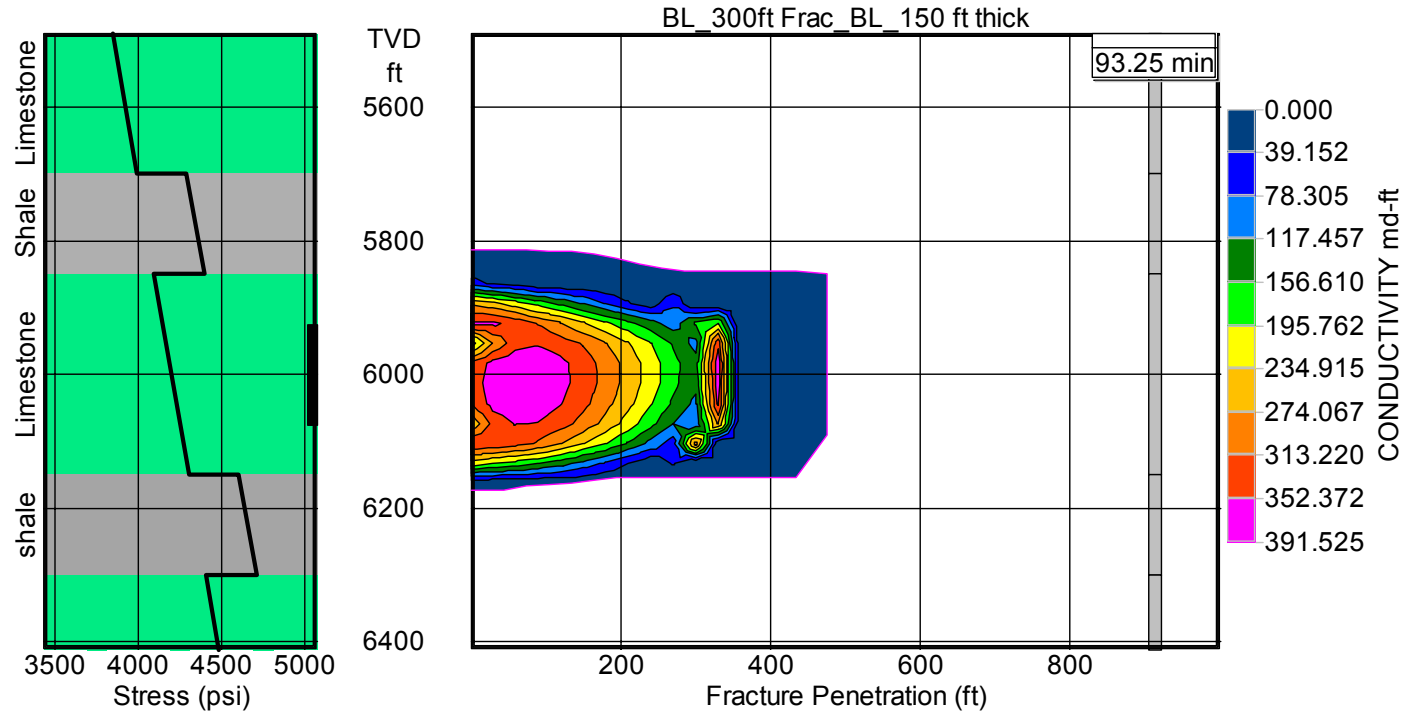

Figure 113 Conductivity for fracture simulated in $300 \mathrm{ft}$ thick limestone formation with $150 \mathrm{ft}$ thick shale layers

The cross section of fracture width for a fracture in a $300 \mathrm{ft}$ thick limestone formation bounded by shale layers $150 \mathrm{ft}$ thick is roughly egg shaped within the limestone formation (Figure 114). As the fracture approaches the lower shale layer, the curve becomes flatter, intruding only $13 \mathrm{ft}$ into the lower layer. As the fracture interacts with the top layer, the curve of the fracture gets tighter and terminates approximately $19 \mathrm{ft}$ above the limestone-shale interface. This leaves $131 \mathrm{ft}$ 
of clearance between the upper fracture terminus and the layer above the shale. The maximum pressurized width is 0.31 in at a depth of $6000 \mathrm{ft}$ (Figure 114).

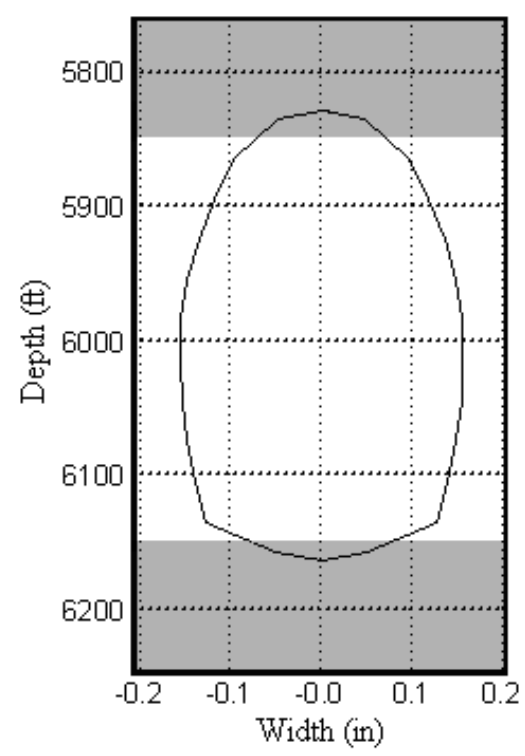

Figure 114 Cross section of fracture width for a fracture simulated in a $300 \mathrm{ft}$ thick limestone formation with a $150 \mathrm{ft}$ thick adjacent layer. Grey boxes represent the shale laver.

\section{$\underline{\text { Adjacent Layer Thickness }}$}

Variations in the thickness of the adjacent layers $(1 \mathrm{ft}, 10 \mathrm{ft}, 25 \mathrm{ft}, 50 \mathrm{ft}, 75 \mathrm{ft}, 100 \mathrm{ft}, 150$ $\mathrm{ft}$ and $200 \mathrm{ft}$ ) were simulated to predict the effects of adjacent formation thickness on fracture height. As the thickness of the adjacent layers increases, the total fracture height decreases (Figure 115). There is a steep decrease in fracture height as the adjacent layer thickness increases from $1 \mathrm{ft}$ to $75 \mathrm{ft}$ and there is less variation in the total fracture height at adjacent formation thicknesses greater than $75 \mathrm{ft}$ (Figure 115).

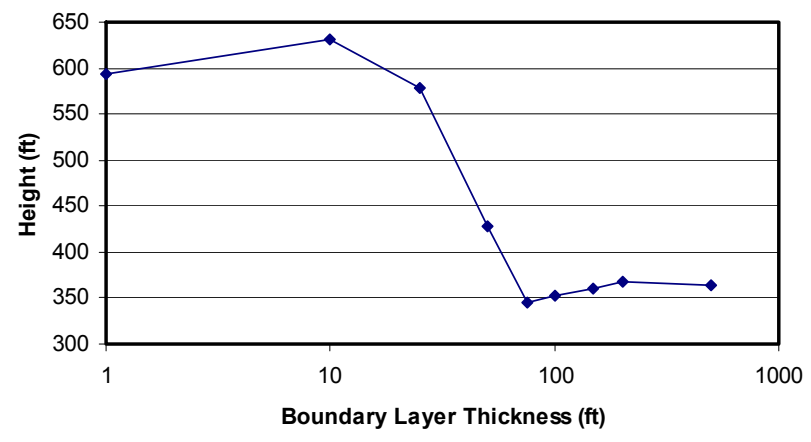

Figure 115 Total vertical fracture height at well bore for variations in adjacent layer thickness 
Intrusion into the upper layers as a result of variations in adjacent layer thickness has a similar trend. There is a steep decrease in vertical growth up to a 75-ft-thick adjacent layer with less variation when the adjacent layer thickness is greater than $75 \mathrm{ft}$ (Figure 116). The fracture completely breaches the adjacent layer and intrudes into the formation above the adjacent layer for thickness less than $75 \mathrm{ft}$. When the adjacent layer thickness is $75 \mathrm{ft}$ or greater, there is clearance between the fracture and the limestone above the adjacent layer that increases with increasing thickness (Figure 118).

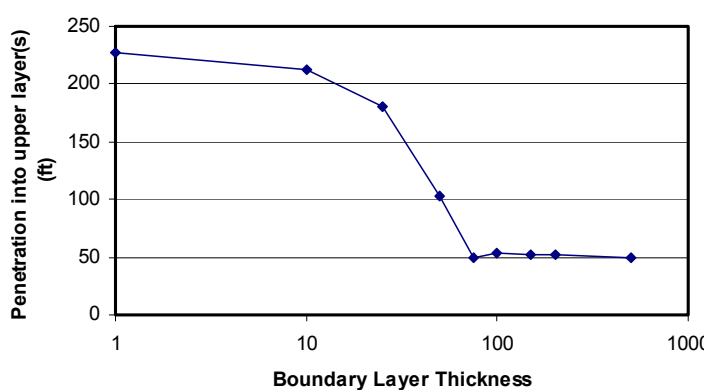

Figure 116 Fracture intrusion into upper formations as function of adjacent layer thickness

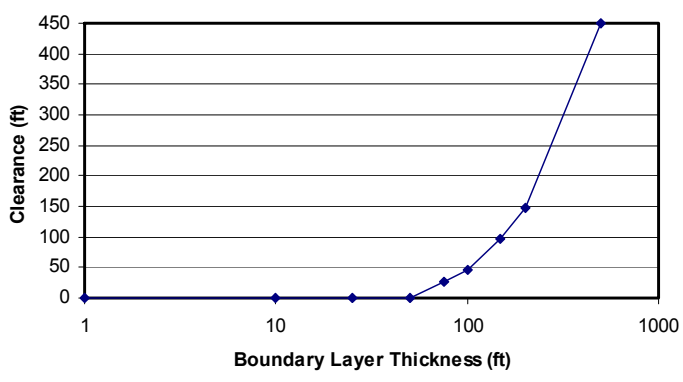

Figure 118 Clearance between material overlying the upper layer and upper fracture tip as a function of adjacent layer thickness

\section{Summary of Fracture Modeling Results}

Simulations of hydraulic fractures in limestone were conducted using a range of parameters representing expected conditions at a site for the creation of a gas storage facility by acid dissolution. Results indicate the typical characteristics for a baseline case, as well as ranges of fracture characteristics based on the expected parameters (Table 47). The simulations demonstrate how hydraulic fracturing can increase conductivity in a formation, and what factors influence fracture characteristics. Inherent properties such as the stratigraphy and in-situ stress for the rock layers have a significant impact on the resulting fracture characteristics. Whereas other factors such as perforated interval, pumping schedule, pumping rate, proppant and fracturing fluid can be modified to influence the predicted fracture geometry. The data presented in this report demonstrate the influence of different parameters on fracture characteristics and estimate fracture characteristics expected in typical limestone formations. Prior to any fracturing job, detailed information about the physical characteristics and stratigraphy of the site should be collected and simulations should be run in order to predict the ideal pumping schedule and slurry combination that would produce a fracture with the optimal geometry and conductivity. 
Table 47 Range of fracture characteristics for all simulations

Half-length (ft)

Propped length (ft)

Height (ft)

Avg. Width (in)

\begin{tabular}{|c|c|c|}
\multicolumn{1}{c}{ Low } & \multicolumn{1}{c}{ Baseline } & \multicolumn{1}{c}{ High } \\
\hline $43 \mathrm{ft}$ & $291 \mathrm{ft}$ & $485 \mathrm{ft}$ \\
\hline $28 \mathrm{ft}$ & $200 \mathrm{ft}$ & $353 \mathrm{ft}$ \\
\hline $175 \mathrm{ft}$ & $363 \mathrm{ft}$ & $790 \mathrm{ft}$ \\
\hline $0.05 \mathrm{in}$ & $0.19 \mathrm{in}$ & $1.74 \mathrm{in}$ \\
\hline $115 \mathrm{md}-\mathrm{ft}$ & $396 \mathrm{md}-\mathrm{ft}$ & $8166 \mathrm{md}-\mathrm{ft}$ \\
\hline
\end{tabular}




\section{Development of a Numerical Model to Predict Formation of Storage Volume during the Dissolution Process (Task 8) \\ by Ron Falta}

\section{Introduction}

The initial feasibility study documented in the first years report (Castle et al., 2004) showed that hydrochloric acid $(\mathrm{HCl})$ is the most suitable for our proposed cavern creation process. For this reason, our attention has focused entirely on this acid in a carbonate rock. The reaction of $\mathrm{HCl}$ with carbonate rocks is well understood. The reaction of limestone with hydrochloric acid is:

$$
2 \mathrm{HCl}+\mathrm{CaCO}_{3} \Leftrightarrow \mathrm{CaCl}_{2}+\mathrm{H}_{2} \mathrm{O}+\mathrm{CO}_{2}
$$

For limestone dissolution, two moles of $\mathrm{HCl}$ react with a mole of limestone to produce one mole of calcium chloride $\left(\mathrm{CaCl}_{2}\right)$, one mole of carbon dioxide $\left(\mathrm{CO}_{2}\right)$, and a mole of water. The reaction equilibrium for the above reaction very strongly favors the products, so at equilibrium, the reaction is essentially $100 \%$ complete (see, for example, Williams et al., 1979 for calculation method).

In the first year report, we showed that for every kilogram of limestone that is dissolved, $728.7 \mathrm{~g}$ of $\mathrm{HCl}$ are consumed, producing $1109 \mathrm{~g}$ of $\mathrm{CaCl}_{2}, 439.7 \mathrm{~g}$ of $\mathrm{CO}_{2}$, and $180 \mathrm{~g}$ of water. We also defined the volumetric dissolving power of $\mathrm{HCl}$ in terms of the acid strength and limestone density. Using the standard density of limestone of $2710 \mathrm{~kg} / \mathrm{m}^{3}$, and a $30 \%$ (by mass) $\mathrm{HCl}$ concentration, the volumetric dissolving power is 0.175 (Williams et al., 1979). Therefore, each liter of acid solution is capable of dissolving 0.175 liters of rock.

We demonstrated that the large mass of $\mathrm{CO}_{2}$ produced in this reaction is significant in terms of the engineering design of the cavern formation process, and it will be present in the subsurface as a supercritical fluid. The fluid densities will be highly variable during this process, depending on the phase and composition of the fluids. At a pressure of $3000 \mathrm{psi}(20.8 \mathrm{MPa})$, and a temperature of $38 \mathrm{C}$, the supercritical $\mathrm{CO}_{2}$ has a density of $863 \mathrm{~kg} / \mathrm{m}^{3}$, and it can dissolve into water at concentrations of $60-70 \mathrm{~kg}$ per $1000 \mathrm{~kg}$ of $\mathrm{H}_{2} \mathrm{O}$. The injected $\mathrm{HCl}$ acid, at a concentration of $30 \%$ by weight, has a density of $1149 \mathrm{~kg} / \mathrm{m}^{3}$, and the $\mathrm{CaCl}_{2}$ brine that results from this reaction has a density of $1360 \mathrm{~kg} / \mathrm{m}^{3}$. Because the acid dissolution products $\left(\mathrm{CO}_{2}\right.$, $\mathrm{H}_{2} \mathrm{O}$, and $\left.\mathrm{CaCl}_{2}\right)$ all have a lower density than limestone $\left(\rho_{\mathrm{CaCl}_{2}}=2710 \mathrm{~kg} / \mathrm{m}^{3}\right)$, the reaction has the potential to cause very large pressure changes in the subsurface.

In first years' literature review, we found many studies that focused on matrix acidizing and acid fracturing. While these fields have some relevance to the current project, the goals of matrix acidizing and acid fracturing are much different than our goal of creating a large open cavern. The closest field process to our cavern creation method that is in wide use is solution mining of salt formations. Solution mining of salt formations is used to form cavities for hydrocarbon storage, and to mine the salt itself. In this process fresh water is injected into the formation, the rock salt dissolves, and brine is removed. The dissolution of the salt formation leaves a cavity that can be used for storage (including natural gas storage). We previously showed how a modified version of the DOE T2VOC code (Falta et al., 1995) was capable of accurately modeling the field scale salt cavern dissolution process. In the present report, we use 
this simulator to investigate three-dimensional rock dissolution patterns in both fractured and unfractured rock formations.

A unique aspect of concentrated ( $>10 \%)$ acid dissolution of carbonates is the large volume of $\mathrm{CO}_{2}$ that is produced in the reaction. At these high acid concentrations and volumes, this generated $\mathrm{CO}_{2}$ will form a separate phase that is supercritical at the reservoir temperature and pressure. We did several simulations using the new DOE TOUGHREACT code (Xu et al., 2004) coupled with the ECO2 module (Pruess and Garcia, 2002; Xu et al., 2003a,b) to simulate the full geochemical reaction including the supercritical $\mathrm{CO}_{2}$ phase behavior. However, we experienced some numerical difficulties when we tried to simulate high strength acid injection into limestone. We believe that this may have been due to the decoupled approach used in TOUGHREACT, where the multiphase flow is solved separately from the reactive transport at each time-step. High strength acid injection into limestone involves extremely strong coupling between the multiphase fluid flow, reactions, and chemical transport. While we are confident that TOUGHREACT could be suitable for these kinds of simulations, we also thought that it might be beneficial to produce a fully coupled simulator that only considered the primary acidlimestone reaction. Therefore, we decided to modify the TOUGH2 code EWASG (Pruess et al., 1999; Battistelli et al., 1997) with the ECO2 module from Pruess and Garcia (2002) to get a fully coupled simulator for the acid-rock dissolution problem.

This chapter is organized into two sections, a section dealing with three-dimensional patterns of rock dissolution, where in-situ $\mathrm{CO}_{2}$ production is neglected; and a section that describes the new fully coupled numerical simulator that includes supercritical $\mathrm{CO}_{2}$ generation. A series of cavern dissolution simulations using different strength acid solutions are described, and two main strategies for dissolving out caverns are discussed.

\section{Three-Dimensional Simulation of Cavern Formation Neglecting $\mathrm{CO}_{2}$ Production}

Salt solution mining is an old process that started in the 1800's, and the use of solution mined salt caverns for hydrocarbon storage started in the 1940's. Typical dimensions of salt caverns used for strategic petroleum reserve storage are $2000 \mathrm{ft}$ high and a $300 \mathrm{ft}$ diameter. Salt caverns used by the private sector for hydrocarbon storage are generally smaller than the strategic petroleum reserve caverns.

From a chemical standpoint the process of salt cavern creation by solution mining is different from acid cavern dissolution in carbonates, primarily due to the production of $\mathrm{CO}_{2}$ during the carbonate reaction. At low acid concentrations ( $<10 \%$, depending on the depth), the produced $\mathrm{CO}_{2}$ will remain in solution, and the process does not involve a gas or supercritical $\mathrm{CO}_{2}$ phase. At higher acid strengths, separate phase $\mathrm{CO}_{2}$ will be present in the cavern, and this can have a large effect on the dissolution process. Nonetheless, there are many similarities with salt solution mining including the fact that both are essentially mass transfer limited rock dissolution processes in which there are very strong buoyancy gradients. Because salt dissolution is not reaction rate limited, the mass transfer of fresh water to the fluid-salt interface controls the rate of dissolution (Saberian and Podio 1977). Reaction rates between carbonate and $\mathrm{HCl}$ are also fast, therefore the reaction is also often mass transfer limited and the rate at which acid is delivered to the reaction surfaces has a dominating influence on the rate of carbonate dissolution (Williams et al. 1979). Numerical simulations of the carbonate dissolution process therefore must be able to account for the rate of acid and product mass transfer to and 
from the rock-solution boundary. Consideration of local reaction kinetics is probably of secondary importance.

Salt $(\mathrm{NaCl})$ has a very high solubility in water, $311.3 \mathrm{~g} / 1$ (CRC, 1987). As fresh water with a density of $1000 \mathrm{~kg} / \mathrm{m}^{3}$ becomes saturated with salt, its density rises to $1199 \mathrm{~kg} / \mathrm{m}^{3}$, an increase of $20 \%$. The resulting buoyancy forces thus play a central role in the fluid flow as they will in the acid dissolution of limestone. Considering the solubility of salt in fresh water, and rock salt density of $2170 \mathrm{~kg} / \mathrm{m}^{3}$, the equivalent dissolving power of fresh water is 0.168 , which is remarkably close to the volumetric dissolving power of $30 \% \mathrm{HCl}$ on pure limestone (.175). With important exception of $\mathrm{CO}_{2}$ generation, the processes of salt solution mining with fresh water and $\mathrm{HCl}$ dissolution of limestone are very similar.

In the first years report (Falta et al., 2004), we showed how a modified version of the DOE T2VOC simulator was capable of accurately modeling field salt cavern formation using fresh water injection. In this section, we use the modified T2VOC code to simulate cavern dissolution for several 3-dimensional geometries. While these simulations do not consider the production of $\mathrm{CO}_{2}$, they provide basic insights into solution mining strategies are most promising for developing the natural gas storage caverns in carbonates.

T2VOC considers the three-phase flow of gas, water, and a nonaqueous phase liquid (NAPL) in three-dimensional porous or fractured media. The model is fully compositional, so that the NAPL phase can dissolve into the aqueous phase with associated aqueous phase density effects (calculated assuming volume additivity). Since T2VOC does not directly consider rock dissolution or precipitation, the NAPL phase in the code was given the properties of rock salt. Thus the "rock" component in T2VOC had a density of $2170 \mathrm{~kg} / \mathrm{m}^{3}$, zero relative permeability, infinite viscosity, and an aqueous solubility of $311 \mathrm{~g} / \mathrm{l}$.

The porosity of the model domain was then set to one, and is not used as a variable in this case. With this formulation, the water phase saturation, $S_{w}$ is used to model the dynamic rock porosity, and the NAPL phase, with a volumetric saturation of $S_{R}$, is used to model the fraction of rock. Therefore, in this model the "porosity" is

$$
\phi_{R}=1-S_{R}=S_{w}
$$

and when $\mathrm{S}_{\mathrm{R}}=0$, the rock has completely dissolved away.

Multiphase flow formulations model phase permeabilities as the product of the rock intrinsic permeability with a phase saturation dependent relative permeability. For the aqueous (water) phase,

$$
k_{w}=k_{r o c k} k_{r w}
$$

where $\mathrm{k}_{\text {rock }}$ is the rock intrinsic permeability, and $\mathrm{k}_{\mathrm{rw}}$ is the relative permeability of the aqueous phase. In the present work, the water saturation is an analogue for porosity, so when $S_{w}=1$, there is no rock present, and $\mathrm{k}_{\mathrm{rw}}=1$. The T2VOC model assumes darcian flow, so the "permeability" of the open sections of a cavern, $\mathrm{k}_{\text {rock }}$, was set to a very high value, $10^{-6}$ or $10^{-5} \mathrm{~m}^{2}$ (one to ten million darcys). While this neglects possibly important turbulent flow effects, it allows for fluids to freely flow in open parts of the cavern in response to buoyancy and pressure effects. The change in rock intrinsic permeability as a function of porosity was modeled using the aqueous phase relative permeability function: 


$$
k_{r w}=S_{w}^{3}
$$

so the effective intrinsic permeability of the dissolving rock depends on the cube of the rock porosity. Other porosity-permeability models could be used (see, for example, Pruess et al., 1999), but as will be shown, this cubic model is theoretically correct for a dissolving fracture embedded in an element.

Using Equations (18) and (19), the rock permeability can vary from zero to the assumed effective cavern permeability $\left(\mathrm{k}_{\mathrm{rock}}\right)$. In the current simulations, the initial intact rock permeability was assumed to be $10^{-17}$ or $10^{-16} \mathrm{~m}^{2}$, or 10-100 microdarcy. This is obtained in the model using Equation (19) by initializing the water saturation $\left(S_{\mathrm{w}}\right)$ at a value of 0.0002154 to get a permeability reduction of $10^{-11}$. Therefore, the intrinsic permeability in each dissolving rock gridblock in this model will vary by eleven orders of magnitude during a simulation of cavern formation. This rapid change causes the problem to be extremely nonlinear, but the multiphase numerical treatment in T2VOC and similar multiphase codes is designed to specifically to deal with this numerical issue as long as all terms are fully coupled in the Jacobian Matrix during the Newton Raphson iteration process. For a non-zero initial rock porosity, Equation (19) could easily be modified by using a scaled saturation with $\mathrm{k}_{\mathrm{rw}}$ equal to zero at a nonzero $\mathrm{S}_{\mathrm{w}}$ value.

The modified version of T2VOC used here includes aqueous diffusion. Mathematically, the diffusive flux is calculated as the product of an effective diffusion coefficient with the concentration gradient between two adjacent finite difference cells. This is mathematically equivalent to a first order mass transfer expression driven by the concentration difference in the adjacent cells. Therefore, the aqueous diffusion in T2VOC was used to model a first order mass transfer reaction between open parts of the cavern, and the cavern walls (see, also, Williams et al., 1979). Following Falta (2000), the mass transfer reaction between the open cavern and the rock is modeled in adjacent gridblocks by:

$$
Q_{C-R}=\frac{D^{\prime} A_{C-R}}{d_{C-R}}\left(C_{w, R}-C_{w, C}\right)
$$

where $\mathrm{Q}_{\mathrm{C}-\mathrm{R}}$ is the rate of mass transfer of rock into solution at the cavern-rock interface $\left(\mathrm{kg} /\left(\mathrm{s}^{*} \mathrm{~m}^{3}\right), \mathrm{A}_{\mathrm{C}-\mathrm{R}}\right.$ is the interfacial area of the cavern-rock interface normalized to the cavern-rock gridblock volume, $\mathrm{d}_{\mathrm{C}-\mathrm{R}}$ is the average distance from center of the cavern gridblock to the center of the rock gridblock, and D' is a diffusion-like fitting parameter. The concentration gradient between the open cavern element and the rock element, $\left(\mathrm{C}_{\mathrm{w}, \mathrm{R}}-\mathrm{C}_{\mathrm{w}, \mathrm{C}}\right)$, drives this first order reaction. For simple rock salt dissolution, the mass transfer rate, and the rate of rock dissolution are maximized when the salt concentration in the cavern gridblock is zero. The rate of mass transfer is zero when the salt concentration in the cavern gridblock is equal to the concentration in local equilibrium with the rock salt. As the rock dissolves away, the location of the cavernrock interface changes with time, and this is automatically accounted for with this approach. Based on the field scale salt cavern simulations we reported last year, D' was set to a value of $10^{-}$ ${ }^{4} \mathrm{~m}^{2} / \mathrm{s}$.

One of the most important operational issues to be addressed in this study is the basic configuration of the rock dissolution scheme. Our original proposal called for hydraulic fracturing, followed by acid dissolution. However, salt caverns are commonly formed without 
fracturing, using open boreholes. A series of three-dimensional simulations were used to investigate three different dissolution configurations: a) injection into an open borehole with production from that same borehole and no fracture; b) injection into an open borehole with production from that same borehole, with an open fracture; and c) injection into an open borehole connected by a fracture to an adjacent borehole from which the fluids are produced.

The three-dimensional grid consists of 2520 gridblocks, and it is aligned parallel to a fracture face (Figure 119). The model has dimensions of $40 \mathrm{~m}$ in the $y$-direction, parallel to the fracture, $12 \mathrm{~m}$ in the $\mathrm{z}$-direction, perpendicular to the fracture, and $51 \mathrm{~m}$ in the $\mathrm{z}$-direction. Due to symmetry, only one-half of the problem is simulated, using the center of the fracture as the plane of symmetry. The open boreholes are simulated by a columns of gridblocks that are initialized with $\mathrm{S}_{\mathrm{w}}=1$. An initial effort to model this problem involved discretizing a small $3 \mathrm{~mm}$ fracture, with element sizes slowly increasing in the x-direction. This resulted in unacceptable numerical behavior, so a new approach was developed that uses a coarser discretization, but still captures the important physics of this problem. A fracture transmissivity, $\mathrm{T}_{\mathrm{f}}$ can be defined as the product of the fracture aperture, $\mathrm{b}$, and the fracture permeability, $\mathrm{k}_{\mathrm{f}}$ :

$$
T_{f}=k_{f} b
$$

In a porous media model, the equivalent gridblock transmissivity would be

$$
T_{m}=k_{r o c k} k_{r w} \Delta x
$$

where $\Delta \mathrm{x}$ is the horizontal thickness of the gridblock perpendicular to the fracture. Using Equation (19), the initial $S_{w}$ value that produces the desired fracture transmissivity can be calculated:

$$
S_{w}=\left(\frac{k_{f} b}{k_{\text {rock }} \Delta x}\right)^{\frac{1}{3}}
$$

The hydraulic fracture modeling discussed elsewhere in this report has indicated that it is feasible to make a vertical fracture with an aperture of approximately $3 \mathrm{~mm}$ and dimensions of at least $25 \mathrm{~m}$ in the horizontal direction and $50 \mathrm{~m}$ in the vertical direction. This fracture will be initially held open with a proppant. If we assume that the proppant filling the fracture has an intrinsic permeability of $2 \times 10^{-10} \mathrm{~m}^{2}$, then the effective fracture transmissivity, $\mathrm{T}_{\mathrm{f}}$ is $6 \times 10^{-13} \mathrm{~m}^{2}$. Using Equation (23), this initial fracture transmissivity can be obtained in a $2 \mathrm{~cm}$ thick gridblock with $\mathrm{k}_{\text {rock }}$ equal to $10^{-5} \mathrm{~m}^{2}$ by using an initial $\mathrm{S}_{\mathrm{w}}$ equal to 0.0144 . In the field, as the fracture dissolves, the proppant will drop away, leaving an open fracture or channel with higher permeability than the propped fracture. The numerical model can account for this through the $\mathrm{k}_{\mathrm{rw}}$ term. This is illustrated in Table 48 which shows the equivalent gridblock transmissivity $\left(T_{m}\right)$ as a function of the fracture element $S_{w}$. The equivalent open fracture aperture calculated using the cubic law:

$$
T_{f}=\frac{b^{3}}{12}
$$


is also shown. As the rock in the fracture element dissolves, the permeability increases and approaches the open fracture cubic law transmissivity.

Table 48. Effective fracture transmissivity in the $2 \mathrm{~cm}$ thick fracture elements as they dissolve.

\begin{tabular}{|c|c|c|}
\hline $\mathbf{S}_{\mathbf{w}}$ & $\mathbf{T}_{\mathbf{m}}, \mathbf{m}^{\mathbf{3}}$ & $\begin{array}{c}\text { Equivalent b using cubic law } \\
\text { for open fractures, } \mathbf{m m}\end{array}$ \\
\hline 0.0144 & $6.0 \times 10^{-13}$ & 0.19 \\
\hline 0.02 & $1.6 \times 10^{-12}$ & 0.27 \\
\hline 0.05 & $2.5 \times 10^{-11}$ & 0.67 \\
\hline 0.10 & $2.0 \times 10^{-10}$ & 1.34 \\
\hline 0.20 & $1.6 \times 10^{-9}$ & 2.68 \\
\hline 0.40 & $1.3 \times 10^{-8}$ & 5.36 \\
\hline 0.60 & $4.3 \times 10^{-8}$ & 8.03 \\
\hline 0.80 & $1.0 \times 10^{-7}$ & 10.72 \\
\hline 1.00 & $2.0 \times 10^{-7}$ & 13.40 \\
\hline
\end{tabular}

Based on these arguments, the grid spacing in the $\mathrm{x}$-direction, beginning at the center of the fracture (only one-half of the problem is modeled) is $1 \mathrm{~cm}, 3 \mathrm{~cm}, 6 \mathrm{~cm}, 10 \mathrm{~cm}, 20 \mathrm{~cm}, 60 \mathrm{~cm}$, expanding to $2 \mathrm{~m}$. Parallel to the fracture, in the y-direction coarser spacing is used. The wells are assumed to have a $20 \mathrm{~cm}$ diameter ( $\sim \mathrm{inch})$, so the y-spacing at the wells is $20 \mathrm{~cm}$, increasing between the wells up to $6 \mathrm{~m}$. The vertical spacing is $7 \mathrm{~m}$, except for the bottom 3 layers, which have thicknesses of $4 \mathrm{~m}$. Each well occupies one gridblock in the y-direction, 3 gridblocks in the x-direction, and the boreholes extend from the second layer from the top, to the layer above the bottom.

The first set of simulations do not include a fracture, so the $S_{w}$ in the fracture is set equal to 0.0002154 as in the other rock gridblocks. The $k_{\text {rock }}$ value was set to $10^{-6} \mathrm{~m}^{2}$ giving a formation intrinsic permeability of $10^{-17} \mathrm{~m}^{2}$. Only a single well is simulated, with fresh water injection at a rate of 100 gallons per minute (full well basis) near the vertical center of the well. The brine is produced from the bottom of the well against a downhole well pressure of 20.2 $\mathrm{MPa}$, or $2900 \mathrm{psi}$. Images of the cavern formation during the 140 day injection period are shown in Figures 120 through 126. By the end of the simulation, the cavern has just extended to the model boundaries, and the cavern volume (full basis) is $10,384 \mathrm{~m}^{3}\left(366,700 \mathrm{ft}^{3}\right)$. The total water injection (full basis) was $73,306 \mathrm{~m}^{3}$, so the injected water to cavern volume ratio is 7.35 , giving an average volumetric dissolving power of 0.136 . Comparing this value to the theoretical maximum of 0.168 , it can be seen that this process operated at $81 \%$ efficiency, which is typical of field salt solution mining efforts. Many approximations and assumptions were used in calculating the mass transfer during this simulation (darcy flow in cavern; constant mass transfer coefficient; equilibrium reaction between rock and fluid), so the predicted efficiency should be viewed with some caution. Nonetheless, this model predicts that a single-well configuration without a fracture could be viable for cavern formation.

The second case that was considered was similar to the first one, except that a $3 \mathrm{~mm}$ aperture fracture was considered, and $\mathrm{k}_{\text {rock }}$ was increased to $10^{-5} \mathrm{~m}^{2}$, giving a formation intrinsic permeability of $10^{-16} \mathrm{~m}^{2}$. The fracture is initially assumed to contain a 200 darcy permeability proppant, and as it dissolves, the permeability follows Table 48. As in the previous example, water is injected at $100 \mathrm{gpm}$ in the center of the borehole, and brine is produced from the bottom 
against a constant wellbore pressure. The dissolved rock pattern is similar to the previous case, but it becomes elongated somewhat in the direction of the fracture (Figures 127 through 133). This elongation is particularly evident in the plot at 56 days (Figure 130). At the end of water injection, this cavern has a volume (full basis) of $11,474 \mathrm{~m}^{3}$. Using the cumulative water injection of $73,306 \mathrm{~m}^{3}$, the injected water to cavern volume ratio is 6.39 , giving an average volumetric dissolving power of 0.156 . This represents $93 \%$ efficiency, and it can be concluded that the presence of the fracture improved the mass transfer in this case relative to the unfractured case.

The final case involves water injection into the center of one borehole, with production from the bottom of the other borehole, located $23 \mathrm{~m}$ away. The boreholes are connected by a 3 $\mathrm{mm}$ fracture initially filled with a 200 darcy proppant. Otherwise, this simulation is identical to the previous case. Here the pattern of dissolution is much different, because flow is forced into the fracture (Figures 134 through 140).

Initially, the cavern forms around the injection borehole (Figures 134 and 135), but by 56 days of injection (Figure 137), a strong influence of the fracture is seen. A strong buoyancy flow is apparent in the fracture, as the dissolution occurs preferentially near the top of the fracture. After about 70 days of injection (Figure 138), the rock dissolution front breaks through into the production well, and after this time rock dissolution occurs throughout the cavern, including the production borehole. The resulting cavern at the end of the 140 day injection (Figure 140) has a complex geometry that is clearly dominated by the effects of the fracture. A similar simulation that used a lower permeability proppant (20 darcy) did not produce this type of pattern, and the cavern that formed was more spherical in shape. Therefore, it appears that the transmissivity of the fracture is a critical parameter in the dissolved cavern morphology.

The two-well cavern shown in Figure 140 has a volume (full basis) of 12,508 $\mathrm{m}^{3}$. Using the cumulative water injection of $73,306 \mathrm{~m}^{3}$, the injected water to cavern ratio is equivalent to an average volumetric dissolving power of 0.170 . This is slightly greater that the theoretical maximum dissolving efficiency (101\%), so it may indicate a small mass balance error during the simulation. Despite this small inconsistency, it is apparent that this two-well configuration maximizes the overall mass transfer from the rock to the fluid, but it results in a complex cavern shape. 


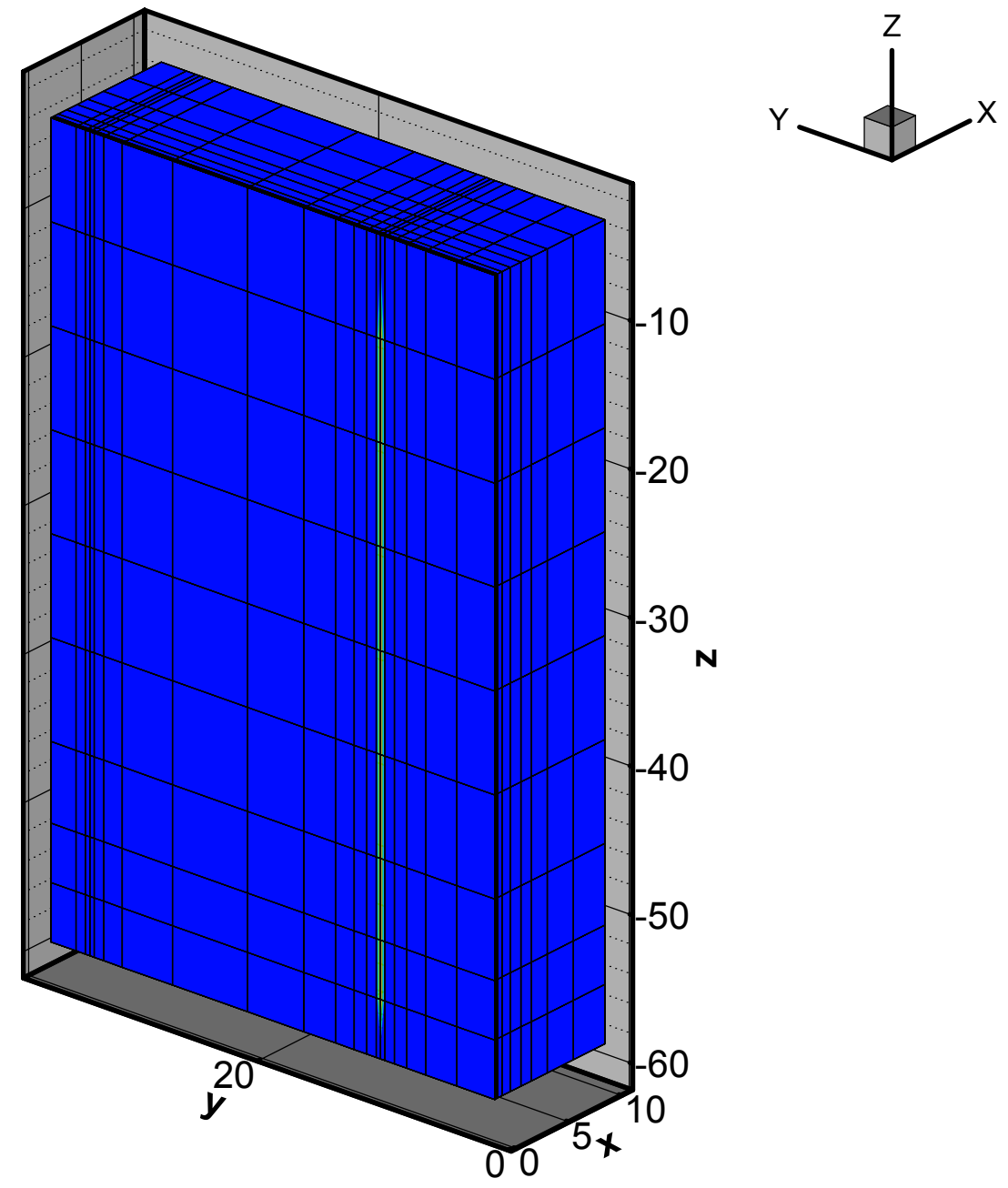

Figure 119. Numerical grid used in 3-D rock dissolution simulations. One well is shown, and the fracture extends along the $x=0$ face. 


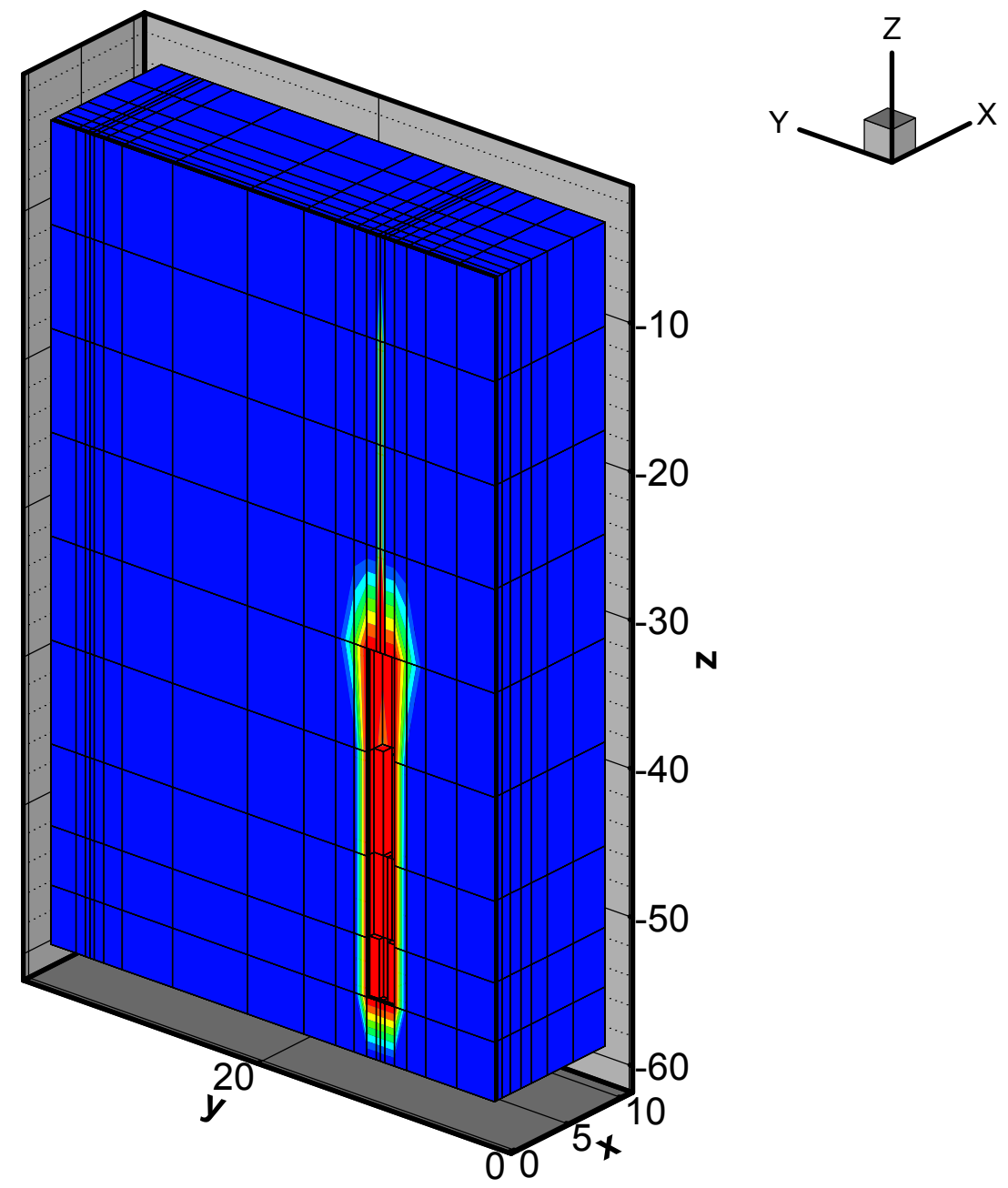

Figure 120. Single borehole with no fracture, inject 100 gpm for 5.5 days. 


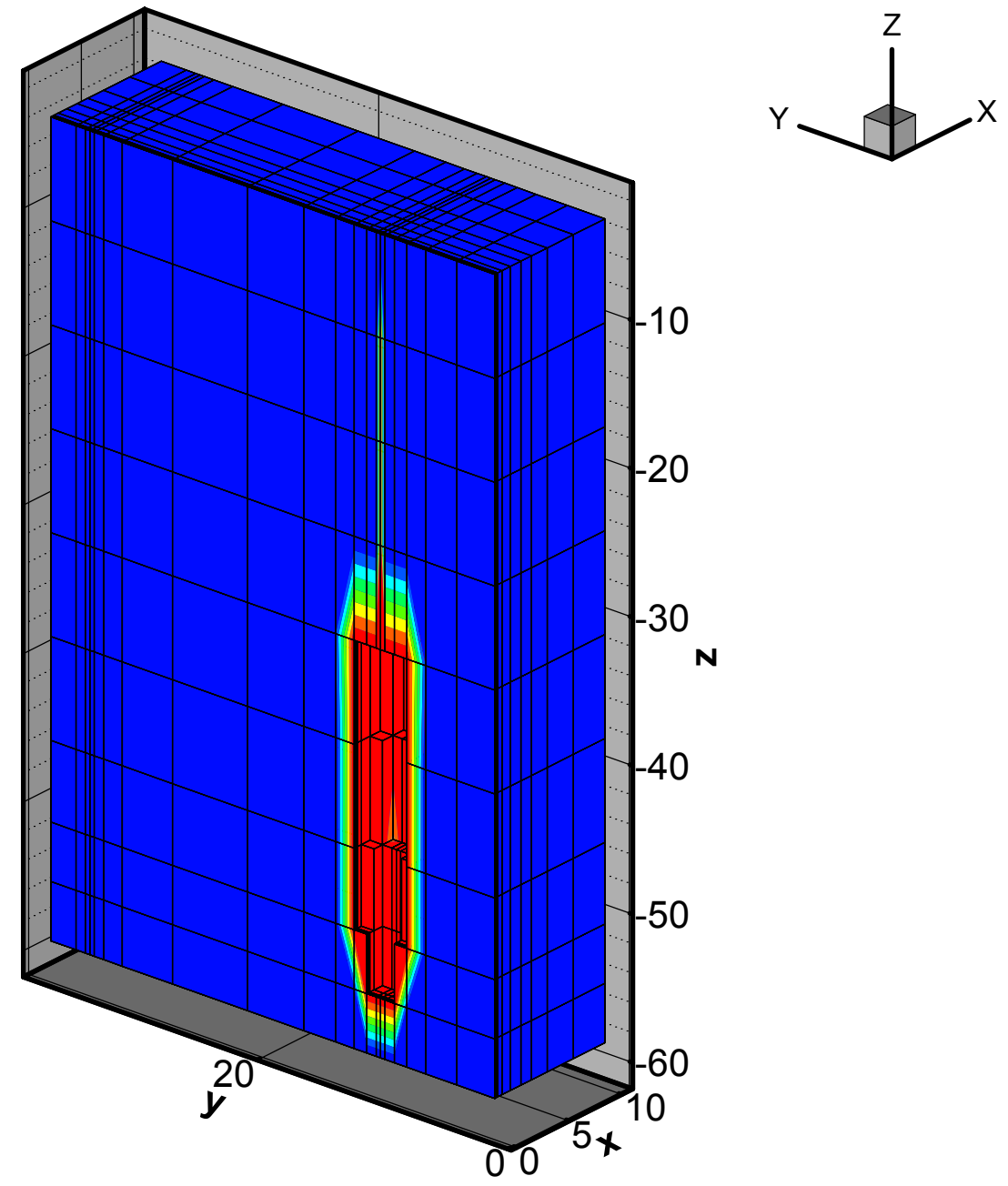

Figure 121. Single borehole with no fracture, inject 100 gpm for 14.0 days. 


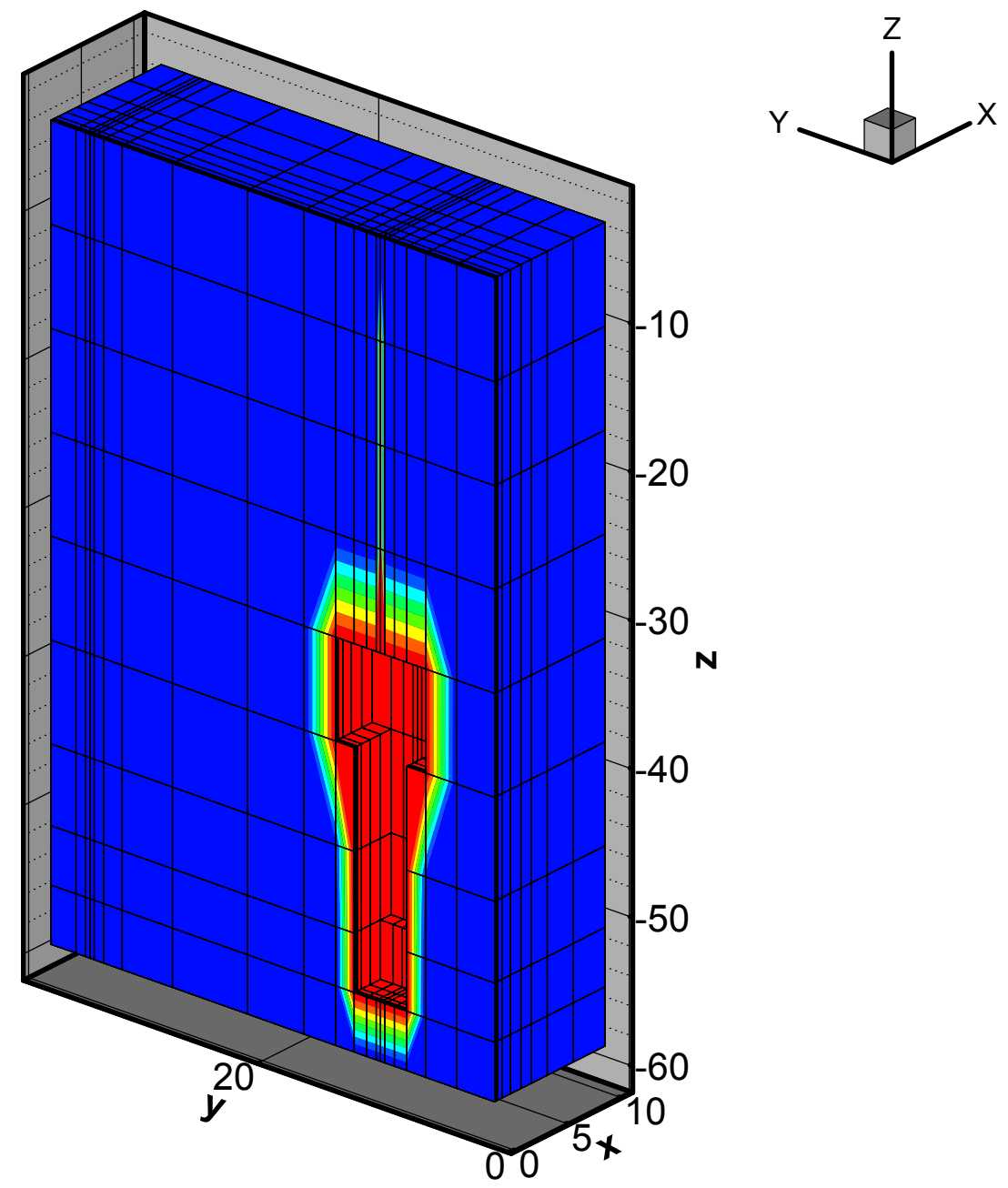

Figure 122. Single borehole with no fracture, inject $100 \mathrm{gpm}$ for 28 days. 


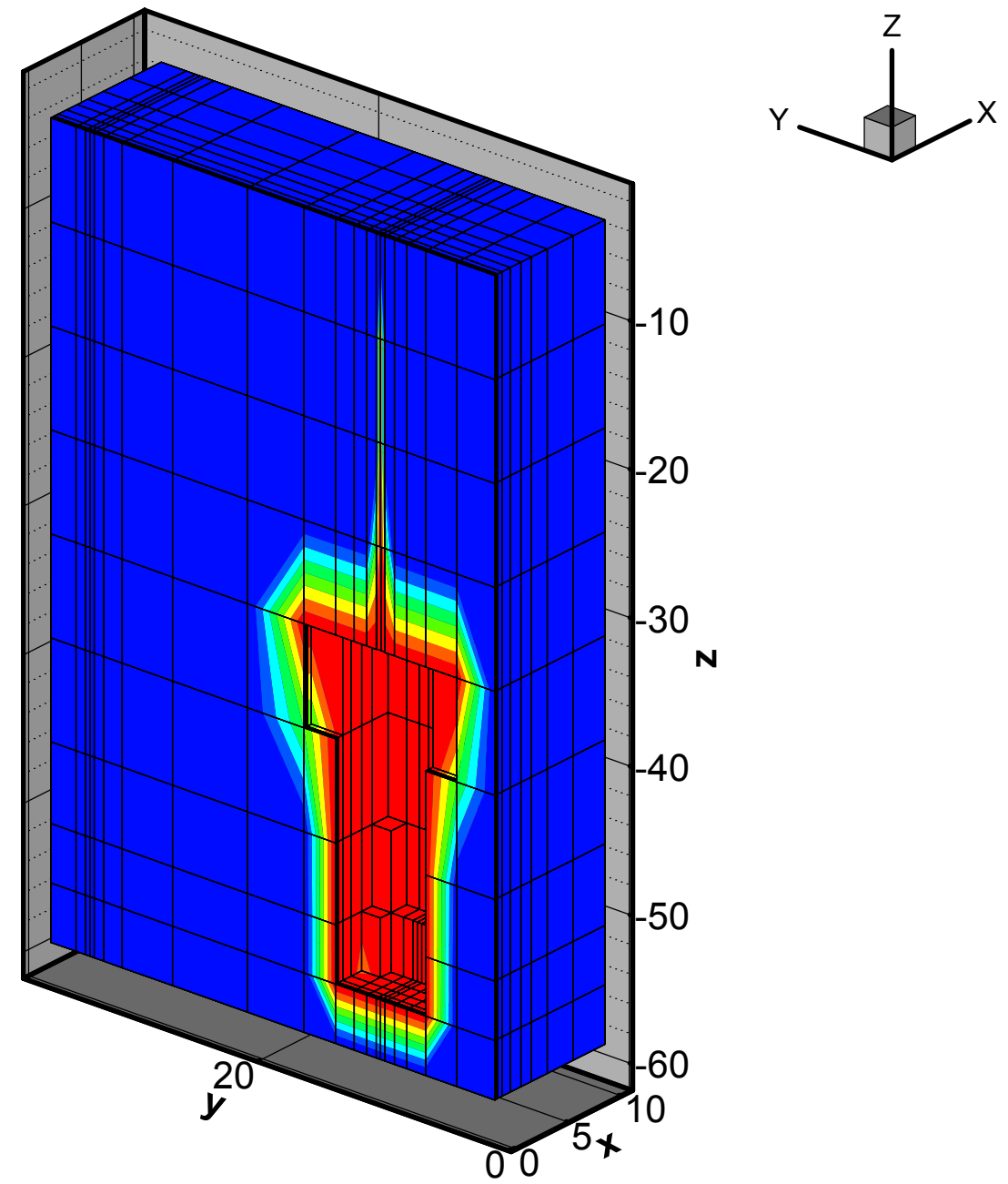

Figure 123. Single borehole with no fracture, inject $100 \mathrm{gpm}$ for 56 days. 


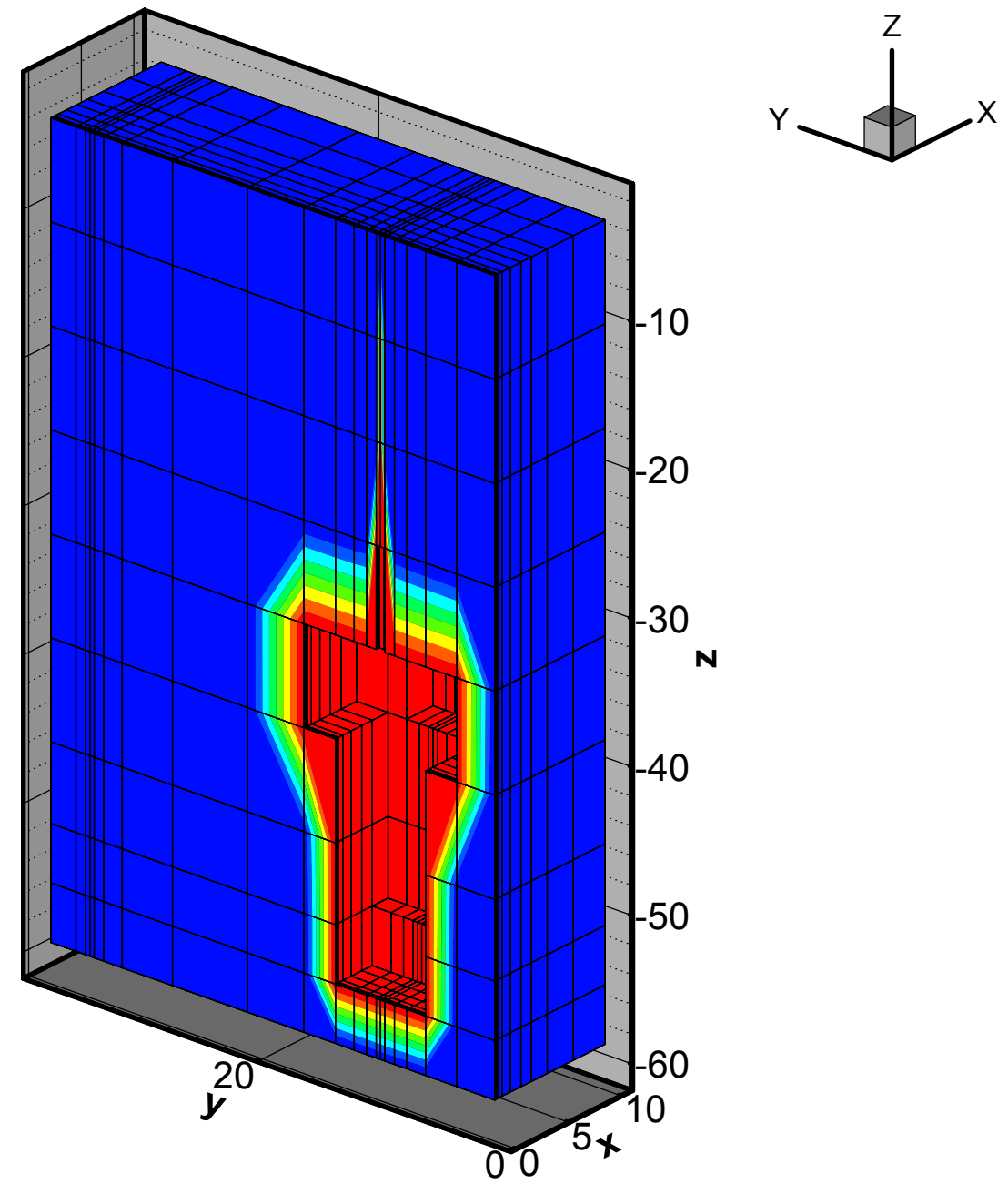

Figure 124. Single borehole with no fracture, inject $100 \mathrm{gpm}$ for 70 days. 


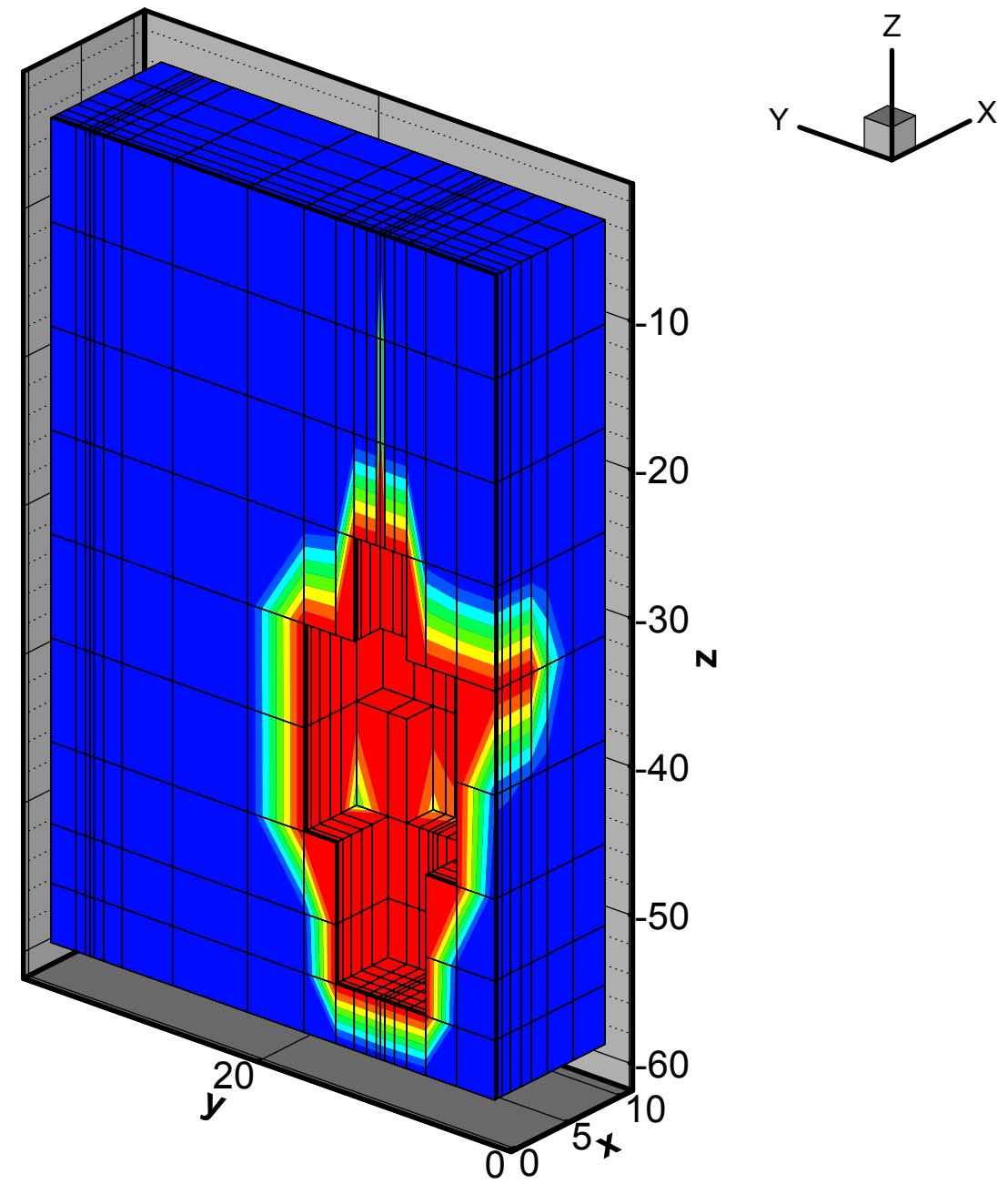

Figure 125. Single borehole with no fracture, inject $100 \mathrm{gpm}$ for 98 days. 


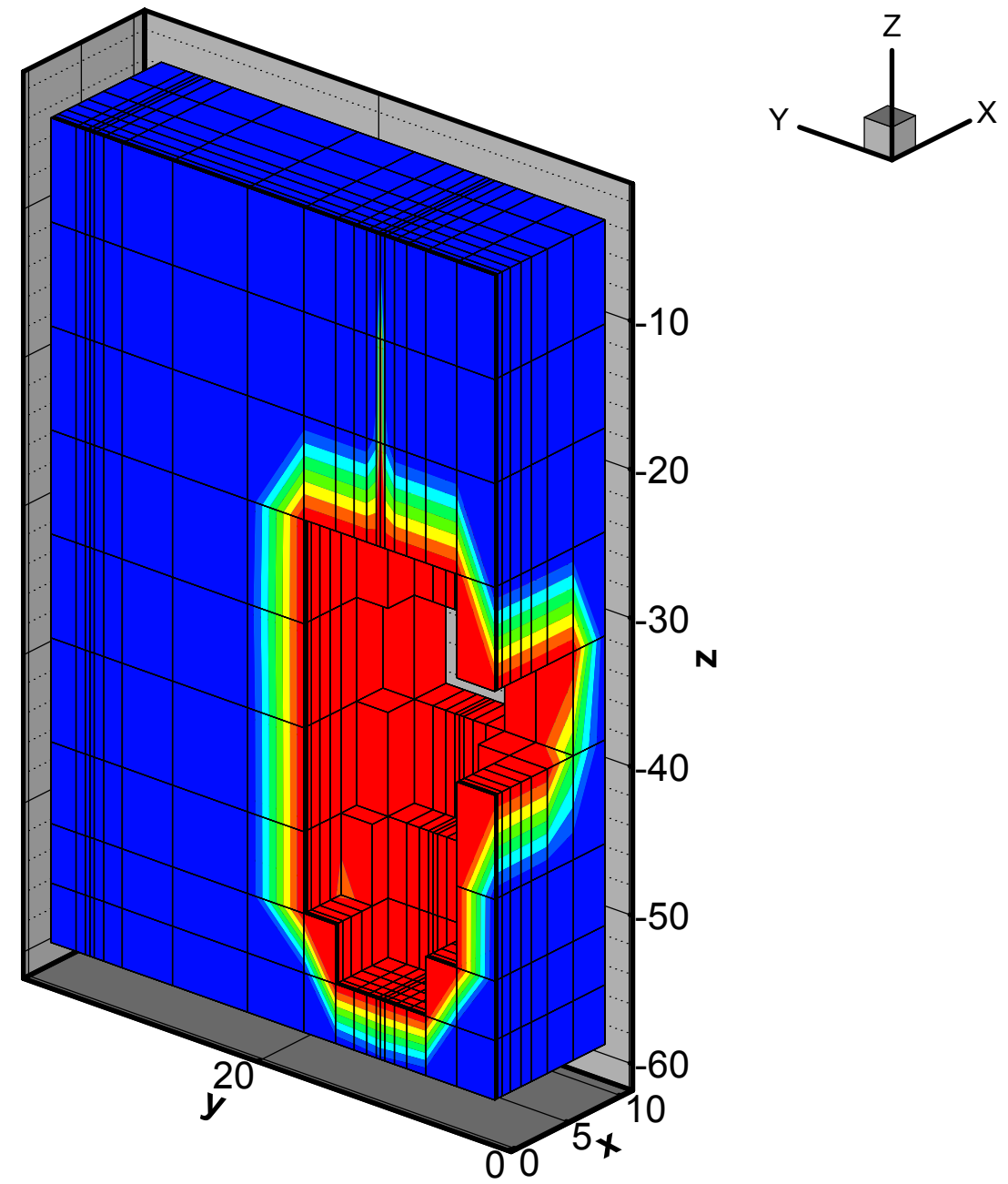

Figure 126. Single borehole with no fracture, inject 100 gpm for 140 days. 


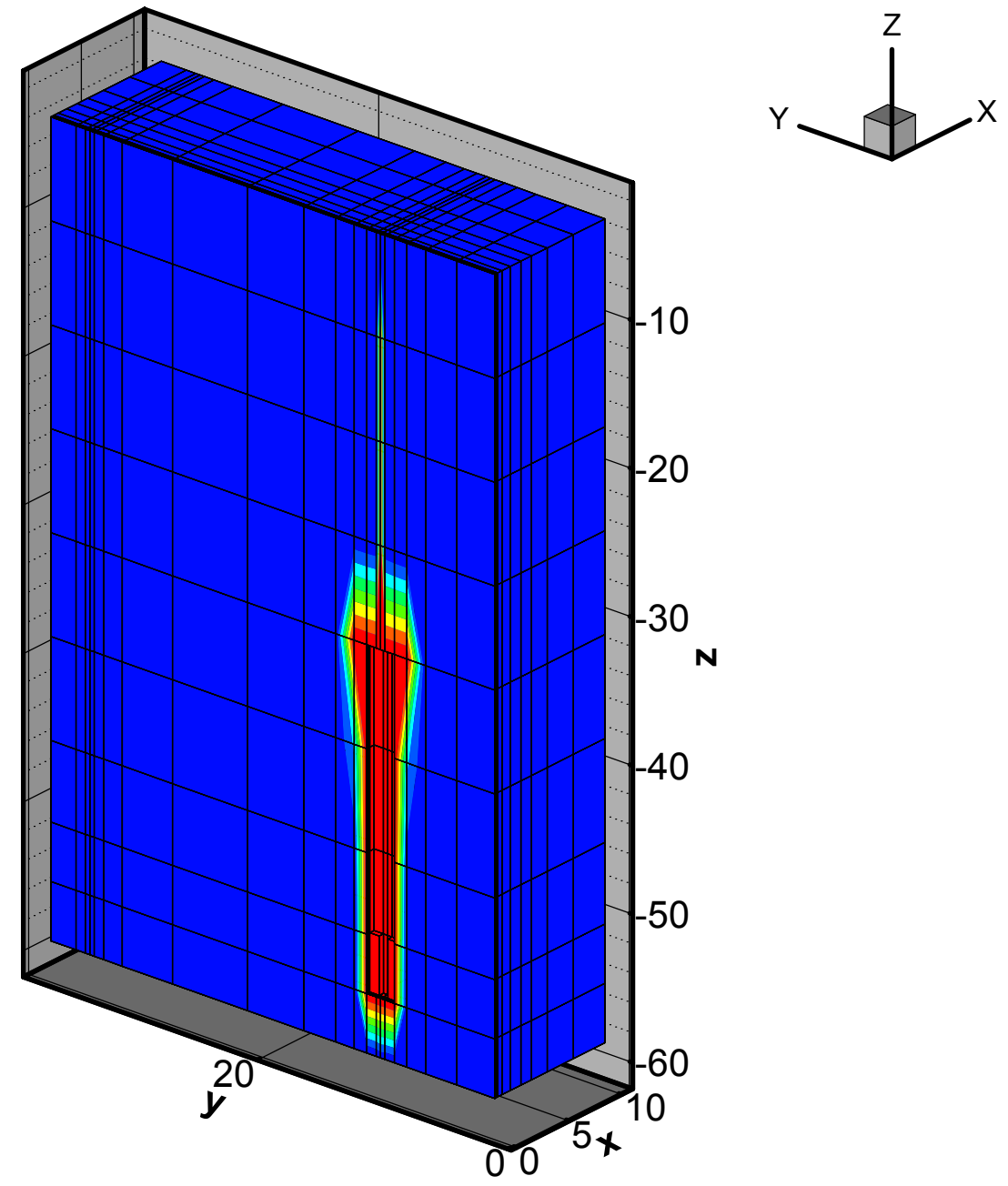

Figure 127. Single borehole with a $3 \mathrm{~mm}$ fracture, inject $100 \mathrm{gpm}$ for 4 days. 


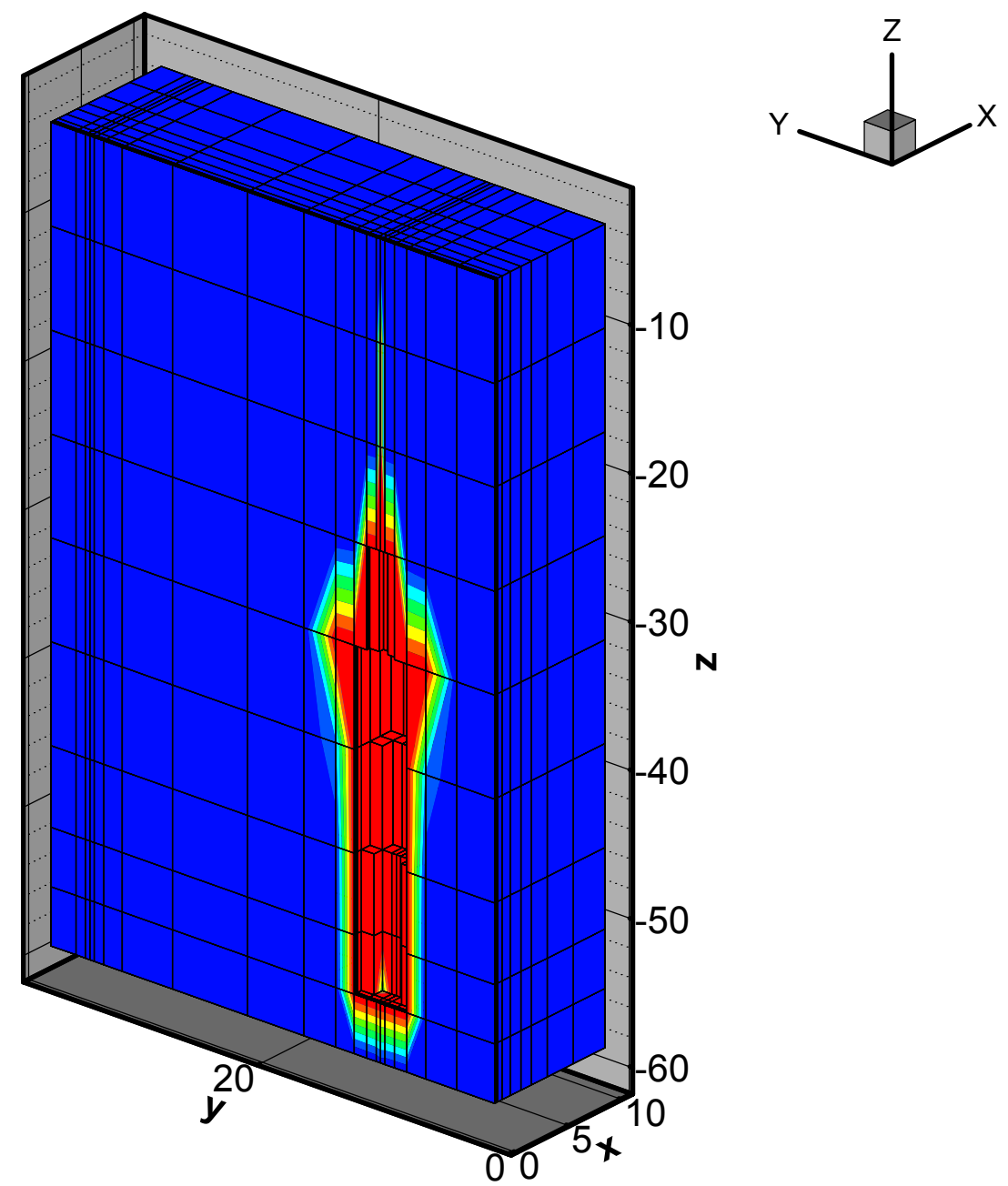

Figure 128. Single borehole with a $3 \mathrm{~mm}$ fracture, inject $100 \mathrm{gpm}$ for 14 days. 


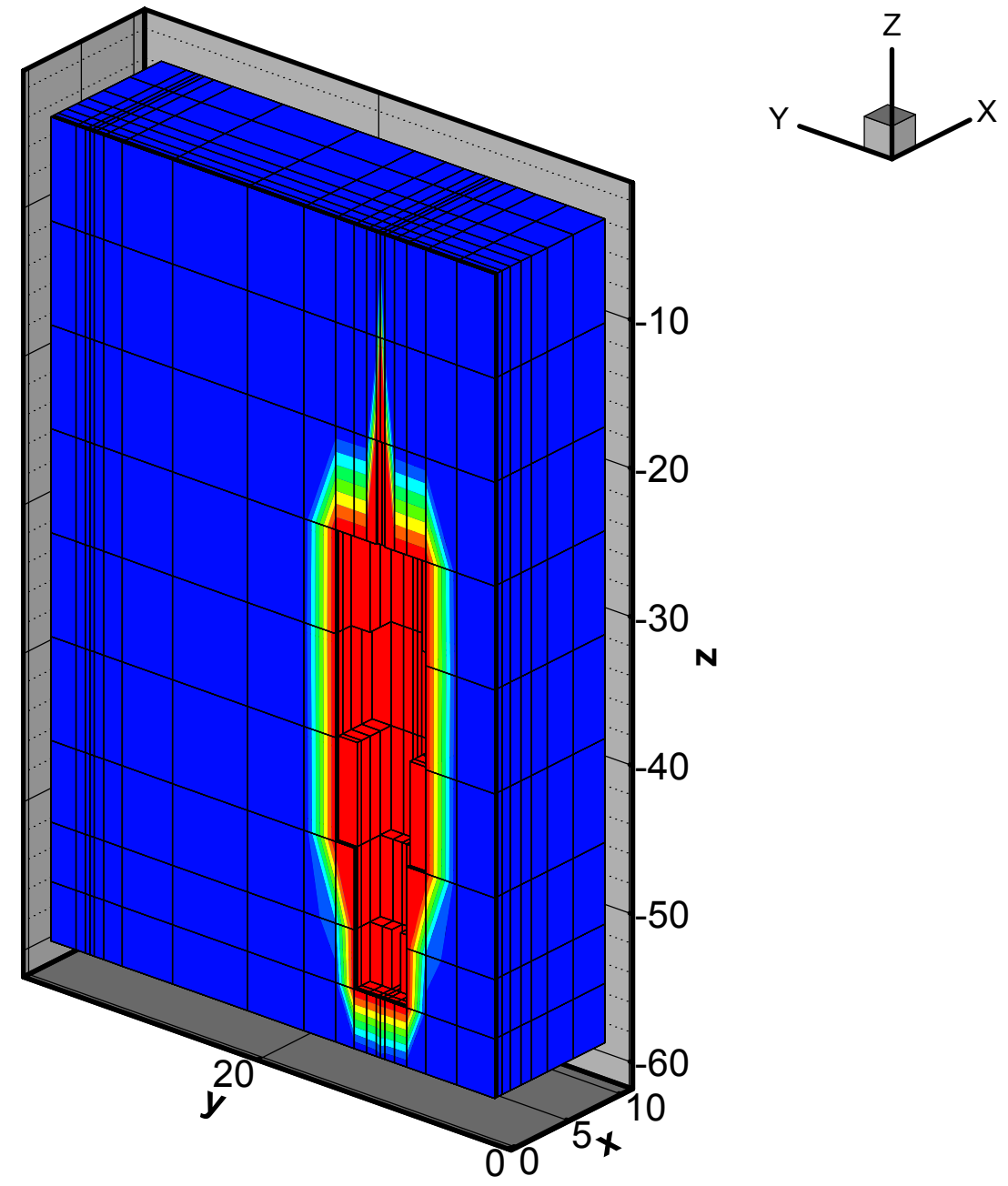

Figure 129. Single borehole with a $3 \mathrm{~mm}$ fracture, inject $100 \mathrm{gpm}$ for 28 days. 


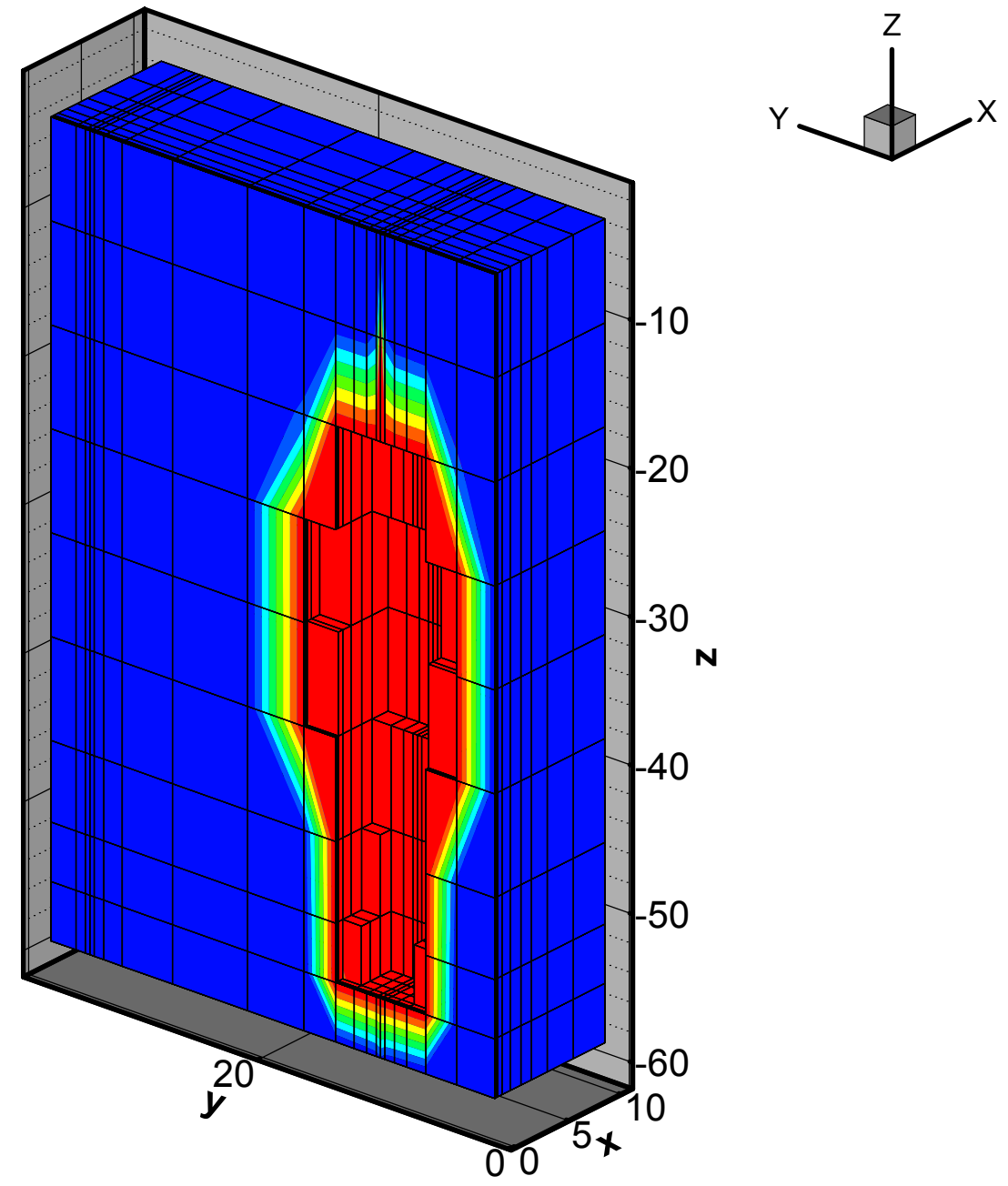

Figure 130. Single borehole with a $3 \mathrm{~mm}$ fracture, inject $100 \mathrm{gpm}$ for 56 days. 


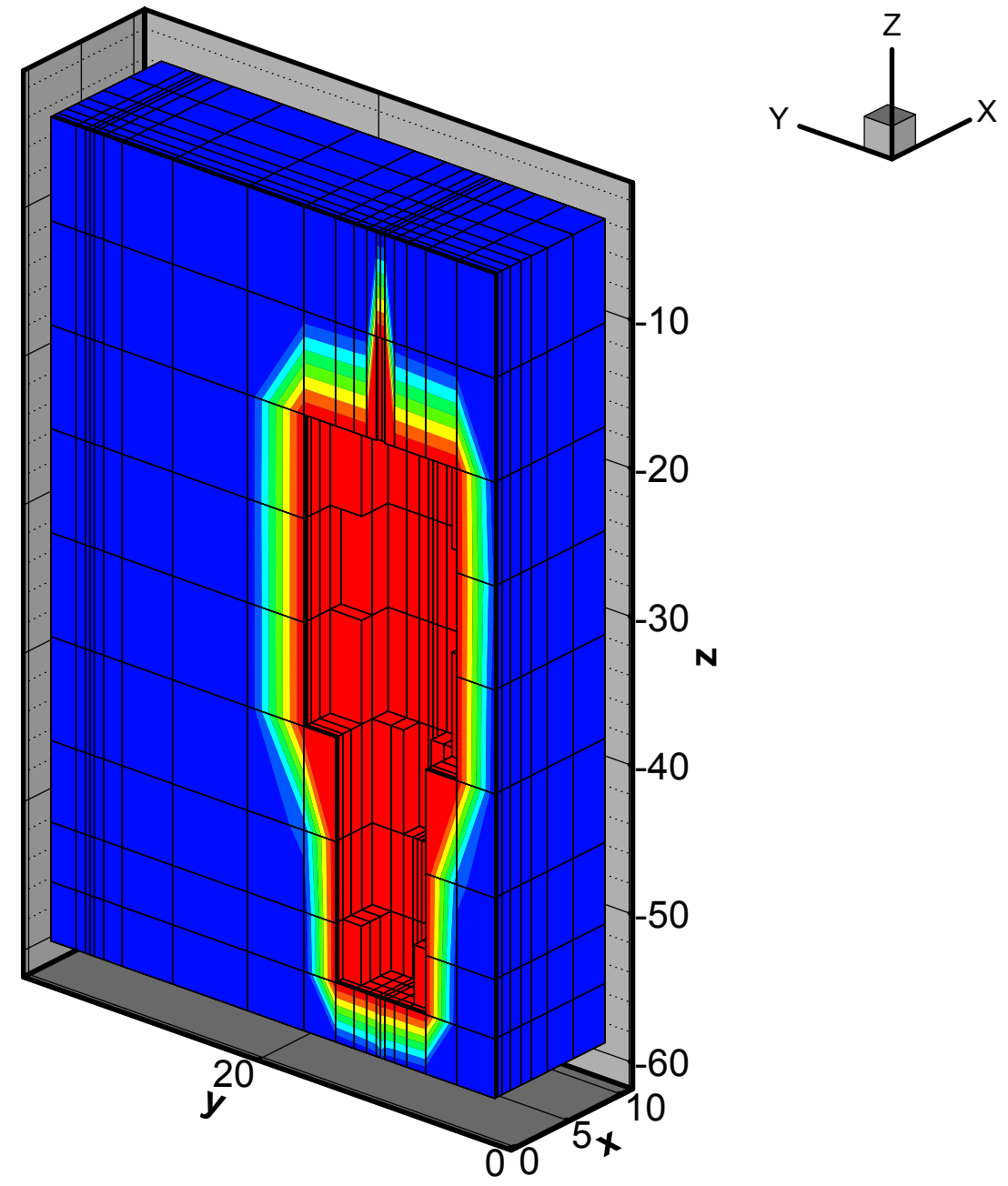

Figure 131. Single borehole with a $3 \mathrm{~mm}$ fracture, inject $100 \mathrm{gpm}$ for 70 days. 


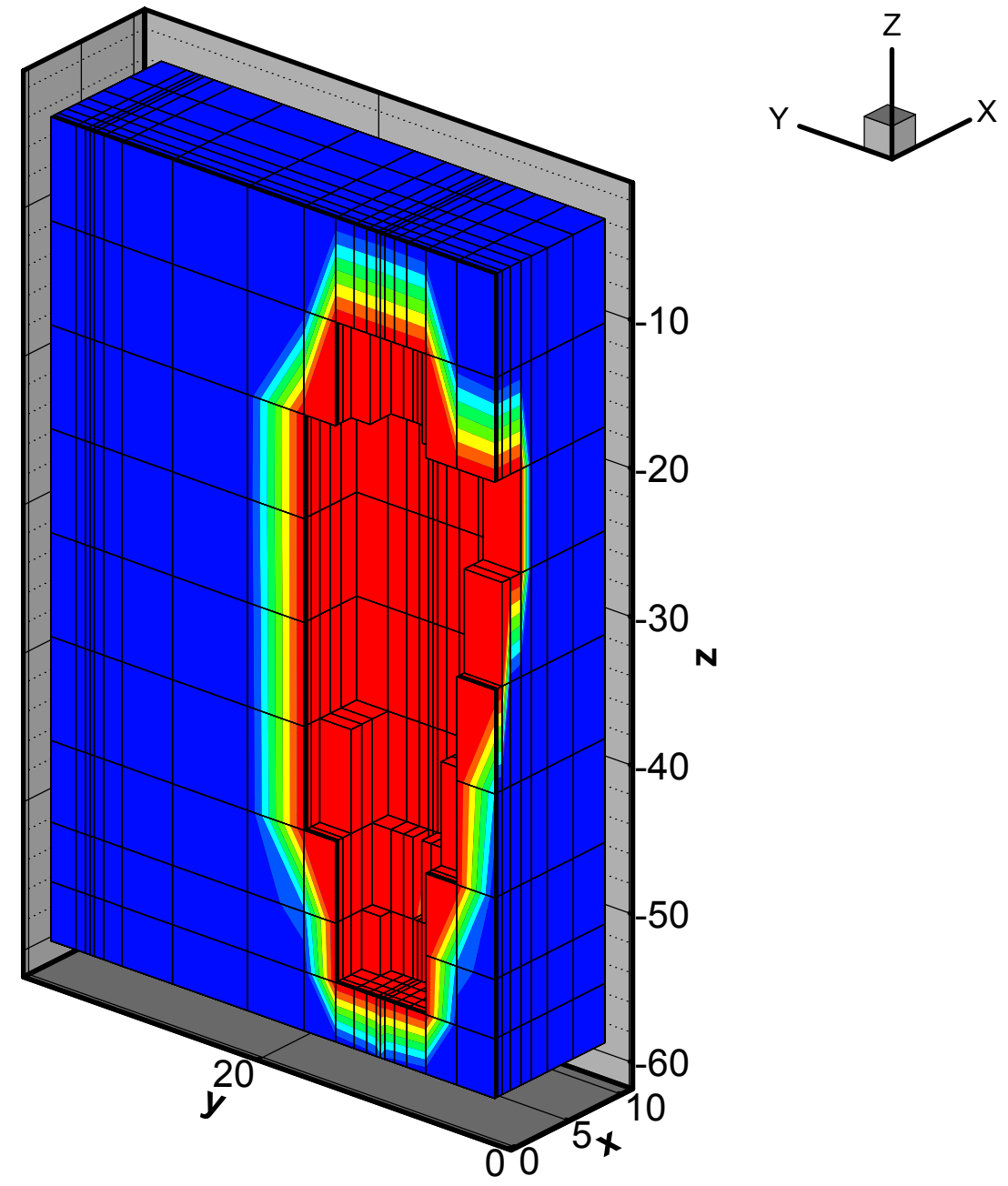

Figure 132. Single borehole with a $3 \mathrm{~mm}$ fracture, inject $100 \mathrm{gpm}$ for 98 days. 


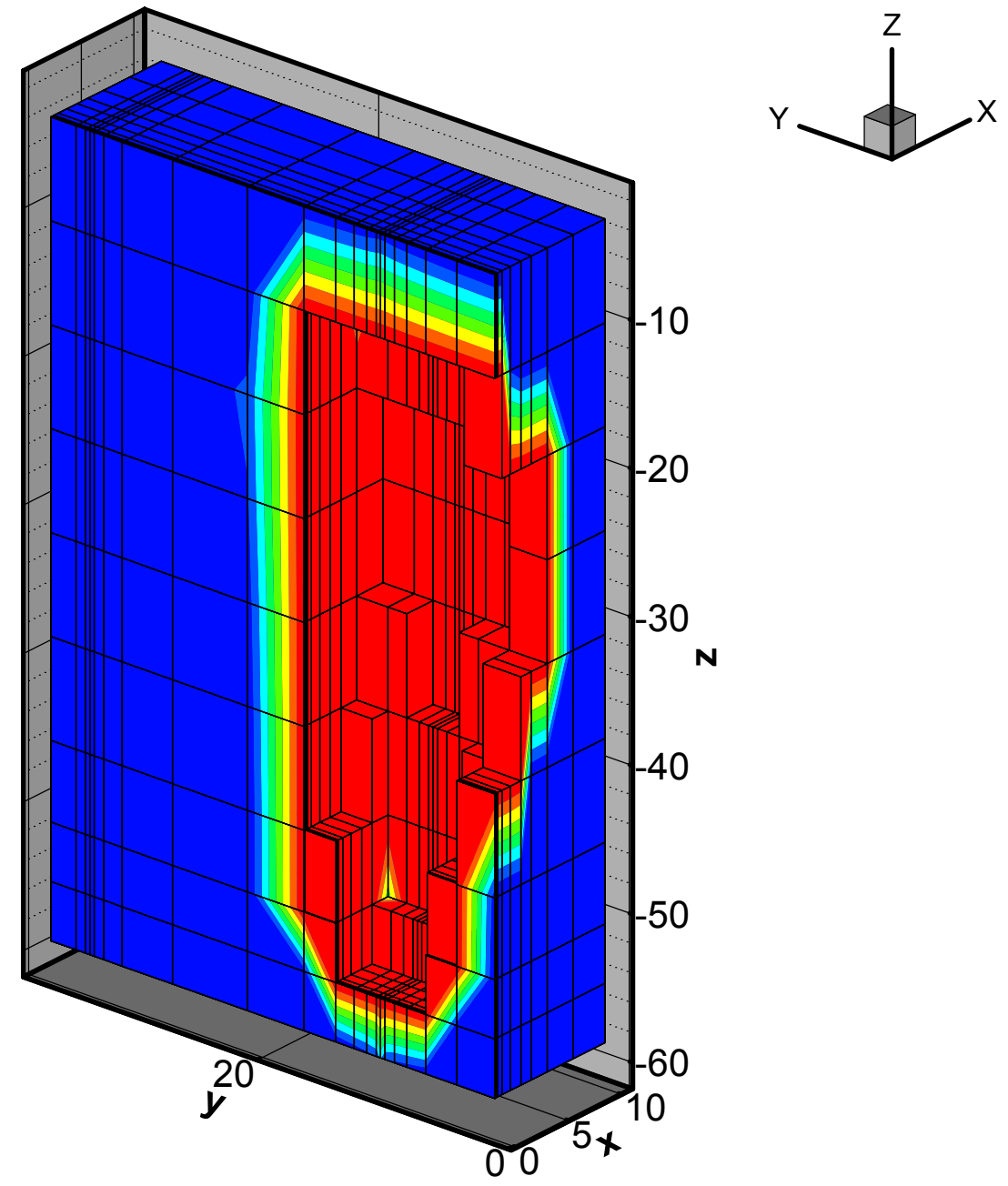

Figure 133. Single borehole with a $3 \mathrm{~mm}$ fracture, inject $100 \mathrm{gpm}$ for 140 days. 

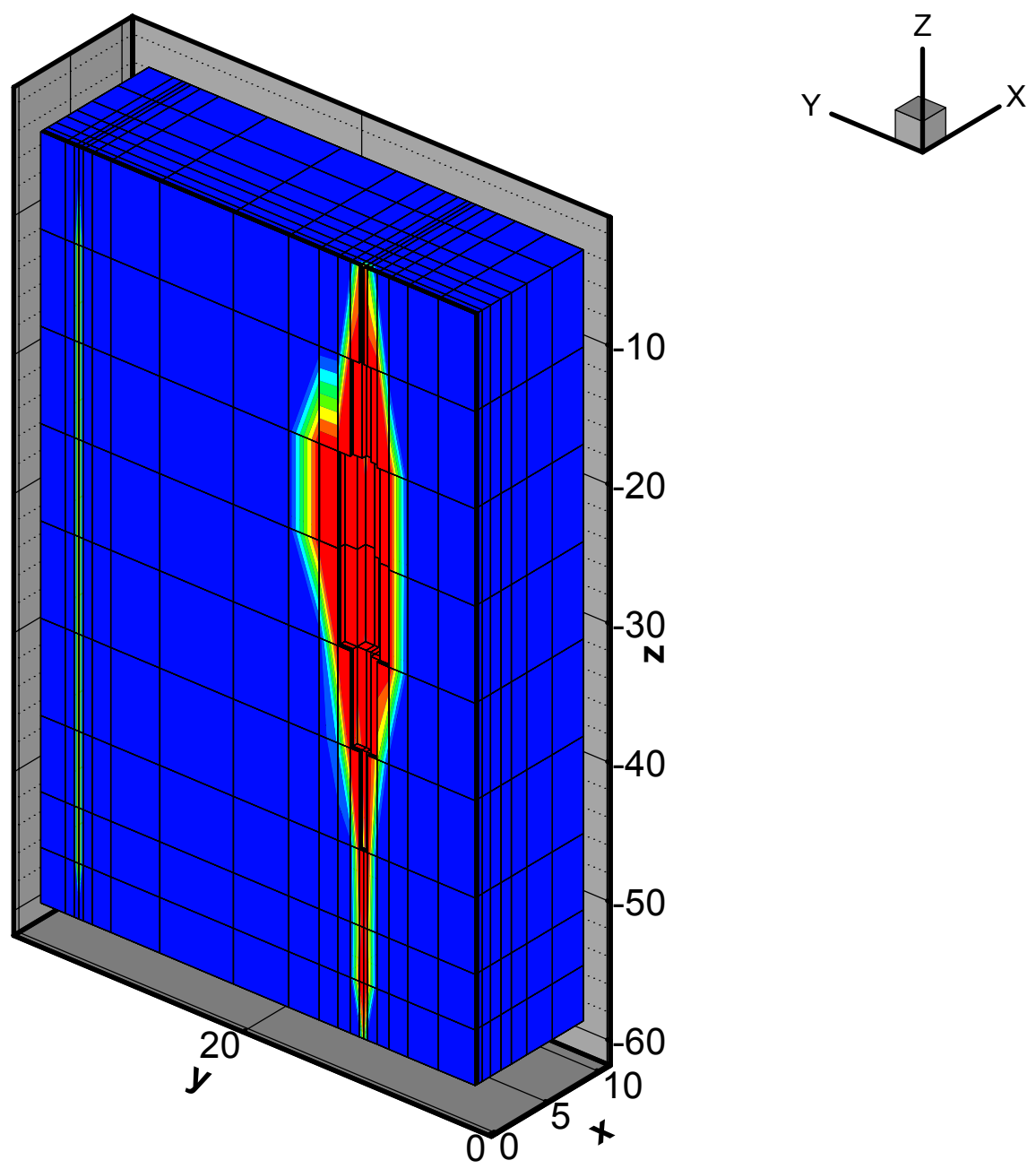

Figure 134. Two boreholes connected by a $3 \mathrm{~mm}$ fracture, inject $100 \mathrm{gpm}$ for 4.9 days. 

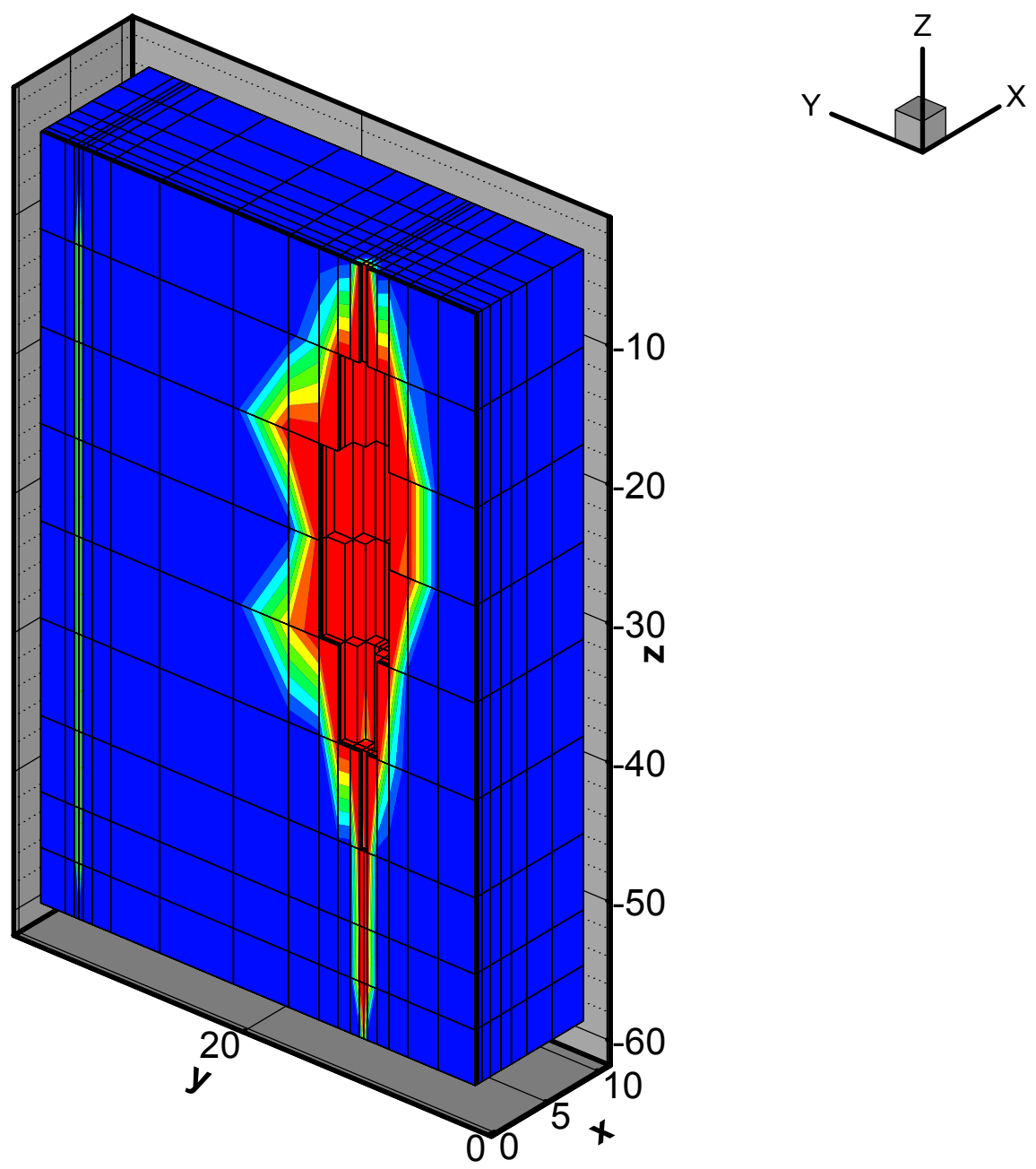

Figure 135. Two boreholes connected by a $3 \mathrm{~mm}$ fracture, inject $100 \mathrm{gpm}$ for 14 days. 

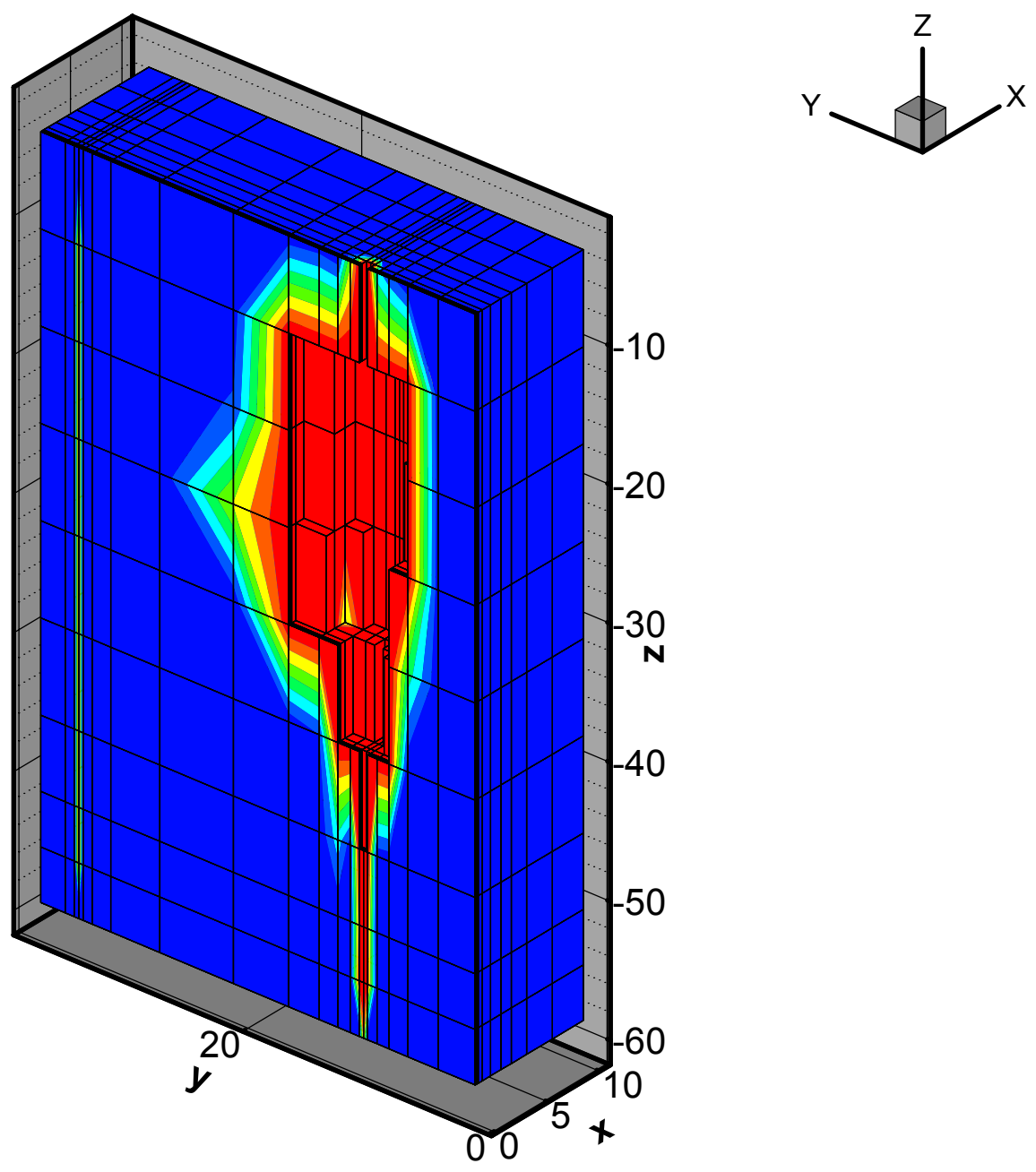

Figure 136. Two boreholes connected by a $3 \mathrm{~mm}$ fracture, inject $100 \mathrm{gpm}$ for 28 days. 

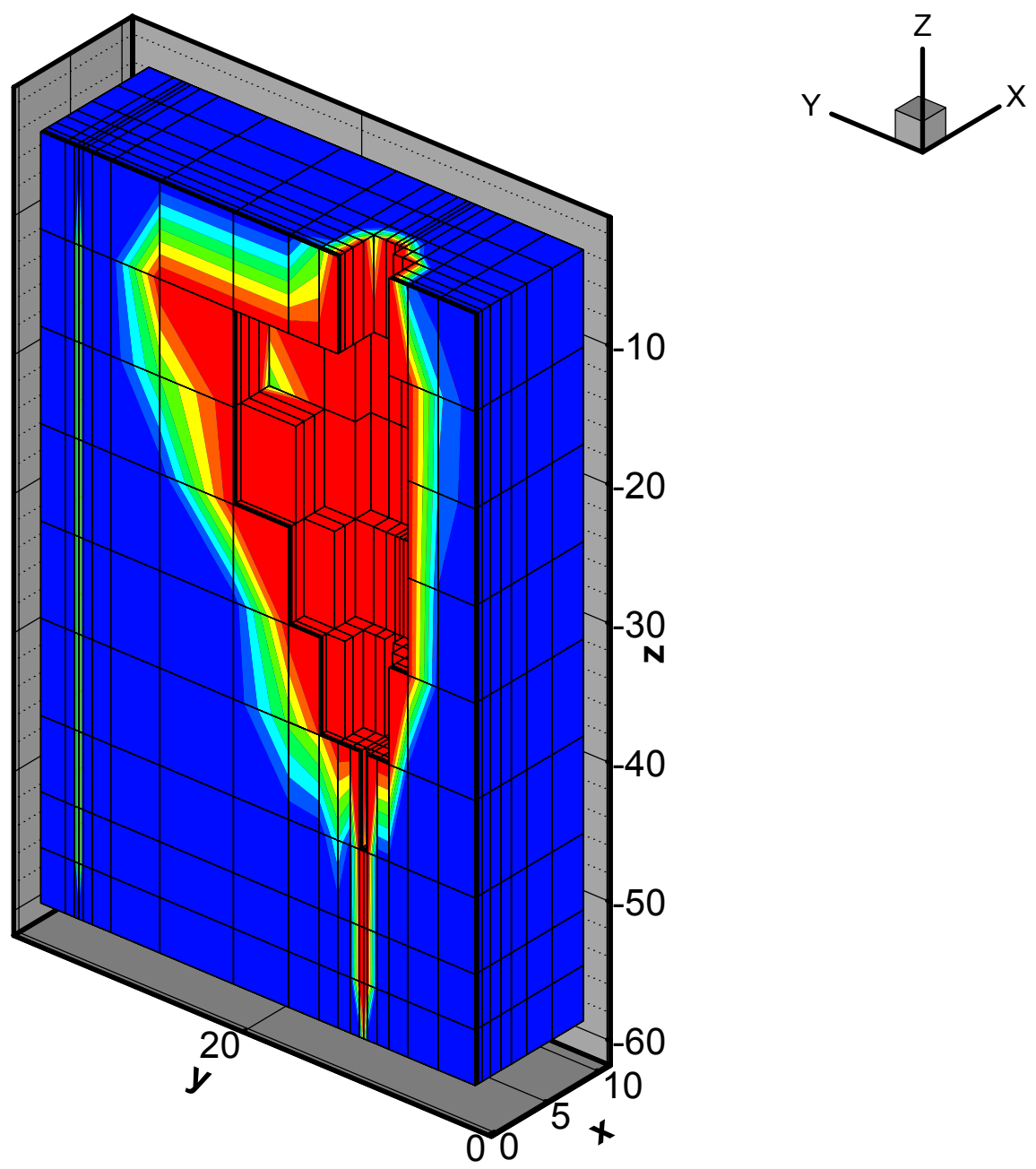

Figure 137. Two boreholes connected by a $3 \mathrm{~mm}$ fracture, inject $100 \mathrm{gpm}$ for 56 days. 

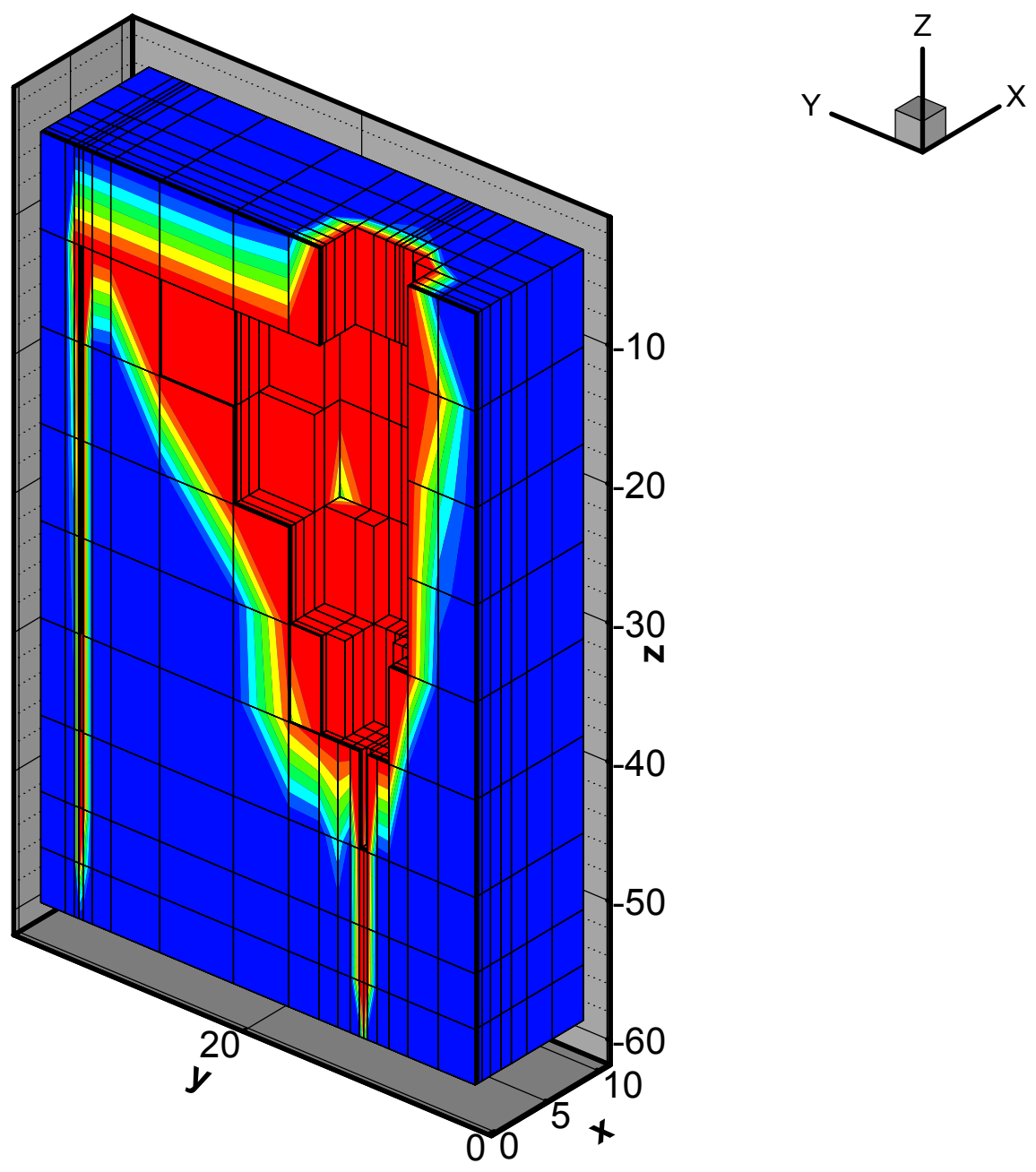

Figure 138. Two boreholes connected by a $3 \mathrm{~mm}$ fracture, inject $100 \mathrm{gpm}$ for 70 days. 

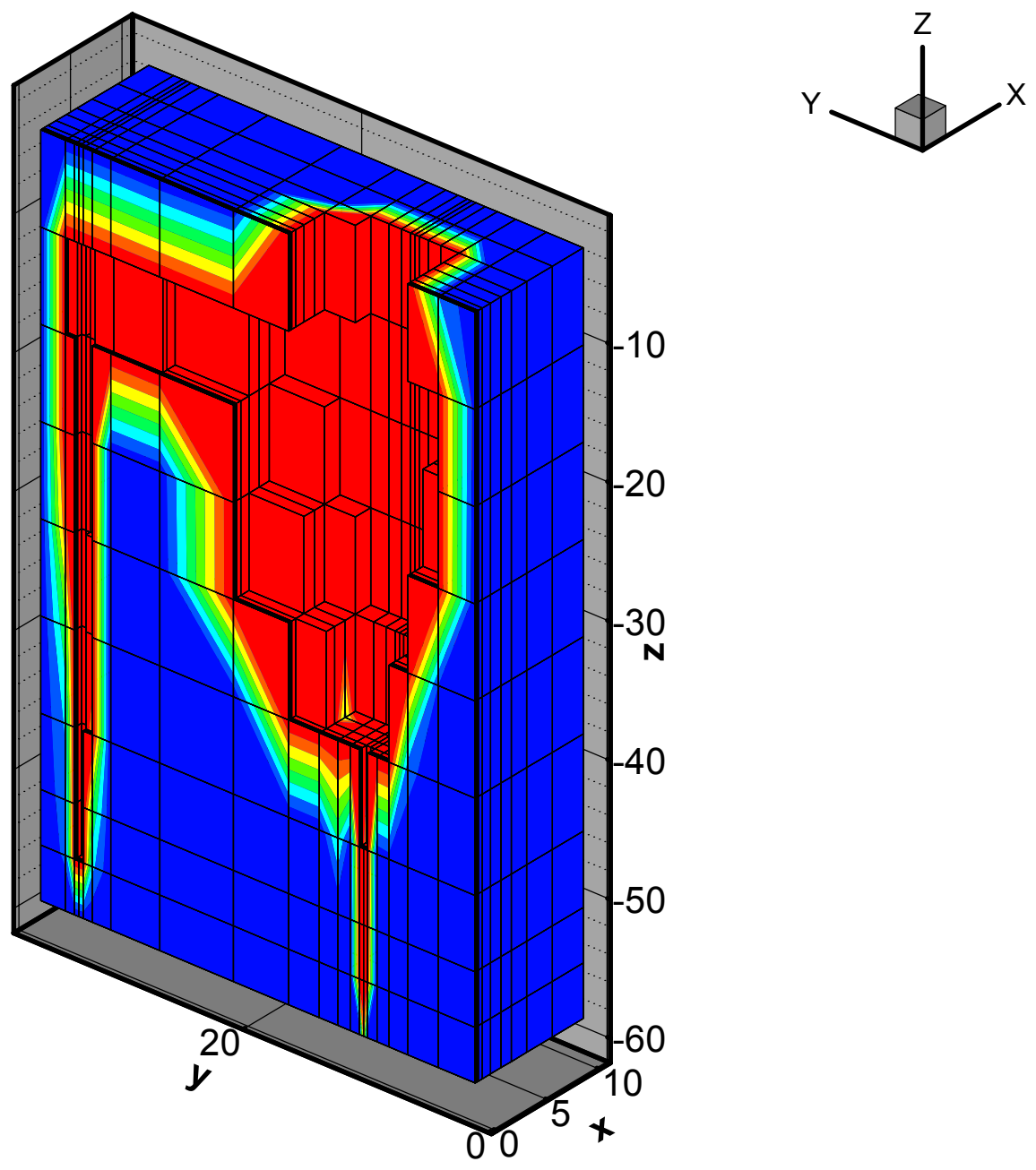

Figure 139. Two boreholes connected by a $3 \mathrm{~mm}$ fracture, inject $100 \mathrm{gpm}$ for 98 days. 

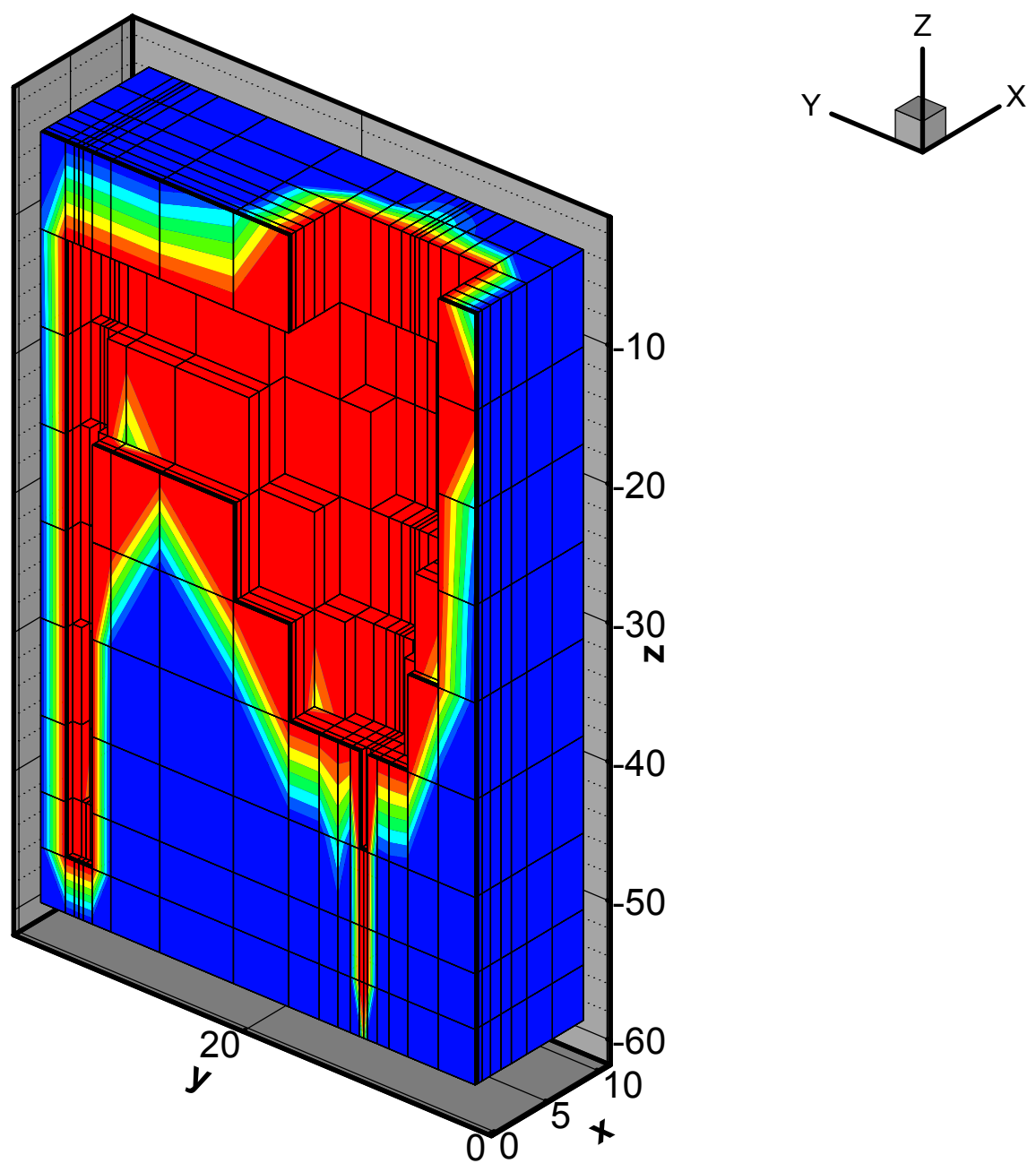

Figure 140. Two boreholes connected by a $3 \mathrm{~mm}$ fracture, inject $100 \mathrm{gpm}$ for 140 days. 


\section{Development of a Fully Coupled Numerical Simulator for the Acid Dissolution Process with Supercritical $\mathrm{CO}_{2}$ Generation}

A numerical approach that is robust, but which does not include all of the secondary reactions considered in TOUGHREACT, involves modifying the TOUGH2 EWASG code (Pruess et al., 1999; Battistelli et al., 1997) to simulate carbonated dissolution by HCl. EWASG simulates the two-phase flow of a gas and aqueous phases, with an additional $\mathrm{NaCl}$ salt component. The $\mathrm{NaCl}$ may be present as a solid (rock salt or halite), or it may dissolve into the aqueous phase. The noncondensible gas may be $\mathrm{CO}_{2}$, and if the ECO2 package from Pruess and Garcia (2002) is used, the $\mathrm{CO}_{2}$ may be supercritical. The ECO2 module for TOUGH2 was developed for simulating $\mathrm{CO}_{2}$ disposal in deep saline aquifers. It provides an accurate model for the thermophysical behavior of mixtures of $\mathrm{CO}_{2}$ and water at temperatures between 5 and $103 \mathrm{C}$, and pressures between 75 and 400 bar (Pruess and Garcia, 2002).

EWASG accounts for the change in porosity and intrinsic permeability that occurs as rock salt dissolves or precipitates by tracking a "solid saturation". This solid saturation represents the fraction of the porosity occupied by solid salt. This approach is analogous to the method used in the T2VOC rock salt dissolution simulations described in the previous section., and the same mass transfer approximation is used.

The modification to EWASG/ECO2 for the limestone cavern dissolution process involved switching the $\mathrm{NaCl}$ component to $\mathrm{CaCO}_{3}$, and adding $\mathrm{HCl}$ and $\mathrm{CaCl}_{2}$ components. The acid-rock reaction is approximated as an equilibrium process that is limited by smaller of the acid or rock mass. This new code is called T2ADS (TOUGH2 Acid Dissolution Simulator).

The relationship between the porosity and the intrinsic permeability used in EWASG and T2ADS is slightly different than that described in the previous section. EWASG and T2ADS track the reactive solid phase (limestone for T2ADS) using a variable called the "solid saturation", $\mathrm{S}_{\mathrm{s}}$. The solid saturation is the volume fraction of the porosity occupied by the reactive solid. For the case of pure limestone, the porosity in the code is set equal to one, and the effective porosity, $\phi^{\prime}$ is

$$
\phi^{\prime}=\left(1-S_{s}\right)
$$

As before, the background intrinsic permeability, $\mathrm{k}_{0}$ is set to a very high value, on the order of $10^{-7}$ or $10^{-8} \mathrm{~m}^{2}$ to simulate the open cavern. The permeability is reduction with varying solid saturations is calculated from a power function:

$$
\frac{k}{k_{0}}=\left(1-S_{s}\right)^{n}
$$

A desired formation permeability and porosity is obtained by adjusting the exponent in Equation (26). For example if $\mathrm{k}_{0}$ is set to $10^{-8} \mathrm{~m}^{2}$, and the exponent $n$ is set equal to 4 , then an initial solid saturation of 0.99 corresponds to an initial porosity of $1 \%$, and an initial permeability of $10^{-16} \mathrm{~m}^{2}$.

The new code, T2ADS was tested on a number of simple batch and one-dimensional cases to verify correct mass balances, reaction stoichiometry, phase densities, and $\mathrm{CO}_{2}$ solubility. We found that this code easily and accurately simulates injection of high strength $\mathrm{HCl}$ solutions into low porosity limestone rocks, with complete rock dissolution. Following these simple tests, 
several field scale simulations were performed. These field simulations fall into two categories: low acid strength dissolution schemes, in which all of the produced $\mathrm{CO}_{2}$ remains dissolved in the aqueous phase, and high acid strength dissolution schemes, where the generated $\mathrm{CO}_{2}$ mass exceeds the aqueous solubility, and separate phase supercritical $\mathrm{CO}_{2}$ is present. The critical acid strength where this transition takes place depends on the depth, because the $\mathrm{CO}_{2}$ solubility is a function of pressure. The $\mathrm{CO}_{2}$ solubility and maximum $\mathrm{HCl}$ acid strength that can be used without forming a separate $\mathrm{CO}_{2}$ phase are plotted with depth in Figure 141. Depending on the depth, the critical acid strength is approximately 8 to $12 \%$. This is still a fairly concentrated acid, so it may be feasible to dissolve caverns using $\mathrm{HCl}$ without having to deal with a separate $\mathrm{CO}_{2}$ phase in the cavern. It should be noted, however, that dissolved $\mathrm{CO}_{2}$ will tend to come out of solution as the brine is brought to the ground surface, and the pressure is reduced.

The field scale simulations were designed to model a moderate scale field demonstration or pilot project. Larger scale simulations would have the same general features, but they would involve higher injection rates over larger vertical intervals, over longer periods of time. The basic configuration use here was a single 8 inch diameter open borehole, $33 \mathrm{ft}$ in length, located at a depth of $6700 \mathrm{ft}$. Acid is injected at $1 \mathrm{~kg} / \mathrm{s}$ (about $15 \mathrm{gpm}$ ) at a single location for either 10 days $(30 \% \mathrm{HCl})$, or 30 days $(10 \% \mathrm{HCl})$. Fluids are produced from the bottom of the open borehole against a constant bottomhole pressure, that was set to hydrostatic pressure. The formation intrinsic permeability was $10^{-16} \mathrm{~m}^{2}$ (100 millidarcy), and the porosity was $1 \%$. A radially symmetric r-z numerical grid is used.

The first case involves injecting a $30 \% \mathrm{HCl}$ solution into the top of the open borehole with production at the bottom (Figure 142). Over the 10 day acid injection, the cavern develops primarily near the fluid outlet at the bottom of the borehole. This occurs because of the supercritical $\mathrm{CO}_{2}$ phase that develops, and occupies the upper part of the cavern (Figure 143). As more and more $\mathrm{CO}_{2}$ is generated by the acid reaction, it pushes the fluid interface down towards the outlet, until finally, some of the $\mathrm{CO}_{2}$ starts to escape from the outlet. As this happens, the injected acid falls down through the $\mathrm{CO}_{2}$ phase until it hits the fluid interface, where it spreads out laterally towards the cavern wall (Figure 144). When the acid hits the cavern wall, it dissolves the limestone, creating $\mathrm{CO}_{2}$ and $\mathrm{CaCl}_{2}$. The $\mathrm{CO}_{2}$ moves upward because it is less dense than the acid or the brine, while the $\mathrm{CaCl}_{2}$ moves downward because it is more dense than the acid or the $\mathrm{CO}_{2}$. This particular configuration is inefficient, because a substantial fraction of the injected acid flows out of the outlet, due to the low fluid level in the cavern from the $\mathrm{CO}_{2}$

A second case consists of the exact same configuration as the first case, but with the lower acid strength of $10 \%$. In this case, the cavern forms mainly upward from the injection point (Figure 145), due to the fact that the injected acid is less dense than the $\mathrm{CaCl}_{2}$ brine with dissolved $\mathrm{CO}_{2}$. Interestingly, dissolving $\mathrm{CO}_{2}$ in water results in an increase in the aqueous phase density. This simulation resulted in the cavern reaching the upper boundary of the numerical grid, a no-flow boundary. A similar effect might be seen in a real system if an non-reactive rock such as a shale were present at this elevation.

Because of the problem of the second simulation encountering the boundary, a 10\% acid injection was repeated, but with a lower acid injection point (Figure 146). Again, the cavern moves upward from the injection point, due to the buoyancy contrast that causes the acid to move towards the upper part of the cavern (Figure 147). If a tall, cylindrical volume was desired, the acid injection point could be slowly moved upwards, as is done in some salt cavern 
projects.

The final case uses a high acid concentration, with acid injection approximately twothirds of the way up the borehole, with an extraction tube at both the top and the bottom of the cavern. These extraction points were constrained to different pressures, with a pressure difference equal to the hydrostatic pressure over the borehole length. This pressure difference was chosen so that a supercritical $\mathrm{CO}_{2}$ - brine interface would stabilize near the midpoint of the borehole, with liquid brine production from the bottom extraction point, and supercritical $\mathrm{CO}_{2}$ production from the top extraction point (Figure 148). Once the liquid interface stabilizes, the acid drops down through the $\mathrm{CO}_{2}$, and spreads out towards the cavern wall, where it reacts to form $\mathrm{CO}_{2}$ and $\mathrm{CaCl}_{2}$ (Figure 149). The extraction well pressures were held constant in this simulation, but if they were varied slightly, the liquid interface, and hence the location of acidrock contact, could be moved up and down with time.

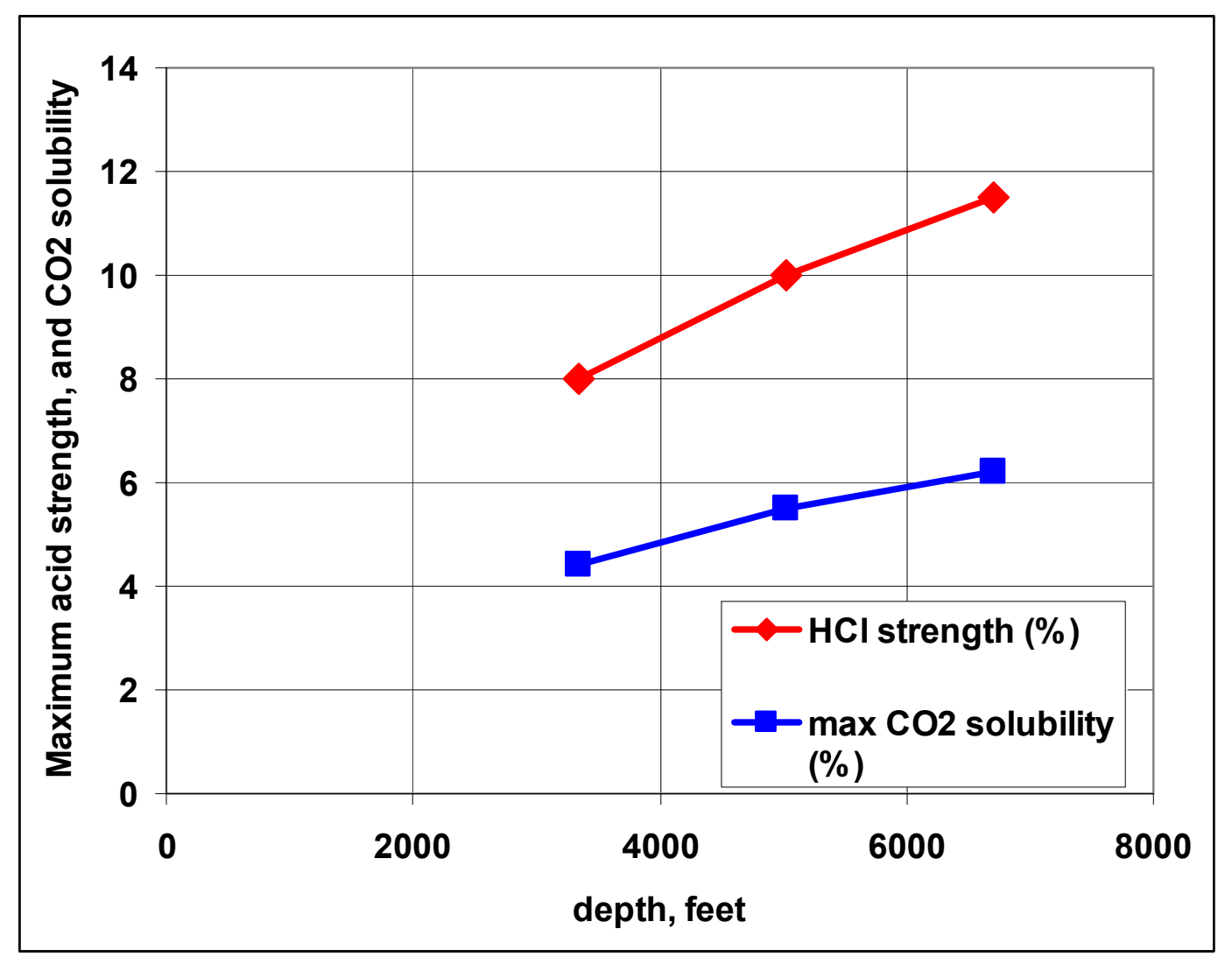

Figure 141. $\mathrm{CO}_{2}$ solubility and maximum acid strength (to prevent separate phase $\mathrm{CO}_{2}$ ) as a function of depth, assuming hydrostatic pressure. 

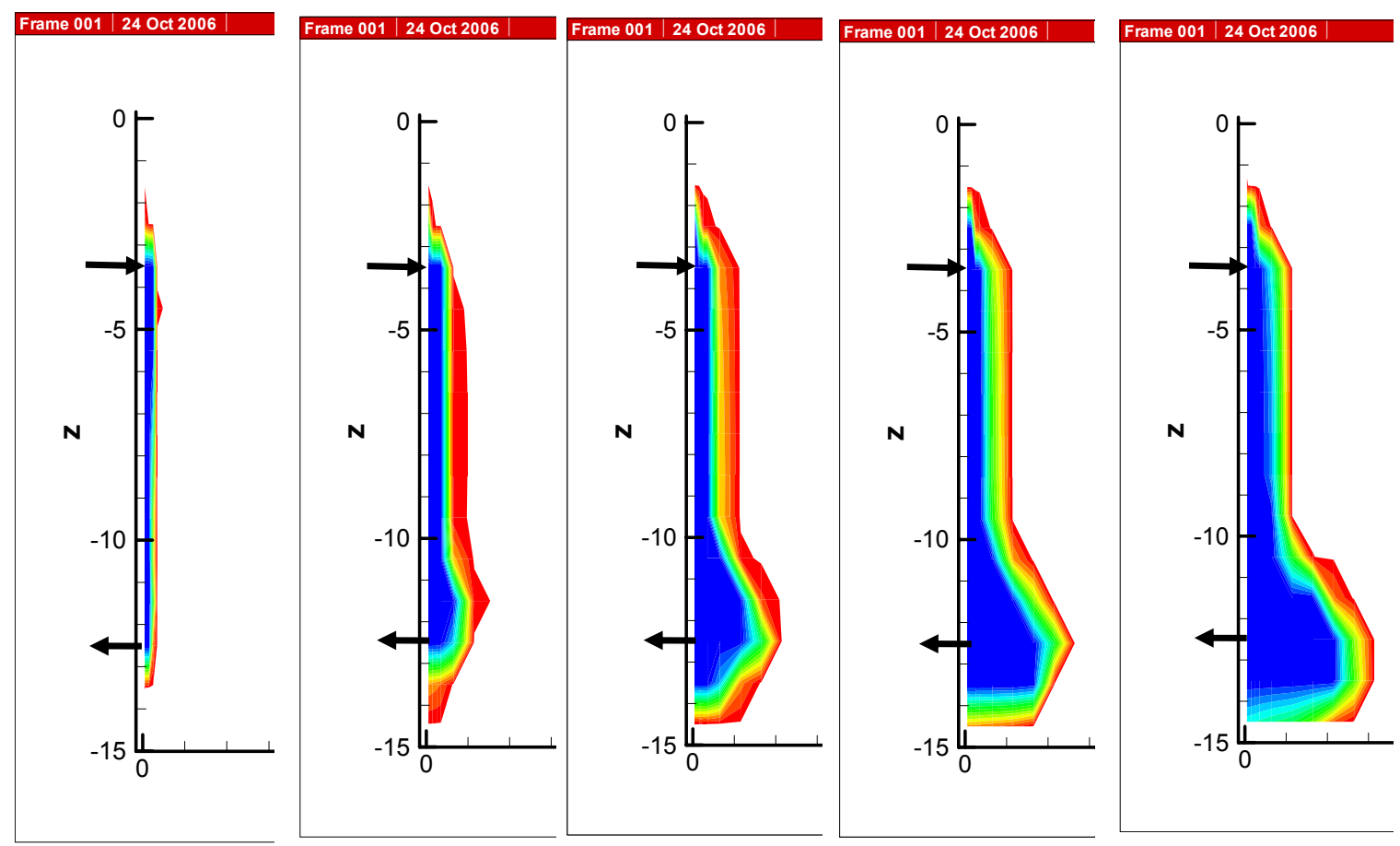

Figure 142. Cavern formation during the injection of $30 \% \mathrm{HCl}$. Cavern is shown at $0.2,1,3,5$, and 10 days of acid injection.
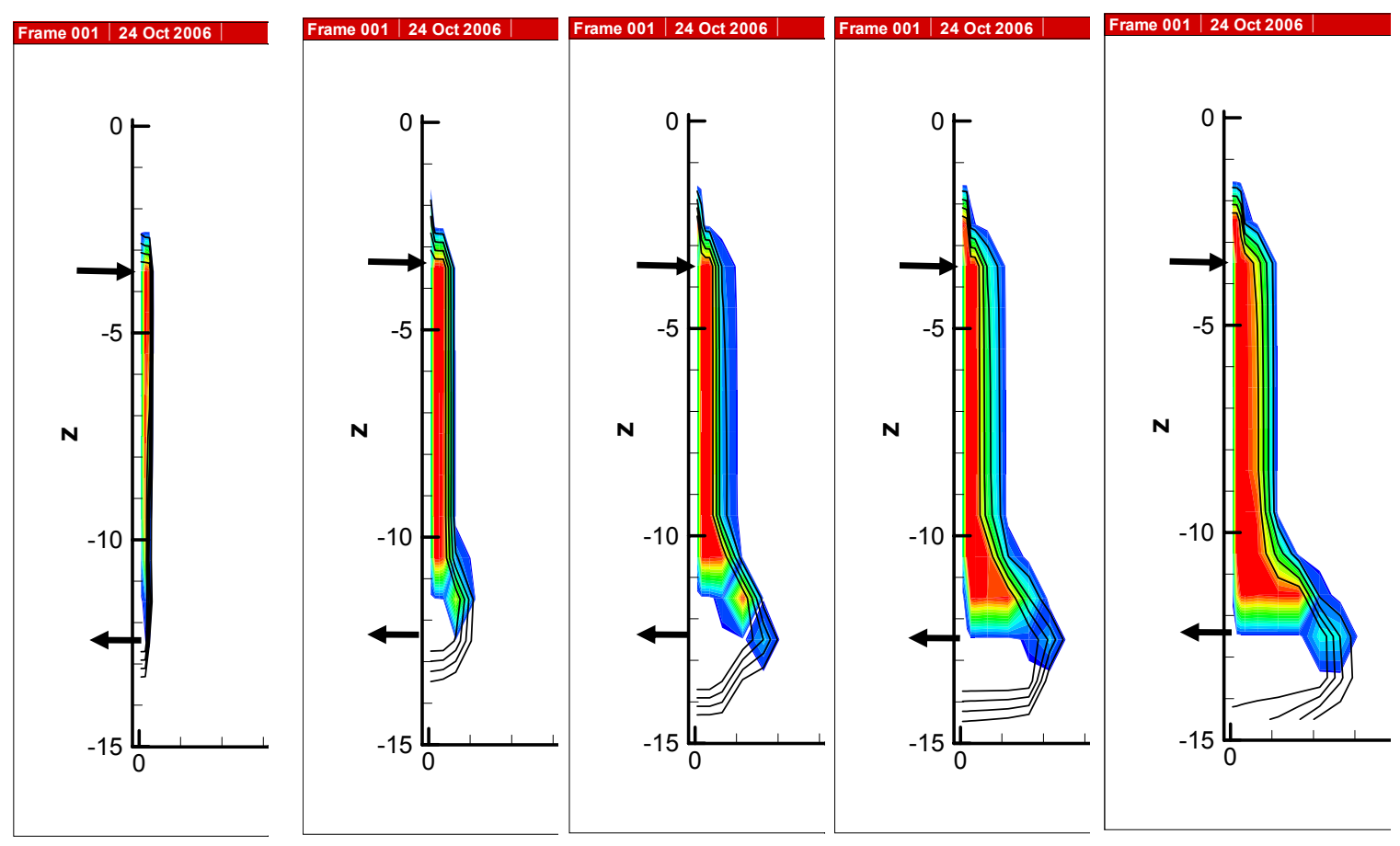

Figure 143. $\mathrm{CO}_{2}$ volume during the injection of $30 \% \mathrm{HCl}$. Cavern is shown at $0.2,1,3,5$, and 10 days of acid injection. Red indicates more than $90 \% \mathrm{CO}_{2}$, and the solid contours show the extent of the cavern. 

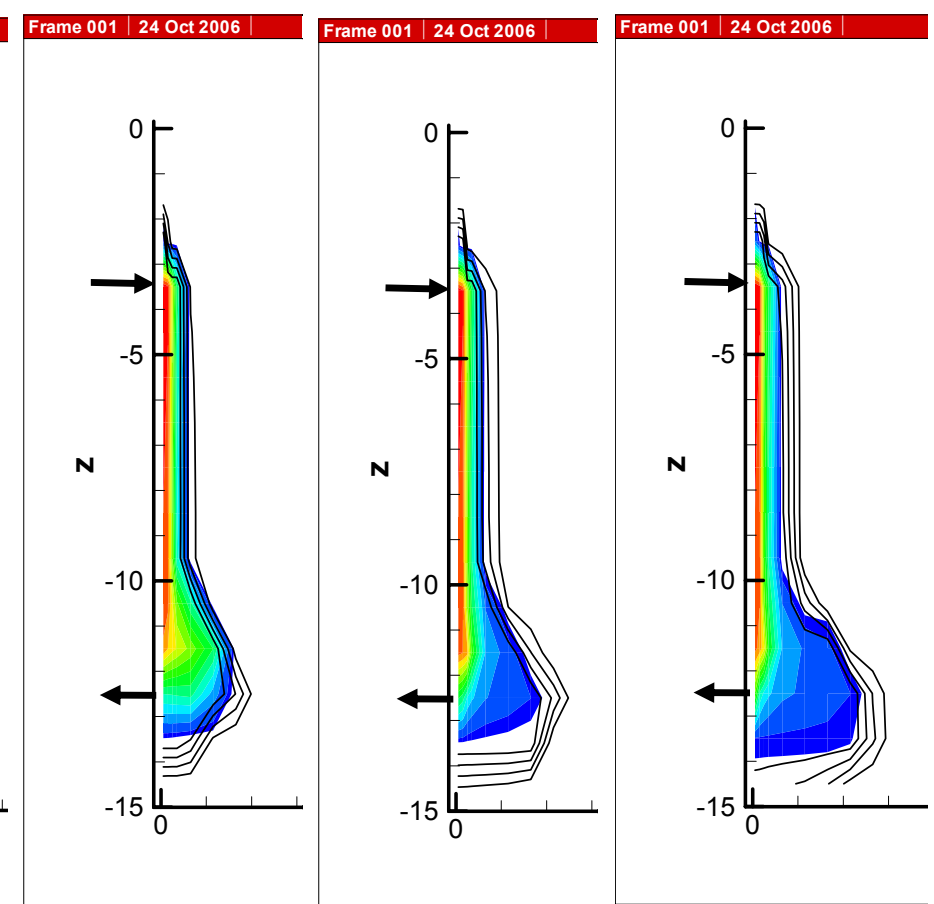

Figure 144. $\mathrm{HCl}$ mass fraction during the injection of $30 \% \mathrm{HCl}$. Cavern is shown at $0.2,1,3,5$, and 10 days of acid injection. Red indicates more than $25 \% \mathrm{HCl}$, and the solid contours show the extent of the cavern.
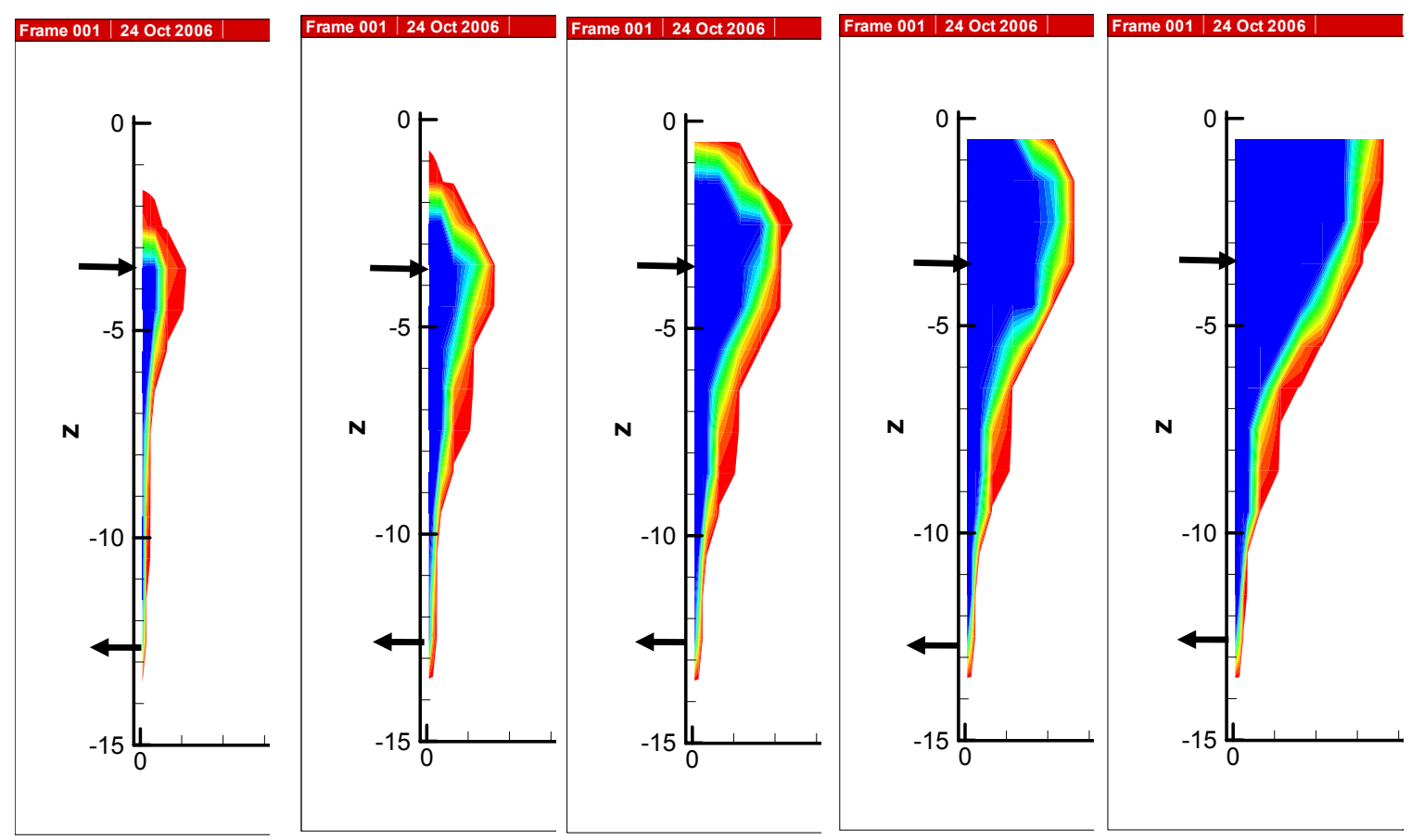

Figure 145. Cavern formation during the injection of $10 \% \mathrm{HCl}$. Cavern is shown at $0.5,3,9$, 15 , and 30 days of acid injection. 

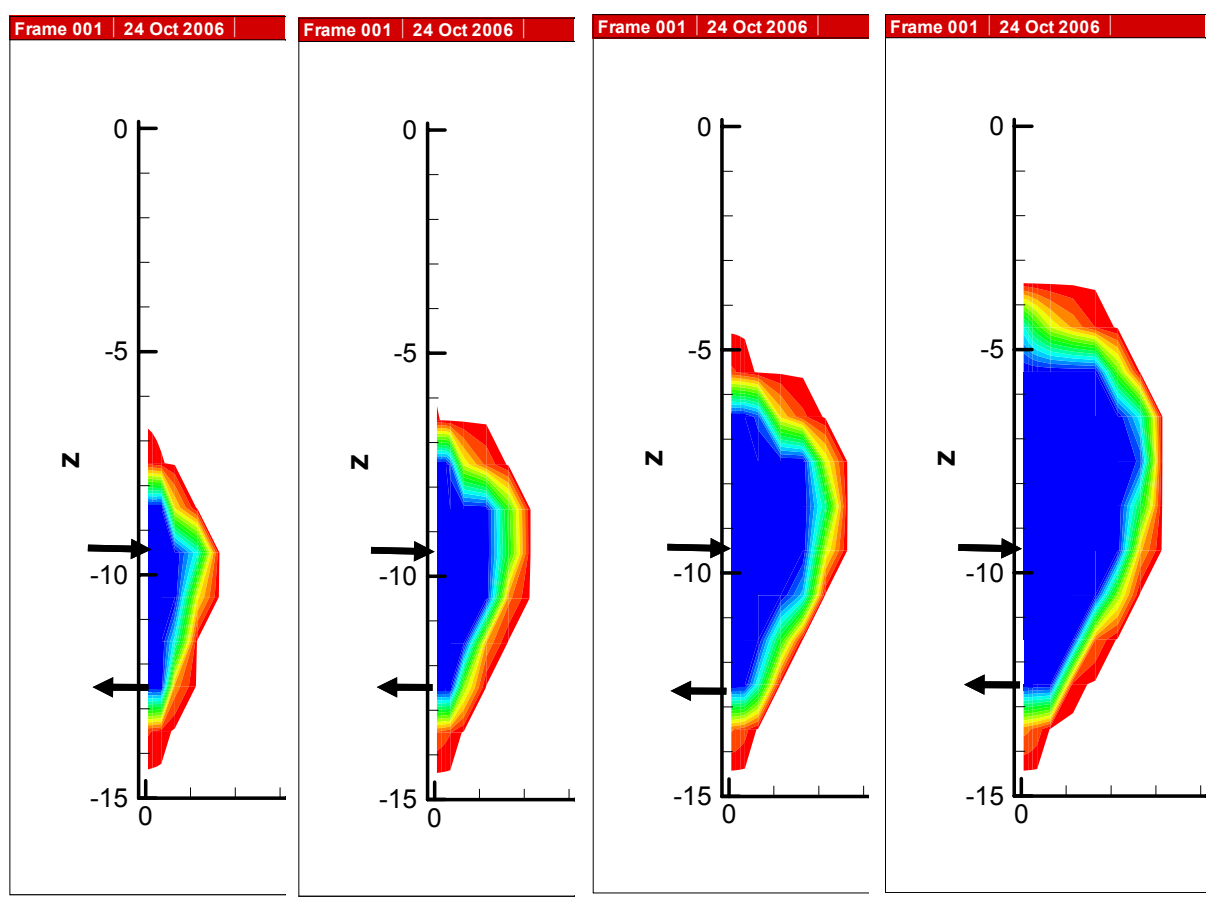

Figure 146. Cavern formation during the injection of $10 \% \mathrm{HCl}$. Cavern is shown at $0.5,3,9$, 15 , and 30 days of acid injection.
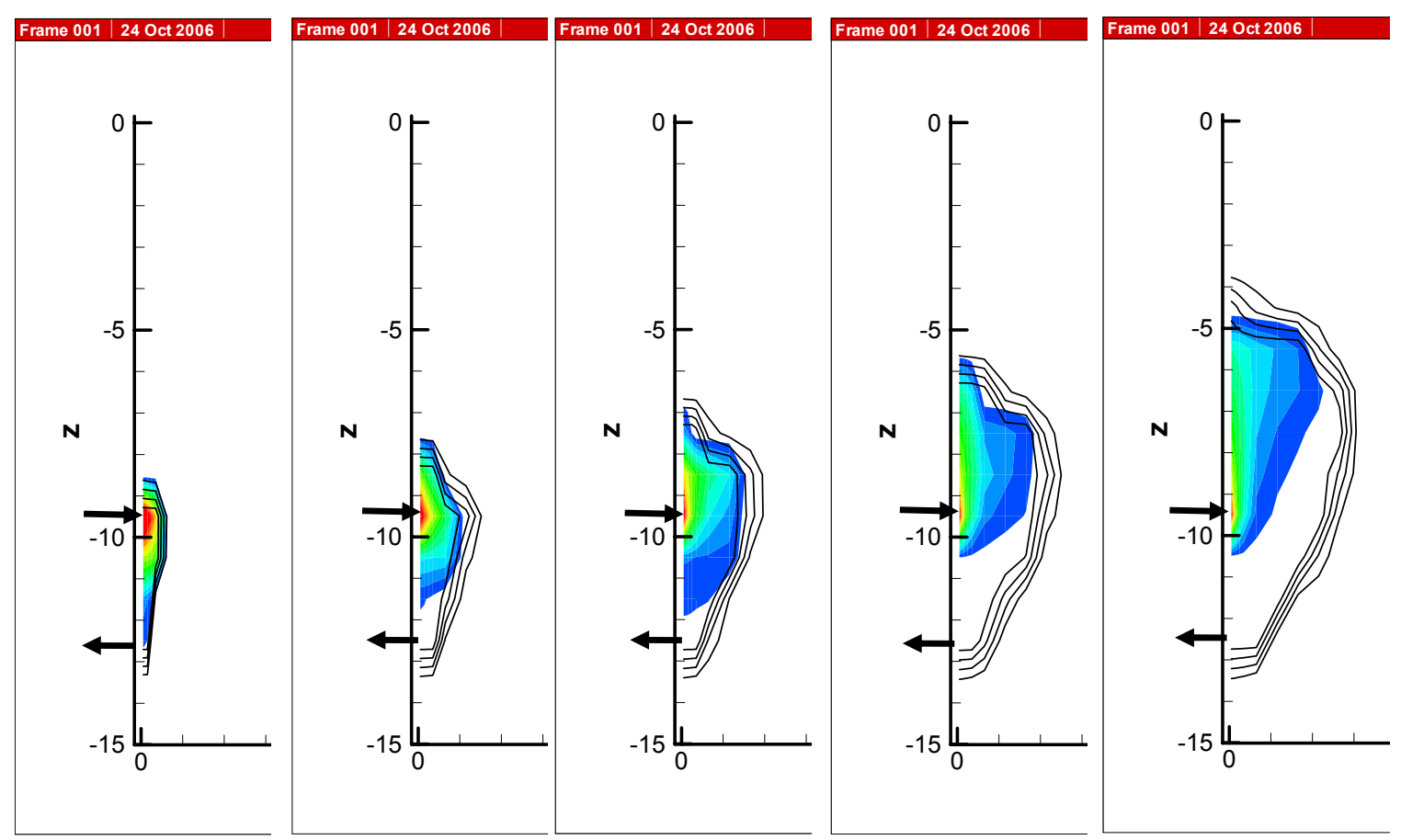

Figure 147. $\mathrm{HCl}$ mass fraction during the injection of $10 \% \mathrm{HCl}$. Cavern is shown at $0.5,3,9$, 15 , and 30 days of acid injection. Red corresponds to acid concentrations greater than $8 \%$, and the black contours show the extent of the cavern (which is liquid filled). 

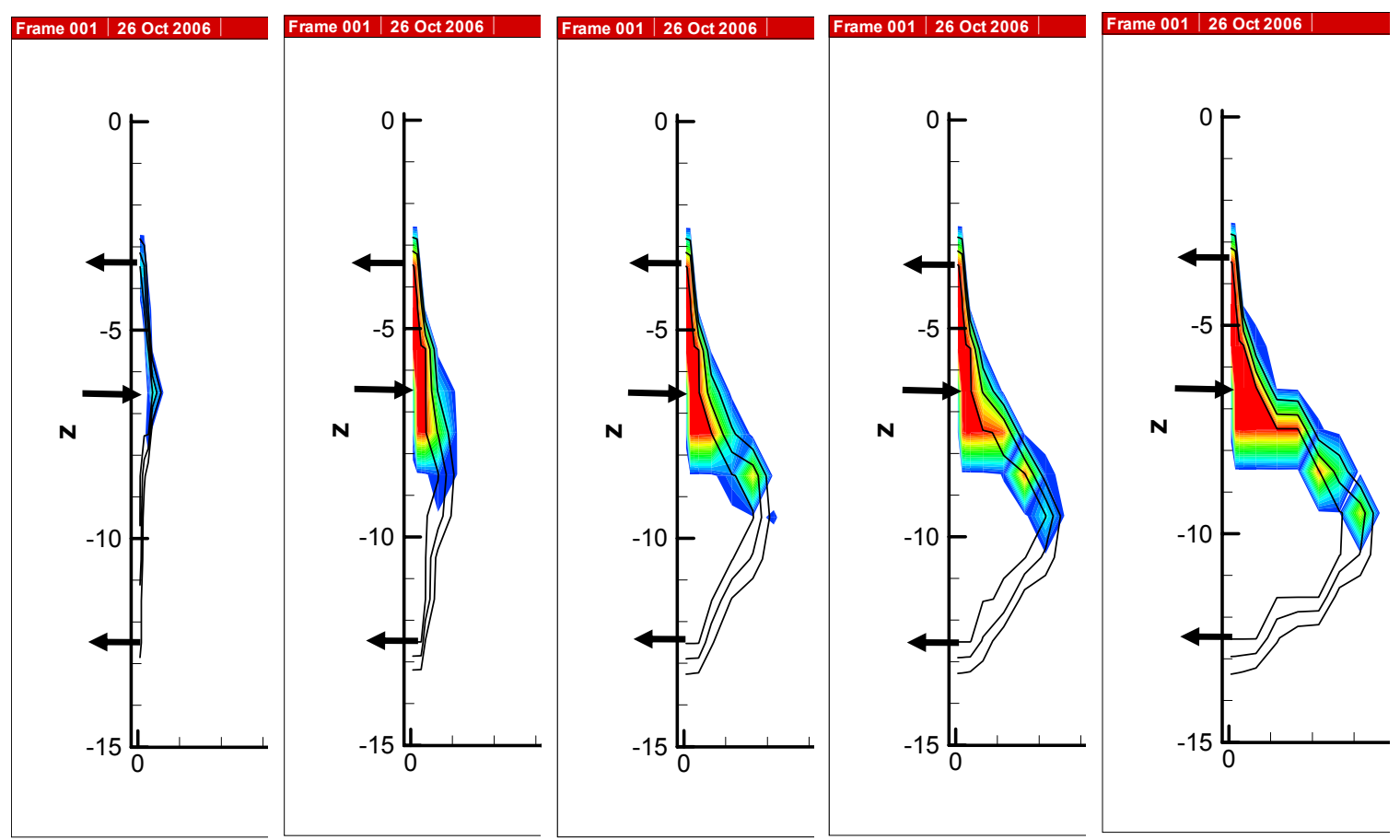

Figure 148. Cavern formation and $\mathrm{CO}_{2}$ volume during the injection of $30 \% \mathrm{HCl}$. Cavern is shown at $0.2,1,3,5$, and 10 days of acid injection. Red corresponds to greater than $90 \% \mathrm{CO}_{2}$, and the black contours show the extent of the cavern.
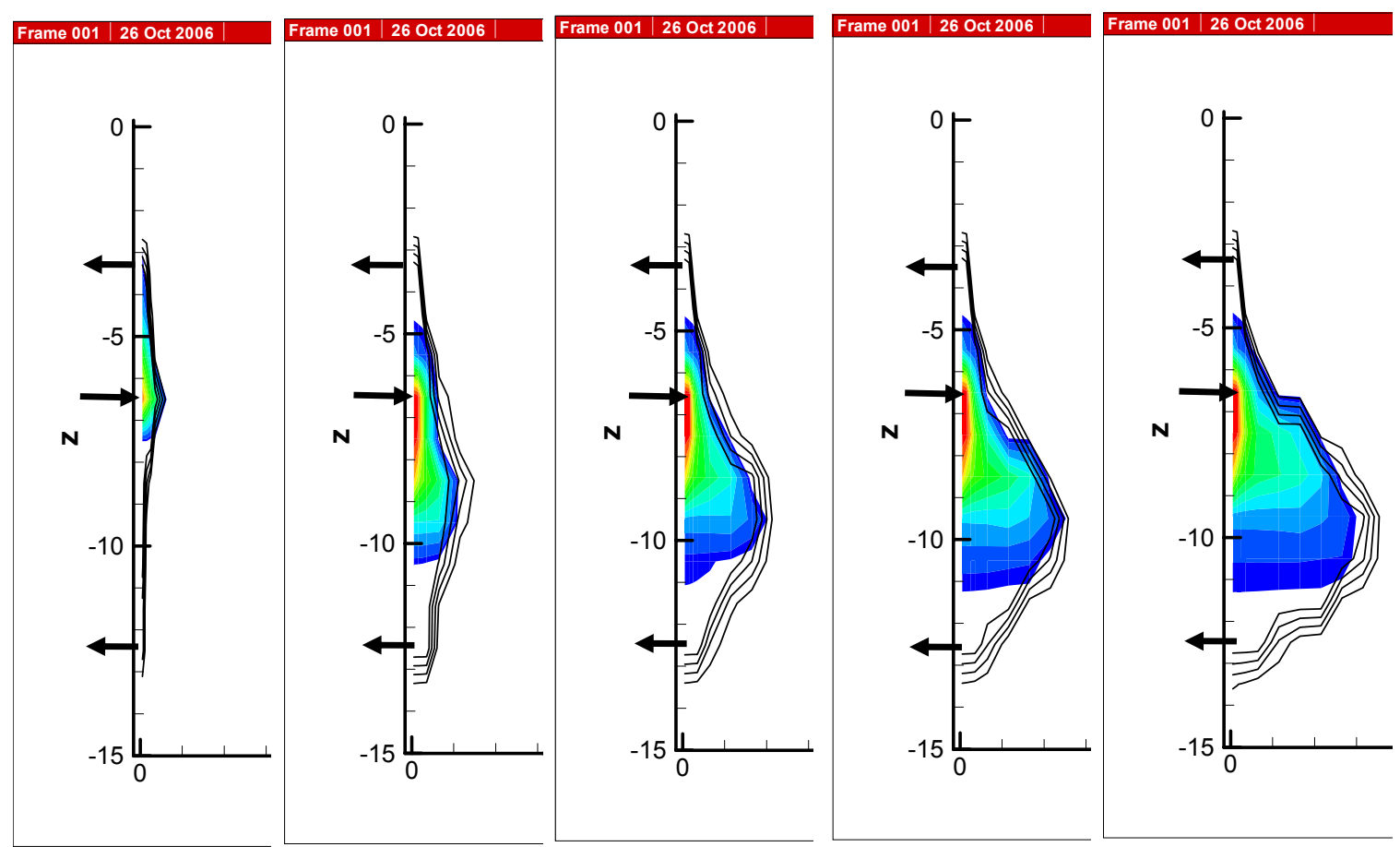

Figure 149. HCL mass fraction during the injection of $30 \% \mathrm{HCl}$. Cavern is shown at $0.2,1,3$, 5 , and 10 days of acid injection. Red corresponds to acid concentrations greater than $25 \%$. 


\section{Modeling Field Performance (Task 9) \\ By Ron Falta}

Numerical simulations were performed to evaluate the ability of an open cylindrical cavern in a porous media to store natural gas. These simulations were performed using the TMVOC multiphase simulator (Pruess and Battistelli, 2002). This simulator can consider multiple condensable and noncondensable hydrocarbon gases, using the real gas law. The simulations of cavern storage only considered the injection of pure methane $\left(\mathrm{CH}_{4}\right)$, but other gas mixtures could be considered. The simulations used a radially symmetric r-z grid with 20 elements in the radial dimension, and 52 elements in the vertical dimension. The cavern was discretized as a vertical cylinder, with a radius of $10 \mathrm{~m}$, and a height of $180 \mathrm{~m}$. The volume of this cavern is therefore $56,549 \mathrm{~m}^{3}$, or $2,000,000 \mathrm{ft}^{3}$. The numerical grid extends out to a radius of $500 \mathrm{~m}$, and it is $525 \mathrm{~m}$ tall (Figure 150 ).

The top of this cavern is located at a depth of $1840 \mathrm{~m}(6000 \mathrm{ft})$, and hydrostatic boundary conditions are used on all of the model boundaries (top, bottom, outer edge) to reflect this depth. The reservoir temperature is assumed to be constant at $65 \mathrm{C}$. Each simulation consists of two parts. In the first part, methane is injected into the top of the cavern, displacing water from the bottom of the cavern against a downhole pressure of $19.8 \mathrm{MPa}(2850 \mathrm{psi})$. Methane is injected for 60 days at a constant mass rate of $1.3 \mathrm{~kg} / \mathrm{s}$. for a total of $6,740,000 \mathrm{~kg}$, or about $360 \mathrm{MMCF}$. This is just enough gas to fully fill the cavern if there is no gas leakage into the surrounding formation, and the gas compression at this temperature and pressure is about a factor of 180 times above standard conditions, yielding a downhole methane gas density of about $120 \mathrm{~kg} / \mathrm{m}^{3}$. Following this gas injection period, the gas is stored for 5 years.

Simulations were run using formation permeabilities of $10^{-18} \mathrm{~m}^{2}$ to $10^{-15} \mathrm{~m}^{2}$, or from 1 microdarcy to 1 millidarcy. The formation porosity was set to 0.1 in each case, and standard two-phase gas-water relative permeability curves were used in the formation. The cavern was given a porosity of 1 and permeability of $10^{-9} \mathrm{~m}^{2}$.

The gas phase saturation after the 60 day injection period for the 1 microdarcy case is shown in Figure 150. As can be seen, all of the gas is contained in the cavern with no leakage into the surrounding formation. After 5 years of storage (Figure 151), virtually all of the methane remains in the cavern.

The case with a formation permeability of 10 microdarcies behaves in a similar fashion. After the 60 day injection period, virtually all of the methane is contained in the cavern. After a 5 year storage period (Figure 152), almost all of the methane is still contained by the cavern. When the formation permeability is increased to 100 microdarcies ( 0.1 millidarcy), the behavior starts to change. After the 60 day injection period, almost all of the gas is contained within the cavern. However, after 5 years, about $15 \%$ of the gas has leaked out of the top of the cavern into the formation (Figure 153).

When the formation permeability is increased to 1 millidarcy, the behavior of the gas in the cavern is dramatically different. The gas distribution at the end of the 60 day injection period is shown in Figure 154. Although most of the gas is contained in the cavern at this time, there is also significant gas leakage into the formation. After 180 days ( 60 days of injection, 120 days of storage), more leakage is evident (Figure 155), although most ( $85 \%)$ of the gas is still contained in the cavern. However, after 1 year (Figure 156), much of the gas has leaked out of the cavern, 
and the bottom of the cavern is filling with water. At this time, the cavern only contains about two-thirds of the injected amount. After 2 years, more than half of the methane has leaked out of the cavern, and by 3 years (Figure 157), less than a third of the methane remains in the cavern. By a time of 5 years the cavern is full of water, and all of the methane is in the permeable formation.

These simulations suggest that formation permeabilities that are greater than 1 millidarcy may allow for substantial gas leakage out of the cavern (Table 49). If the top of the cavern is bounded by a lower permeability formation, this may be acceptable, but if the formation is continuous, the leakage rate may be too high, depending on storage requirements.

Table 49. Long term storage of methane in caverns of varying wall permeability

\begin{tabular}{|c|c|}
\hline Intrinsic Permeability & $\begin{array}{c}\text { Percent of Injected Methane Remaining in } \\
\text { Cavern after Five Years }\end{array}$ \\
\hline 1 microdarcy & $100 \%$ \\
\hline 10 microdarcy & $100 \%$ \\
\hline 100 microdarcy & $85 \%$ \\
\hline 1 millidarcy & $0 \%$ \\
\hline
\end{tabular}

An important characteristic of a gas storage cavern is its ability to retain the gas during a cyclical operation. Gas can be cyclically stored in a cavern using one of two configurations. As shown in the previous simulations, gas can be injected into a water filled cavern, displacing the water against a specified downhole pressure (most likely the hydrostatic pressure at that depth). In this scenario, the gas could be produced by injecting water back into the cavern, and producing the gas. Therefore, the gas cycle would involve repeated filling and emptying of the cavern, and pressures would remain fairly close to hydrostatic pressure.

A second method of cycling the gas would be to initially fill the cavern with gas, displacing the water against a hydrostatic pressure, as before. Once the cavern was filled with gas, the water production tube could be closed, sealing the cavern. Additional gas would be injected into the cavern, pressurizing it above the hydrostatic pressure. In this case, the addition gas storage occurs as the constant gas volume is pressurized, increasing the gas density. Gas would be produced by simply letting it flow out of the cavern, allowing the gas pressure to drop as the gas expanded. With this scenario, the cavern always remains gas filled, but the pressure cycles fairly dramatically. This pressure cycling could lead to excess leakage of gas out of the cavern if the surrounding rock permeability is too high.

A numerical simulation of a pressure cycle was performed using the same model grid and conditions as in the previous gas storage simulations. This simulation uses a rock intrinsic permeability of 100 microdarcy, which was shown earlier to be capable of storing most of the gas volume over a 5 year period. The simulation first models the filling of the cavern by displacing the water over a 60 day period. Once the cavern is full of gas, at a pressure of 19.8 $\mathrm{MPa}(2850 \mathrm{psi})$, the water outlet is shut. Gas is injected for an additional 30 days at the same rate of $1.3 \mathrm{~kg} / \mathrm{s}$, before the cavern is shut in. At this time, the cavern pressure is about $30 \mathrm{MPa}$ (4275 psi), and the total gas in storage is $10,109,000 \mathrm{~kg}$, or $540 \mathrm{MMCF}$. The cavern pressure during the pressurization and shut in periods are shown in Figure 158. With a 100 millidarcy formation permeability, the over pressure dissipates over a one-year period as some of the gas leaks into the surrounding formation (Figure 159). This simulation suggests that at this depth, 
over-pressurization cycling in a cavern with a formation permeability of 100 microdarcy may lead to a significant gas loss. This loss would be much lower at lower permeabilities.

The cavern geometry used in these simulations was a long, narrow vertical cylinder. Due to the low methane density at reservoir temperature and pressure (about $120 \mathrm{~kg} / \mathrm{m}^{3}$ ), as the cavern is filled with gas, a pressure imbalance with respect to the formation water develops. The formation water is at hydrostatic pressure, and in order to displace water from the cavern, the gas pressure at the bottom of the cavern is at least as high as the hydrostatic pressure at this elevation. However, because the gas density is much lower than that of water, the gas pressure at the top of the cavern is substantially greater than the hydrostatic pressure at this elevation. This results in gas leakage out of the top of the cavern if the formation permeability is high. This pressure imbalance would be reduced if the vertical dimensions of the cavern were reduced. 


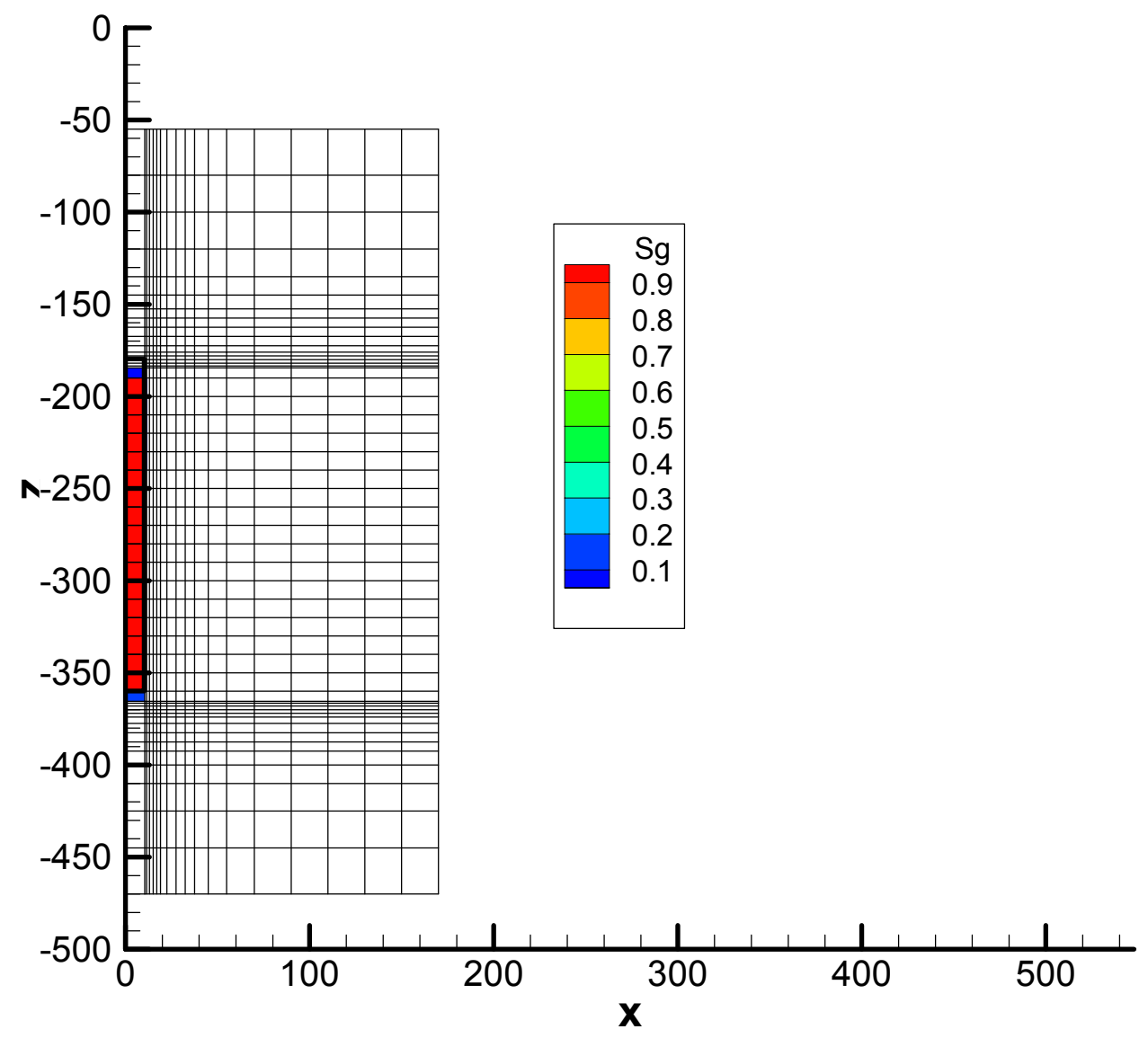

Figure 150. Radially symmetric grid used for gas storage simulations. The cylindrical cavern has been filled with methane for the case where the formation permeability is 1 microdarcy. 


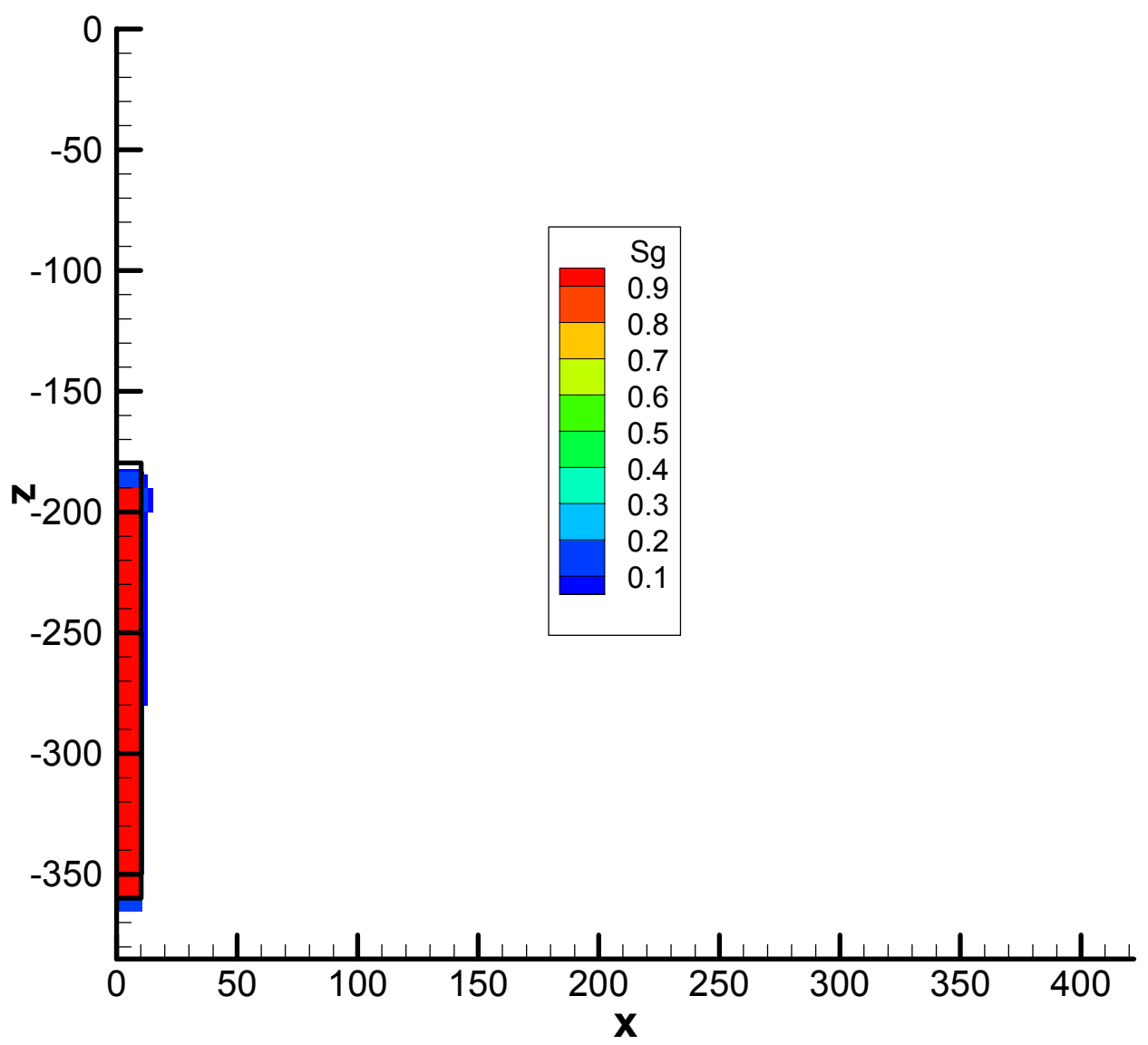

Figure 151. Methane gas distribution after 5 years of storage for the 1 microdarcy case. 


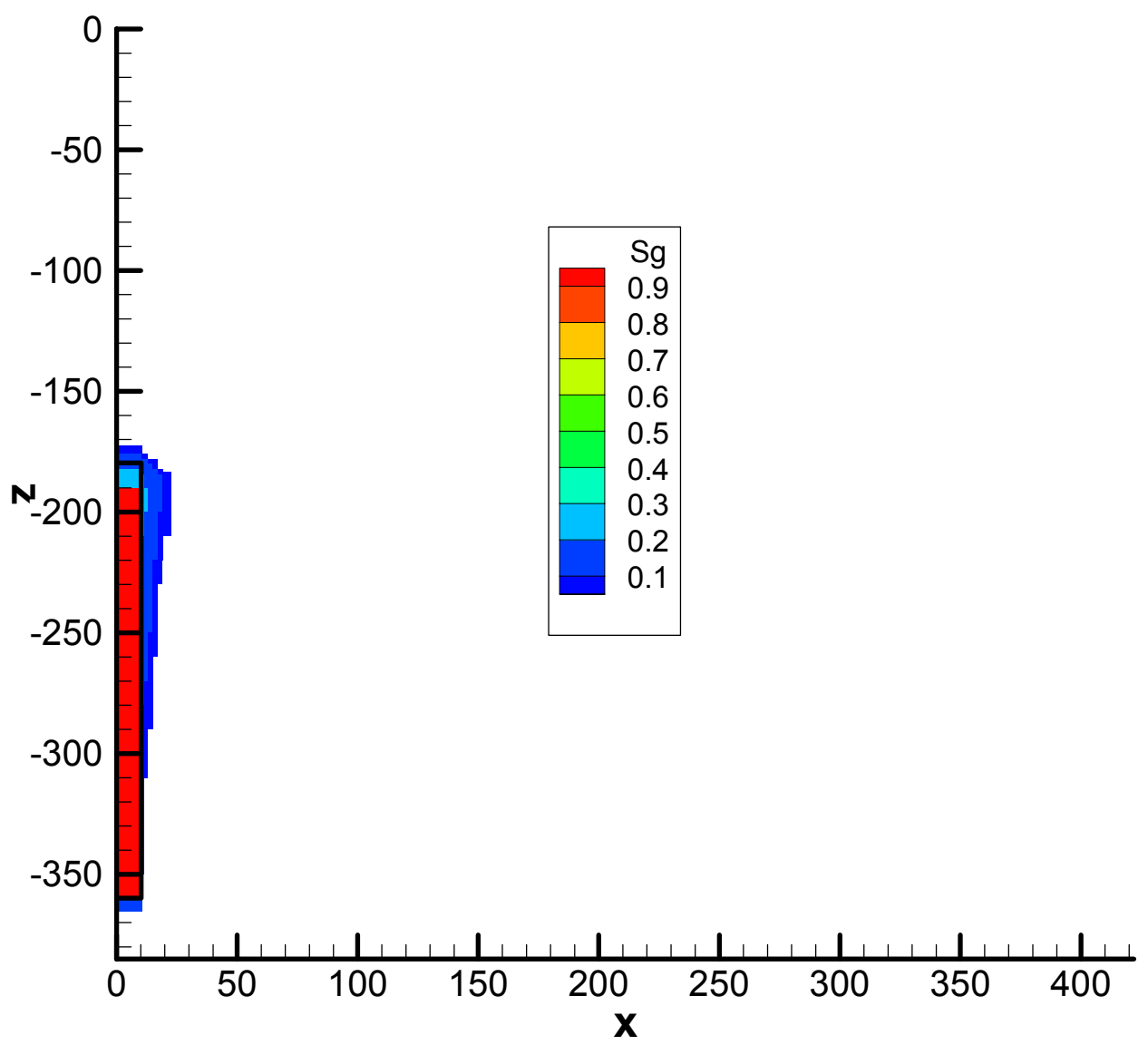

Figure 152. Methane gas distribution after 5 years of storage for the 10 microdarcy case. 


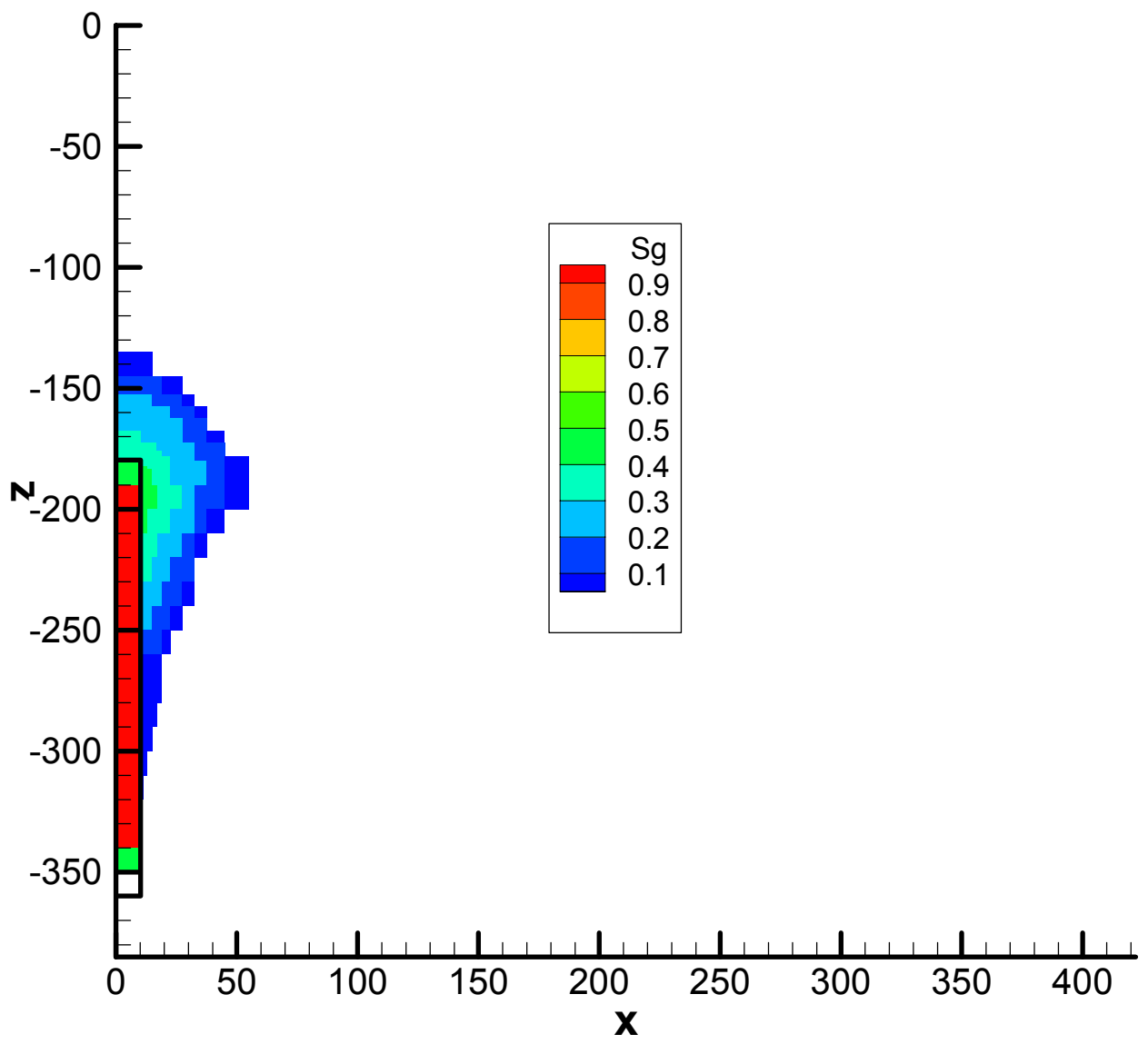

Figure 153. Methane gas distribution after 5 years of storage for the 100 microdarcy case. 


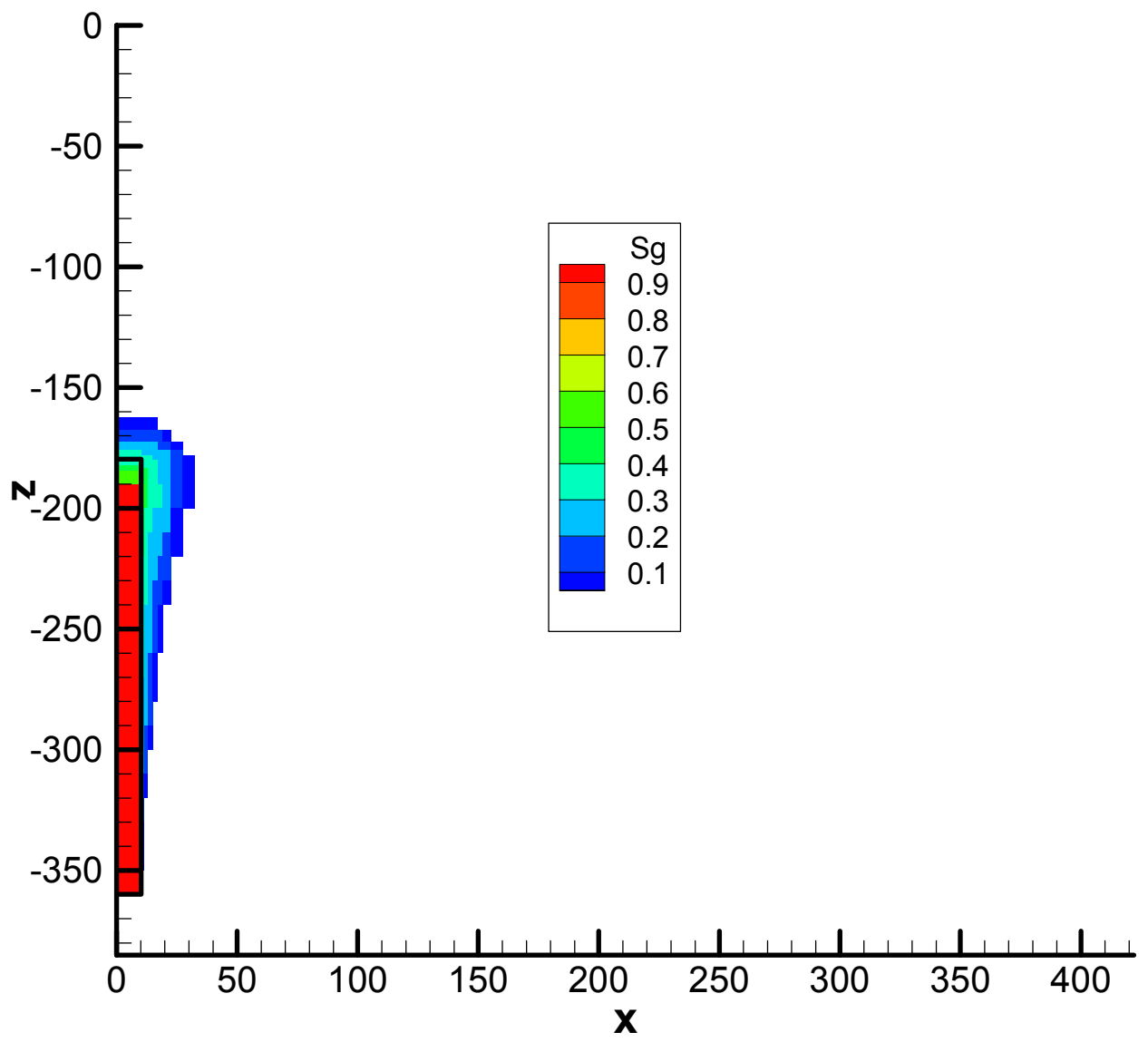

Figure 154. Methane gas distribution at the end of the 60 day injection period for the 1 millidarcy case. 


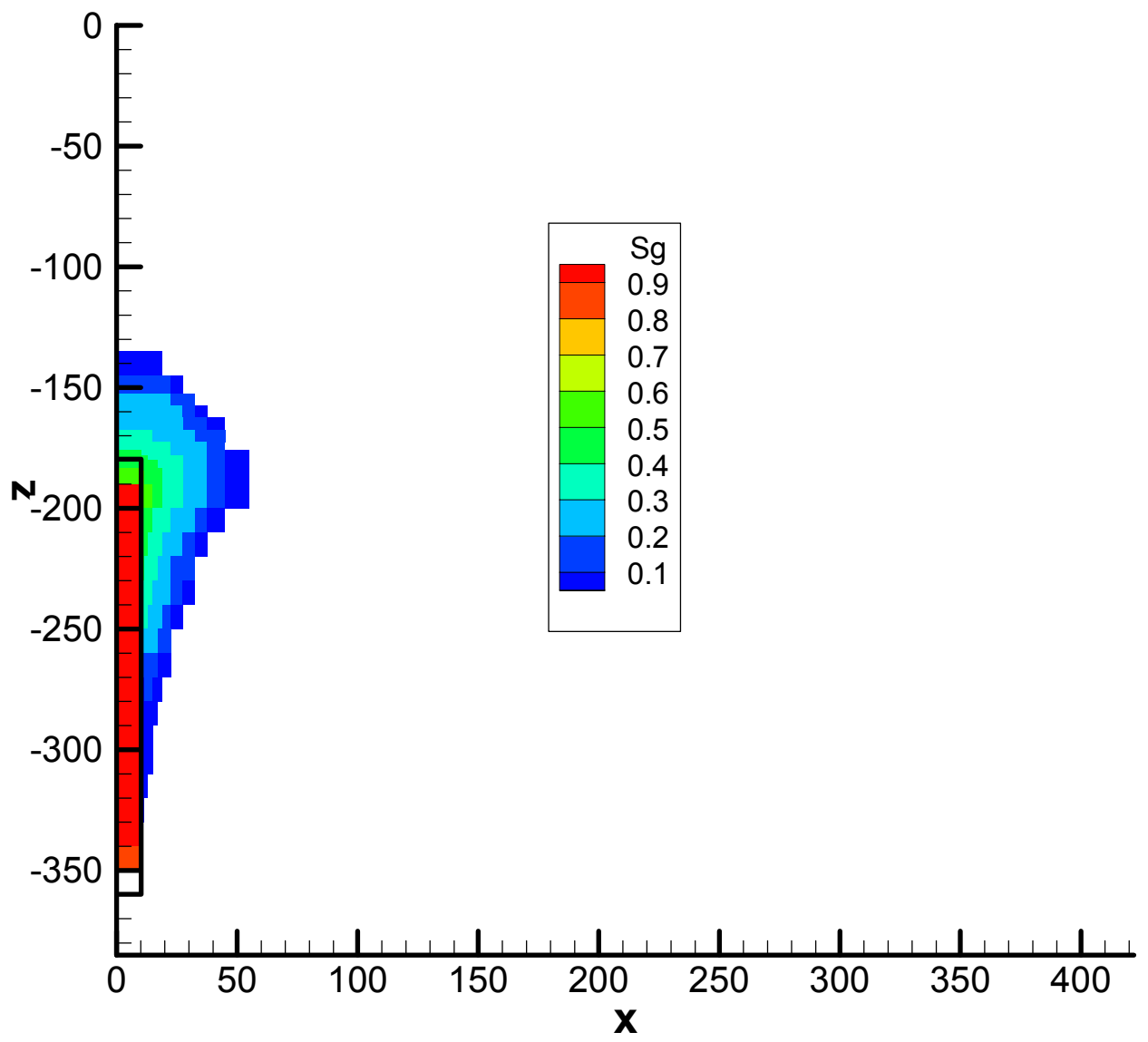

Figure 155. Methane gas distribution after 180 days of storage (including the 60 day injection period) for the 1 millidarcy case. 


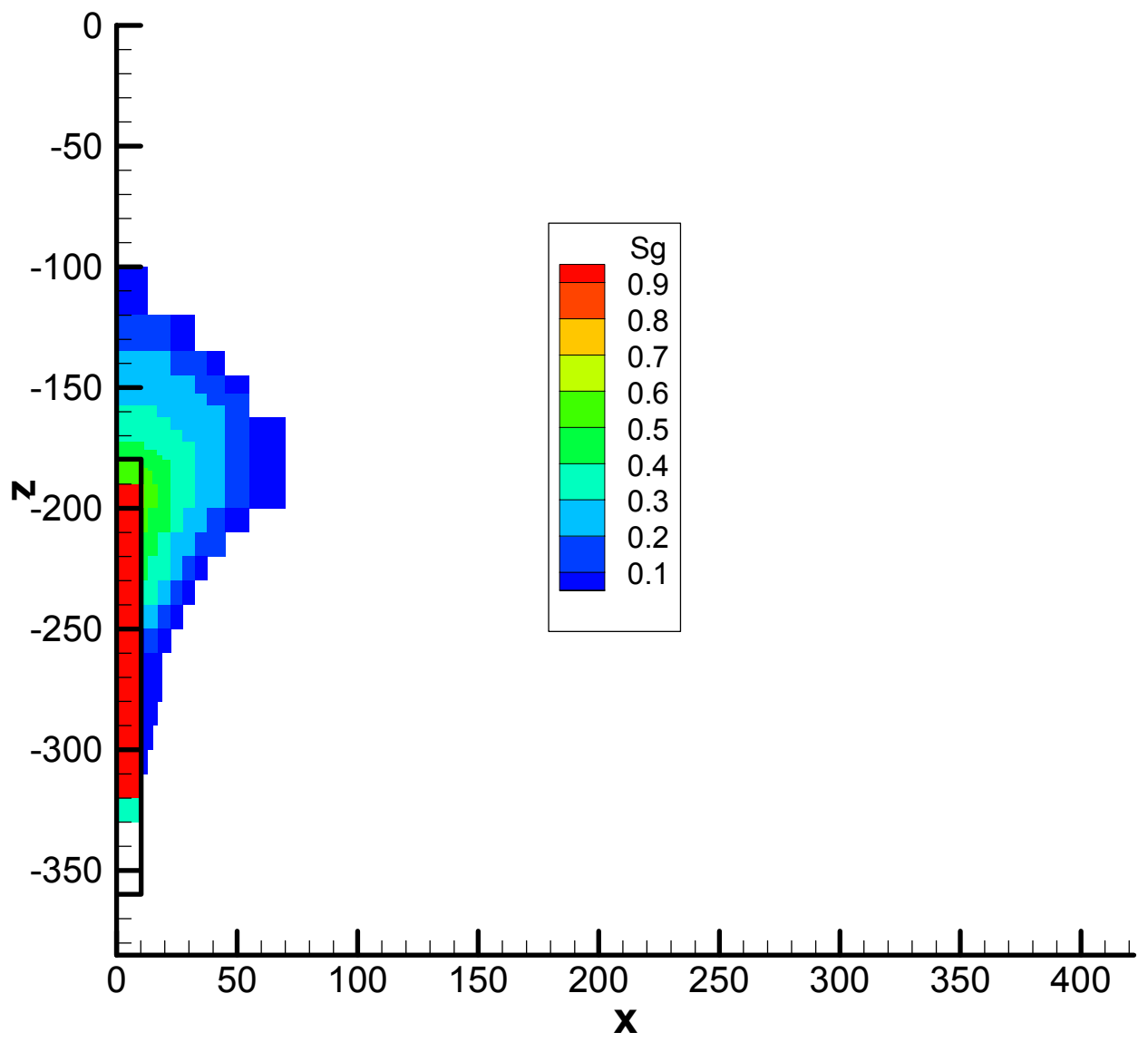

Figure 156. Methane gas distribution after 1 year of storage (including the 60 day injection period) for the 1 millidarcy case. 


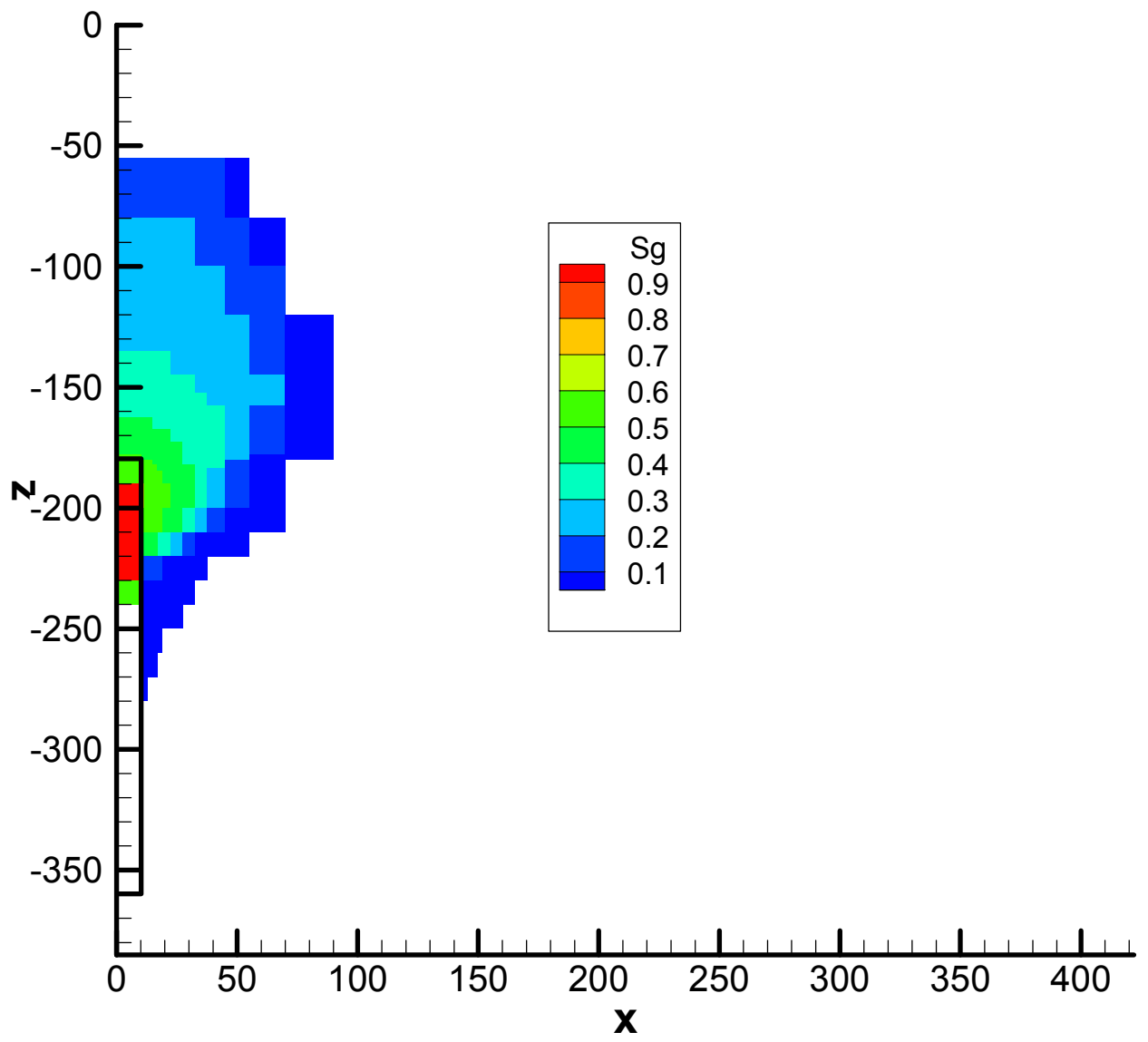

Figure 157. Methane gas distribution after 3 years of storage for the 1 millidarcy case. 


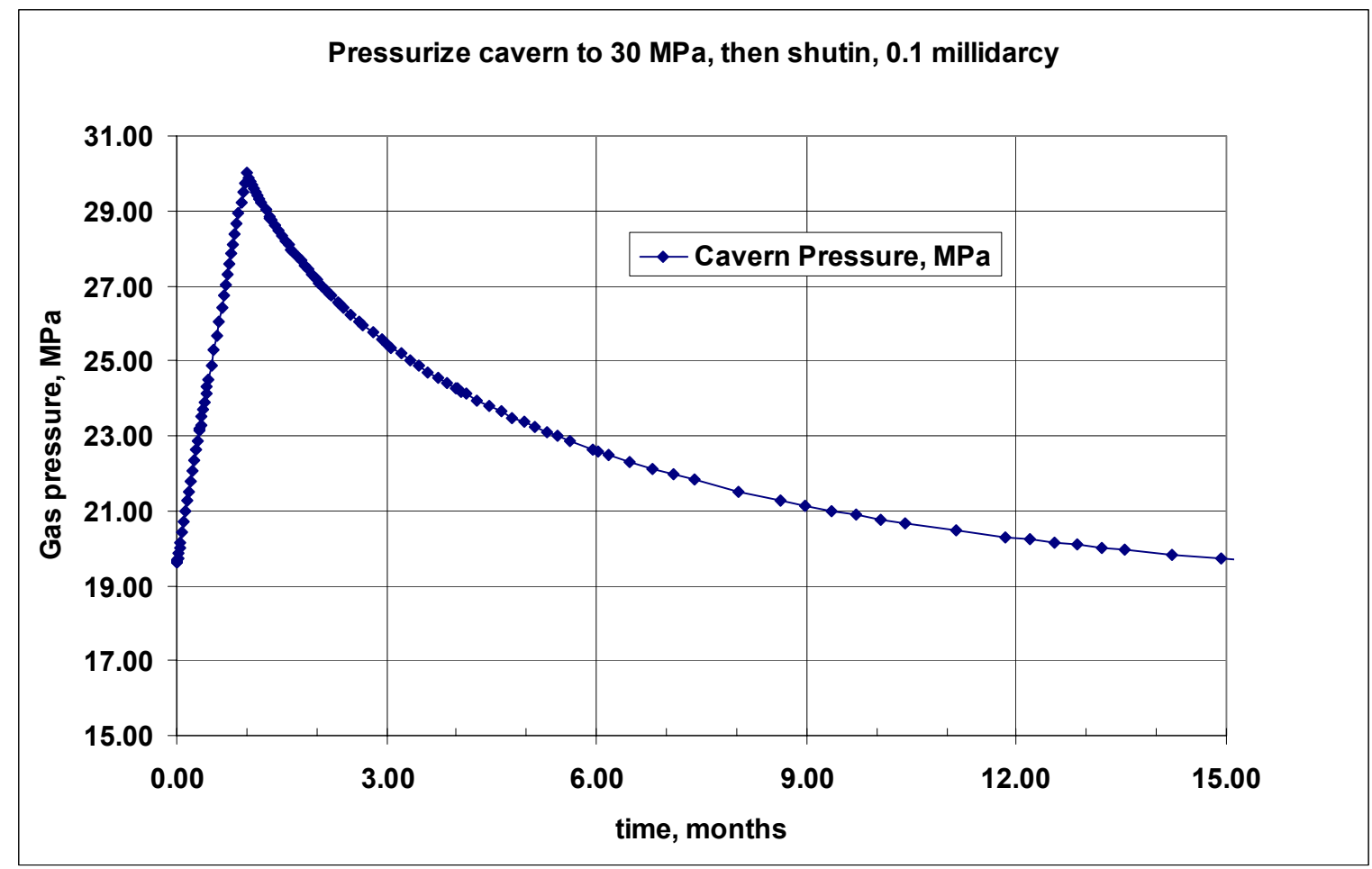

Figure 158. Gas pressure in cavern during an over-pressurization cycle, with shut in after one month of injection. 


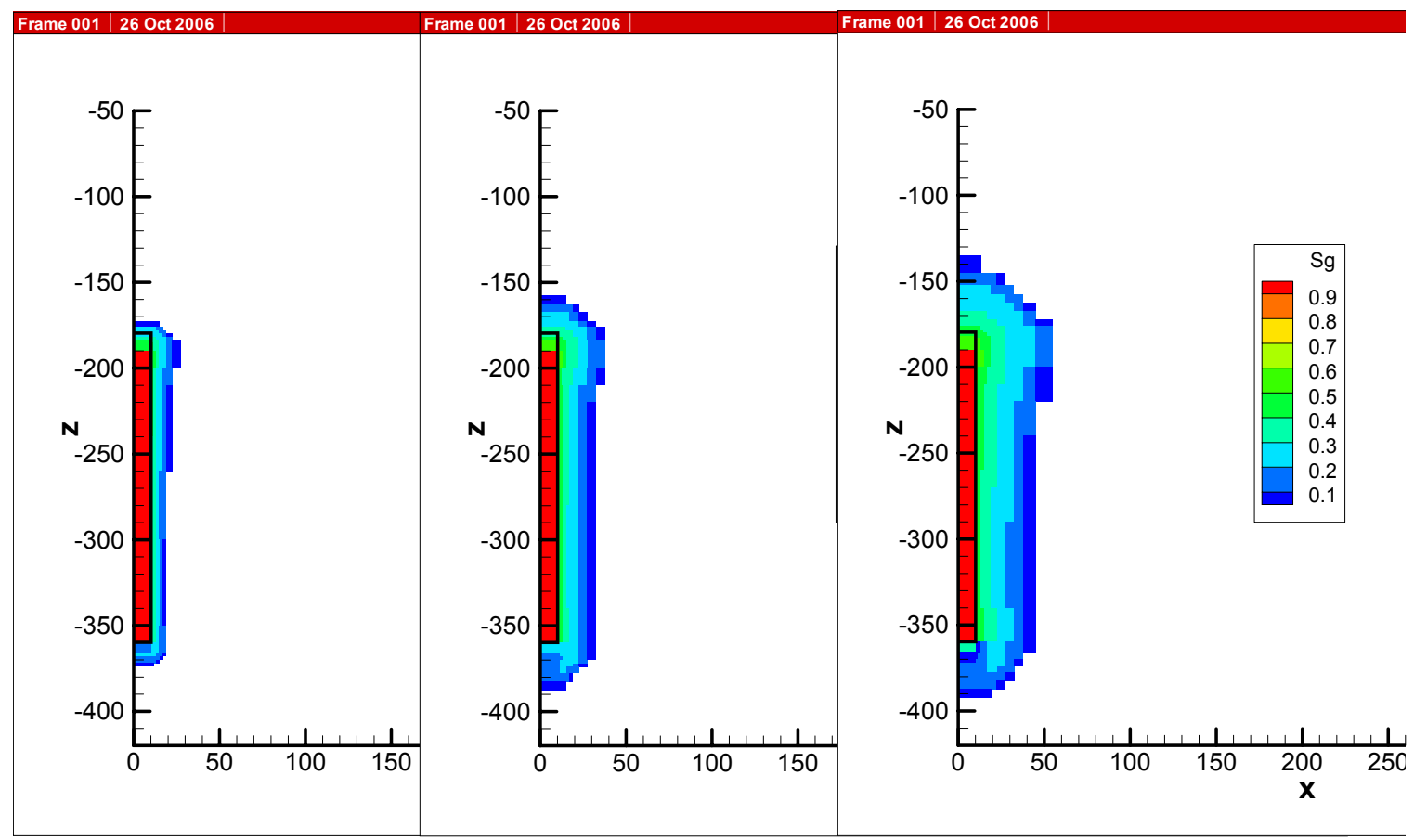

Figure 159. Gas distribution at the end of the pressure cycle (30 days), and after 60 and 335 days of storage. 


\section{Field Characterization Methods (Task 10)}

This part is divided into two distinct sections. The first section deals with using pressure transients measured at the surface to monitor and assess cavern formation development and the second part evaluates the stability of a cavern during acid dissolution formation.

\section{Analysis of Operational Pressure Transients to Assess Cavern Dissolution (Part 1 of Task 10) By Larry Murdoch, Jong-Won Choi, and Leonid Germanovich}

The objective of this study was to evaluate the feasibility of using fluid pressure transients to detect the interface between brine and $\mathrm{CO} 2$ in a developing gas storage cavern, where it is expected that acid will accumulate and dissolution will be strongest.

\section{Summary}

Implementation of the cavern dissolution process will be most effective when information about the developing cavern can be used to guide operational decisions at the ground surface. We evaluated the feasibility of using pressure transients measured at the ground surface as a means to evaluate cavern formation. Pressure transients will be created when the flowrate of the acid changes due to adjustments in the operational parameters, or they could be generated intentionally for assessment purposes. As a result, creating these transients will require no additional equipment down hole and so using information from the transients will require little additional expense beyond two transducers and a datalogger.

We considered a configuration that consists of two pipes extending to the cavern. One pipe would be used to inject acid, and it was assumed to extend to the top of the cavern. Another pipe would be used to recover brine and it was assumed to extend to near the bottom of the cavern. We assumed pressure transients were generated at the top of the acid-injection pipe, then traveled down the pipe and into the cavern where they either reflected back up the injection pipe or were transmitted to the brine pipe. Transients transmitted to the brine pipe would be transmitted up that pipe and detected by a pressure transducer at the ground surface.

Analysis of the pressure transients was conducted using a mathematical approach similar to that used to analyze water hammer. However, this application requires using a new form of the water hammer equations where changes in the pressure outside of a pipe are coupled to the conditions within the pipe. This is required to properly analyze the pressure signal in the brine pipe.

The results indicate that a pressure perturbation created in the injection pipe will be reflected by changes in cavern diameter. This should give a detectable response as the cavern diameter increases up to approximately 1 to 2 meters. Changes in diameter when the cavern is larger than 1 to 2 meters will probably be undetectable, according to the results of the sensitivity analysis. 
A pressure perturbation created in the injection pipe will be transmitted into the cavern itself where it will compress the pipe used to recover brine. The perturbation will also be transmitted into the end of the brine recovery pipe, but this effect appears to be much less than that caused by the external compression of the pipe and probably will be undetectable.

The external compression of the brine pipe will be affected by the properties of the fluid in the cavern, and this will affect the magnitude and arrival time of the wave at the ground surface. In particular, the pressure perturbation in the brine pipe will be diminished in amplitude and delayed in arrival as the thickness of the CO2-filled region increases. This effect will be particularly well expressed when the cavern in small. The magnitude of this response decreases as the cavern expands, however, just as the magnitude of the reflected wave decreases.

These findings suggest that pressure transients can be used to detect the location of an interface between $\mathrm{CO}_{2}$ and brine while the cavern is relatively small, but the current study suggests they will be of limited use when the cavern diameter exceeds a few meters. These results indicate that the best application will be to use the pressure transient data to calibrate a numerical model of the cavern dissolution process similar to the numerical models discussed elsewhere in this report. The calibration process would occur while the cavern was relatively small. Results from the calibrated model would be used to guide the cavern dissolution process after the cavern was large enough to diminish pressure transient signals enough so they could not be reliably separated from background effects.

\section{Basis of Governing Equations}

Transient flow involves pressures that change rapidly with time. One of typical fluid transient problems is water hammer. The analogy is that of a closed pipe connected to a reservoir with constant depth as shown in Figure 160 (a).

Initially, the valve at the right end of the pipe is open, so that water flows through the pipe with constant velocity $\left(V_{0}\right)$ as shown in Figure 160 (a). If the valve is closed abruptly, a pressure wave would be created and propagates with wave velocity $\left(a_{\text {wave }}\right)$ toward the reservoir as shown in Figure 160 (b) (Chaudhry, 1987).

In the same manner, a pressure wave can be created by changing the flow rate. During acid injection, every change in flow rate will produce a pressure wave that propagates through the pipe system and cavern. If the wave meets any interface, a reflection wave is created and returns back up the injection pipe, and a transmitted wave propagates across the interface and up the brine return pipe. 


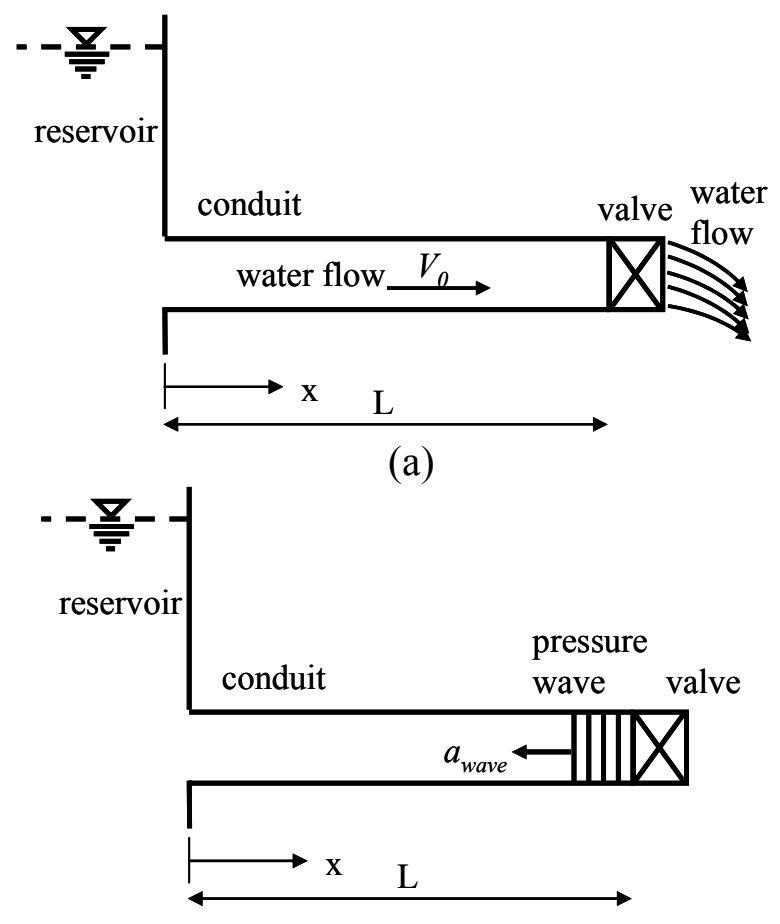

(b)

Figure 160 Schematic of water hammer phenomenon (a) a closed conduit connected to a reservoir with a constant depth and full open valve (b) propagation of pressure wave due to an abrupt closure of valve (Wylie and Streeter, 1978).

\section{Assumptions used in Derivation of Governing Equations}

Derivation of the governing equations to describe fluid flow in a pipeline is based on following assumptions;

- The fluid flow is one-dimensional, that is the characteristic quantities are cross-sectionally averaged

- Hydraulic losses are quasi-steady; that is the same losses are assumed for a steady and transient flow at given mean velocity of the liquid

- The dynamic fluid-pipe interaction is neglected and a quasi-steady pipe response to pressure surges is assumed

- The change of cross-sectional area of the pipe and cavern due to wave propagation is relatively small

For the first assumption, if the length of a pipe is long compared to the diameter, lateral flow can be neglected, so that fluid flow can be considered to be one-dimensional (Thomson, 1972). For the second assumption, the friction factor $f$ usually varies with the Reynolds number. However, the 
effects of such a variation of $f$ on transient conditions are small and can usually be neglected (Chaudhry, 1987).

\section{Continuity and Momentum Equations for Transient Fluid Flow}

Behavior of transient fluid flow in closed pipes can be described by continuity and momentum equations. (Chaudhry, 1987). Consider a fluid flow in a pipe with elastic walls and circular cross-section as shown in Figure 161.

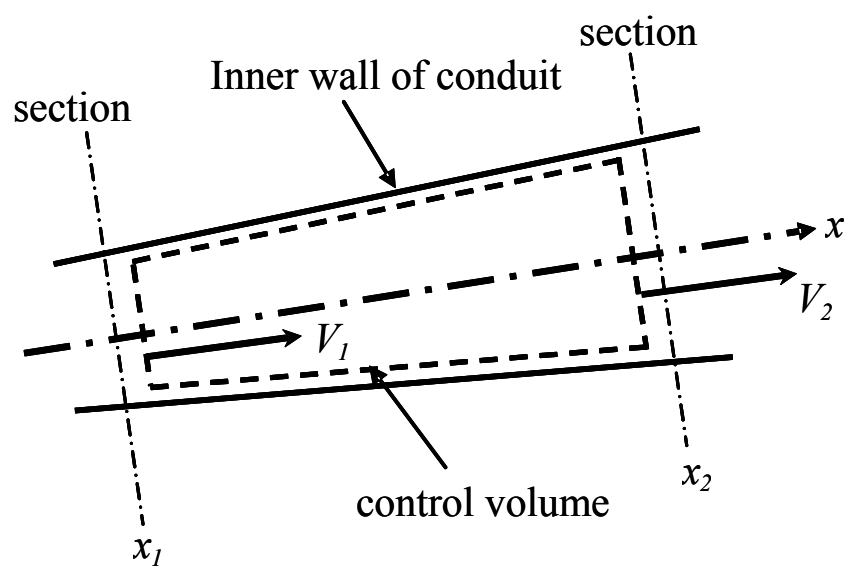

Figure 161 Fluid flow in a conduit (Chaudhry, 1987)

In Figure 161, the control volume is shown in dashed line, and fluid flow velocity into section 1 and 2 are $V_{1}$ and $V_{2}$, respectively. $x$ is the Eulerian coordinate fixed in space.

For the momentum equation, consider fluid flow in a pipe as shown in Figure 162. Similarly to Figure 161, the control volume is shown by the dashed line, and $x$ is the Eulerian coordinate fixed in space.

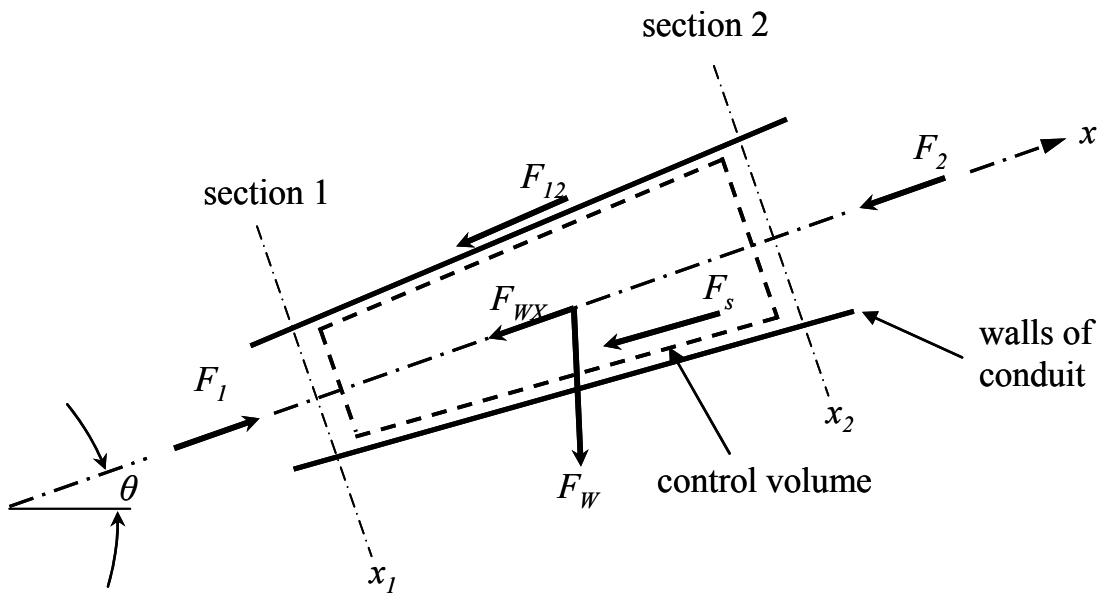

Fig 162. Forces applied to a fluid system in a conduit. $F_{1}, F_{2}, F_{12}, F_{s}$, and $F_{W X}$ are force due to pressure applied to section 1 , force due to pressure applied to section 2 , force due to pressure applied on the side of diameter changing, and frictional force between fluid and conduit wall, and gravitational force in $x$-direction. (Chaudhry, 1987) 
In the case of a pipe loaded by external pressure $p_{e}$ as well as internal pressure $p$, the continuity equation can be expressed as follows

$$
\frac{\partial p}{\partial t}+\frac{\rho_{0} a^{2}}{A} \frac{\partial Q}{\partial x}=c_{1} \frac{\partial p_{e}}{\partial t}
$$

where $\mathrm{p}=$ internal pressure, $p_{e}=$ external pressure, $t=$ time, $Q=$ flow rate of the fluid, $x=$ distance,

$$
a^{2}=\frac{K_{0} / \rho_{0}}{1+\frac{K_{0}}{G}}
$$

where $K_{0}$ = bulk modulus of a fluid and $G$ is shear modulus of the material around a cavern,

and a constant $c_{1}$ :

$$
c_{1}=\frac{1}{1+\frac{h E}{K_{0} c D}}
$$

where $h$ is the pipe wall thickness, $\mathrm{D}=$ internal pipe diameter, and $\mathrm{E}=E$ Young's modulus, and $\mathrm{c}=$ plane stress.

The continuity equation can also be expressed as

$$
\frac{\partial p}{\partial t}+\frac{p}{A} \frac{\partial Q}{\partial x}+\frac{Q}{A} \frac{\partial p}{\partial x}=0
$$

and

$$
\frac{\partial Q}{\partial t}+\frac{Q}{A} \frac{\partial Q}{\partial x}+\frac{Z R T A}{M p} \frac{\partial p}{\partial x}+\frac{2 f Q|Q|}{D A}-\mu \frac{Z R T}{M p} \frac{\partial^{2} Q}{\partial x^{2}}=0
$$

where $Z, R, T, M$, and $\mu$ are compressibility factor of fluid, gas constant, temperature, molar mass of fluid, and dynamic viscosity of fluid, respectively. For Equations 27, 30 and 31, $p$ and $Q$ are perturbations, and, if Equation 27 is used, the initial conditions for these equations must be $Q(x, 0)=$ 0 , i.e. zero initial flow rate condition.

It is noteworthy that the analysis of this problem requires using equations that go beyond those typically used to analyze water hammer. In the final derived equations, coupling the change of pressure in the cavern to the continuity in the second pipe has to our knowledge never been described. 


\section{Supercritical CO2 and Cavern Stability}

To create a gas storage cavern in carbonate rock formation, a well is drilled into the formation and then hydrochloric acid is injected into the well to dissolve the rock formation. Carbonate rock is dissolved, the byproducts are pumped out and a cavern is created. $\mathrm{CO}_{2}$ and brine are created as by-products of the reaction. Brine is pumped out and fluid pressure is controlled to maintain stability of the cavern.

The physical properties of carbon dioxide depend on the temperature and pressure. If the temperature and pressure of carbon dioxide are both increased beyond a critical point, it behaves as a supercritical fluid. A supercritical fluid is a substance with both gas- and liquid like properties. The density is similar to liquid, but the compressibility is similar to gas. The critical point of carbon dioxide is $31.1^{\circ} \mathrm{C}\left(87.9^{\circ} \mathrm{F}\right)$ and $7.3 \mathrm{MPa}(1063 \mathrm{psi})$ as shown in Figure 163 .

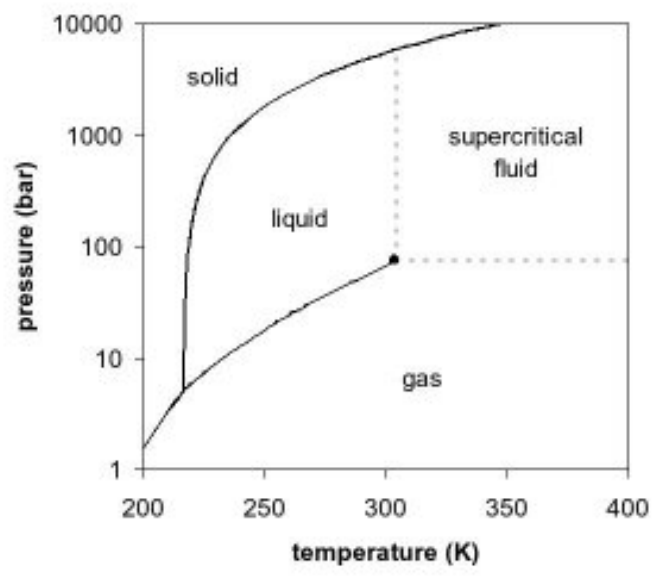

Figure 163 Phase diagram for $\mathrm{CO}_{2}$. The critical point of $\mathrm{CO}_{2}$ is $31.1^{\circ} \mathrm{C}\left(87.9^{\circ} \mathrm{F}\right)$ and $7.3 \mathrm{MPa}$ (1063 psi) (Dean, 1993).

Density of supercritical $\mathrm{CO}_{2}$ is lower than that of water but higher than subcritical gaseous $\mathrm{CO}_{2}$, and its compressibility is lower than that of subcritical gaseous $\mathrm{CO}_{2}$. As an example, if a cavern is located at depth below $750 \mathrm{~m}(2460 \mathrm{ft})$, hydrostatic pressure around the cavern is $7.35 \mathrm{MPa}$, and temperature of the carbonate rock formation may be over $31.1{ }^{\circ} \mathrm{C}$ $\left(87.9^{\circ} \mathrm{F}\right)$. Then, the $\mathrm{CO}_{2}$ created by chemical reaction is in supercritical state. At temperature of $38^{\circ} \mathrm{C}\left(100^{\circ} \mathrm{F}\right)$ and pressure of $10.4 \mathrm{MPa}(1500 \mathrm{psi})$, the density of supercritical $\mathrm{CO}_{2}$ is (Falta, et al., 2004);

$$
\rho_{\mathrm{CO}_{2}}=\frac{P M_{\mathrm{CO}_{2}}}{z R T}=\frac{\left(10.4 \times 10^{6} \mathrm{~Pa}\right)(44.1 \mathrm{~g} / \mathrm{mole})}{0.27 \cdot 8314.4 \cdot 311 \mathrm{~K}}=656 \mathrm{~kg} / \mathrm{m}^{3}
$$

where $\rho_{\mathrm{CO}_{2}}, P, M_{\mathrm{CO}_{2}}, z, R$, and $T$ are density of $\mathrm{CO}_{2}$, pressure, molar weight of $\mathrm{CO}_{2}$, compressibility factor of $\mathrm{CO}_{2}$, universal gas constant, and temperature, respectively.

$\mathrm{CO}_{2}$ rises up to the top of the cavern whereas brine sinks to the bottom of the cavern due to the difference of the density. Between $\mathrm{CO}_{2}$ and brine layers, a layer of mixture composed of $\mathrm{HCl}$, brine, and $\mathrm{CO}_{2}$ may be formed (Figure 164). The physical properties of the mixture depend 
on the fraction of each component.

Dissolution will occur where acid contacts limestone, and this will be localized along the interface between brine and carbon dioxide. If acid remains at a fixed depth, the radius of the cavity may expand to form a flat, narrow cavity. This geometry is unstable and probably will collapse.

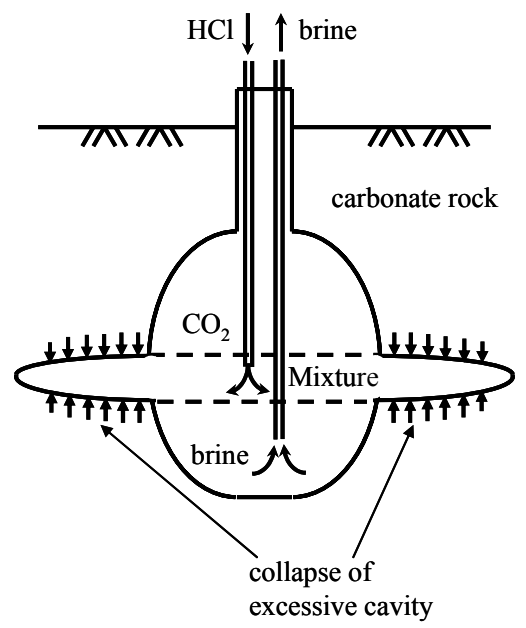

Figure 164 Schematic description of collapse of unstable excessive cavity due to vertical stress.

To determine the injection point, the location of the interface between mixture and brine is required because most of the dissolution of carbonate rock may occur in the mixture zone.

\section{Pressure History Factors}

In this study, a gas storage cavern is characterized by fluid transients; that is, characteristics of the construction process are obtained by measuring pressure histories in pipe 1 and pipe 2. The pressure histories are generated by a perturbation at a wellhead in pipe 1 . Pressure histories at wellhead in pipe 1 and pipe 2 represent only the pressure difference between total pressure and initial pressure, so that only pressure histories induced by perturbation are shown.

The pressure histories may be affected by three factors; diameter change of cavern, material properties of fluids in pipe 1 and pipe 2 , and the location of the mixture-brine interface.

In the early stage of acid injection, the diameter of cavern is the same as the initial well bore, and the amount of byproducts, i.e., $\mathrm{CO}_{2}$ and brine are relatively small. Hence, it can be assumed that the cavern is filled with acid, so that the main issue in the early stage is the diameter change of cavern.

As the injection of acid proceeds, a mixture-brine interface will develop in the cavern. The detection of the interface is a major concern as well as the diameter change of the cavern. For simplicity it is assumed that the $\mathrm{CO}_{2}$ behaves as a liquid although it has both liquid-like and gas-like properties. Later, the results of calculations from the assumption of liquid-like $\mathrm{CO}_{2}$ will be compared with those from the assumption of gas-like $\mathrm{CO}_{2}$. 


\section{Effect of Diameter Change During Early Stage of Construction}

The pressure history changes as a function of diameter of the cavern early in the dissolution process (Figure 165). The first peaks for each case in Figure 165 (a) and (b) are the input perturbation created by the change of flow rate, and the second peaks are the reflected waves from the interface of pipe and cavern. The third and the fourth peaks are created by the reflection of waves at the wellhead and interface between pipe and cavern. If there is no diameter change and no material change from steel pipe and cavern, the second peak would not be present in the pressure history at $x=0 \mathrm{~m}$ in pipe 1 .

In Figure 165 (a), as the diameter of the cavern increases, the magnitude of the second peaks which are reflected from the pipe-cavern interface increase. However, in Figure 166 (b), there is little difference in the magnitude of second peak in the case of $\mathrm{D} 2=1.0 \mathrm{~m}$ and $\mathrm{D} 2=3.0 \mathrm{~m}$, which means that the increase of diameter change cannot be detected by pressure history at wellhead in pipe 1 if the diameter of the cavern is increased more than $1.0 \mathrm{~m}$.

Pressure histories at $x=10 \mathrm{~m}$ in pipe 2 with respect to diameter (D2) change of cavern shown Figure 166 show similar tendency as shown in Figure 165 (a) and (b). Pressure histories at $x=10 \mathrm{~m}$ in pipe 2 also show a response to changes in diameter of the cavern. Pressure histories around the first peak are plotted to exclude the reflected waves from the wellhead in pipe 2. The diameter change of cavern can be clearly detected from the decrease of peak value of pressure histories. As diameter of cavern increases from $0.15 \mathrm{~m}$ to $3.0 \mathrm{~m}$, peak pressure difference at $x=0 \mathrm{~m}$ in pipe 2 is decreased, and it is shown in the Figure 167.

Figure 167 shows the peak pressure difference at $x=0 \mathrm{~m}$ in pipe 2 with respect to the diameter of cavern. Like the pressure histories at $x=0 \mathrm{~m}$ in pipe 1 , the peak pressure difference is decreased monotonically as cavern diameter increases up to $1.0 \mathrm{~m}$. As the diameter of cavern increases beyond $1.0 \mathrm{~m}$, the peak pressure difference decreases dramatically.

The analysis outlined above suggests that it could be feasible to detect the early increases in diameter of the cavern during the dissolution process. The analysis also shows that changes in diameter probably will be undetectable using this method after the cavern diameter exceeds approximately $1 \mathrm{~m}$. 


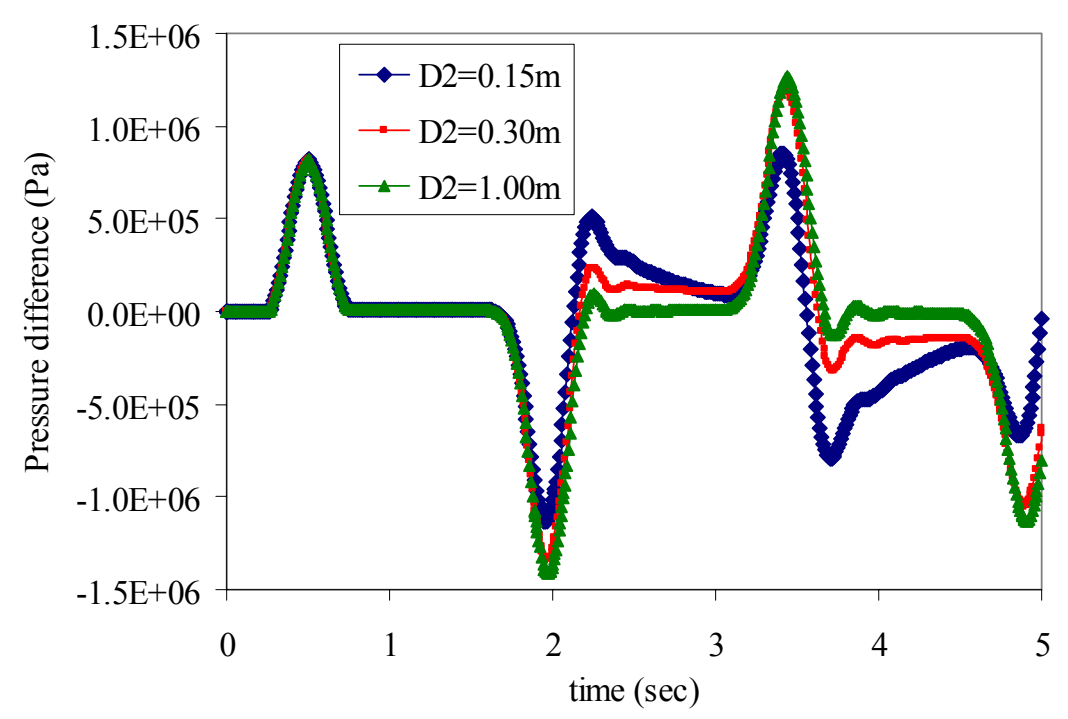

(a) Pressure histories for cavern diameters from $0.15 \mathrm{~m}$ to $1.0 \mathrm{~m}$

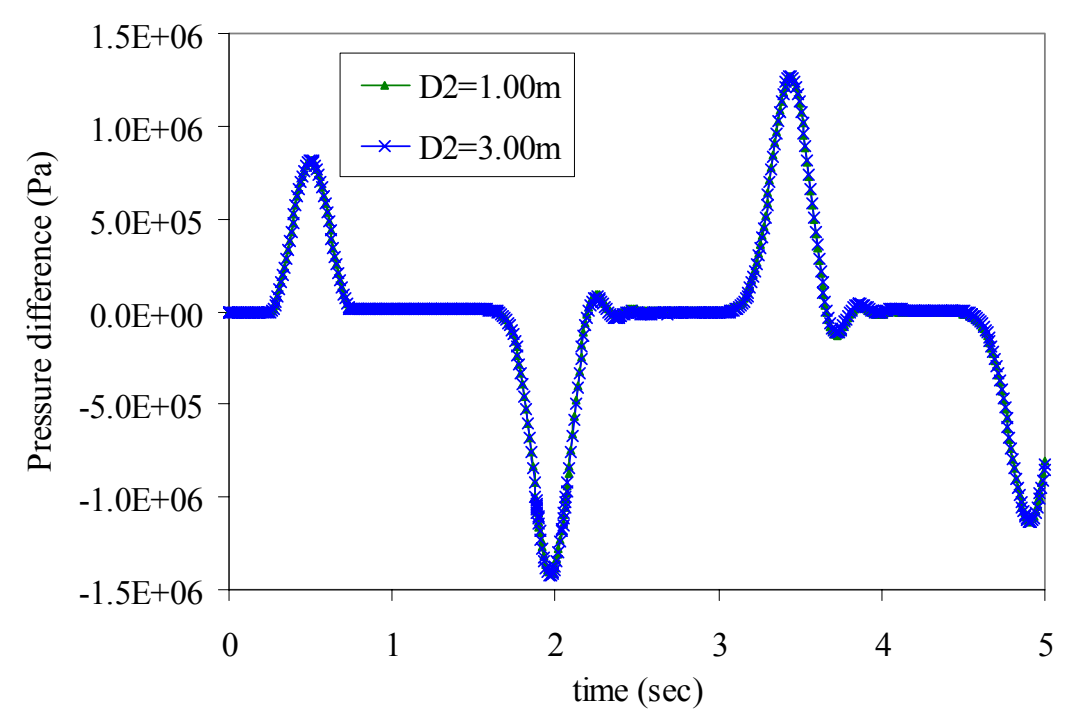

(b) Change of cavern diameter from $1.0 \mathrm{~m}$ to $3.0 \mathrm{~m}$

Figure 165 Pressure histories at $x=0 \mathrm{~m}$ in pipe 1 with respect to diameter (D2) change of cavern 


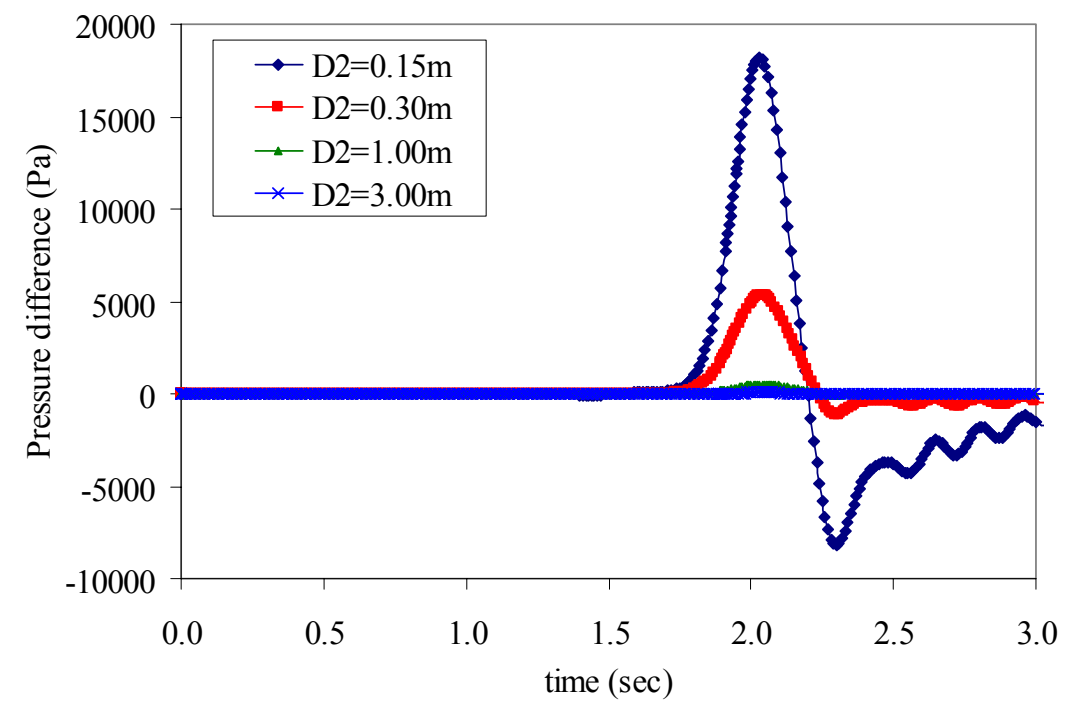

Figure 166 Histories at $x=10 \mathrm{~m}$ in pipe 2 with respect to diameter (D2) change of cavern

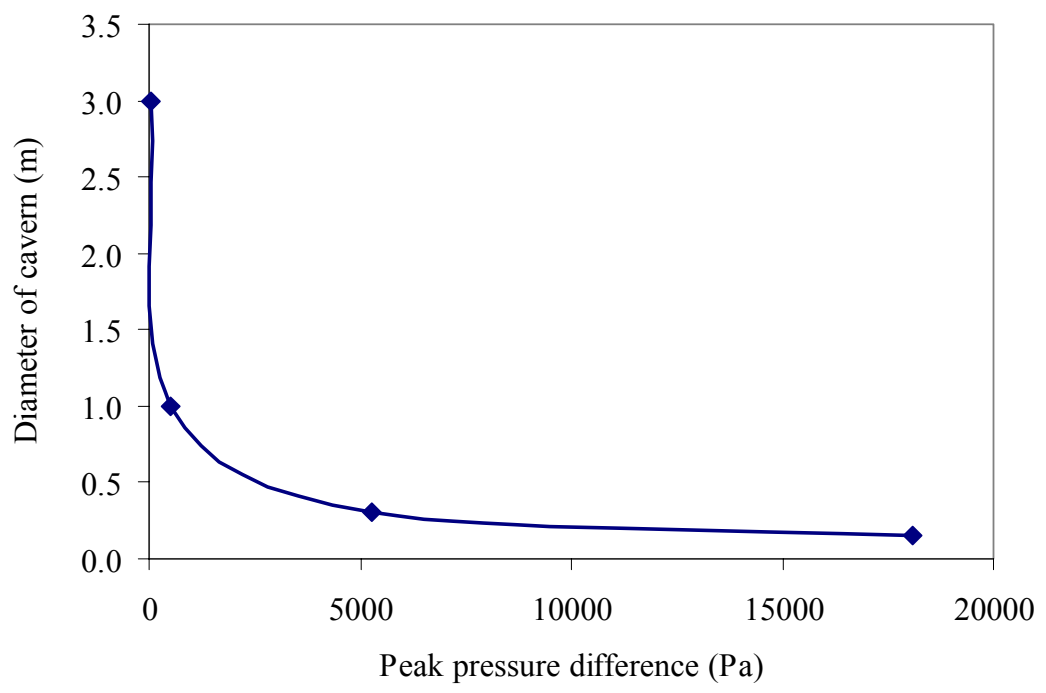

Figure 167 Effect of diameter change on peak pressure difference in pipe 2

\section{Effect of Mixture (Liquid CO2)}

As the injection of acid continues, the carbonate rock around a cavern is dissolved and the amounts of dissolution byproducts increase, so that the thickness of the mixture and brine layers also increase. This change in the two layers will be present in the pressure histories. This effect can be observed in Figure 168, in which two cases are compared. The first one is for the pipe 1 and pipe 2, and they are filled only with acid. The second one is for the pipe 1 with $\mathrm{CO}_{2}$ and brine in the cavern part. 


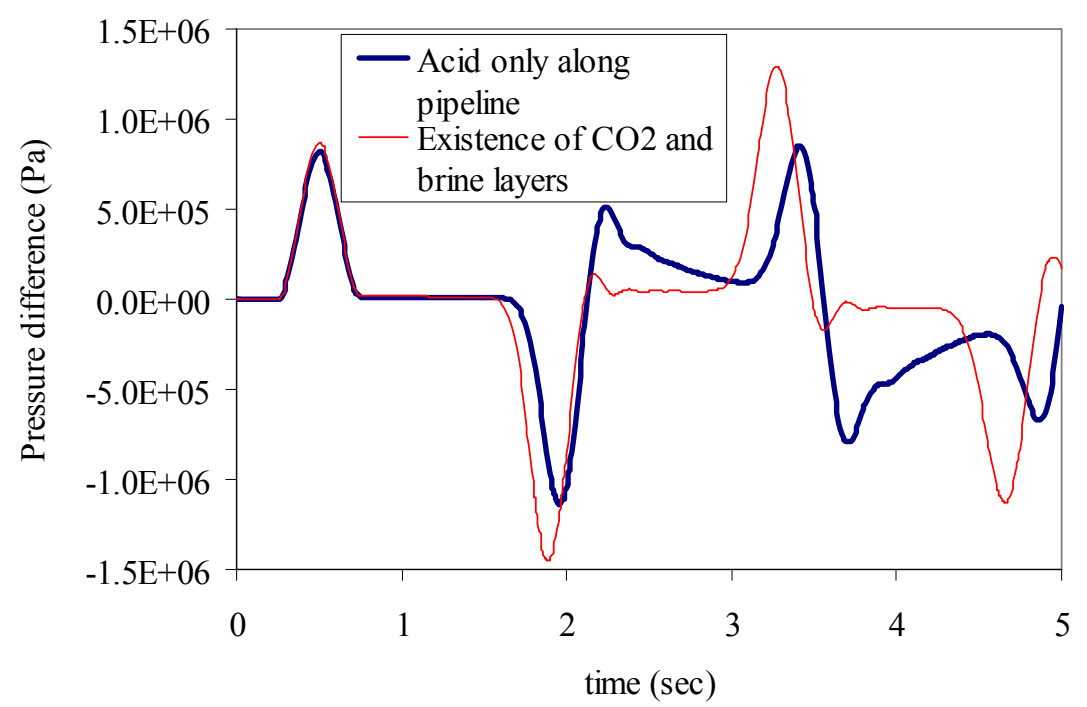

(a) Pressure histories at $x=0 \mathrm{~m}$ in pipe 1

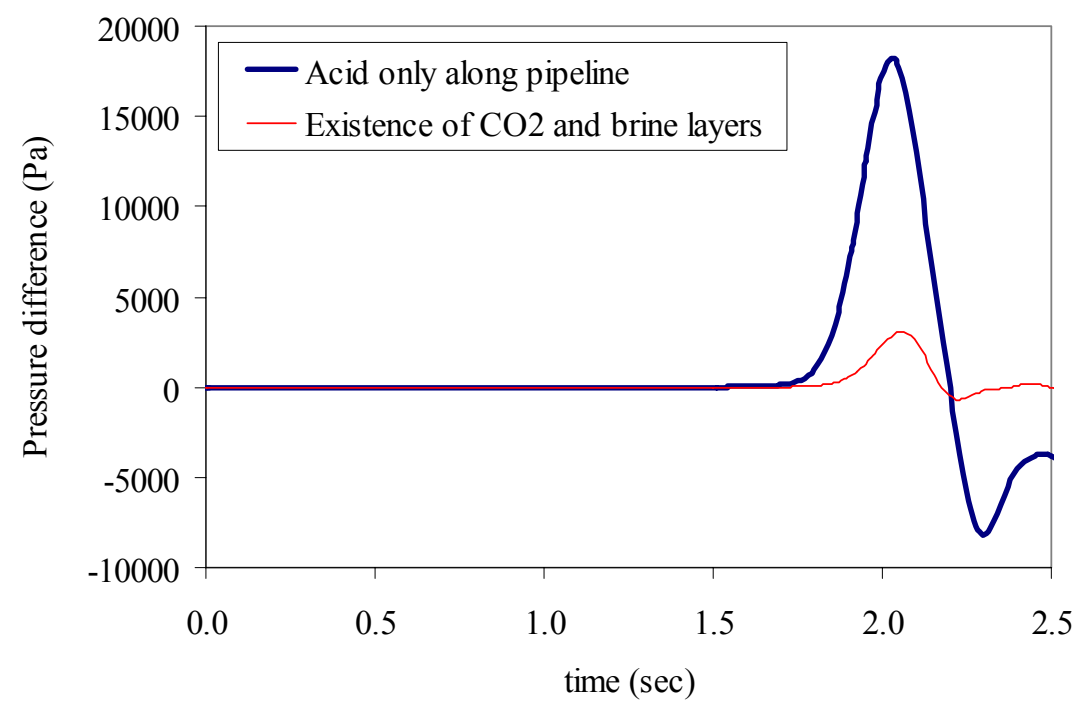

(b) Pressure histories at $x=10 \mathrm{~m}$ in pipe 2

Figure 168 Comparison of pressure histories from two cases

If $\mathrm{CO}_{2}$ and brine layers exist in pipe 1, the magnitude of the reflected wave from pipecavern interface, i.e. the second peaks in the pressure histories, is larger than that in the case where pipe 1 and pipe 2 are filled with acid only (Figure 168a). The wave velocity in the $\mathrm{CO}_{2}$ in the cavern with diameter $0.15 \mathrm{~m}$ is $188 \mathrm{~m} / \mathrm{sec}$ and in the acid in the steel pipe with diameter $0.04 \mathrm{~m}$ is $1280 \mathrm{~m} / \mathrm{sec}$. Thus, due to the great difference in the wave velocities between the two fluids, more energy is reflected back to the wellhead if $\mathrm{CO}_{2}$ exists in the cavern. The material properties of brine are similar to those of acid, so that the existence of a layer induces very small reflection of waves at the interface compared to $\mathrm{CO}_{2}$. 
The existence $\mathrm{CO}_{2}$ in pipe 1 can also affect the pressure histories at $x=10 \mathrm{~m}$ in pipe 2 as shown in Figure 168 (b). The peak values in the case of pipe 1 and pipe 2 filled with only acid, and in the case of the existence of $\mathrm{CO}_{2}$ in pipe 1 are $18094 \mathrm{~Pa}$ and $3031 \mathrm{~Pa}$, respectively. If $\mathrm{CO}_{2}$ exists in pipe 1, most of energy is reflected back to the wellhead, so that the peak value of the pressure wave that arrives at $x=10 \mathrm{~m}$ in pipe 2 is much smaller that that in the case where the pipes are filled with only acid.

Changes in cavern diameter still can be changed due to dissolution, even with $\mathrm{CO}_{2}$ in the cavern (Figure 168 (a)). The effect of the diameter change of the cavern is shown in Figure 169, in which the location of the mixture-brine interface $(\mathrm{L})$ from is $20 \mathrm{~m}$ in pipe 1 .

Figure 169 (a) shows that the pressure histories at $x=0 \mathrm{~m}$ in pipe 1 , and the diameter change of cavern has little effect on the pressure histories at $x=0 \mathrm{~m}$ in pipe 1 . It seems that the effect of $\mathrm{CO}_{2}$ is greater than that of cavern diameter change on the pressure histories at $x=0 \mathrm{~m}$ in pipe 1 . However, pressure histories at $x=10 \mathrm{~m}$ in pipe 2 are definitely affected by the diameter change of cavern. As the diameter of cavern increases from $0.15 \mathrm{~m}$ to $3.0 \mathrm{~m}$, the peak pressure difference values of the first arrived pressure waves decrease from $3031 \mathrm{~Pa}$ to $8.1 \mathrm{~Pa}$ (Figure 169 b). Hence, the diameter change in the case of the existence of $\mathrm{CO}_{2}$ can be detected by measuring pressure histories in pipe 2 instead of those in pipe 1.

During the injection of acid, the location of the $\mathrm{CO}_{2}$-brine interface (L) can be changed, and the effect of change of the location of the interface can also affect the wave propagation. The location of $\mathrm{CO}_{2}$-brine interface is changed from $20 \mathrm{~m}$ to $50 \mathrm{~m}$ and $80 \mathrm{~m}$. The pressure histories in the case of $\mathrm{L}=50 \mathrm{~m}$ and $\mathrm{L}=80 \mathrm{~m}$ are shown in Figure 170 and 173 , respectively.

Similarly in the case of $\mathrm{L}=20 \mathrm{~m}$, the diameter change of the cavern has little effect on the pressure histories at $x=0 \mathrm{~m}$ in pipe 1 as shown in Figure 170 (a) and Figure 171 (a). However, its effect can be clearly observed in the histories at $x=10 \mathrm{~m}$ in pipe 2 as shown in Figure 170 (b) and Figure 171 (b). As the diameter of cavern increases, the peaks of the first pressure waves are decreased conspicuously. The effects of diameter change on the peak pressure difference in the case of $\mathrm{L}=20 \mathrm{~m}, \mathrm{~L}=50 \mathrm{~m}$, and $\mathrm{L}=80 \mathrm{~m}$ is summarized in Figure 172 .

If diameter of the cavern is fixed, the peak value of first arrived pressure wave is decreased as the location of interface is moved from $\mathrm{L}=20 \mathrm{~m}$ to $\mathrm{L}=80 \mathrm{~m}$ (Figure 172). In addition, if the location of interface the fixed, the peak value of the first arrival is decreased as cavern diameter is increased from $0.15 \mathrm{~m}$ to $3.0 \mathrm{~m}$.

On the other hand, the arrival time of the first peak at $x=10 \mathrm{~m}$ in pipe 2 are changed due to the change of interface location (Figure 173). 


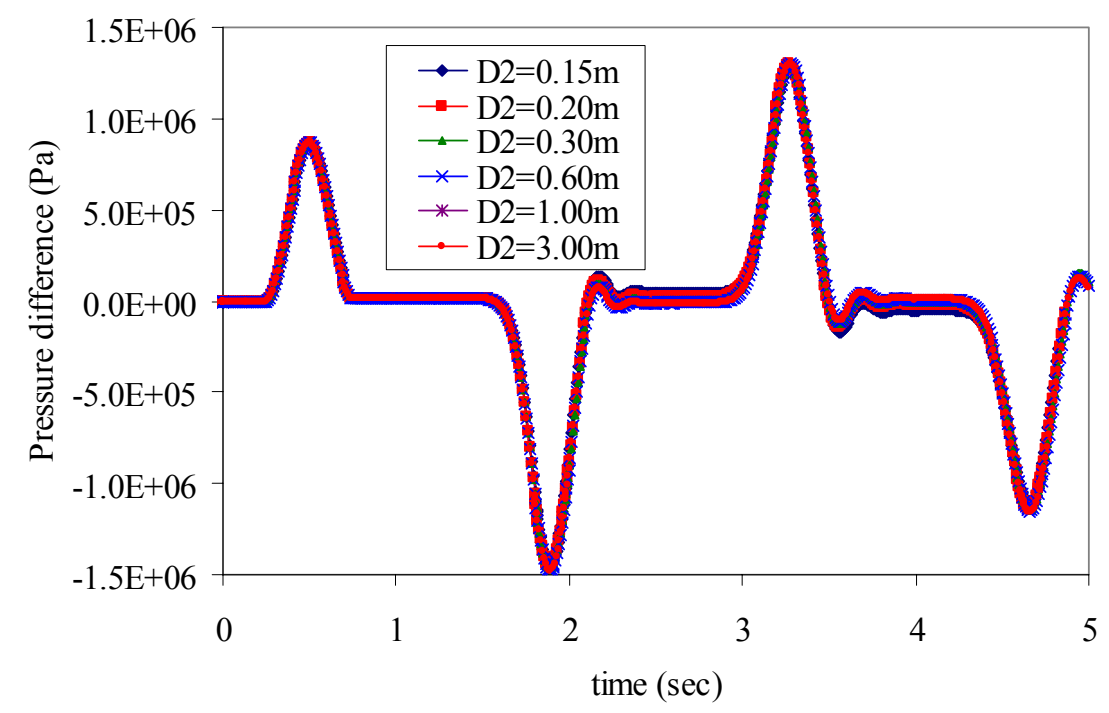

(a) Pressure histories at $x=0 \mathrm{~m}$ in pipe 1

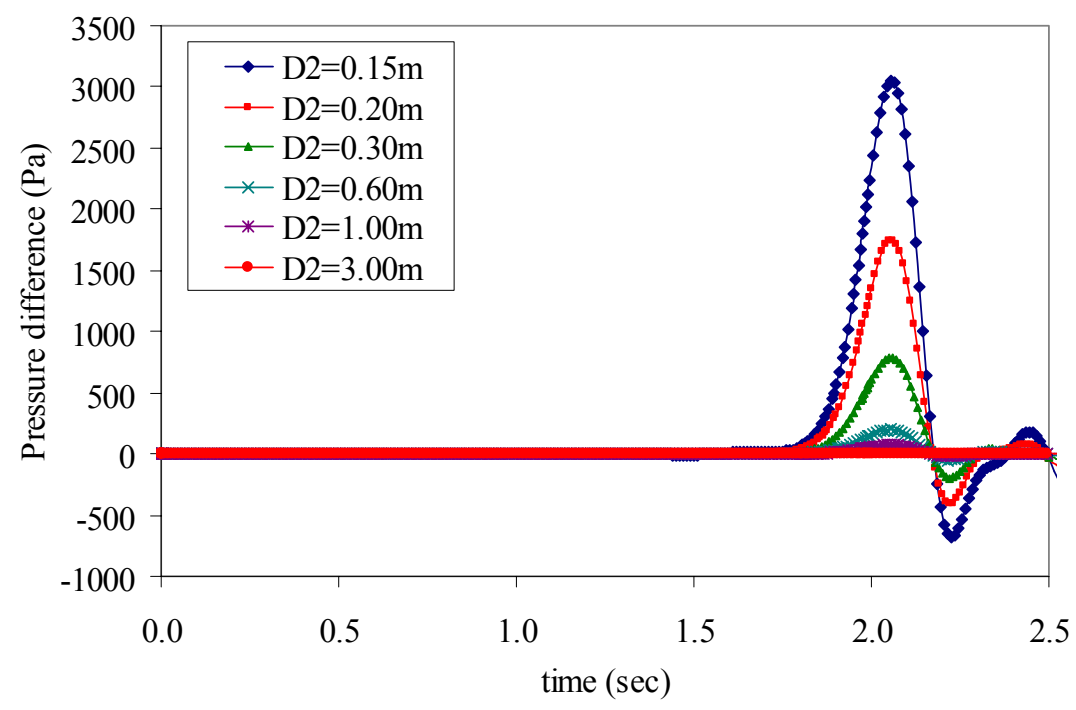

(b) Pressure histories at $x=10 \mathrm{~m}$ in pipe 2

Figure 169 Pressure histories at wellhead in pipe 1 and pipe 2 with respect to diameter change of cavern in the case of $\mathrm{L}=20 \mathrm{~m}$ 


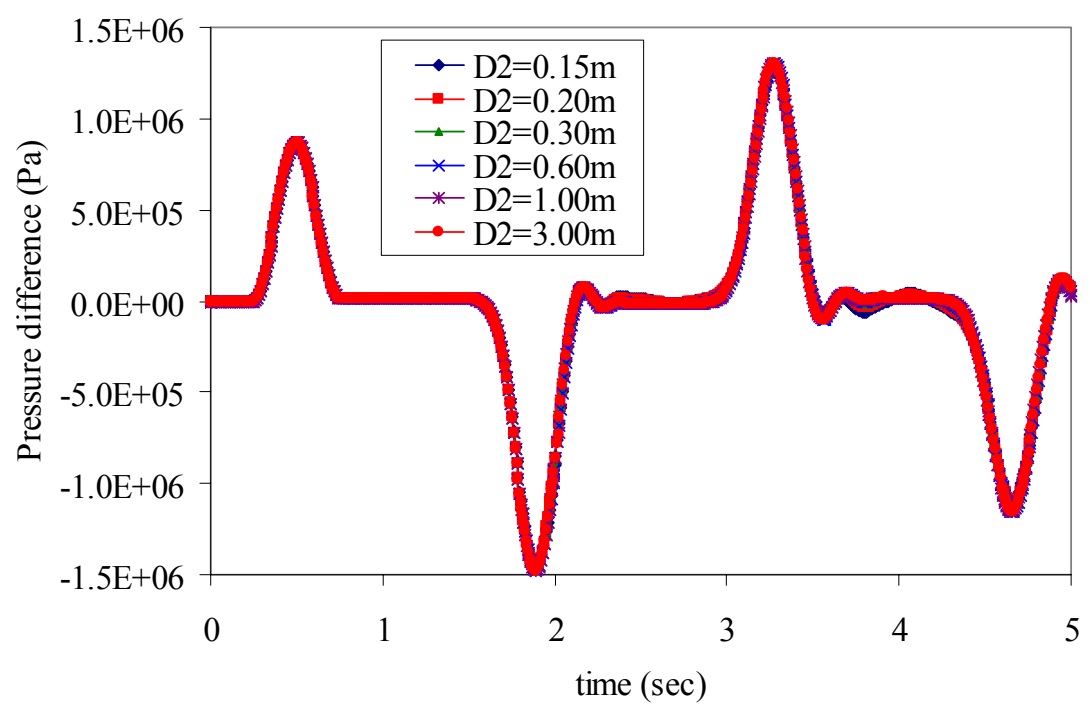

(a) Pressure histories at $x=0 \mathrm{~m}$ in pipe 1

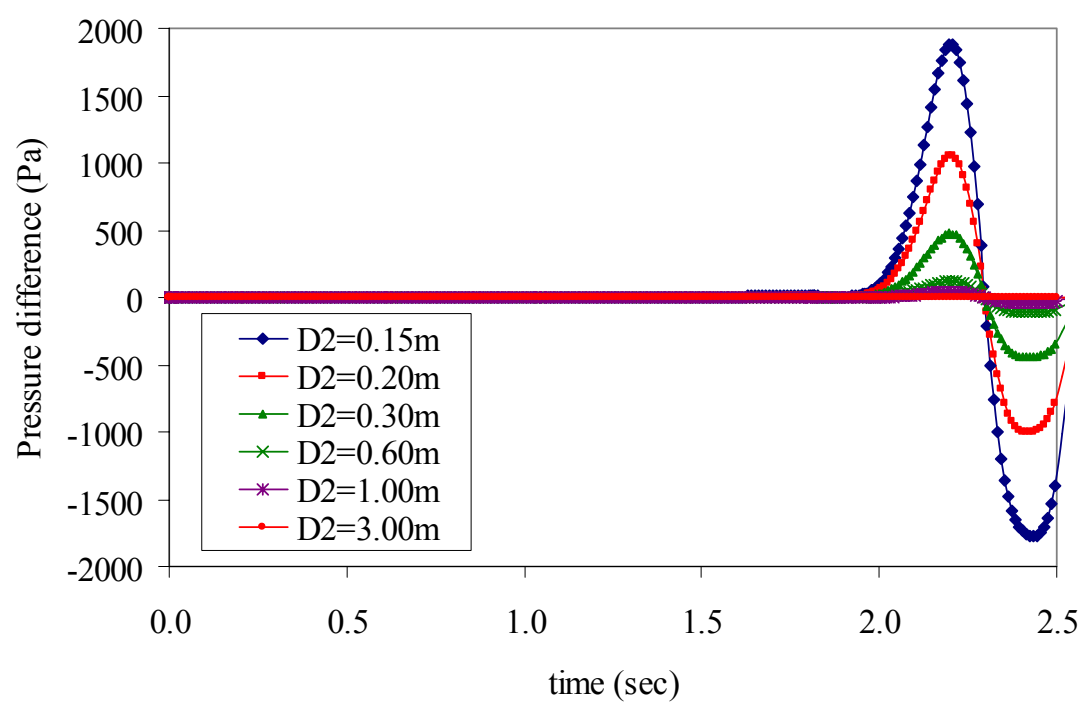

(b) Pressure histories at $x=10 \mathrm{~m}$ in pipe 2

Figure 170 Pressure histories at wellhead in pipe 1 and pipe 2 with respect to diameter change of cavern in the case of $\mathrm{L}=50 \mathrm{~m}$ 


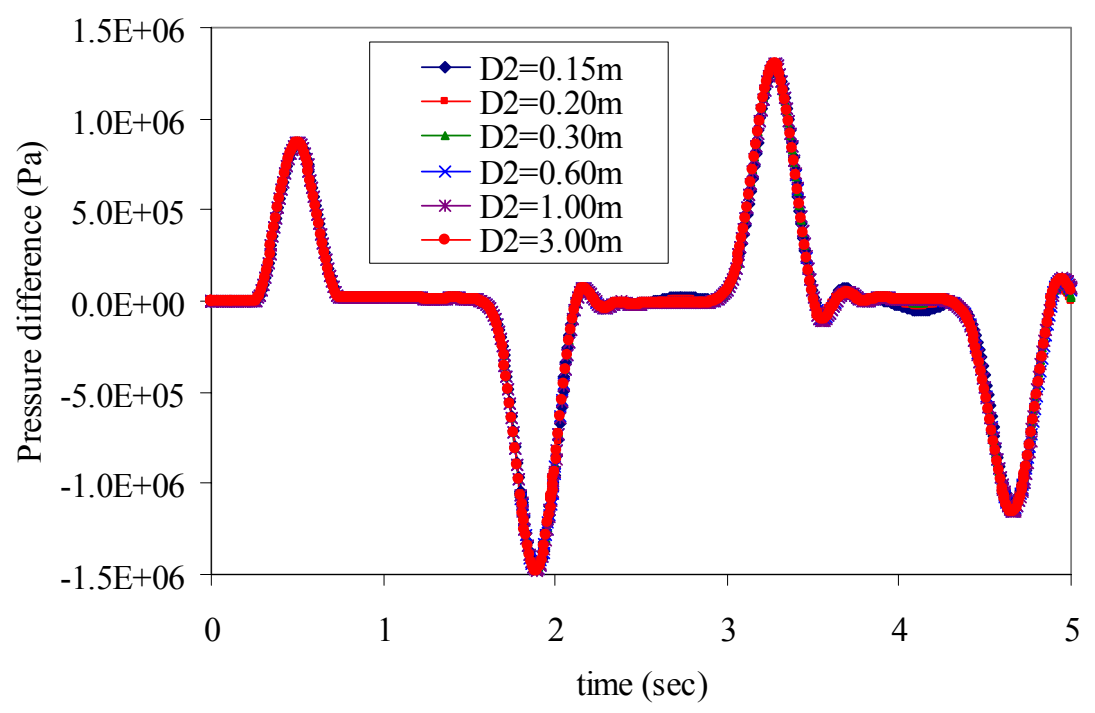

(a) Pressure histories at $x=0 \mathrm{~m}$ in pipe 1

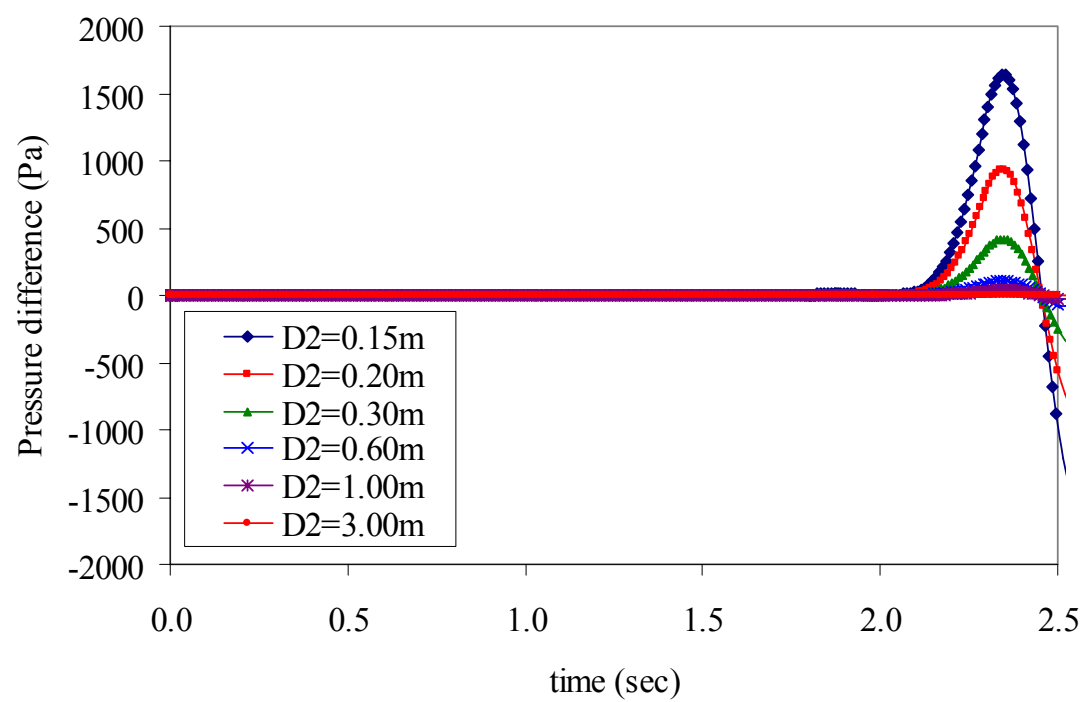

(b) Pressure histories at $x=10 \mathrm{~m}$ in pipe 2

Figure 171 Pressure histories at wellhead in pipe 1 and pipe 2 with respect to diameter change of cavern in the case of $\mathrm{L}=80 \mathrm{~m}$ 


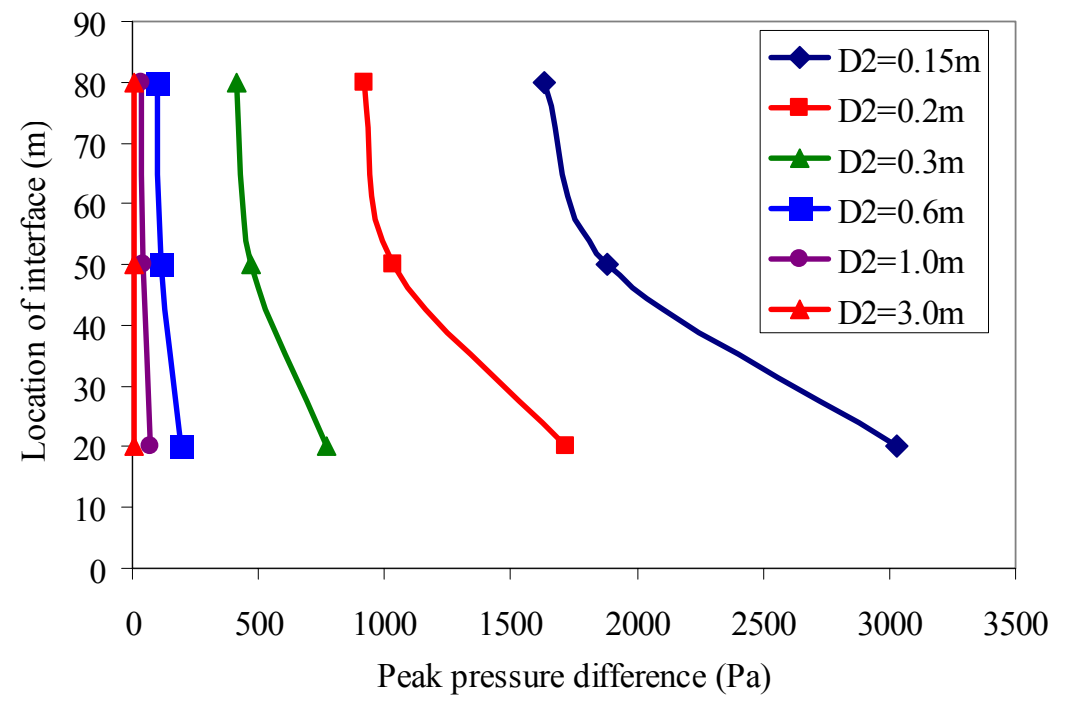

Figure 172. Peak pressure difference change due to location of interface and diameter (D2) change of cavern

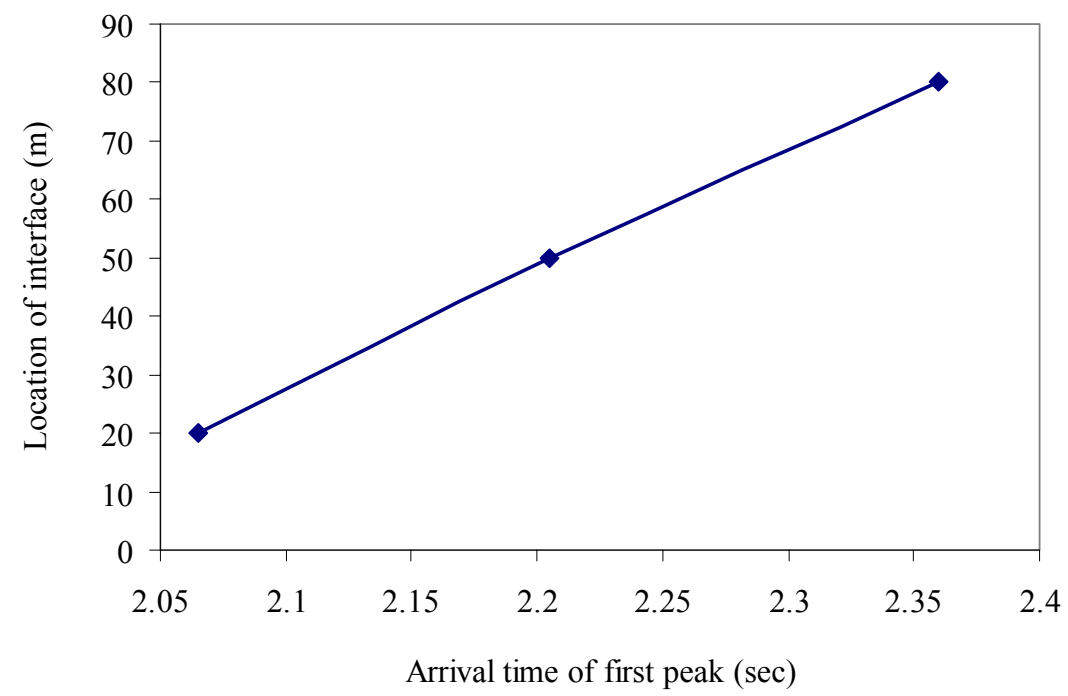

Figure 173 Arrival time of the first peak with respect to the location of the $\mathrm{CO}_{2}$-brine interface

Although only one curve is presented in Figure 173, it represents six different cases; i.e., diameter change of cavern from $0.15 \mathrm{~m}$ to $3.0 \mathrm{~m}$. The arrival times of first peaks at $x=10 \mathrm{~m}$ in pipe 2 with diameter of cavern from $0.15 \mathrm{~m}$ to $3.0 \mathrm{~m}$ are similar. The wave velocity in the $\mathrm{CO}_{2}$ zone is determined and it is a function only of the material properties of the fluid and cavern material instead of cavern diameter, so that the diameter change of cavern does not affect the arrival time of the pressure wave. The change of the interface location from $20 \mathrm{~m}$ to $80 \mathrm{~m}$ delays the arrival time of the first peak at $x=10 \mathrm{~m}$ in pipe 2 due to the increase of thickness of the $\mathrm{CO}_{2}$ 
layer since wave velocity in $\mathrm{CO}_{2}$ is much slower than that in the acid zone.

\section{Comparison of Liquid and $\mathrm{Gas} \mathrm{CO}_{2}$}

It is not known whether the supercritical $\mathrm{CO}_{2}$ will behave either like a nearly incompressible liquid, or like a compressible gas. Therefore, the results of the calculations using the assumption of liquid-like $\mathrm{CO}_{2}$ should be compared with those using the assumption of gaslike $\mathrm{CO}_{2}$. In the case of $\mathrm{L}=20 \mathrm{~m}$ and $\mathrm{D} 2=0.15 \mathrm{~m}$, the pressure histories are compared in Figure 174.

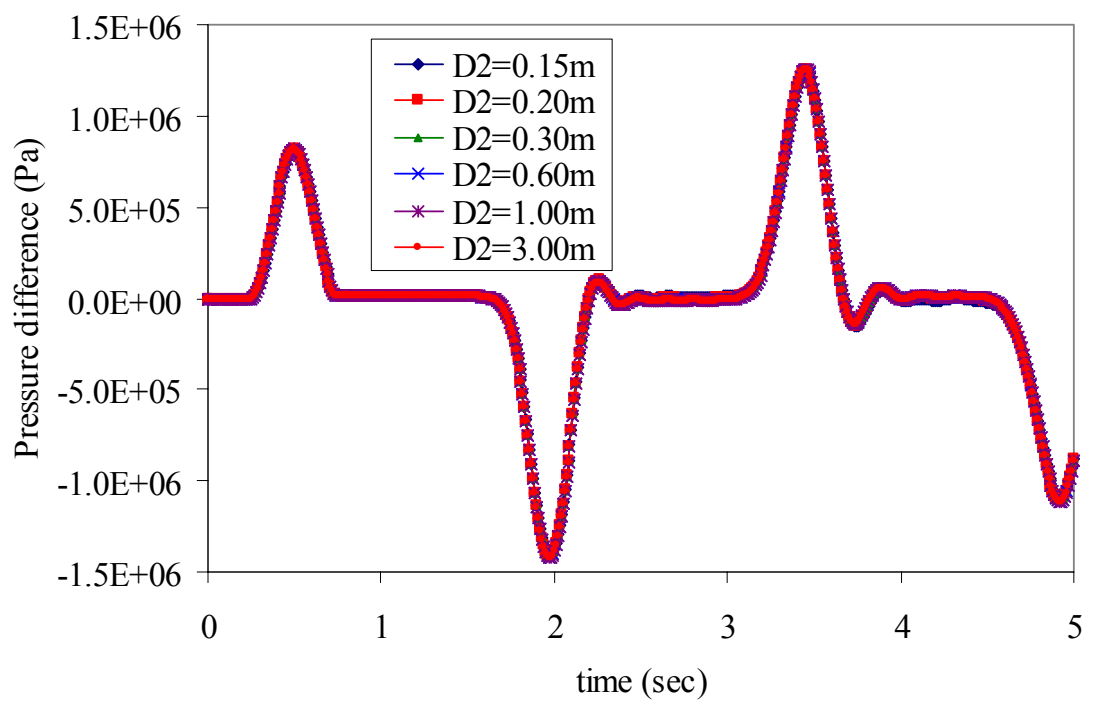

(a) Pressure histories at $x=0 \mathrm{~m}$ in pipe 2

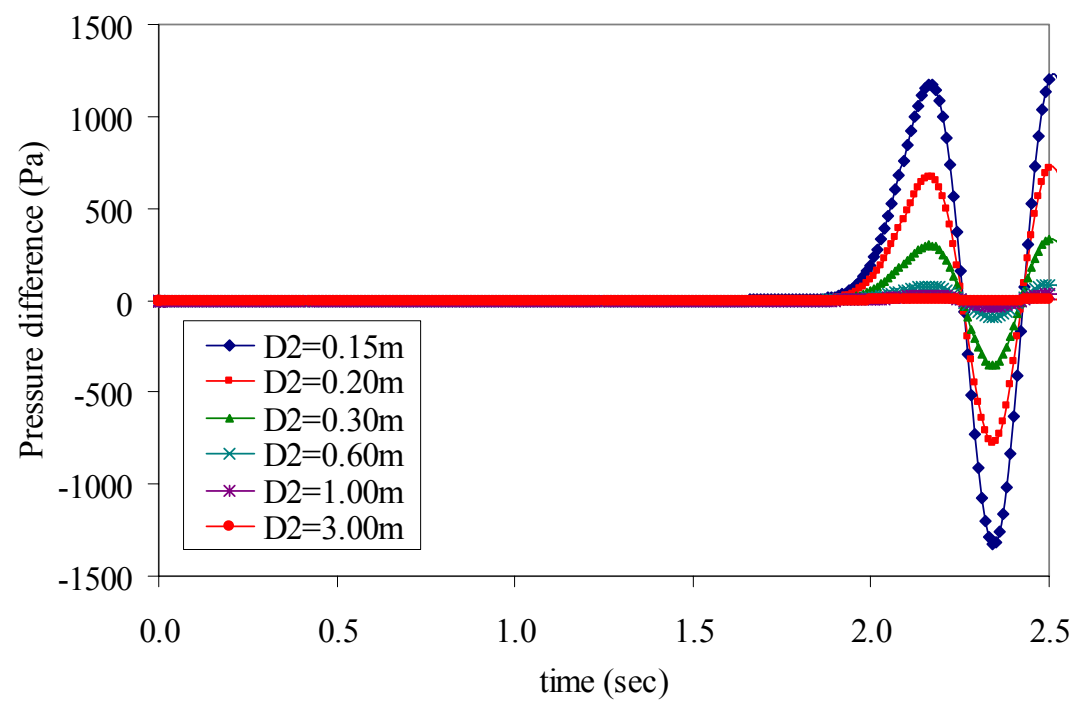

(b) Pressure histories at $x=10 \mathrm{~m}$ in pipe 2

Figure 174 Pressure histories at wellhead in pipe 1 and pipe 2 with respect to diameter change of cavern in the case of $\mathrm{L}=20 \mathrm{~m}$, and gas-like $\mathrm{CO}_{2}$ 
For the case of liquid $\mathrm{CO}_{2}$, Figure 174 (a) shows that the difference between the curves can be ignored, so that the effect of diameter change in the case of $\mathrm{L}=20 \mathrm{~m}$ on the pressure histories at $x=0 \mathrm{~m}$ in pipe 1 can be considered very small. In Figure $174(\mathrm{~b})$, as diameter of the cavern increases, the peak value of first arrived pressure wave is decreased.

In Figure 175, the results using the different analytical approaches, using the case of $\mathrm{L}=20 \mathrm{~m}$ and $\mathrm{D} 2=0.15 \mathrm{~m}$, are compared.

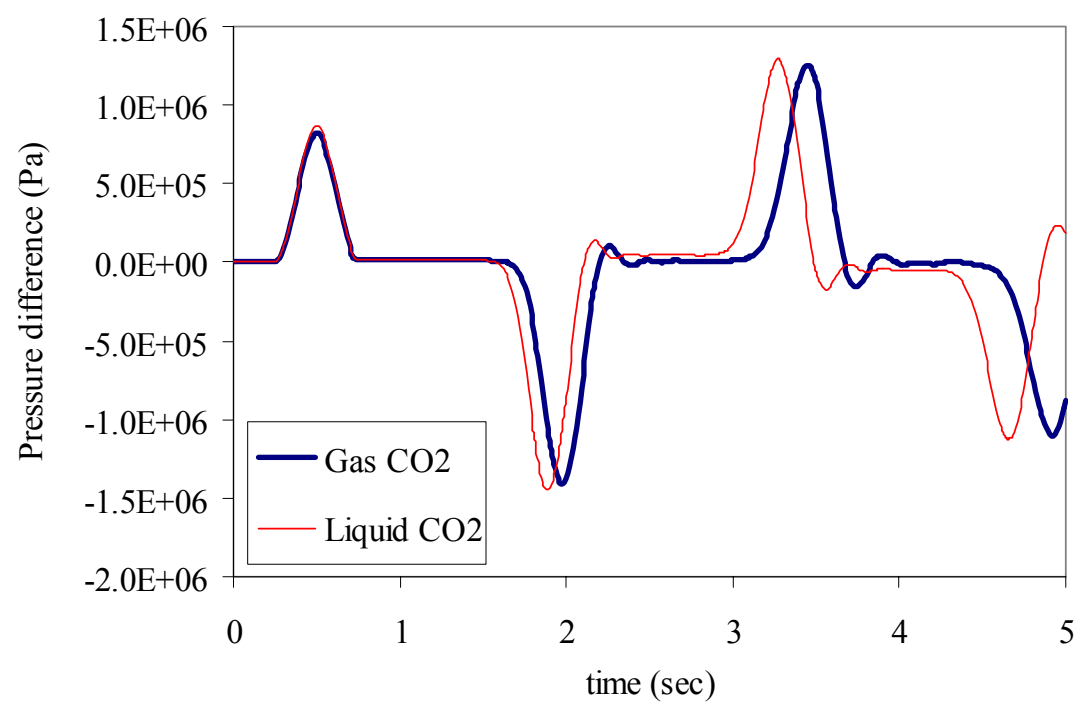

(a) Pressure histories at $x=0 \mathrm{~m}$ in pipe 1

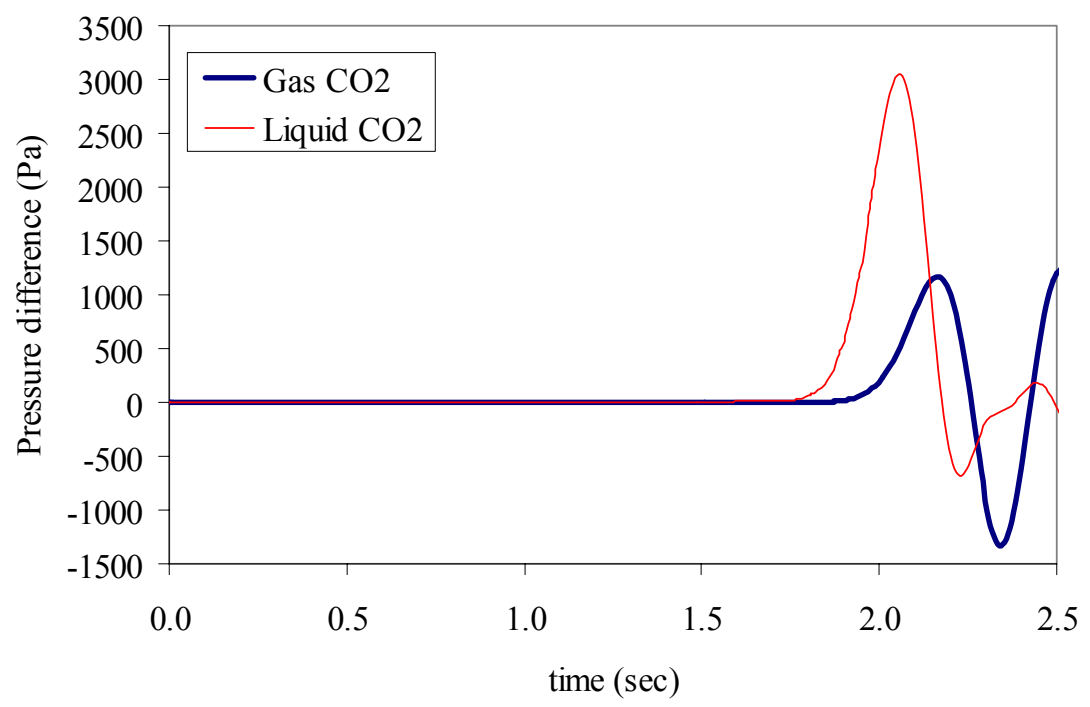

(b) Pressure histories at $x=10 \mathrm{~m}$ in pipe 2

Figure 175 Comparison of pressure histories at wellhead in pipe 1 and pipe 2 between gas-like $\mathrm{CO}_{2}$ and liquid-like $\mathrm{CO}_{2}$ 
From Figure 175 (a), it can be observed that there is some difference in the arrival time of the second peaks between the case of gas $\mathrm{CO}_{2}$ and liquid $\mathrm{CO}_{2}$, which have already been observed, whereas the difference in magnitude of the second peak values is quite small. On the other hand, the difference in the arrival time of the first peaks at $x=10 \mathrm{~m}$ in pipe 2 is relatively large as shown in Figure 175 (b). 


\section{Evaluation of the Stability of a Cavern Created by Dissolution of Carbonate Rock (Part 2 of Task 10) \\ By Larry Murdoch and Jim Foley}

\section{Introduction}

The results of plasticity indicators, predicted changes in maximum and minimum stress and predicted maximum and minimum pressure range are presented for the $10 \times 200 \mathrm{~m}$ domed cylindrical cavern at a $k$ ratio of 0.8 . The effects of variations in the $\mathrm{k}$ ratio on stability range for all shapes tested are presented next, followed by how depth and size affect stability of the baseline cavern.

\section{Cavern Geometry}

There were seven cavern geometries of approximately the same volume simulated: three right cylindrical caverns with base radius and height dimensions of $40 \times 12 \mathrm{~m}, 20 \times 50 \mathrm{~m}$ and 10 × 200 m; a 10 x 200 m domed cylindrical cavern; a spherical cavern with a 24.6 m radius; a conical cavern with a base radius of $25 \mathrm{~m}$ and a height of $95.6 \mathrm{~m}$ and a tunnel cavern $200 \mathrm{~m}$ long with a $10 \mathrm{~m}$ radius circular cross. The cylindrical caverns with a narrower base and greater height $(10 \times 200 \mathrm{~m} ; 20 \times 50 \mathrm{~m})$ are more stable than the short cavern with a wide base $(40 \times 12$ $\mathrm{m})$. All of the cylindrical caverns indicated failure along the flat roof and floor at low internal pressures during depressurization. An internal cavern pressure of approximately $P^{*}=1.0$ was necessary to maintain stability in the cylindrical caverns. The $10 \times 200 \mathrm{~m}$ cylindrical cavern has the broadest stability range for variations in the stress field while the $40 \times 12 \mathrm{~m}$ cylindrical cavern was the least stable with suitable stability indicated only at a $k$ ratio of 1.2.

The $10 \times 200 \mathrm{~m}$ domed cylindrical cavern was the most stable geometry simulated. This cavern is stable over the broadest pressure range and was the only geometry simulated to maintain cavern stability at blowout conditions of $P^{*} \approx 0$. The spherical cavern has the next best performance when compared to the domed cylindrical cavern. While the spherical cavern has a greater percentage of the edge at yield during pressurization, it is able to maintain stability to a lower internal pressure $\left(\approx P^{*}=0.6\right)$ than the flat roofed cylindrical caverns $\left(\approx P^{*}=1.0\right)$ and is stable over a broader in-situ stress range. The tunnel cavern has a narrower range of stable conditions than the spherical cavern or cylindrical caverns. It is most stable at a $k$ ratio of 0.8 , but the stability range decreases in other stress fields. The tunnel cavern is able to maintain stability to a lower internal pressure $\left(P^{*}=0.6\right)$ than the cylindrical caverns during depressurization. The conical cavern is stable at higher internal pressures and could contain at least $0.5 \mathrm{BCF}$ of gas, although there is greater then 20 pey. The majority of the yield occurs along the flat base of the cavern. A curved base would probably increase the stability range of the cavern.

Failure is predicted along the flat roofs and floors of the conical and cylindrical caverns. While the simulations indicate that failure is more likely to occur along the flat roofs and floors, these general shapes could be stable under field conditions. The plasticity indicators are localized around the flat roofs and floors. It is inferred that failure of the roof would result in a stable, domed roof. Incorporating a domed roof as part of the cavern design would be more stable than a flat roofed cavern. 


\section{Stress Field}

The ratio of the horizontal to vertical stress had a greater than expected influence on cavern stability. Failure was predicted for all of the cavern geometries at a stress ratio of 0.4. Failure is predicted for the conical, $40 \times 12 \mathrm{~m}$ and $20 \times 50 \mathrm{~m}$ cylindrical caverns at cavern creation and during the initial gas fill at a $k$ of 0.6 (Figure 176). The other shapes contain at least $0.5 \mathrm{BCF}$ of gas before failure is indicated at a $k$ of 0.6 , but a high percentage of the cavern edges are at yield (Figure 176). All of the cavern geometries can contain at least 0.5 BCF of gas before failure is indicated at a $k$ of 0.8 and 1.0 (Figure 176). Both of the $10 \times 200 \mathrm{~m}$ cylindrical caverns could contain up to $1.0 \mathrm{BCF}$ of gas before failure is indicated at a $k$ of 0.8 and 1.0 , but there is a higher percentage of the cavern at yield (Figure 176). Failure is indicated for the tunnel and $20 \mathrm{x}$ $50 \mathrm{~m}$ cylindrical cavern at cavern creation when $k$ is 1.2 (Figure 176). The other cavern geometries could contain $0.5 \mathrm{BCF}$ of gas prior to indications of failure when $k$ is 1.2 (Figure 176).

Cavern stability is low for all shapes at $k$ ratios of 0.6 and lower. Stability is predicted for all shapes when the $\mathrm{k}$ ratio ranges from 0.8 to 1.0 , but some shapes are unstable when the $k$ ratio is 1.2 (Figure 176). While there is little information on the stress ratio at the proposed cavern depths, the $k$ ratio for the Appalachian basin at depths greater than $1200 \mathrm{~m}$ probably ranges from 0.8 to 1.2 based on measurements at other locations in North America (Hoek and Brown, 1980; Zoback and Zoback, 1980; Evans and Engelder, 1986; Evans et al., 1989a; Evans et al., 1989b; Wuming et al., 1992; Zoback, 1992; Engelder, 1993; Reinecker, 2004). A cylindrical cavern with a domed roof and a height greater than the width is predicted to be the most stable over this $k$ range.

\section{Cavern Depth}

The cavern at $1220 \mathrm{~m}$ is stable over a slightly greater range of $P^{*}$ values than the cavern at $1830 \mathrm{~m}$, while failure is indicated much sooner for the cavern at $2420 \mathrm{~m}$. While failure is predicted at a lower $P^{*}$ in the deeper cavern during pressurization, the caverns at the different depths contain roughly the same volume at less than 20 pey due to the compressibility of natural gas. The shallower cavern is stable to a lower $P^{*}$ during depressurization of the cavern while the deeper cavern needs a higher internal pressure to maintain stability. All other parameters being equal, shallower caverns will be more stable over a broader range of internal pressures than a deeper cavern. Whereas deeper caverns would be able to contain a larger volume of gas at lower pressures due to the compressibility of gas.

The major factor that influences cavern stability is the increased in-situ stresses with depth. The $k$ ratio can also vary with depth. Compared to caverns at shallower depths, caverns formed in deeper formations would be located in an overall higher in-situ stress field. This will cause greater magnitudes of stress changes around the cavern. At shallower depths the in-situ stress will be lower and stresses around the cavern will be less than deeper caverns. This would probably lead to a more stable cavern. 

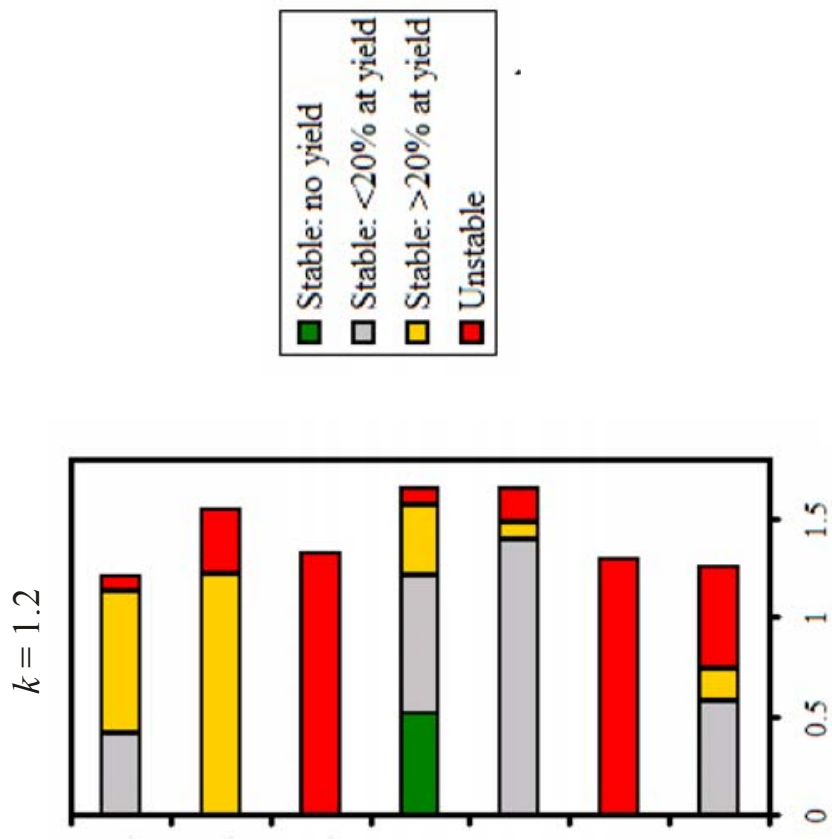

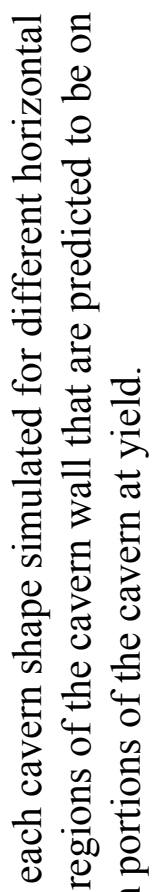

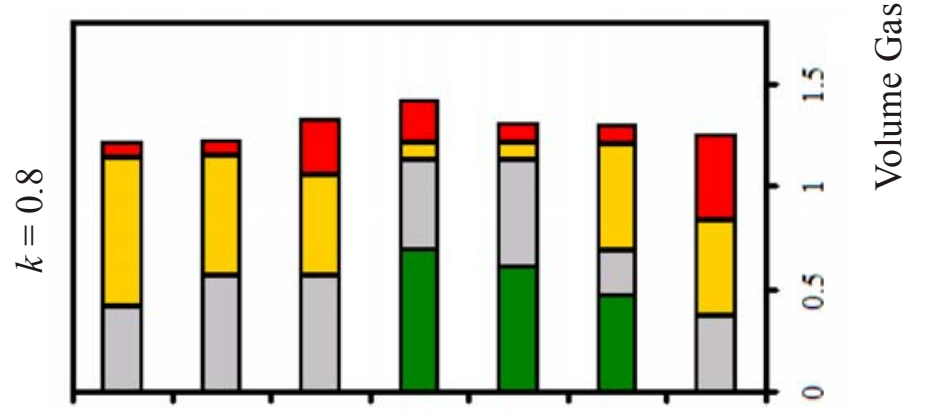

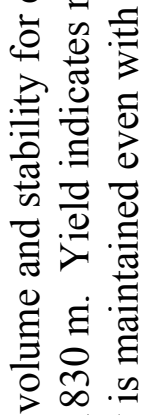

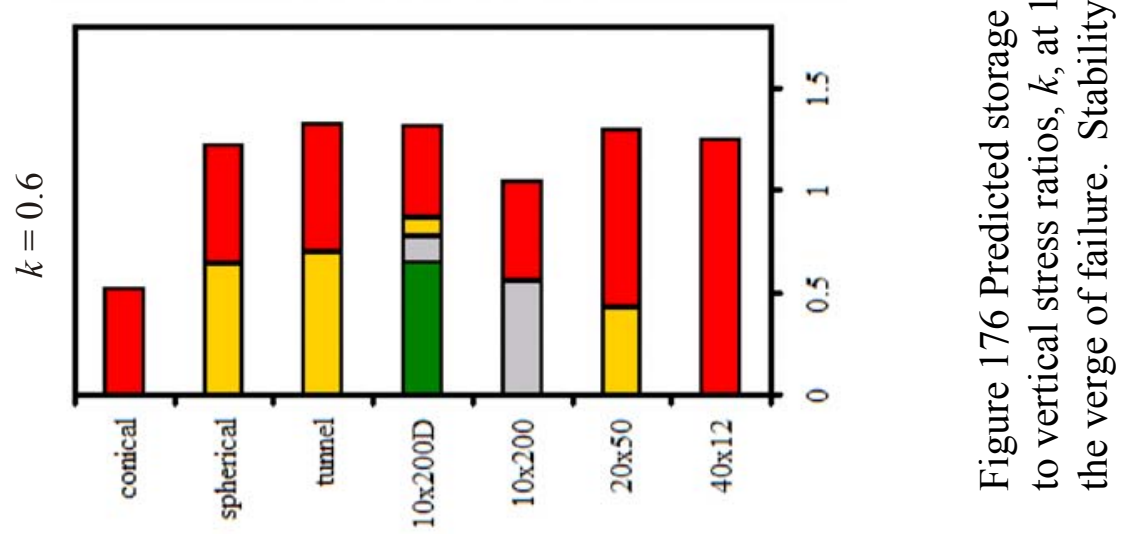




\section{Cavern Size}

Cylindrical caverns with intended storage volumes of $0.25,0.5$ and $1.0 \mathrm{BCF}$ and approximately the same height to width ratio of 2.5 were simulated to help predict variations in cavern size. There is limited effect of cavern size on cavern stability factors over the range simulated. The major difference during pressurization was that the $1.0 \mathrm{BCF}$ had less than 20 pey over a greater $P^{*}$ range than the other caverns. During cavern depressurization the $0.25 \mathrm{BCF}$ cavern was stable at lower $P^{*}$ values than the larger caverns. Overall, cavern size is not a major factor for cavern stability for caverns less than 1.0 BCF with the same height to width ratio.

\section{Pressure Cycling}

The rate of pressure change will affect cavern stability. Abrupt, instantaneous changes in pressure can shock the system and reduce cavern stability. Slower, stepped changes in internal pressure increase cavern stability. The actual rate of pressure change was not simulated but caverns under working conditions will probably undergo gradual pressure fluctuations which would help increase cavern stability.

\section{Pressure Range}

The maximum and minimum pressures during cycling will also affect cavern stability. While a large range could increase storage capacity, it could reduce cavern stability. Failure is indicated for most of the caverns at approximately $P^{*}=2.8$ during pressurization and at approximately $P^{*}$ $=1.0$ during depressurization. This will vary with geometry and stress state, but operational pressures for the cavern should fall within this range with the most stable range between $P^{*}=$ 1.0 and $P^{*}=1.5$.

\section{Stability Analysis}

This research was conducted to assess the stability of caverns created in limestone for natural gas storage. Simulations using FLAC 5.0 indicate that some caverns for natural gas storage in limestone could be stable under conditions expected in the Appalachian basin. The caverns were assumed to be created instantaneously and loaded at hydrostatic pressure to simulate the stability behavior after dissolution and during operation. This analysis is a conservative predictor of cavern stability as the simulations assume instantaneous changes in cavern conditions. The actual cavern creation and operation will be transient, which may result in caverns that are more stable than those predicted by the model.

The geometry of the cavern and in-situ stress state have the greatest effect on cavern stability. A tall, narrow $10 \times 200 \mathrm{~m}$ cylindrical cavern with a domed roof and floor is predicted to be stable over the broadest range of conditions for the cavern shapes tested (Figure 176; Table 50 and Table 51). The $10 \times 200$ m cylindrical cavern with the flat roof and floor has the next greatest stability range (Figure 176; Table 50). Plasticity indicators are localized at the flat roof of this cavern and displacements indicate downward bulging of the roof. It is inferred that failure would occur along the roof and the result would be a more dome-like shape with improved 
stability. As the simulations assume that the cavern was instantaneously created, the cavern may evolve to the most stable geometry during dissolution. Flat roofed caverns may be created where an insoluble rock layer creates a boundary or, from the acid injection process. A flat roof would be the likely location for failure during cavern operation. If roof failure damaged the well, the cavern could be rendered unusable for gas storage.

Other cavern shapes, such as a $20 \times 50 \mathrm{~m}$ cylinder, sphere and cone could potentially be utilized for natural gas storage depending on the thickness of the limestone formation and in-situ stress conditions (Table 50). These caverns have a higher percent of the edge at yield or failure indicated along a flat roof or base, but could evolve to a stable cavern suitable for gas storage. A tunnel and puck-like cylinder are geometries that would be less suitable for a gas storage cavern based on stability considerations (Figure 176; Table 50; Table 51).

The in-situ stress state can have a substantial effect on cavern stability. Failure is predicted for all of the geometries at the low end of the range of horizontal to vertical stress ratio $(k=0.4)$. Cavern stability generally increases with an increasing $k$ value (Figure 176; Table 50). At the high end of the $k$ range, stability tends to depend on cavern geometry (Figure 176; Table 50). The ratio of horizontal to vertical stress, $k$, is poorly known in the Appalachian Basin at the depths proposed for the storage facility, but is quite variable up to depths of $1000 \mathrm{~m}$ (Hoek and Brown, 1980; Zoback and Zoback, 1980; Evans and Engelder, 1986; Evans et al., 1989a; Evans et al., 1989b; Wuming et al., 1992; Zoback, 1992; Engelder, 1993; Reinecker, 2004). Stress measurements will be an important consideration in storage cavern design because the in-situ stress influences cavern stability.

The magnitude of the in-situ stresses will depend on the depth that the cavern is created as the vertical stress is a function of the weight of the overburden. Shallower caverns $(\sim 1220 \mathrm{~m})$ are predicted to have a greater stability range than deeper caverns $(\sim 2400 \mathrm{~m})$, as the in-situ stresses would be less at shallower depths.

The rate of pressure change during injection and removal from storage can affect cavern stability. Rapid changes in pressure can reduce stability, whereas gradual changes help to maintain stability (Table 51). The cycling of internal cavern pressure can also lead to failure after several pressure cycles. Cavern shapes that are predicted to be stable during initial filling may become unstable after repeated pressure cycling. Failure induced from cycling can be reduced depending on the pressure range and cavern geometry (Table 51).

The maximum and minimum pressures in the cavern also influence cavern stability. Higher internal pressures will increase the storage volume, but they will reduce stability both at the high pressure as well as during cavern depressurization. A safe working pressure for most cavern shapes ranges from a minimum pressure of $P^{*} \approx 1.0$ to a maximum pressure of $P^{*} \approx 1.5$ (Table 51). Water could be utilized to act as a "cushion" to maintain stability and reduced pressure changes, but this may increase operational costs.

\section{Suggestions for Cavern Design}

Site specific modeling should be conducted to predict the optimal cavern shape and operational pressure range for the cavern because there are many parameters that influence cavern stability. To assist in future cavern designs, a methodology for cavern stability modeling of gas storage caverns based on this research has been constructed. 
I. Select a target storage volume that would make the storage facility economically viable.

II. Identify a suitable limestone formation for the storage facility that is located near existing infrastructure (Castle et al., 2004; Yang, 2004: Atteberry, 2005).

III. Collect the following data: lithology, porosity, permeability, physical and mechanical properties, $\mathrm{HCl}$ solubility, in-situ stress, fractures, faults, stratigraphic section, unit boundaries.

IV. Select one or two idealized cavern geometries to create (Table 50). The cavern should be of a shape that would contain the target storage volume, remain within the limestone formation with some buffer between the cavern and adjacent formations and be a stable geometry for the in-situ stress. Ideally the shape should be cylindrical, with a height greater than width and domed floor and roof.

V. Simulate the selected shapes using FLAC 2D. Simulations should incorporate known data on the formation and stratigraphy, or utilize reasonable estimates for input parameters.

VI. In the simulations, create the cavern at hydrostatic pressure then step internal pressure up to failure. Determine a maximum internal pressure and decrease pressure to determine a minimum internal cavern pressure.

VII. Observe where yield and failure are indicated. If failure would alter cavern geometry, run another model that would simulate the new predicted geometry.

VIII. If this new shape is predicted to be stable over a broader range, cycle the internal cavern pressure between the predicted maximum and minimum values.

IX. If stability is predicted, cavern displacements are within an acceptable range, and the following additional considerations are accounted for, the general cavern geometry could be attempted to be created in the field. 
Table 50 Predicted suitability of different cavern geometries at different horizontal stress ratios for caverns at $1830 \mathrm{~m}$. Caverns created at shallower depths $(\sim 1200 \mathrm{~m})$ should have greater stability whereas caverns created at deeper depths $(\sim 2400 \mathrm{~m})$ should be less stable.

In-Situ Horizontal to Vertical Stress Ratio $(k)$

\begin{tabular}{|c|c|c|c|c|}
\hline & 0.6 & 0.8 & 1.0 & 1.2 \\
\hline $\begin{array}{l}40 \times 12 \\
\text { Cylindrical }\end{array}$ & $\begin{array}{l}\text { Failure } \\
\text { Indicated }\end{array}$ & $\begin{array}{l}\text { Conditionally } \\
\text { Stable }(B, C) \text { : } \\
\text { Unsuitabl }\end{array}$ & $\begin{array}{l}\text { Conditionally } \\
\text { Stable }(B, C) \text { : } \\
\text { Unsuitabl }\end{array}$ & $\begin{array}{l}\text { Conditionally } \\
\text { Stable }(B, C) \text { : } \\
\text { Low Possibility }\end{array}$ \\
\hline $\begin{array}{l}20 \times 50 \\
\text { Cylindrical }\end{array}$ & $\begin{array}{l}\text { Failure } \\
\text { Indicated }\end{array}$ & $\begin{array}{l}\text { Conditionally } \\
\text { Stable }(C) \text { : } \\
\text { Probabl } \\
\end{array}$ & $\begin{array}{l}\text { Conditionally } \\
\text { Stable }(\mathrm{C}) \text { : } \\
\text { Probabl } \\
\end{array}$ & $\begin{array}{l}\text { Failure } \\
\text { Indicated }\end{array}$ \\
\hline $\begin{array}{l}10 \times 200 \\
\text { Cylindrical }\end{array}$ & $\begin{array}{l}\text { Conditionally } \\
\text { Stable }(\mathrm{C}) \text { : } \\
\text { use domed }\end{array}$ & $\begin{array}{l}\text { Conditionally } \\
\text { Stable }(C) \text { : } \\
\text { use domed }\end{array}$ & $\begin{array}{l}\text { Conditionally } \\
\text { Stable }(\mathrm{C}) \text { : } \\
\text { use domed }\end{array}$ & $\begin{array}{l}\text { Conditionally } \\
\text { Stable }(\mathrm{C}) \text { : } \\
\text { use domed }\end{array}$ \\
\hline $\begin{array}{l}10 \text { x } 200 \\
\text { Dome } \\
\text { Cylindrical }\end{array}$ & $\begin{array}{l}\text { Stable } \\
\text { Recommended }\end{array}$ & $\begin{array}{l}\text { Stable } \\
\text { Recommended }\end{array}$ & $\begin{array}{l}\text { Stable } \\
\text { Recommended }\end{array}$ & $\begin{array}{l}\text { Stable } \\
\text { Recommended }\end{array}$ \\
\hline $\begin{array}{l}\text { Tunnel } \\
10 \times 200\end{array}$ & $\begin{array}{l}\text { Conditionally } \\
\text { Stable (B): } \\
\text { Unsuitabl }\end{array}$ & $\begin{array}{l}\text { Conditionally } \\
\text { Stable (A): } \\
\text { Low possibility }\end{array}$ & $\begin{array}{l}\text { Conditionally } \\
\text { Stable (B): } \\
\text { Unsuitabl }\end{array}$ & $\begin{array}{c}\text { Failure } \\
\text { Indicated }\end{array}$ \\
\hline $\begin{array}{l}\text { Spherical } \\
\mathrm{r}=24.6\end{array}$ & $\begin{array}{l}\text { Conditionally } \\
\text { Stable (B): } \\
\text { Probabl } \\
\end{array}$ & $\begin{array}{l}\text { Conditionally } \\
\text { Stable (A): } \\
\text { Probabl } \\
\end{array}$ & $\begin{array}{l}\text { Conditionally } \\
\text { Stable (B): } \\
\text { Probabl } \\
\end{array}$ & $\begin{array}{l}\text { Conditionally } \\
\text { Stable (B): } \\
\text { Probabl } \\
\end{array}$ \\
\hline $\begin{array}{l}\text { Conical } \\
25 \times 95.6\end{array}$ & $\begin{array}{l}\text { Failure } \\
\text { Indicated }\end{array}$ & $\begin{array}{l}\text { Conditionally } \\
\text { Stable }(B, C): \\
\text { Probabl }\end{array}$ & $\begin{array}{l}\text { Conditionally } \\
\text { Stable }(B, C) \text { : } \\
\text { Probabl }\end{array}$ & $\begin{array}{l}\text { Conditionally } \\
\text { Stable }(B, C): \\
\text { Probabl }\end{array}$ \\
\hline
\end{tabular}

Approximate cavern volume: $62570^{3}$

Conditionally Stable:

(A Stability predicted with less than $20 \%$ of cavern wall at yield

(B) Stability predicted with greater than $20 \%$ of cavern wall at yield

(C Stability predicted over one cycle, failure of flat roof or floor predicted upon cycling. The same dimensions with a domed roof or floor could result in a suitable cavern. 
Table 51 Parameters affecting cavern stability.

\begin{tabular}{|c|c|c|}
\hline & Tends to be more stable & $\begin{array}{l}\text { Tends to be less stable/ } \\
\text { leads to failure }\end{array}$ \\
\hline Cavern Shape & $\begin{array}{c}\text { Column-like cylindrical } * * \\
\text { Spherical; Conical }\end{array}$ & $\begin{array}{c}\text { Puck-like cylindrical** } \\
\text { Tunnel-like }\end{array}$ \\
\hline $\begin{array}{c}\text { Cylindrical } \\
\text { Cavern Ratio** }\end{array}$ & $\begin{array}{l}\text { Height to base ratio }>1 \\
\qquad(10,1.25)\end{array}$ & $\begin{array}{l}\text { Height to base ratio }<1 \\
\qquad(0.15)\end{array}$ \\
\hline $\begin{array}{l}\text { Shape of Cavern } \\
\text { Roof and Floor }\end{array}$ & Domed & Flat \\
\hline Pressure & $1.0<P^{*}<1.6$ & $\begin{array}{l}P^{*}<0.9 \\
P^{*}>2.8\end{array}$ \\
\hline $\begin{array}{c}\text { Rate of Pressure } \\
\text { Change }\end{array}$ & $\begin{array}{l}\text { Stepped Change in } P^{*} \\
\text { "Slow Change" }\end{array}$ & $\begin{array}{l}\text { Instant Change in } P^{*} \\
\text { "Rapid Change" }\end{array}$ \\
\hline Pressure Range & $\begin{array}{l}\text { Smaller range } \\
P^{*} \text { range }<0.5\end{array}$ & $\begin{array}{l}\text { Larger range } \\
P^{*} \text { range }>0.5\end{array}$ \\
\hline Depth & $\begin{array}{l}\text { Shallower } \\
(\sim 1200 \mathrm{~m})\end{array}$ & $\begin{array}{c}\text { Deeper } \\
(\sim 2400 \mathrm{~m})\end{array}$ \\
\hline Size & \multicolumn{2}{|c|}{ Not a major factor for $<1.0 \mathrm{BCF}$ caverns simulated } \\
\hline
\end{tabular}

\section{Other Considerations}

There are some factors that could be important to stability in cavern design that were not addressed. The caverns were simulated in a isotropic, homogeneous limestone formation. Heterogeneities in the formation or interaction with adjacent formations of different lithologies could affect cavern stability. Utilizing a different formation as cavern boundary could greatly impact cavern stability. The physical characteristics of the limestone formation will be a factor in cavern stability and the poroelastic effects could also play a role. Faults could also have a significant affect on cavern stability. All of these factors should also be taken into consideration during cavern design.

\section{Conceptual Model of Failure Mechanisms}

The internal cavern pressure was increased in the simulations until failure was indicated and decreased until failure was indicated (with the exception of the $10 \times 200 \mathrm{~m}$ domed 
cylindrical cavern which was stable to $\mathrm{P}^{*} \approx 0$ ). Based on the plasticity indicators and displacements from all of the simulations run, a conceptual model of cavern failure was developed. The mechanism of failure could affect the usefulness of the cavern for gas storage as localized failure could result in a more stable cavern whereas large-scale failure could lead to collapse and loss of cavern functionality. Optimally the cavern will be stable under normal operating conditions.

Cavern failure will depend on geometry, in-situ stresses, and internal pressure, but there are some generalizations that can be made to describe general behavior. A cylindrical cavern is used to develop a conceptual model of failure because this shape tended to exhibit all of the failure mechanisms under different conditions. The behavior depends on the state of stress, so a low horizontal stress case considers when $\sigma_{h}$ is less than $\sigma_{v}$, and a high horizontal stress case considers when $\sigma_{h}$ is greater than $\sigma_{\nu}$. The states of stress are represented as symbols at the sides and above the caverns in Figure 177. The style of failure also depends on the fluid pressures in the cavern. Baseline assessments are given for caverns filled with water at hydrostatic pressure. This represents the cavern after it has been created and prior to gas injection. The upper internal pressure is when $P^{*}$ is greater than lithostatic pressure and failure is indicated. The lower pressure represents depressurization simulations where $P^{*}$ is less than hydrostatic pressure and failure has been indicated in the models.

\section{Low Horizontal Stress State}

The low horizontal baseline model is characterized by an increase in $\sigma_{v}$ at the sides and an increase in $\sigma_{h}$ above the cavern when loaded by hydrostatic pressure (Figure 177A). Plasticity indicators suggest yield in tension when the internal cavern pressure is increased to failure. The inferred mechanism of failure at high internal cavern pressures is tensile cracking. Dilatational fractures are expected to be driven by high fluid pressure and propagate into the formation (Figure 177A). This could increase the migration of gas away from the storage cavern.

The internal cavern pressure was decreased below hydrostatic to predict the cavern behavior at low pressures. There is an increase in $\sigma_{v}$ at the side of the cavern and an increase in $\sigma_{h}$ above the cavern when the internal pressure is decreased at the low horizontal stress state (Figure 177A). The simulations indicated that shear bands develop due to the stress differences. Outward roof faulting may occur when faults develop along these shear bands and splay away from the centerline of the roof, and wall faulting may occur when faults develop along shear bands dipping away from the cavern walls (Figure 177A). The development of faults could lead to collapse of the cavern though large-scale displacements of the wall or block fall from the roof. Downward bulging of the roof was also indicated at low internal pressures, and this could lead to failure as slabs of rock in the roof buckle and collapse (Figure 177B). Another mechanism of failure could be wall cracking. This may lead to oblique fracture where tensile cracks in the wall link in an echelon arrangement that may result in rock bursts or spalling (Germanovich and Dyskin, 2000) (Figure 177B). This process could be similar to borehole breakouts (Ewy and Cook, 1990a; Ewy and Cook, 1990b; Germanovich and Dyskin, 2000)

\section{$\underline{\text { High Horizontal Stress State }}$}

The high horizontal baseline model is characterized by an increase in $\sigma_{v}$ at the sides and 
an increase in $\sigma_{h}$ above the cavern loaded at hydrostatic pressure (Figure 177C). The mechanism of failure during pressurization in this stress is similar to the dilatational fracturing that could occur in other stress states. The orientation of fractures would depend on the stress fields. Fractures will tend to occur where stresses are concentrated and curve so they are aligned with the maximum stress (Figure 177).

Decreasing the internal cavern pressure results in an increase in $\sigma_{h}$ above the roof, and a decrease in $\sigma_{v}$ and $\sigma_{h}$ at the sides the cavern (Figure 177C). Shear bands are predicted to develop in the roof and this is inferred to lead to faults that arch inward over the cavern (Figure 177C) The development of inward roof faults could isolate a section of rock and lead to roof collapse (Figure 177C). Bulging and buckling, or wall cracking may also occur at low internal pressures in the high horizontal stress state (Figure 177B).

Dilatational fracturing is the failure mechanism inferred to occur at high internal pressures, whereas failure at low internal pressures may occur by several mechanisms depending on geometry and stress state. Cavern geometry will affect the distribution of stresses with corners or edges tending to concentrate stresses. The shape of the cavern is also a factor in the mechanism of failure. Bulging in the models was associated with planar surfaces along roofs and floors of the caverns. Shear bands, which could indicate faulting, were more commonly associated with shapes that have a circular geometry in vertical cross section than shapes that lacked this feature. Wall cracking is also inferred for the spherical and tunnel caverns. The ratio of $\sigma_{h}$ to $\sigma_{v}(k)$ for the far-field stress state also influences the mechanism of failure. Shear bands tended to be indicated when $k$ was at the ends of the range tested whereas bulging tended to be indicated when the horizontal to vertical stress ratio, $k$, was closer to being equal. Therefore faults are inferred to be more likely to occur when there is a bigger difference in stresses, and buckling or wall cracking may be more likely to occur when the stresses are similar. 


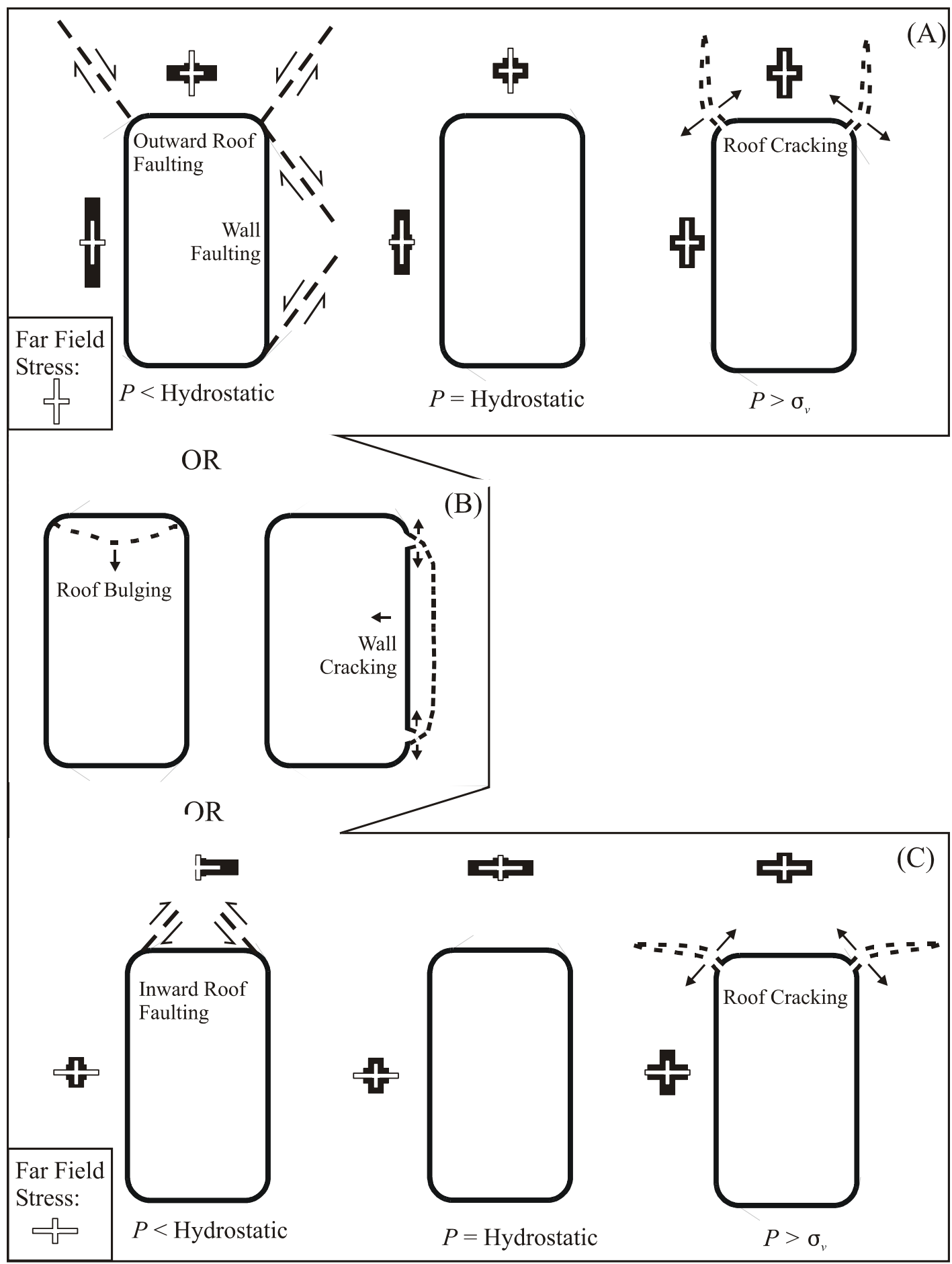

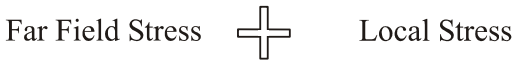

Figure 177 Conceptual models of cavern failure mechanisms at different stress states and internal fluid pressures. A) failure mechanisms at different pressures when $\sigma_{v}>\sigma_{h}$; B) failure mechanism that could occur at low internal pressures in any stress state; and C) failure mechanisms at different pressures when $\sigma_{v}<\sigma_{h}$. 


\title{
Final Design and Updated Economic Analysis (Task 11)
}

\author{
By David Bruce
}

\section{Detailed Economic Analysis for the Acid Dissolution of Carbonate Rock}

It was determined from initial design efforts that the optimum process to create an underground gas storage cavern in low porosity limestone should use low cost hydrochloric acid as the dissolution medium. Further, natural gas compressibility and drilling costs mandated that the optimum cavern depth be between 6,000 and 10,000 ft. Upon modeling the dissolution process, obtaining current cost estimates for equipment and chemicals, and speaking with industry representatives in various relevant fields, it is now possible to more clearly define the economics for the creation of gas storage caverns in limestone via an acid dissolution process.

Development of a detailed process flow diagram and cost estimate revealed that the optimal above ground chemical processing equipment could vary considerably depending on the site chosen for cavern formation. Specifically, the significant site factors affecting process design are the chemical composition of the limestone being dissolved, the distance of the cavern site to rail or barge shipping, and the nature of the seasonal calcium chloride products that are marketable near the specific geographic location. In order to quantify costs more accurately, it was assumed that the cavern to be formed would be in a carbonate layer of sufficient purity that the dissolution products could be sold as a technical grade calcium chloride solution. However, it was assumed that a moderate amount of excess water need be removed in order to create a 35 wt solution. The above ground equipment needed for the described acid dissolution process is shown in Figure 178.

This process involves hydrochloric acid being pumped into a fractured limestone formation, where it will rapidly react and effectively dissolve the limestone deposit. The products of this reaction, calcium chloride and carbonic acid, are highly soluble in water and will be removed via the same well, leaving behind a gas storage cavity capable of high rates of gas deliverability. Some of the key components of the process are: 1) acid storage tanks with secondary containment, 2) an acid pumping station, 3) a filter system to remove fine particulates that would foul downstream equipment, 4) a multiple-effect evaporator to concentrate the dilute $\mathrm{CaCl}_{2}$ product exiting the well, 5) an absorption tower and wetlands waste treatment facility to reduce $\mathrm{HCl}$ and $\mathrm{CO}_{2}$ emissions, and 6 ) a $\mathrm{CaCl}_{2}$ pumping station and storage facility (no secondary containment needed). 


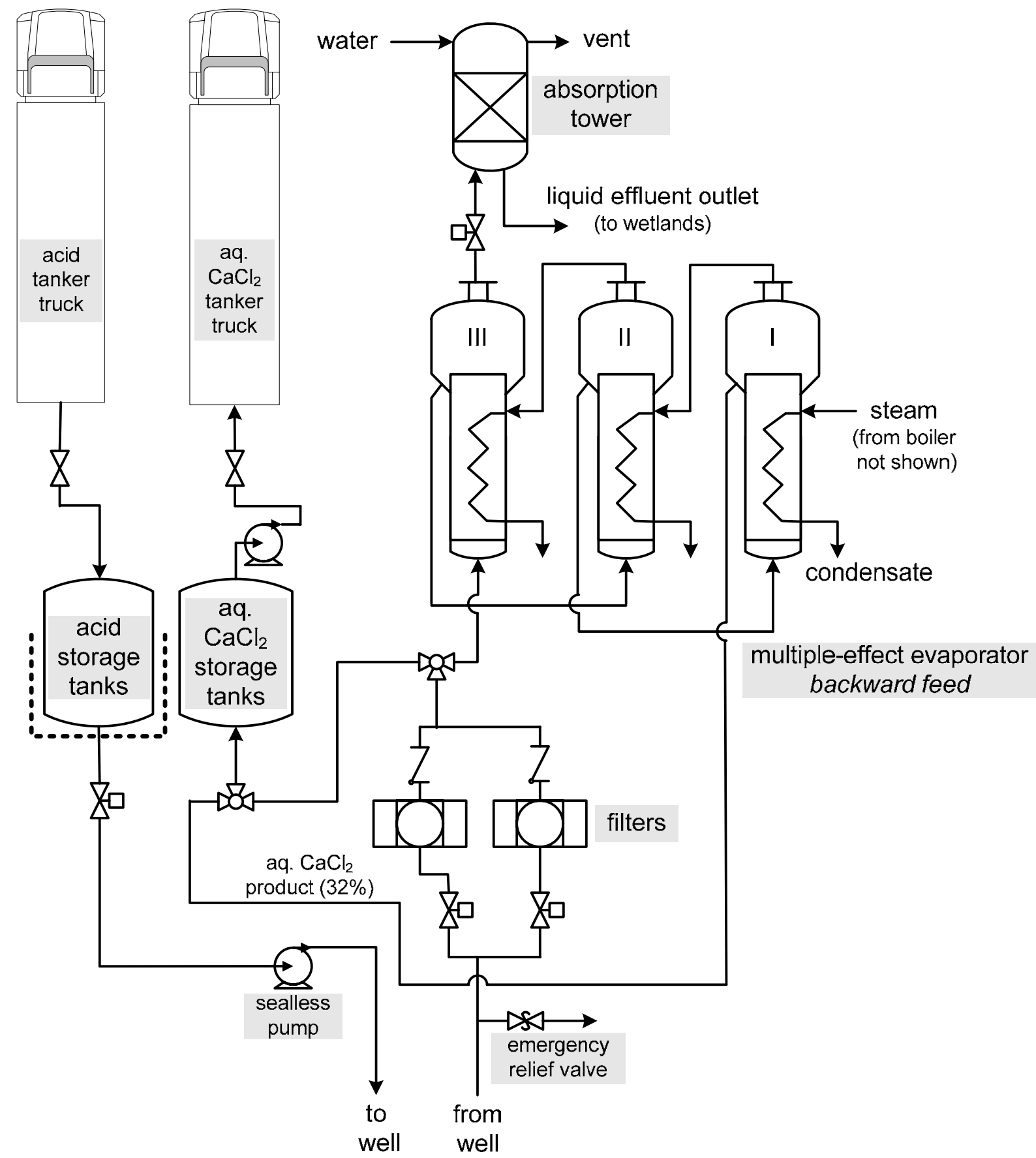

Figure 178. Simplified process flow diagram for the acid dissolution process.

Two strategies will need to be examined in future trials of the technology to determine whether excess water in the product exit stream is needed to prevent the $\mathrm{CO}_{2}$ from becoming a 
separate gas phase in the annulus of the well. Formation of such a gas phase could create instabilities in flow that could be harmful to above ground processing equipment. Upon exiting the well, the dissolution products are to be treated using a centrifugal or stacked filter system, followed by the removal of water in an evaporator, and the gaseous products are to be treated in an absorption tower and eventually sent to a constructed wetland treatment system. The calcium chloride will be sold in a liquid form (35 or $45 \mathrm{wt} \%$ solution) for use in construction related industries or for road deicing purposes in the northern US, where it is the preferred deicing agent for roads $\left(\mathrm{CaCl}_{2}\right.$ is effective as a deicing agent at temperatures as low $\left.-15^{\circ} \mathrm{C}\right)$.

The sale of the calcium chloride product stream significantly enhances the viability/profitability of the dissolution process by offsetting the cost of hydrochloric acid. It should be noted that Tetra Technologies, a large commercial provider of calcium chloride, as well as other similar companies prepare $\mathrm{CaCl}_{2}$ solutions via the above ground mixing of pulverized limestone (mined from surface deposits) with aqueous hydrochloric acid. Thus, the proposed cavern forming process is akin to a commercially viable process for making calcium chloride from limestone, but the proposed process would also yield a subsurface storage cavern that could be used for gas storage.

\section{Well Design Options and Costs}

As previously mentioned, there exist several options for the number and placement of wells for the acid dissolution process for creating gas storage in carbonate rock. From modeling studies it was determined that a single concentric tube well design is most economical and easiest to implement. With this design, fresh acid would be pumped down the well in the acid resistant inner tube. The soluble salt products would be removed from the well using the annulus bounded by the well casing, similar to how salt caverns are created. Costs for a completed injection/withdrawal storage well, $7 \mathrm{inch}$, with a high deliverability flow string to bottom are shown in Table 50.

Table 50. Approximate drilling and fracturing costs in the Northeastern US area (Source Don Brooks - private communications, minimum of 5\% increase in drilling costs per year).

\begin{tabular}{|l|l|l|}
\hline $\begin{array}{l}\text { Total Depth } \\
(\mathrm{ft})\end{array}$ & $\begin{array}{l}\text { Completed } \\
\text { Well }^{\mathrm{a}}\end{array}$ & $\begin{array}{l}\text { Construction } \\
\text { Well }^{\mathrm{b}}\end{array}$ \\
\hline 4,000 & $\$ 290,000$ & $\$ 175,000$ \\
\hline 8,000 & $\$ 1,160,000$ & $\$ 580,000$ \\
\hline 12,000 & $\$ 2,900,000$ & $\$ 1,160,000$ \\
\hline
\end{tabular}

\section{Waste Treatment and Green House Gas Emissions}

The limestone dissolution reaction with aqueous hydrochloric acid yields calcium chloride and carbonic acid as products. Because the calcium chloride is of commercial value it is not considered a waste; therefore, only unreacted $\mathrm{HCl}$ and $\mathrm{CO}_{2}$ are wastes for this process. In 
some geographic locations the warm but uncontaminated water exiting the process could be deleterious to the environment and would need to equilibrate to ambient temperatures in a storage pond or vessel before being discharged into a waterway (this cost would be minimal and was not included in the design). The primary waste treatment facility is an absorption tower with water feed. The secondary treatment facility consists of a newly formed wetlands area that will cover between 5 and 10 acres (depending on the size of the gas storage cavern to be developed). The plants located in this wetlands area can readily absorb dissolved carbonate anions and convert them into biomass, which can then be used to produce biodiesel fuel or be incorporated into animal feed.

Since large quantities of dissolved carbon dioxide will be generated by this process (e.g., the formation of $1 \mathrm{BCF}$ of gas storage at $4000 \mathrm{ft}$ would produce 234 thousand tons of carbon dioxide - approximately $6 \%$ of what a typical coal power plant releases annually), this wetlands treatment system will greatly contribute to the reduction of green house gas emissions from the process. The plants in this wetlands area are also resilient to moderate levels of salts, such as calcium chloride, and have proven to be highly effective in applications involving the treatment of aqueous waste streams from power plant boilers and scrubbing towers. Thus, the waste treatment options described will greatly reduce the emissions of green house gases (carbon dioxide) and provide a revenue source that is derived from the calcium chloride product from the dissolution process.

Although other options for treating the wastewater are possible, a constructed wetland treatment system provides important economic and environmental benefits. Principles of natural wetlands will be applied to constructing a treatment system designed to ensure the desired reactions at predictable rates. This is a proven approach and has been used successfully for the treatment of various waste fluids, including refinery effluent and brines produced from oilfields (e.g., Moshiri, 1993; Hawkins et al., 1997; Gillespie et al., 2000; Huddleston et al., 2000; Moore et al., 2001, Murray-Gulde, 2003).

\section{Hydrochloric Acid Cost and Availability}

(ref. Chemical Marketing Reporter, Jan. 2006)

The acid dissolution reaction of interest is:

$$
\mathrm{HCl}(\mathrm{aq})+\mathrm{CaCO}_{3}(\mathrm{~s}) \leftrightarrow \mathrm{CaCl}_{2}(\mathrm{aq})+\mathrm{H}_{2} \mathrm{CO}_{3}(\mathrm{aq}) \leftrightarrow \mathrm{CaCl}_{2}(\mathrm{aq})+\mathrm{CO}_{2}(\mathrm{~g})
$$

Hydrochloric acid was chosen for the dissolution process because it optimized all of the previously discussed design criteria. In short, hydrochloric acid is the optimal dissolution medium because 1) acid cost per pound of dissolved rock is relatively low, 2) the calcium chloride reaction products are of value and highly soluble, 3 ) reactions rates with limestone are rapid, and 4) waste leakage and remediation concerns have been addressed previously by related industries (i.e., it has been used extensively in the oil and gas industry to enhance flow from producing wells). Hydrochloric acid is most commonly available as a $34 \mathrm{wt} \%$ solution $\left(22{ }^{\circ} \mathrm{Be}\right.$, where ${ }^{\circ} \mathrm{Be}$ is a measure of specific gravity and at $60^{\circ} \mathrm{F}$ a fluid denser than water can be expressed as sp.gr. $=145 /(145$-Baume $)$ ).

One of the two factors most affecting process economics are the cost and availability of 
hydrochloric acid. The availability of $\mathrm{HCl}$ in the USA is listed according to producer in Table 51. Recent years have shown significant variability in the bulk scale pricing of hydrochloric acid on the open markets ( $\$ 24$ to $\$ 100$ per ton of $34 \mathrm{wt} \%$ acid) because of a trend where production barely meets industrial needs. However, analysis of the industry indicates that there is significant additional capacity for $\mathrm{HCl}$ production if additional need arises, but this increased demand would also cause the prices to go closer to the upper end of the range seen in recent years ( $\$ 100$ per ton). All prices discussed in this section are for materials to be delivered in the northeastern US and are for technical grade hydrochloric acid (pricing for food grade and technical grade $\mathrm{HCl}$ are very similar). It should be noted that the quantities of acid required could be significant (e.g., a reservoir $8000 \mathrm{ft}$ below the surface capable of storing 1.0 BCF of natural gas would require approximately $2 \%$ of the nations hydrochloric acid production); therefore, it is very likely that the negotiated price for hydrochloric acid would be 10 to $50 \%$ less than the current market price for technical grade hydrochloric acid.

Table 51. Largest $\mathrm{HCl}$ producing companies in the USA and their relative production capacity (Chemical Market Reporter, Jan. 2006).

\begin{tabular}{ll} 
Company & $\begin{array}{l}\text { Percent of Market } \\
\text { (production weight basis) }\end{array}$ \\
\hline Dow Chemical & 36.8 \\
Dow Corning & 9.2 \\
Occidental Chemical & 7.3 \\
DuPont Fluoroproducts & 4.5 \\
BASF Plastics \& Fibers & 4.0 \\
Magnesium Corp. of America & 3.0 \\
Lyondell Chemical & 2.4 \\
Bayer Polymers & 2.3 \\
PPG Industries & 2.1 \\
Honeywell International & 1.7 \\
Small producers & 26.7 \\
\hline Total US production of HCl & $\mathbf{4 , 3 4 0 , 0 0 0 *}$ \\
(short tons per year) &
\end{tabular}

\footnotetext{
* 100 percent basis excluding data for coproduct $\mathrm{HCl}$ generated and recycled in integrated ethylene dichloride/vinyl chloride monomer (EDC/VCM) plants (capacity at 13 ethylene dichloride/vinyl chloride plants amounts to 4.72 million short tons).
}

Most $\mathrm{HCl}$ sold on the open market $(\sim 90 \%)$ is a byproduct from other chemical processing (e.g., hydrocarbon chlorinations, phosgenation of amines, and chlorofluorocarbons production). 
However, approximately $10 \%$ of the $\mathrm{HCl}$ is produced from the burning of chlorine with hydrogen. There is significant additional capacity for the production of $\mathrm{HCl}$ by this latter method, but this method is only economically favorable when acid prices (relative to the cost of chlorine) are high.

The open market demand for $\mathrm{HCl}$, which equals the sum of $\mathrm{HCl}$ produced and imported minus the amount of $\mathrm{HCl}$ exported, has continued to grow as evidenced by the $\mathrm{HCl}$ demand over the last few years ( $\sim \%$ increase per year). For example, in 20032.813 million short tons were purchased, while in 20043.574 million tons were purchased. It is also projected that in 2008 3.665 million tons will be needed, assuming that there are no significant new processes implemented that need $\mathrm{HCl}$ (such as the proposed dissolution process).

In the past six months (July-Dec. 2006), the tight $\mathrm{HCl}$ market has resulted in price increases of about $\$ 25$ per ton and some distributors have put customers on allocation. But as the price moves above $\$ 100$ per ton, consumers with the capability of burning chlorine with hydrogen to make $\mathrm{HCl}$ will probably do so, especially since demand for $\mathrm{HCl}$ is growing faster than that of the merchant market. In summary, $\mathrm{HCl}$ supply will likely remain tight for the foreseeable future and local shortages are likely to occur, which could lead to additional price increases. These fluctuations make it somewhat difficult to quantify acid costs for the dissolution process.

\section{Calcium Chloride Market Information and Pricing Data}

(ref. Chemical Market Reporter, Mar. 28, 2005)

It was previously determined that the sale of the calcium chloride produced by the dissolution process would significantly reduce the overall cost of cavern formation. Therefore, a thorough understanding of the existing calcium chloride markets could help identify geographic locations and times of the year best suited to develop a gas storage cavern in limestone.

Commercial production of calcium chloride in the US is through the refining of natural brine or via the reaction of byproduct hydrochloric acid with pulverized limestone. The market share of calcium chloride producers is listed in Table 52 along with total $\mathrm{CaCl}_{2}$ production rates for 2005. In general, calcium chloride is used for road and airplane runway deicing (22\%), gravel/dirt road stabilization and dust control (20\%), industrial processing $(20 \%)$, oil and gas well fluids (17\%), concrete (12\%), tire ballast (5\%), and miscellaneous (4\%). Currently, the calcium chloride market is undergoing moderate growth because of 1) increases in oil and gas well drilling as a result of high fuel costs, 2) expanded uses in deicing as a result of data showing that highway mixtures with sodium chloride may be less corrosive than the use of $\mathrm{NaCl}$ alone, and 3 ) increased construction in the southern states that have lead to increased demand for liquids for dust control. Industry capacity is more than adequate to meet future demands, which are estimated to increase at a rate of 3-6\% per year, as the industry's operating at approximately $60 \%$ of full capacity. Though there is additional capacity available, there would need to be an extended time need for companies to reopen calcium salt processing units that have been idled in recent years. 
Table 52. Largest $\mathrm{CaCl}_{2}$ producing companies in the USA and their relative production capacity (Chemical Market Reporter, Mar. 2005).

\begin{tabular}{ll} 
Calcium Chloride Producers & $\begin{array}{l}\text { Percent of Market } \\
\text { (production weight basis)* }\end{array}$ \\
\hline Dow Chemical & 41.5 \\
Tetra Technologies & 34.9 \\
OSCA & 8.9 \\
Honeywell & 5.7 \\
Wilkinson & 3.2 \\
\hline Magnesium Corporation of America & 2.6 \\
\hline Small producers & 3.2 \\
\hline Total U.S. Production of $\mathbf{C a C l}_{\mathbf{2}}$ & $\mathbf{1 , 3 6 1 , 0 0 0}$ \\
(short tons per year) &
\end{tabular}

*All forms (flake, anhydrous and liquid).

Current delivered pricing for calcium chloride is $\$ 250$-\$ 260 /tonne (flake), \$ 345-\$ 350 /tonne (pellets) and \$180-\$200/tonne (liquid). It should be noted that the actual value of the produced calcium chloride is approximately one third to one half that of the as delivered material.

In order to identify a commercial outlet for the calcium chloride products, it is desirable to work with an existing supplier. To this end, discussions with Tetra Technologies proved fruitful as they currently have production facilities in West Virginia and other locations across the eastern U.S. that could be contracted to handle the purification of acid dissolution well effluents if it was deemed desirable not purify the calcium chloride on sight. Obviously, the economics of such an operation would vary considerably depending on the location of the well and the interests of the collaborative company, which may or may not be Tetra Technologies. In general, calcium chloride suppliers are interested in working on this type of process because the excess salt introduced to the market could be harmful to their own business unless it is introduced at an appropriate rate and possibly other calcium chloride production is idled during the period of time that the dissolution process was ongoing.

\section{Fixed Capital Cost Estimation}

Fixed capital costs, including both direct and indirect costs, were estimated for a limestone dissolution process that would use hydrochloric acid to create a 0.1 to 1 BCF gas storage reservoir. The various costs were calculated using Lang factors (see Table 53), which relate the costs of construction to total purchased equipment costs. The Lang factors used for this report were obtained from the process design text by Peters and Timmerhaus (1991) and are specifically for processes built in the US that require both liquids and solids handling. For this 
cost estimate, delivered equipment costs were used to estimate fixed capital costs, and these values are shown in Table 54. The key equipment items include corrosion resistant pumps, hydrochloric acid and calcium chloride holding tanks (20,000 gal tanks), filter equipment, an absorption tower for $\mathrm{HCl}$ and $\mathrm{CO}_{2}$ capture, a multiple-effect evaporator and boiler for concentrating the calcium chloride product solution, and a wetlands wastewater treatment area for carbonic acid (and residual $\mathrm{HCl}$ ) removal. Despite the process being reasonably well defined, there are significant site variablility costs, and therefore, it was decided to maintain a relatively high contingency cost factor (30) for this later stage design. These calculations yield a fixed capital cost of $\$ 1,660,848$ US.

Table 53. Estimated fixed capital cost factors for a $0.25 \mathrm{BCF}$ gas storage facility created via acid dissolution of limestone using hydrochloric acid and a single well.

\begin{tabular}{|l|l|l|}
\hline Operation & $\begin{array}{l}\text { Lang Factors, Solid-Liquid } \\
\text { (Peters and Timmerhaus, 1991) }\end{array}$ & Cost (\$ US) \\
\hline Direct Costs & 100 & 494,300 \\
\hline Purchased equipment & 29 & 143,347 \\
\hline Installation & 13 & 64,259 \\
\hline Instrumentation & 31 & 153,233 \\
\hline Piping & 10 & 49,430 \\
\hline Electrical & 18 & 88,974 \\
\hline Buildings & 10 & 49,430 \\
\hline Yard Improvements & 15 & 74,145 \\
\hline Service facilities & 2 & 9,886 \\
\hline Land & \multicolumn{2}{|l|}{} \\
\hline Indirect Costs & 32 & 158,176 \\
\hline Engineering \& Supervision & 32 & 138,404 \\
\hline Construction expenses & 28 & 88,974 \\
\hline Contractor's fee & 18 & 148,290 \\
\hline Contingency & 30 & $1,660,848$ \\
\hline $\begin{array}{l}\text { Total Fixed Capital } \\
\text { Investment }\end{array}$ & 336 & \\
\hline
\end{tabular}


Table 54. Estimated delivered equipment costs for a $0.25 \mathrm{BCF}$ gas storage facility created via acid dissolution of limestone using hydrochloric acid.

\begin{tabular}{|l|l|}
\hline Purchased Equipment & Cost (\$ US) \\
\hline Acid and salt polyethylene storage tanks ${ }^{\dagger}$ & 78,000 \\
\hline Sealless, acid-resistant centrifugal pumps & 52,000 \\
\hline Filters & 31,000 \\
\hline Triple-Effect Evaporator and Boiler & 258,300 \\
\hline Absorption tower & 45,000 \\
\hline Wetlands treatment area & 30,000 \\
\hline Total Equipment Costs (delivered) & $\mathbf{4 9 4 , 3 0 0}$ \\
\hline
\end{tabular}

$\dagger$ Hydrochloric acid storage consists of two double walled cross-linked polyethylene tanks $(8,700$ gal capacity, cost each $=\$ 24,500)$, calcium chloride storage consists of two single walled cross-linked polyethylene tanks $(10,300$ gal capacity, cost each $=\$ 14,500)$

\section{Estimation of Total Facility Costs}

The total gross-earnings cost for developing an underground gas storage facility via the acid dissolution of limestone equals the difference between total income derived from the sale of calcium chloride salts minus the total development cost. The total development cost for the gas storage facility can be estimated by summing the direct production costs, fixed charges, and facility overhead charges. The Lang factors for these various costs were taken from the text by Peters and Timmerhaus (1991) and are a primarily a function of the hydrochloric acid cost, and the total capital investment cost. These economic factors are reported in Table 55 and the total gross-earnings cost for a 0.25 gas storage facility in limestone is shown in Figure 179 as a function of limestone porosity at depth. Though no data are presented in this report on dolomite dissolution costs (for brevity), these costs were evaluated and found to be approximately $6 \%$ more than that for limestone formations. This is primarily due to the higher density of the dolomite rock as compared to limestone. 
Table 55. Estimated total production cost factors for a 0.25 gas storage facility created via acid dissolution of limestone using hydrochloric acid.

\begin{tabular}{|l|l|}
\hline Item & \% Total Development Cost \\
\hline \multicolumn{2}{|l|}{ Direct Production Costs } \\
\hline Raw Materials & 64.5 \\
\hline Labor & 3 \\
\hline Utilities & 10 \\
\hline Maintenance & 1.5 \\
\hline Fixed Charges & \multicolumn{2}{|l|}{} \\
\hline $\begin{array}{l}\text { Depreciation - Fixed Capital } \\
\text { Cost }\end{array}$ & 5 \\
\hline Taxes & 1.5 \\
\hline Insurance & 0.5 \\
\hline Plant overhead & 4 \\
\hline General Expenses & 2 \\
\hline Administration Costs & 8 \\
\hline $\begin{array}{l}\text { Distribution and selling } \\
\text { costs }\end{array}$ & 100 \\
\hline \begin{tabular}{l} 
Total \\
\hline
\end{tabular} & \\
\hline
\end{tabular}




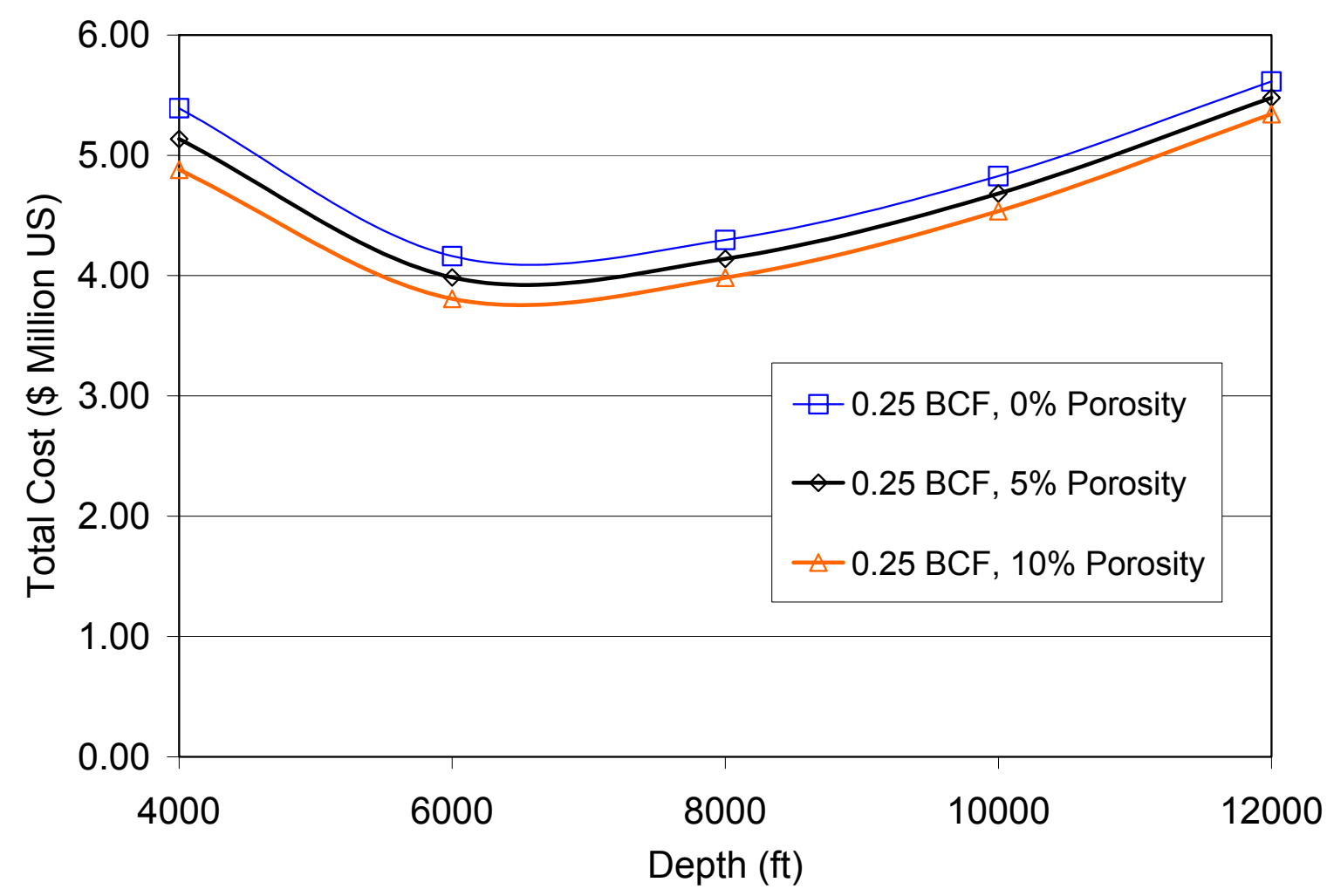

Figure 179. Total cost for a $0.25 \mathrm{BCF}$ natural gas storage facility in limestone of varying porosity at varying depths in the northeastern US. The hydrochloric acid sale price assumed is $75 \mathrm{USD} /$ ton, the $\mathrm{CaCl}_{2}$ sale price assumed is $63 \mathrm{USD} /$ ton, and it is assumed that $95 \%$ of the calcium salt produced can be sold.

\section{Comparison of Gas Storage Costs}

In order to evaluate the economic feasibility of the limestone dissolution process, cost comparisons were made to existing or newly created underground gas storage facilities and are shown in Figure 180. This figure shows cost for salt storage and storage created using the new single well acid-dissolution process. The total gross-earnings cost analysis shows that reductions in cost are achieved with increases in rock porosity and are significantly influenced by the sales price of hydrochloric acid and calcium chloride. If hydrochloric acids costs can be negotiated to a value lower than the average list sales price, then the new process is even more competitive with other means for creating underground gas storage. Such reductions in acid cost are very likely given the quantity of acid to be purchased and the ability to use low purity hydrochloric acid. 


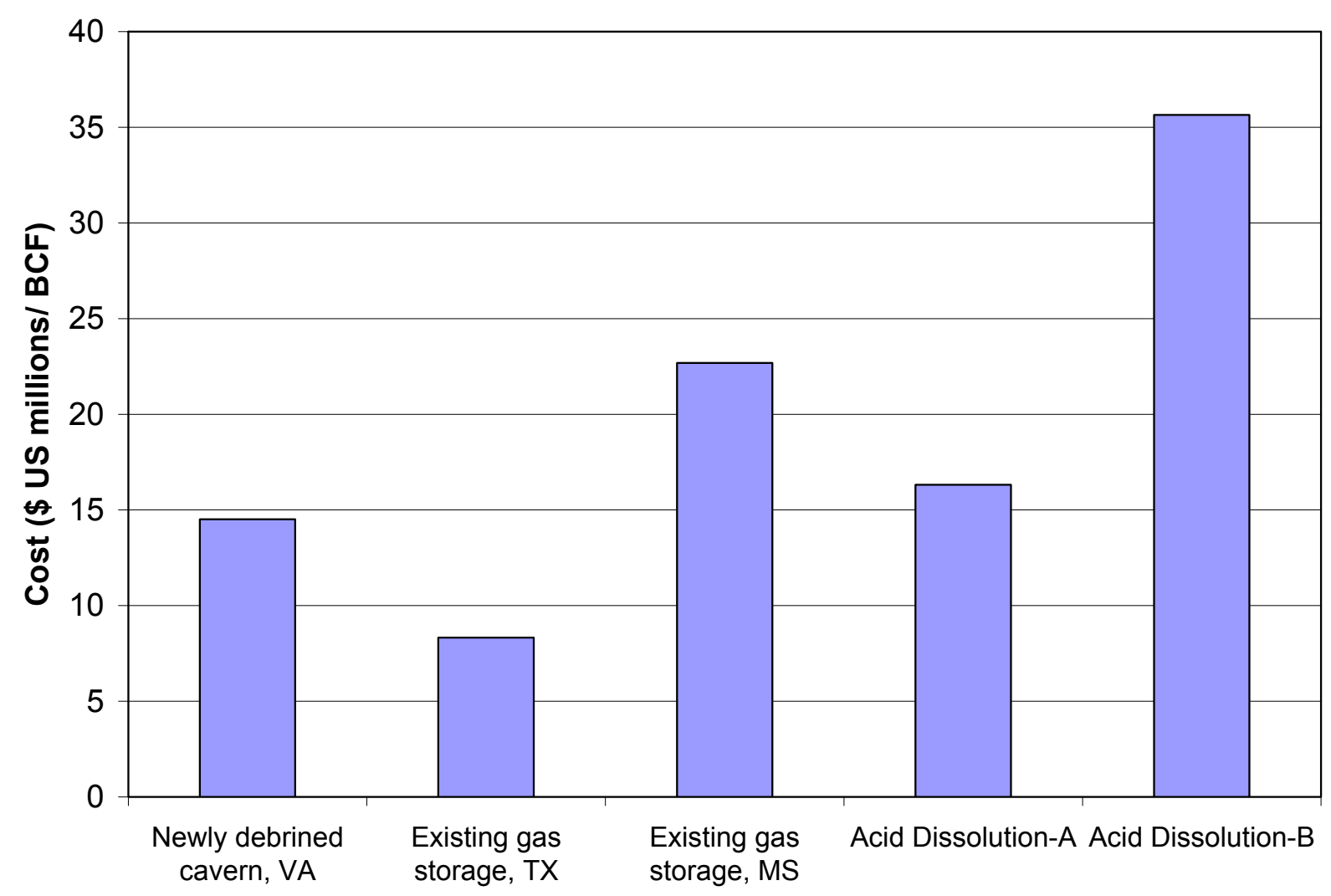

Figure 180. Cost comparison between various underground gas storage methods, where Acid Dissolution-A represents $0.25 \mathrm{BCF}$ of storage, $0 \%$ Porosity limestone, $75 \mathrm{USD} /$ ton $\mathrm{HCl}, 63$ USD/ton $35 \mathrm{wt} \% \mathrm{CaCl} 2,95 \%$ of $\mathrm{CaCl}_{2}$ sold, and a cavern depth of $6000 \mathrm{ft}$; Acid Dissolution-B represents $0.25 \mathrm{BCF}$ of storage, $5 \%$ Porosity limestone, $75 \mathrm{USD} /$ ton $\mathrm{HCl}, 30 \mathrm{USD} /$ ton $35 \mathrm{wt} \%$ $\mathrm{CaCl} 2,85 \% \mathrm{CaCl}_{2}$ sold, $8000 \mathrm{ft}$.

\section{Summary of Results}

The final process design and economic analysis showed that the proposed acid dissolution process is economical, but costs are sensitive to the market price of the hydrochloric acid dissolution media and the ability to sell a significant fraction of the produced calcium chloride at or near market value. Assuming that a moderate to high purity limestone (magnesium and transition metal impurities could limit the sale of the calcium salt products) can be found for cavern formation at depths between 6,000 and 10,000 feet and that appropriate shipment methods are within close proximity to the well site, the proposed process is cost competitive to other gas storage facilities. 


\section{CONCLUSIONS}

An initial process design for creating gas storage by carbonate dissolution using acid was developed through regional geologic investigation of suitable formations and by preliminary economic analysis. Hydrochloric acid was determined to be the best acid to use because of low cost, high acid solubility, fast reaction rate with carbonate rock, and highly soluble products (calcium chloride) that allow for the easy removal of calcium waste from the well. The process design incorporates proven technologies for drilling wells, storing and pumping acid, and treating the aqueous waste streams exiting the underground storage cavern. The preliminary economic analysis of this design considered capital costs, well-design options and costs, waste treatment options, and comparison with other gas storage costs.

The next phase of the investigation involved analysis and modeling of the processes of creating storage capacity by acid dissolution of carbonate rock. Physical and chemical analyses of core samples taken from prospective geologic formations for the acid dissolution process revealed that many of the limestone samples readily dissolved in hydrochloric acid. Some samples contained oily residues that may help to seal the walls of the final cavern structure. These results suggest that there exist carbonate rock formations well suited for the dissolution technology and that the presence of inert impurities had no noticeable effect on the dissolution rate for the carbonate rock.

A sensitivity analysis was performed for characteristics of hydraulic fractures induced in carbonate formations to enhance the dissolution process. A realistic range of physical parameters for Paleozoic limestone formations at 4000 to $8000 \mathrm{ft}$ depth in the northeastern United States was estimated and used to predict the characteristics of fractures that could be created. Multiple fracture simulations were conducted using modeling software that has a fully 3-D fracture geometry package. The simulations, which predict the distribution of fracture geometry and fracture conductivity, show that the stress difference between adjacent beds is the physical property of the formations that has the greatest influence on fracture characteristics by restricting vertical growth. The results indicate that by modifying the fracturing fluid, proppant type, or pumping rate, a fracture can be created with characteristics within a predictable range, which contributes to predicting the geometry of storage caverns created by acid dissolution of carbonate formations.

For modeling the development of caverns by acid dissolution of carbonate rock, the TOUGHREACT code was selected initially as the optimal simulation package. While we are confident that TOUGHREACT could be suitable for these kinds of simulations, we realized that it might be beneficial to produce a fully coupled simulator that considered only the primary acidlimestone reaction. Therefore, we decided to modify the TOUGH2 code EWASG (Battistelli et al., 1997; Pruess et al., 1999) with the ECO2 module from Pruess and Garcia (2002) to get a fully coupled simulator for the acid-rock dissolution. A series of three-dimensional simulations were used to investigate three different dissolution configurations: a) injection into an open borehole with production from that same borehole and no fracture; b) injection into an open borehole with production from that same borehole, with an open fracture; and c) injection into an open borehole connected by a fracture to an adjacent borehole from which the fluids are produced. The two-well configuration maximizes the overall mass transfer from the rock to the fluid, but it results in a complex cavern shape.

The final phase of the project involved modeling field performance, evaluating field 
characterization methods, preparing a final design, and updating the economic analysis. Analyses were conducted to evaluate the feasibility of creating a storage cavern in limestone that would be stable as gas was injected and withdrawn from the cavern. Simulations were conducted using FLAC2D, a commercially available geotechnical analysis and design software. The analysis considered cavern shapes resembling a tall cylinder, a roughly equidimensional cylinder, a puck-like shape (short, wide cylinder), a tunnel, a sphere, and a cone. Analyses were derived to predict the standard volume of gas stored in each cavern geometry as a function of pressure. The effects of depth, in-situ stress state, and cycling of the internal pressure on cavern stability were evaluated. The analyses indicate that a tall cylindrical cavern with a domed roof and floor will be stable under the expected range of in situ and operational conditions. This result suggests that it should be feasible to avoid mechanical instabilities that could potentially diminish the effectiveness of the storage facility. In addition, numerical simulations were performed using the TMVOC multiphase simulator (Pruess and Battistelli, 2002) to evaluate the ability of a tall cylindrical cavern in porous media to store natural gas. This simulator can consider multiple condensable and noncondensable hydrocarbon gases, using the real gas law.

The feasibility of using pressure transients measured at the ground surface was investigated as a means to evaluate cavern formation. The configuration studied consists of two pipes extending to the cavern. One pipe would be used to inject acid, and it was assumed to extend to the top of the cavern. Another pipe would be used to recover brine, and it was assumed to extend to near the bottom of the cavern. Pressure transients will be created when the flow rate of the acid changes due to adjustments in the operational parameters, or pressure transients could be generated intentionally for assessment purposes. The results indicate that a pressure perturbation created in the injection pipe will be reflected by changes in cavern diameter. This should give a detectable response as the cavern diameter increases up to approximately 1 to 2 meters. Changes in diameter when the cavern is larger than 1 to 2 meters will probably be undetectable, according to the results of the sensitivity analysis. Pressure transient data collected during cavern formation can be used to calibrate numerical models of the dissolution process used to create the storage cavern. Results from the calibrated model would be used to help guide the cavern dissolution process.

The final process design and economic analysis showed that the process of creating storage caverns by using acid to dissolve carbonate formations is economical, with the costs sensitive to market price of hydrochloric acid and the ability to sell a significant fraction of the produced calcium chloride at or near market value. The proposed process is cost competitive with other gas storage facilities assuming that a moderate to high purity limestone is used for cavern formation at depths shallower than 10,000 feet and that appropriate shipment methods are within reasonable proximity to the well site.

The final design parameters and economic analysis will facilitate deployment of the new technology for creating storage caverns by dissolution using acid. Results of our investigation provide a strong framework for performing a field demonstration of the technology and are very encouraging for moving ahead. Successful demonstration of the technology has the potential for opening up new geographic areas for developing storage capacity. The technology is expected to have application to many geographic areas because of the widespread occurrence of carbonate formations. 


\section{REFERENCES CITED}

Adamkowski, A. (2003), Analysis of transient flow in pipes with expanding or contracting sections, Journal of Fluids Engineering, 125, 716-722.

American Gas Association, 2002, 2001 Survey of Underground Storage of Natural Gas in the United States and Canada, American Gas Association, Washington, DC.

Anderson, R. W., Cooke Jr., C. E. and Wendorff, C. L., 1989, Propping Agents and Fracture Conductivity, in J. L. Gidley, S. A. Holditch, D. E. Nierode and R. W. J. Veatch, eds., Recent Advances in Hydraulic Fracturing: Richardson, TX, Society of Petroleum Engineers, p. 109-146.

Angus, S.; Armstrong, B.; de Reuck, K.M., 1976, International Thermodynamic Tables of the Fluid State: Carbon Dioxide, Int. Union of Pure and Applied Chemistry, Pergamon Press: Oxford.

Arfaie, M., and A. Anderson (1991), Implicit finite-differences for unsteady pipe flow, Mathematical Engineering in Industry, 3, 133-151.

Atkinson, B. K. and Meredith, P. G., 1987, Experimental Fracture Mechanics Data for Rocks and Minerals, in B. K. Atkinson, ed., Fracture Mechanics of Rock: London, Harcourt Brace Jovanovich, p. 477-525.

Atteberry, J. T., 2005, An Assessment of Carbonate Formations in the Appalachian Basin for Gas Storage Using Acid Dissolution. M.S. thesis. Clemson University. Clemson, South Carolina.

Baidyuk, B. V. e., 1967, Mechanical properties of rocks at high temperatures and pressures: New York, Consultants Bureau, 75 p. p.

Battistelli, A., C. Calore, and K. Pruess, 1997, The Simulator TOUGH2/EWASG for Modeling Geothermal Reservoirs with Brines and Non-Condensible Gas, Geothermics, Vol. 26, No. 4, pp. 437-464.

Bebout, D. G., W. A. White, T. F. Hentz, and M. K. Grasmick (editors), 1993, Atlas of Major Midcontinent Gas Reservoirs, Gas Research Institute, coordinated by Bureau of Economic Geology, The University of Texas at Austin.

Buschbach, T.C. and D.C Bond, 1974, Underground Storage of Natural Gas in Illinois-1973, Illinois State Geological Survey, Urbana, IL.

Castle, J. W., Bruce, D. A., Brame, S. E., Brooks, D. A., Falta, R. W. and Murdoch, L. C., 2004, Design and Feasibility of Creating Gas-Storage Caverns by Using Acid to Dissolve Carbonate Rock Formations: SPE Eastern Regional Meeting, p. 10. Society of Petroleum Engineers, Paper SPE 91436.

Castle, J. W., Bruce, D., Falta, R. W., Murdoch, L., Brame, S. E., and Brooks, D., 2004a, Fracture Dissolution of Carbonate Rock: An Innovative Process for Gas Storage: Topical Report (Budget Period One), DE-FC26-02NT41299, March 5, 2004, 163 p.

Chaudhry, M. H. (1987), Applied hydraulic transients, Van Nostrand Reinhold Company.

Chen, M. and Zhang, G.-q., 2004, Laboratory measurement and interpretation of the fracture 
toughness of formation rocks at great depth: Journal of Petroleum Science and Engineering, v. 41, p. 221-231.

COMSOL (2005), COMSOL Multiphycis User's Guide, COMSOL AB.

CRC, 1987, Handbook of Chemistry and Physics, CRC Press, Boca Raton, Fl.

Dean, J. R. (Ed.) (1993), Application of supercritical fluids in industrial analysis, Blackie academic \& professional.

Eckstein, Y. and G. Mauruth, 1999, Terrestrial heat-flow data, in Geology of Pennsylvania:

Schultz, C.H., ed., Pennsylvania Geological Survey.

Economides, C., Harrison, D. and Jones, L., 2004, Oilfield Glossary; Well Testing Module, Schlumberger, http://www.glossary.oilfield.slb.com/default.cfm.

Energy \& Environmental Analysis, Inc., 1999, GASIS Release 2 (NETL version), database on CD-ROM, Department of Energy, Morganton, WV.

Engelder, T., 1993, Stress regimes in the lithosphere: Princeton, N.J., Princeton University Press, xxiv, $457 \mathrm{p}$.

Evans, K. F. and Engelder, T., 1986, A Study of Stress in Devonian Shale: Part I-3D Stress Mapping Using a Wireline Microfrac System: 61st Annual Technical Conference and Exhibition of the Society of Petroleum Engineers, p. 12. SPE Paper 15609.

Evans, K. F., Engelder, T. and Plumb, R. A., 1989a, Appalachian Stress Study 1. A Detailed Description of In Situ Stress Variations in Devonian Shales of the Appalachian Plateau: Journal of Geophysical Research, v. 94 (B6), p. 7129-7154.

Evans, K. F., Oertel, G. and Engelder, T., 1989b, Appalachian Stress Study 2. Analysis of Devonian Shale Core: some Implications for the Nature of Contemporary Stress Variations and Alleghanian Deformation in Devonian Rocks: Journal of Geophysical Research, v. 94 (B6), p. 7155-7170.

Ewy, R. T. and Cook, N. G. W., 1990a, Deformation and fracture around cylindrical openings in rock--I. Observations and analysis of deformations: International Journal of Rock Mechanics and Mining Science \& Geomechanics Abstracts, v. 27 (5), p. 387-407.

Ewy, R. T. and Cook, N. G. W., 1990b, Deformation and fracture around cylindrical openings in rock--II. Initiation, growth and interaction of fractures: International Journal of Rock Mechanics and Mining Science \& Geomechanics Abstracts, v. 27 (5), p. 409-427.

Falta, R. W., et al. (2004), Review of current thechnology for acid dissoution and hydraulic fracturing, Clemson University.

Falta, R.W., 2000, Numerical Modeling of Kinetic Interphase Mass Transfer During Air Sparging Using a Dual-Media Approach, Water Resources Research, Vol., 36, No. 12, 33913400 .

Falta, R.W., K. Pruess, S. Finsterle, and A. Battistelli, 1995, T2VOC User's Guide, Lawrence Berkeley Laboratory Report LBL-36400,

Falta, R.W., L.C. Murdoch, and G.K. Chambers, 2004, Fracture Dissolution of Carbonate Rock: 
An Innovative Process for Gas Storage, Review of Current Technology for Acid Dissolution and Hydraulic Fracturing (Task 5), Report Submitted to DOE, February 28, 2004.

Fjær, E., R.M. Holt, P. Horsrud, A.M. Raaen, and R. Risnes, 1992, Petroleum-Related Rock Mechanics: Developments in Petroleum Science 33, Elsevier Science.

Foley, J. M. S. (2006), An analysis of cavern stability and hydraulic fractures in relation to natural gas storage in limestone formation, Clemson University, Clemson.

Gere, J. M., and S. P. Timoshenko (1992), Mechanics of materials, Third SI edition ed., Chapman \& Hall.

Germanovich, L. N. and Dyskin, A. V., 2000, Fracture mechanisms and instability of openings in compression: International Journal of Rock Mechanics and Mining Sciences, v. 37 (1-2), p. 263-284.

Gillespie, W.B., Jr., W.B. Hawkins, J.H. Rodgers, Jr., M.L. Cano, and P.B. Dorn, 2000, Transfers and transformations of zinc in constructed wetlands: mitigation of a refinery effluent: Ecological Engineering, v. 14, p. 279-292.

Goodman, R. E. (1989), Introduction to rock mechanics, John Wiley \& Sons.

Goodman, R. E., 1980, Introduction to rock mechanics: New York, Wiley, xii, 478 p.

Hart, R., 2005, Personal Communication; Director, Software Services: Itasca Consulting Group, Inc. Minneapolis, Minnesota

Hatheway, A. W. and Kiersch, G. A., 1989, Engineering Properties of Rock, in R. S. Carmichael, ed., Practical Handbook of Physical properties of Rocks and Minerals: Boca Raton, FL, CRC Press.

Hawkins, W.B., Rodgers, Jr. J.H., Gillespie, Jr. W. B. Dunn, A.W., Dorn, P.B., and M.L. Cano, 1997, Design and construction of wetlands for aqueous transfers and transformations of selected metals: Ecotoxicology and Environmental Safety, v. 36, p. 238-248.

Hoek, E. and Brown, E. T., 1980, Underground excavations in rock: London, Institution of Mining and Metallurgy, $527 \mathrm{p}$.

Horton, A. I., 1981, A comparative analysis of stimulations in the Eastern Gas Shales: Morgantown, WV, Department of Energy.

Huddleston, G.M. III, W.B. Gillespie, Jr., and J.H. Rodgers, Jr., 2000, Using constructed wetlands to treat biochemical oxygen demand and ammonia associated with a refinery effluent: Ecotoxicology and Environmental Safety, v. 45, p.188-193.

Istok, J. D. (1989), Groundwater Modeling by the Finite Element Method, American Geophysical Union.

Itasca, 2005, Fast Lagrangian Analysis of Continua (FLAC 5.0) Manual: Minneapolis, Mn, Itasca Consulting Group.

Janna, W. S. (1993), Introduction to fluid mechanics, International Thomson Publishing.

Lacy, L. L. and Smith, M. B., 1989, Fracture Azimuth and Geometry Determination, in J. L.

Gidley, S. A. Holditch, D. E. Nierode and R. W. J. Veatch, eds., Recent Advances in Hydraulic 
Fracturing: Richardson, TX, Society of Petroleum Engineers, p. 341-356.

Lillie, R. J., 1999, Whole Earth Geophysics: Prentice Hall, Upper Saddle River, NJ.

Mack, M. G. and Warpinski, N. R., 2000, Mechanics of Hydraulic Fracturing, in M. J.

Economides and K. G. Nolte, eds., Reservoir Stimulation: Chichester, England, John Wiley \& Sons, LTD, p. 6.1-6.49.

Matsuki, K., 1989, Size effect and size requirement in fracture toughness evaluation of rock, in H. Mihashi, H. Takahashi and F. H. Wittmann, eds., Fracture Toughness and Fracture Energy: Rotterdam, A.A. Balkema, p. 287-303.

Meredith, P. G., 1989, Comparative fracture toughness testing of rocks, in H. Mihashi, H.

Takahashi and F. H. Wittmann, eds., Fracture Toughness and Fracture Energy: Rotterdam, A.A. Balkema, p. 265-277.

Miller II, W. K. and Smith, M. B., 1989, Reanalysis of the MWX Fracture Stimulation Data From the Paludal Zone of the Mesaverde Formation: 64th Annual Technical Conferene and Exhibition of the Society of Petroleum Engineers, p. 671-680. Society of Petroleum Engineers, Paper SPE 19772.

Moshiri, G.A. (ed.), 1993, Construction Wetlands for Water Quality Improvement: Lewis Publishers, Ann Arbor, Michigan.

Murray-Gulde, C.L., J.E. Heatley, T. Karanfil and J.H. Rodgers, Jr., 2003, Performance of a hybrid reverse osmosis-constructed wetland treatment system for brackish produced water: Water Research, v. 37, p. 705-713.

Nathenson, M. and Guffanit, M., 1988, Geothermal Gradients in the Conterminous United States: Journal of Geophysical Research, v. 93 (B6), p. 6437-6450.

NIST (2006), NIST Chemistry WebBook, http://webbook.nist.gov/.

Nolte, K. G., 2000, Appendix: Evolution of Hydraulic Fracturing Design and Evaluation, in M. J. Economides and K. G. Nolte, eds., Reservoir Stimulation: Chinchester, England, John Wiley \& Sons, LTD, p. A5.1-A5.22.

NSI, 2004b, StimPlan Users manual, NSI Technologies Inc., Tulsa Okalahoma

Oldenburg, C. M., 2003, Carbon Dioxide as Cushion Gas for Natural Gas Storage: Energy \& Fuels, v. 17 (1), p. 240-246.

Patchen, D.G., K.L. Avary, and R.B. Erwin, 1984a, Northern Appalachian Region Correlation Chart: American Association of Petroleum Geologists, Correlation of Stratigraphic Units of North America (COSUNA) Project, 1 sheet.

Patchen, D.G., K.L. Avary, and R.B. Erwin, 1984b, Southern Appalachian Region Correlation Chart: American Association of Petroleum Geologists, Correlation of Stratigraphic Units of North America (COSUNA) Project, 1 sheet.

Peters, M.S. and K.D. Timmerhaus, 1991, Plant Design and Economics for Chemical Engineers, McGraw-Hill, New York, 4th ed.

Pruess, K., 1991, TOUGH2: A general numerical simulator for multiphase fluid and heat flow, 
Lawrence Berkelely National Lab. Report LBL-29400, Berkeley, CA.

Pruess, K., C. Oldenburg, and G. Moridis, 1999, TOUGH2 User's Guide, Version 2.0, Lawrence Berkeley National Laboratory Report LBNL-43134, Berkeley, CA.

Pruess, K., and A. Battistelli, 2002, TMVOC, A Numerical Simulator for Three-Phase NonIsothermal Flows of Multicomponent Hydrocarbon Mixtures in Saturated-Unsaturated Heterogeneous Media, Lawrence Berkeley National Laboratoroy Report LBNL-49375, 192 p.

Pruess, K., and J. Garcia, 2002, Multiphase flow dynamics during CO2 disposal into saline aquifers, Environmental Geology, Vol. 42, 282-295.

Ranostaj, E. J., 1976, Massive Hydraulic Fracturing the Eastern Devonian Shales: ERDA Symposium on Enhanced Oil \& Gas Recovery, p. C-3/1-11. The Petroleum Publishing Company.

Reinecker, J., Heidbach, O., Tingay, M., Connolly, P. and Müller, B., 2004, The 2004 release of the World Stress Map (available online at www.world-stress-map.org).

Riley, R.A, J.A. Harper, M.T. Baranoski, C.D. Laughery, and R.W. Carlton, 1993, Measuring and Predicting Reservoir Heterogeneity in Complex Deposystems: The Late Cambrian Rose Run Sandstone of Eastern Ohio and Western Pennsylvania, Appalachian Oil and Natural Gas Research Consortium, Morgantown, WV.

Robertson, E. C., 1959, Physical Properties of Limestone and Dolomite Cores from the Sandhill Well, Wood County, West Virginia, Charleston, West Virginia Geological Society, p. 112-144.

Robertson, J.M., R.F. Broadhead, A.W. Goody, and C.A. Hjellming (editors), 1993, Atlas of Major Rocky Mountain Gas Reservoirs; New Mexico Bureau of Mines and Mineral Resources, Socorro, NM.

Rocha, L.A. and A.T. Bourgoyne, 1996, A new simple method to estimate fracture pressure gradient: SPE Drilling and Completion, September, 1996, p. 153 - 159.

Roen, J.B. and B.J. Walker (editors), 1996, Atlas of Major Appalachian Gas Plays, Publication V-25, West Virginia Geological and Economic Survey, Morganton, WV.

Rupp, J.A., 1991, Structure and Isopach Maps of the Paleozoic Rocks of Indiana: Special Report 48, Indiana Geological Survey, Bloomington, IN.

Saberian, A., and Podio, A. L., 1977, A Computer Model for Describing the Development of Solution-Mined Cavities. IN SITU, V. 1, n. 1, pp 1-36.

Schmidt, R. A., 1976, Fracture-toughness Testing of Limestone: Experimental Mechanics, v. 16 (5), p. 161-167.

Shumbera, D. A., Ellis, R. C. and Loya, D., 2003, Design and Long-Term Production Performance of Frac Pack Completions in a Gulf of Mexico Deepwater Turbidite Field Having Inverted Sand-Shale Stress Contrasts: Case History: SPE Annual Technical Conference and Exhibition, Proceedings-Mile High Meeting of the Minds, Oct 5-8 2003, Denver, CO, United States, p. 1789-1796. Society of Petroleum Engineers, Paper SPE 84259.

Smith, M. B. and Shlyapobersky, J. W., 2000, Basics of Hydraulic Fracturing, in M. J. Economides and K. G. Nolte, eds., Reservoir Stimulation: Chichester, England, John Wiley \& 
Sons, LTD, p. 5.1-5.28.

Smith, M. B., 2004a, Personal Communication; President: NSI Technologies Inc.

Somerton, W. H., Esfandiari, F. and Singhal, A., 1969, Further Studies of the Relation of Physical Properties of Rock to Rock Drillability: Fourth Conference on Drilling and Rock Mechanics. Society of Petroleum Engineers of AIME.

Spycher, N. F.; Reed M.H., 1988, Fugacity Coefficients of H2, CO2, CH4, H2O, and of H2OCO2-CH4 mixtures: A Virial Equation Treatment for Moderate Pressures and Temperatures Applicable to Calculations of Hydrothermal Boiling, Geochimica et Cosmochimica Acta, 52, 739-749.

Szymkiewicz, R., and M. Mitosek (2005), Analysis of unsteady pipe flow using the modified finite element method, Communication in numerical methods in engineering, 21, 189-199.

Thiercelin, M. C. and Roegiers, J.-C., 2000, Formation Characterization: Rock Mechanics, in M. J. Economides and K. G. Nolte, eds., Reservior Stimulation: Chichester, England, John Wiley \& Sons, LTD, p. 3.1-3.35.

Veatch, R. W. J., 1983a, Overview of Current Hydraulic Fracturing Design and Treatment Technology-Part 1: Journal of Petroleum Technology, v. 35 (4), p. 677-687.

Veatch, R. W. J., 1983b, Overview of Current Hydraulic Fracturing Design and Treatment Technology-Part 2: Journal of Petroleum Technology, v. 35 (May), p. 853-864.

Veatch, R. W. J., Moschovidis, Z. A. and Fast, R. C., 1989, An Overview of Hydraulic Fracturing, in J. L. Gidley, S. A. Holditch, D. E. Nierode and R. W. J. Veatch, eds., Recent Advances in Hydraulic Fracturing: Richardson, TX, Society of Petroleum Engineers, p. 1-38.

Wang, H. F., and M. P. Anderson (1980), Introduction to groundwater modelling: Finite Difference and Finite Element Methods, W.H. Freeman and Company.

Wickstrom, L.H., J.D. Gray, and R.D. Stieglitz, 1992, Stratigraphy, Structure, and Production History of the Trenton Limestone (Ordovician) and Adjacent Strata in Northwestern Ohio: Report of Investigation No. 143, Division of Geological Survey, Columbus, Ohio.

Wikipedia (2006a), Calcium chloride, http://en.wikipedia.org/wiki/Calcium_chloride.

Wikipedia (2006b), Hydrochloric acid, http://en.wikipedia.org/wiki/Hydrochloric_acid.

Williams, B. B., Gidley, J. L., and Schechter, R. S., 1979, Acidizing Fundamentals. Soc. Pet. Eng., Richardson, TX, 124 pages.

Wuming, B., Vigny, C., Ricard, Y. and Froidevaux, C., 1992, On the Origin of Deviatoric Stresses in the Lithosphere: Journal of Geophysical Research, v. 97 (B8), p. 11729-11737.

Wylie, E. B., and V. L. Streeter (1978), Fluid transients, McGraw-Hill International Book Company.

Xu, T., E. Sonnenthal, N. Spycher, and K. Pruess, 2004, TOUGHREACT User's Guide: As Simulation Program for Non-isothermal Multiphase Reactive Geochemical Transport in Variably Saturated Geologic Media, Lawrence Berkeley National Laboratory Report LBNL/PUB-3179, $192 p$. 
Xu, T., J.A. Apps, and K. Pruess, 2003a, Reative geochemical transport simulation to study mineral trapping for $\mathrm{CO} 2$ disposal in deep aranaceous formations, Journal of Geophysical Research, Vol. 108, No. B2, 2071, p. ECV 3-1 - ECV 3-13.

Xu, T., E. Sonnenthal, N. Spycher, and K. Pruess, 2003b, TOUGHREACT: A new code of the TOUGH family for non-isothermal multiphase reactive geochemical transport in variably saturated geologic media, Proceedings, TOUGH Symposium 2003, Lawrence Berkeley National Laboratory, Berkeley, CA, May 12-14, 2003.

Xu, T., Pruess, K., and Brimhall, G., 1999, An Improved Equilibrium-Kinetics Speciation Algorithm for Redox Reactions in Variably Saturated Subsurface Flow Systems. Computers \& Geosciences, v 25, p 655-666.

Yang, Y., 2004, GIS analysis of carbonate formations in six northeastern states for a suitability assessment of using new technology to develop natural gas storage. M.S. thesis. Clemson University. Clemson, South Carolina.

Zoback, M. L. and Zoback, M. D., 1980, State of stress in the conterminous United States: Journal of Geophysical Research, v. 85 (11), p. 6113-6156.

Zoback, M. L., 1992, Stress Field Constraints on Intraplate Seismicity in Eastern North America: Journal of Geophysical Research, v. 97 (B8), p. 11761-11782.

Zoback, M.D. and J.H. Healy, 1984, Friction, Faulting and In-Situ Stress: Annales Geophysicae, p. 689-698. 